KAPL, Inc.

Knolls Atomic Power Laboratory

Post Office Box 1072 Schenectady, N.Y. 12301-1072

Telephone (518) 395-4000 Facsimile (518) 395-4422

SPP-SEC-0039

April 10, 2006

\title{
Subject: Documentation of Naval Reactors Papers and Presentations for the Space Technology and Applications International Forum (STAIF) 2006
}

Reference: SPP-67110-0008, “Project Prometheus Reactor Module Final Report,” April 2006.

This letter provides internal documentation of the papers and presentations prepared by KAPL and Bettis for the 2006 STAIF conference that summarize our work on the Prometheus Project space reactor development. Eighteen presentations and six papers were prepared and approved for public utterance. Table 1 provides a list of the presentations and papers. The presentations cover:

1) The project overview and the reactor design features

2) The reactor plant and instrumentation development work

3) Hydraulic and reactor plant transient modeling

4) Reactor core and plant materials (two sessions)

The intent of the papers and presentations is to provide future space reactor developers an overview of the Naval Reactors program work on Project Prometheus and direct them to the more complete documentation that will be stored in the Office of Scientific and Technology Information (OSTI) Database. The reference above summarizes the Project Prometheus development work.

$<<$ original signed by $>>$

John Ashcroft, Manager

Space Energy Conversion

Space Power Program 
Table 1: List of STAIF Conference Presentations

Shaded Presentations Also Include Public Utterance Approved Presentations

\begin{tabular}{|c|c|c|}
\hline $\begin{array}{c}\text { Enclosure } \\
\#\end{array}$ & Title & Authors \\
\hline \multicolumn{3}{|c|}{ Session 1: Prometheus Space Reactor Design Overview } \\
\hline 1 & Summary of NR Program Prometheus Efforts & $\begin{array}{l}\text { John Ashcroft and Curtis } \\
\text { Eshelman }\end{array}$ \\
\hline 2 & $\begin{array}{l}\text { Aspects of Gas Reactor Physics for NRPCT Project } \\
\text { Prometheus Applications }\end{array}$ & Jonathan Witter \\
\hline 3 & Reactor Mechanical Design Concept and Performance & Dennis Kedzierski \\
\hline \multicolumn{3}{|c|}{ Session 2: Prometheus Space Reactor Plant Characteristics } \\
\hline 4 & $\begin{array}{l}\text { Key Factors Influencing the Decision on the Number of } \\
\text { Brayton Units for the Prometheus Space Reactor }\end{array}$ & John Ashcroft, et al \\
\hline 5 & $\begin{array}{l}\text { Pressure Vessel and Reflector Temperature Sensitivity Studies } \\
\text { of a Notional Gas-Cooled Space Reactor }\end{array}$ & David Volk and K. Robb \\
\hline 6 & Prometheus Hot Leg Piping Concept & $\begin{array}{l}\text { Anastasia Gribik and } \\
\text { Peter DiLorenzo }\end{array}$ \\
\hline 7 & Reactor Instrumentation and Control: Systems and Sensors & $\begin{array}{l}\text { Kent Loomis, John Boyle, } \\
\text { Darren Robare }\end{array}$ \\
\hline \multicolumn{3}{|c|}{ Session 3: Prometheus Space Reactor Materials } \\
\hline 8 & $\begin{array}{l}\text { Fuel for Thought: Considerations for a Space Nuclear } \\
\text { Reactors }\end{array}$ & Scott Simonson, et al \\
\hline 9 & $\begin{array}{l}\text { Summary of Structural Material Considerations for } \\
\text { Prometheus Space Nuclear Power }\end{array}$ & Thomas Angeliu, et al \\
\hline 10 & $\begin{array}{l}\text { Mass Transport Modeling and Supporting Experimental } \\
\text { Tasks for the Prometheus Space Reactor System }\end{array}$ & $\begin{array}{l}\text { Tymm Schumaker and } \\
\text { Wayne Ohlinger }\end{array}$ \\
\hline 11 & $\begin{array}{l}\text { Compatibility of Space Nuclear Power Plant Materials in an } \\
\text { Inert He/Xe Working Gas Containing Reactive Impurities }\end{array}$ & Meryl M. Hall \\
\hline \multicolumn{3}{|c|}{ Session 4: Modeling } \\
\hline 12 & $\begin{array}{l}\text { Use of RELAP5-3D for Dynamic Analysis of a Closed-Loop } \\
\text { Brayton Cycle Coupled to a Nuclear Reactor }\end{array}$ & Larry McCann \\
\hline 13 & $\begin{array}{l}\text { Ex-core CFD Analysis Results for the Prometheus Gas } \\
\text { Reactor }\end{array}$ & Donald Lorentz \\
\hline 14 & $\begin{array}{l}\text { Review of Helium and Xenon Pure Component and Mixture } \\
\text { Transport Properties and Recommendation of Estimating } \\
\text { Approach for Project Prometheus }\end{array}$ & $\begin{array}{l}\text { Melissa Haire } \\
\text { David Vargo }\end{array}$ \\
\hline 15 & $\begin{array}{l}\text { Modeling Compact Counter-Flow Heat Exchangers with } \\
\text { RELAP5-3D }\end{array}$ & Jacob Crittenden \\
\hline \multicolumn{3}{|c|}{ Session 5: Additional Space Reactor Materials } \\
\hline 16 & $\begin{array}{l}\text { NRPCT Perspective on Lithium Hydride for Use in a Space } \\
\text { Shield }\end{array}$ & Brian Campbell, et al \\
\hline 17 & Reflector Material Selection for Space Nuclear Applications & Brian Campbell, et al \\
\hline 18 & $\begin{array}{l}\text { Assessing the Radiation Damage of Ni-base Superalloys for } \\
\text { Prometheus Space Nuclear Power }\end{array}$ & $\begin{array}{l}\text { Tom Angeliu, John Ward } \\
\text { and Jonathan Witter }\end{array}$ \\
\hline
\end{tabular}


Enclosure 1 to

SPP-SEC-0039

\title{
Summary of NR Program Prometheus Efforts
}

\author{
Ashcroft, J.M., and Eshelman, C.D
}


This page is intentionally blank.

PRE-DECISIONAL - For planning and discussion purposes only 


\title{
Summary of NR Program Prometheus Efforts
}

\author{
John Ashcroft and Curtis Eshelman \\ Naval Reactors Prime Contractor Team
}

STAIF 2006

February 2006 


\section{Agenda}

- Brief History of NR Program Involvement in Prometheus

- Concept Selection Summary

- Key Technical Accomplishments and Findings

- Reactor

- Materials

- Shielding

- Plant and Energy Conversion

- Instrumentation and Control

- Extensibility

- Conclusions 


\section{History}

- April 2004: DOE Secretary Commissioned Naval Reactors and its National Laboratories to Design, Build and Operationally Support Civilian Space Reactor.

- "NRPCT" is Formed

- Team with JPL and Other NASA Centers

- Coordinate use of DOE Labs

- August 2004: Signed Memorandum of Understanding Between NASA and NR Program

- October 2004: Northrop Grumman Space Technologies Selected as JIMO Spacecraft Contractor

- November 2004: NRPCT Completes Feasibility Evaluation

- April 2005: NRPCT Selects Direct Gas Brayton System and Begins PreConceptual Development

- June 2005: NASA Redirect Space Nuclear Focus to Surface Missions

- July 2005: PMSR Closes out Phase A of JIMO Work. No Further work Pursued

- September 2005: NASA and NR Program Dissolve Partnership and NRPCT begins Closeout 


\section{DOE/NASA Collaboration}

\section{NASA Centers}

JPL

- Program Coordination

- Instrumentation and Control Integration

- Environmental Effects

- Radiation Hardening

- Thermoelectrics Expertise

GRC

- Brayton Expertise

- Stirling Expertise

- Brayton System Testing

- HRS Interface

- Power Management

- Structural Materials

MSFC

- Core and Loop Mocksp Testing

- Heat Pipe Testing

- Liquid Metal Testing KSC

- ATLO Coordination

ARC

- Aeroshell Design
Collaboration of National Infrastructure with NRPCT Coordination of Nuclear Work was Effective Program Structure
DOE Labs

Oak Ridge

- Shielding Development

- Irradiation Testing (HFIR)

- Sensor Development

- Reactor Safety

- Structural Materials

- Compatibility Testing

- Independent Cost Estimate

Los Alamos

- Rx design support

- Fuel fabrication

- Critical assembly testing (FA8)

- Heat Pipe Development

- Transient Model Development

$\mathrm{Y}-12$

- Shield and Fuel Fabrication

INL

- ATR Testing

- Modeling Support

PNNL

- Foreign Test Reactor Support

- Fuel Modeling

Sandia

- Safety Testing Guidance

- Independent Cost Estimate

- Gas Brayton Modeling

Argonne

- Fast Reactor Experience

Lawrence Livermore

- Reactor safety modeling

- Fuel Science 


\section{Major NRPCT Documents}

- Feasibility Report

- Additional Concept and Materials Review

- Compared Various Coolants and Conversion Options

- Recommended Focused Study of Leading Options

- Concept Selection Report

- 5 Reactor and Coolant Options Evaluated

- Formal Decision Process

- Space Reactor Planning Estimate

- Initial Program Plan and Cost Estimate

- Fuel Type Selection Report

- Down-select between $\mathrm{UO}_{2}$ \& UN

- Closeout Summary Report and References

- Reactor and Plant Pre-Conceptual Design

- Summary of Material Reviews and Test Results

- Technical And Programmatic Conclusions

\section{All will be Stored in DOE OSTI Database}




\section{Mission Objectives and Requirements}

- Explore the Icy Moons of Jupiter

- Orbit Moons

- $1500 \mathrm{~kg}$ Instrument and Communications Payload

- Develop and Demonstrate Nuclear Electric Propulsion

- Develop Technologies Applicable to Other NEP and Surface Power Missions

\begin{tabular}{|c|c|}
\hline Power & $\begin{array}{l}\sim 1 \mathrm{MW}_{\mathrm{th}} \\
\sim 185 \mathrm{~kW}_{\mathrm{e}}\end{array}$ \\
\hline $\begin{array}{l}\text { Calendar } \\
\text { Life }\end{array}$ & 20 Years \\
\hline Energy & $\begin{array}{l}\text { Sufficient for } 12-15 \text { years at full } \\
\text { power }\end{array}$ \\
\hline $\begin{array}{l}\text { Reactor } \\
\text { Temperature }\end{array}$ & $\begin{array}{l}-900-1150 \mathrm{~K} \\
\text { Fuel Surface Temperature to } \\
1400 \mathrm{~K}\end{array}$ \\
\hline Transients & $\begin{array}{l}\text { Startup, Up-Power \& Down- } \\
\text { Power for Coast }\end{array}$ \\
\hline Shielding & $\begin{array}{l}\text { To protect Power Plant } \\
\text { Equipment and Science } \\
\text { Package Instruments }\end{array}$ \\
\hline $\begin{array}{l}\text { Launch/ } \\
\text { Re-entry } \\
\text { Casualty }\end{array}$ & Public Protected \\
\hline Size & $\begin{array}{l}\text { To fit launch fairing (Radiator } \\
\text { Area) }\end{array}$ \\
\hline Mass & Integrated plant mass minimized \\
\hline
\end{tabular}




\section{Overall Spacecraft Concept}

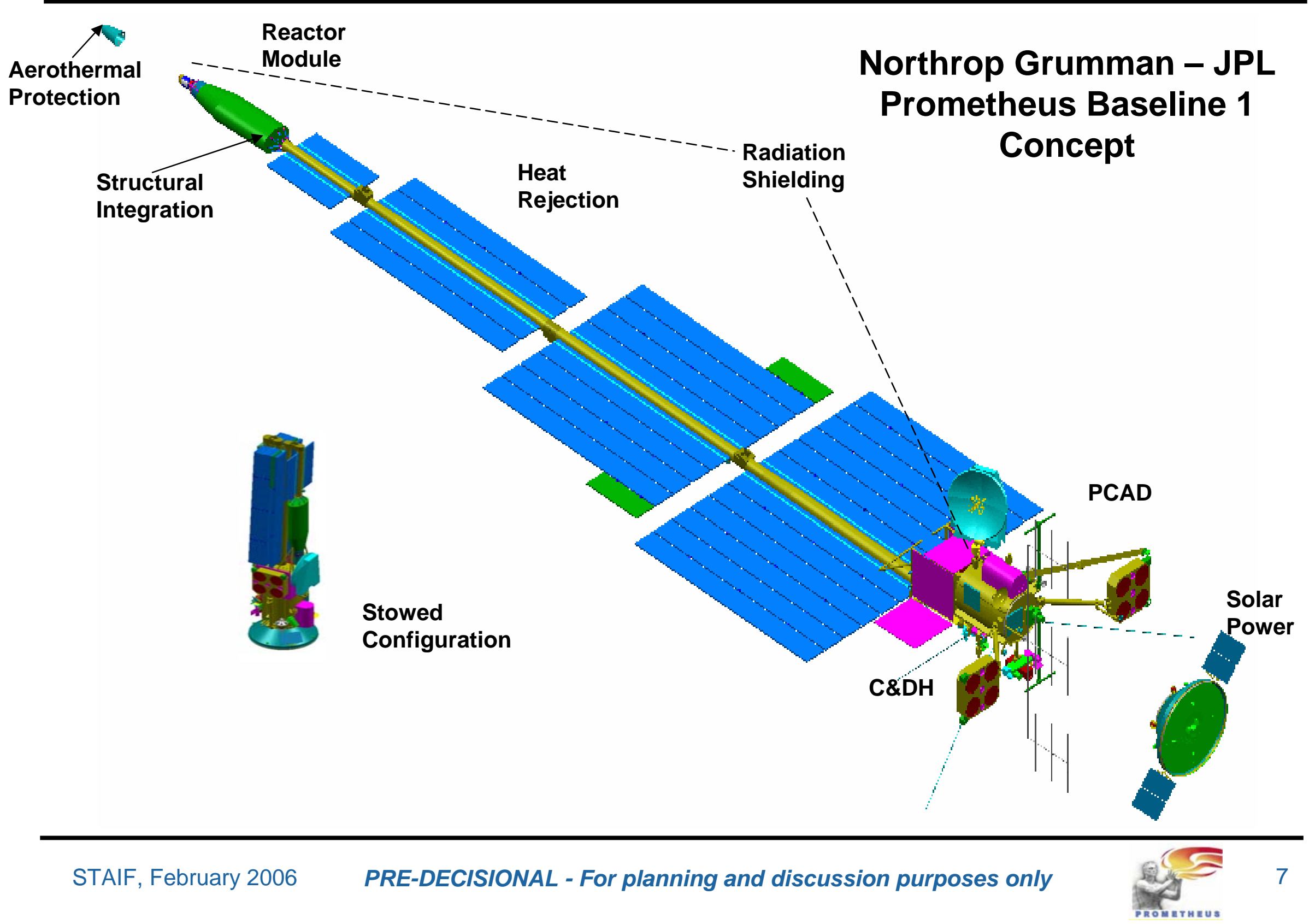




\section{Concept Selection}

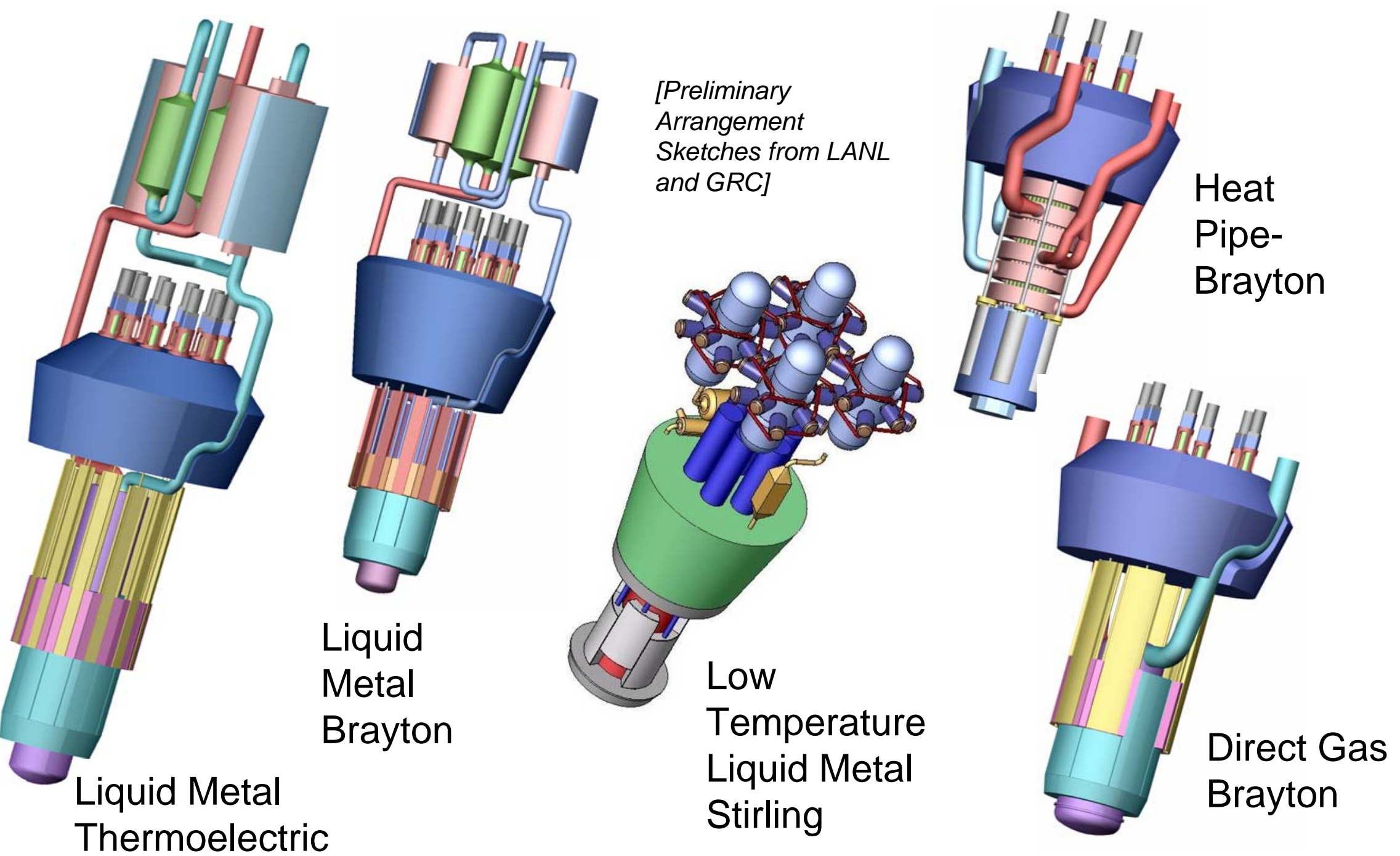

Direct Gas Reactor Selected Because it Met Performance Requirements, Minimized Development Challenges and was Most Readily Tested 


\section{Reactor Concept}

Major Components:

- Fueled Core Region -

Produces heat for transfer to the energy conversion system

- Unfueled core region Provides plena to collect gaseous fission products

- Radiation Shield - Reduces radiation dose to spacecraft

- Fixed/moveable reflector Reduces neutron leakage; provides reactor startup/shutdown/control

- Inlet/outlet nozzles - Gas from/to Brayton energy conversion, respectively

- Safety rod dry well - Contains safety rod, which ensures reactor shutdown until it is ejected when ready for startup

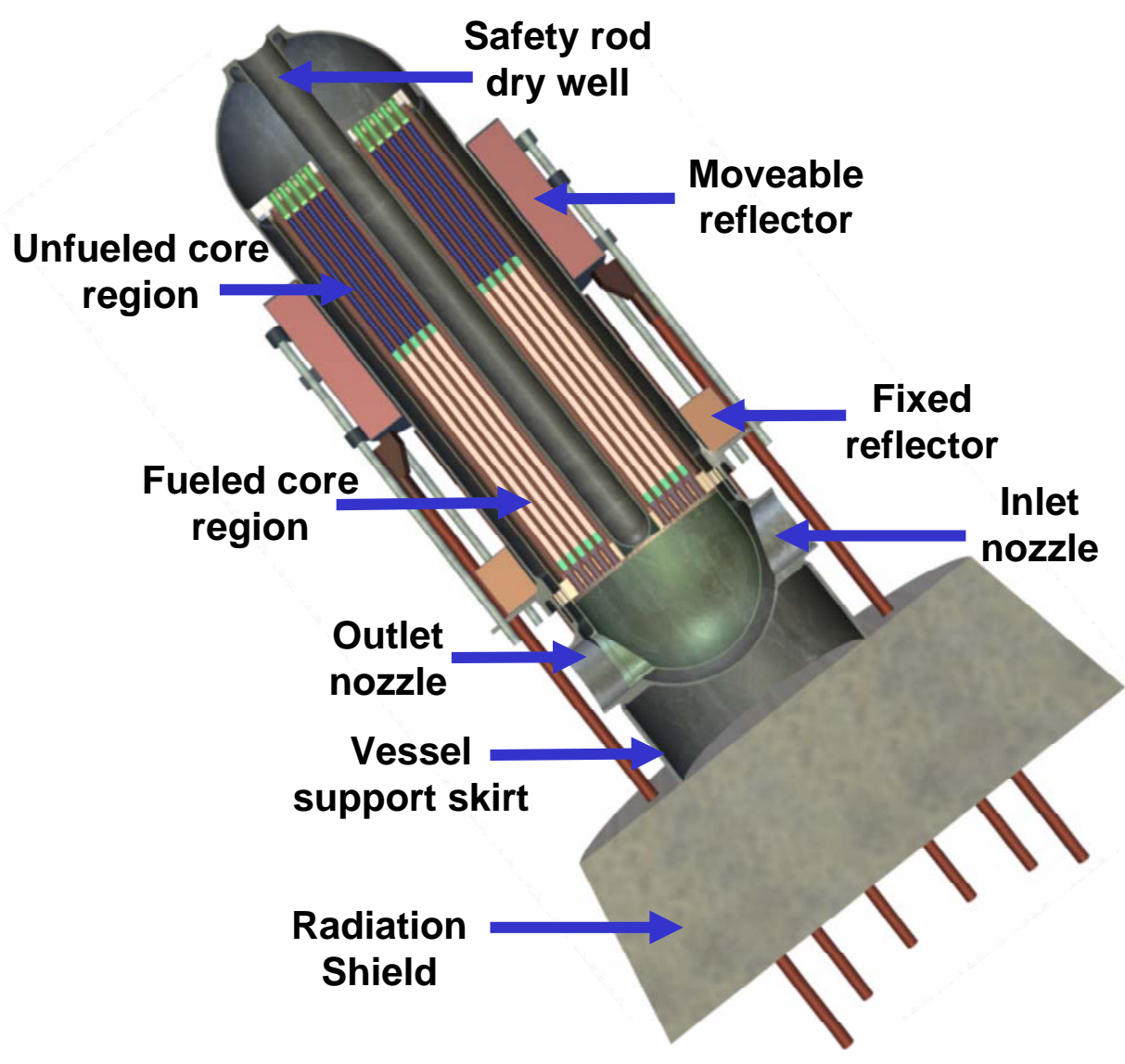

- Vessel support skirt Structural attachment between reactor vessel and shield 


\section{Reactor Design}

- Evaluated Range of Reactor Arrangements and Materials

- Metal \& Ceramics

- Fast and Moderated

- Open Lattice \& Block

- Fuel Pins \& Cermets

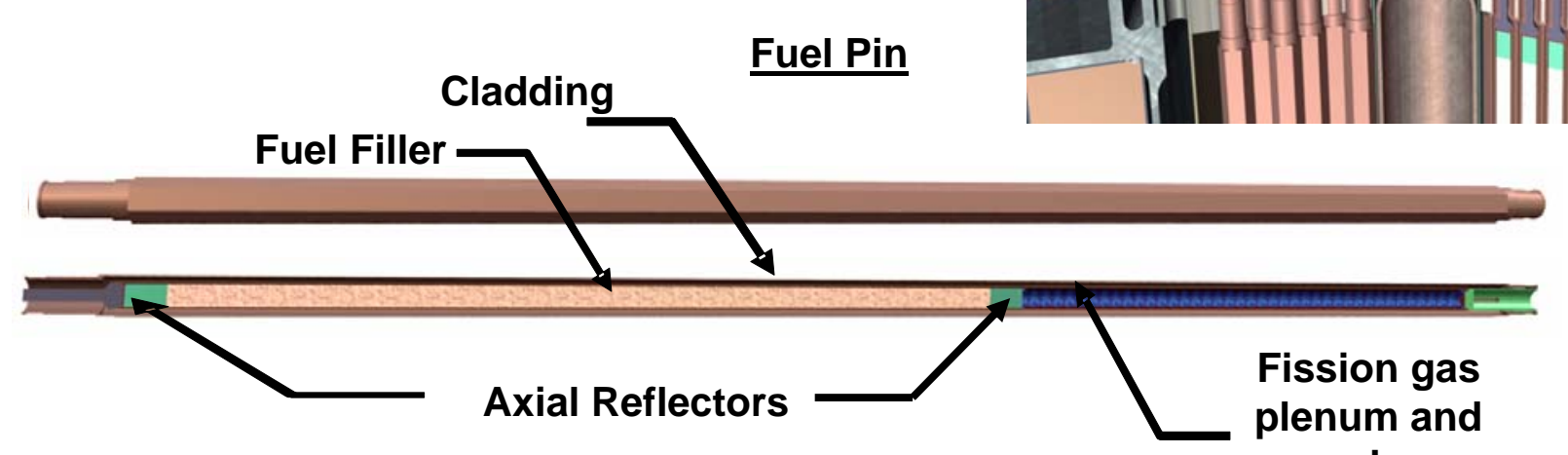

spring

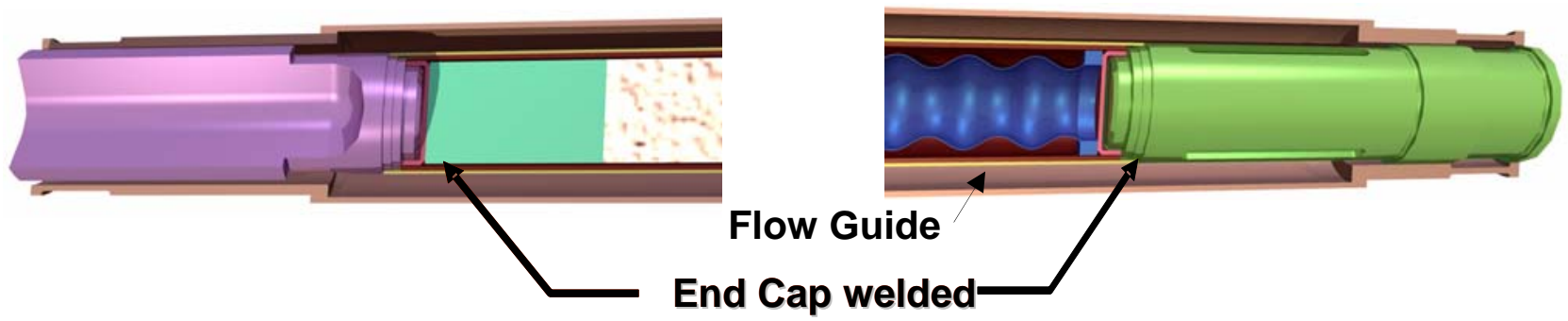

to Clad 


\section{Reactor Design Accomplishments}

- Established consistent performance criteria and assumptions (e.g., material properties) for concept comparisons

- Developed nuclear safety design criteria and safety analysis methods.

- Performed parametric studies on operating conditions, core arrangements, and materials, optimized to performance requirements.

- Evaluation of a heavy water moderated gas cooled reactor concept with a silicon carbide-based fuel system.

- Developed reactor physics and thermal hydraulic test plans.

- Developed preliminary reactor core mechanical design concepts and reactor assembly approaches. 


\section{Mass Sensitivity to Reactor Materials and Arrangement}

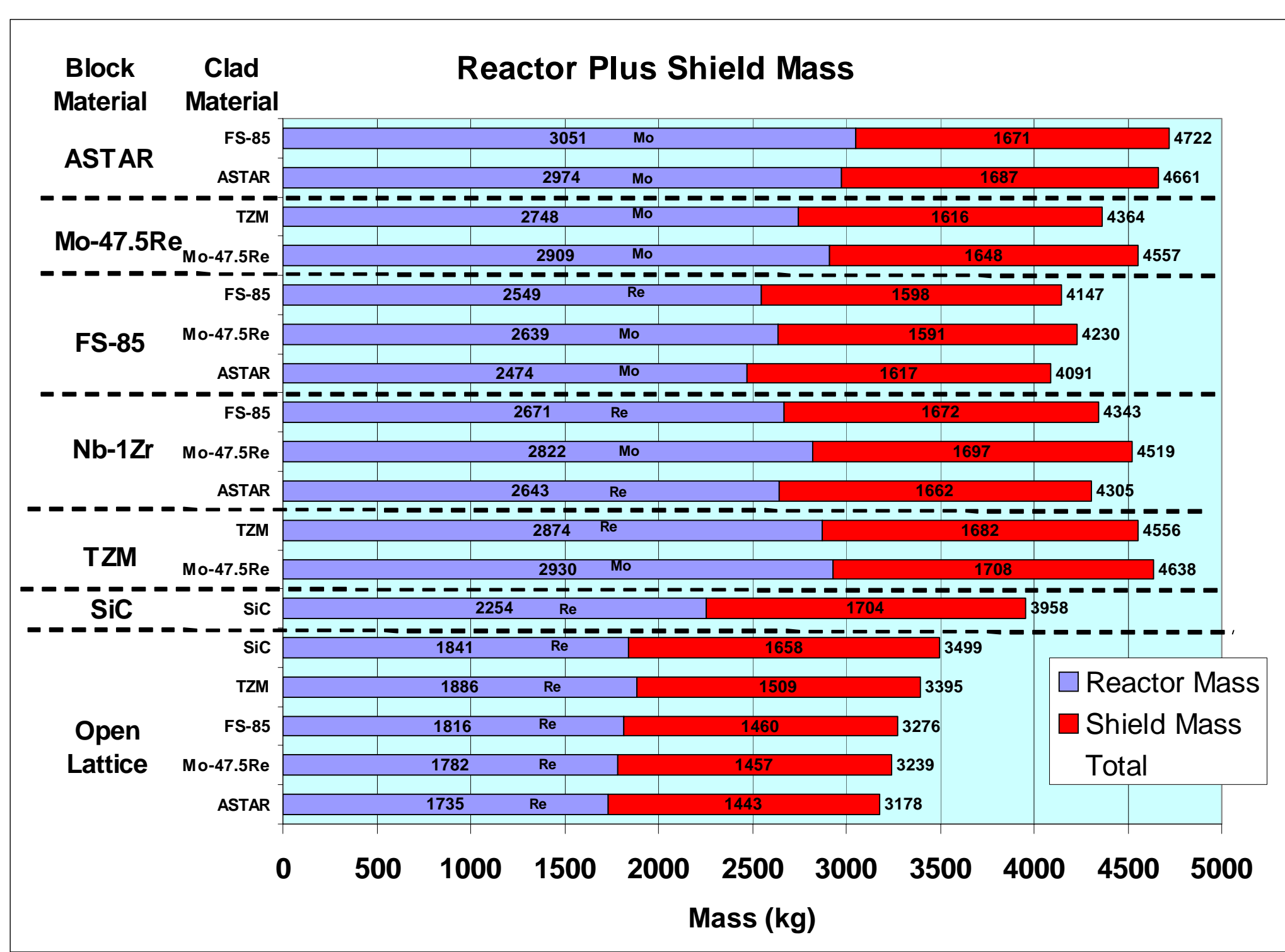

STAIF, February 2006

PRE-DECISIONAL - For planning and discussion purposes only 


\section{Reactor Safety}

- Core compaction on impact following launch or re-entry accident is an unresolved issue

- Preliminary impact calculations

- Show significant core compaction and distortion at $>200 \mathrm{~m} / \mathrm{s}$ impact

- Compaction weak function of core geometry and materials

- Criticality and energy release not yet studied

- Mitigation Approaches

- Use of multiple safety rods

- Lower fuel loading density

- High drag aeroshell to reduce impact velocity

- Moderated reactor concept

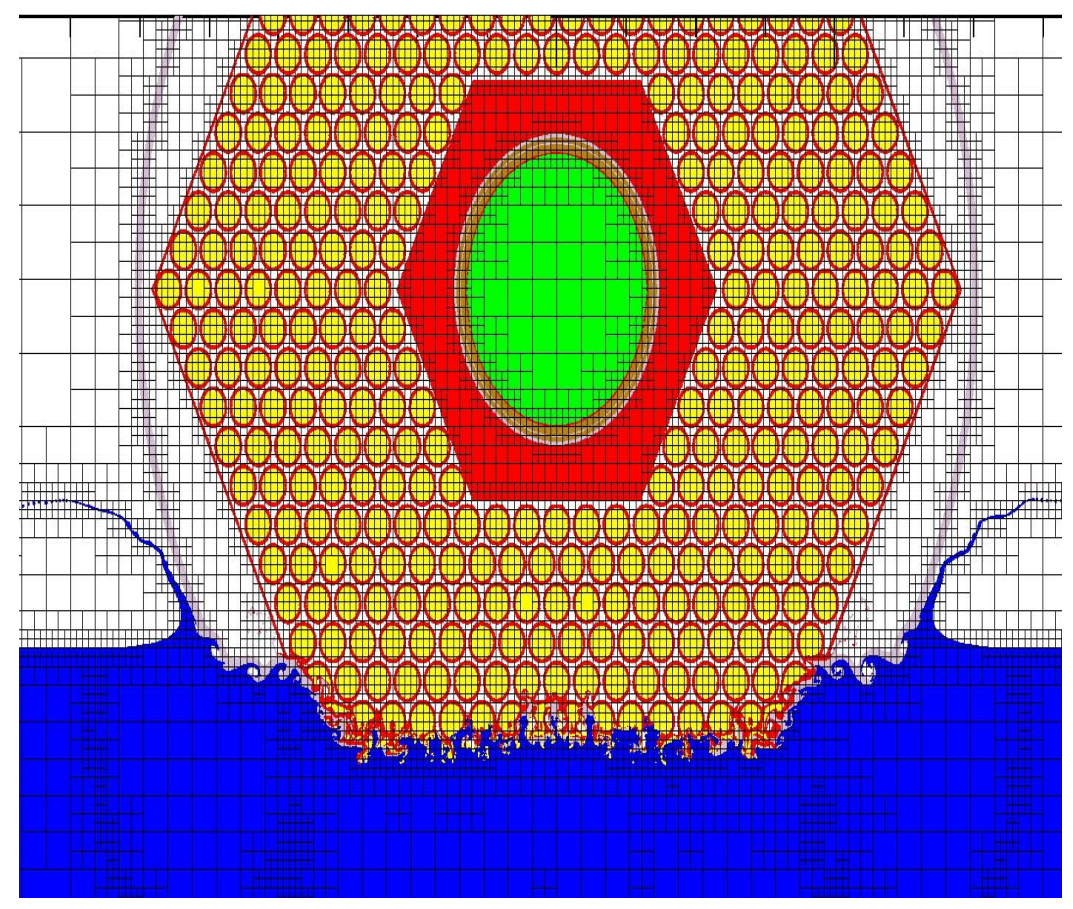

\section{Fully Addressing Launch Safety May Increase} Reactor Mass and Complexity 


\section{Moderated Reactor Concept}

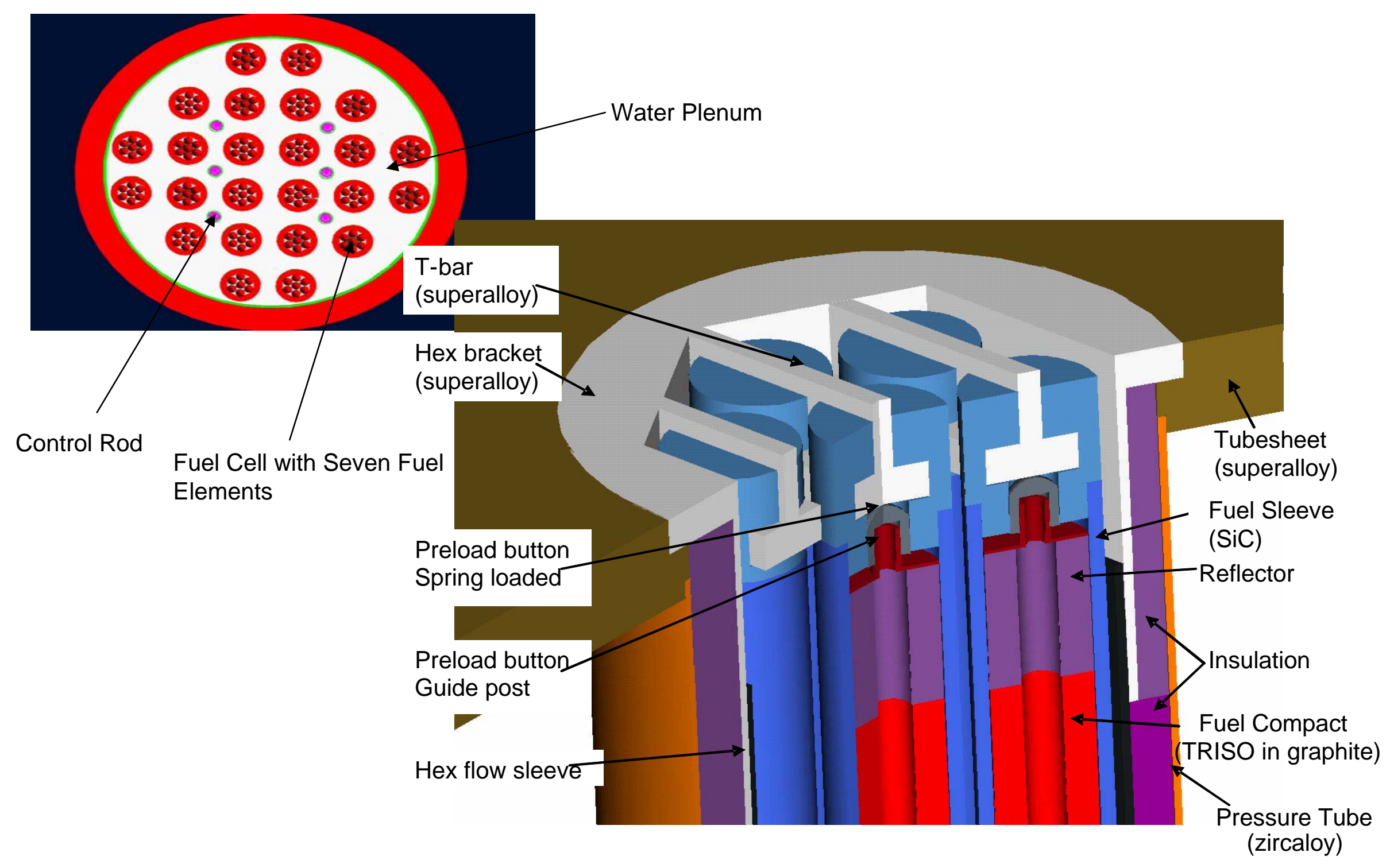




\section{Reactor Design Findings}

- No clear "best choice" at this time - need material performance data

- Core compaction on re-entry requires further study and may necessitate design modifications to demonstrate safety

- Fast reactors are smaller and less massive but require substantially more fuel than moderated reactors

- Slider control devices offer a smaller diameter, but drums offer simpler mechanical and actuator design

- Cermet fuel elements offer most compact reactor configuration but fuel performance uncertainties are high

- Core thermal design is challenging due to low pressure and gas mixture physical properties

- Core mechanical design allows for transition between refractory or ceramic core and superalloy vessel with non-welded joints. Further design development needed to minimize thermal stresses. 


\section{Reactor Materials Accomplishments}

- Evaluated Refractory Metal and Ceramic Cladding

- Nb-1Zr and FS-85

- Mo-Re Alloys

- Ta-10W and ASTAR-811C

- SiC/SiC composites

- Performed Thorough Literature Review and Developed

Databases

- Initiated Thermal and Irradiation Testing in HFIR and plans for JOYO

- Resurrected UN Fabrication

- Fabricated $\mathrm{UO}_{2}$ Pellets
- Evaluated Range of Reflector and Shielding Materials

- BeO and Be Metal

- $\mathrm{LiH}, \mathrm{Be}, \mathrm{B}_{4} \mathrm{C}$, Water

- Performed Initial Compatibility Studies and Developed Mass Transport Models 


\section{Reactor Material Conclusions}

- Selected $\mathrm{UO}_{2}$ fuel as baseline

- Acceptable neutronics

- Better fabricability

- Better FP chemical stability

- All Cladding Materials have Development Issues

- $\mathrm{Nb}-1 \mathrm{Zr}$ has insufficient creep strength

- Other Refractories have phase stability concerns

- Nb and Ta alloys have poor oxidation tolerance and need coatings

- SiC/SiC cladding on pellet fuel more developmental

- Cermet fuel less thoroughly evaluated

- Nickel Superalloy Pressure Vessel and Loop Piping was Selected as Reference

\section{High Flux Isotope Reactor (HFIR)}

Aged to $\sim 1 \%$, irradiated to $10 \& 20 \%$ of mission life

Comparing annealed to aged to irradiated

Tensile testing - total elongation

Mo-Re alloys exhibit radiation-induced embrittlement

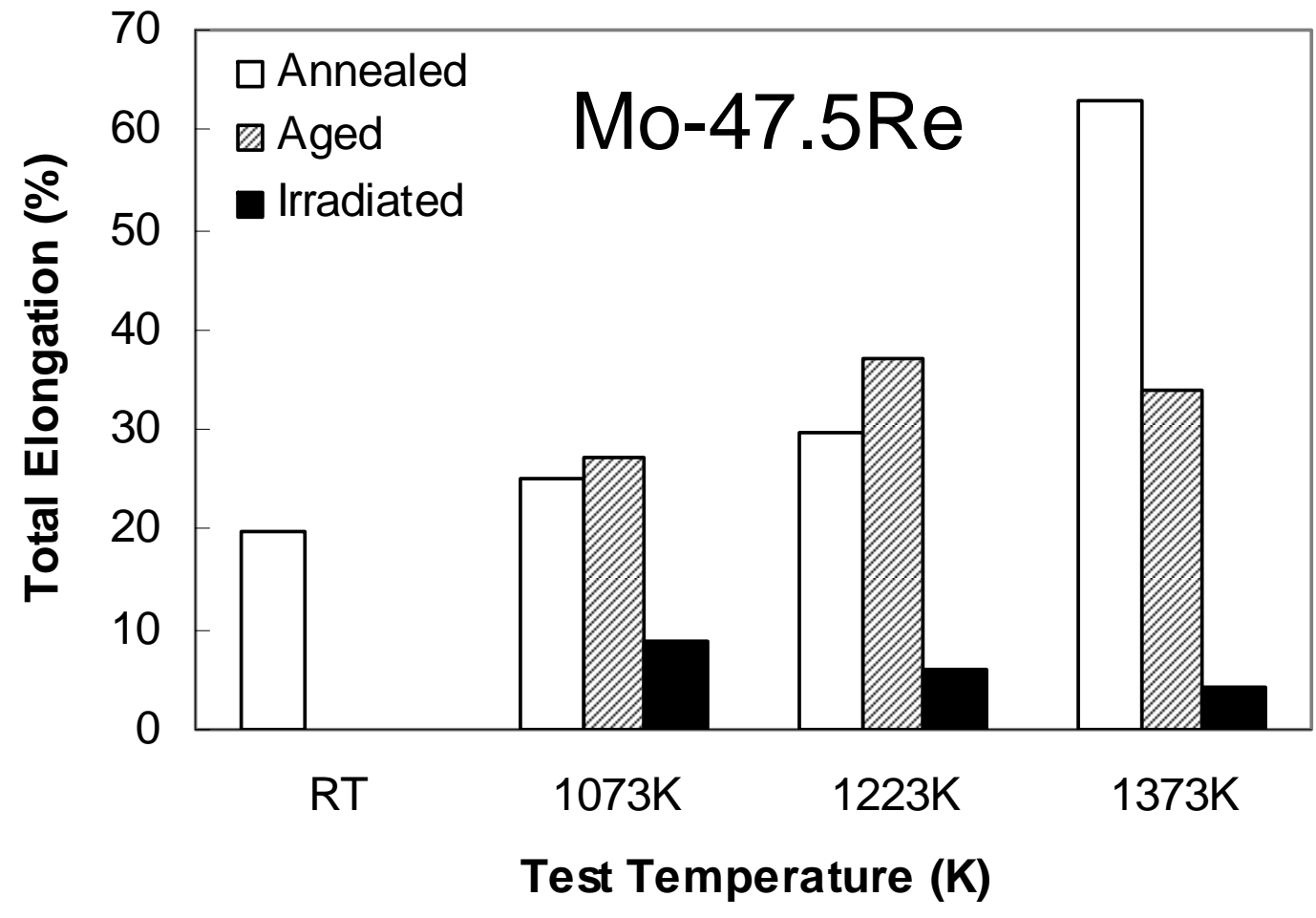




\section{Shielding}

- Shielding Mass Most Sensitive to Core Diameter and Core to Shield Distance

- $\mathrm{Be}, \mathrm{B}_{4} \mathrm{C}, \mathrm{LiH}$, and Water Neutron Shielding Options all Produce Similar Mass

- Tungsten, incorporated into the shield, provides best gamma attenuation

- $\mathrm{LiH}$ Swelling Correlates with Processing

- Piping Penetrations Best Handled with Spiral Through Shield

- CDM Penetrations have small impact on shield effectiveness

- Some fission product release to coolant $\left(-10^{-3} \mathrm{R} / \mathrm{B}\right)$ likely acceptable

- More complete trades of reactor and local shielding may reduce overall mass

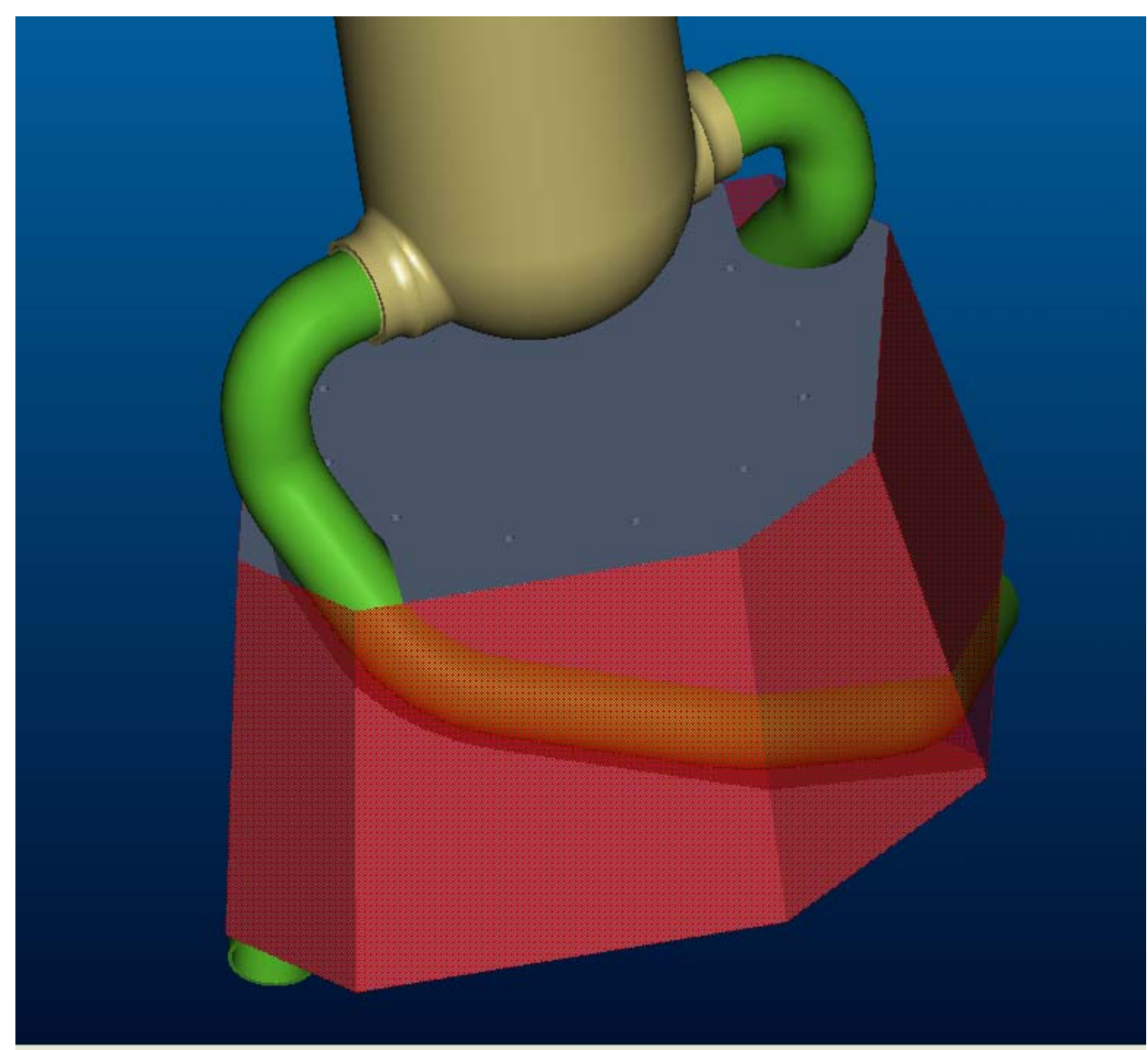




\section{Reactor Plant Accomplishments}

- Evaluated Architecture Options

- 1-4 Braytons

- Interfaces with HRS and PCAD

- Developed Reactor Plant Transient Models

- Evaluated System Reliability

- Developed Preliminary Plant Arrangements

- Developed Hot Leg Piping Approach

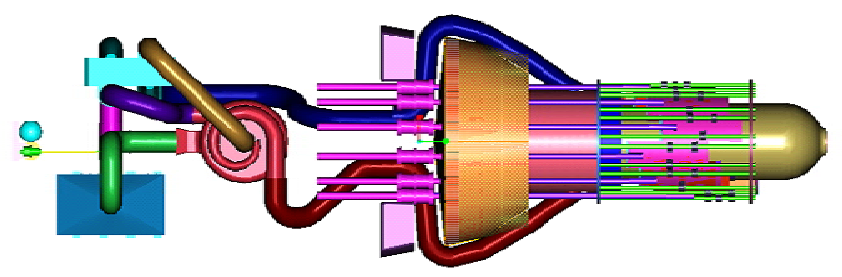

- Performed Initial Component Design and Development

- Estimated Integrated System Mass

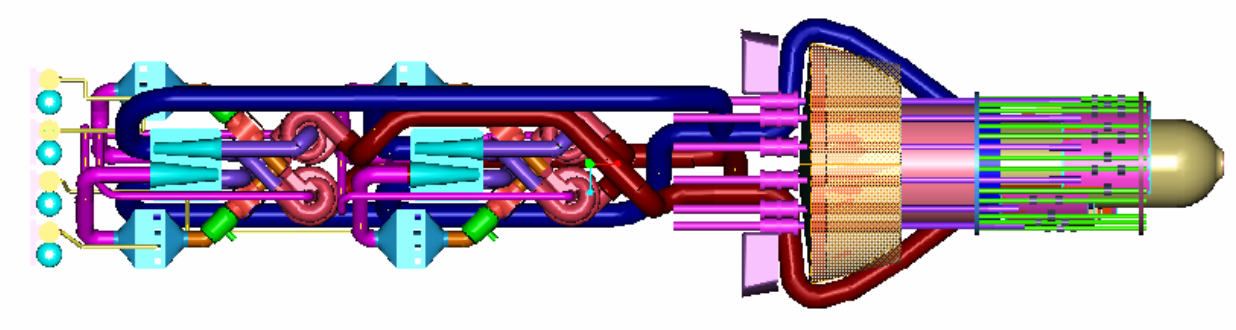




\section{Reactor Plant Transient Example Loss of Speed Control with no Control Response}

Brayton Shaft Speed for Overspeed of 1 of 2 Braytons Initial Speed is $4712.4 \mathrm{rad} / \mathrm{s}$ (45,000 RPM)

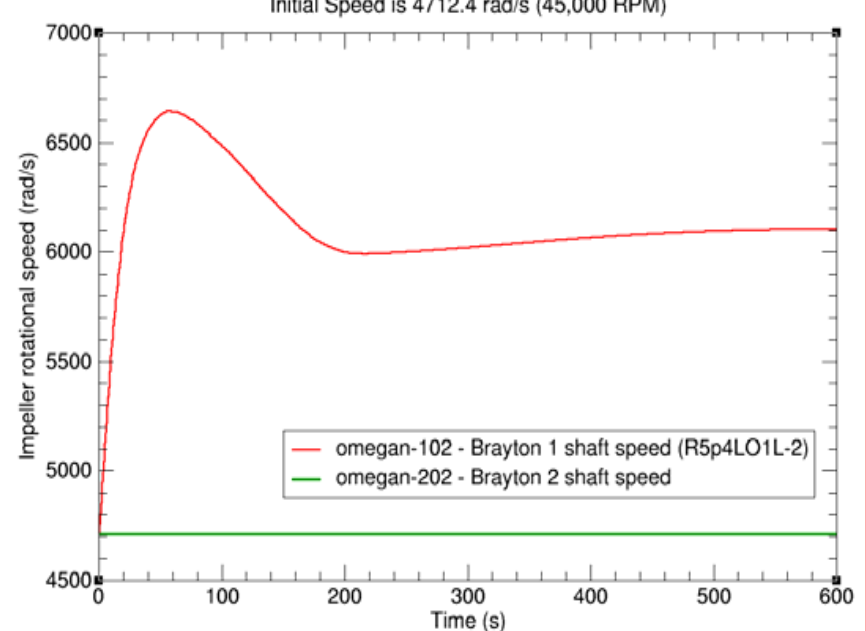

Hot Spot Fuel Temp for Overspeed of 1 of 2 Braytons Ref design gas RX from SPP-67110-0007 (7/27/05) UN fuel, Block/pin annular fllow

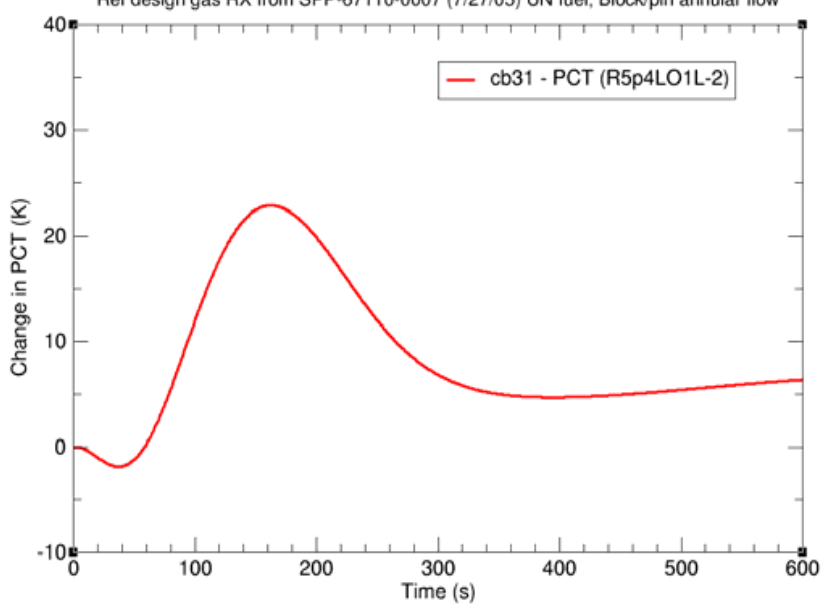

Reactor Power - Loss of Load (overspeed) in 1 of 2 Braytons Ref RX trom SPP-67110-0007 (7/27/05). React FB coeft. UN fuel = -6 8E-6dK/K Geometric = -6.8E-6dK/K

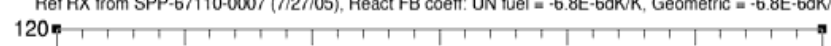

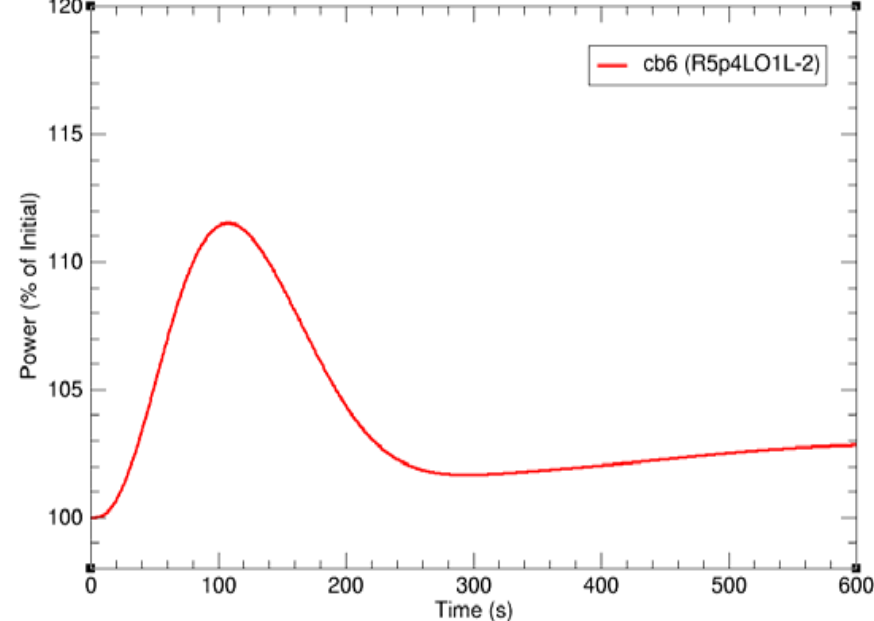

Gas Cooler Water Temps for Overspeed of 1 of 2 Braytons Constant B1 HRS pump speed - HRS Boiling and overpressure (1120 to $1760 \mathrm{psi})$

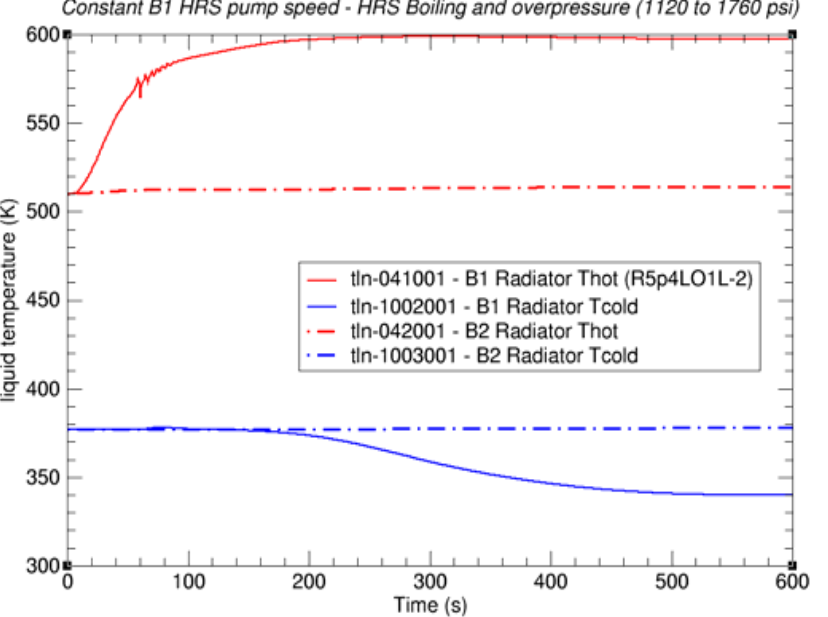




\section{Integrated Mass and Design Space}

\section{System Efficiency}
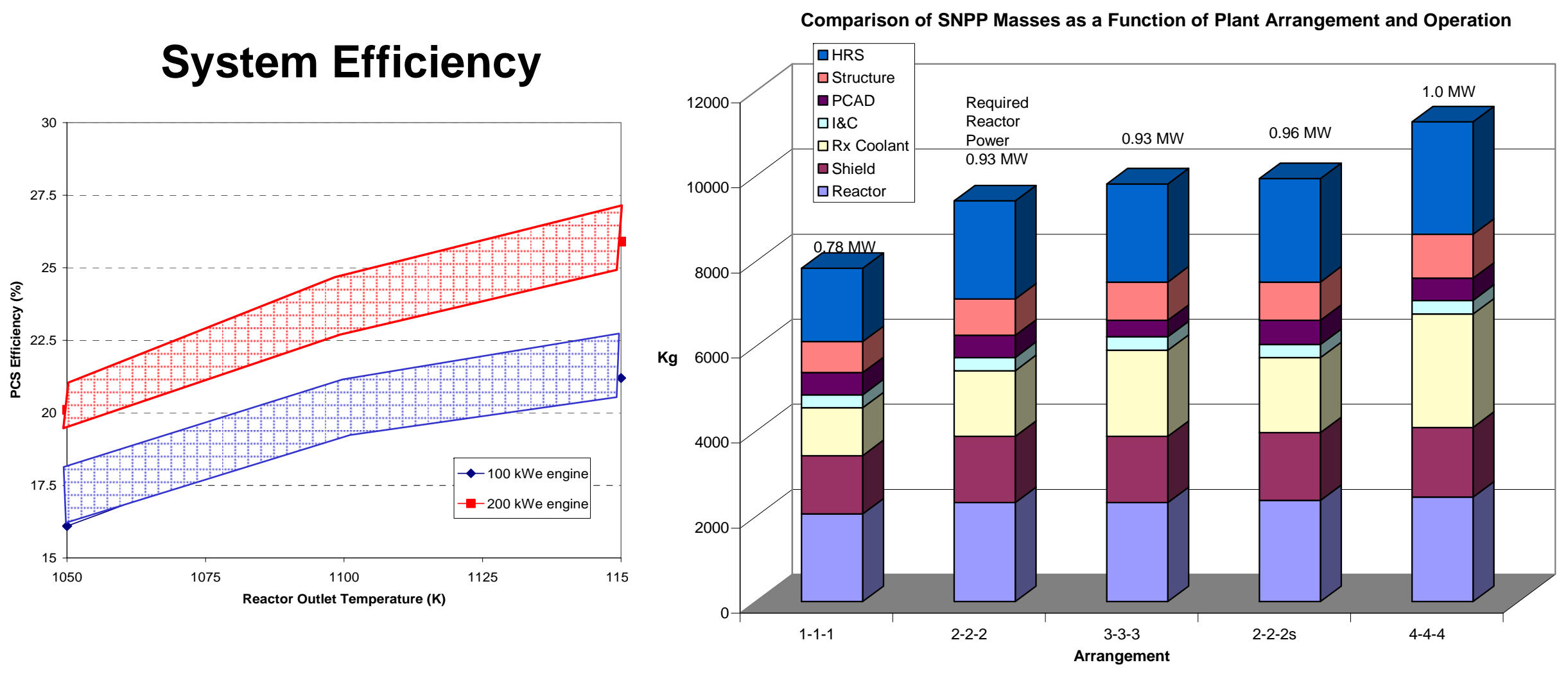

Component performance and loop resistance are substantially better for a single Brayton system. This results in substantially lower system mass and greater design space flexibility 


\section{Instrumentation and Control Accomplishments and Findings}

- Developed Spacecraft Control System Architecture

- Completed Software Development Plan for JIMO project

- Reactor Start-up Process Developed

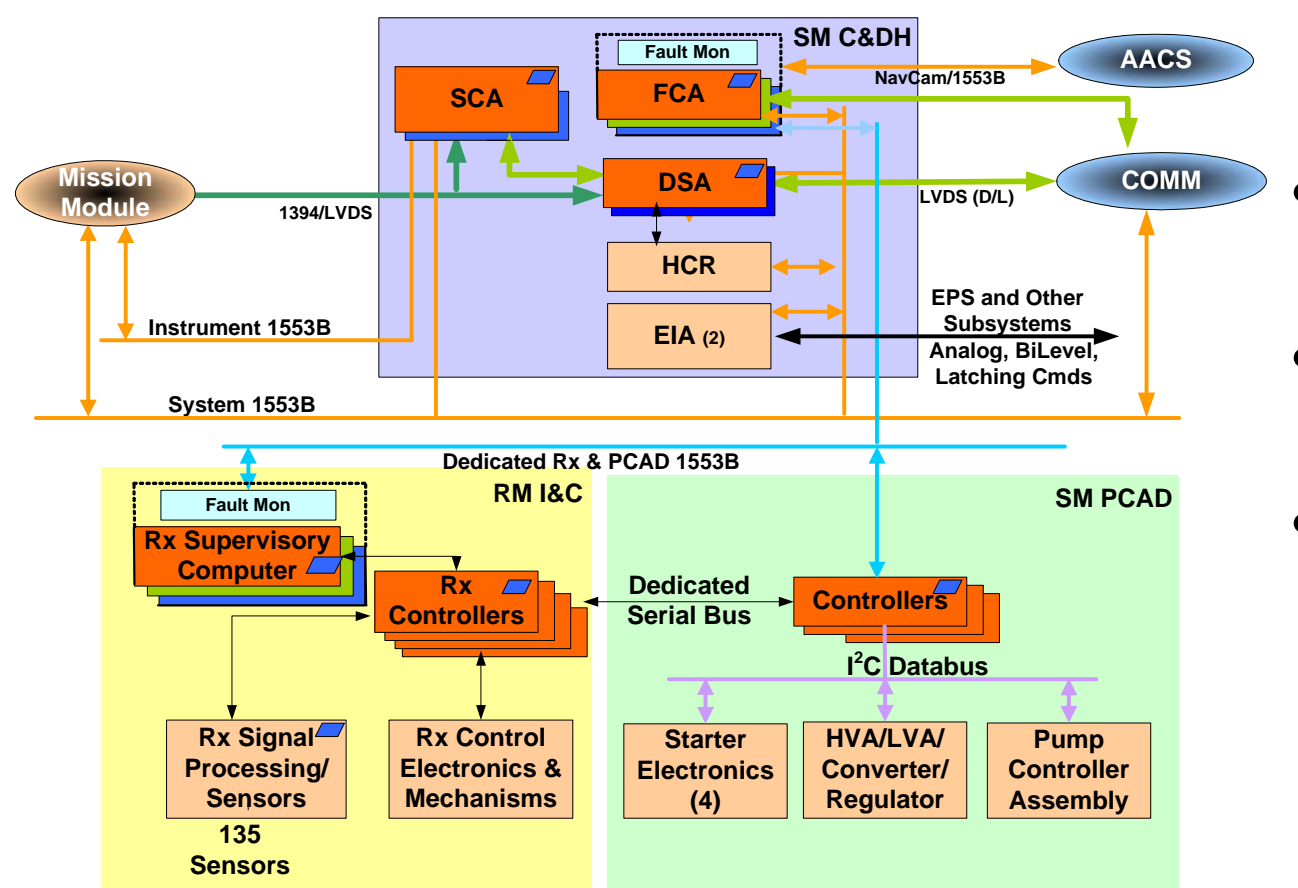

Evaluated Sensor Needs and Sensor Options:

- Hot Leg Temperature Sensors Most Challenging

- Concurrent Development of Options

- Control schemes that avoid use of hot leg temperature measurement

- Fission Chambers selected for nuclear instrumentation

- Rad hard computing electronics for Jovian environment available

- Rad hard sensor electronics require substantial development 


\section{Testing Needs}

- Thermal Testing

- "Test How You Fly"

- Reactor and Plant Hydraulics

- System Integration

- Mass Transport

- Control System Response

- Physics Testing

- Insufficient Existing Benchmarks for Small Fast Reactors

- Fundamental Criticality Experiment

- Cold Critical Mock-up for Integrated Effects

- Hot Critical Experiments for Temperature/Growth Effects
- Materials Testing

- All Fuel System Options Unproven

- Modeling Alone is Insufficient

- Fuel System Performance

- Irradiation Embrittlement and Creep

- Fission Product Corrosion

- Nuclear Prototype

- Integrated Nuclear System

- Lifetime Effects

- Diagnostics

- $\quad$ Flight Unit Testing

- Final Testing

- Thermal testing with Rx Mockup

- Cold Critical on Flight Unit Reactor

\section{Extensive Developmental and Integrated System Testing Needed for Successful Nuclear Development Program}




\section{Extensibility}

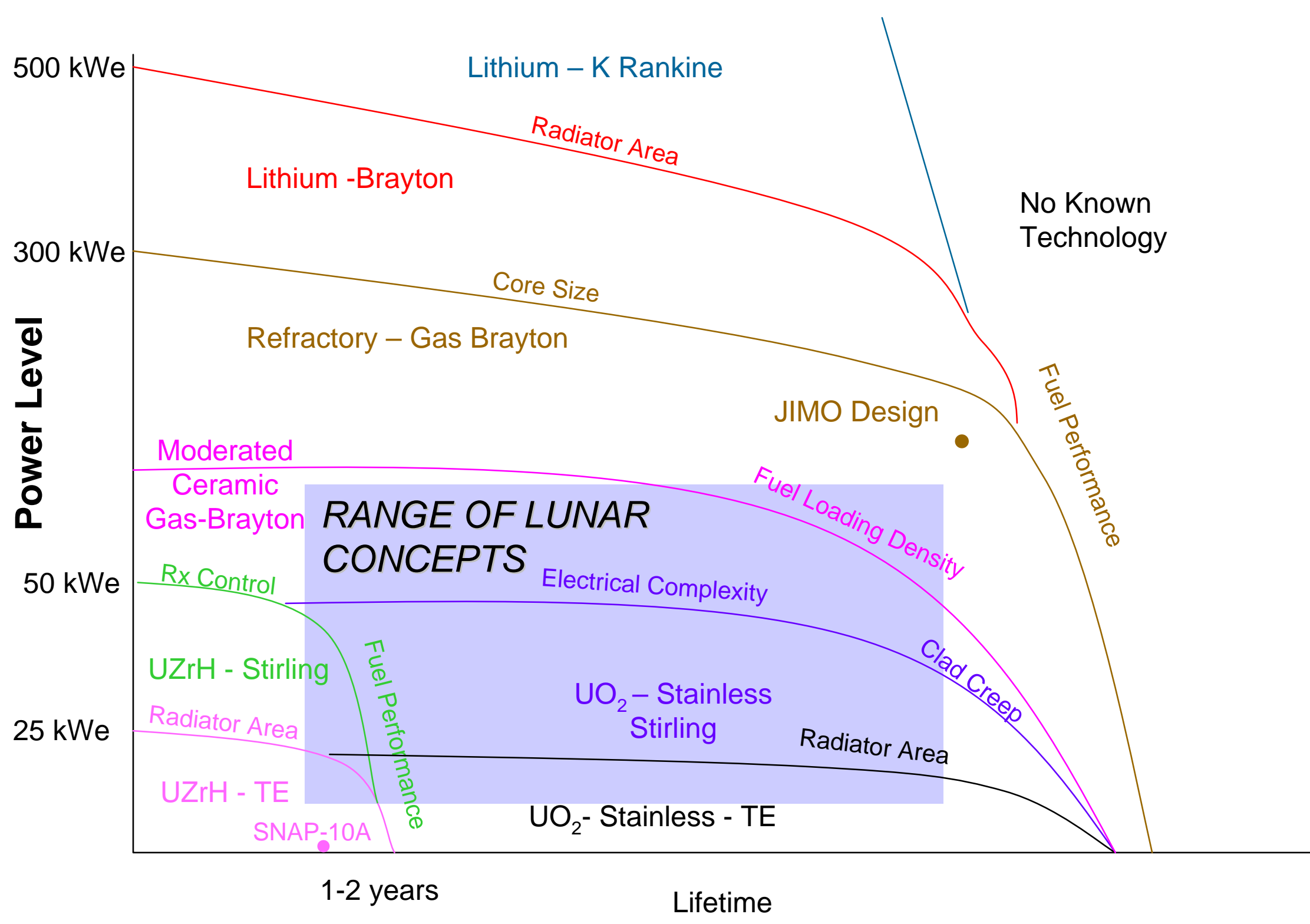

No One Reactor Plant Concept Fits All Missions 


\section{Conclusions}

- Nuclear Electric Propulsion Missions Involving Fission Reactors are Challenging and will Require Substantial Development

- Lifetime

- Autonomy

- Launch/Re-Entry Safety

- Pragmatic Engineering Approach to Reactor Development Led to Selection of Gas Brayton System Based on Deliverability and Testability

- Detailed Evaluation of All Reactor Plant Concepts and their Integration Illuminates Additional Challenges

- Robust Test Program is Essential

- Need to maximize utility of existing infrastructure and expand where essential

- Sufficient Development Timeline and Consistency in Requirements, Funding, Direction and Oversight Needed in any Future Space Reactor Endeavor

- Continued Technology Development, Particularly in Core Materials, is Needed to Better Position Future Space Reactor Development 


\title{
Summary of NR Program Prometheus Efforts
}

\author{
John Ashcroft ${ }^{1}$ and Curtis Eshelman ${ }^{2}$ \\ ${ }^{1}$ Space Energy Conversion, Lockheed Martin KAPL Inc. \\ ${ }^{2}$ Space Reactor Engineering, Bechtel Bettis Inc.
}

\begin{abstract}
The Naval Reactors Program led work on the development of a reactor plant system for the Prometheus space reactor program. The work centered on a $200 \mathrm{kWe}$ electric reactor plant with a 15-20 year mission applicable to nuclear electric propulsion (NEP). After a review of all reactor and energy conversion alternatives, a direct gas Brayton reactor plant was selected for further development. The work performed subsequent to this selection included preliminary nuclear reactor and reactor plant design, development of instrumentation and control techniques, modeling reactor plant operational features, development and testing of core and plant material options, and development of an overall project plan. Prior to restructuring of the program, substantial progress had been made on defining reference plant operating conditions, defining reactor mechanical, thermal and nuclear performance, understanding the capabilities and uncertainties provided by material alternatives, and planning non-nuclear and nuclear system testing. The mission requirements for the envisioned NEP missions cannot be accommodated with existing reactor technologies. Therefore concurrent design, development and testing would be needed to deliver a functional reactor system. Fuel and material performance beyond the current state of the art is needed. There is very little national infrastructure available for fast reactor nuclear testing and associated materials development and testing. Surface mission requirements may be different enough to warrant different reactor design approaches and development of a generic multi-purpose reactor requires substantial sacrifice in performance capability for each mission.
\end{abstract}

Keywords: Space Reactors, Nuclear Electric Propulsion, Direct Gas Brayton, Prometheus, Naval Reactors Program

\section{INTRODUCTION}

This paper summarizes the work completed and future work recommendations of the Naval Reactors Prime Contractor Team (NRPCT) as part of the NASA Prometheus space reactor development project. The majority of the work undertaken was focused on a reactor system suitable to a deep space nuclear electric propulsion (NEP) system, with the Jupiter Icy Moons Orbiter (JIMO) as the first mission.

The NRPCT was made up of engineers and scientists from the Naval Reactors (NR) Program prime contractors: Knolls Atomic Power Laboratory (KAPL), Bettis Atomic Power Laboratory (Bettis), and Bechtel Plant Machinery Inc (BPMI). The NRPCT was initiated in March 2004 with a request from the Secretary of Energy to have the Naval Reactors program team with NASA to design a civilian space reactor for a specific class of missions. A memorandum of understanding between NASA and NR was established which defined the division of responsibilities for the JIMO/Prometheus project. The NRPCT was responsible for all aspect of the reactor plant development and integration, while NASA and its contractors were responsible for the remainder of the spacecraft, the launch vehicle, and the ground systems. The Jet Propulsion Laboratory (JPL) was assigned lead responsibility, with support from the Glenn Research Center (GRC), Marshall Space Flight Center (MSFC), and other NASA Centers. In November 2004, Northrop Grumman Space Technologies (NGST) and its industry partners won the contract to develop the JIMO spacecraft. The NRPCT placed contracts with other national laboratories, including Los Alamos, Oak Ridge, Sandia, Idaho National Laboratory, and Pacific Northwest National Laboratories for reactor plant design, reactor safety assessments, testing, and materials support. This partnership between NRPCT and NASA and DOE facilities was a key element of the development program. Based on reprioritization of missions and funding within NASA, Naval Reactors and NASA discontinued this collaboration in September 2005. An orderly closeout of NRPCT work proceeded through the remainder of 2005.

Three major reports documenting the NRPCT efforts were developed. The first report, a concept feasibility evaluation, was issued in October 2004 (Reference 1). This report reviewed the developmental challenges of a space reactor system, including the reactor design, fuel and materials performance, shielding design, primary coolant transport and compatibility, energy conversion and heat rejection options, and operational concerns. This report determined that all reactor design approaches for supporting the JIMO mission requirements needed considerable development and that the minimization of such development to support the 2015 launch date required selection of the better developed technologies. From this evaluation, fuel and structural materials, as well as integrated system design and testing emerged as the biggest challenges. The JIMO power and 
calendar life requirements, pushed the reactor system operating parameters well beyond any existing reactor system or established technology basis, particularly in the area of required fuel and structural material performance.

The second report was the concept selection report (Reference 2). This report was issued within the NR program in April 2005, and issued to NASA in August 2005. This report documented a lengthy and formal process used by the NR program to evaluate the candidate integrated reactor plant concepts and select a leading approach for development. Based on the feasibility assessment results five concepts were selected for evaluation:

1) Gas reactor - Brayton energy conversion system

2) Heat pipe cooled reactor - Brayton energy conversion system

3) Liquid lithium cooled reactor - Brayton energy conversion system

4) Liquid lithium cooled reactor - Thermoelectric (TE) energy conversion system

5) Lower temperature liquid sodium reactor - Stirling energy conversion system

Based on the overall system features, including capability, reliability, deliverability, cost and safety, the direct gas reactor concept was recommended to NR headquarters for approval. NR headquarters approved the recommendation. The gas reactor system appears capable of fulfilling the mission requirements for the envisioned NEP missions, simplifies engineering development testing, and offers the fewest hurdles to development.

The final report (Reference 3) and its references summarize the work completed between the concept selection recommendation and the program closeout to better define the features and developmental issues of the direct gas Brayton system. These reports include reactor physics, thermal and mechanical design evaluations, reactor core and plant arrangements, integrated system performance estimates, evaluation of material options, instrumentation and control development, and reactor plant operating scenarios. While the majority of evaluations concerned the JIMO/NEP requirements, some evaluation was done regarding extensibility of the concept to surface missions as required in the Prometheus Project Level 1 requirements. Table 1 shows the impact of the NASA Level 2 requirements on the reactor system requirements. This final report also summarizes the plans established for developing, testing and deploying the gas Brayton system. This paper summarizes that closeout report.

The three major reports, as well as key reference reports, will be provided to NASA and DOE and stored in the Office of Scientific and Technical Information (OSTI) Science Research Connection database, administered by the Oak Ridge National Laboratory.

\section{DESCRIPTION OF REFERENCE REACTOR PLANT}

The reference gas Brayton system is depicted in Figure 1. Table 2 shows the reference reactor plant parameter list. Table 3 shows a list of envisioned materials and the concerns for each of the major components in the system. The gas-Brayton concept uses a single gas reactor attached to the forward end of the spacecraft. An inert gas (a helium and xenon mixture was assumed for initial work) is used to cool the core and transport energy around a shadow shield to the Brayton energy conversion system. The core consists of cylindrical uranium containing fuel elements arranged within the core structure. Gas flows either directly over the fuel pins or through channels in a block into which the fuel pins are inserted. The fuel element concept and the assembly of fuel elements within the core are shown in Figure 2. The elements consist of a fuel filler, a gas gap to accommodate differential swelling, a fission gas plenum to reduce fission gas pressure, a cladding liner to improve material compatibility, and the cladding which prevents fission gas escape. Several refractory metal alloys as well as silicon carbide were considered for the cladding. Several core configurations were also investigated. Most configurations utilized a core block which holds the fuel elements in place (Figure 3). An open lattice of fuel elements has also been investigated. The annular block arrangement allowed for simplified heat transfer and greater flexibility in block material selection but required an increased core size to minimize pressure drop. One option for this block arrangement is to use a cermet fuel system, with a refractory metal matrix and small fuel particles. This approach improves heat transfer, eliminates gas plena and leads to a smaller core and shield. However, cermet fuel fabricability and performance are not well characterized at a mass-competitive fuel loading density . Table 4 provides reactor core parameters for a number of the material and arrangement options investigated. The table compares reactor cases, and their impact on mass and shielding required. The table shows how the core designs change with changes in cladding material, core arrangement, coolant pressure, and required reactor power to meet the nuclear and mechanical design requirements. 
The reactor vessel surrounds the core and a combination of fixed and movable reflectors surround the vessel. The movable reflector is segmented and used to maintain reactivity at the desired operating temperature over life. Instrumentation to monitor power and temperature is used to determine when to move reflector segments during reactor startup and to compensate for uranium burn-up during operation. The reactor uses at least one safety shutdown rod. Safety rods are only used during transport and launch and would be withdrawn from the core prior to initial criticality.

The average gas core exit temperature is limited to $1150 \mathrm{~K}(1610 \mathrm{~F})$ in order to allow use of more conventional materials for the plant and energy conversion system and to reduce pressure loading on the fuel element cladding. The hot gas expands through a turbine, which is connected via a common shaft to a compressor and an alternator. The alternator converts turbine power into electricity used by the on-board ion propulsion system, on-board computers, science and health monitoring instruments, and communications systems. After passing through the turbine, the gas passes through a regenerative heat exchanger (a recuperator) and a gas cooler. The cooled gas is then pumped back through the recuperator and to the core by the compressor. Heat is transferred from the gas cooler to the heat rejection system radiators via a pumped liquid loop (water or NaK). The high frequency, three-phase power coming from the Brayton unit or units is conditioned using the power conditioning and distribution (PCAD) system to provide high voltage to the propulsion units and low voltage to the computers and instruments. Excess power not used by the propulsion system or the on-board electrical equipment is shed via a controllable parasitic load radiator (PLR). The range of component mass estimates and overall heat balances are shown in Figure 4 and 5 respectively. Reactor and shield masses range from 3,000$5,000 \mathrm{kgs}$ for a $1 \mathrm{MWt}$ system. The total SNPP mass is between 7,500 and 11,000 kgs, depending on the reactor type and plant configuration.

\section{Key Technical Findings}

\section{Reactor Design}

Hundreds of parametric studies were performed to understand the range of reactor design options as a function of materials, core arrangements, and operating conditions. No reference reactor core concept was chosen prior to project closeout. A range of reactor design options was considered, including both unmoderated and moderated reactors. A fast (unmoderated) reactor spectrum offers a lower overall mass than a moderated spectrum in the range of JIMO power and lifetime requirements. The fast reactor will require several hundred kilograms of highly enriched uranium. The primary reactor physics challenge is ensuring adequate reactivity level for normal operating conditions while maintaining the reactor sub-critical during assembly, transport or launch accidents. To ensure shutdown during a water flooding, sand immersion, or compaction casualty, a combination of spectral shift poisons and in-core safety shutdown rods are envisioned.

The reactor physics uncertainties with this compact, reflector-controlled fast reactor necessitate a reactor physics qualification approach, including fundamental integral cross section testing, representative material and geometry critical testing, cold and hot critical physics experiments, and detailed physics testing on a ground prototype.

Reactor safety and reactor fuel safeguards need to be an integral part of the reactor development process. Designing the core to ensure public safety during all phases of assembly, transport and launch, including launch casualties, was a key part of the NRPCT development strategy. A key reactor safety challenge is to ensure public safety in the event of a re-entry accident. Considerably more modeling and testing would be needed to fully understand the potential of criticality and energy release on impact. Depending on the impact predictions, additional safety devices may be needed.

Reactor thermal hydraulic performance is challenging due to the low operating pressure (2-3 MPa), the properties of the helium-xenon gas mixture and the need to maintain a low reactor core pressure drop to maximize system performance. The maximum fuel element surface temperature is approximately $1300 \mathrm{~K}$ during normal full power operation. Sensitivity studies were performed for the range of fuel element sizes, flow configurations, and reactor materials to balance heat transfer and pressure drop through the core.

No final decision was made regarding segmented axially translating reflector sections ("sliders") versus rotating drums for reactivity control. Control drums offer simpler control mechanism design, greater certainty in measuring control device position, and a more rugged mechanical design, but have reduced reactivity control worth relative to sliders. Sliders offer a lower mass system and a more linear differential control worth. Most of the reference reactor nuclear and mechanical design work assumed sliders. 


\section{Reactor Materials}

The NRPCT developed preliminary estimates for both uranium nitride and uranium oxide fuel performance in order to judge their acceptability for NEP missions, including the expected rate of fuel swelling, the fission gas release rate, and the chemical compatibility with the fuel liner and cladding. Both uranium nitride and uranium oxide fuels were judged as feasible (in concept) to meet NEP mission requirements. Uranium nitride will lead to a lower mass reactor due to its higher fuel density and higher thermal conductivity. As part of the program, Los Alamos National Lab reproduced the uranium nitride processing approach used during the SP-100 program (Figure 6). However, demonstrating long term compatibility with the fuel cladding systems would be more challenging for the nitride system than for the more fully tested oxide fuel system. NRPCT planned to pursue the uranium oxide fuel system for the JIMO mission in order to minimize the development challenge.

All of the fuel element cladding options considered require substantial development. $\mathrm{Nb}-1 \mathrm{Zr}$, the reference alloy used in past space reactor concept development (SP-100 and SNAP-50), has poor creep capability. Using Nb$1 \mathrm{Zr}$ cladding will reduce the allowable reactor temperature, increase the gas plenum size, and increase reactor assembly mass relative to stronger refractory alloys. Stronger refractory metal alloys such as FS-85, Ta-10W, and ASTAR-811C offer potentially better creep strength. However, niobium and tantalum alloys likely require protection, via liners and coatings, from fission product corrosion and from the low oxygen and carbon partial pressures in the gas coolant. Mo-Re alloys offer the potential of improved fuel and coolant compatibility, but suffer from phase instability and irradiation embrittlement. A silicon carbide composite clad fuel system requires more work to evaluate cladding hermeticity, toughness, and irradiation performance. Based on the developmental challenges with each system, a number of candidate materials were being carried through initial testing, including irradiation testing. Preliminary materials tests were underway at the Oak Ridge National Laboratory HFIR reactor and planned for the Japanese JOYO fast reactor.

NRPCT had an objective to use nickel superalloy pressure boundary on all parts of the reactor plant to simplify manufacturing, eliminate dissimilar material bonds at pressure boundaries, and allow for extensibility to lunar and Martian surface missions. Superalloy pressure boundaries are limited in temperature by creep capability. The reactor vessel and loop piping concept developed concentrates on maintaining the pressure boundaries at or below $\sim 900 \mathrm{~K}(1160 \mathrm{~F})$. Properties for Alloy 617 were used in reactor vessel and loop piping analysis due to the greater data pedigree compared to other wrought nickel superalloys being considered. The reactor vessel is cooled using a combination of the cooler reactor inlet gas and radiative cooling. The hot leg piping temperature is maintained below $900 \mathrm{~K}$ through the use of internal insulation in the piping. Compatibility between the nickel superalloy structure and core materials remained an open issue. Nickel superalloys were shown to be more compatible with silicon carbide, graphite, and molybdenum alloy core structures than with the niobium or tantalum alloys based on thermochemical analysis and review of limited test data. One potential issue that may have precluded the use of nickel superalloys for the entire pressure boundary is the higher temperature and fluence on the safety rod enclosure (thimble). Approaches for effectively cooling the thimble, or for internal safety rods were under consideration. Refractory metals were considered as a back-up approach for the hot pressure boundaries. However, refractory metals at operating temperature are intolerant of oxygen and carbon containing impurities. The use of refractory metals in the pressure boundary would require development of dissimilar material joining, increase the difficulty of earth-based testing, limit lunar and Mars surface extensibility. Potential methods to mitigate these incompatibilities using coatings were being evaluated.

\section{Reactor Shielding}

Shielding the remainder of the spacecraft from reactor radiation is a trade-off between mass, materials development, and the allowable dose to mission electronics. Neutron shielding material options evaluated included lithium hydride, water, beryllium, and boron carbide. Tungsten is considered to be the best gamma shield material based on its high density and moderate cost. Lithium hydride-based neutron shielding, which require $\mathrm{Be} / \mathrm{B} 4 \mathrm{C}$ for the high flux portion of the shield, provide a slightly lower overall mass than concepts without lithium hydride. However, a full Be/B4C shield is considered to be a lower cost, lower risk option. Water shielding is also mass competitive with lithium hydride. Reliability of $\mathrm{LiH}$ or water shielding systems would require further evaluation.

Shielding model results showed that the control drive mechanism penetrations can be made without substantial impact on the shield effectiveness. Gas pipe radiation streaming can be controlled by spiraling the piping around within the outer surface of the shield. The overall shield thickness must increase to retain the same shielding effectiveness as a reactor without large gas piping. Additional pipe shielding was not required. The effectiveness of the shielding remains adequate even for relatively high rates of fission product release (up to 
$10^{-3}$ release to birth ratio of volatile fission products) from the fuel into the gas coolant. However, the effect on the alternator would require further study.

\section{Reactor Plant Design}

As with the reactor design, parametric studies were completed to understand the range of design option available for integrating the reactor and the energy conversion system within the gas loop. Preliminary design and analysis indicates that the overall gas reactor plant performance is sensitive to the detailed design and system layout. Parasitic heat loss and pressure drop, as well as minor inefficiencies in energy conversion components can lead to large impacts on overall system performance. Similarly, the system performance is very sensitive to the operating conditions such as temperature and the uncertainty in those operating conditions. This leads to a need for careful design and developmental testing, and a strong development program to reduce performance, operational and measurement uncertainties.

Reactor plant transient analysis, performed on a range of concepts with three separate modeling tools, has not revealed any inherent instabilities in the plant response to planned and unplanned transients, either with a single Brayton or multiple units, assuming the overall reactor temperature coefficient is negative. A negative temperature coefficient is predicted for the core designs considered. The sufficiently high thermal mass of the reactor core and recuperator limit the rate of temperature change during the analyzed transients and minimize over-temperature concerns. No rapid reactor control system response is required to maintain the reactor within the desired temperature range during these transients. The most severe operational transient appears to be a loss of Brayton load and speed control, which leads to an increase in reactor power and flow and the potential for overloading the heat rejection system. The likelihood of such a Brayton control system failure must be minimized through reliable electrical system design. Figure 7 shows the plant response, assuming no control system function, to a loss of load in a two unit Brayton plant. Note that while the reactor temperature increase is relatively mild, the heat rejection temperature increases considerably, creating concern for heat rejection system materials and operability. Responding to this loss of load casualty with an increased heat rejection system flow and/or closing of control valves in the affected Brayton loop would be required to protect against overpressurizing the gas cooler in this loop.

Evaluation of Brayton system component performance, in cooperation with NASA GRC and turbomachinery vendors, has confirmed the conceptual feasibility of developing a long lived 100-200 kWe Brayton system. Similar open loop, combustion heated Brayton engine system units have operated at similar power levels in terrestrial and aerospace applications. Rotordynamic evaluations, bearing and alternator cooling studies, and recuperator and gas cooler design and performance studies all indicate such a system could be successfully developed. Known open issues include integrated system response, materials compatibility within the system, and gas leakage through welds, electrical feed-throughs, and heat exchangers. Separate effects testing and integrated system testing, as envisioned for the next steps in this program, would be necessary to better judge Brayton system performance and reliability.

Early in the design development, NRPCT investigated both direct and indirect gas cycles. The indirect gas cycle allowed for separation of the reactor coolant gas from the Brayton working fluid. This allowed for isolation of the Brayton loops and optimization of the gas composition in each loop. However, the indirect system required powerful gas circulators for the primary coolant and massive gas to gas hot heat exchangers. The direct gas system is considered to be the only practical gas reactor approach.

A decision concerning the energy conversion system redundancy was not made. A range of concepts, from a single Brayton unit to concepts with multiple operating units and spares have been considered. Figure 8 depicts the potential arrangement of one, two, three or four Brayton units. For the NEP missions, use of a single Brayton converter offers the simplest and most efficient system, eliminating piping manifolds and valves (and associated pressure drop), minimizing arrangement complexity and mass, and simplifying operation. Based on NASA-developed turbomachinery models and pressure drops from the investigated loop arrangements, the efficiency of a single loop system was expected to be $10-20 \%$ higher than that of a four loop system. This could allow for either reduction in the required reactor power and radiator area, or a reduction in maximum gas temperature. However, failure of this single Brayton would be a mission ending failure. The next simplest system that would require two operational units (each producing half power) with a single spare. If spare units are carried, using an on/off control approach for the spare unit best preserves system performance compared to operating all units at a fraction of full capacity.

The capability and performance of the heat rejection system is intimately linked to that of the reactor system. This is particularly true of a water heat rejection loop since the pressure of the water loop will be very sensitive to the operating temperature and the uncertainty in operating temperature. Analysis of the failure modes in the 
Brayton system and the heat rejection system indicated the need to design the water heat rejection loops to handle operating pressures as high as $10 \mathrm{MPa}$. Lifetime degradation of radiator performance, due to changes in effective emissivity and isolated heat pipe failures will lead to a slow increase in radiator temperature. This will require a comparable increase in reactor exit temperature to compensate. NRPCT analysis confirmed NGST estimates of water heat pipe performance capability, but water heat pipe performance at high temperature and high heat flux requires continued development and demonstration.

The performance of the gas cooler, which is the interface between the reactor system and the heat rejection system, is key to the reliability of the overall plant due to its high surface area and the high heat rejection system pressure. Preliminary vendor design concept development, sponsored by the NRPCT, studied plate-fin, shell and tube, printed circuit board, and hybrid heat exchanger configurations. Mass estimates from all of these vendors are considerably higher than the initial NASA and contractor estimates.

\section{Instrumentation and Control}

A robust evaluation of candidate sensors has been completed. Technologies appear to be available for all key plant parameters including temperature, neutron flux, pressure, mechanism position, and coolant flow. Significant development remains to deliver and qualify both sensors and interface electronics for long duration space missions. Major technical challenges are lifetime, operating temperature, accumulated radiation dose, and the need to operate without recalibration. The most challenging sensor application is hot leg temperature due to the lifetime degradation of the sensors at temperature and the need to integrate the sensor with internally insulated loop piping. The most promising sensor technology for this application is judged to be sapphire fiber Bragg gratings, which have the potential for adequate stability over life.

A control system architecture has been developed, including recommended redundancy, interfaces with the spacecraft, number of sensors and board count. The control architecture provides for autonomous reactor operation and fault management with a simple system. Electronics for the control system that can withstand the Jovian radiation environment for the intended mission duration appear to be available. Computing electronics in particular are judged to be low risk based on available technologies. Analog electronics for use particularly in the sensor conditioning circuits are a significant technical challenge and would require development of custom application-specific integrated circuits to achieve the level of radiation hardness and reliability needed, The JIMO mission schedule would have required immediate near term actions to develop these electronics.

A plan for control system software development for JIMO was completed, and selections made for process management, interfaces with other systems, and software design. For the reactor controller, emphasis was placed on high reliability software design with simple operating structures. Algorithms for system control and autonomy are not yet developed.

Reactor and reactor plant startup is the most complex operation envisioned for the control system. Start-up requires tight control over the reactor through the rate of reactivity insertion, and simultaneous control of the Brayton speed through use of a start inverter and parasitic load regulator. A reference start-up procedure has been developed. This startup approach has not been fully modeled or refined.

\section{PROGRAMMATIC CONCLUSIONS}

\section{Testing Needs}

As mentioned above, the selection of a cladding materials for the reactor could not be finalized because of the uncertainties associated with all of the material options. Both in-core irradiation testing and out-of-pile creep and thermal stability tests of the candidate alloys are needed. Similarly, irradiation, creep and compatibility testing are needed for core and plant structural materials. This testing is expensive, time consuming and requires use of assets with capabilities no longer available in the United States. Specifically, it should be noted that a fuel system with sufficient capability to meet the long time (>10 years) at high temperature (up to $1800 \mathrm{~K}$ ) is unprecedented and the consequences of widespread fission product release on radiation dose levels behind the shield, coolant chemistry, and corrosion necessitate this testing. The fast spectrum associated with the space reactor also dictates the use of a fast reactor for irradiation testing, both to mimic the prototypical conditions and to speed accumulation of fast neutron fluence in accelerated tests. Since the United States has no such facilities, the NRPCT was preparing to utilize the JOYO test reactor in Japan. Even for more modest space reactor missions, where use of more well established materials is possible, some irradiation testing will be needed. Such irradiation testing of potential reactor fuel systems is a critical and challenging long-term development need. 
Fast reactor neutronic performance is very sensitive to both materials and geometry. Less conventional materials, such as tantalum, tungsten, molybdenum, and rhenium were considered. Some of these materials have never been used in meaningful quantities in a reactor before. Uncertainties with rhenium and other nuclear material cross-sections must be resolved to improve confidence in design predictions during the early design stages. Similarly, the reactor neutronic performance is sensitive to small changes in reactor geometry due to thermal expansion, fuel swelling, thermal creep and irradiation induced creep. Developing and demonstrating the ability to design for these effects dictates a need for cold and hot critical reactor physics performance testing. There are currently no operational critical facilities in the United States. Options for recreating these test facilities have been evaluated, but no conclusions on the optimal site for such tests were made.

Overall nuclear plant performance is predicted to be very sensitive to minor losses and inefficiencies in the system and the accuracy of the instrumentation. At this early stage, overall uncertainty in the system efficiency is as large as $50 \%$. That is, the worst case estimates of temperature measurement accuracy, turbomachinery performance and loop flow resistance lead to a $\sim 50 \%$ change in output compared to the most optimistic case. Therefore, system testing is needed to better understand and reduce these losses as well as to bring to light system engineering and control challenges and issues. Another reason to prioritize these tests early in the development process is to uncover any system chemical incompatibilities. While careful materials selection minimizes gross material incompatibilities, early testing often points out overlooked issues that can be corrected prior to larger scale testing. Early integrated system testing was planned using electrically heated reactor mockups with the thermal test module (TTM), followed by a more prototypical engineering model (EM) and a fully prototypical qualification model (QM). Figure 9 shows a representation of the system testing approach envisioned. Such integrated system testing of gas Brayton systems is a critical and challenging long term need.

Development of test hardware and test results is predicated on development of manufacturing methods for key components. NRPCT had performed initial manufacturing trials on candidate fuel and structural materials, primarily through subcontract. Small quantities of all refractory alloys under consideration were manufactured for materials testing and NRPCT was preparing to purchase production ingots of promising materials at project termination. Long term space reactor development will need to re-establish material supplies and manufacturing capabilities to ensure high quality and repeatable component performance.

A final conclusion on the need for a ground prototype reactor plant was not made during the course of the project. However, a ground prototype was a baseline NRPCT project assumption and planning was initiated in accordance with the requirements of the National Environmental Protection Act (NEPA). A prototype would likely be necessary as a means to demonstrate manufacturing and assembly, establish nuclear performance, confirm system dynamic operating characteristics, investigate lifetime effects, and uncover any additional system integration issues. All prospective sites considered in the initial prototype scoping study required considerable facility modifications.

\section{Assembly, Test and Launch.}

NRPCT developed a draft approach for prototype and flight unit construction, transport and assembly with the spacecraft. This approach, as outlined in Figure 10, minimizes the transport and safeguards requirements for the reactor cores by minimizing the number of facilities required to handle the small, highly enriched core. Considerable early planning for core fabrication, assembly, transport and testing prior to launch is needed.

\section{Formal Engineering Design Basis}

Development of a formal engineering design basis was initiated as an essential near term priority. Development of a consistent set of material properties, updated to include emerging data, was underway. The reactor and core structural design basis was being developed based on guidelines from the ASME high temperature code, foreign gas reactor structural design bases, and from past space reactor development. Reducing uncertainties while maintaining appropriate design conservatism requires careful review of data and analytical methodologies. Formal design bases were also being developed for reactor safety, reactor nuclear design, and fuel performance limits.

\section{Formal and Timely Decision Making}

Over the course of the 18 month program, the NRPCT evaluated all reasonable reactor and energy conversion technologies and selected a reference coolant and energy conversion approach that offered the best prospect of meeting NASA mission requirements within the schedule and cost constraints. The NRPCT also recommended the use of uranium oxide fuel. NRPCT was working to select reference core and plant structural materials, a 
reference plant arrangement and reference operating conditions in fiscal year 2006. Each of these major decisions was being made through detailed study, formal review and debate, and formal recommendation to Naval Reactors headquarters. The rapid pace of these early design decisions was needed to concentrate efforts and maintain the design and testing schedules. While some back-up materials would have been carried, in general NRPCT determined that the best prospects for successful delivery lay in devoting most resources to engineering the best system rather than maintaining multiple back-up design concepts.

\section{Regulatory Review}

For the Prometheus project, public information sessions were held by NASA and NR to initiate the process for a preliminary environmental impact statement (PEIS), as dictated by the National Environmental Protection Act (NEPA). Work was initiated to define the reactor plant options and ground based testing needs using a predecisional scoping approach. The schedule of follow-on design and testing activities would be guided by compliance with NEPA requirements.

\section{Development Timeline and Cost}

The timeframe for development and deployment of the JIMO mission reactor system was $\sim 11$ years. Given the need for materials testing, criticality testing, system testing and a ground based prototype, the development timeline established for the JIMO program was very aggressive. There was little or no time to recover if initial technology choices proved unworkable, and basic technology testing and validation would have to be completed in parallel with plant construction and operation, adding to program risk. To ameliorate this concern in future projects, the scope and timescale required for an engineering development, manufacturing and testing effort of this magnitude must be understood from the beginning, and appropriate funding and mission consistency must be sustained through the duration the program. Consideration of less aggressive mission requirements for initial missions could allow for initial applications with more readily available technologies, while longer term advanced technologies are pursued in parallel for follow-on missions.

The gas reactor concept was selected in part because it minimized the expected development time and cost. However, the space reactor planning estimate for the work, including a ground test reactor, was still substantial ( $\$ 3.5$ billion). The development scope was driven by the functional requirements for JIMO, particularly the very long core calendar life. Development of long-lived nuclear reactors is exacting, time consuming and testing intensive. This necessitates high labor and facility costs starting early in the development process. Expectation of a rapid and inexpensive reactor development and deployment to meet unprecedented performance requirements would be unwise and misleading.

\section{Programmatic Leadership and Decision Making}

The central programmatic challenge for this project was to develop a single integrated engineering culture from the many organizations, diverse technical cultures, and limited overlapping experience base, for a space reactor project possessing unprecedented requirements. Reactor development requires tight coordination and communication within and across many government agencies, laboratories, and industrial partners. The responsibility and authority of a central DOE agency, in this case the NR Program, to lead and manage all aspect of the space reactor power plant development and use is essential to a successful long term program. During the Prometheus effort, the NR Program managed all aspect of the nuclear work, including subcontracted development effort at other DOE Laboratories. Work performed by other National Laboratories and NASA Centers partners was essential to the progress made by the NRPCT. Table 5 summarizes the key roles played by these organizations. While the work did not proceed to completion, a centralized authority which develops the reactor design and coordinates the use of the limited national nuclear infrastructure remains the best approach for completion of new nuclear development tasks.

\section{Extensibility to Other Missions}

The NRPCT performed a limited amount of work to judge the extensibility of the gas reactor Brayton concept. The direct gas Brayton concept remains mass competitive with other reactor concepts over a range of powers between $25 \mathrm{kWe}$ and $300 \mathrm{kWe}$. Figure 11 shows the approximate range of reactor coolant, fuel material and energy conversion technology applicability as a function of power and energy. At the low end of this power range, the reactor and its shield become the mass limiting items, allowing lower temperature liquid metal concepts to become more mass competitive. Linking a lower temperature liquid metal reactor with a Stirling energy conversion system maintains system efficiency at more moderate temperatures $(\sim 900 \mathrm{~K})$ and allows for the use of more conventional stainless steel - uranium oxide fuel systems. However, trade studies performed on potential electric power distribution systems show a clear preference for Brayton cycle energy conversion 
when compared to thermoelectrics or Stirling. This advantage is due to the inherent ability of Brayton converters to produce high frequency AC power which is simpler to convert and distribute over long distances.

Thermoelectric and Stirling power conditioning systems are feasible, but have substantial mass and reliability drawbacks when compared to Brayton systems at these power levels. Also, even low temperature liquid metal systems require special facilities for liquid metal processing, purification, and safe testing.

At the high end of the power range (above $300 \mathrm{kWe}$ ), the mass and hydraulic advantages of a high temperature liquid lithium reactor system over a gas reactor system become more pronounced. The mass advantage of a liquid lithium system would need to be balanced against its increased design and materials development, testing, and operational complexity.

One approach for a mission architecture that has been proposed is to deploy a space reactor with an easier low temperature liquid metal for a low power application and then "scale up" to a higher power capable system for follow-on missions. However, scaling up liquid metal systems, for example from NaK to lithium, from steel to refractory metals, and from TE to dynamic converters has a number of critical and varying engineering development challenges with regard to the higher power system that are not directly addressed with the low power application. In essence, such an approach would require working on two completely different systems.

Gas reactor Brayton systems also conceptually appear well suited for surface missions. The environmental conditions such as electrostatic dust and sink temperature variability bring a greater desire for conventional structural materials and non-freezing transport fluids. Surface missions may also bring with them more modest power and lifetime requirements than for JIMO or other NEP missions. Lower power levels and shorter lifetime demands reduce some of the development requirements for the gas reactor.

Notional low power and lifetime requirements for surface missions also open up the possibility of a mass competitive neutronically moderated gas reactor. Such a system could allow for conventional gas reactor fuel systems, require substantially less fuel, simplify reactor control, and reduce the need for extensive criticality testing. One approach is a water moderated gas reactor (Figure 12). In this concept, gas flows over fuel elements housed within pressure tubes within a vessel containing a mixture of light and heavy water. The water softens the neutron spectrum, enabling the use of a TRISO high temperature particle fuel system. This reactor has considerable mechanical and thermal design challenges and would require detailed concept development, based on firm mission requirements, to better judge feasibility. At the JIMO power and lifetime requirements, advanced TRISO particles, with higher than current state-of-the-art loading densities would be necessary to attain a mass-competitive design.

\section{Future Technology Development}

The scope and nature of the development challenges, together with the flexibility and extensibility of the gas reactor concept makes it well suited, in concept, for a number of space reactor missions. Therefore, any future concept development work should include the gas reactor Brayton system in its evaluation. Any continuing funding of space reactor work should include funding for non-nuclear testing of a $\sim 100 \mathrm{kWe}$ Brayton system. However, mission requirements may dictate solutions other than a gas reactor. A knowledgeable and experienced nuclear systems engineering organization should be intimately involved in early mission planning stages to provide a realistic understanding of what nuclear systems engineering and development are needed to accomplish mission objectives.

A key parameter in satisfying a large range of missions for space reactors is high temperature operation. Conventional materials, operating with reactor outlet temperatures of $\sim 900 \mathrm{~K}$, can provide only marginal capability to surface missions and NEP missions. Gas-Brayton systems extend power capability by raising coolant temperature to $1150 \mathrm{~K}$ or more while maintaining conventional high temperature materials for majority of the reactor plant. NRPCT concludes that the technologies for a gas-Brayton system are within reach for a first space reactor mission, either for surface power or NEP. Further improvements in power and energy density beyond the capabilities of a gas reactor system can only be achieved through widespread use of refractory metals in liquid metal systems, which will require greater development, particularly for materials compatibility and lifetime integrity. Given that there may be time prior to initiation of another large scale space reactor project, development of these key technologies and test hardware might create the potential for improved reactor power and energy density:

1) Irradiation testing of refractory metal clad uranium nitride fuel elements.

2) Thermal and irradiation creep testing, together with thermal and chemical stability testing of candidate refractory metals. 
3) A high temperature $(>1200 \mathrm{~K}$ ) refractory metal liquid lithium flow loop to demonstrate electromagnetic pumping, gas separation, freeze/thaw behavior, and long term compatibility.

4) Reactor safety modeling and testing, to better understand impact dynamics and effect on reactor design.

5) Demonstration of water heat pipes for heat rejection systems with operation at greater than $550 \mathrm{~K}$ and greater than $10 \mathrm{~W} / \mathrm{cm}^{2}$ radial heat flux and development of heat pipe coolants for operation above 550 $\mathrm{K}$.

\section{CONCLUSIONS}

A substantial amount of work was initiated by the NRPCT to select and develop a concept for a gas-Brayton space reactor for the Prometheus project. The three major technical reports - the feasibility study, the concept selection report, and the close-out report - have been formally issued and stored in the Office of Scientific and Technical Information (OSTI) Science Research Connection database. These reports can inform future developers of space reactors on the work completed during this phase of the Prometheus program.

\section{REFERENCES}

1) KAPL Letter SPP-67410-0014, "Documentation of the NR Program Assessment of the Design Space for the Prometheus 1 Project," Reissue Date 2/13/2006.

2) KAPL Letter SPP-67110-0007 / Bettis Letter B-SE-0143, "Documentation of Space Nuclear Power Plant Concept Selection," July 2005.

3) KAPL Document 67110-0008 "Prometheus Project Reactor Module Final Report" Dated $1 / 31 / 2006$. 
Table 1. Design Requirements and Their Impact on Reactor Requirements

\begin{tabular}{|c|c|c|}
\hline Key Level 2 Requirement & Impact on Reactor Module & Implementation \\
\hline $\begin{array}{l}\text { The Space Nuclear Reactor design shall } \\
\text { utilize technologies that facilitate } \\
\text { extensibility to surface operations. }\end{array}$ & $\begin{array}{l}\text { Drives selection of design and materials } \\
\text { compatible with Lunar and Mars } \\
\text { missions. }\end{array}$ & $\begin{array}{l}\text { Must consider compatibility of } \\
\text { pressure boundaries and external } \\
\text { surfaces with surface } \\
\text { environments. }\end{array}$ \\
\hline $\begin{array}{l}\text { The Project shall use a Deep Space Vehicle } \\
\text { that provides jet power greater than or equal } \\
\text { to [130] } k W \text { of primary thrust during thrust } \\
\text { periods. }\end{array}$ & $\begin{array}{l}200 \mathrm{kWe} \text { reactor module power output } \\
\text { required to deliver net thruster power. }\end{array}$ & $\begin{array}{l}\text { Plant Electrical Power }=200 \mathrm{~kW} \\
\text { Plant Thermal Power } \sim 1 \mathrm{MW}\end{array}$ \\
\hline $\begin{array}{l}\text { The Project shall design the Deep Space } \\
\text { Vehicle to have an operating lifetime greater } \\
\text { than or equal to [20] years. }\end{array}$ & $\begin{array}{l}20 \text { year life is long term requirement for } \\
\text { very deep space missions. The JIMO } \\
\text { requirement is for } 12 \text { years. }\end{array}$ & $\begin{array}{l}\text { Initial design efforts to support } 15 \\
\text { year operational life. } \\
\text { Long term design goal is to satisfy } \\
20 \text { year life requirement. }\end{array}$ \\
\hline $\begin{array}{l}\text { The Project shall use a Reactor Module that } \\
\text { is capable of generating the maximum } \\
\text { electrical power required by the Spaceship } \\
\text { for a cumulative minimum of [10] years, and } \\
\text { is capable of generating the minimum } \\
\text { required electrical power for the rest of the } \\
\text { operating lifetime. }\end{array}$ & $\begin{array}{l}\text { This requirement permits the option of } \\
\text { reducing power in order to conserve } \\
\text { reactor energy or reduce pressure and } \\
\text { temperature during non-thrust phases. } \\
\text { This may maximize reactor module life } \\
\text { for the most demanding follow-on } \\
\text { missions to the outer solar system. }\end{array}$ & $\begin{array}{l}\text { Trade studies would be required } \\
\text { to determine if reduction of power } \\
\text { would improve reactor module } \\
\text { longevity. }\end{array}$ \\
\hline $\begin{array}{l}\text { The Project shall comply with the } \\
\text { Prometheus Single Point Failure Policy as } \\
\text { documented in the Prometheus Project } \\
\text { Policies Document 982-00057. }\end{array}$ & $\begin{array}{l}\text { Single point failure locations shall be } \\
\text { avoided. Where this is not practical } \\
\text { (e.g., reactor), must demonstrate that } \\
\text { alternatives to single point failure are } \\
\text { not available and show sufficient } \\
\text { robustness to mitigate risk of failure. }\end{array}$ & $\begin{array}{l}\text { Where possible, redundancy } \\
\text { would be part of the reactor } \\
\text { module design. }\end{array}$ \\
\hline $\begin{array}{l}\text { The Project shall be able to autonomously } \\
\text { detect and correct any single fault that } \\
\text { prevents thrusting in less than or equal to [1 } \\
\text { hour]. } \\
\text { (Note: Missing thrust during many of the } \\
\text { mission phases severely jeopardizes } \\
\text { mission success, and therefore should be } \\
\text { prevented or minimized.) }\end{array}$ & $\begin{array}{l}\text { This requirement must be considered in } \\
\text { the design of instrumentation and } \\
\text { control for a self-regulating plant and } \\
\text { design for recovery from transients for } \\
\text { which the module would be designed. }\end{array}$ & $\begin{array}{l}\text { Robust and redundant system } \\
\text { architecture for instrumentation } \\
\text { and control } \\
\text { Automatic recovery from } \\
\text { transients must be considered in } \\
\text { system design. }\end{array}$ \\
\hline $\begin{array}{l}\text { The Spaceship shall survive without Ground } \\
\text { System commanding for at least [50] days } \\
\text { in the presence of a single failure. }\end{array}$ & $\begin{array}{l}\text { Must consider this, with other autonomy } \\
\text { and single point failure requirements, in } \\
\text { design of the control system. }\end{array}$ & $\begin{array}{l}\text { Design for redundancy and } \\
\text { robustness wherever practical. } \\
\text { The spaceship cannot survive in } \\
\text { deep space for more than a short } \\
\text { time without reactor power. }\end{array}$ \\
\hline $\begin{array}{l}\text { The Project shall assure that all Science } \\
\text { System hardware in its deployed } \\
\text { configuration, except approved science } \\
\text { hardware, shall remain within the protected } \\
\text { zone of the reactor radiation shield. }\end{array}$ & $\begin{array}{l}\text { Coordination between the shield and } \\
\text { spaceship designs is required to assure } \\
\text { that maximum dose levels are not } \\
\text { exceeded. Shielding of local } \\
\text { electronics will also be required. }\end{array}$ & $\begin{array}{l}\text { Shielding Sufficient to reduce } \\
\text { neutron flux } \sim 10^{5} x \text { and Gamma } \\
\text { Flux } 100 x \text { and must cover roughly } \\
\text { a } 12^{\circ} \text { by } 6^{\circ} \text { cone angle. }\end{array}$ \\
\hline $\begin{array}{l}\text { The Project shall obtain launch approval as } \\
\text { specified in the Prometheus Launch } \\
\text { Approval Plans. }\end{array}$ & $\begin{array}{l}\text { To meet this requirement, satisfaction } \\
\text { of various governing safety } \\
\text { requirements would have to be } \\
\text { demonstrated by NRPCT and NASA. }\end{array}$ & $\begin{array}{l}\text { Design features will be required to } \\
\text { assure safety. Safety assurance } \\
\text { must be considered during design } \\
\text { of certain Reactor Module } \\
\text { elements. }\end{array}$ \\
\hline $\begin{array}{l}\text { The Spaceship total dry mass at launch } \\
\text { shall not exceed }[25,000] \mathrm{kg} \text {. }\end{array}$ & $\begin{array}{l}\text { Minimum module mass is goal and } \\
\text { selection criteria for design. }\end{array}$ & $\begin{array}{l}\text { High temperature reactor is } \\
\text { required to minimize overall mass }\end{array}$ \\
\hline
\end{tabular}


Table 2. Reference Reactor Plant Parameters

\begin{tabular}{|c|c|c|}
\hline Parameter & Pre-Conceptual Base Case & Range/Options \\
\hline Mission Duration & 15 years & 10-20 years \\
\hline Nominal Core Thermal Power & $1000 \mathrm{kWt}$ & $0.5-1.5 \mathrm{MWt}$ \\
\hline Reactor Inlet Temperature & $891 \mathrm{~K}\left(1144^{\circ} \mathrm{F}\right)$ & $810-935 \mathrm{~K}\left(998-1220^{\circ} \mathrm{F}\right)$ \\
\hline Reactor Outlet Temperature & $1150 \mathrm{~K}\left(1610^{\circ} \mathrm{F}\right)$ & $1050-1200 \mathrm{~K}\left(1430-1700^{\circ} \mathrm{F}\right)$ \\
\hline Reactor Nozzle-to-Nozzle Pressure Drop (dP/P) & $2.5 \%$ & $2.0-4.0 \%$ \\
\hline Gas Molecular Weight & $\begin{array}{c}31.5 \mathrm{~g} / \mathrm{mol} \\
(\text { He mole fraction }=0.784)\end{array}$ & $\begin{array}{c}20-45 \mathrm{~g} / \mathrm{mol} \\
(\text { He mole fraction }=0.874-0.560)\end{array}$ \\
\hline Pipe Outer Diameter & $16 \mathrm{~cm}(6.3 \mathrm{in})$ & TBD \\
\hline Number of Shield Penetrations for Pipping & 2 & $1-4$ \\
\hline Rx + Space Gamma (TID) & 0.5 GRad Si Damage & TBD \\
\hline Number of Braytons & 4 (2 op at $100 \%$ capacity, 2 spare) & $\begin{array}{c}4 \text { (2 op at } 100 \% \text { capacity, } 2 \text { spare) } \\
3 \text { (2 op at } 100 \% \text { capacity, } 1 \text { spare) } \\
3 \text { ( } 3 \text { op at } 66 \% \text { capacity) } \\
2 \text { ( } 2 \text { op at } 50 \% \text { capacity) } \\
2 \text { (1 op at } 100 \% \text { capacity, } 1 \text { spare) } \\
1 \text { (1 op at } 100 \% \text { capacity) }\end{array}$ \\
\hline Brayton Shaft Speed & $45000 \mathrm{rpm}$ & $30000-75000 \mathrm{rpm}$ \\
\hline Power delivered from alternator & $200 \mathrm{kWe}$ & $195-220 \mathrm{kWe}$ \\
\hline Compressor Outlet Pressure & $2000 \mathrm{kPa}(290 \mathrm{psi})$ & $1380-4000 \mathrm{kPa}(200-580 \mathrm{psi})$ \\
\hline Compressor Inlet Temperature & $390 \mathrm{~K}\left(242^{\circ} \mathrm{F}\right)$ & $350-450 \mathrm{~K}\left(170-350^{\circ} \mathrm{F}\right)$ \\
\hline Compressor Pressure Ratio & 2.0 & $1.8-2.2$ \\
\hline Check Valves & 1 at Compressor Outlet & $\begin{array}{c}\text { NONE } \\
1 \text { at Compressor Inlet } \\
1 \text { at Compressor Outlet } \\
1 \text { at Alternator Bleed Flow Outlet } \\
\end{array}$ \\
\hline Number of Recuperators & 4 & $1-4$ \\
\hline High Pressure side of Recuperator dP/P & $0.8 \%$ & $0.5-1.5 \%$ \\
\hline Low Pressure side of Recuperator dP/P & $1.5 \%$ & $1.0-3.0 \%$ \\
\hline Recuperator effectiveness & 0.92 & $0.86-0.94$ \\
\hline Number of Gas Coolers & 4 & $1-4$ \\
\hline Gas Side of Gas Cooler dP/P & $1.0 \%$ & $0.5-2.0 \%$ \\
\hline Pressure Drop in HRS Side of Gas Cooler & $25 \mathrm{kPa}(3.6 \mathrm{psi})$ & $20-30 \mathrm{kPa}(2.9-4.4 \mathrm{psi})$ \\
\hline Gas Cooler effectiveness & 0.94 & $0.90-0.96$ \\
\hline Heat Rejection System Fluid & Water & Water, NaK \\
\hline Two-Sided Radiator Area with $14.5 \%$ Margin & $450 \mathrm{~m}^{2}\left(4840 \mathrm{ft}^{2}\right)$ & $400-650 \mathrm{~m}^{2}\left(4300-7000 \mathrm{ft}^{2}\right)$ \\
\hline Inlet Coolant Temperature & $505 \mathrm{~K}\left(449^{\circ} \mathrm{F}\right)$ & $485-530 \mathrm{~K}\left(413-494^{\circ} \mathrm{F}\right)$ \\
\hline Emmisivity & 0.9 & $0.75-0.95$ \\
\hline HRS Operating Pressure & 7.8 MPa (1130 psi) & 5-11 MPa (725 - $1595 \mathrm{psi})$ \\
\hline Pressure Drop in Loop & $365 \mathrm{kPa}(53 \mathrm{psi})$ & $100-400 \mathrm{kPa}(15-58 \mathrm{psi})$ \\
\hline Number of Loops & 4 & $1-4$ \\
\hline Number of Pumps per Loop & 2 & $1-2$ \\
\hline
\end{tabular}


Table 3. List of Materials Envisioned for Use in the Prometheus Program

\begin{tabular}{|c|c|c|c|}
\hline Component & $\begin{array}{c}\text { Material } \\
\text { Option }\end{array}$ & $\begin{array}{l}\text { Operating } \\
\text { Condition }\end{array}$ & Developmental Concern \\
\hline \multirow[t]{2}{*}{ Fuel } & $\mathrm{UO}_{2}$ & \multirow[t]{2}{*}{$\begin{array}{l}900-1700 \mathrm{~K} \\
\sim 10^{22} \mathrm{n} / \mathrm{cm}^{2}\end{array}$} & $\begin{array}{l}\text { Swelling/Cracking at Low Fluence/Burn-up/burn-up rate, fission gas } \\
\text { release rate uncertainty }\end{array}$ \\
\hline & UN & & Fission Product Chemistry, fission gas release rate, porosity evolution \\
\hline \multirow[t]{8}{*}{ Fuel Cladding } & $\mathrm{Nb}-1 \mathrm{Zr}$ & \multirow{8}{*}{$\begin{array}{l}900-1300 \mathrm{~K} \\
\sim 10^{22} \mathrm{n} / \mathrm{cm}^{2}\end{array}$} & Creep Capability, Radiation-Induced and Interstitial Embrittlement \\
\hline & FS-85 & & Phase Stability, Radiation-Induced and Interstitial Embrittlement \\
\hline & T-111 & & Phase Stability, Radiation-Induced and Interstitial Embrittlement \\
\hline & Ta-10W & & Radiation-Induced and Interstitial Embrittlement \\
\hline & ASTAR-811C & & Interstitial Embrittlement, Phase Stability, Fabricability \\
\hline & Mo TZM & & Irradiation Embrittlement, Irradiated Creep Capability, Fabricability \\
\hline & Mo-47Re & & Radiation-Induced Embrittlement, Phase Instability \\
\hline & $\mathrm{SiC} / \mathrm{SiC}$ & & Hermeticity, Fracture Toughness, Conductive Compliant Layer \\
\hline \multirow[t]{2}{*}{ Liner } & $\mathrm{Re}, \mathrm{W}$, or W-Re & \multirow{2}{*}{$\begin{array}{l}900-1500 \mathrm{~K} \\
\sim 10^{22} \mathrm{n} / \mathrm{cm}^{2} \\
\end{array}$} & Embrittlement, Hermeticity, Reaction with fuel/cladding, Neutron Poison \\
\hline & None & & FP attack of cladding \\
\hline \multirow{2}{*}{ Fuel Spring } & $\mathrm{W}-25 \mathrm{Re}$ & \multirow{2}{*}{$\begin{array}{l}800-1300 \mathrm{~K} \\
\sim 10^{22} \mathrm{n} / \mathrm{cm}^{2} \\
\end{array}$} & Radiation-Induced Embrittlement, Relaxation \\
\hline & Ta alloys & & Radiation-Induced and Interstitial Embrittlement, Relaxation \\
\hline $\begin{array}{l}\text { In-Pin Axial } \\
\text { Reflector }\end{array}$ & $\mathrm{BeO}$ & $\begin{array}{l}900-1300 \mathrm{~K} \\
\sim 10^{22} \mathrm{n} / \mathrm{cm}^{2} \\
\end{array}$ & $\begin{array}{l}\text { Irradiation swelling, He Gas Release, }{ }^{6} \mathrm{Li} \text { Neutron Poisoning, } \mathrm{BeO} \\
\text { Handling Concerns }\end{array}$ \\
\hline \multirow[t]{3}{*}{ Core Block } & Refractory Metal & \multirow{3}{*}{$\begin{array}{l}900-1200 \mathrm{~K} \\
\sim 10^{22} \mathrm{n} / \mathrm{cm}^{2}\end{array}$} & Fabricability, Neutron Absorption \\
\hline & Graphite & & Fracture Toughness, $\mathrm{C}$ transport to refractory metal fuel \\
\hline & Nickel Superalloy & & Irradiation Damage, $\mathrm{C} / \mathrm{O}$ transport to refractory metal fuel \\
\hline In-Core Structure & Refractory Alloys & $\begin{array}{l}900-1200 \mathrm{~K} \\
10^{22} \mathrm{n} / \mathrm{cm}^{2}\end{array}$ & Fabricability, Radiation-Induced and Interstitial Embrittlement \\
\hline \multirow[t]{3}{*}{ Reactor Vessel } & Nimonic PE-16 & \multirow{3}{*}{$\begin{array}{l}\text { Up to } 900 \mathrm{~K} \\
10^{21} \mathrm{n} / \mathrm{cm}^{2}\end{array}$} & \multirow[t]{3}{*}{ Radiation-Induced Embrittlement, Creep Capability } \\
\hline & Alloy 617 & & \\
\hline & Haynes 230 & & \\
\hline \multirow{2}{*}{$\begin{array}{l}\text { Safety Rod } \\
\text { Thimble (if used) }\end{array}$} & Same as Vessel & \multirow{2}{*}{$\begin{array}{l}\text { Up to } 1050 \mathrm{~K} \\
10^{22} \mathrm{n} / \mathrm{cm} 2\end{array}$} & Irradiation Embrittlement, Creep Capability \\
\hline & Refractory Metal & & Irradiation Embrittlement, Creep, Dissimilar Material Joining \\
\hline \multirow[t]{2}{*}{ Reflector } & $\mathrm{BeO}$ & \multirow{2}{*}{$\begin{array}{l}\text { Up to } 900 \mathrm{~K} \\
10^{21} \mathrm{n} / \mathrm{cm}^{2} \\
\end{array}$} & Irradiation Swelling and $\mathrm{He}$ Gas Release, ${ }^{6} \mathrm{Li}$ poisoning, $\mathrm{Be} / \mathrm{BeO}$ \\
\hline & $\mathrm{Be}$ & & Handling Restrictions \\
\hline \multirow[t]{4}{*}{ Shielding } & Water & Up to $500 \mathrm{~K}$ & Thermal Management \\
\hline & $\mathrm{Be}$ & \multirow[t]{3}{*}{ Up to $800 \mathrm{~K}$} & Be Handling Restrictions \\
\hline & $\mathrm{B}_{4} \mathrm{C}$ & & \\
\hline & $\mathrm{LiH}$ & & Neutron and gamma swelling vs. temp. \\
\hline \multirow[t]{2}{*}{$\begin{array}{l}\text { Shielding and } \\
\text { Reflector Canning }\end{array}$} & $\begin{array}{l}\text { Steel or } \mathrm{Ni} \\
\text { Superalloy }\end{array}$ & $\begin{array}{l}\text { Same Range } \\
\text { as shielding }\end{array}$ & \\
\hline & Titanium Alloy & & \\
\hline Loop Piping & Alloy 617 & $300-900 \mathrm{~K}$ & Maintenance of internal insulation @ $900 \mathrm{~K}$, Joining \\
\hline & Haynes 230 & & Maintenance of internal insulation @ $900 \mathrm{~K}$, Joining \\
\hline Insulation & $\begin{array}{l}\text { Porous Metal or } \\
\text { ceramic }\end{array}$ & Up to $1150 \mathrm{~K}$ & Thermal conductivity, Loop Material Compatibility \\
\hline & Ceramic Fiber & & Thermal conductivity, Loop Material Compatibility \\
\hline Insulation Liner & Mo Alloy & Up to $1150 \mathrm{~K}$ & Fabricability, Compatibility with insulation, embrittlement \\
\hline & Superalloy & & Compatibility with insulation \\
\hline Turbine Casing & $\ln -792$ & Up to $1150 \mathrm{~K}$ & Creep Capability, Dissimilar Materials Joining (to piping) \\
\hline (scroll) & Mar-M-247 & & \\
\hline & $\begin{array}{l}\text { Alloy } 617 \text { or } \\
\text { Haynes } 230\end{array}$ & Up to $900 \mathrm{~K}$ & Requires internal insulation \\
\hline Turbine Wheel & $\ln -792$ & Up to $950 \mathrm{~K}$ & Creep capability, Carburization/Decarburization/Deoxidation \\
\hline & Mar-M-247 & & \\
\hline Compressor & Ti-Al-V & $400-600 \mathrm{~K}$ & Compatibility w/ gas loop \\
\hline & Superalloy & & \\
\hline Shaft & 1018 Steel & $400-900 \mathrm{~K}$ & \\
\hline & Superalloy & & \\
\hline $\begin{array}{l}\text { Alternator } \\
\text { Magnets }\end{array}$ & Sm-Co & $400-450 \mathrm{~K}$ & Loss of magnet strength, compatibility with gas loop \\
\hline $\begin{array}{l}\text { Electrical } \\
\text { Insulators }\end{array}$ & Ceramic or Glass & $400-450 \mathrm{~K}$ & Hermeticity, compatibility with gas loop \\
\hline Recuperator Core & Alloy $625 / 690$ & $600-900 \mathrm{~K}$ & Thermal Stability at Hot Side Temp, Braze Material concerns \\
\hline & Carbon/Carbon & & Compatibility with other loop components (C transport), Fabricability \\
\hline Cooler Core & CP Titanium & $400-550 \mathrm{~K}$ & Compatibility with gas and water loops \\
\hline & Alloy $625 / 690$ & & \\
\hline
\end{tabular}


Table 4. Representative Reactor Core Parameter Lists

\begin{tabular}{|c|c|c|c|c|c|c|}
\hline General Parameters & Base Case & Low Power & $\begin{array}{l}\text { High Pressure } \\
\text { PCEH-129 }\end{array}$ & $\begin{array}{c}\text { Open Lattice } \\
\text { PCFD-474 }\end{array}$ & TZM & Sic \\
\hline Power (MWth) & 1 & 0.5 & 1 & 1 & 1 & 1 \\
\hline Full Power Years & 15 & 15 & 15 & 15 & 15 & 15 \\
\hline Fuel Type & UO2 & $\mathrm{UO2}$ & $\mathrm{UO} 2$ & $\mathrm{UO2}$ & UO2 & $\mathrm{UO} 2$ \\
\hline Fuel Form & Ceramic & Ceramic & Ceramic & Ceramic & $\begin{array}{c}\text { Ceramic w/Euo3 } \\
\text { Poison }\end{array}$ & $\begin{array}{c}\text { Ceramic w/Euo3 } \\
\text { Poison }\end{array}$ \\
\hline Geometry & $\begin{array}{l}\text { Modular Annular } \\
\text { Flow Block }\end{array}$ & $\begin{array}{l}\text { Modular Annular } \\
\text { Flow Block }\end{array}$ & $\begin{array}{l}\text { Modular Annular } \\
\text { Flow Block }\end{array}$ & Open Lattice & $\begin{array}{l}\text { Modular Annular } \\
\text { Flow Block }\end{array}$ & $\begin{array}{l}\text { Modular Annular } \\
\text { Flow Block }\end{array}$ \\
\hline Clad Material & Mo-47.5Re & Mo-47.5Re & Mo-47.5Re & Mo-47.5Re & TZM & $\mathrm{SiC}$ \\
\hline Control Device & Sliders & Sliders & Sliders & Sliders & Sliders & Sliders \\
\hline System Pressure $(\mathrm{MPa})$ & 2 & 2 & 4 & 2 & 2 & 2 \\
\hline Gas Composition (\%He/\%Xe) & $78 / 22$ & $78 / 22$ & $78 / 22$ & $78 / 22$ & $78 / 22$ & $78 / 22$ \\
\hline Gas Composition $(\mathrm{g} / \mathrm{mol})$ & 31.5 & 31.5 & 31.5 & 31.5 & 31.5 & 31.5 \\
\hline Vessel Material & Alloy-617 & Alloy-617 & Alloy-617 & Alloy-617 & Alloy-617 & Alloy-617 \\
\hline Block Material & Mo-47.5Re & Mo-47.5Re & Mo-47.5Re & $\mathrm{N} / \mathrm{A}$ & TZM & $\mathrm{SiC}$ \\
\hline Shield Material & Be-B4C-W & Be-B4C-W & Be-B4C-W & Be-B4C-W & Be-B4C-W & Be-B4C-W \\
\hline Tcold - Average @ nozzle B.E. (K) & 880 & 880 & 880 & 880 & 880 & 880 \\
\hline Thot - Average @ nozzle B.E. (K) & 1150 & 1150 & 1150 & 1150 & 1150 & 1150 \\
\hline \multicolumn{7}{|l|}{ Dimensions } \\
\hline Vessel Outside Diameter $(\mathrm{cm})$ & 61.81 & 49.71 & 54.55 & 54.88 & 61.87 & 63.32 \\
\hline Vessel Thickness $(\mathrm{cm})$ & 0.48 & 0.38 & 0.84 & 0.43 & 0.48 & 0.49 \\
\hline Vessel Length $(\mathrm{cm})$ & 159.6 & 131.2 & 139.9 & 137.2 & 149.8 & 145.8 \\
\hline Reflector Outside Diameter $(\mathrm{cm})$ & 85.1 & 73.1 & 78.1 & 78.45 & 85.44 & 86.9 \\
\hline Fuel Pellet OD $(\mathrm{cm})$ & 1.819 & 2.238 & 1.72 & 1.476 & 1.862 & 2.057 \\
\hline Gap Thickness (cm) & 0.022 & 0.024 & 0.022 & 0.021 & 0.022 & 0.032 \\
\hline Clad Thickness $(\mathrm{cm})$ & 0.051 & 0.051 & 0.051 & 0.135 & 0.051 & 0.102 \\
\hline Fuel Pin OD $(\mathrm{cm})$ & 1.965 & 2.388 & 1.866 & 1.788 & 2.008 & 2.325 \\
\hline Fuel Pellet U235 Loading Density (g U235/cc) & 8.26 & 8.26 & 8.26 & 8.26 & 7.58 & 7.44 \\
\hline Channel Thickness (MAFB) $(\mathrm{cm})$ or Distance Between Pins $(\mathrm{OL})(\mathrm{cm})$ & 0.216 & 0.188 & 0.135 & 0.145 & 0.213 & 0.234 \\
\hline Pitch $(\mathrm{cm})$ & 2.614 & 2.977 & 2.35 & 1.94 & 2.213 & 3.01 \\
\hline Core Volume $(\mathrm{L})$ & 135.6 & 79.48 & 96.53 & 88.0 & 137.1 & 145.9 \\
\hline Number of Pins & 288 & 144 & 288 & 402 & 288 & 228 \\
\hline Core Fuel Height $(\mathrm{cm})$ & 60.8 & 55.5 & 53.3 & 49.8 & 59.9 & 61.0 \\
\hline Gas Plenum Height $(\mathrm{cm})$ & 31 & 20 & 26 & 26.5 & 22 & 15.5 \\
\hline Number of Control Elements & 12 & 12 & 12 & 12 & 12 & 12 \\
\hline Number of Safety Rods & 1 & 1 & 1 & 1 & 1 & 1 \\
\hline Safety Rod Diameter (cm) & 12.72 & 9.52 & 11.00 & 11.98 & 12.95 & 15.17 \\
\hline Shield Thickness $(\mathrm{cm})$ & 66.03 & 66.71 & 67.39 & 68.07 & 66.17 & 65.91 \\
\hline Shield Leading Edge Diameter $\left[\mathrm{D}_{6 \text { degree }}\right](\mathrm{cm})$ & 102.66 & 89.54 & 94.84 & 93.32 & 103.26 & 104.78 \\
\hline Shield Cone Angle (degrees) & $6 / 12$ & $6 / 12$ & $6 / 12$ & $6 / 12$ & $6 / 12$ & $6 / 12$ \\
\hline \multicolumn{7}{|l|}{ Masses } \\
\hline U235 Fuel Load (kg) & 376 & 256.8 & 294.9 & 283 & 356 & 344 \\
\hline Reactor $(\mathrm{kg})$ & 2078 & 1360 & 1731 & 1340 & 1793 & 1432 \\
\hline \begin{tabular}{|l|l|} 
Additional Reactor Components (kg) \\
\end{tabular} & 831 & 544 & 692 & 536 & 717 & 573 \\
\hline Shield $(\mathrm{kg})$ & 1648 & 1334 & 1520 & 1511 & 1665 & 1681 \\
\hline Total Mass (Rx with Shield) $(\mathrm{kg})$ & 4557 & 3238 & 3943 & 3387 & 4175 & 3686 \\
\hline \multicolumn{7}{|l|}{ Key Results } \\
\hline \multicolumn{7}{|l|}{ Nuclear } \\
\hline Peak Burnup-B.E. (\% FIMA) & 2.18 & 1.58 & 2.78 & 2.88 & 2.1 & 2.14 \\
\hline Max Local Peaking Factor & 1.49 & 1.49 & 1.49 & 1.48 & 1.48 & 1.48 \\
\hline Slider/Drum Worth - Most Reactive/Least Reactive Rod Out $(\Delta \rho)$ & 0.11 & 0.14 & 0.1 & 0.13 & 0.13 & 0.16 \\
\hline \multicolumn{7}{|l|}{ Mechanical } \\
\hline Peak EOL Volumetric Fuel Swelling (\%) & 4.9 & 4.1 & 4.8 & 5.1 & 4.8 & 3.8 \\
\hline Metal - EOL Primary Membrane Von-Mises Clad Stress (MPa) & 21.8 & 25.2 & 32.4 & 13.7 & 44.4 & N/A \\
\hline Primary Membrane Clad Creep Strain (\%) & 1 & 1 & 1 & 1 & 1 & 1 \\
\hline Primary Membrane Vessel Hoop Stress (Mpa) & 22.6 & 26.6 & 32.4 & 12.6 & 48.1 & 25.0 \\
\hline \multicolumn{7}{|l|}{ Thermal Hydraulic } \\
\hline DPcore/Psystem (CORE ONLY) (\%) & 1.12 & 1.06 & 1.10 & 0.99 & 1.01 & 1.00 \\
\hline Max Surface Heat Flux $\left(\mathrm{W} / \mathrm{cm}^{\wedge} 2\right)$ & 16.6 & 14.9 & 19.9 & 15.8 & 16.3 & 17.5 \\
\hline Max Linear Heat Generation Rate $(\mathrm{W} / \mathrm{cm})$ & 102.2 & 111.9 & 116.6 & 88.8 & 101.9 & 127.8 \\
\hline In-Fuel Power Density Core Average (W/cc) & 26.4 & 19.1 & 33.7 & 35.1 & 25.6 & 26.0 \\
\hline Peak Fuel Temp BOL - B.E. (K) & 1636 & 1637 & 1638 & 1622 & 1636 & 1646 \\
\hline Peak Fuel Temp over Life - B.E. (K) & 1773 & 1771 & 1775 & 1775 & 1769 & 1720 \\
\hline Peak Clad Temp over Life - B.E. (K) & 1275 & 1262 & 1232 & 1311 & 1274 & 1284 \\
\hline
\end{tabular}


Table 5. National Laboratory and NASA Center Areas of Support and Collaboration

\section{NASA Centers}

- JPL

- Program Coordination

- Instrumentation and Control Integration

- Environmental Effects

- Radiation Hardening

- Thermoelectrics Expertise

- $\quad \mathrm{GRC}$

- Brayton Expertise

- Stirling Expertise

- Brayton System Testing

- HRS Interface

- Power Management

- Structural Materials

- MSFC

- Core and Loop Mockup Testing

- Heat Pipe Testing

- Liquid Metal Testing

- $\mathrm{KSC}$

- ATLO Coordination

- $\quad$ ARC

- Aeroshell Design
DOE Labs

- Oak Ridge

- Shielding Development

- Irradiation Testing (HFIR)

- Sensor Development

- Reactor Safety

- Structural Materials

- Compatibility Testing

- Independent Cost Estimate

- Los Alamos

- Rx design support

- Fuel fabrication

- Critical assembly testing (T-A8)

- Heat Pipe Development

- Transient Model Development

- $\mathrm{Y}-12$

- Shield and Fuel Fabrication

- INL

- ATR Testing

- Modeling Support

- PNNL

- Foreign Test Reactor Support

- Fuel Modeling

- Sandia

- Safety Testing Guidance

- Independent Cost Estimate

- Gas Brayton Modeling

- Argonne

- Fast Reactor Experience

- Lawrence Livermore

- Reactor safety modeling

- Fuel Science 
Figure 1. Reference Spacecraft Concept (from Northrop Grumman) and Reactor Plant Concept

- Spaceship Configuration PB1

- Gas cooled reactor with 200 kW Brayton output power

- Nearly 58 meters in length

- 36,375 kg estimated mass at launch

- Stows in $5 \mathrm{~m}$ diameter fairing
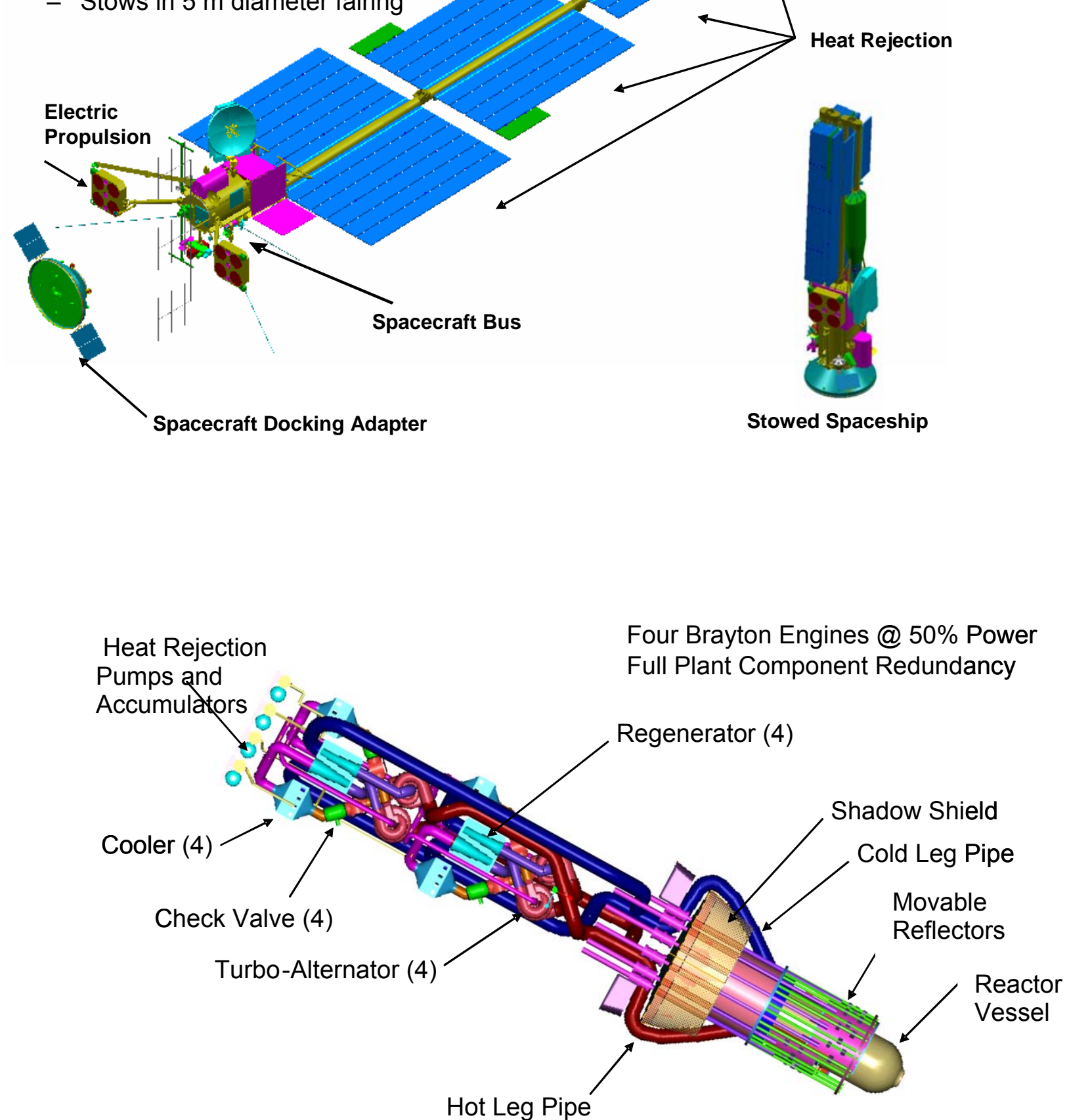
Figure 2. Reference Core and Fuel Element

Overall Reactor Configuration

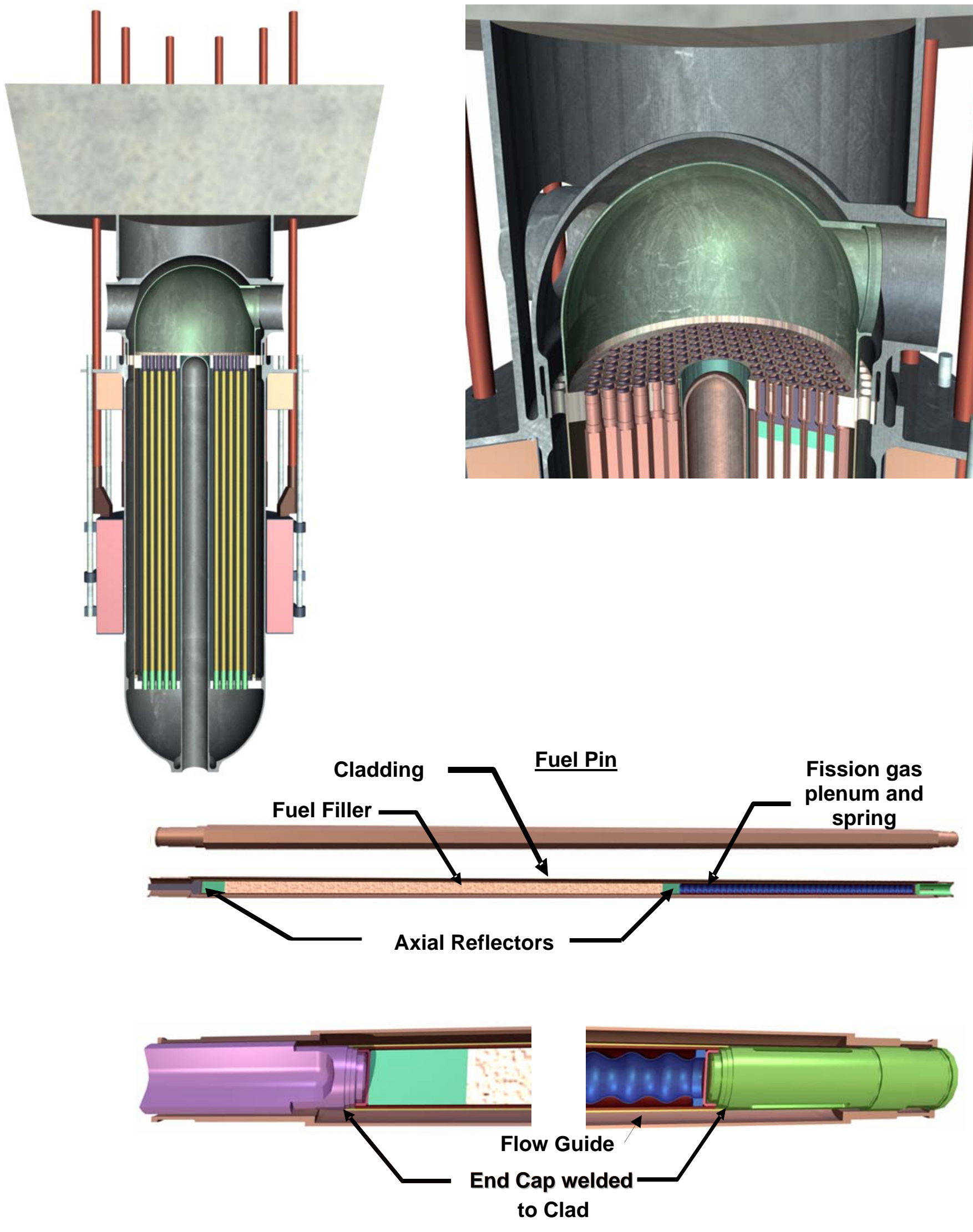

Outlet Plenum Detail

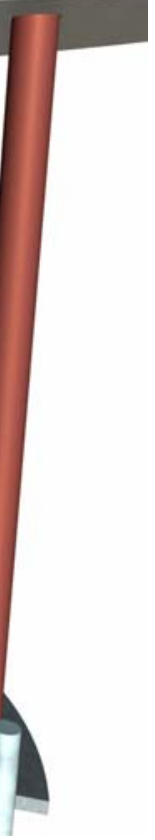


Figure 3. Reactor Core Configuration Options

PP File 
Figure 4. Estimated Range of Space Nuclear Power Plant Mass as a Function of Reactor Design and Plant Arrangement. Reactor and shield mass shows masses as a function of core materials and arrangement for $1 \mathrm{MW}$ reactor systems. The total SNPP mass shows the contributions to the SNPP mass, by subsystem, as a function of the number of energy conversion loops and the operating conditions. Note that the higher cycle efficiency of the simpler plant options leads to a lower required reactor power.
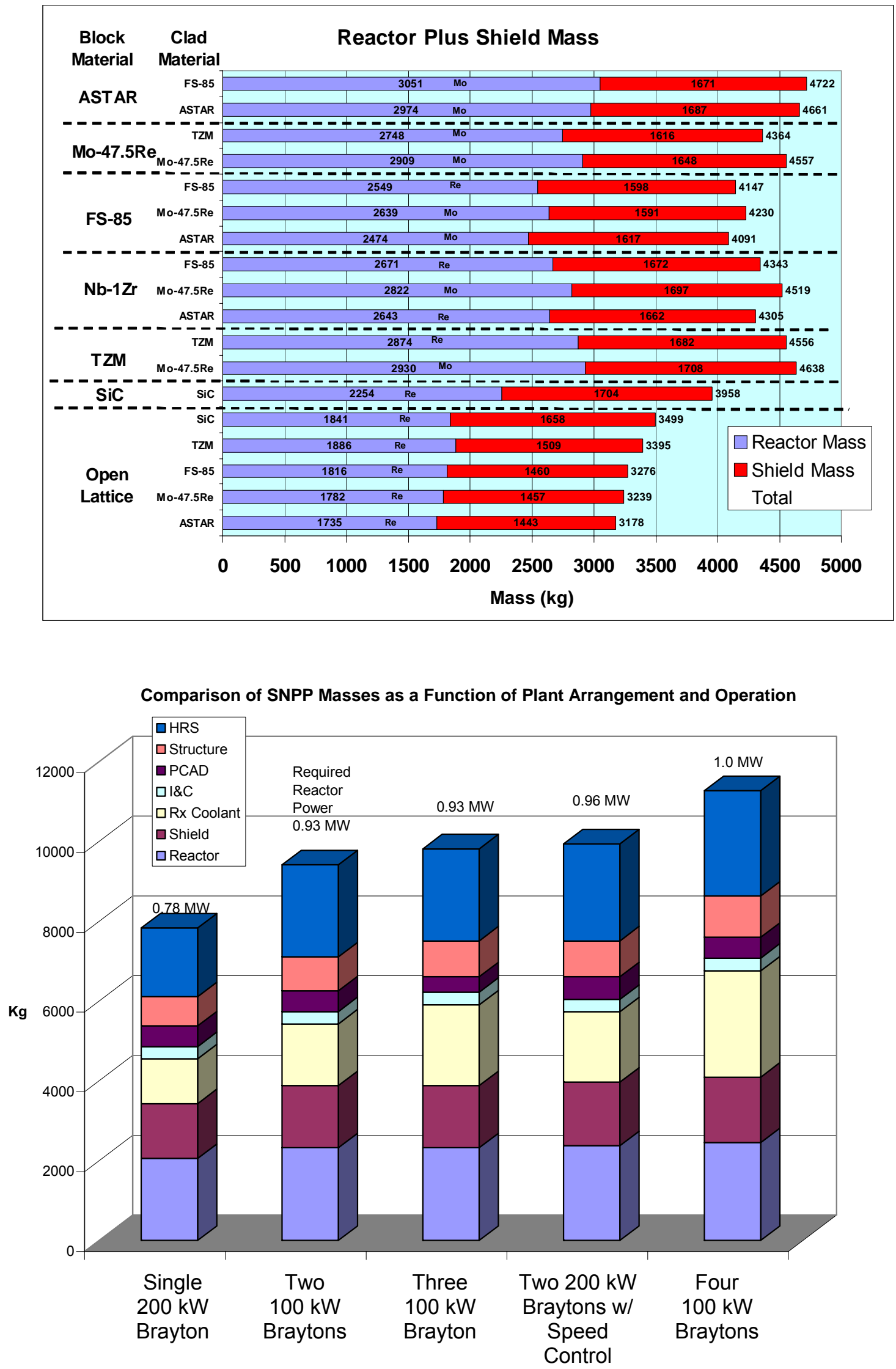
Figure 5. Reference Heat Balances for Single Brayton and Multi-Brayton System

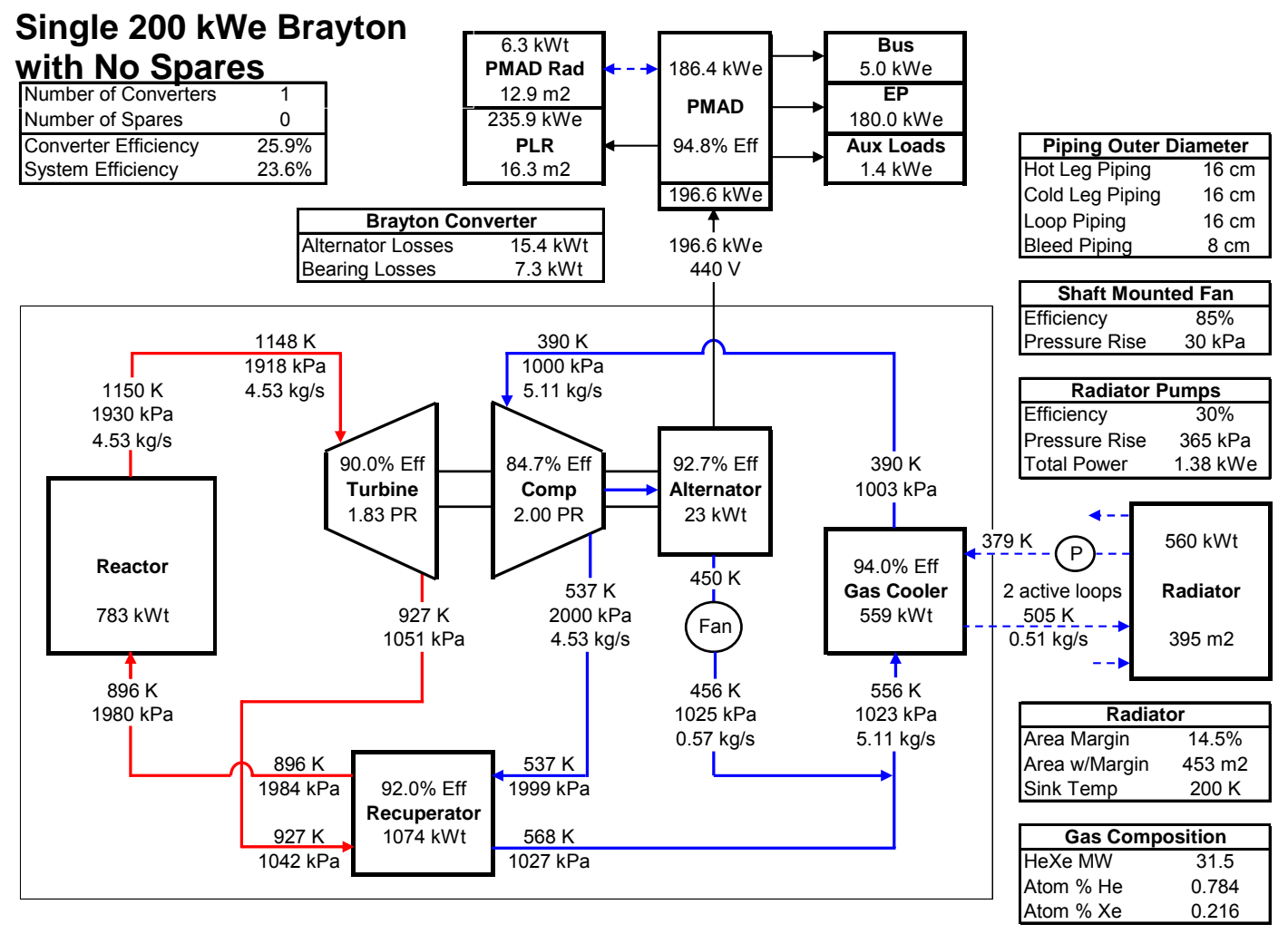

\section{System with Two Operating 100 kWe}

\section{Braytons and 2 Spares}

\begin{tabular}{|lc|}
\hline Number of Converters & 4 \\
Number of Spares & 2 \\
\hline Converter Efficiency & $19.9 \%$ \\
System Efficiency & $18.2 \%$ \\
\hline
\end{tabular}

\section{Brayton Converter} Alternator Losses $\quad 9.4 \mathrm{kWt}$ Bearing Losses

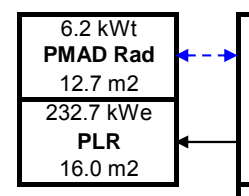

$4.2 \mathrm{kWt}$
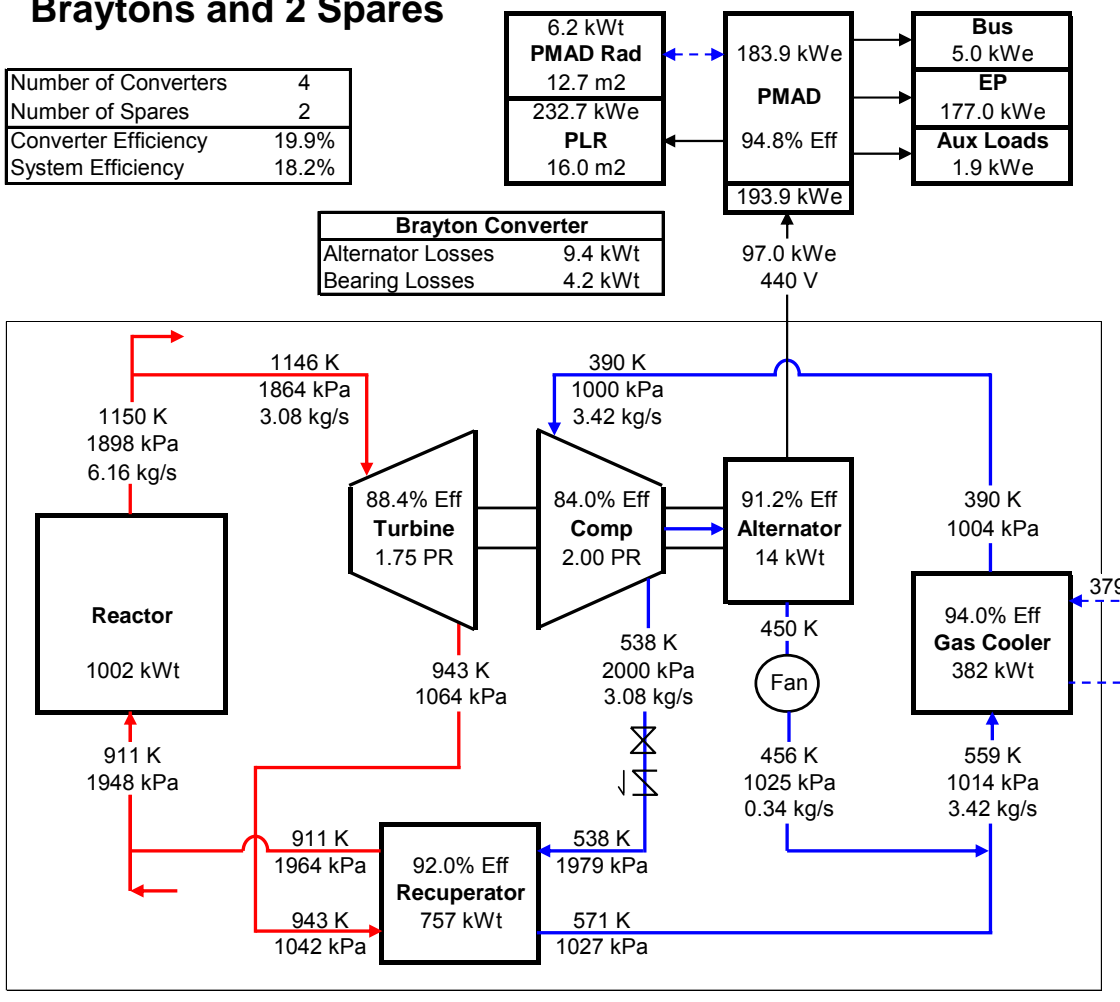

\begin{tabular}{|lc|}
\hline \multicolumn{2}{|c|}{ Piping Outer Diameter } \\
\hline Hot Leg Piping & $16 \mathrm{~cm}$ \\
Cold Leg Piping & $16 \mathrm{~cm}$ \\
Loop Piping & $10 \mathrm{~cm}$ \\
Bleed Piping & $5 \mathrm{~cm}$ \\
\hline
\end{tabular}

\section{Valve Pressure Drops}

Isolation Valve $1.3 \mathrm{kPa}$ Check Valve $\quad 11.3 \mathrm{kPa}$

\begin{tabular}{|lc|}
\hline \multicolumn{2}{|c|}{ Shaft Mounted Fan } \\
\hline Efficiency & $85 \%$ \\
Pressure Rise & $30 \mathrm{kPa}$ \\
\hline
\end{tabular}

Radiator Pumps

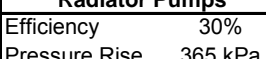

Pressure Rise $\quad 365 \mathrm{kPa}$

Total Power $1.88 \mathrm{kWe}$

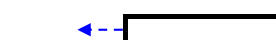

$-(P--767 \mathrm{~kW}$

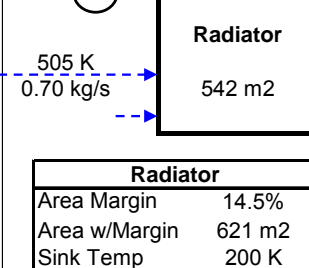

\begin{tabular}{|lc|}
\hline \multicolumn{2}{|c|}{ Gas Composition } \\
\hline HeXe MW & 31.5 \\
Atom \% He & 0.784 \\
Atom \% Xe & 0.216 \\
\hline
\end{tabular}

PMAD - Power Management and Distribution

PLR - Parasitic Load Regulator and associated Resistive Load Bank Radiator EP - Electric Propulsion

Aux Loads - Loads for Heat Rejection System Pumps and Reactor Plant Instrumentation PMAD Rad - Radiator for rejection of heat from electrical loads 
Figure 6. UN Fuel Processing Approach and Resulting UN Pellets and Microstructure

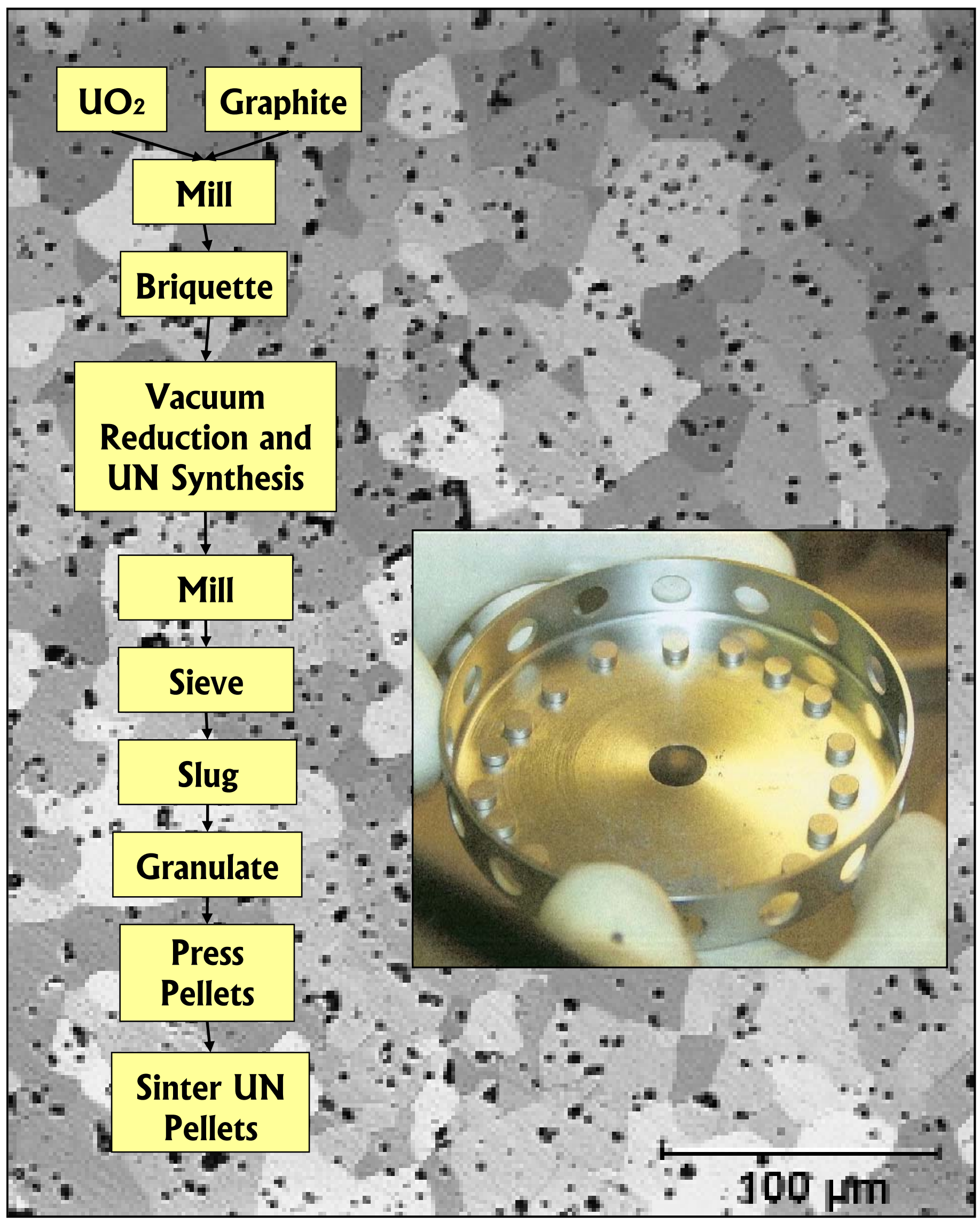


Figure 7. Reactor Plant Response to a Loss of Load Control in a Multi-Brayton Plant
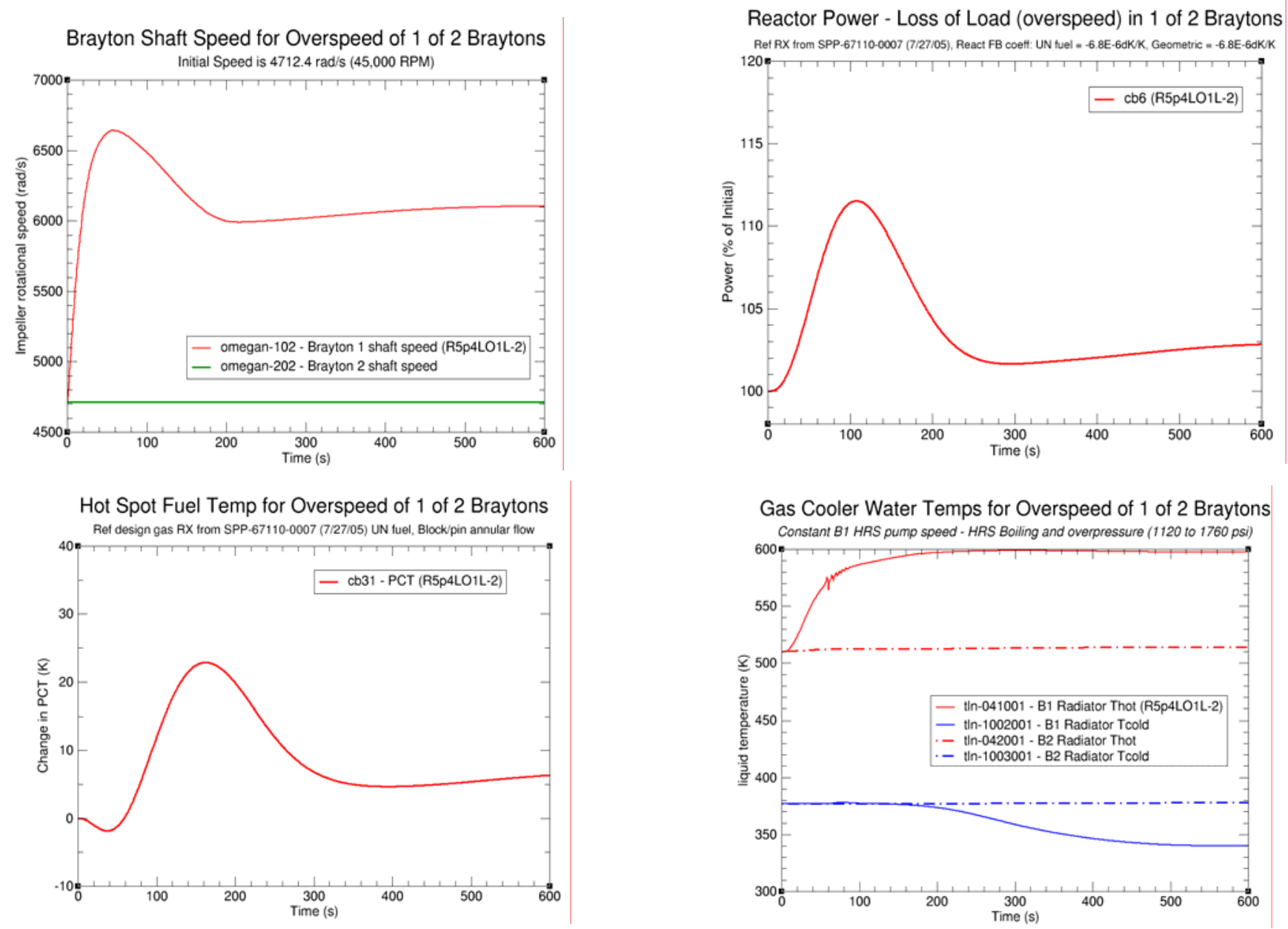

The upper left plot shows the speed up of a turbine due to a loss of load on the alternator in that turbine. The speed increases until the point for the condenser work balances the turbine work. This increase in speed leads to a corresponding increase in flow which effects the entire plant. The upper right plot shows the change in power level following a loss of Brayton load in one of two operating loops. The lower left figure shows the corresponding change in maximum fuel temperature. Note that since the Brayton speed and flow rate increase during a loss of Brayton load transient, both the reactor power and peak fuel temperature rise. The lower right figure shows the change in heat rejection system coolant temperature for the two operating Brayton loops. Note that the temperature exiting the gas cooler rises sharply during this transient. This leads to an increase in pressure and the potential for boiling in this heat rejection loop and also leads to an increase in the likelihood of radiator heat pipe failures. Thus, this casualty has a greater impact on the heat rejection system than on the reactor. 
Figure 8. Multiple Brayton Arrangement Options

Single Brayton

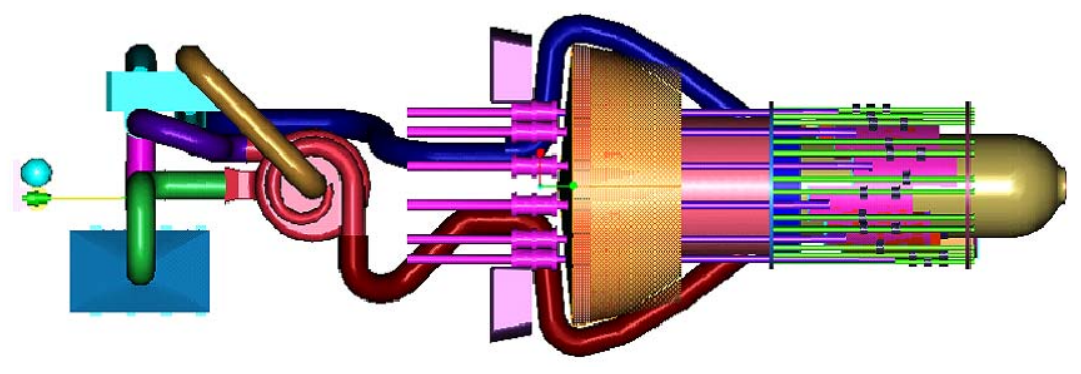

Two 100\% Power Braytons
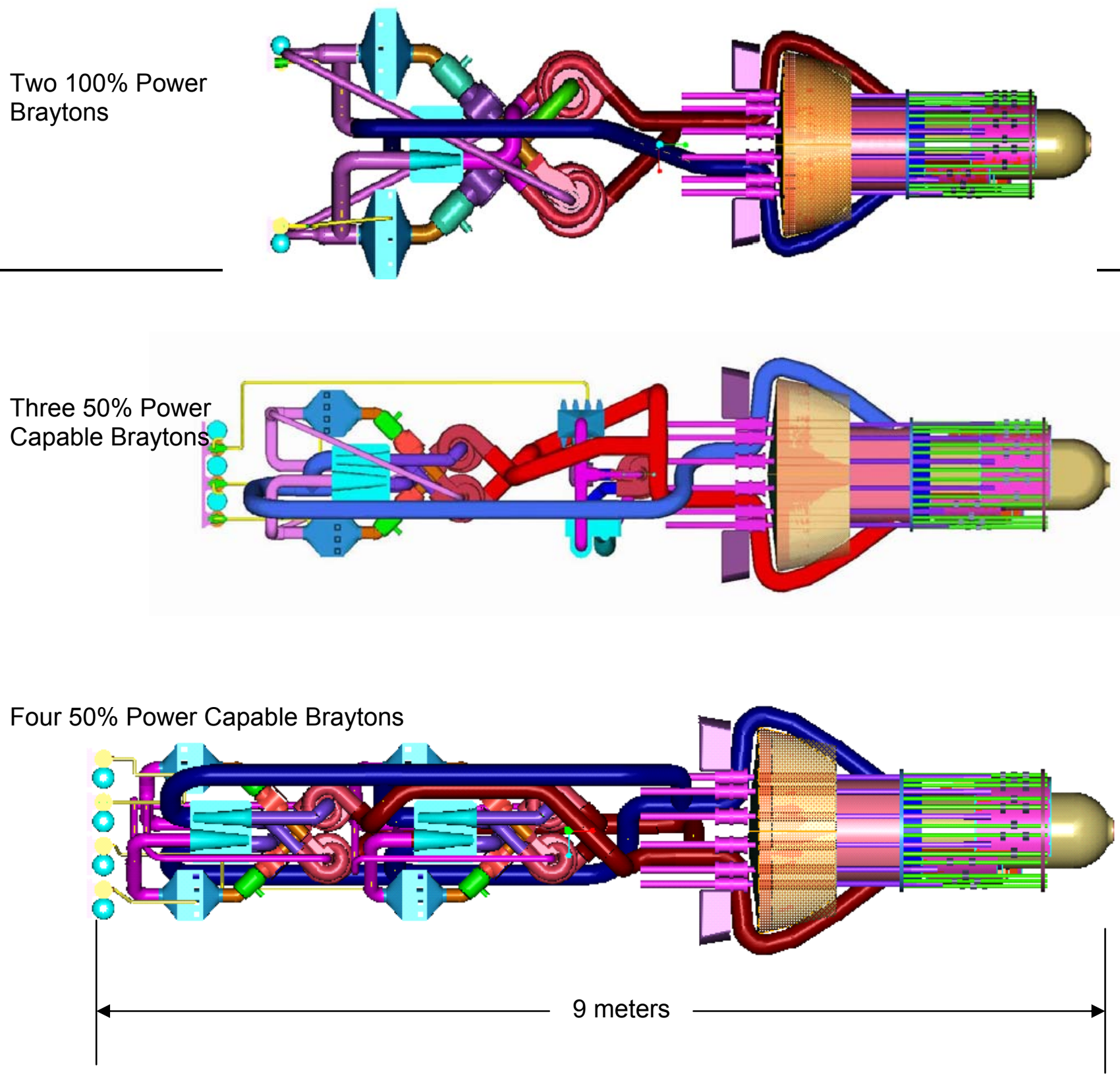
Figure 9. Approach and Timeline for System Testing

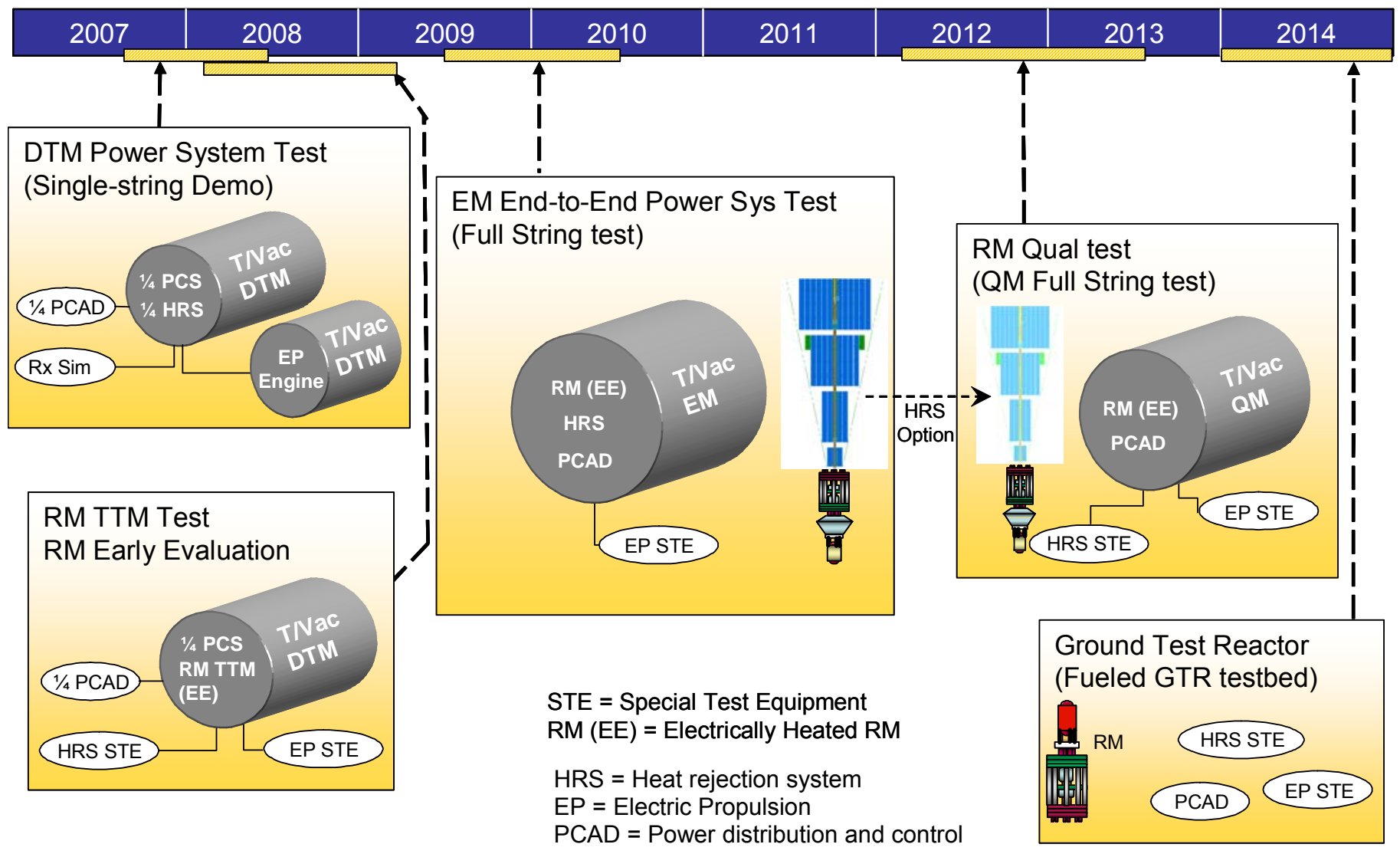

System testing proceeds from small scale components tests to the first integrated system test (the "DTM") to larger scale and more integrated testing to demonstrate system features in electrically heats tests (EM and QM). Comparable cross-section testing, cold critical and hot critical testing was planned. 


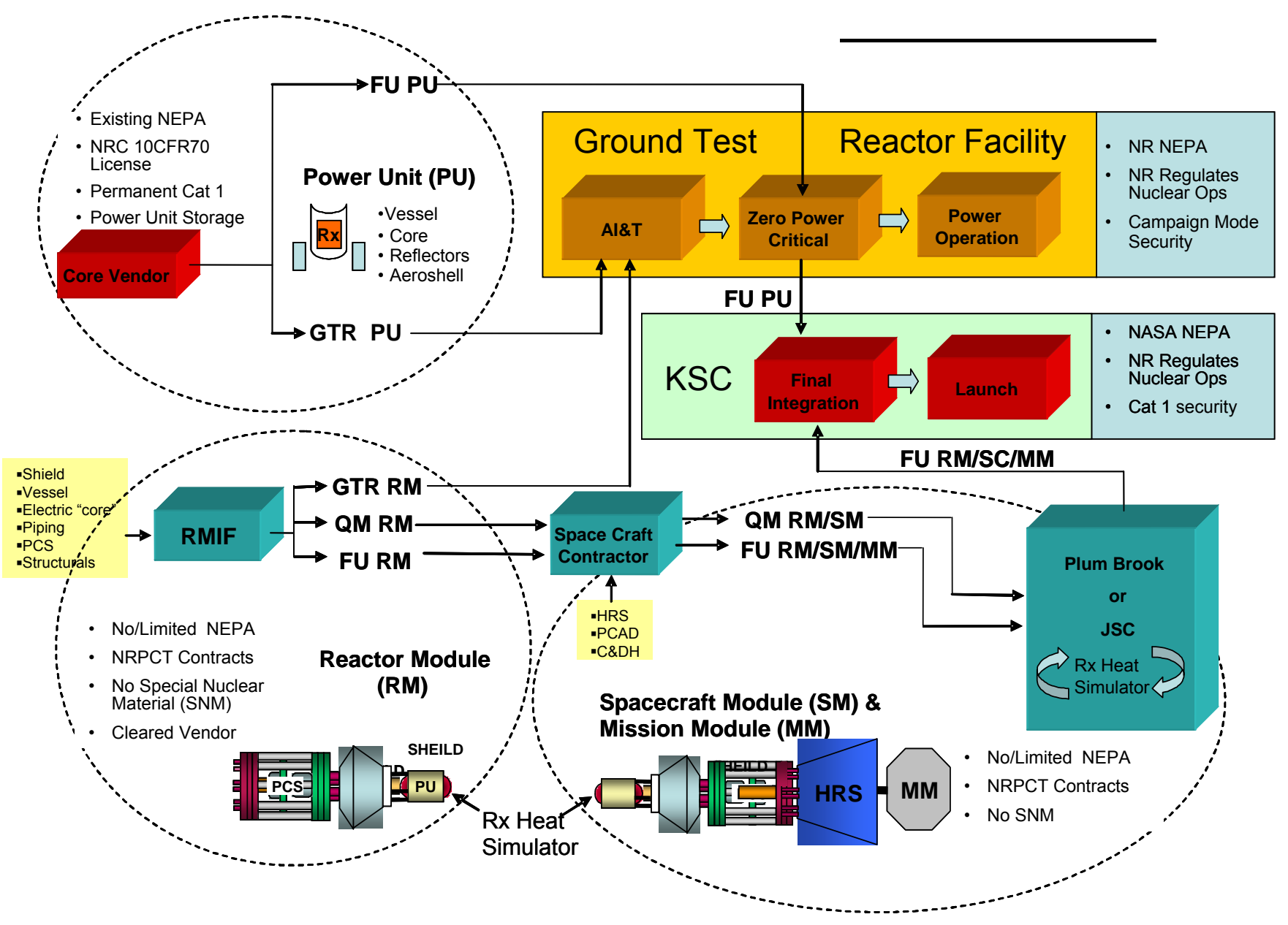

The goal of ATLO flow was to minimize transport of special nuclear material while assuring that flight components were tested to the maximum extent practical. Separate fabrication and testing paths were created for the nuclear materials and all other portions of the reactor module.

RMIF - Reactor module integration facility

GTR - Ground Test Reactor

EM - Engineering Module

QM - Qualification Module

FU - Flight Unit

Cat 1 - Category 1 Nuclear Security Facility 
Figure 11. Reactor Technology Applicability as a Function of Power and Energy

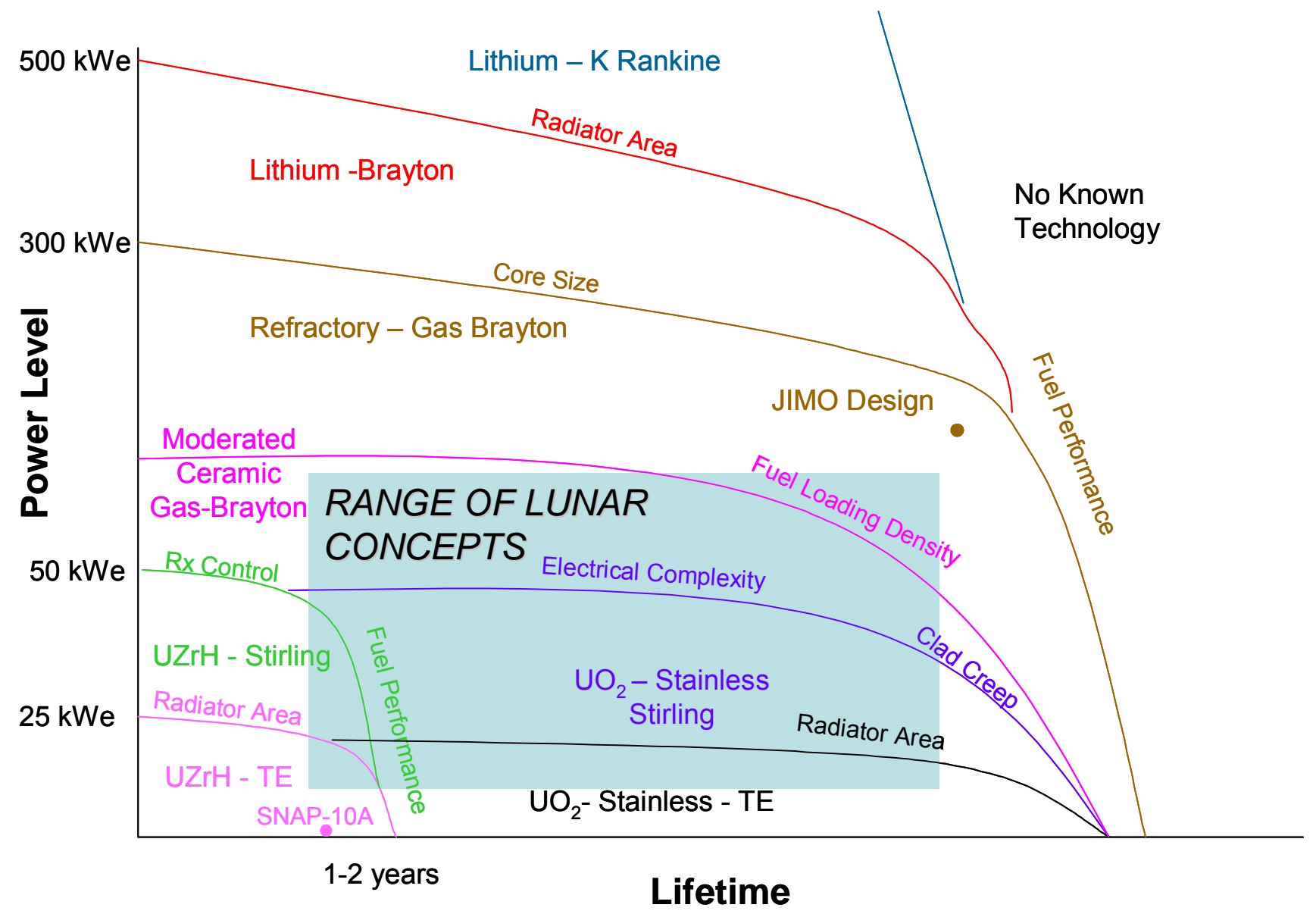

The lower temperature, more readily available reactor technologies require greater energy conversion system development and provide limited power and lifetime capability 


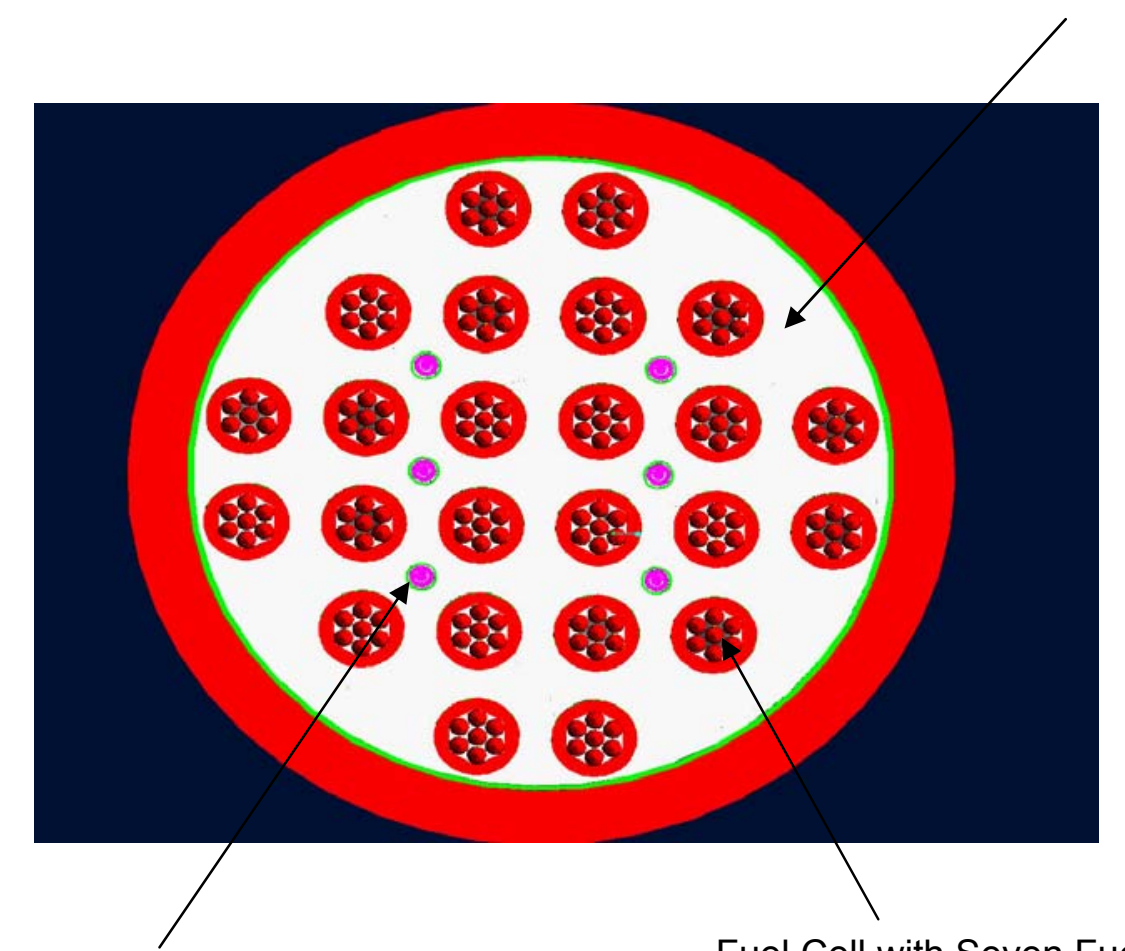

Modifying the spacing between fuel cells and the relative fraction of light and heavy water can optimize core mass and fuel loading within a limited range

Fuel Cell with Seven Fuel Elements

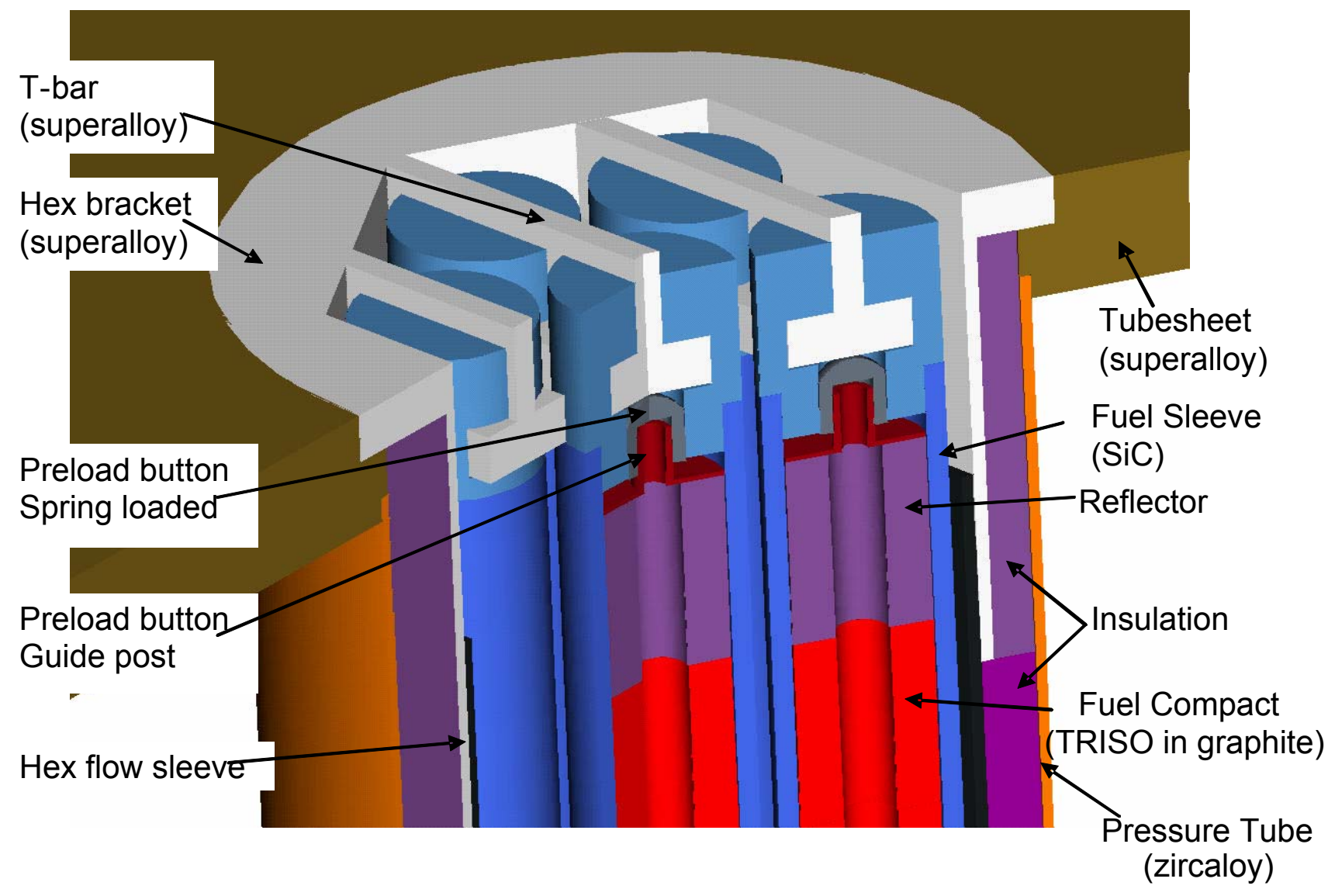


Enclosure 2 to

SPP-SEC-0039

\title{
Aspects of Gas Reactor Physics for NRPCT Project Prometheus Applications
}

\author{
Witter, J.K.
}


This page is intentionally blank.

PRE-DECISIONAL - For planning and discussion purposes only 


\title{
Aspects of Gas Reactor Physics for NRPCT Project Prometheus Applications
}

\author{
Dr. Jonathan Witter \\ Space Power Program, Reactor Engineering Nuclear Design \\ Knolls Atomic Power Laboratory, Inc., \\ Lockheed Martin Corporation
}

STAIF 2006

February 2006 


\section{Overview of Physics Considerations for JIMO}

- Many geometric configurations and materials considered

- Material choices for structural components must balance neutronic considerations along with the manufacturing, mechanical, and thermal hydraulic needs

- Reactivity level and fuel loading requirements

- Temperature coefficient magnitude

- Choices for control devices may impact power distribution shapes

- Energy spectrum dependent capture cross sections relative to the U235 fission cross section play a role in accident scenarios

- Fuel geometric performance will impact reactivity behavior with life

- Normal depletion of the U235 inventory

- Fuel swelling as a function of temperature and burnup 


\section{Reactor Model Configurations}

- Monte Carlo Reactor Physics Models

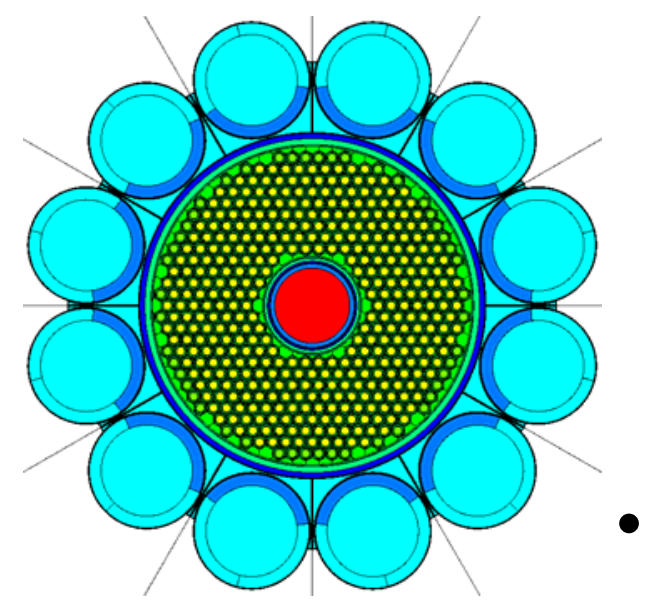
were used for wide range of configurations

- Pin in Annular Flow Block

- Pins in Open Lattice

- Modular Tubular Flow Fuel Element

- Reflector Control with Drums or Sliders

- Materials included considerations for structural and manufacturing

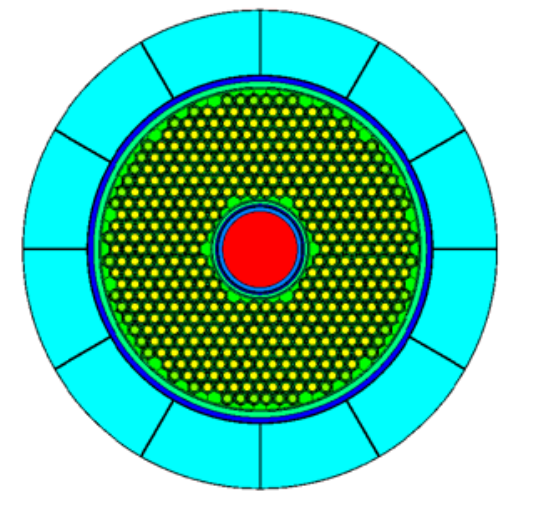

- Refractories: MoRe, ASTAR, FS85, $\mathrm{Nb} 1 \mathrm{Zr}$

- Ceramics: SiC, C

- Cermets: Mo, W, ASTAR base metals

- Fuels: UN, UO2 in pellets and TRISO

- Reflectors: BeO, Be

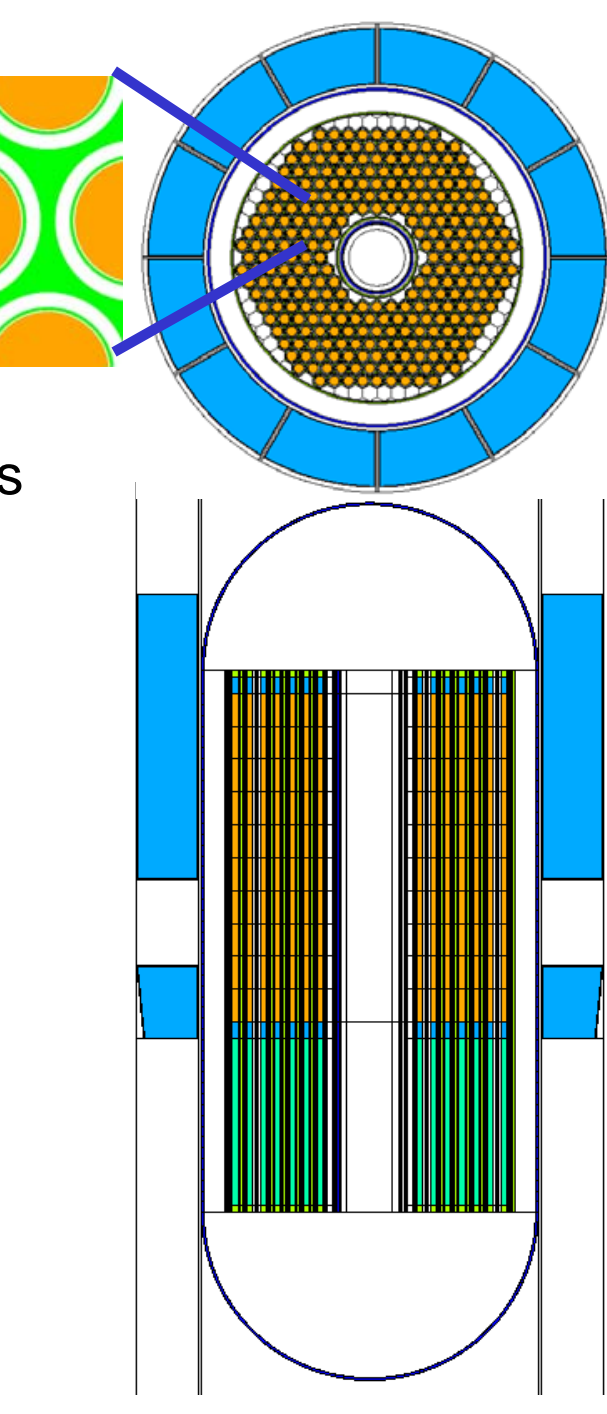




\section{Fuel Region Reactor Geometry Options}

\section{Open Lattice Design}

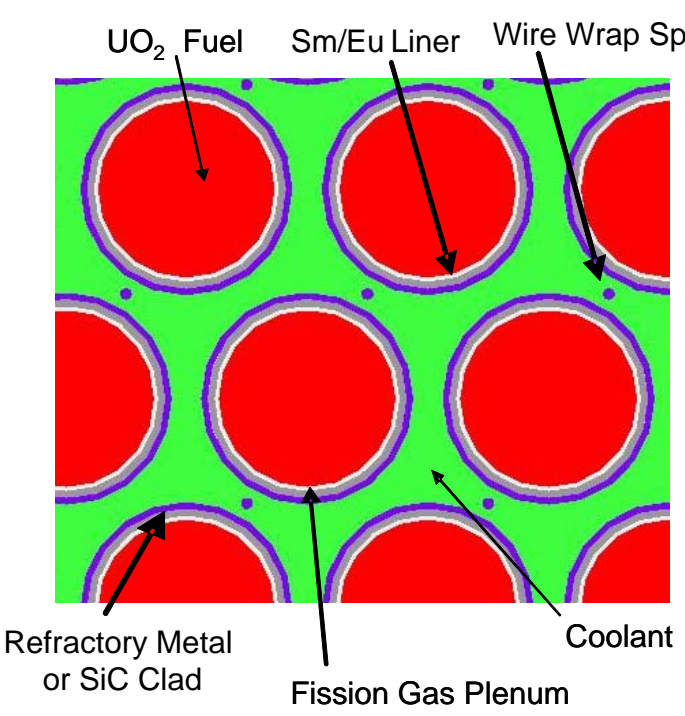

Pros:

- Lower Pressure Drop

- Simple Design

\section{Cons/lssues}

- No Radial Flow Control

- Lateral Movement of Pins Must be Controlled
"Pin In Block" Design

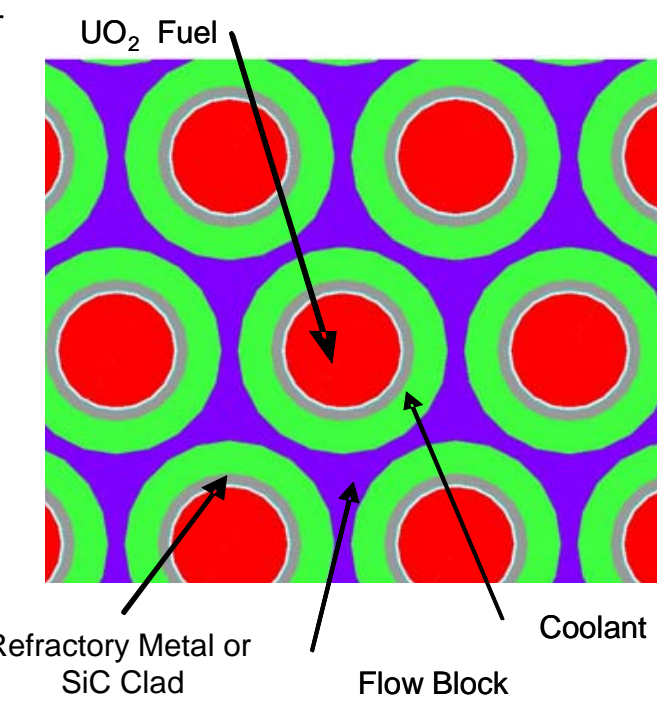

Pros:

- Improved Heat Transfer

- Ability to Match Flow to Power

\section{Cons/lssues}

- Highest Pressure Drop

- Mass of Block

- Largest Core

\section{"Monoblock" Design}

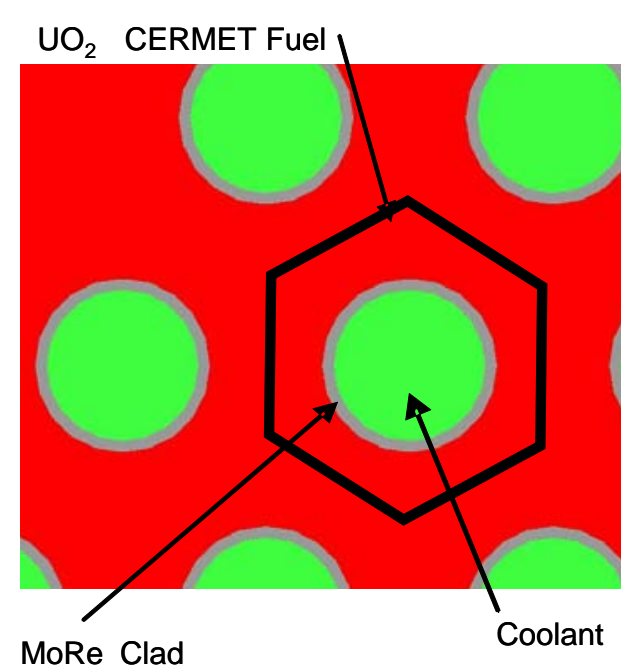

\section{Pros:}

-Well Defined Flow Channel

- Lowest Pressure Drop

- Most Compact and Lightest Core

\section{Cons/Issues}

- Manufacturing Complexity

- Greater Fuel Performance Uncertainty 


\section{Reactor Design Basis}

- Nuclear Criteria

- 15 MW-Yrs endurance

- Cold flooded or dry sand shutdown

- Operation and Shutdown with One Stuck Control Device

- Negative Temperature, Geometric and Power Coefficient

- Thermal Criteria

- Preliminary Limits on Fuel Element Peak Centerline Temperature to minimize Fission Product Swelling

- Limited Core Pressure Drop

- Mechanical Design

- Limit Fuel Cladding Creep to $1 \%$

- Limit Vessel Creep to 1\%

- No contact between fuel and cladding

Operational Reactivity Levels for a Pre-Conceptual Core with Drums

Reactivity (k-effective)

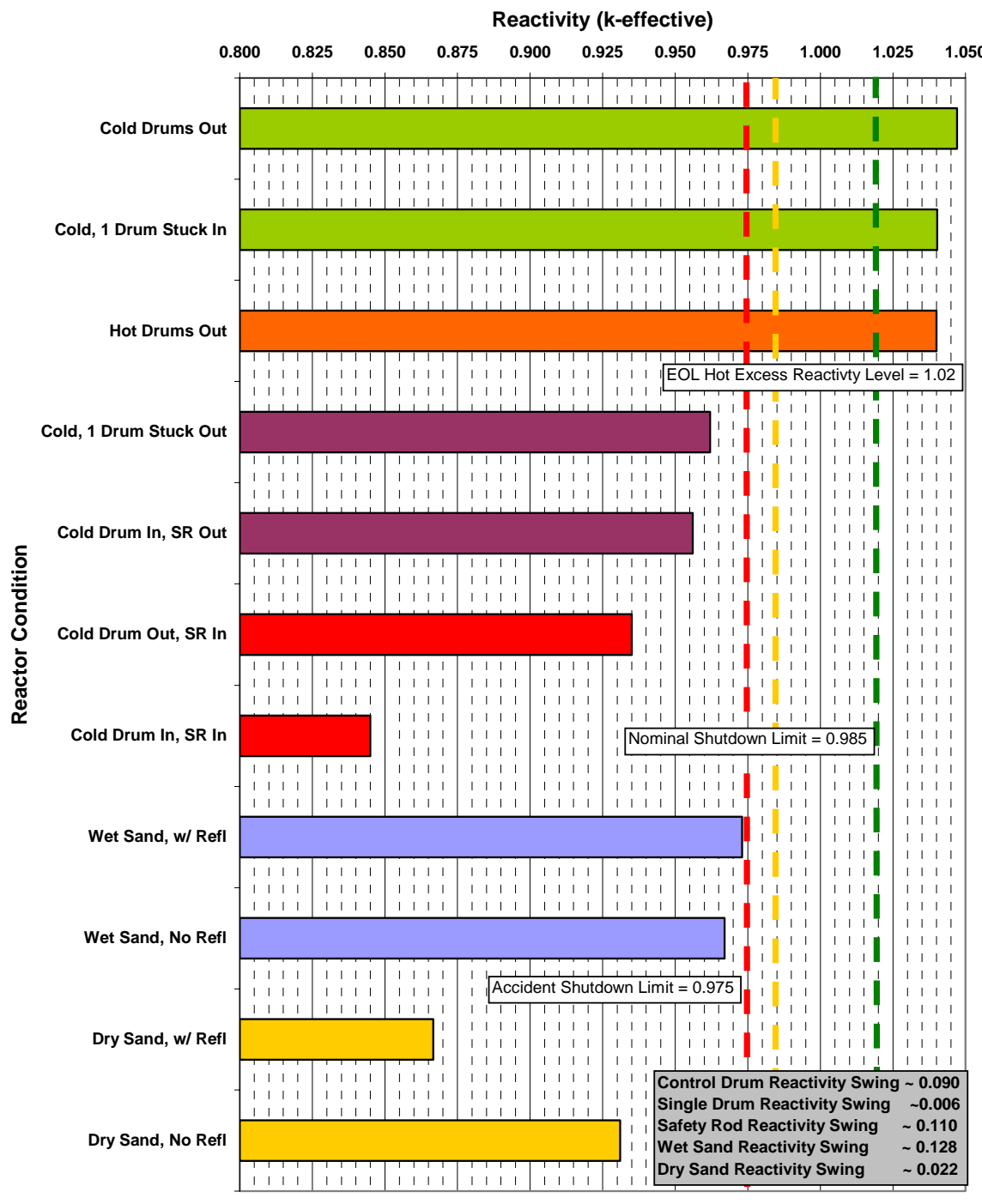




\section{Typical Relative Power Distributions for Drums versus Sliders}

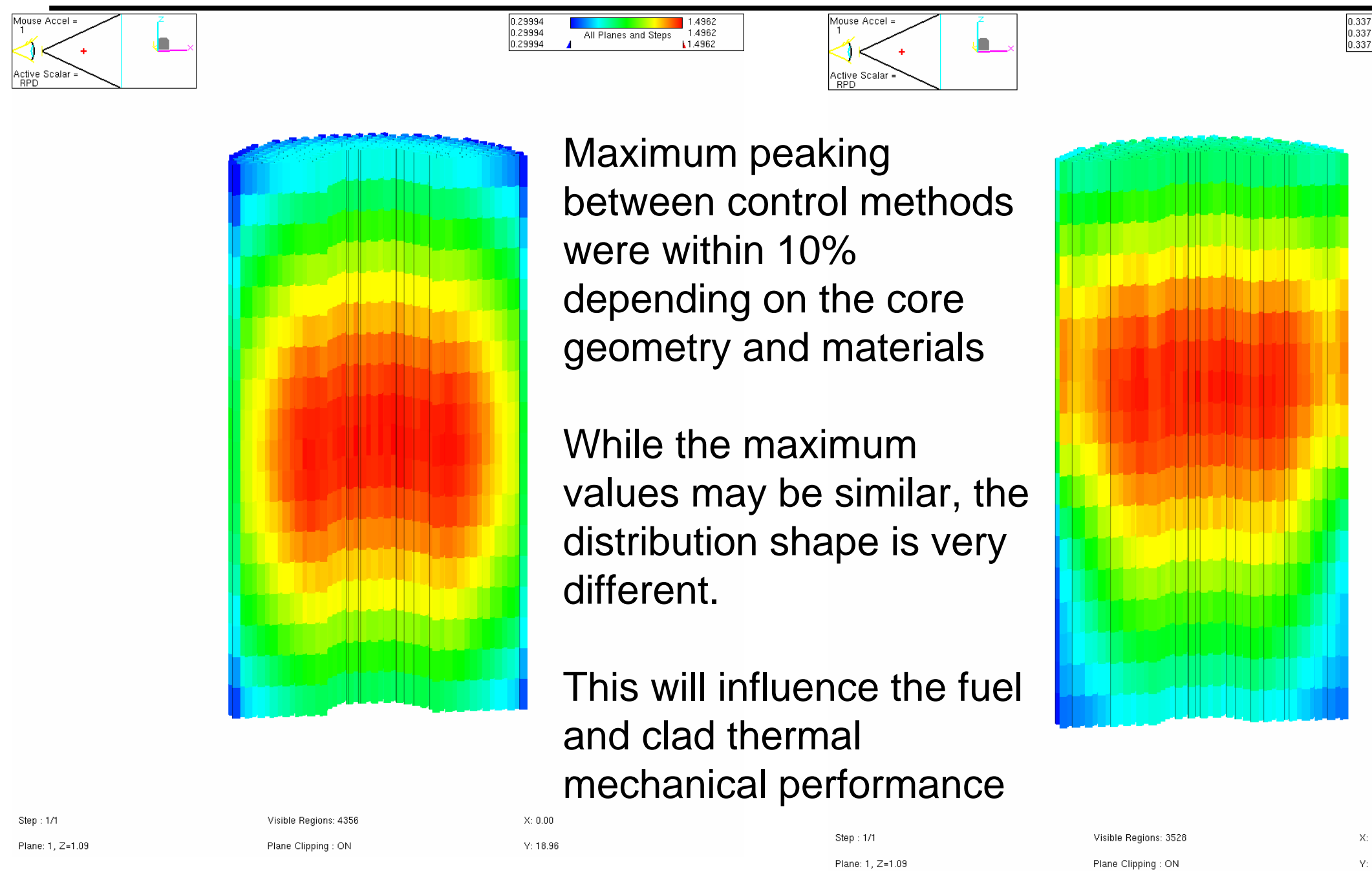

Control Devices and Strategies can Influence more than just Reactivity Design 


\section{Example of Fast Fluxes for 1MWth Reactor}

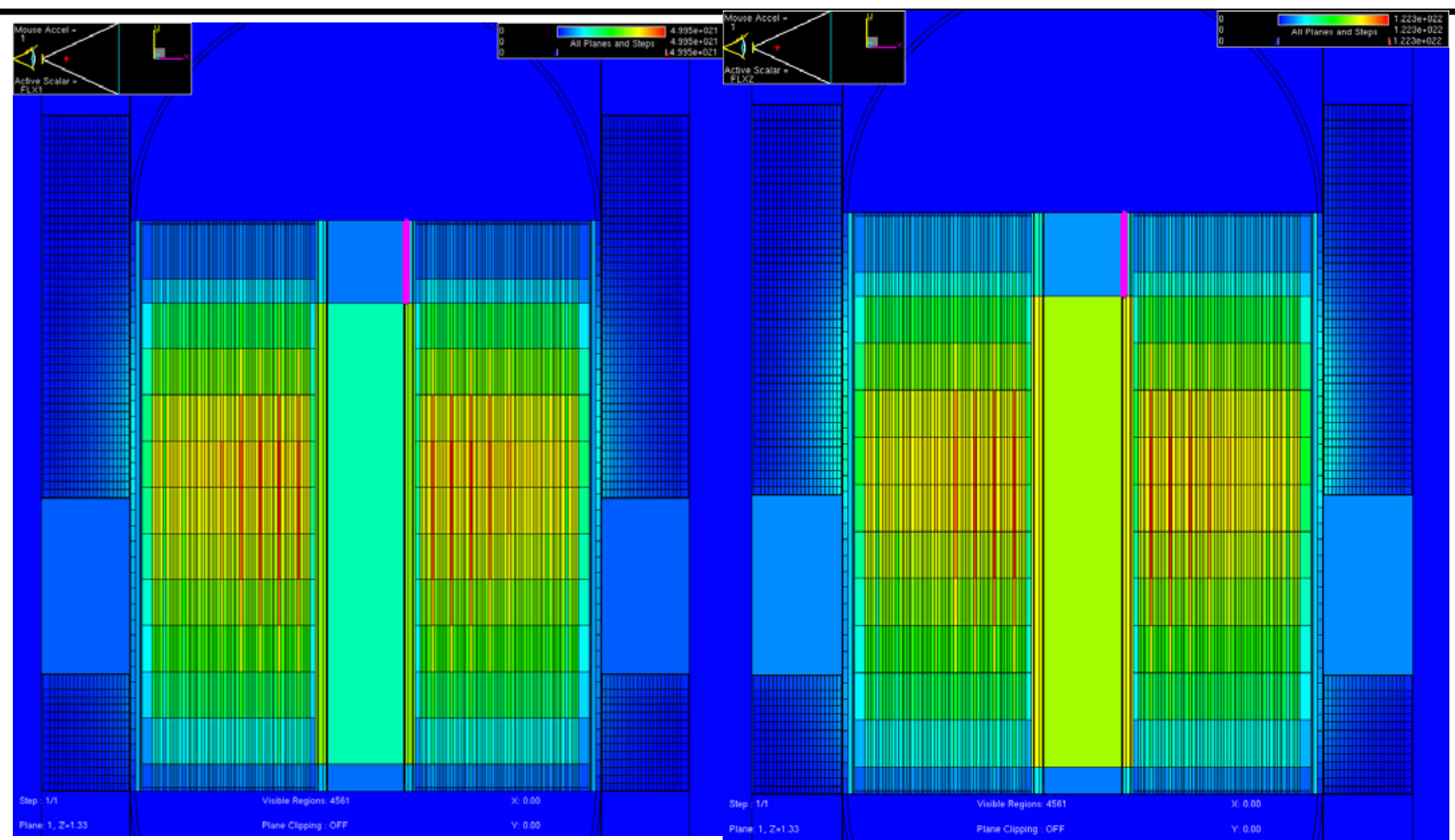

$(>1 \mathrm{MeV})$ scale $0-1.06 \times 10^{13}$

$(0.1-1 \mathrm{MeV})$ scale $0-2.58 \times 10^{13}$

- The fluxes with energies greater than $0.1 \mathrm{MeV}$ make up $90 \%$ of the total flux

- Shape distribution follows the power density distribution of the fuel

- The peak $\mathrm{E}>0.1 \mathrm{MeV}$ fluences at $15 \mathrm{MW}$-yrs $\left(\mathrm{n} / \mathrm{cm}^{2}\right)$ range from:

- $\quad \sim 160 \times 10^{20}$ inside thimble vessel

- $\quad$-80x1020 outside reactor pressure vessel 


\section{Example of Epithermal and Thermal Fluxes for 1MWth Reactor}

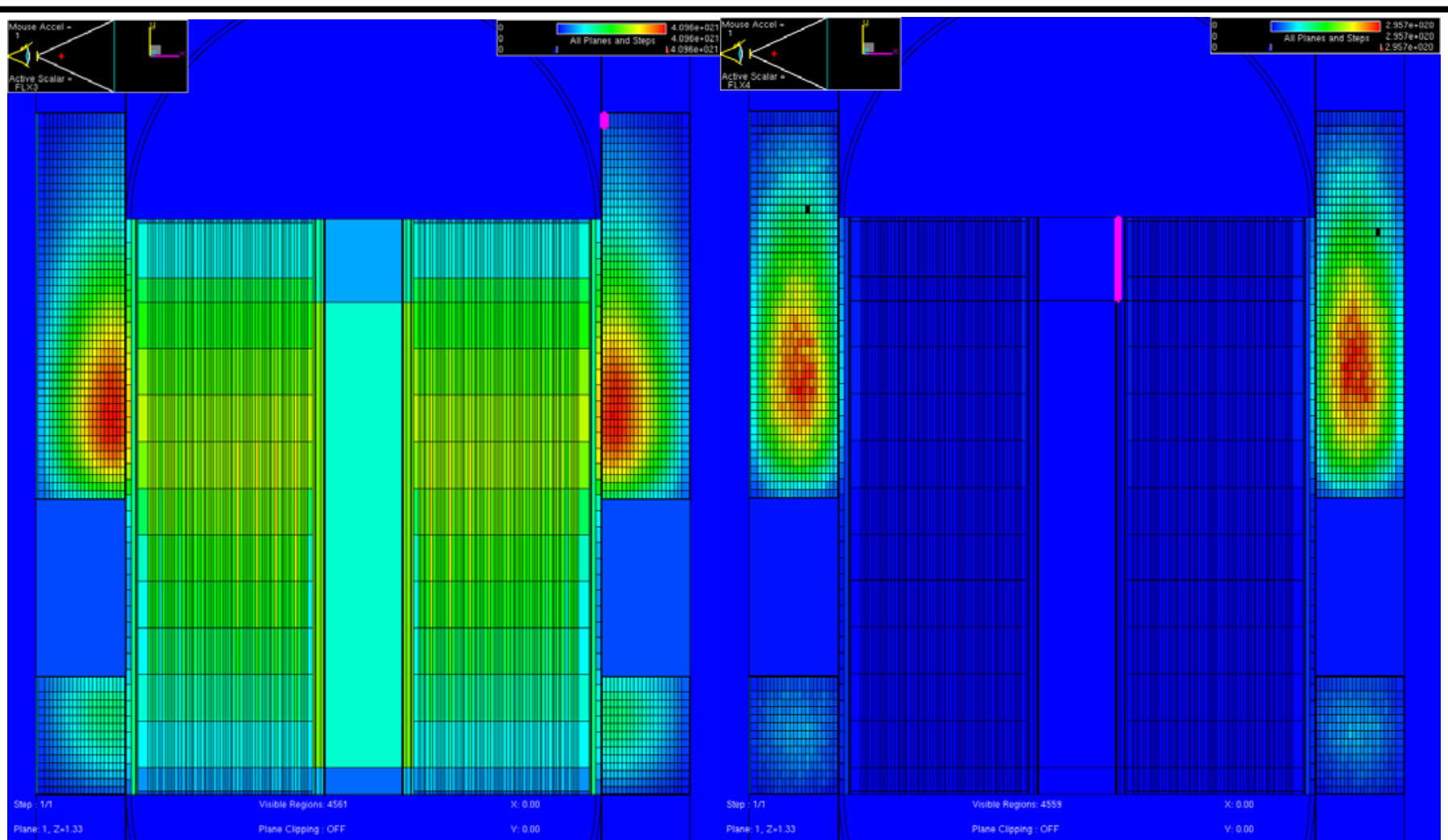

$(3 e V-0.1 \mathrm{MeV})$ scale $0-8.6 \times 10^{12} \quad(<3 e V)$ scale $0-6.3 \times 10^{11}$

- The fluxes in the epithermal regions are a result of the slowing down in the moderating reflector and scattering in the block material

- The reflected neutrons influence the power distribution adjacent to the reflector pieces

- The thermal flux is determined by the continued slowing down of the flux in the reflector and is the lowest magnitude 


\section{Refractory Materials Sensitivities for Reactor Mass and Performance}

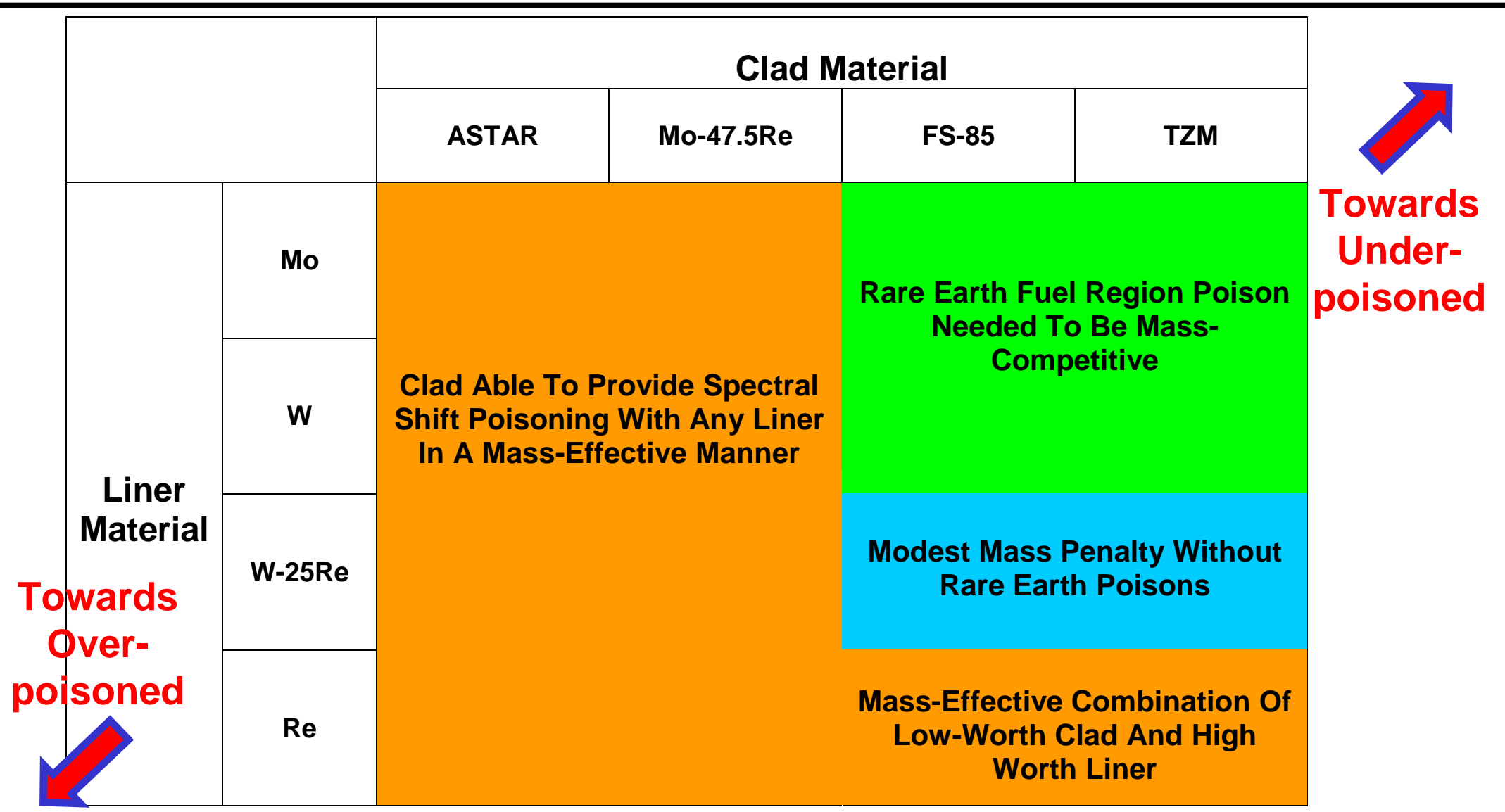

- Material Drivers for Reactor Mass:

- Density of the material and the volume required

- Interaction of the mechanical and nuclear performance attributes

- Structural materials with low neutron absorption required extra structure $(R e)$ or fuel volume (rare earth mixture) to meet shutdown reactivity requirements 


\section{Absorption Distribution in Fuel Pellets and Structure}

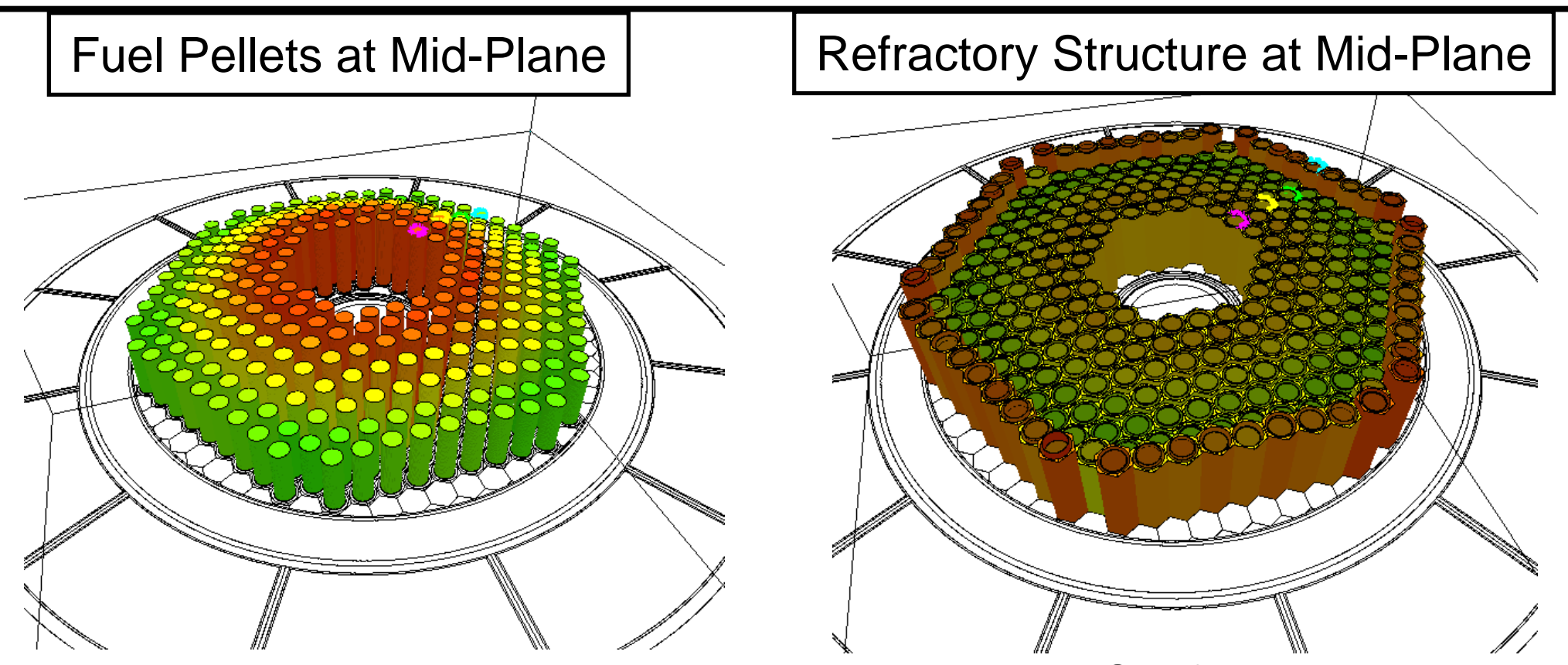

For Mo:47.5Re Pin and Annular Flow Block Configuration

- Fuel region absorptions follow the power shape and flux buckling

- Structural materials increase absorptions at the outer radius due to the softer spectrum at the edge and the increased capture worth of the materials

- Cores with a mixed spectrum as a result of moderating reflectors with have radially varying neutronic considerations

- There will be some additional neutron and gamma heating of materials that will need consideration for cooling and the requirements on the over-all heat balance 


\section{Refractory and Rare Earth Parasitic Neutron Absorption - Fast Range}
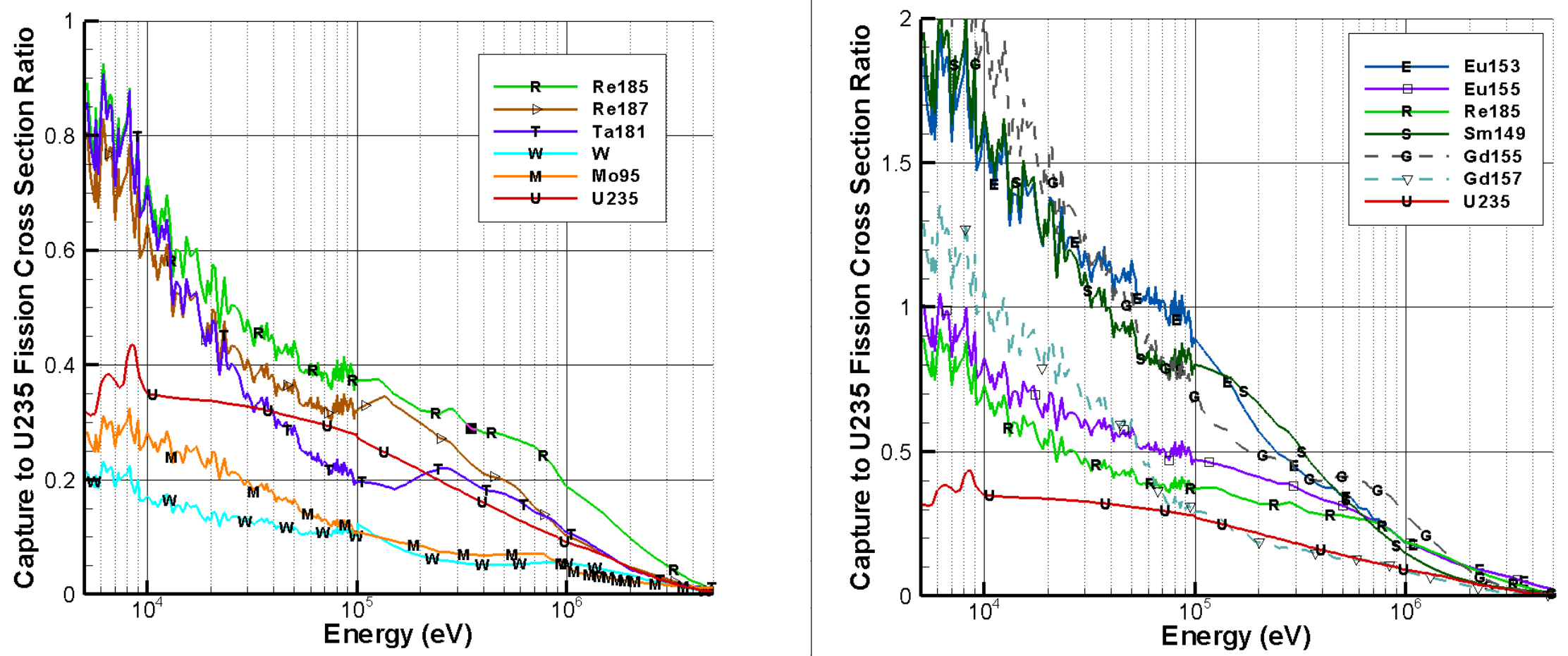

- Refractory Structural Materials contain Mo, Re, W, and/or Ta

- Parasitic worth of Re and Ta doubles in the shift of 100's of keV to 10's of keV

- Rare Earth Poisons mixable with UO2 include Eu, Sm, and Gd

- Nearly twice as worthy as the refractories

- U235 Capture to Fission Ratio also nearly doubles

- This reduces the reproduction factor by $10 \%$ (poisons cause another $10 \%$ reduction)

- Shifts to harder spectrums can cause a small positive reactivity addition 


\section{Accident Scenario Neutron nu-Fission Spectrum Shifts}

- For Dry Sand cases, safety rod(s) are required to meet the intact geometry shutdown reactivity limit

- For Flooded and Wet Sand cases, any of the spectral shift absorptions were effective especially in the 10-100keV energy range

- For the lowest energies the capture resonances below $1 \mathrm{eV}$ come into play, but the fraction of nu-fissions is an order of magnitude lower

- Rare earth poisons (Eu, Sm, and $\mathrm{Gd}$ ) can be more mass effective
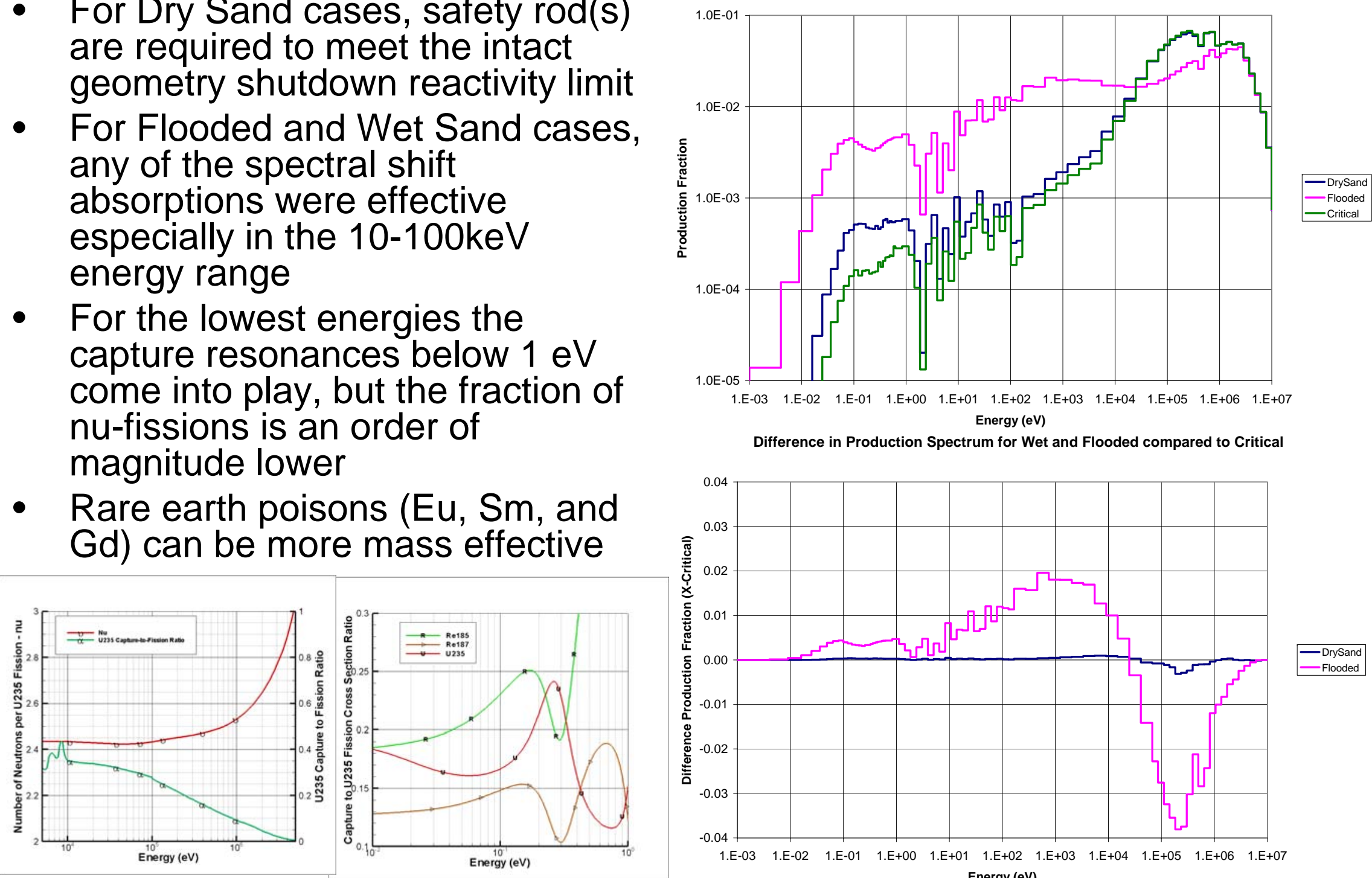

Difference in Production Spectrum for Wet and Flooded compared to Critical

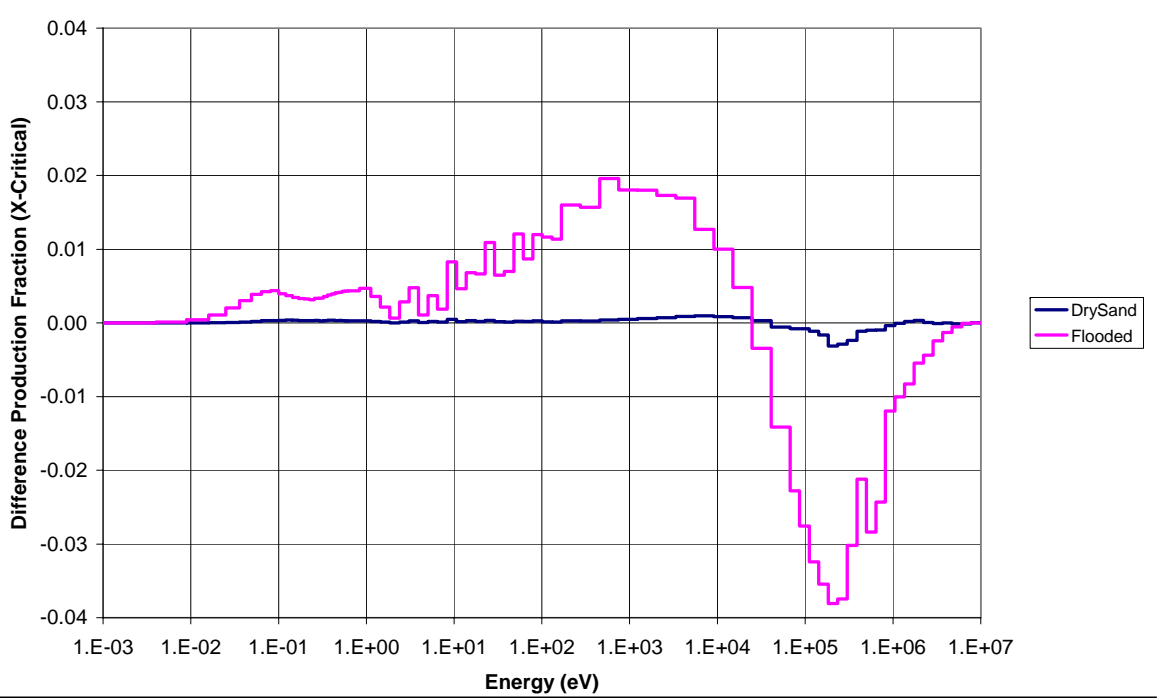


Flux Distribution for Most Reactive and Flooded Conditions

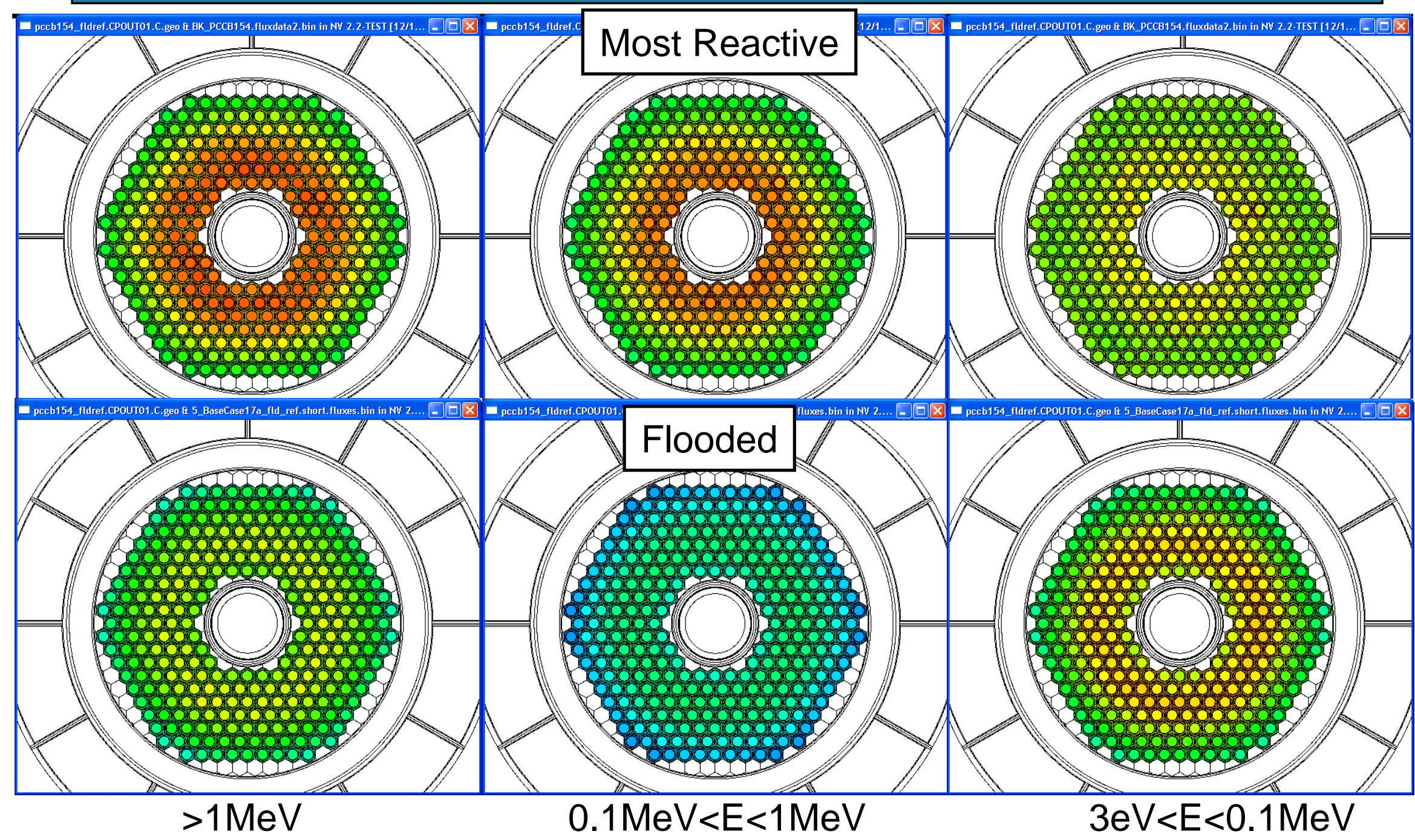

Fluxes shift from the high energies to the lower energies The middle flux is depressed further by the spectral shift poisons in the structures 


\section{Ex-Core Geometry Reactivity Effects}

- Changes to Leakage and Reflection due to thickness of:

- Vessel

- Downcomer

- Vessel to Reflector Gap

- Azimuthal Gap between Reflector Components

- Reflector Canning

- For these high leakage systems, the impact from void spacings can be 0.01-0.02 $\Delta \mathrm{keff} / \Delta \mathrm{cm}$

- To optimize the mass, the various requirements and uncertainties for thermal hydraulics, mechanical, nuclear, materials, and, manufacturing need to be balanced
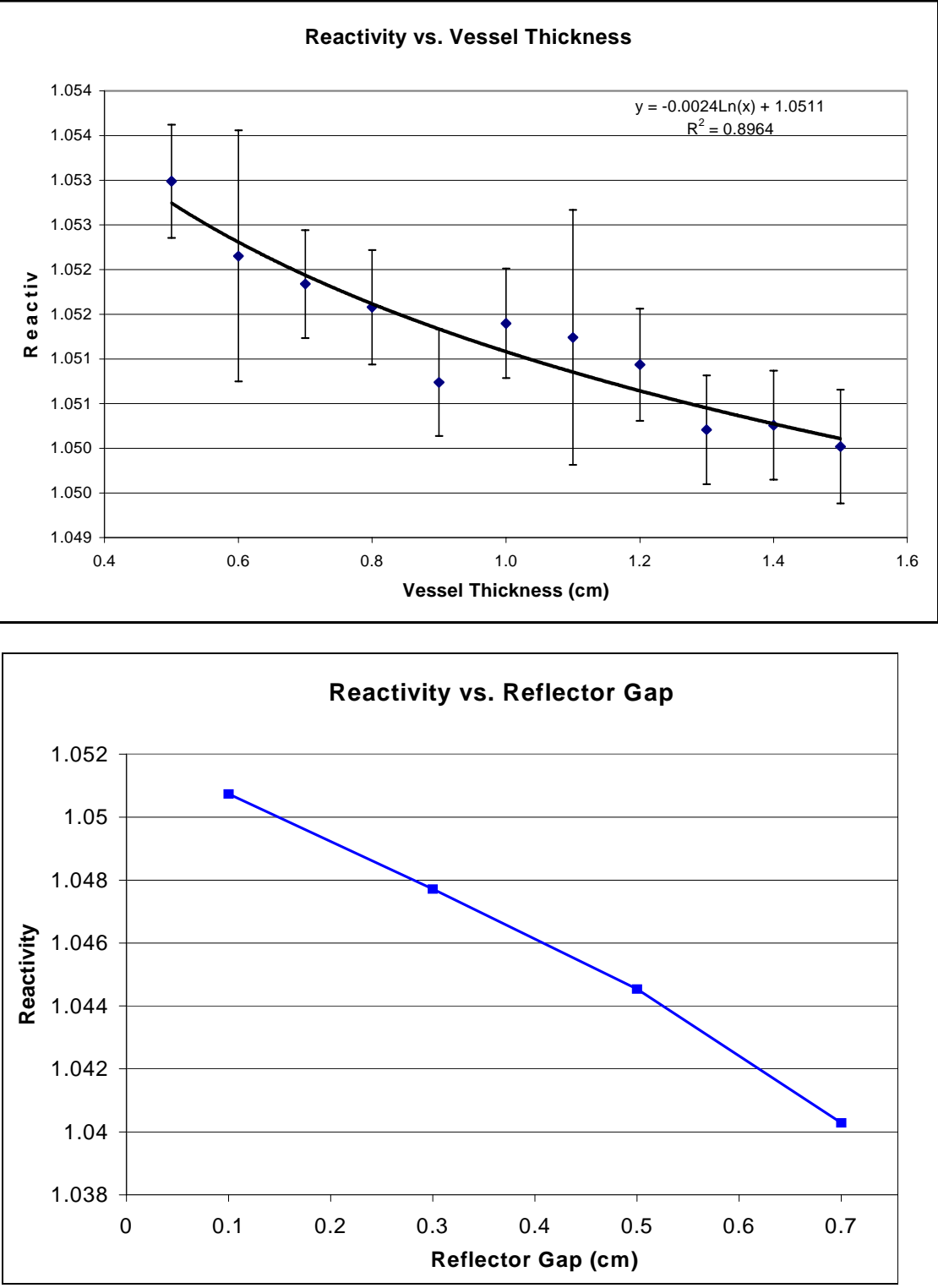


\section{Loading Density and Core Diameter}

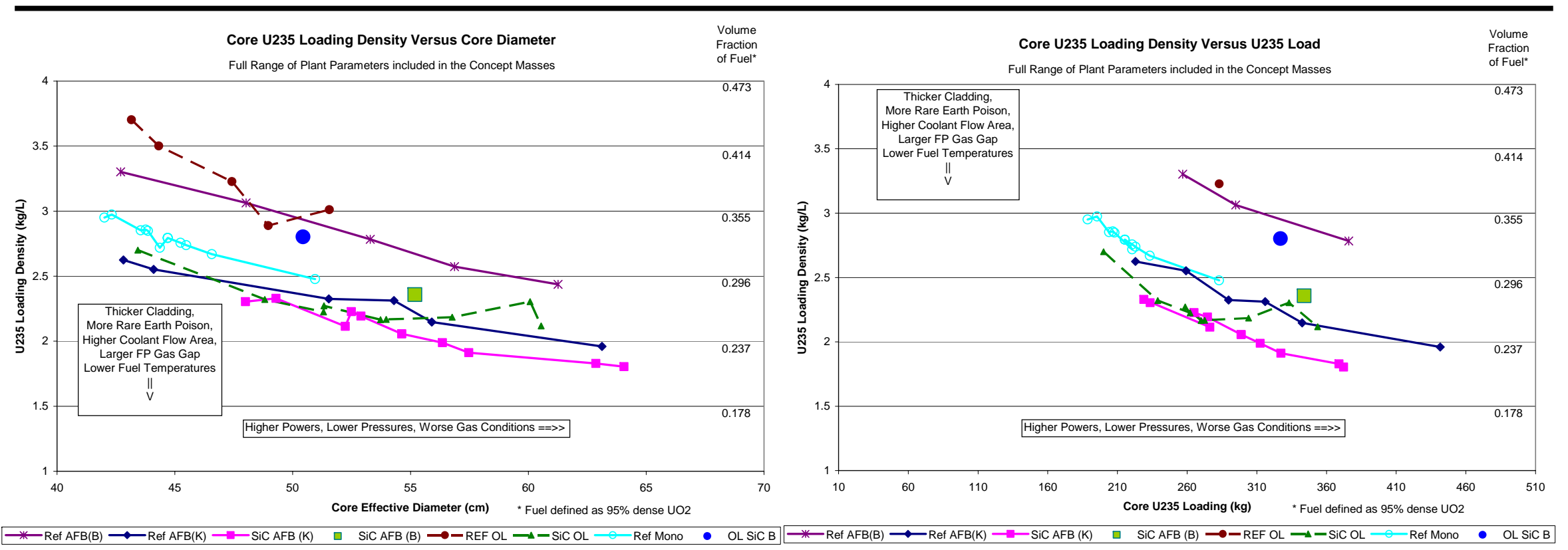

- Thermal Hydraulic and Mechanical performance set volume fractions of fuel, structure, and coolant

- Heat transfer area to limit peak fuel temperature

- Fuel pin gas gaps to accommodate lifetime fuel swelling

- Clad thickness and plenum lengths to maintain low material creep

- Coolant flow area to meet core pressure drop limits

- Liner volume fraction for chemical compatibility of fuel/clad/coolant and accident shutdown reactivity

- $\quad$ Lower Effective Core Loading Density of U235

- Means larger diameter core (to reduce buckling)

- Means higher fuel load (to reduce leakage and increase utilization) and even larger core diameter

- Means potential need for more spectral poison which then also requires more fuel 


\section{Core Compaction Scenarios Increase Fuel Loading Density}

- Accident Scenarios for Launch and Failure to Reach Orbit can result in configurations with less void

- Fission Product Gas Gaps Collapsed

- Coolant Spaces Compressed

- Metals Density Increased

- Reduces neutron mean free path (and thus leakage)

- Increases core reactivity level

- Enough to overcome initial intact least reactive level?

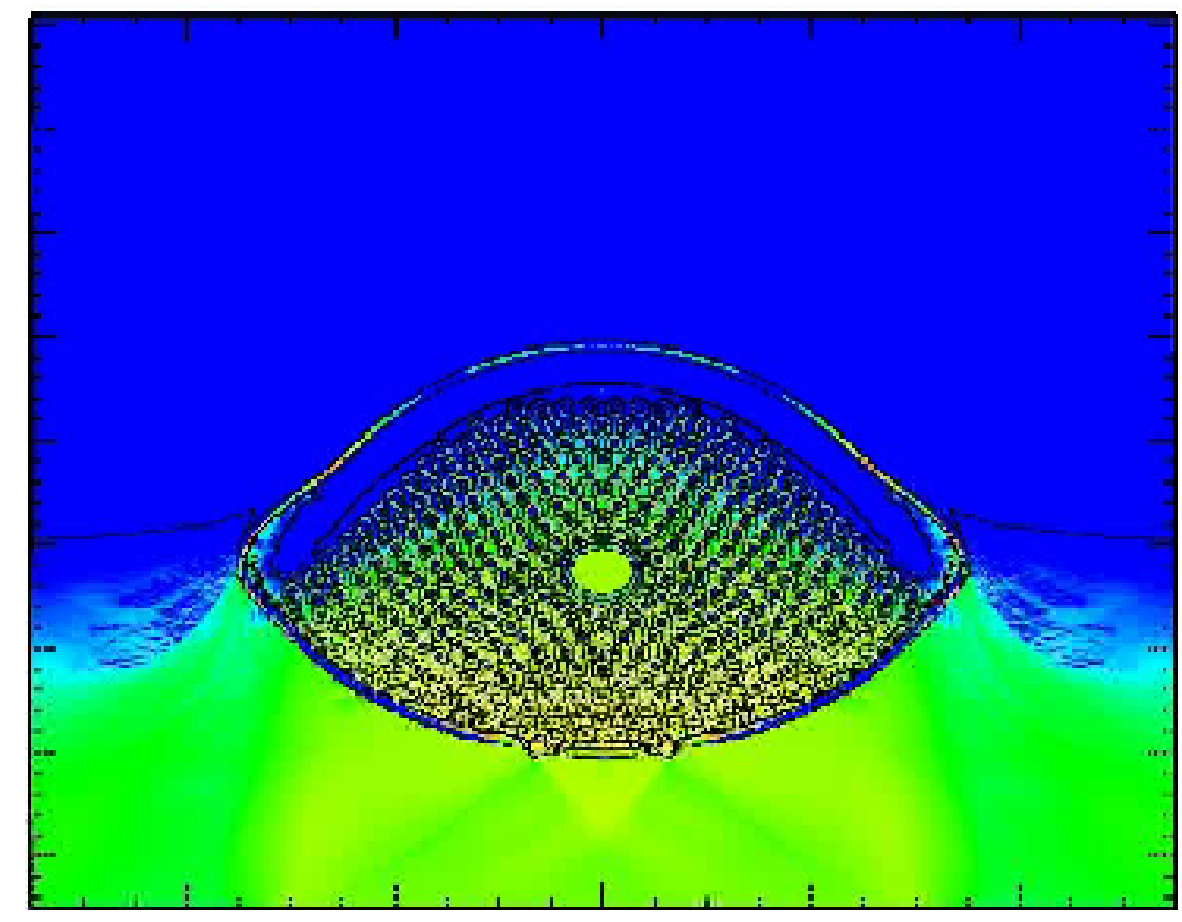




\section{Coefficients of Thermal Expansion and Potential Reactivity Coefficients}

Mean Coefficient of Thermal Expansion

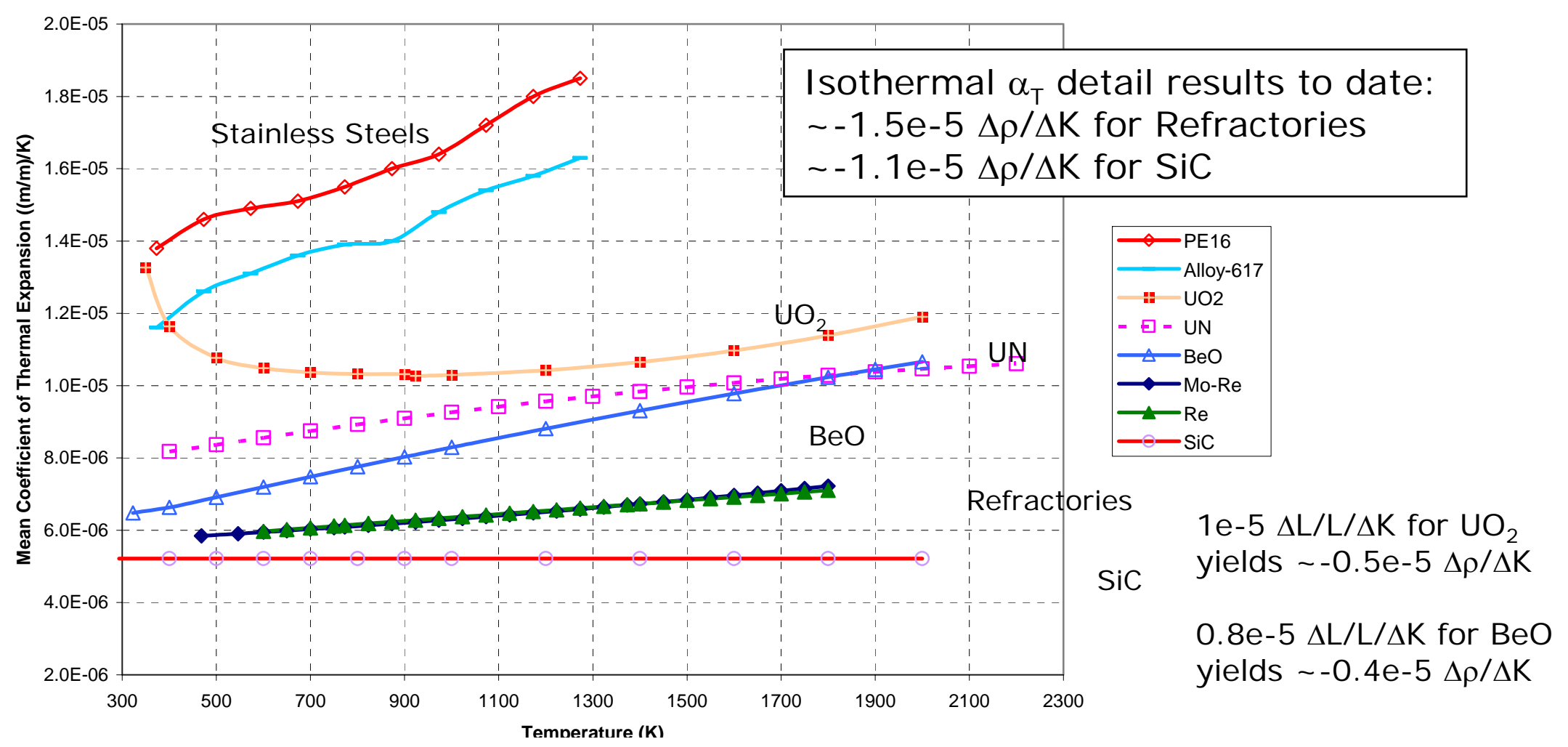

- Heat capacitance and timing of component heating/cooling affect response rate (Rank: fuel, clad, block/grid plate, vessel, reflector)

- Fuel fission product swelling and thermal expansion are of same reactivity defect magnitude as depletion of $\mathrm{U} 235$ for lifetime control $(0.6 \% \mathrm{dk} / \mathrm{k}) /(\% \mathrm{dm} / \mathrm{m})$

- The effects of fuel pin and core structural distortion would have to be considered 


\section{Swelling of Fuel Acts Like a Depletion of U235}

UO2 Fuel Volumetric Swelling as a Function of Burnup and Temperature $-1800 \mathrm{~K}=1700 \mathrm{~K}=1500 \mathrm{~K}-1000 \mathrm{~K}=-\% \mathrm{FIFA}$

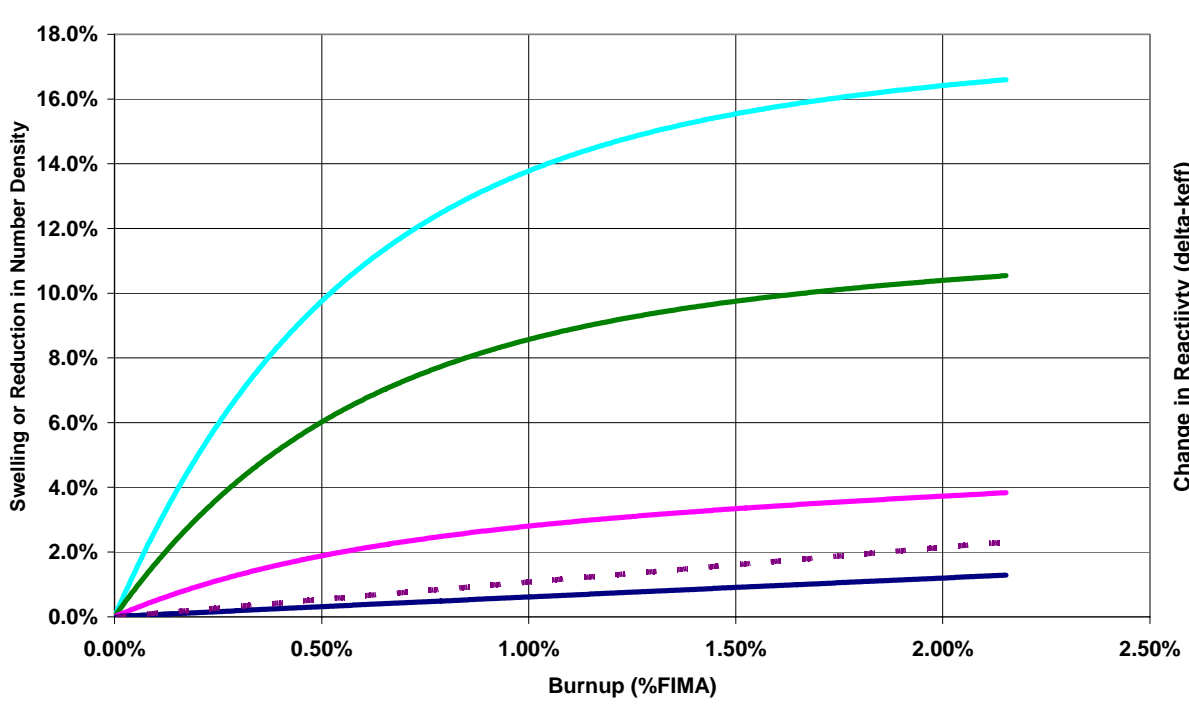

Potential Reactivity Impact from Depletion and Fission Product Swelling - - $\mathrm{dkDepl}=\mathrm{dK} 1000 \mathrm{~K}=\mathrm{dk} 1700 \mathrm{~K}$

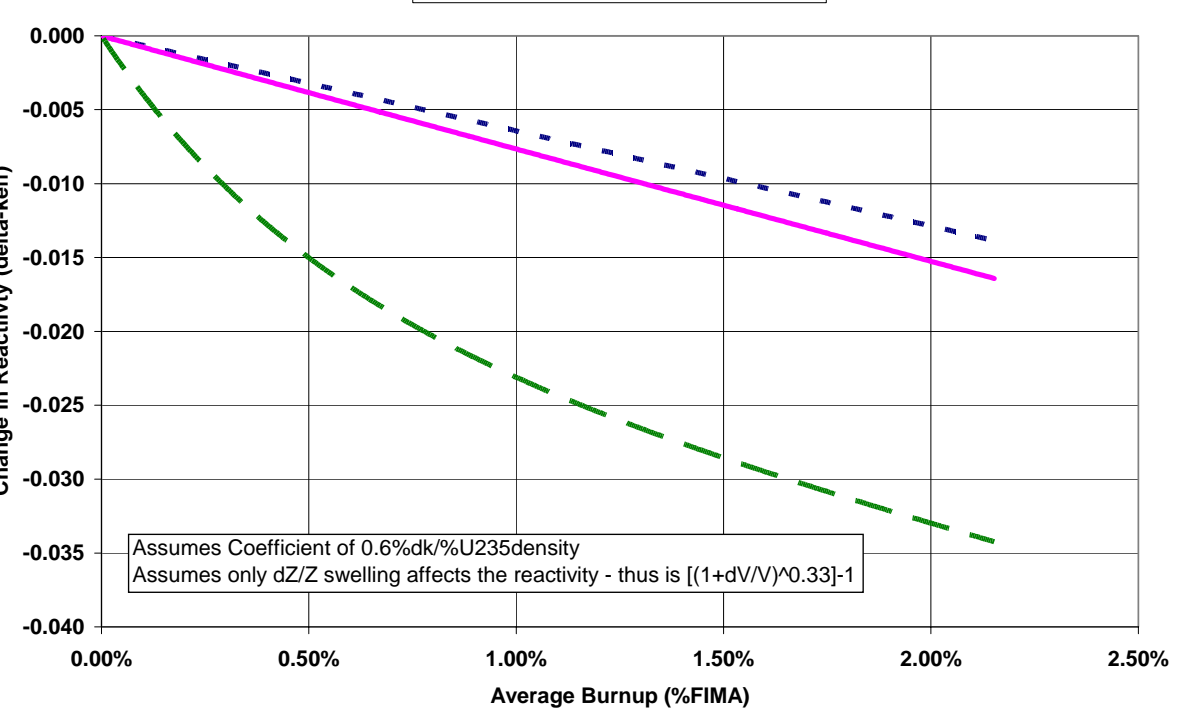

- Fuel swelling contributes to the pin sizing (fission gas gap) and the reactivity defect

- Typically see $\sim 0.6 \%$ delta-keff per $1 \%$ change in density in the axial direction

- \%FIMA can be limited by lowering power peaking and lowering enrichment

- Swelling can be limited by lowering burnup and lowering average fuel temperature

- This is addition to the initial cold to hot expansion reactivity defect during plant heatup

- Some limit on the allowed amount of swelling may be required

- Tolerances for the fuel density, dimensions, etc. are needed to limit reactivity uncertainty 


\section{Summary}

- Thermal and mechanical features often played a dominant role in the reactor size

- The fast spectrum reactor system sizing is sensitive to fuel loading capability in the core and the void space interfaces to the reflector

- Mixed energy spectrum of the reflector moderated system requires study of subtle neutronic effects

- The use of rare earth poisons can have the best reactivity worth per unit mass, except one must trade off the fuel loading density

- Intact Dry Sand Immersion scenario is often the limiting safety condition for the refractory metal cores

- Understanding the $\mathrm{UO}_{2}$ performance with lifetime requires integration of the thermal hydraulics, mechanical, and nuclear analyses

- Geometry impacts fuel temperature, clad stress, and core reactivity

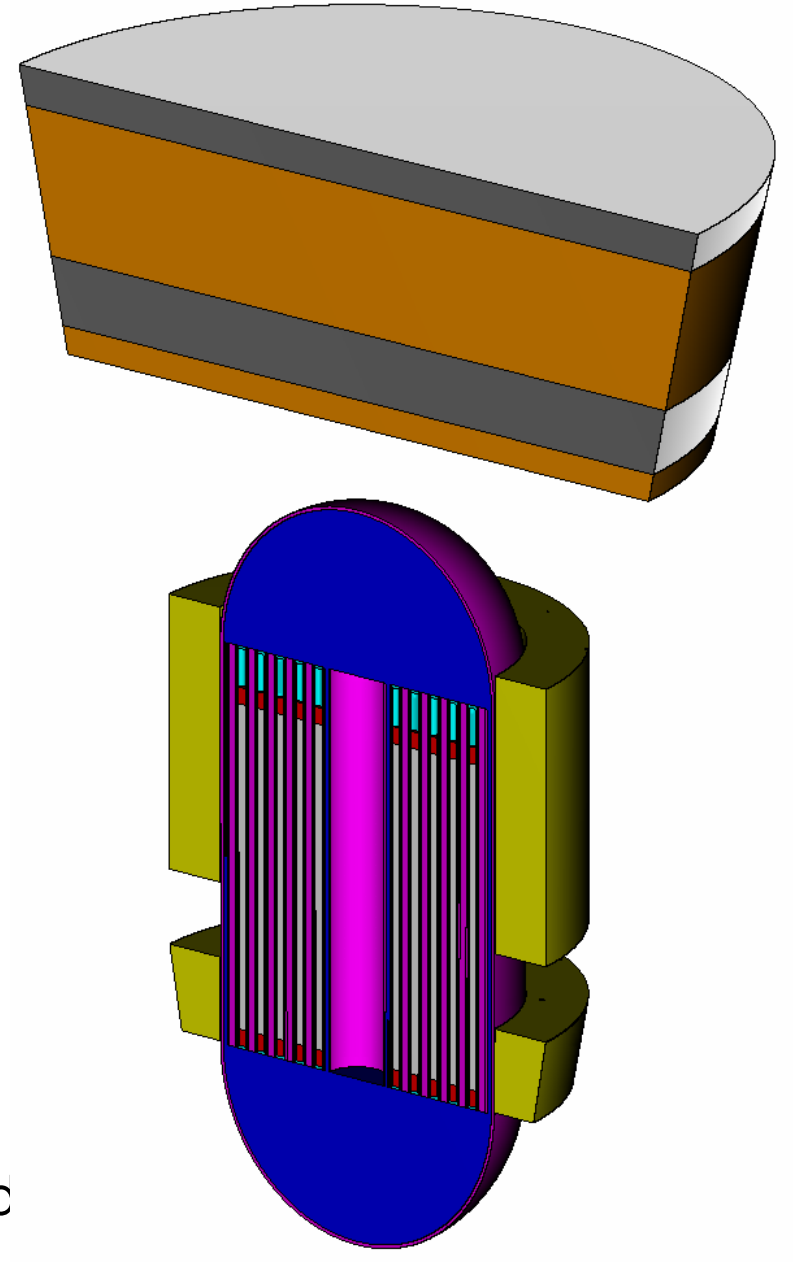


Enclosure 3 to

SPP-SEC-0039

\title{
Reactor Mechanical Design Concept and Performance
}

\author{
Kedzierski, D.
}


This page is intentionally blank.

PRE-DECISIONAL - For planning and discussion purposes only 


\section{Reactor Mechanical Design Concept and Performance}

Dennis Kedzierski

Space Reactor Engineering - Bechtel Bettis Inc.

STAIF 2006

February 2006 


\section{Discussion Points}

- Key design parameters

- Mechanical design features for the baseline concept (Annular Flow Concept)

- Structural and thermal performance

- Other mechanical design concepts

- Key open issues 


\section{Gas Reactor - Key Design Parameters}

- $\quad$ T inlet $=880 \mathrm{~K}$

- $\quad$ T outlet $=1150 \mathrm{~K}$

- Gas pressure: 1.38 - $4 \mathrm{MPa}$

- Irradiation fluence over 15 year lifetime:

- Vessel shell $\left(60 \times 10^{20} \mathrm{n} / \mathrm{cm}^{2} \mathrm{E}>0.1 \mathrm{Mev}\right)$

- Safety rod thimble $\left(160 \times 10^{20} \mathrm{n} / \mathrm{cm}^{2} \mathrm{E}>0.1 \mathrm{Mev}\right)$

- Loads (based on 1.4 X NASA Prometheus Environmental Requirements Document)

- 9G axial and 3G lateral

- Mechanical design limits

- Based on ASME Section III Subsection NH

- $\sigma_{\text {Allow }}$ lesser of 2/3 Sy or $1 / 3$ Su

- Total average strain $<1 \%$ for base metal and $<0.5 \%$ for weld metal

- Satisfy Code of Federal Regulations 10CFR70 requirements

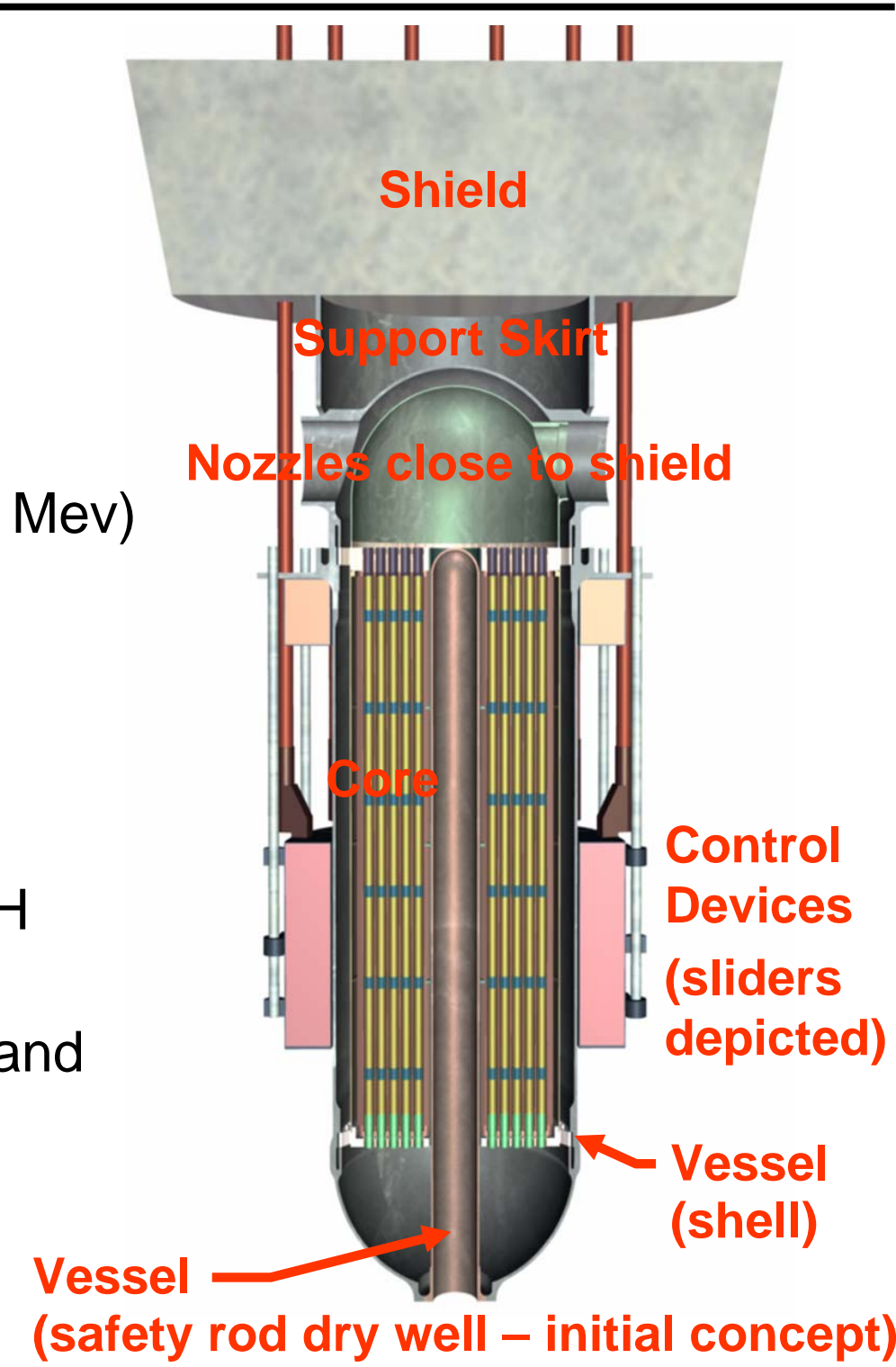




\section{Gas Reactor Vessel Concept}

- Nickel superalloy (A617, Haynes 230, and Nimonic PE-16)

- Cooled by inlet flow

- Single central safety rod dry well (internal safety rod is option)

- Vessel connected to shield structure via support skirt (minimizes structure around core)

- Support ring provided for reactivity control devices

- Shell thickness is $0.64-3.2 \mathrm{~cm}$ depending on pressure and temperature

- Welds are critical links

- Full penetration

- Inspectable via NDE (to address He leakage issue)

- Creep limit $1 / 2$ base metal limit

- Mechanical properties

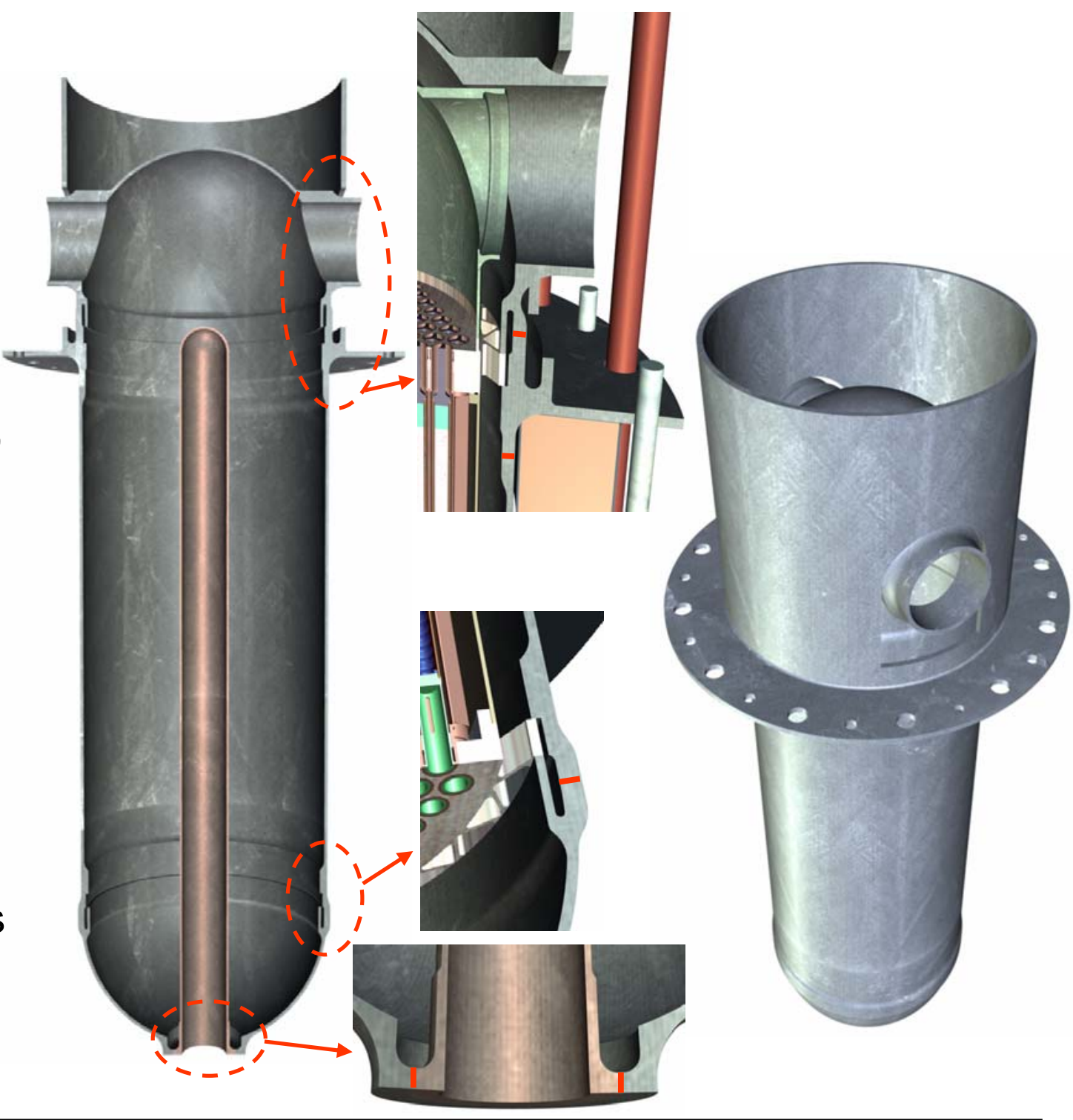




\section{Vessel Shell and Dry Well Thermal Performance}

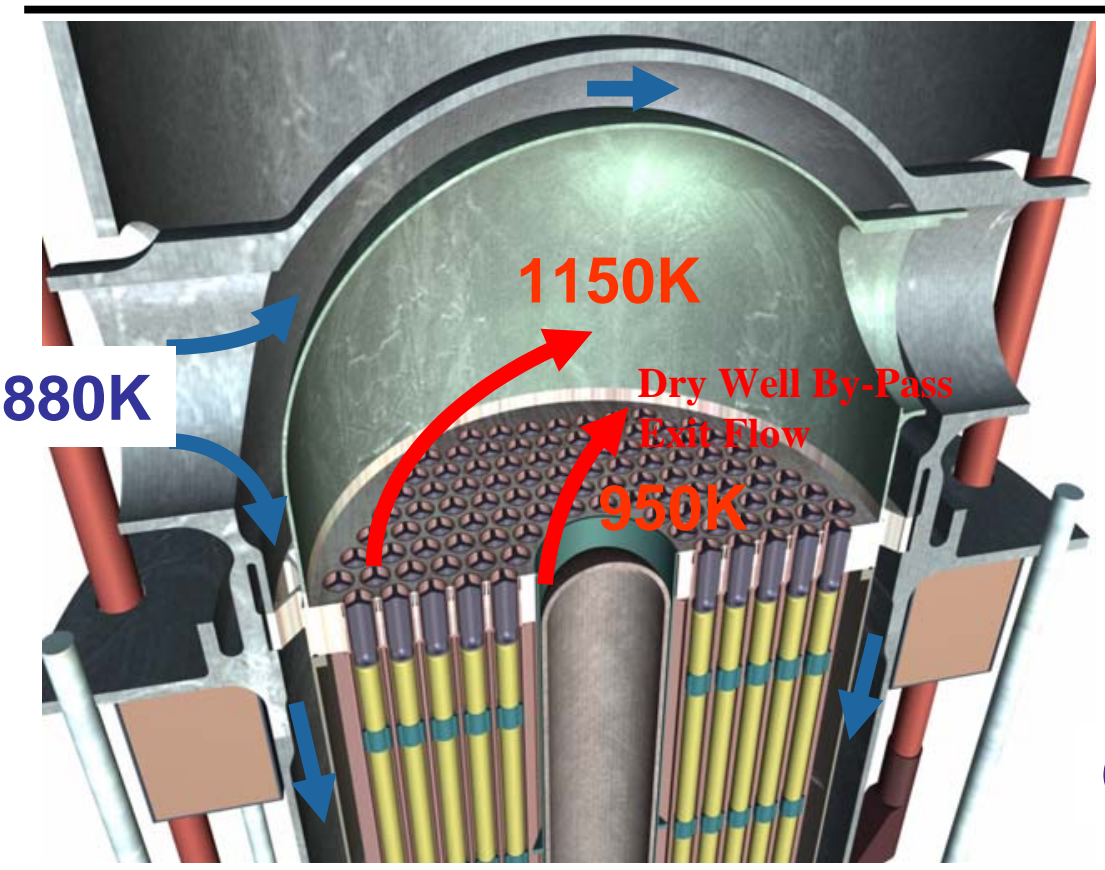

No Micrometeoroid Shield

- 897K in Shell (0.5 W/cc $\gamma$ htg

- 955K in Thimble (1 W/cc g htg)

- 995K in Thimble (10 W/cc $\gamma$ htg)

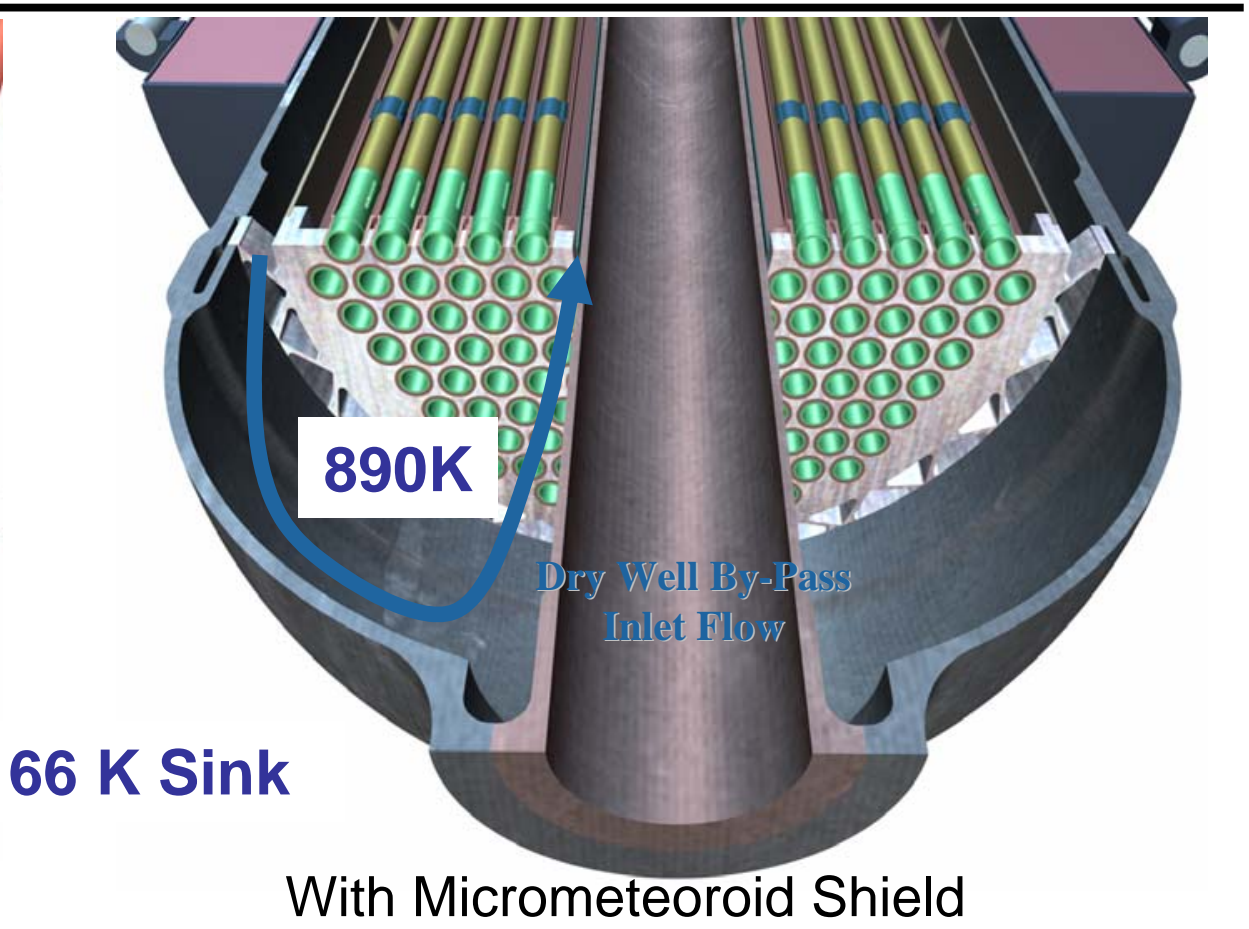

- Up to $977 \mathrm{~K}$ in Shell (assumes adiabatic BC)

- Same

- Same

- Using internal safety rod moves limiting location to vessel shell

- $T_{\text {maximum }}$ in range where material limits are expected (900-1000K)

- Dry well feasibility dependent on irradiated material properties 


\section{Reactor Support Skirt Performance}

- 3D Model of reactor assembly

- Alloy 617 vessel (0.76 cm thick) and skirt (1.9 cm thick)

- Solid skirt (initial assumption)

- No piping connections

- Reactor mass $=1000 \mathrm{Kg}$ (vs $1100 \mathrm{Kg}$ min and $3000 \mathrm{Kg}$ max from core sizing study)

- 9G Axial + 3G Lateral

- Room temperature

Maximum stress $=57 \mathrm{MPa}\left(<160 \sigma_{\mathrm{m}}\right.$ limit $)$

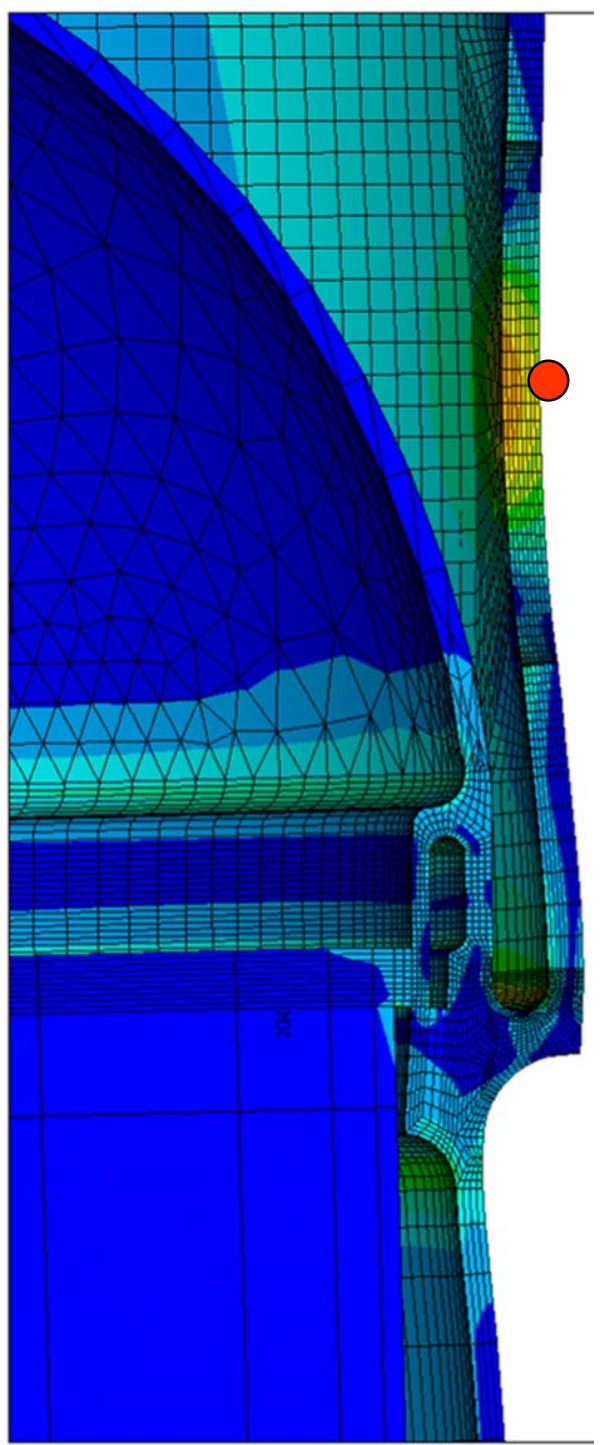




\section{Gas Reactor Core - Overall Characteristics}

- Refractory metal alloy concepts discussed herein (SiC options were also assessed)

- Goal to maintain section thicknesses $<0.64 \mathrm{~cm}$ (based on refractory metal vendor experience)

- Core assembly interfaces include:

- Welds

- Interference fit/braze

- Slip-fit

- $\quad$ Same material preferred throughout

- Dissimilar material welds limited to:

- Nb/Ta Alloys (ASTAR, FS-85, Nb-1Zr)

- Mo-Re/Mo-TZM

- Core is built-up with vessel (not a core cartridge assembly)

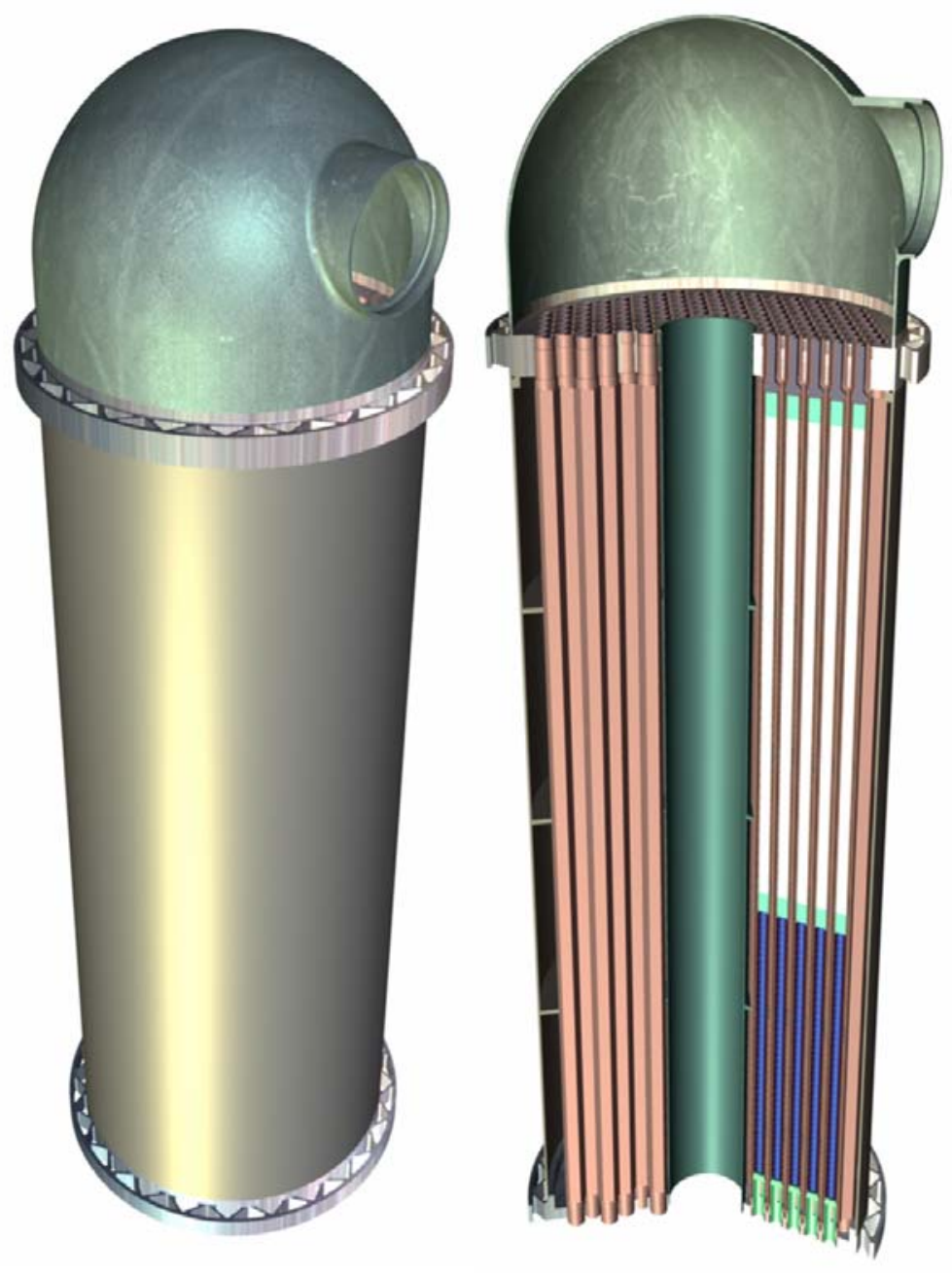




\section{Annular Flow Concept (AFC) - Block vs Unit Cells}

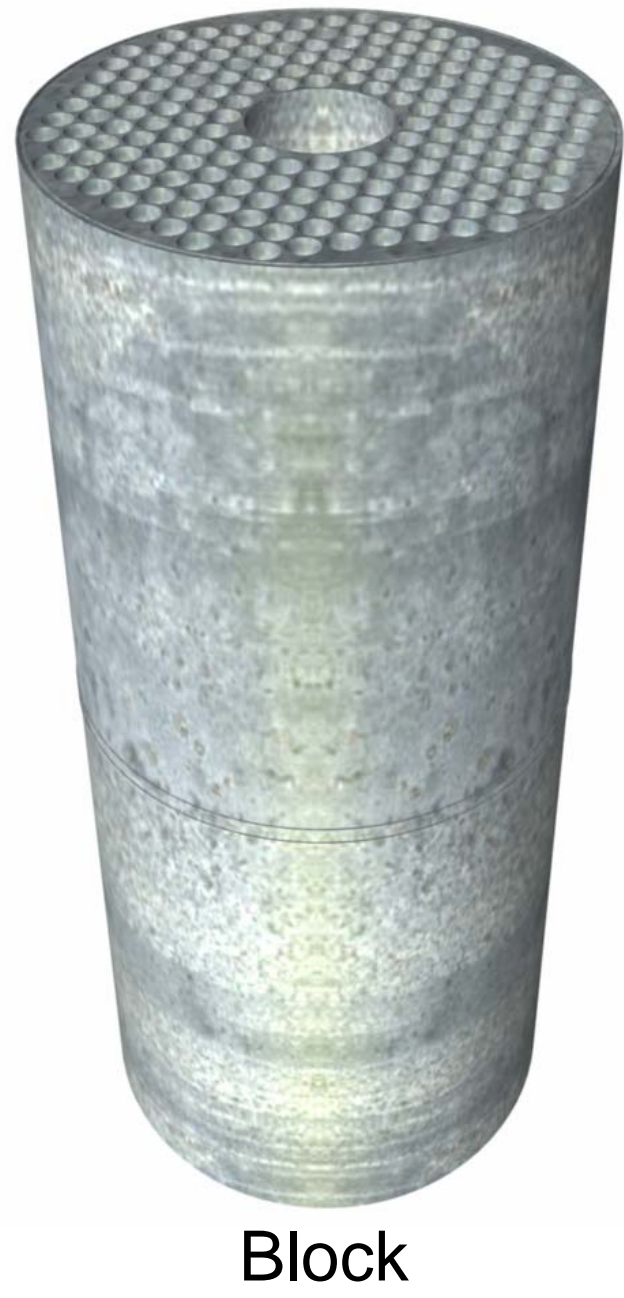

- Block more difficult to manufacture

- Stacked and HIP'ed plates

- Inspection difficult

- Higher manufacturing risk

- Unit cells simplify manufacturing

- Machined from tubing

- Simpler inspection

- Lower manufacturing risk

- Unit cells experience lower thermal stress and creep

Block

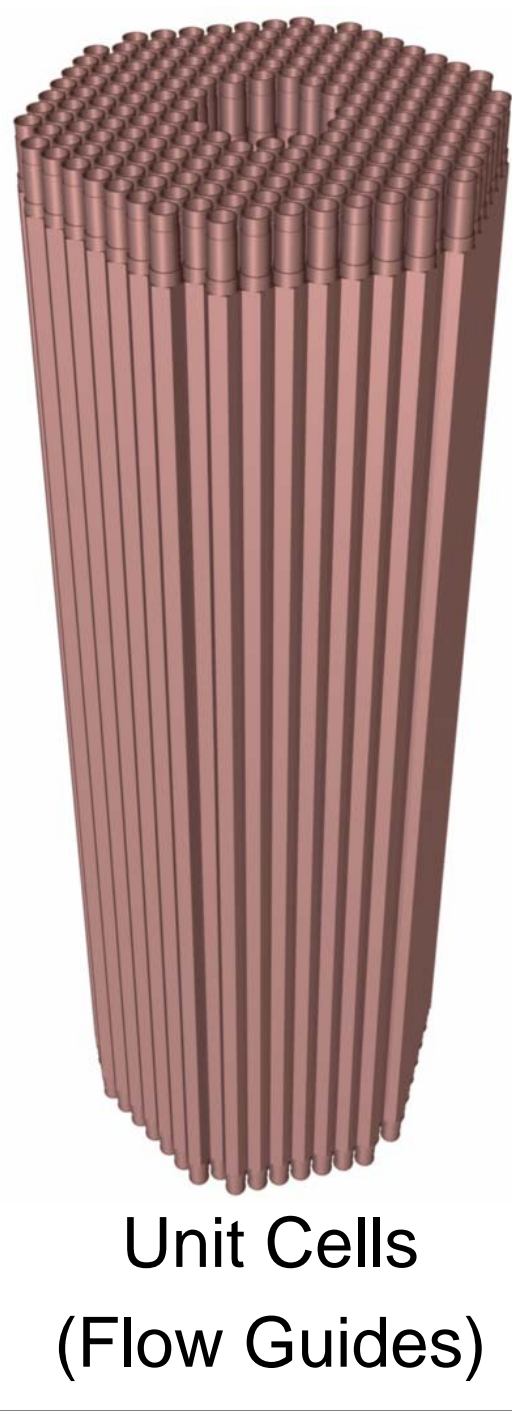




\section{Core Block vs Unit Cell Performance}

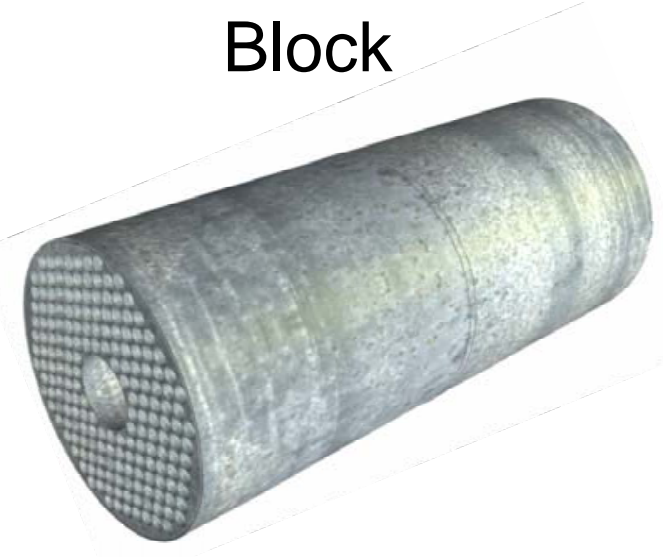

-3D Model

- 890K inlet

- 1150K outlet

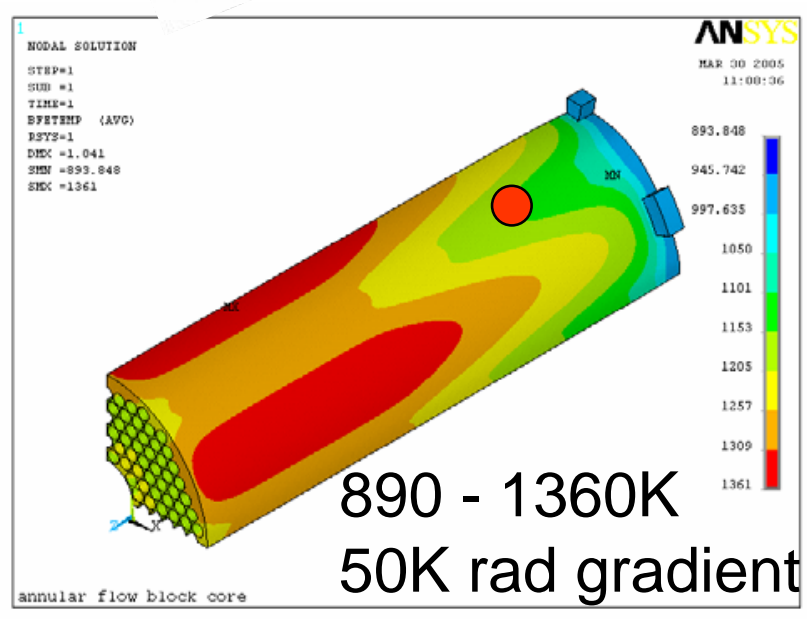

- $10 \mathrm{~W} / \mathrm{cc} \gamma \mathrm{htg}$

- Mo-47.5Re

O $300 \mathrm{MPa} \max \sigma$ and $0.5 \% \varepsilon$ (10 W/cc)

- $150 \mathrm{MPa}$ max $\sigma$ and $0.3 \% \varepsilon$ (1 W/cc)

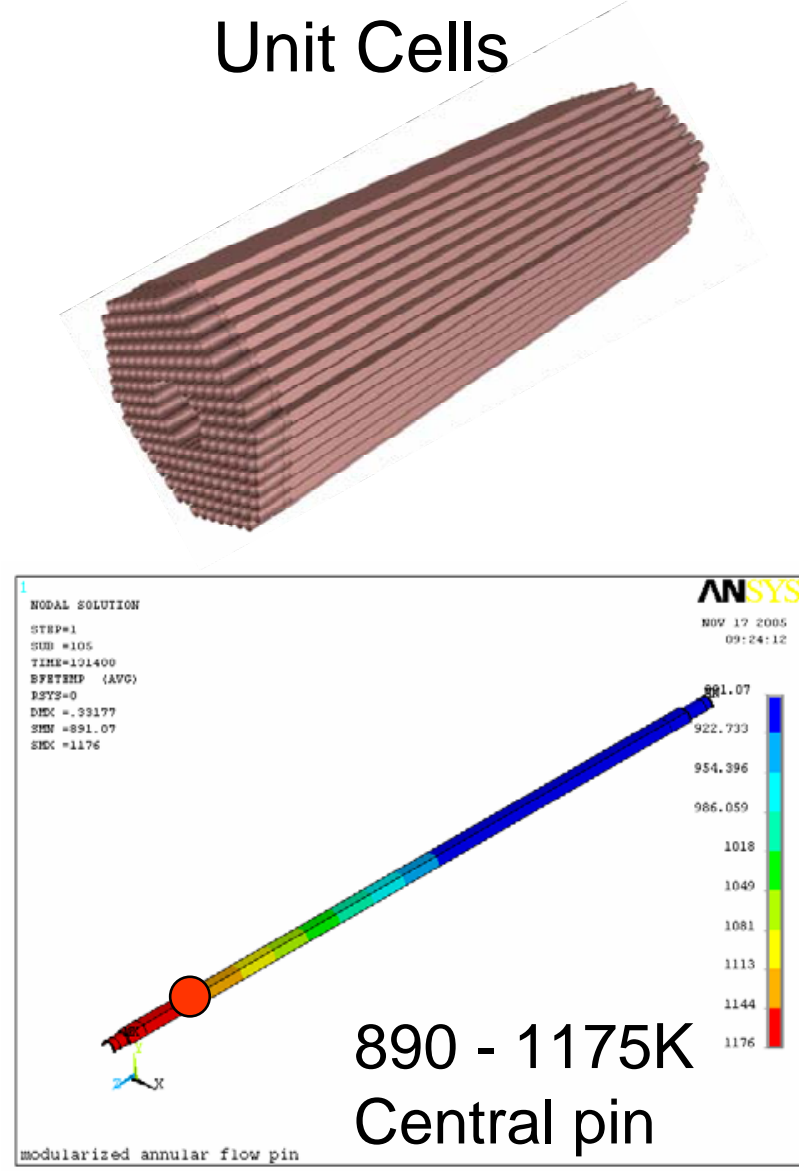

0 1.2 MPa max $\sigma$ No measurable $\varepsilon$ 


\section{Annular Flow Concept - Core Assembly}

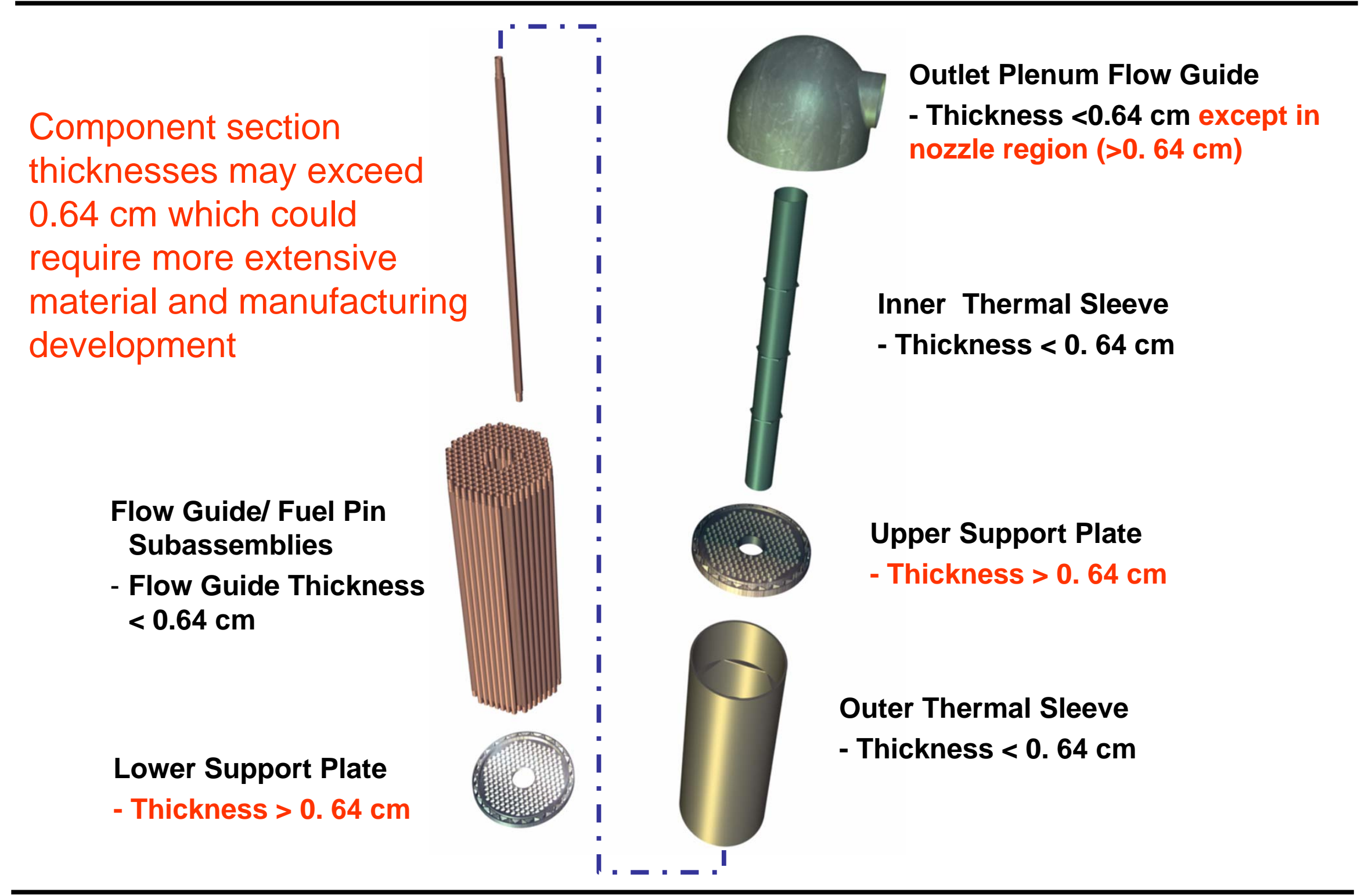




\section{Annular Flow Concept - Core Assembly}

- All core components (except fuel pin assemblies) attached to upper support plate

- Welding depicted - attachment options exist (threading, crimping)

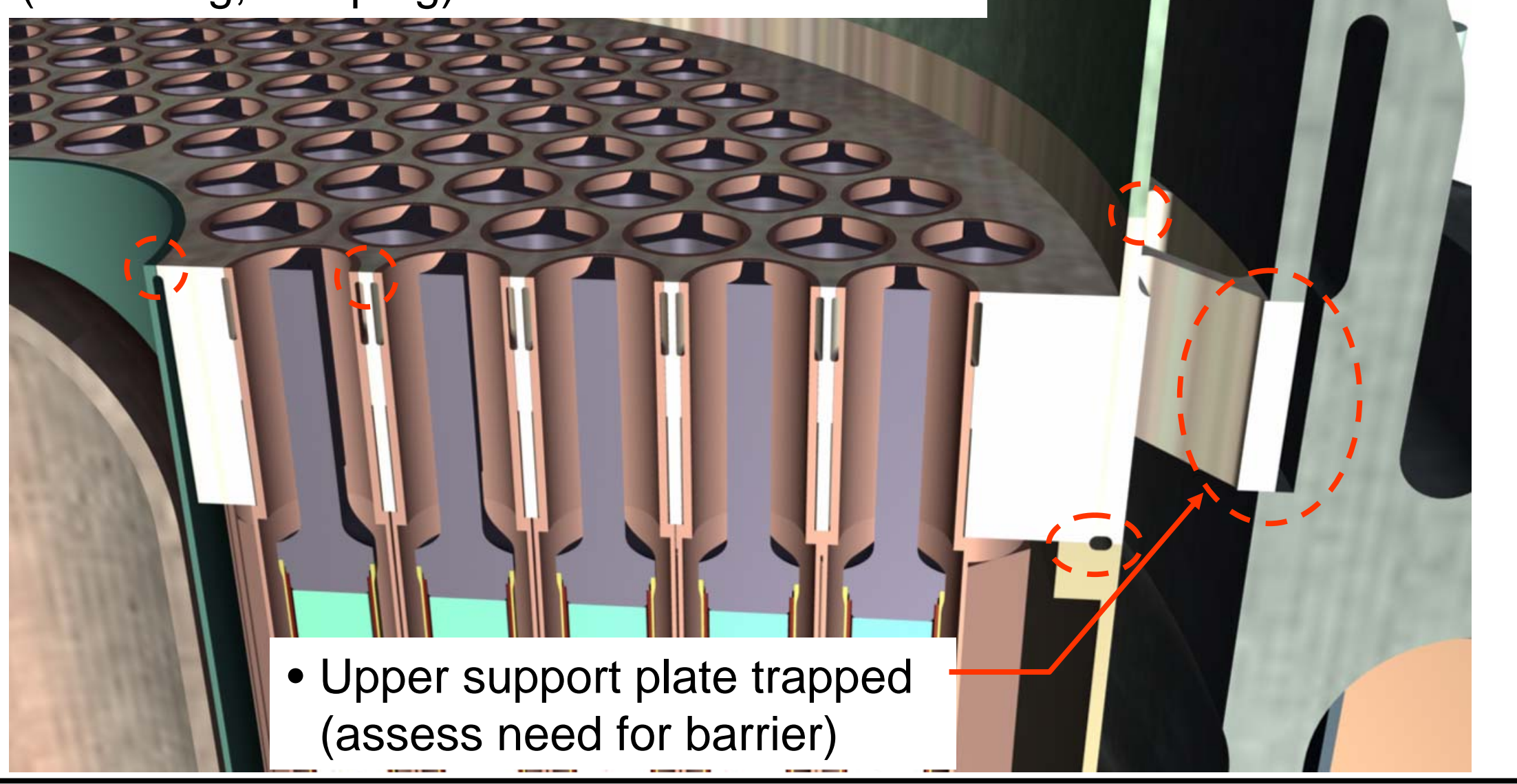




\section{Annular Flow Concept - Core Assembly}

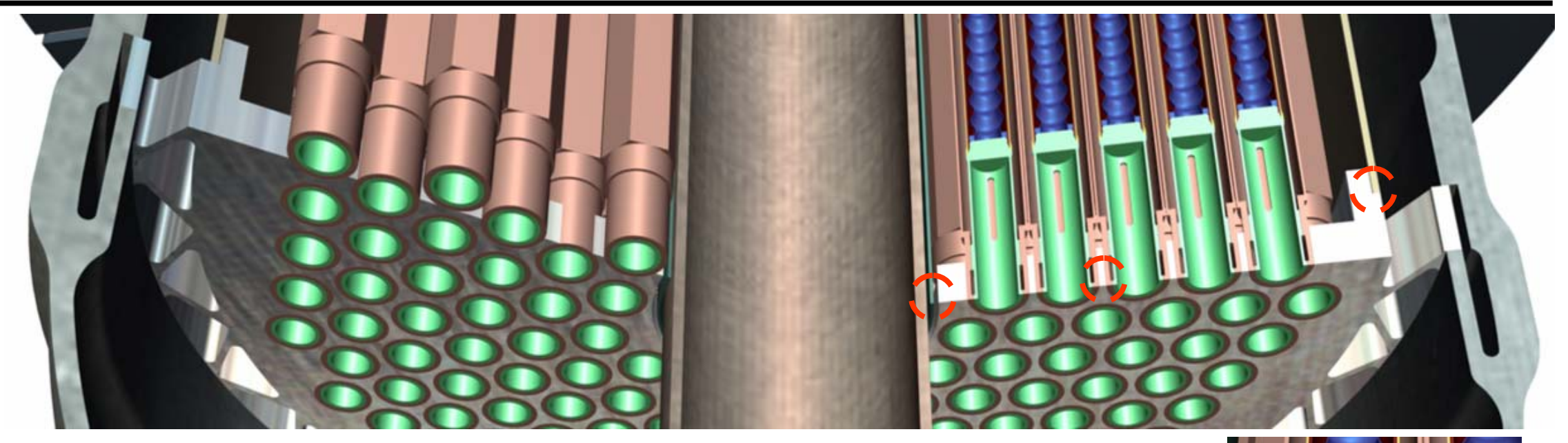

- Core components (except fuel pins) slip fit with bottom support plate

- Fuel pin welded to bottom of flow guide

- Weld does not overlap flow guide-to-support plate weld

- Accessible for re-dressing if unacceptable weld is achieved

- Attachment options exist (threading, crimping)

- Flow Guide slip fit with lower support plate

- Lower support plate trapped (assess need for barrier)

- Non-metallic interface at slip-fit locations needs assessed

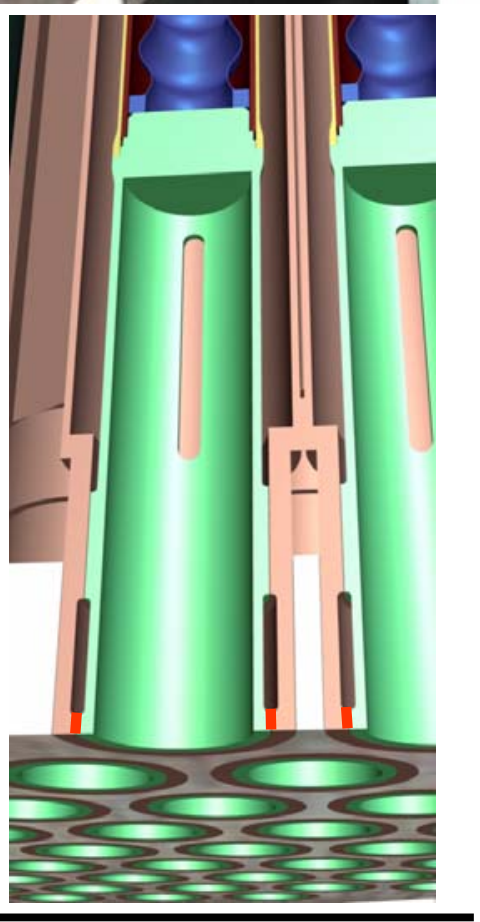




\section{Annular Flow Concept - Fuel Pin Assembly}
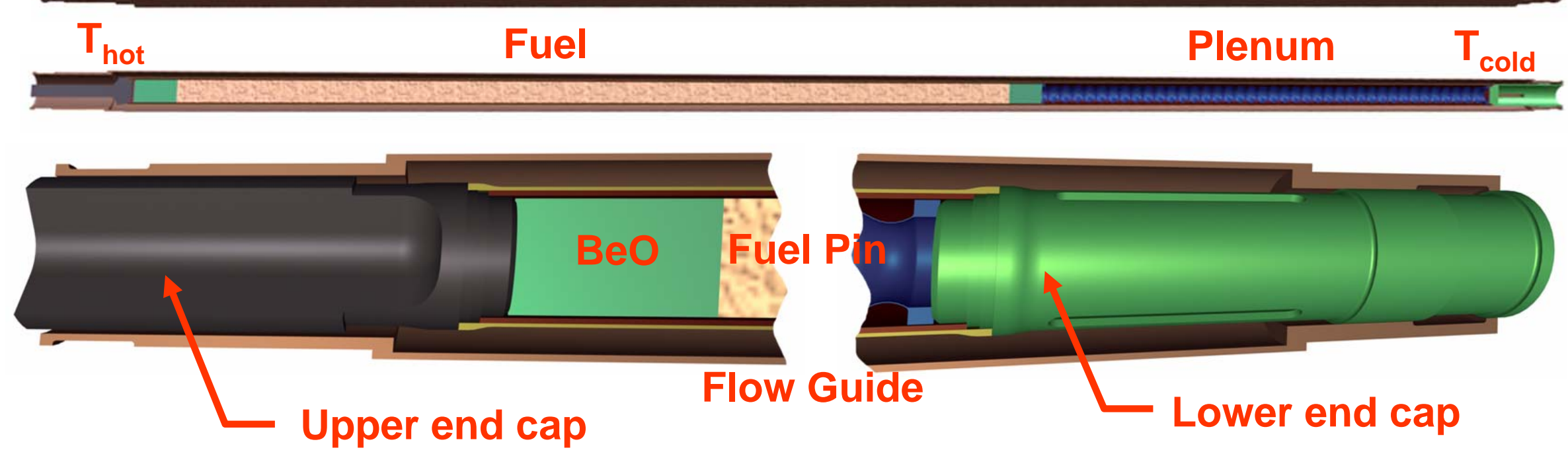

Clad and liner pressure bonded (contact but not metallurgical)

Fuel pellet retention spring

-Clad thickness satisfies $1 \% \varepsilon$ limit at end of life -Clad weld thickness (2X clad thickness) satisfies $0.5 \%$ strain limit at end of life

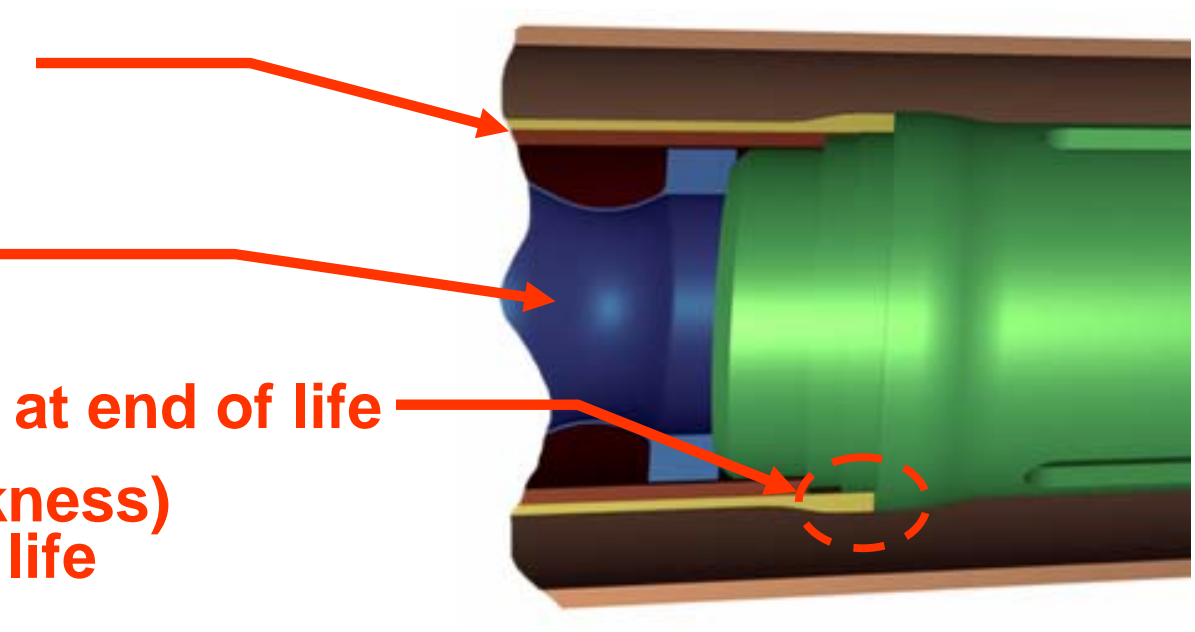




\section{Annular Flow Concept - Fuel Pin Alignment Collars}

\section{Flow $\sim 24 \mathrm{~m} / \mathrm{sec}$}

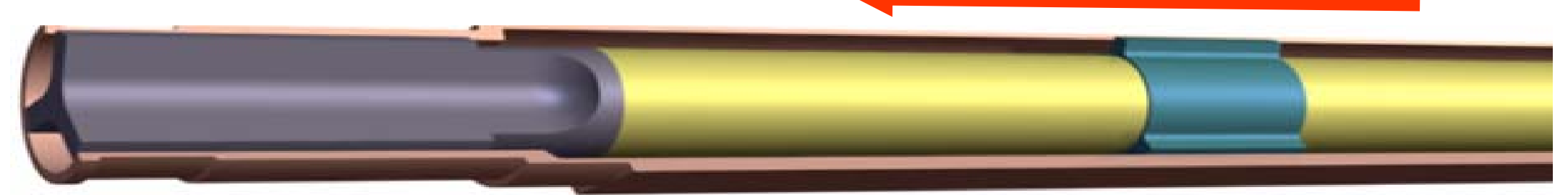

- Fuel Pin-to-Flow Guide Alignment Collars (Shrink fit or Brazed to Fuel Pin)

- Prevents fuel pin bow

- Minimal impact on flow area

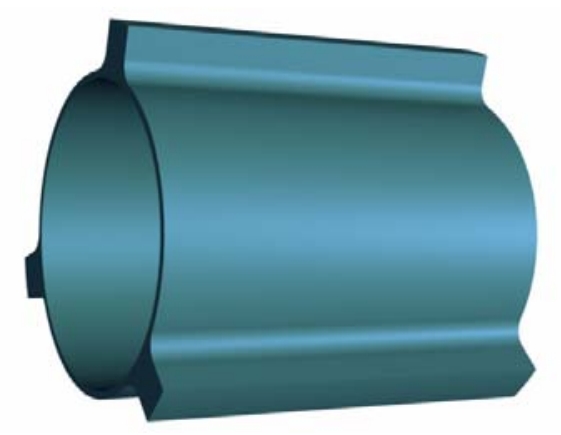

- Provides wear surfaces

- Limits motion if susceptible to vibration 


\section{Annular Flow Concept - Core Assembly Animation}

The original powerpoint presentation

incorporated an assembly movie, which can not

be saved in a pdf format. For documentation

purposes, key frames from this movie are

provided on the next five sheets.

- Mechanical design supports safe assembly

- Satisfies Code of Federal Regulations 10CFR70 requirements (for manufacturing facilities) where:

$\mathrm{k}_{\text {eff }}<0.92$ normal conditions, and

$\mathrm{k}_{\text {eff }}<0.95$ accident conditions

- Assembled core requires fixturing around vessel for handling/shipping to eliminate material that could reflect neutrons back to core 


\section{Annular Flow Concept - Core Assembly Operations}

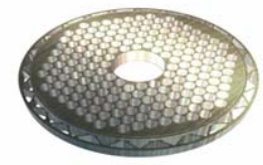

Upper Support Plate

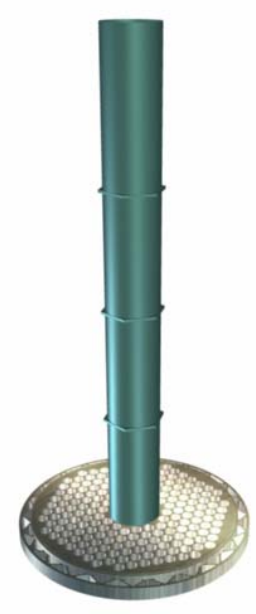

Attach Inner Thermal Sleeve

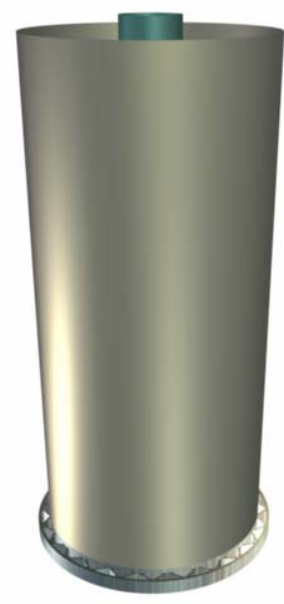

Attach Outer Thermal Sleeve

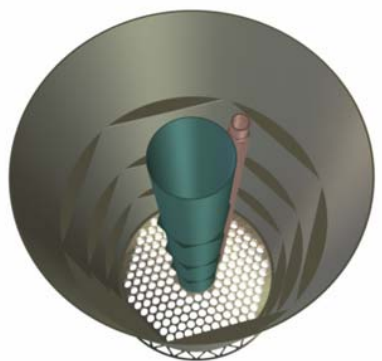

Hexagonal shaped lateral alignment/support plates on thermal sleeves are aligned 


\section{Annular Flow Concept - Core Assembly Operations}
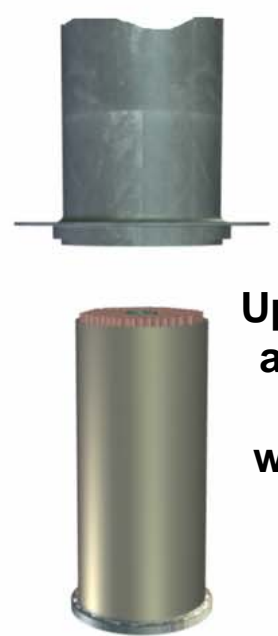

Upper Support plate assembly inserted into and seated within Vessel Shell

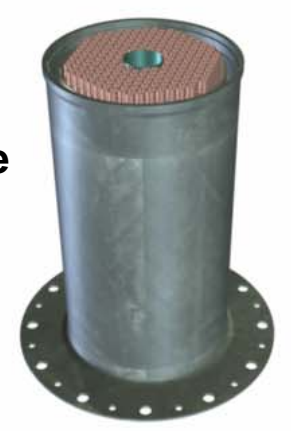

Lower Support Plate seated on ledge within Vessel Shell and temporarily fixtured in place

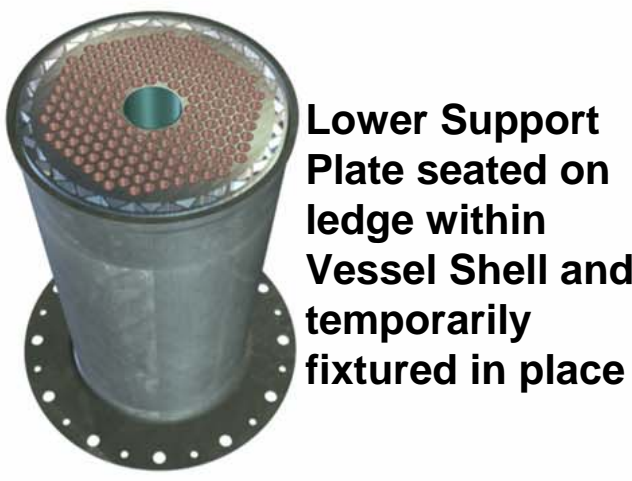

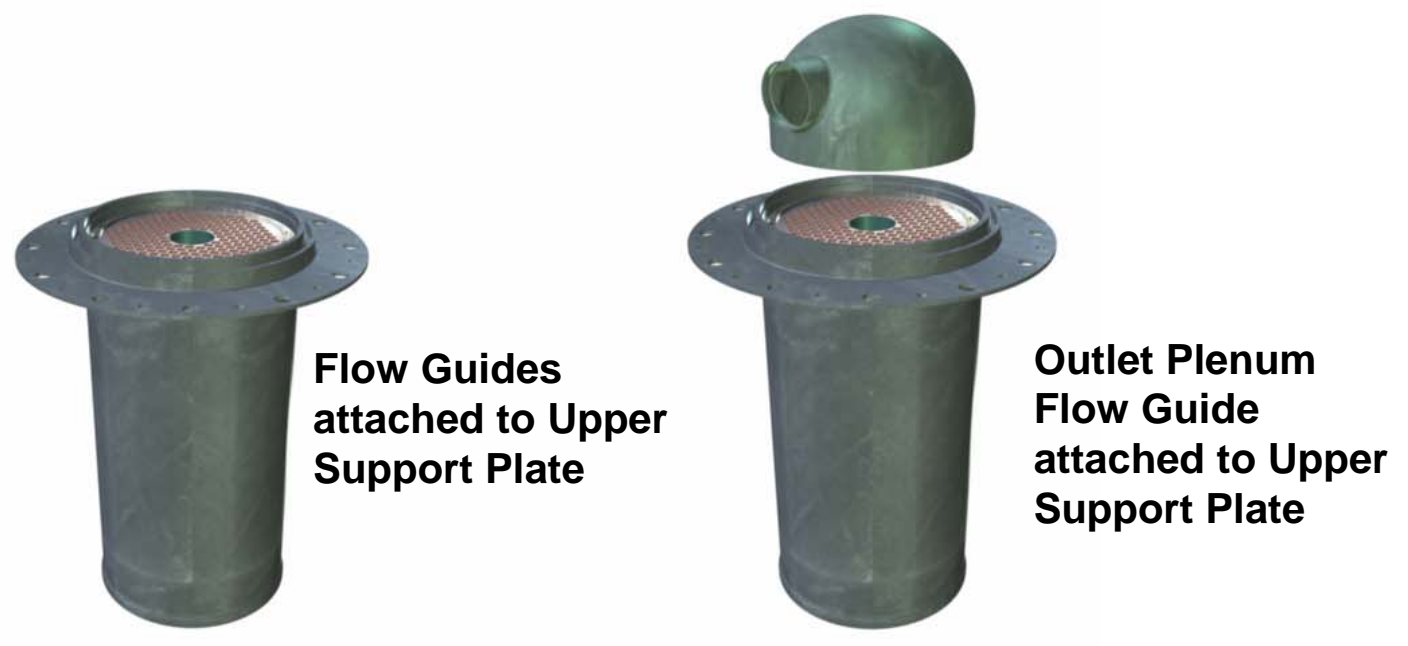

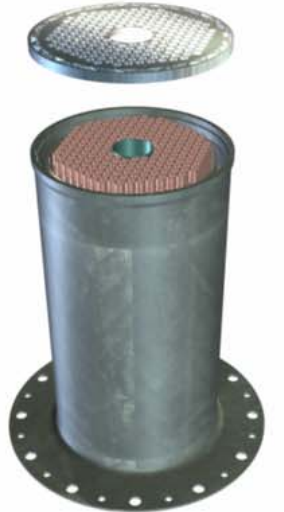

Lower Support Plate slip fit over bottom of Flow Guides (requires tapered nylon cones in bottom of Flow Guides - during assembly only - to facilitate installation of Lower Support Plate) 


\section{Annular Flow Concept - Core Assembly Operations}

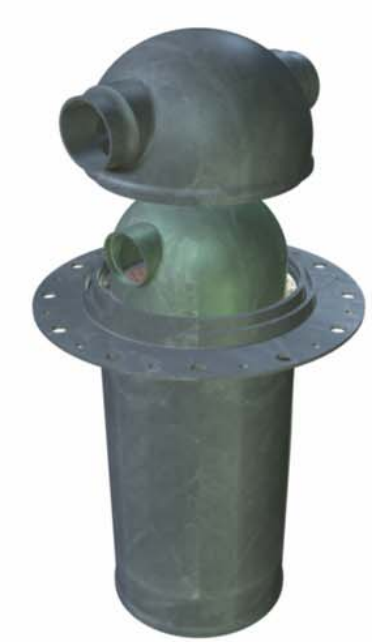

Vessel Upper Head welded to Vessel Shell

Reactor Subassembly oriented to facilitate fuel pin installation
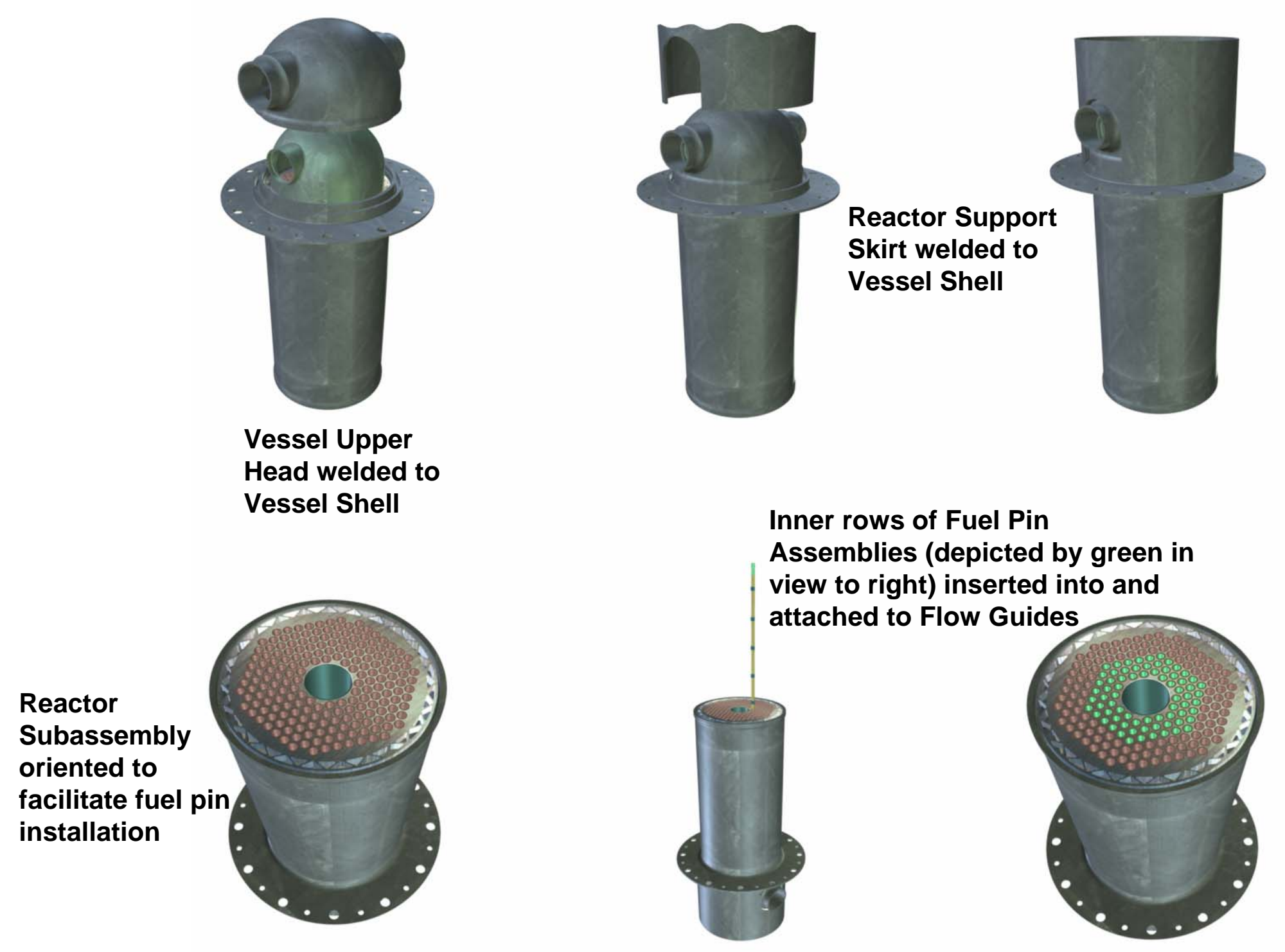


\section{Annular Flow Concept - Core Assembly Operations}

Safety Rod

inserted into

Safety Rod

Dry Well

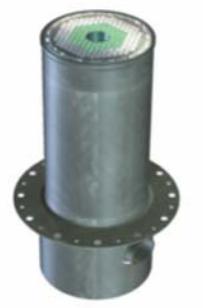

Safety Rod/Dry

Well inserted

into reactor

subassembly

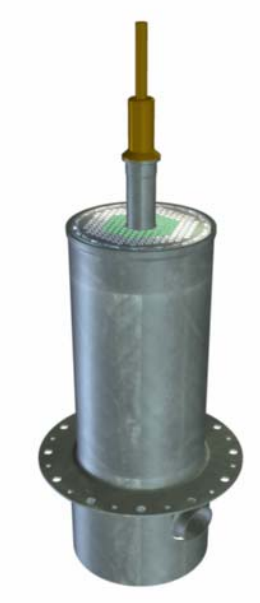

Safety Rod/Dry well temporarily fixtured at proper elevation using support clamps
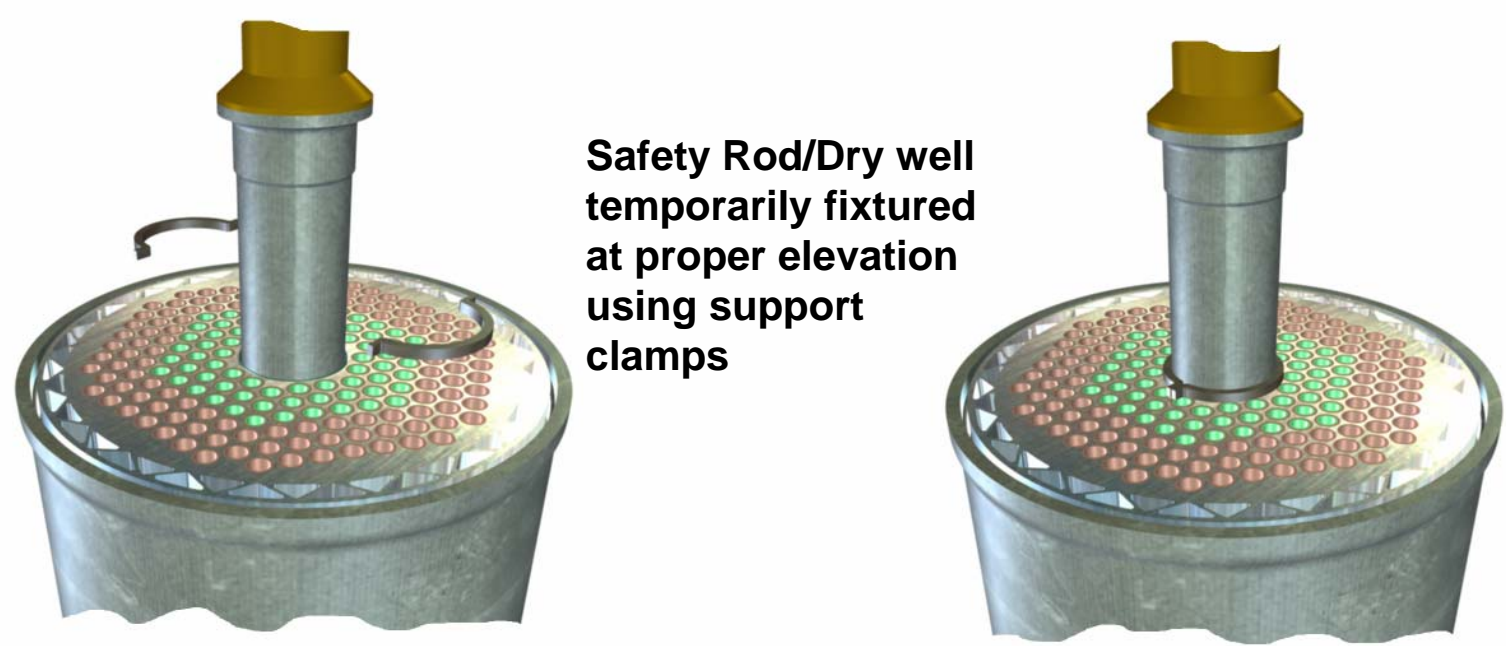


\section{Annular Flow Concept - Core Assembly Operations}

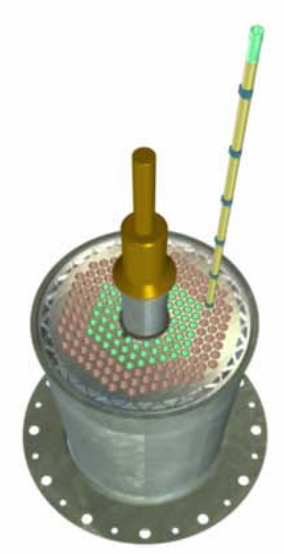

Remaining Fuel Pin Assemblies inserted into and attached to Flow Guides

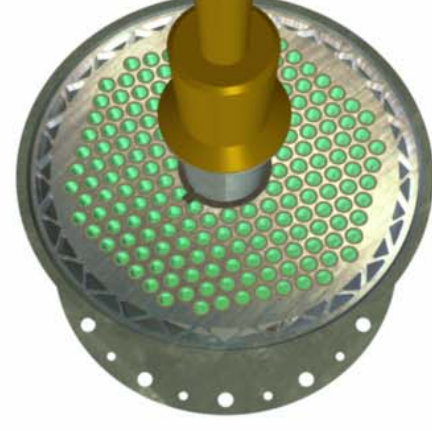

Vessel Lower Head seated onto

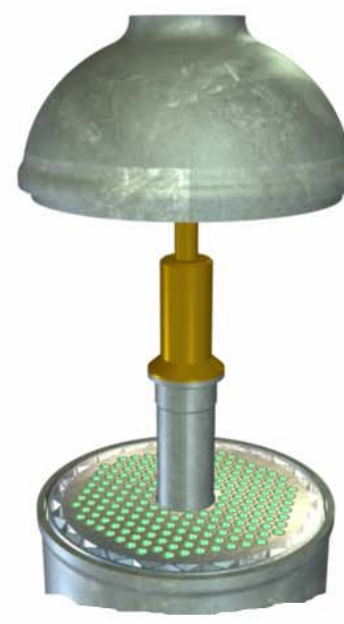
and welded to Vessel Shell.

Safety Rod Dry Well flange welded to Vessel Lower Head.

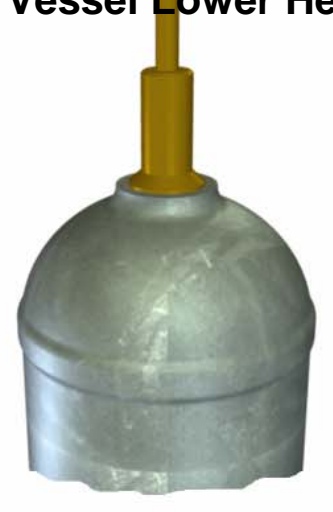

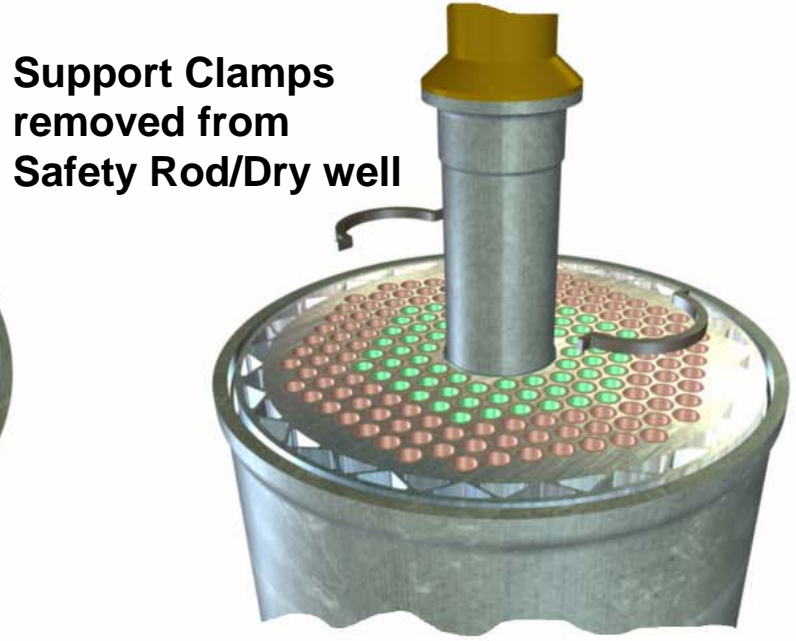

Completed Reactor Assembly without reactivity control devices attached.
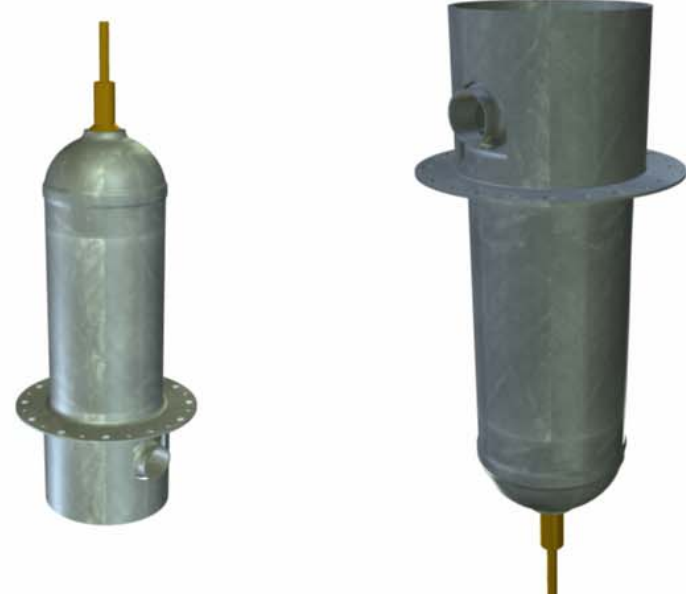


\section{Optional Core - Open Lattice Pins}

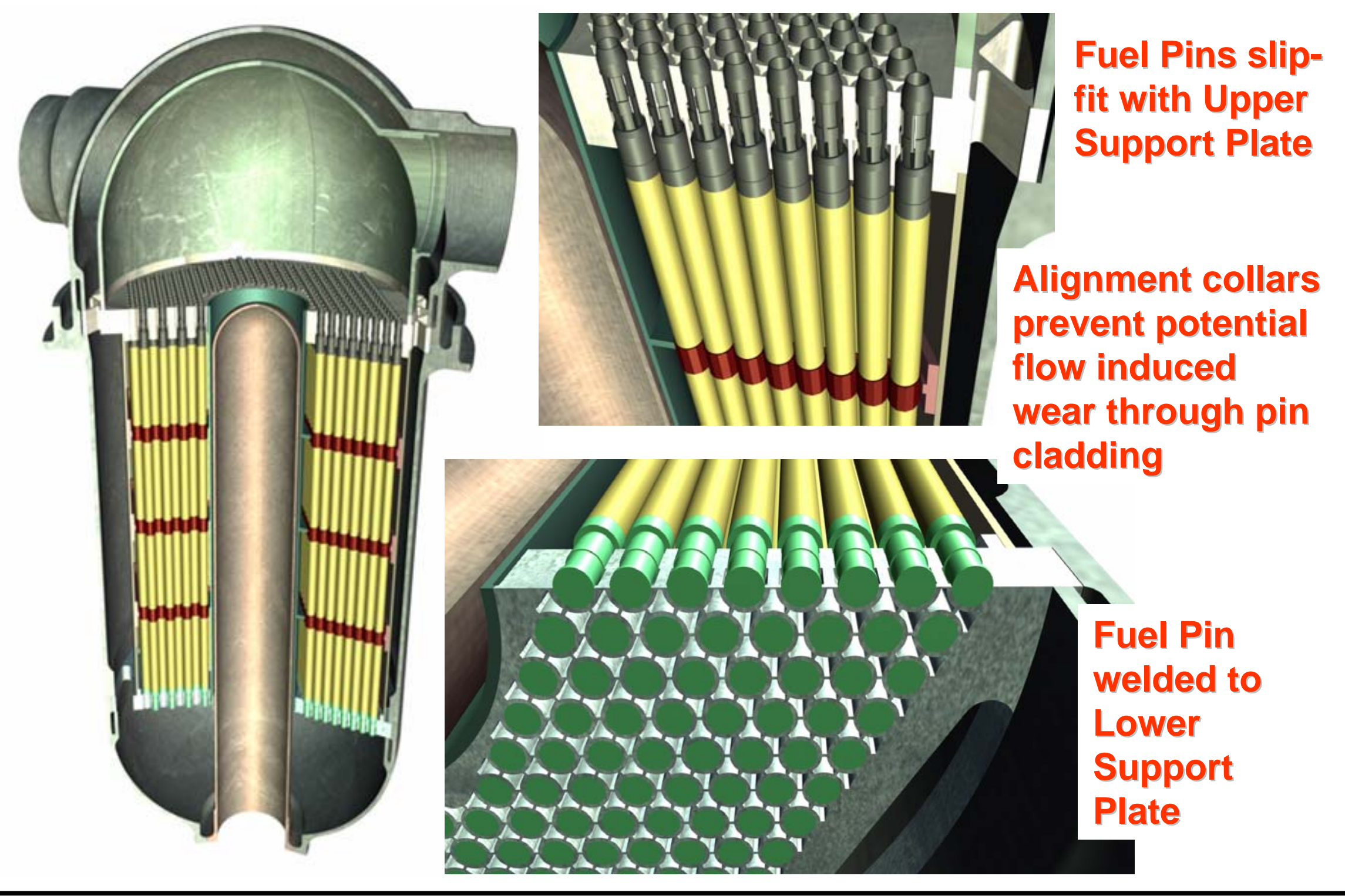

STAIF, February 2006 


\section{Optional Core - Finned Pin Concept}
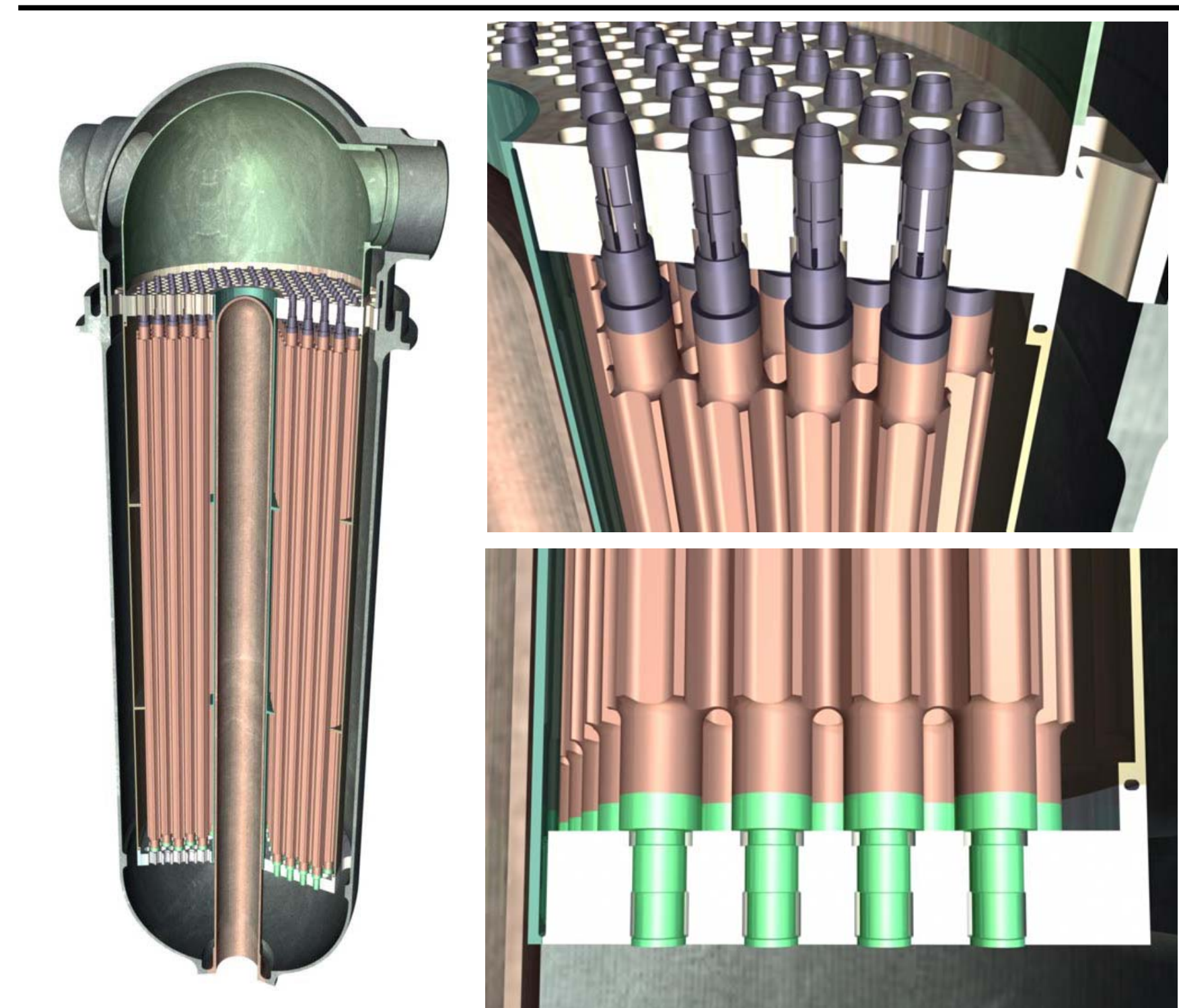

Fuel Pin slip-fit with Upper Support Plate

Fins prevent potential flow induced wear

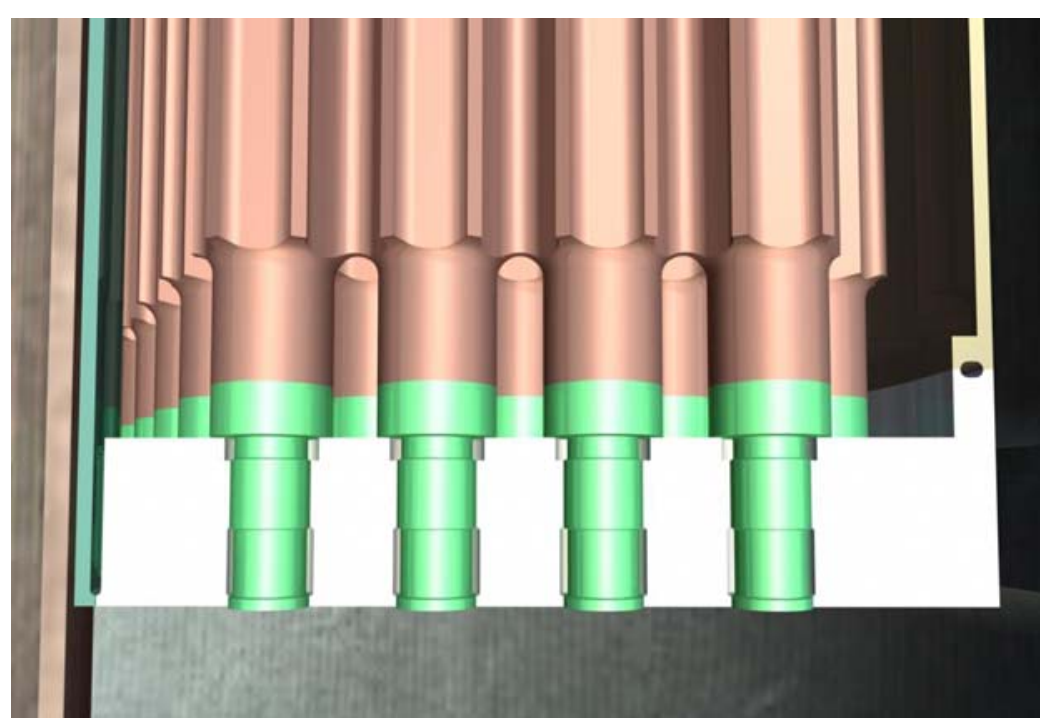
through pin cladding

Fuel Pin welded to Lower Support Plate 


\section{Fuel Pin Clad-to-Liner Performance}

Clad materials: Liner materials:

- ASTAR-811C - Re

- FS-85 - W

- Mo-47.5Re $\quad-$ W-25Re

- Mo-TZM - Mo

- From recent core sizing studies

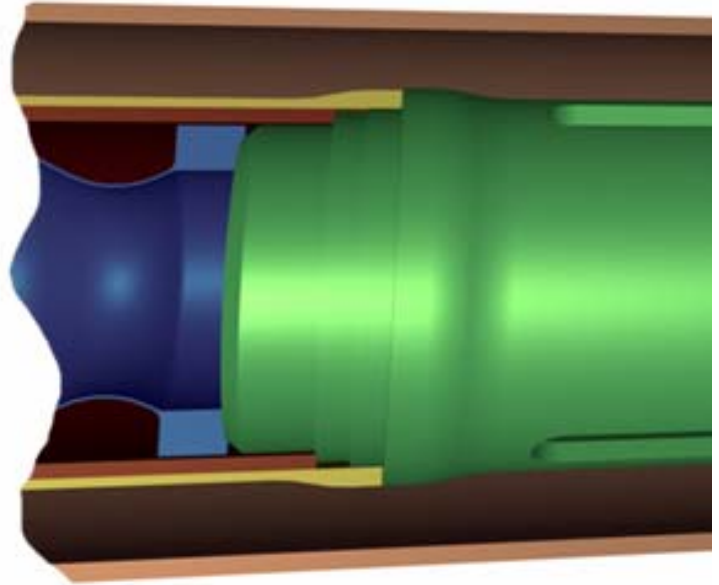

- Clad thickness ranged from $0.051-0.27 \mathrm{~cm}$ (sized for fission gas pressure and $1 \% \varepsilon$ limit)

- Liner thickness ranged from $0.002-0.33 \mathrm{~cm}$

- Typical design has $0.051 \mathrm{~cm}$ clad/0.013 cm liner

- Atypical designs had from $0.051 \mathrm{~cm}$ clad $/ 0.33 \mathrm{~cm}$ liner

to $0.27 \mathrm{~cm} \mathrm{clad} / 0.013 \mathrm{~cm}$ liner

- Bonded clad and liner results in higher but acceptable stresses and creep for steady state conditions 


\section{Fuel Pin Plenum Spring Performance}

- Focused on coil springs

- Materials (preferred order)

- W-25Re

- ASTAR-811C

- Mo-TZM

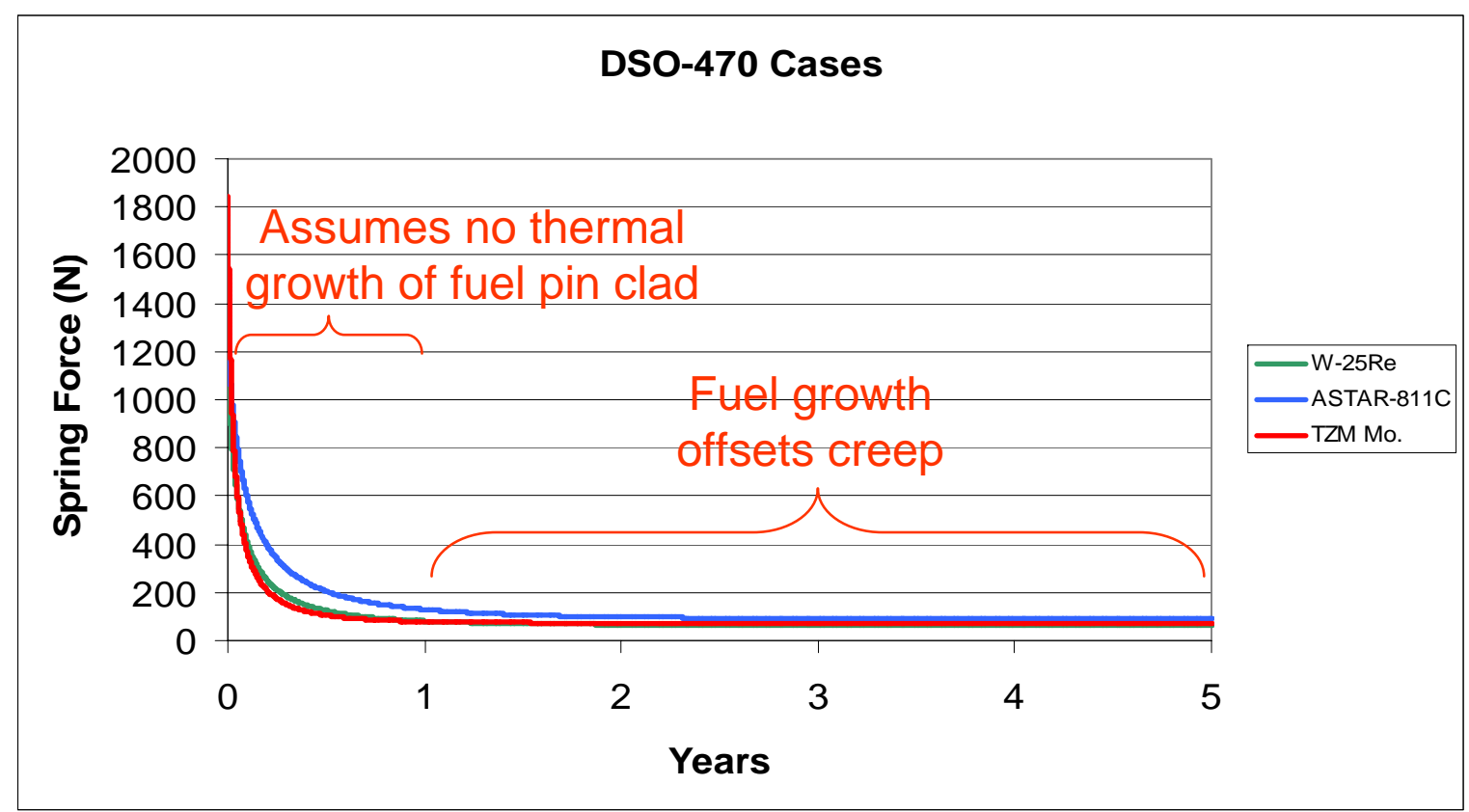

- Sized for 18G axial lift-off load (2X 9G axial design load) at room temperature

- Operating temperature: $880 \mathrm{~K}$

- Irradiation creep $10^{3}-10^{9}>$ thermal creep at 880K

- Thermal creep becomes more significant between $1100 \mathrm{~K}$ and $1400 \mathrm{~K}$

- Spring load relaxes quickly/Remaining load may be acceptable with fuel pelletto-clad clearance (design case) 


\section{Outlet Plenum Flow Dome Performance}

- 3D Model of outlet plenum flow divider

- Mo-47.5Re (0.64 cm thick shell)

- $880 \mathrm{~K} \mathrm{~T}$ ext and $1150 \mathrm{~K} \mathrm{~T}_{\text {int }}$

- Core Block temperature distribution at bottom surface (conservative assumption) with $1 \mathrm{~W} / \mathrm{cc} \gamma \mathrm{htg}$

- $0.029 \mathrm{MPa} \Delta \mathrm{P}(4.2 \mathrm{psi})$

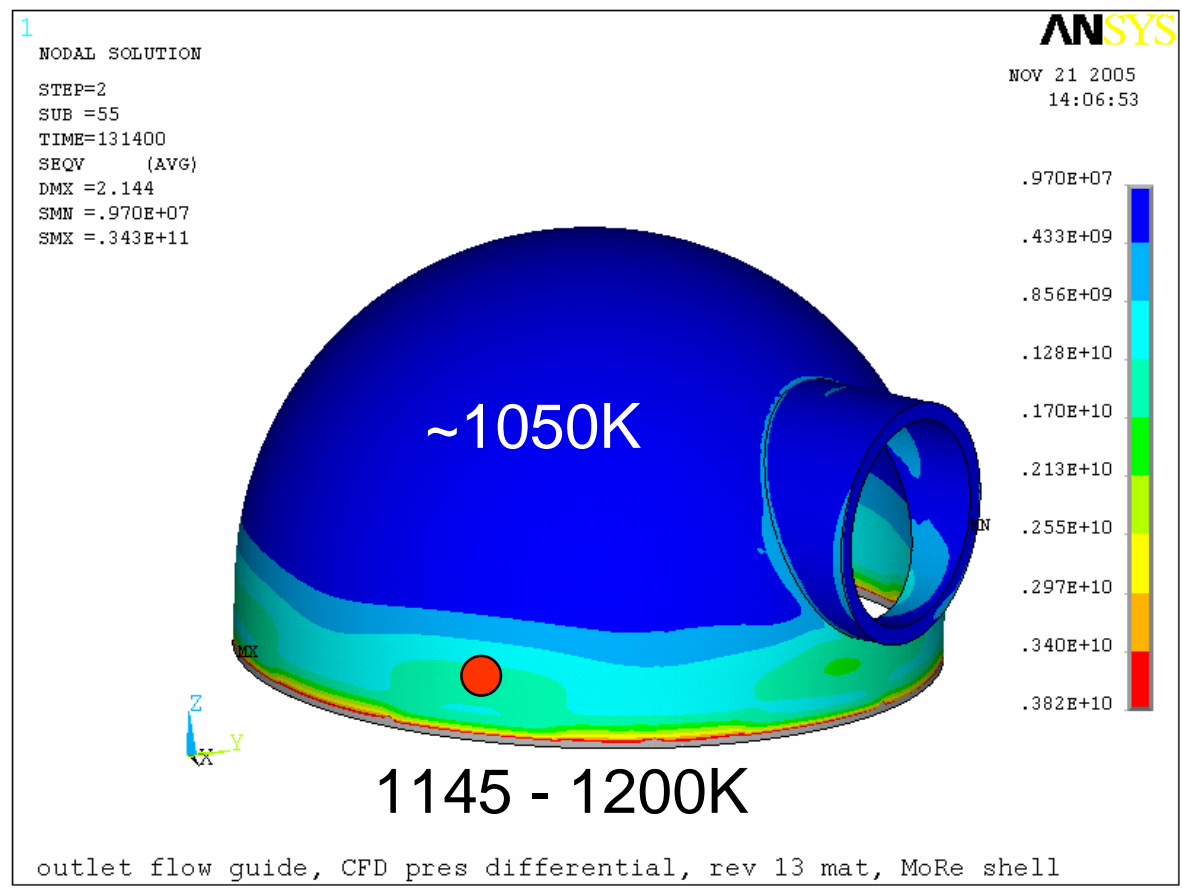

O Maximum stress $=200 \mathrm{MPa}(<270$

$\sigma_{\mathrm{m}}$ limit at $1073 \mathrm{~K}$ ) 


\section{Support Plate Performance}

- 3D Model of upper support plate

- Mo-47.5Re (5 cm thick)

- Room temperature analysis (upper plate)

- 9G Axial + 3G Lateral

- Core mass $=700 \mathrm{Kg}$ (open lattice)

- $\sigma$ for fixed and pinned BC $<$ allowable of $300 \mathrm{MPa}$

- Core mass $=1400 \mathrm{Kg}$ (AF Concept)

- $\sigma$ for fixed and pinned BC $>$ allowable of $300 \mathrm{MPa}$

- Operating temperature analysis (lower plate)

- $1 \mathrm{~W} / \mathrm{cc} \gamma$ htg

- Vessel $\alpha_{m} 2.5 X$ support plate

- Need slip fit for stresses < allowable of $200 \mathrm{MPa}$ at $900 \mathrm{~K}$
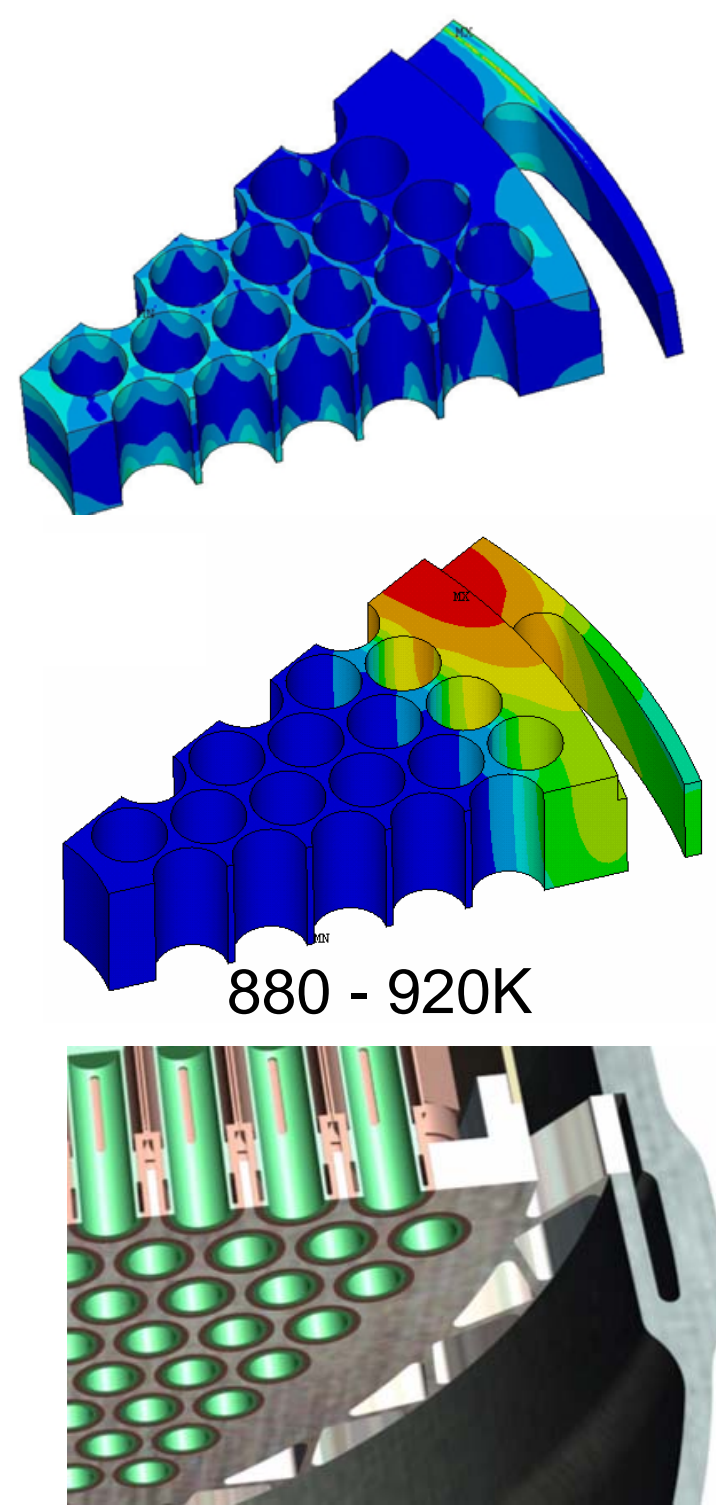


\section{Key Issues That Need to Be Addressed}

- Design properties versus performance impact

- Temperature and irradiation impact

- Range of section thicknesses

- Welds

- Design versus best estimate properties

- Impact of impurity contamination of refractory metal alloys

Define design factors

- Lift-off loads

- Creep-fatigue performance (steady state + transients)

- Operating temperatures

- Nickel-based superalloys versus refractory metal alloys

- Transient versus steady state

- Potential for self-welding

- Mechanical features to preclude sudden positive reactivity

- Fuel pellet retention spring

- Flow induced vibration

- Features to accommodate re-entry accident 
Enclosure 4 to

SPP-SEC-0039

\title{
Key Factors Influencing the Decision on the Number of Brayton Units for the Prometheus Space Reactor
}

\author{
Ashcroft, J.M. \\ Belanger, S. \\ Burdge, W. \\ Clementoni, E. \\ Jensen, K. \\ Proctor, N.B. \\ Zemo-Fulkerson, A.
}


This page is intentionally blank.

PRE-DECISIONAL - For planning and discussion purposes only 


\section{Key Factors Influencing the Decision on the Number of Brayton Units for the Prometheus Space Reactor}

John Ashcroft, Sean Belanger, Wayne Burdge, Eric Clementoni, Krista Jensen, N. Beth Proctor,

Annie Zemo-Fulkerson

NRPCT

STAIF 2006 


\section{Agenda}

- History of Plant Concept Development

- Discussion of Options

- Factors Influencing Selection

- Evaluation of Factors

- Conclusion 


\section{JIMO Prometheus Baseline Configuration}

- $\quad$ Spaceship Configuration PB1

- Gas cooled reactor with 200 kW Brayton output power

- Nearly 58 meters in length

- $\quad 36,375 \mathrm{~kg}$ estimated mass at launch

- $\quad$ Stows in $5 \mathrm{~m}$ diameter fairing

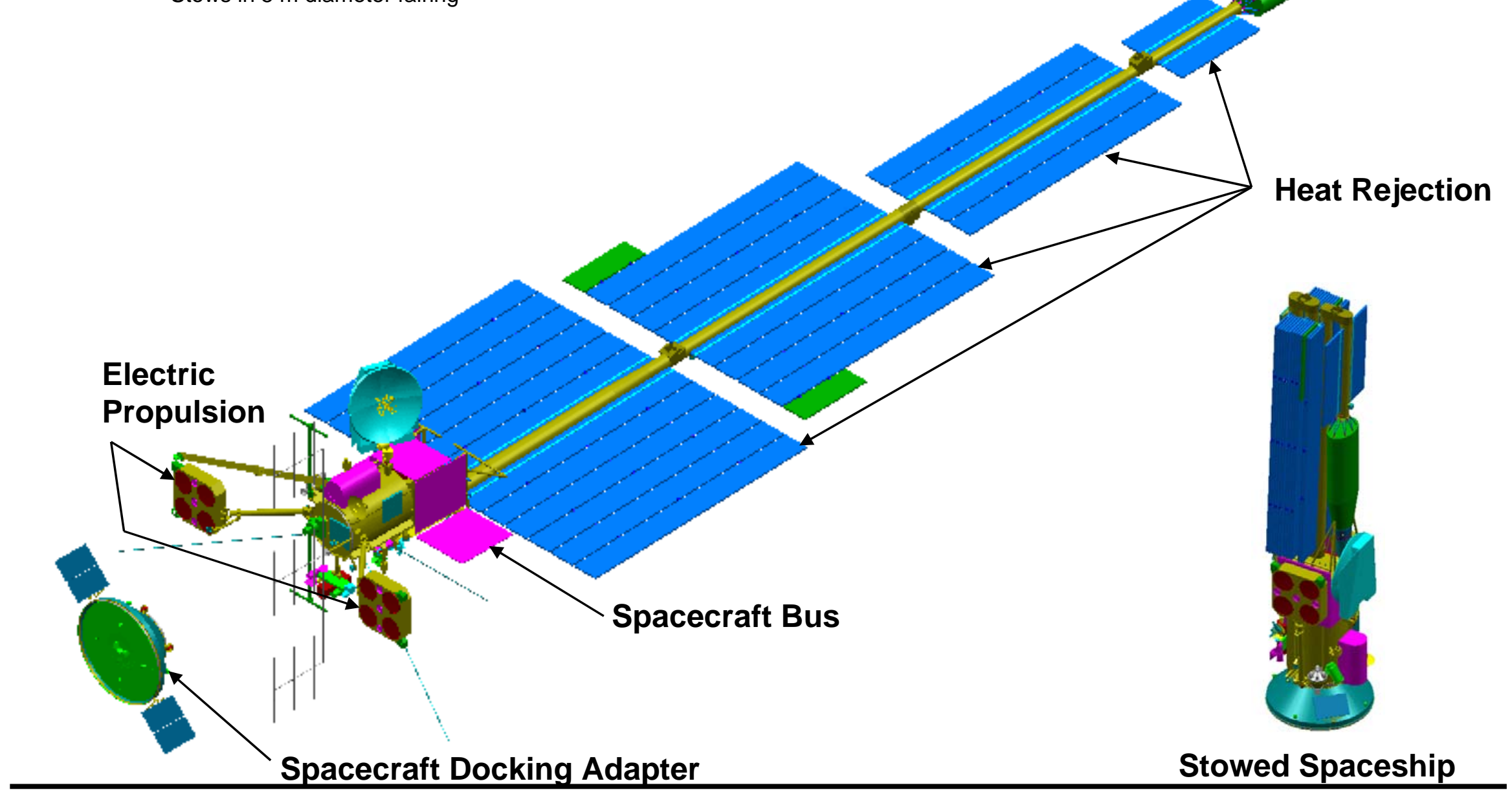

STAIF, February 2006

PRE-DECISIONAL - For planning and discussion purposes only 


\section{Concept Development History}

- Liquid Metal Reactor Initial Focus

- System Configured with 3 or 4 Independent Brayton Loops

- Redundancy in Energy Conversion

- Continuity of Power

- Avoid Single Point Failure

- Momentum Compensation
- Selection of Gas Reactor Requires Revisiting Decision

- Interdependent loops

- Large Mass Impacts

- Better Understanding of System Reliability

\section{NASA Glenn} Concept

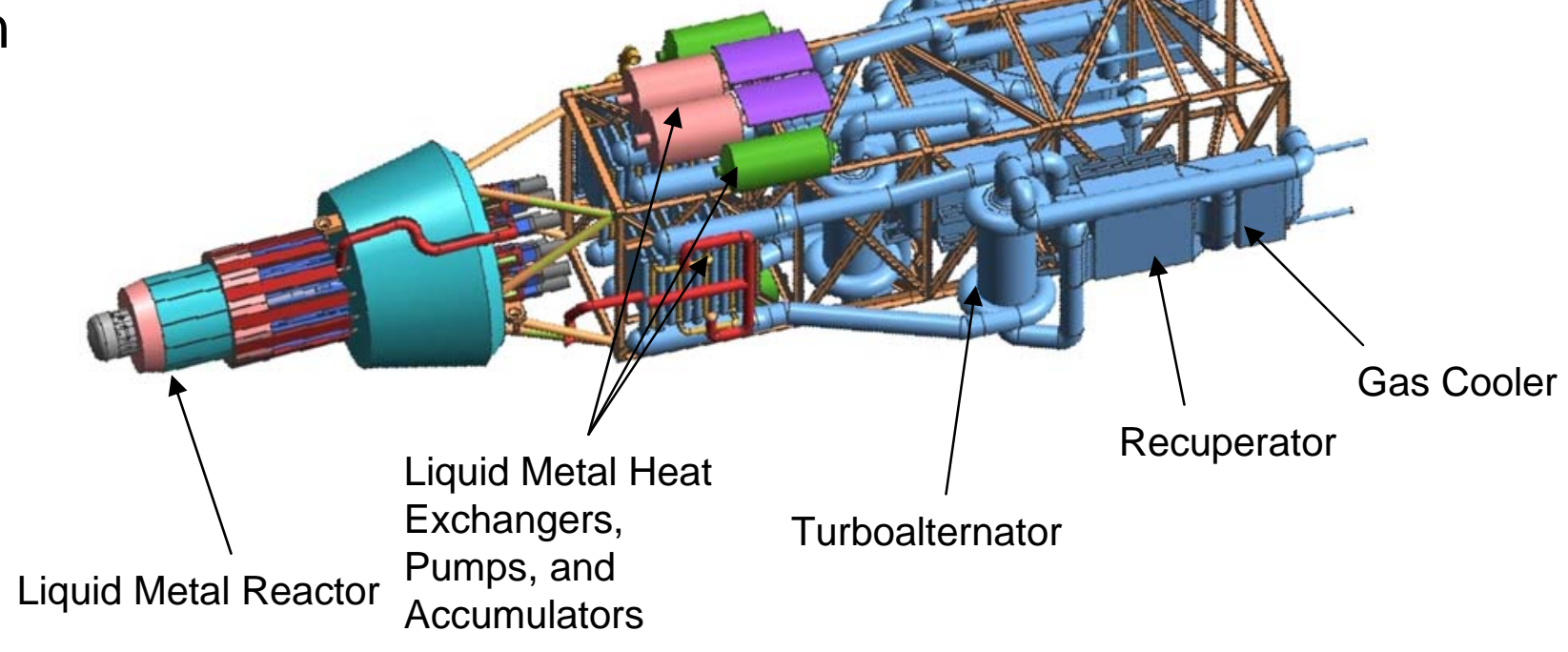




\section{Direct Gas Brayton Concept Options}

- Single Brayton - No Spares

- Two Full Power Capable Braytons Operated at Part

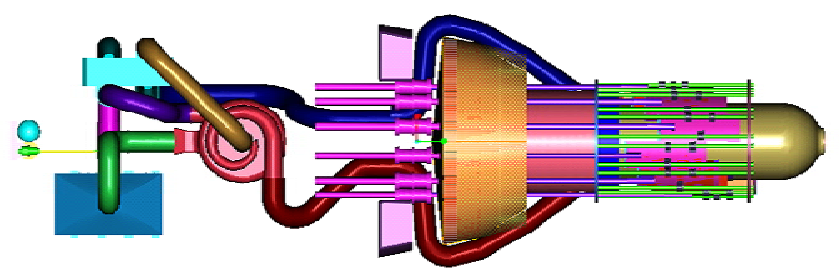
Power

- Two Brayton Loops - on/off

- Three Braytons with one spare

- Four Brayton units with two spares

- Variations with shared heat exchangers
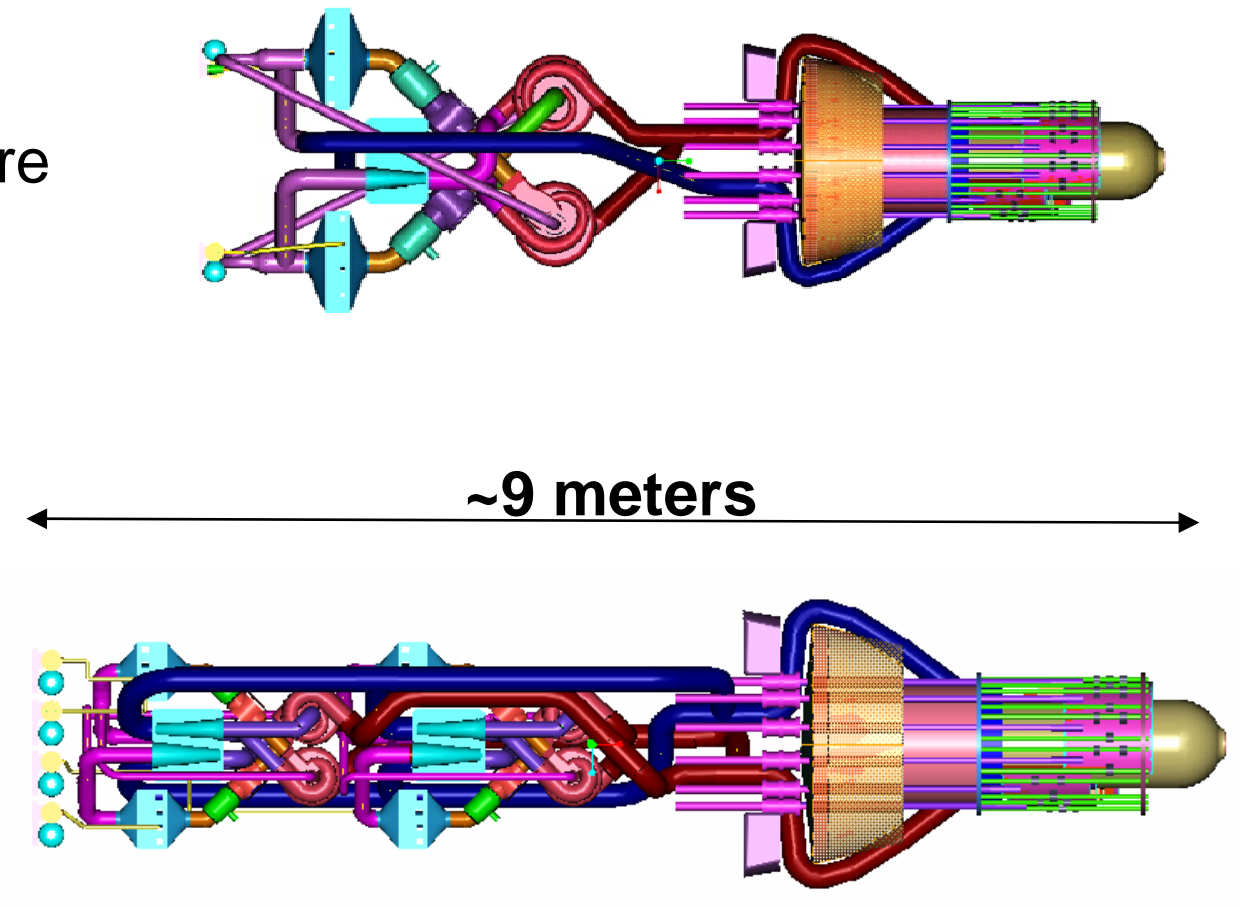


\section{Factors Influencing Selection}

- Arrangement of Brayton System

- Component Capability to Provide Required Power and Lifetime

- Interface of Brayton System with PCAD and HRS

- Operational Flexibility and Start-up Requirements
- Overall Mass and System Performance

- Component and System Reliability

- Extensibility of Concept to Surface Missions 


\section{Brayton Component Capabilities}

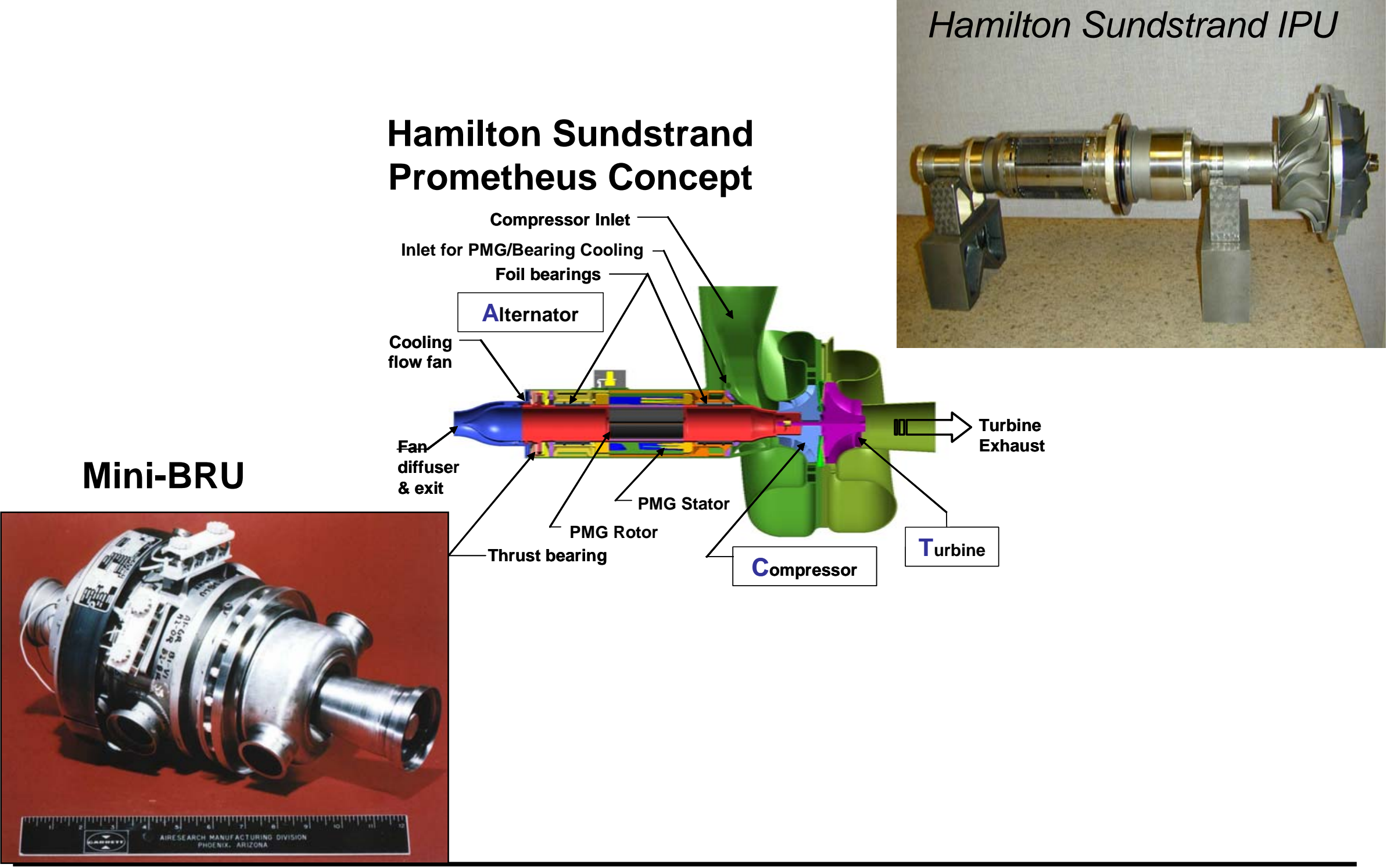

STAIF, February 2006 


\section{Scale-up Issues}

- Rotordynamics

- Alternator Power Density

- Alternator Cooling

- Recuperator Power
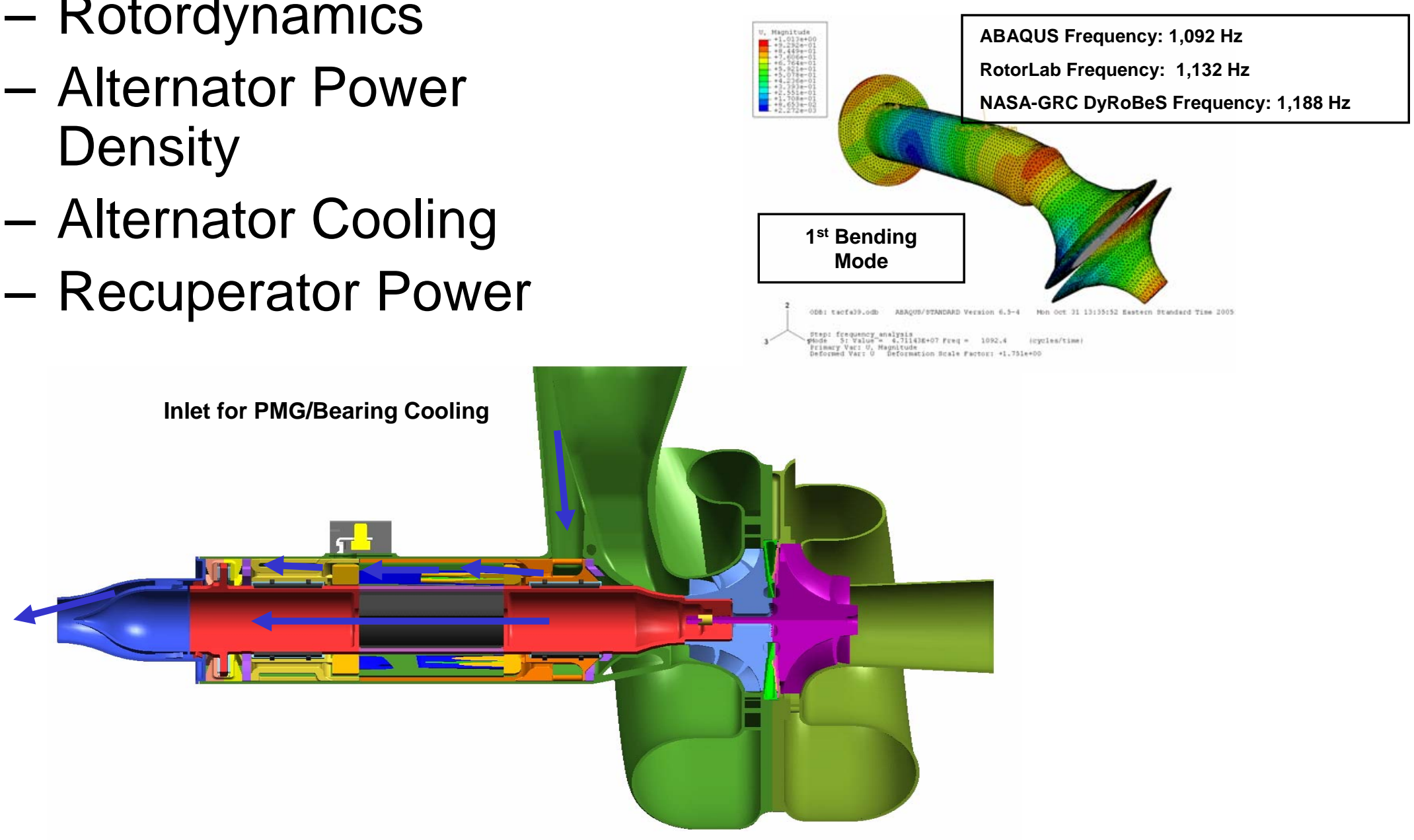


\section{Valves for Multiple Brayton Systems}

- Isolation valves and check valves needed for multiple Brayton system

- 111 - Zero Valves

- 222 - 2 Valves

- 333 - 3 Valves

- 322 - 14 Valves

- 444 - 4 Valves

- Valves developmental Size, Temperature and Lifetime

- Multiple valves must function to switch from a failed Brayton to a spare

- May need to exercise valves during life to prevent sticking

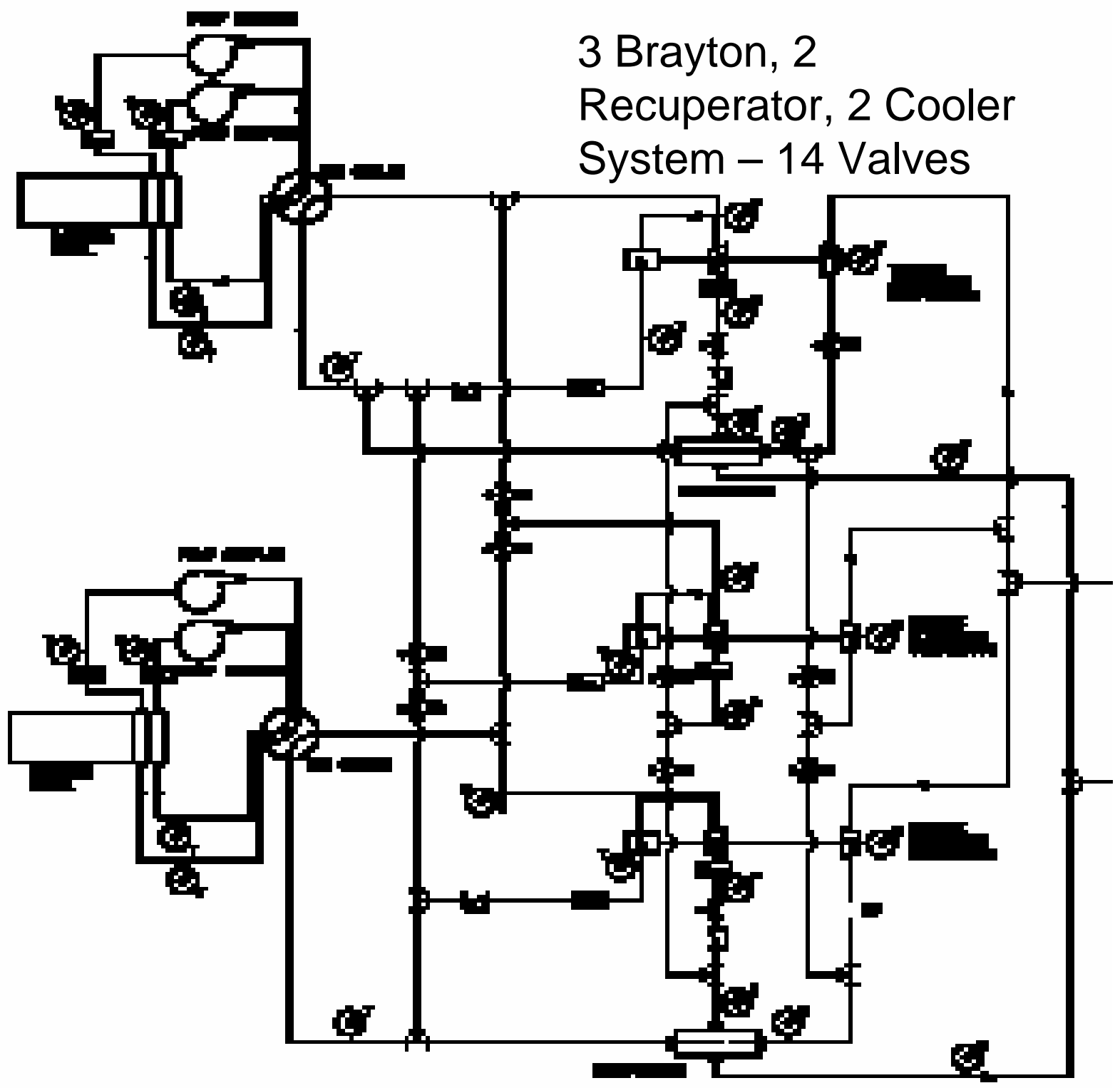




\section{Heat Rejection System Interface}

- All Options have two HRS loops per Radiator Side

- Interface to the radiator most complex for the three Brayton system
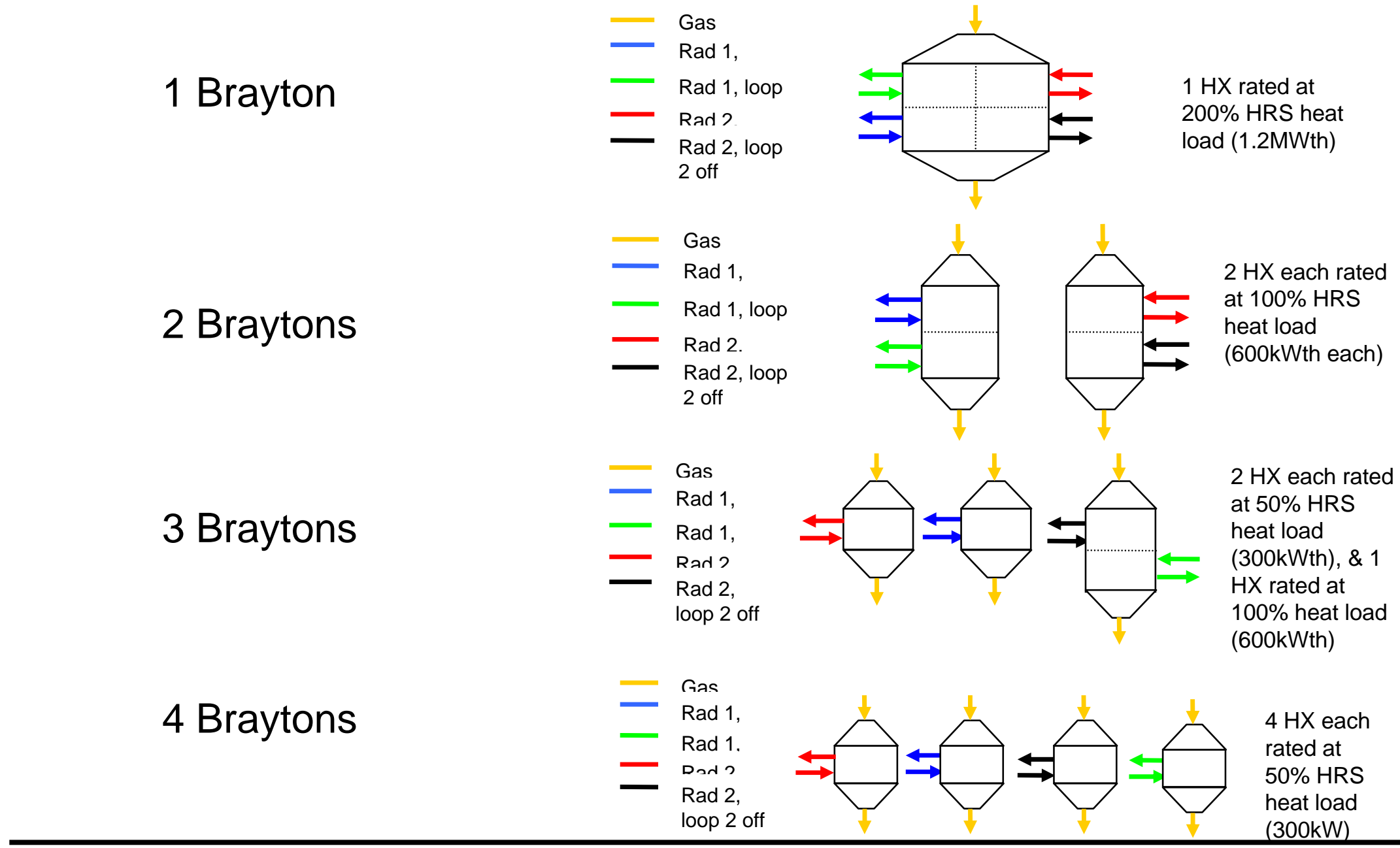


\section{Start-up Transients}

Limited Start-up Studies Completed

Electrical Power Required for Start-up is Limiting. Starting Multiple Braytons

Doubles required Solar Power

Power Requirements as Function of Brayton Power Unknown

Start-up of Second Brayton Challenging Based on Reactivity Feedback of Starting Second Loop

Starting Second Brayton at Slow Rate of Speed Increase from Intermediate Temperature is Likely Most Effective Method in MultiBrayton System.
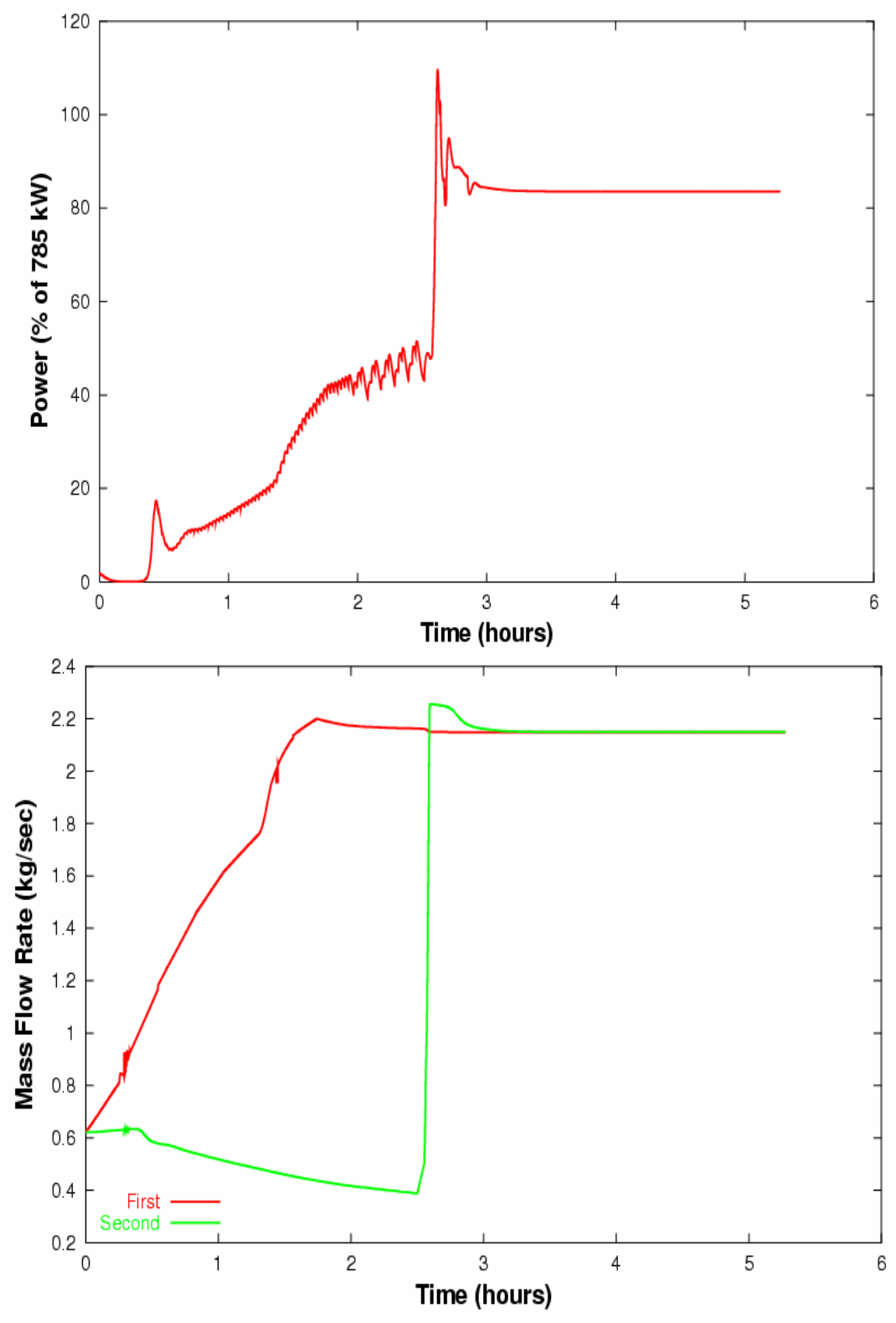


\section{Part Load Control}

All concepts can operate at fraction of full power by adjusting reactor temperature Speed Control Increases Part Load Efficiency with More Complex Electrical System No advantage to on/off control for partload due to lack of start-up power for "spares"

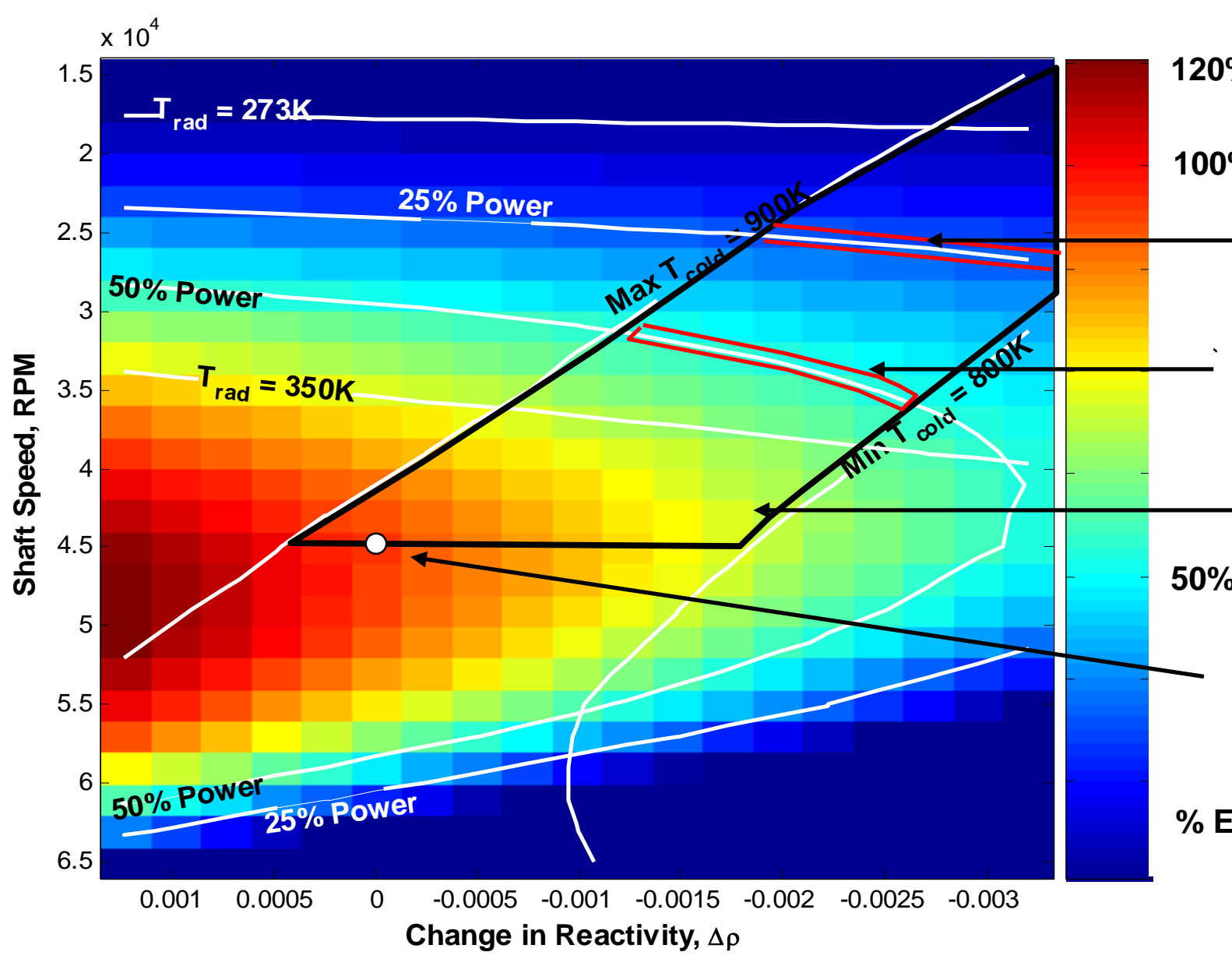

25\% Power Operating Range

50\% Power Operating Range

Reduced Power Operating Range

$5 \%$

Full Power Operating Point

\% Electrical Power 


\section{Operating "Spare" Braytons}

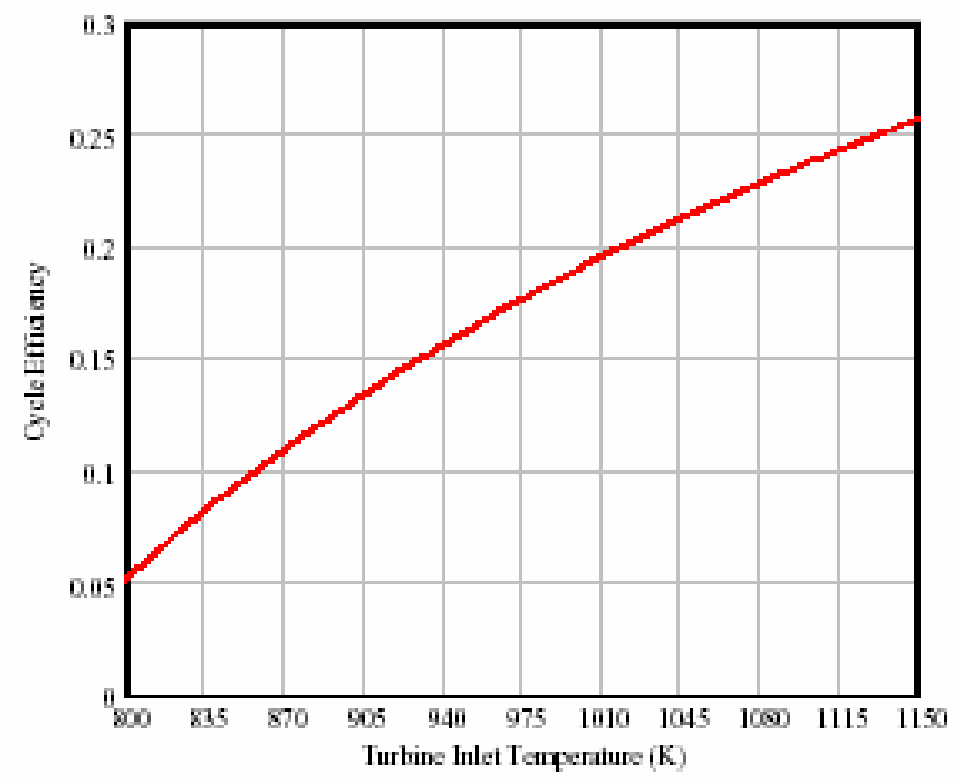

Figure 9 Cycle Efficiency as a Function of TTI

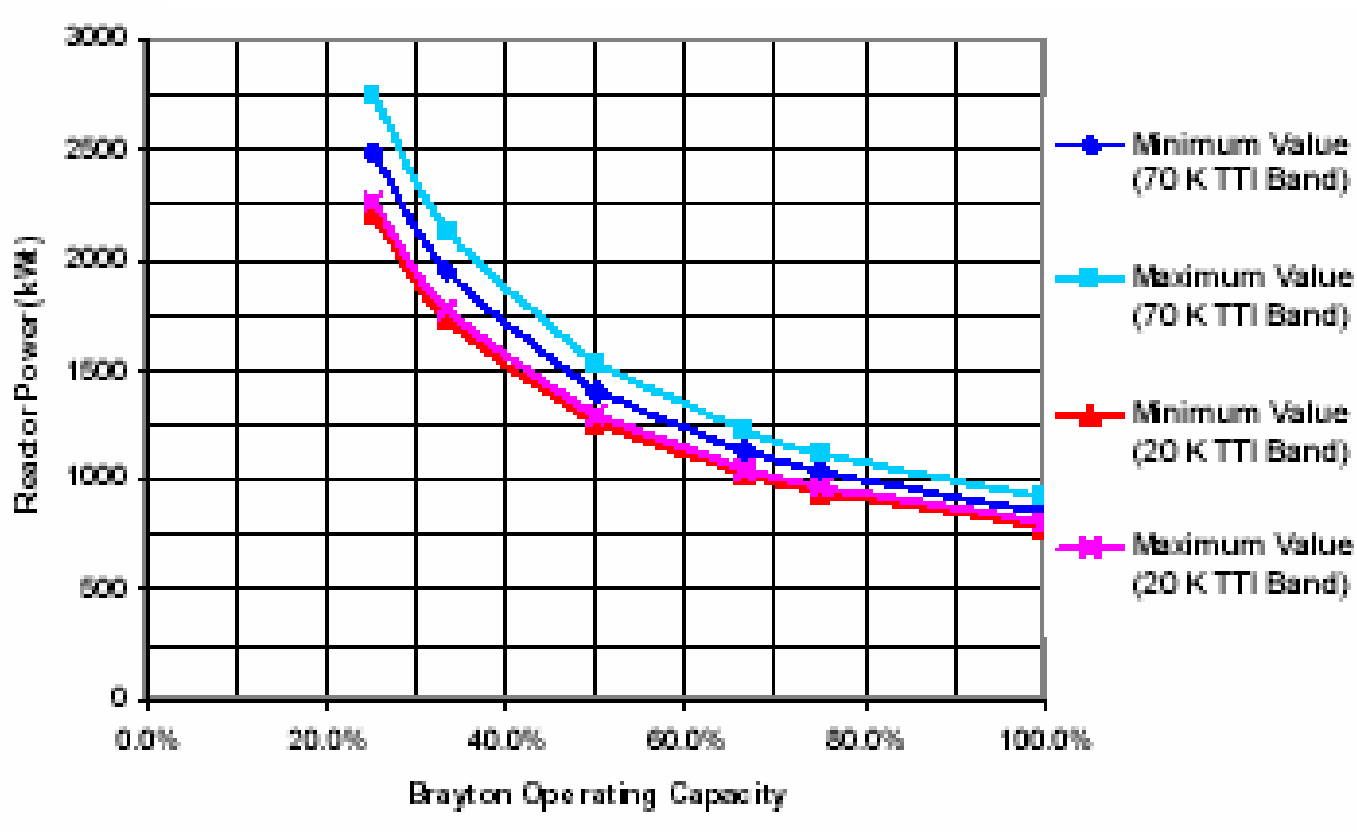

Using "Spare" Braytons at Reduced Capacity and Temperature Leads to Unacceptable Reduction in System Efficiency and the Needs for Larger Reactor and HRS. Operating "Spares" at Reduced Temperature and Speed Only Improves Situation Marginally. 


\section{Performance Capabilities}

\section{Single}

Brayton

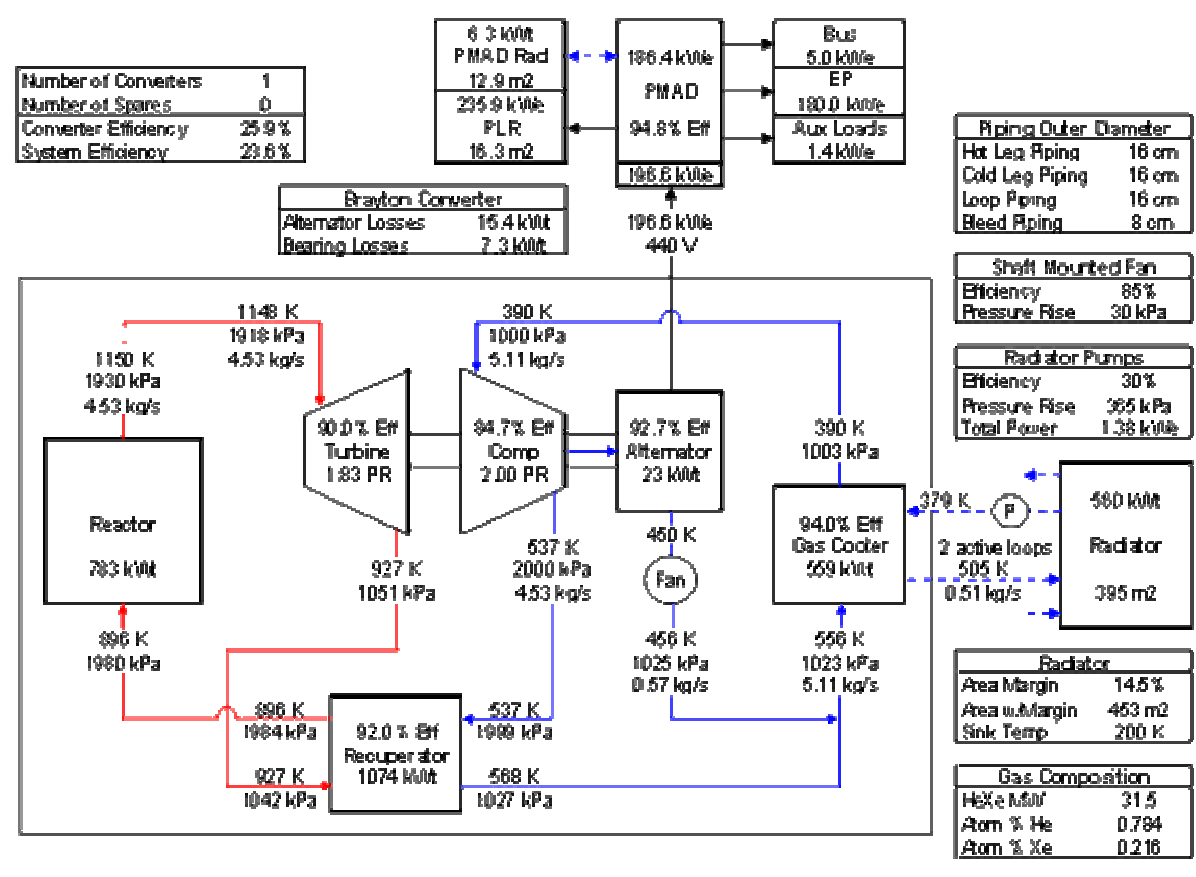

Improved Component Efficiencies and Reduced Loop Pressure Drop Increases Performance of Single Brayton System

\section{Operating \\ 2 Spares}

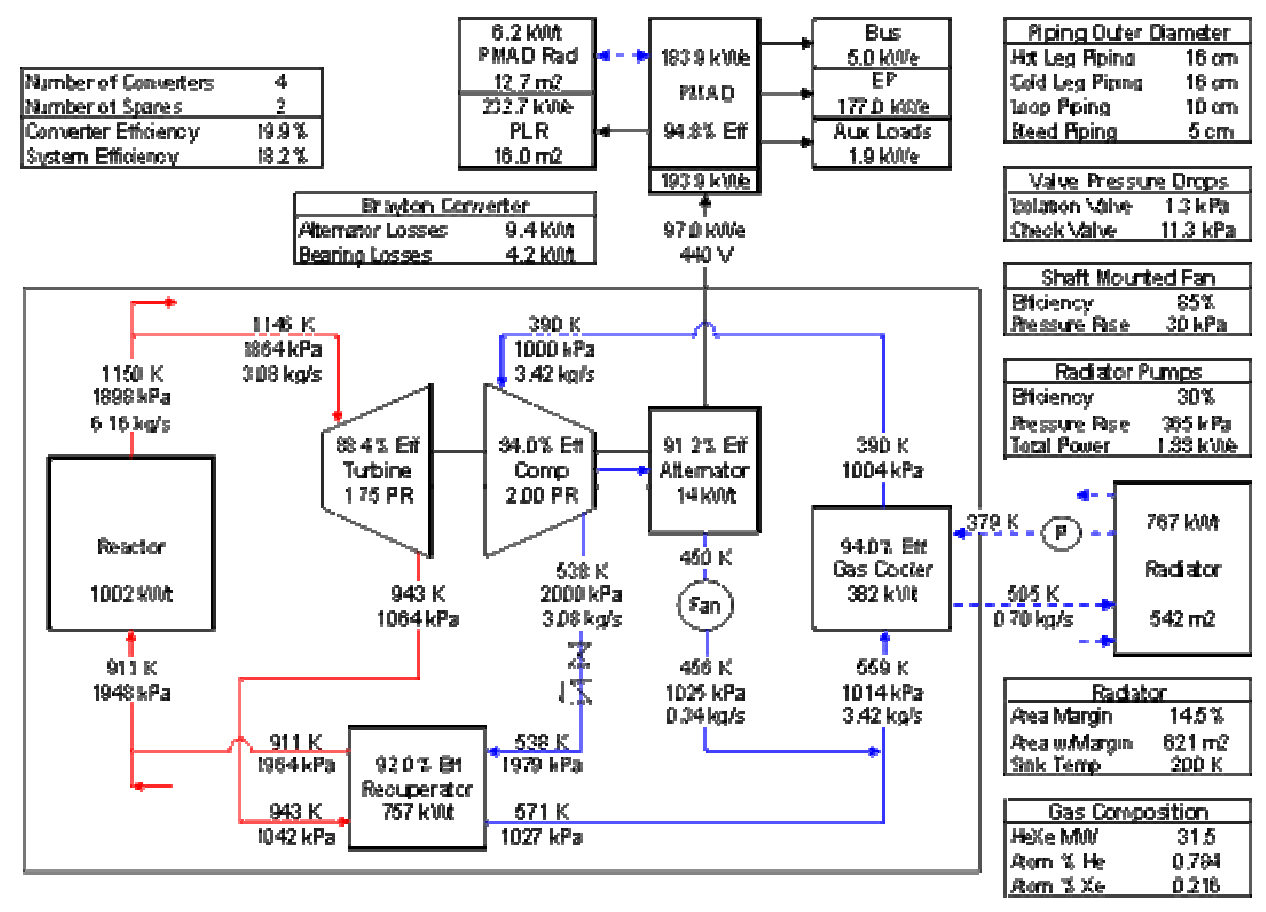




\section{Integrated Mass and Design Space}

\section{System Efficiency}
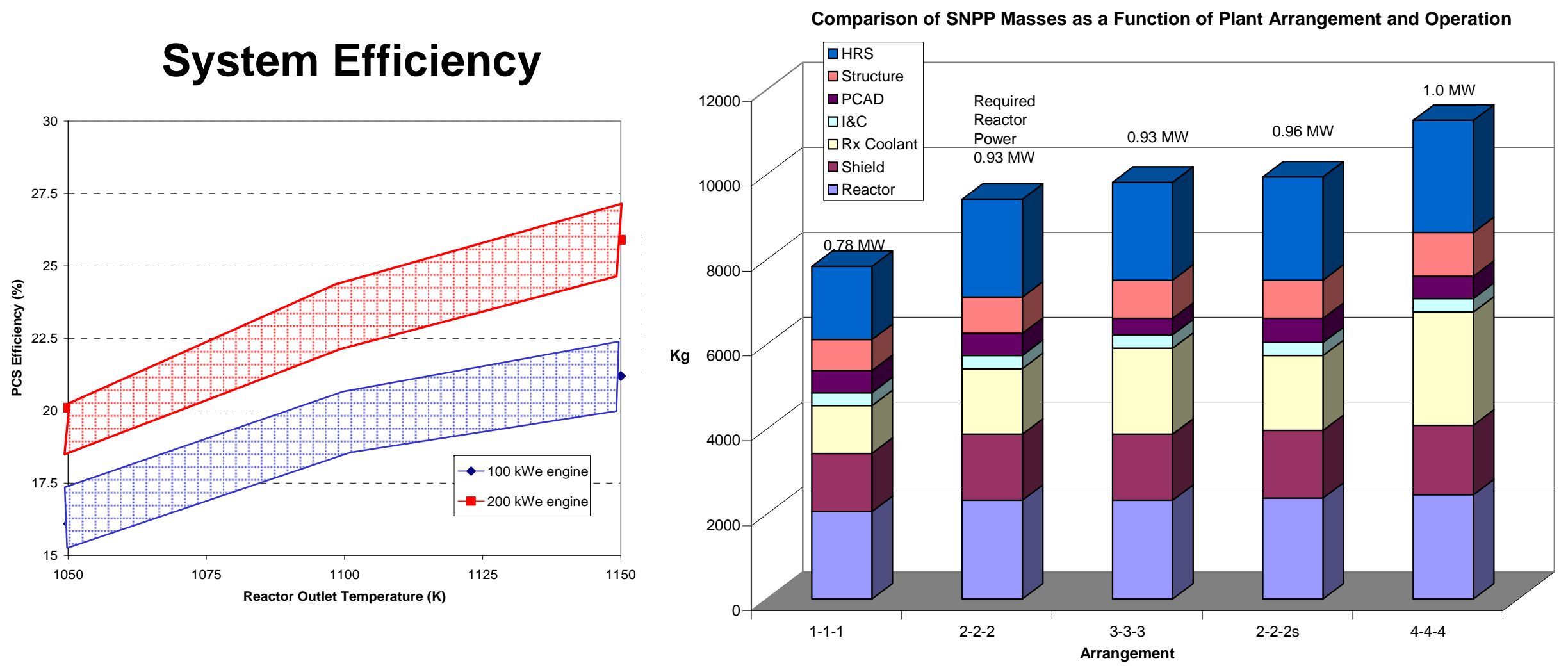

Component performance and loop resistance are substantially better for a single Brayton system. This results in substantially lower system mass and greater design space flexibility 


\section{Reliability}

\section{Garrett Brayton Component \\ Reliability}

\begin{tabular}{|l|c|c|}
\hline \multirow{2}{*}{ Component } & \multicolumn{2}{|c|}{ Failure Rate } \\
\cline { 2 - 3 } & (per hour) & (per year) \\
\hline Foil Bearings & $3 \times 10^{-8}$ & $3 \times 10^{-4}$ \\
\hline Turbine & $1 \times 10^{-8}$ & $1 \times 10^{-4}$ \\
\hline Compressor & $6 \times 10^{-8}$ & $6 \times 10^{-4}$ \\
\hline Alternator & $5 \times 10^{-8}$ & $5 \times 10^{-4}$ \\
\hline Recuperator & $3 \times 10^{-8}$ & $3 \times 10^{-4}$ \\
\hline Bleed Cooler & $9 \times 10^{-8}$ & $9 \times 10^{-4}$ \\
\hline Bellow/ Ducts & $1 \times 10^{-8}$ & $1 \times 10^{-4}$ \\
\hline
\end{tabular}




\title{
System Reliability
}

\section{Brayton Components}

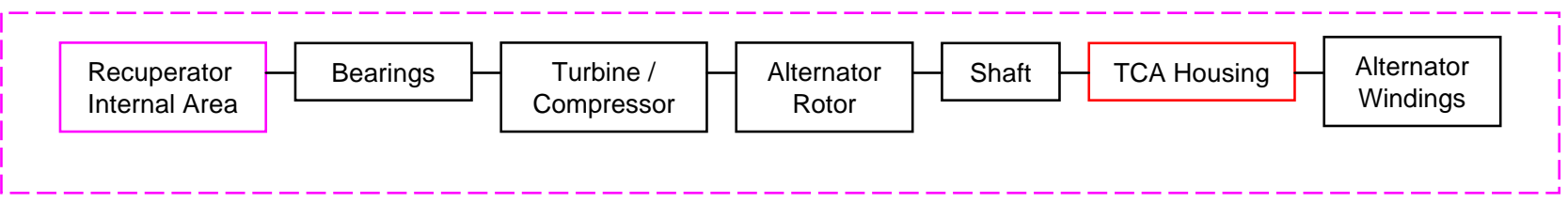

\author{
Single \\ Brayton \\ System
}
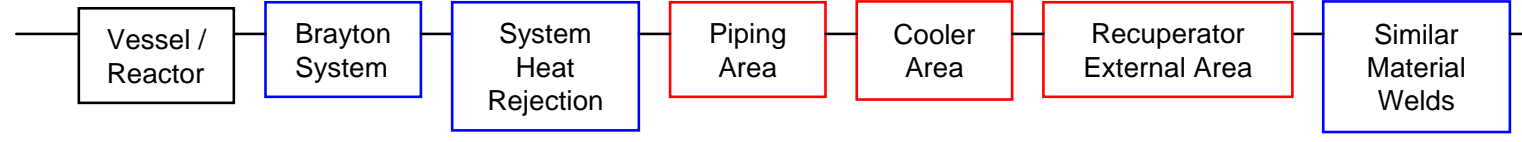

Dissimilar

Material
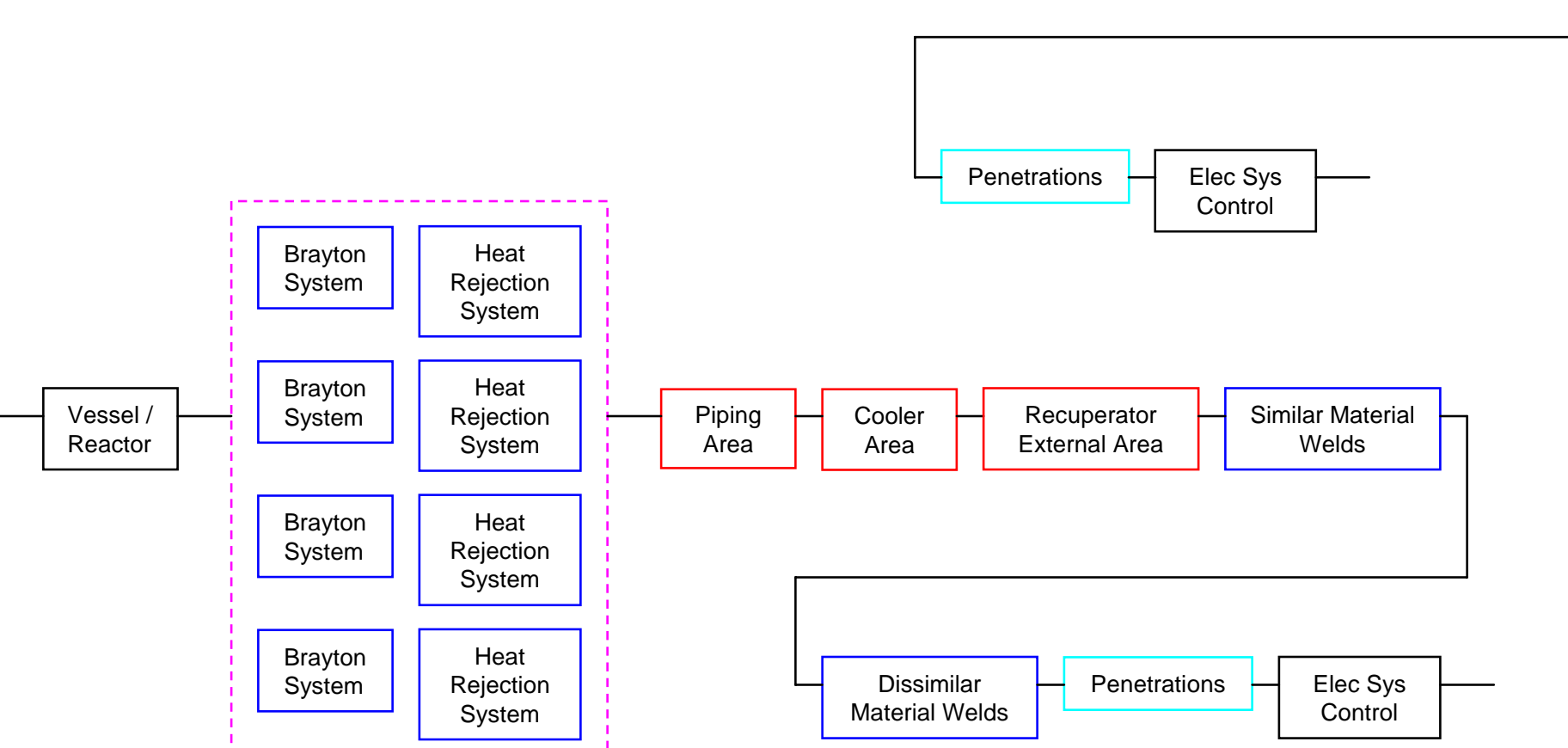


\section{Reliability}

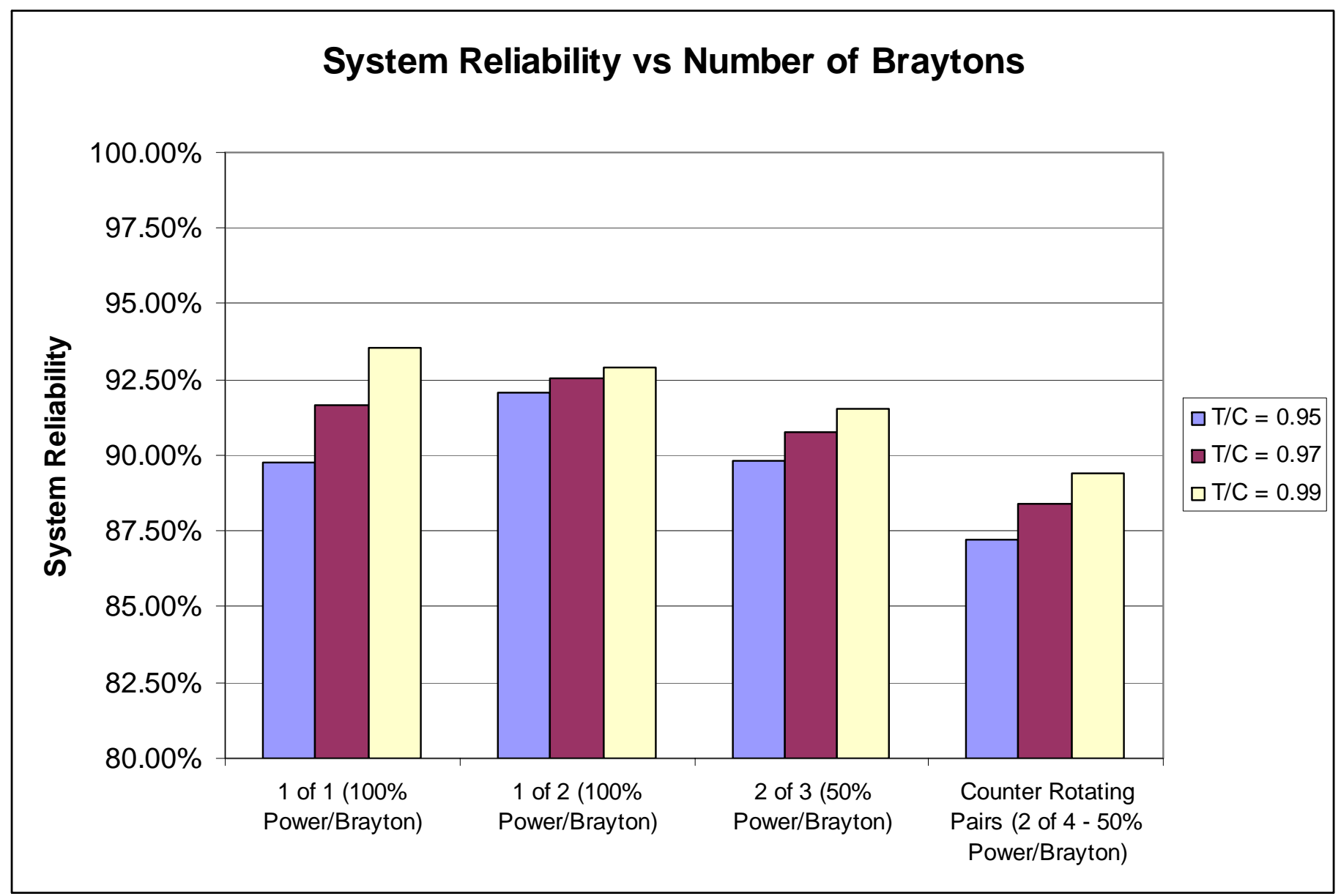

Reliability is Enhanced by Adding a Second Brayton Loop only if Turbine and Compressor Reliability below $97 \%$ 


\section{Extensibility}

- Selection of Number of Converters for Surface Missions Influenced By:

- Availability of Alternate Power for Restart

- Potential for Coolant Make-up and Component Replacement

- Mass Requirements

- Lifetime Requirements

- Decision for NEP may not be the Same as for Surface Missions 


\section{Conclusions}

- Both single Brayton and multi-Brayton system options appear feasible

- NRPCT did not select a reference plant prior to project closeout

- Practical system testing of both single and multi-Brayton system would be needed for the final decision

- A power plant with a Single Brayton would likely have been the focus of development for NEP systems. It offers:

- the best system efficiency

- the lowest mass

- the least component development

- the simplest operational characteristics

- Comparable reliability to a multi-Brayton system

- Developers of future reactor concepts with dynamic converters should thoroughly investigate the benefits and liabilities of converter redundancy 


\title{
Key Factors Influencing the Decision on the Number of Brayton Units for the Prometheus Space Reactor
}

\author{
${ }^{1}$ John Ashcroft, ${ }^{1}$ Sean Belanger, ${ }^{1}$ Wayne Burdge, ${ }^{2}$ Eric Clementoni, \\ ${ }^{1}$ Krista Jensen, ${ }^{1} \mathrm{~N}$. Beth Proctor and ${ }^{2}$ Annie Zemo-Fulkerson \\ ${ }^{1}$ Lockheed Martin KAPL Inc., Schenectady, NY \\ ${ }^{2}$ Bechtel Bettis, West Mifflin, PA
}

\begin{abstract}
The Naval Reactors (NR) Program and its DOE Laboratories, KAPL and Bettis, were assigned responsibility to develop space reactor systems for the Prometheus Program. After investigating all of the potential reactor and energy conversion options, KAPL and Bettis selected a direct gas Brayton system as the reference approach for the nuclear electric propulsion missions, including the Jupiter Icy Moons Orbiter (JIMO). In order to determine the optimal plant architecture for the direct gas system, KAPL and Bettis investigated systems with one or two active Brayton units and up to two spare units. No final decision was made on the optimal system configuration for the NEP gas-Brayton system prior to closeout of the project. The two most promising options appear to be a single system without spares and a three Brayton system with two operating units, each producing half of the required load, with a single spare unit. The studies show that a single Brayton system, without spares, offers the lowest mass system, with potential for lower operating temperature, and a minimum of system and operational complexity. The lower required mass and increased system efficiency inherent in the single Brayton system may be exploited to satisfy other design objectives such as reduced reactor and radiator operating temperatures. While Brayton system lifetimes applicable to a JIMO or other nuclear electric propulsion (NEP) mission have not been demonstrated, there is no fundamental limit on the lifetime of the Brayton hardware. Use of additional Brayton units with installed spares will allow for continued operation in the event of a failure of an individual Brayton unit. However, preliminary system reliability evaluations do not point to any substantial reliability benefit provided by carrying spare Brayton units. If a spare unit is used, operating two of the units at full power with an unpowered spare proved more efficient than operating all three units at a reduced power and temperature. Linking two Brayton units to a single recuperator and gas cooler was also investigated as a mass saving approach, but led to little mass savings relative to the increased operational complexity.
\end{abstract}

Keywords: Prometheus, Nuclear Electric Propulsion, Gas Reactors, Brayton, Reliability

\section{INTRODUCTION}

In March of 2004, NASA and the Department of Energy agreed to collaborate on development of a space reactor for nuclear electric propulsion. The DOE Naval Reactors program assigned this work to its two DOE laboratories, KAPL and Bettis. The assembled team was termed the Naval Reactors Prime Contractor Team (NRPCT). A key element of the NRPCT effort was to establish directed partnerships with DOE laboratories and NASA centers possessing relevant capabilities. ter a review of all of the available reactor coolant and energy conversion concepts, a direct gas Brayton system was selected. The gas Brayton system offered a simplified reactor plant, a greater number of material options, reduced operational complexity, and more straightforward system testing (Reference 1 ).

While the NRPCT developed reactor plant concepts for gas reactors, liquid metal reactors, and heat pipe reactors as part of the concept selection in early 2005, the Jet Propulsion Laboratory (JPL) - the NASA lead for the Prometheus program work, and Northrop Grumman Space Technology (NGST) - the selected spacecraft contractor, developed a preliminary spacecraft arrangement, called the Prometheus Baseline 1 (PB1). The PB1 reactor plant concept was a liquid metal reactor with multiple Braytons. Redundant Braytons were assumed for several reasons:

1) Using two Brayton simultaneously provides continuity of power after a Brayton failure, allowing for starting a spare unit without reliance on auxiliary power.

2) Each Brayton would need to provide power for only a portion of the spacecraft lifetime

3) Operating Braytons in counter-rotating pairs cancels angular momentum

4) Redundancy of components is a NASA preference and provides protection against unforeseen issues.

This approach to using multiple components is based on the fact that NASA experience indicates the prudence of having redundant components, even if they have demonstrated reliability, to ensure that manufacturing defects or human error does not lead to a mission ending failure. For those components where redundancy is considered impractical, exceptions to the single point failure avoidance requirement is provided. For the 
Prometheus spacecraft, the reactor, the reactor primary coolant boundary, the boom, and the xenon propellant tank all require such exceptions.

With the selection of the direct gas reactor concept, one of the key decisions is how many interdependent Brayton loops are used in conjunction with the gas reactor, and, if there is more than one loop, how will the multiple Brayton units be utilized and controlled. The decision on the number of Brayton loop components and their control is influenced by many factors, including:

1) Individual component reliability and system reliability

2) Overall system mass and the potential trade-offs between mass and reliability

3) The operational options and characteristics associated with the plant to provide for part-load operation

4) The capability of the Brayton components to provide the required power and efficiency.

5) The influence that the number of operational Braytons has on other spacecraft systems, including the electrical power demands for plant start-up and the size and complexity of momentum compensating reaction wheels.

6) Influence of the number of Braytons on systems which interface with the Brayton system such as the power conditioning and distribution (PCAD) system and the heat rejection system (HRS).

7) Ability to arrange the necessary hardware in the system behind the shield cone and with appropriate allowance for thermal growth and distortion as well as flow distribution.

8) Desire for creating sufficient redundancy and operational flexibility to accommodate any unforeseen casualties or alternate operating modes.

9) Compatibility of the system configuration with a number of potential future missions including longer duration missions and surface exploration missions.

\section{PLANT CONFIGURATION OPTIONS}

The general arrangement of the space reactor propulsion system is shown in Figure 1 . The reactor sits at the end of a long boom. The reactor heats the mixture of helium and xenon gas flowing through it. The gas is transported around a reactor shield assembly to the Brayton converter(s). The shield protects the spacecraft from the neutron and gamma radiation produced by the reactor. The gas travels first to the turbomachinery assembly. This assembly is shown in Figure 2. It includes the radial flow turbine and compressor, and the alternator, all mounted on a common shaft and supported on gas foil bearings. After flowing through the turbine, the gas flows through a regenerative gas heat exchanger (a recuperator) and through a gas cooler, through the compressor, back through the recuperator and back to the reactor. The gas cooler transfers heat from the gas to a water cooling loop which sheds waste heat from the power conversion system through large radiator panels. The excess work produced by the turbine is converted to electricity by the alternator to supply the ion propulsion system and the on-board instruments. Excess power is shed using a controllable parasitic load radiator (PLR).

A number of different reactor plant architectures could be envisioned. Candidates include:

1) Operate two counter-rotating turbines on and two non-operating spare counter-rotating turbines. Each turbine is capable of producing half of the required electrical output. This is the base case used in the JPL/NGST derived PB1 study.

2) Operate two co-rotating turbines for most of the mission life with one non-operating spare. The spare will rotate in the opposite direction and be initiated with failure of one Brayton or when the spacecraft reaches science orbit to provide momentum compensation.

3) Operate two Braytons with co-rotation with one spare. Use alternate means for momentum compensation.

4) Operate two counter-rotating turbines without spares.

5) Operate two counter-rotating turbines without spares, but provide overpower capability, and separate momentum compensation, to allow for increasing one Brayton power output to full power to compensate for a failure of the other unit.

6) Operate one turbine capable of full electrical power and with one or more non-operating spares. The second unit would be powered up in the event of a failure of the primary unit through the use of an electrical power storage device (battery, flywheel, etc.).

7) Operate one turbine without spares. 
Figure 1

Overall JIMO Spacecraft Arrangement

- Spaceship Configuration PB1

- Gas cooled reactor with 200 kW Brayton output power

- Nearly 58 meters in length

- 36,375 kg estimated mass at launch

- Stows in $5 \mathrm{~m}$ diameter fairing

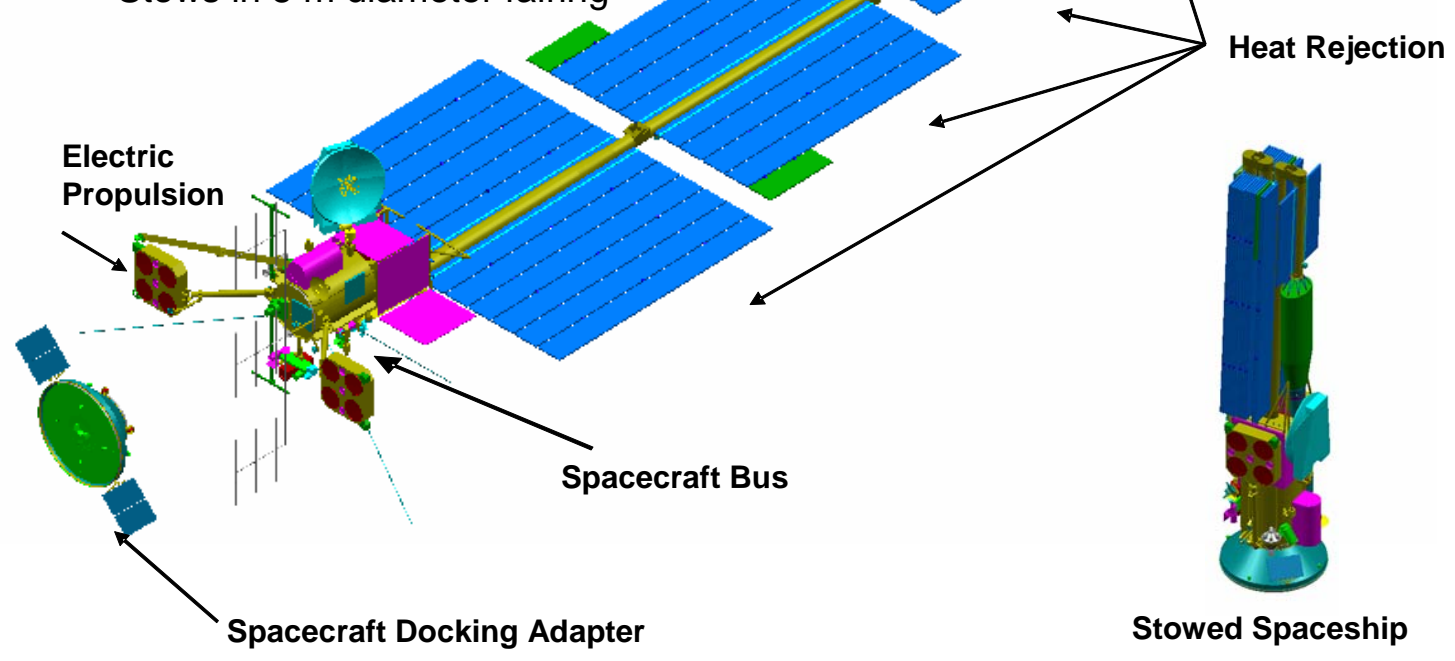

Figure 2

Turboalternator Assembly

(Hamilton-Sundstrand Concept - Reference 5)

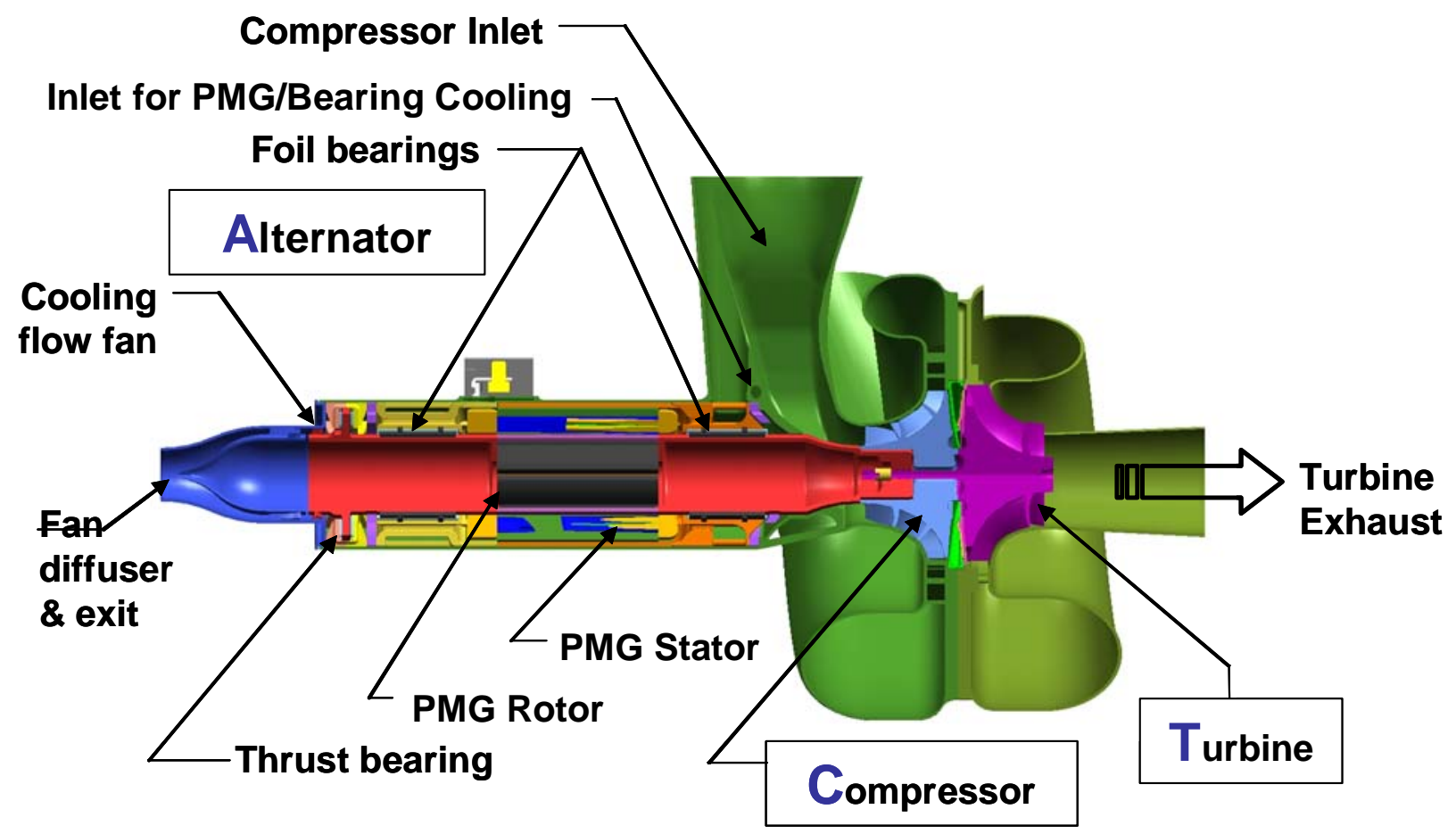


Note that there are additional options associated with combining the heat exchangers from multiple Brayton units or for using separate heat rejection loops even for a single Brayton unit. Figure 3 shows example heat balances for cases with one and two operational Brayton units producing a total of $185 \mathrm{kWe}$ output each.

\title{
COMPONENT CAPABILITY
}

\author{
Brayton Power Output
}

The first question in determining whether a system can be configured with one Brayton, or one Brayton running with an installed spare (options 4, 5, and 6), is to determine whether a single Brayton system is capable of producing the required $\sim 200 \mathrm{kWe}$. Based on fundamental scaling laws established in the NASA Glenn Research Center (GRC) developed SRPS-opt code, and supported by GRC calculations of Brayton performance maps, operation of a $200 \mathrm{kWe}$ Brayton is possible. Operation with a single high power Brayton would allow for higher system efficiency, higher operating pressure, and higher helium content in the gas, all of which will reduce demands on the reactor design by reducing required power level and increasing heat transfer. Operation of a single Brayton at full power would potentially allow for a reduction of the primary side temperature by some margin ( $>50 \mathrm{~K}$ reduction) and still achieve the required power output for comparable reactor power, heat rejected power, and heat rejection radiator area. Figure 4 compares the system efficiency for two units at $100 \mathrm{~kW}$ to one unit at $200 \mathrm{~kW}$ at the optimum operating conditions as a function of $T_{\text {hot }}$. The single Brayton option offers substantially higher efficiency, due to the improved turbomachinery efficiencies and the lower pressure losses in the shorter and less complex loop piping. Note that both the single and multiBrayton cases have considerable uncertainty in predicted efficiency due to uncertainties in component efficiencies and loop flow resistances. Further optimization of the arrangements and operating conditions could also change the magnitude in the efficiency difference between the single and multi-Brayton cases. This advantage in efficiency also allows for a lower radiator area requirement, as shown in Figure 3.

Single shaft radial flow turbine scalability to $200 \mathrm{kWe}$ is possible based on existing turbomachinery. While past NASA closed loop Brayton hardware was low power (up to $15 \mathrm{kWe}$ ), Capstone Turbines has developed a prototype for a $200 \mathrm{kWe}$ unit (Reference 2) and Hamilton Sundstrand built and tested the $200 \mathrm{kWe}$ Integrated Power unit (IPU) for the Air Force (Reference 3). The Capstone unit has gas foil bearings and a permanent magnet alternator, similar to that envisioned for Prometheus.

The stresses on the wheels and on the shaft will be influenced by the mass of the components on the shaft as well as the overall arrangement. Scaling the system to larger power output requires increasing the size of both the turbine and the compressor wheels. This in turn increases the length of the shaft and the loading on the bearings. Preliminary rotordynamic analysis from GRC indicates that the gas foil bearing loads are within their projected capabilities (Reference 4). If larger shaft sizes push the gas bearing loading beyond current capabilities, rearrangement of the shaft, through the use of additional bearings or the use of a center-positioned alternator could allow for increased power capability.

The alternator scalability must also be investigated. Hamilton Sundstrand considers the current $100 \mathrm{kWe}$ alternator test unit (ATU) to be near the limits of alternator power density capability (Reference 7). Therefore, an increase in the required alternator power output would require a large diameter or longer alternator, both of which would increase concerns for shaft dynamics and the resulting bearing performance. Given the higher alternator and bearing temperature and the increased reliability requirements for the Prometheus system, considerable scale-up effort would be anticipated for this design. A comparison of the specific requirements for the Prometheus alternator and that used in the $250 \mathrm{kWe}$ Capstone unit could clarify these alternator scale-up issues.

\section{Valve Operations}

For any system with in-line spares, the system will require check valves or isolation valves to minimize reverse flow through the loop. These valves do not see high operating temperature (300-500 K), but they do need to operate reliably. While gas valves have been used on space systems, large gas valves for 10-16 cm diameter loop piping are considered to be developmental. Note that not all valve failures would be mission ending failures. For instance, if a check valve in a non-operational loop failed to function, this would produce reverse flow in that loop. This in turn could damage the bearing in the turbomachinery in that loop, rendering it inoperable. However, use of the remaining loops, with some temperature difference between the core and the turbines due to the effect of the reverse flow, would still be possible. 
Figure 3: Heat balances for single and multi-loop closed Brayton systems

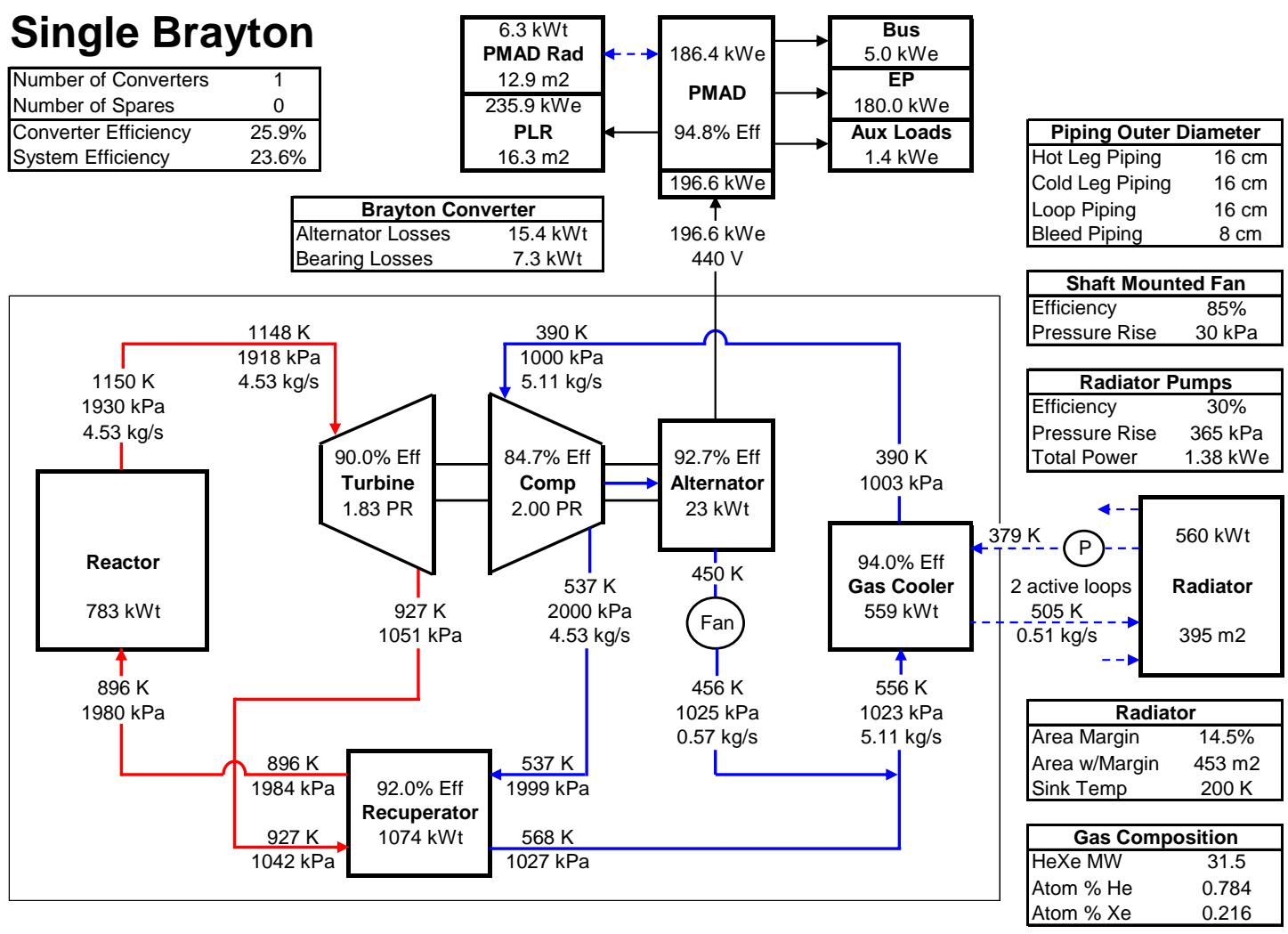

\section{Operating- 2 Spare Brayton System}

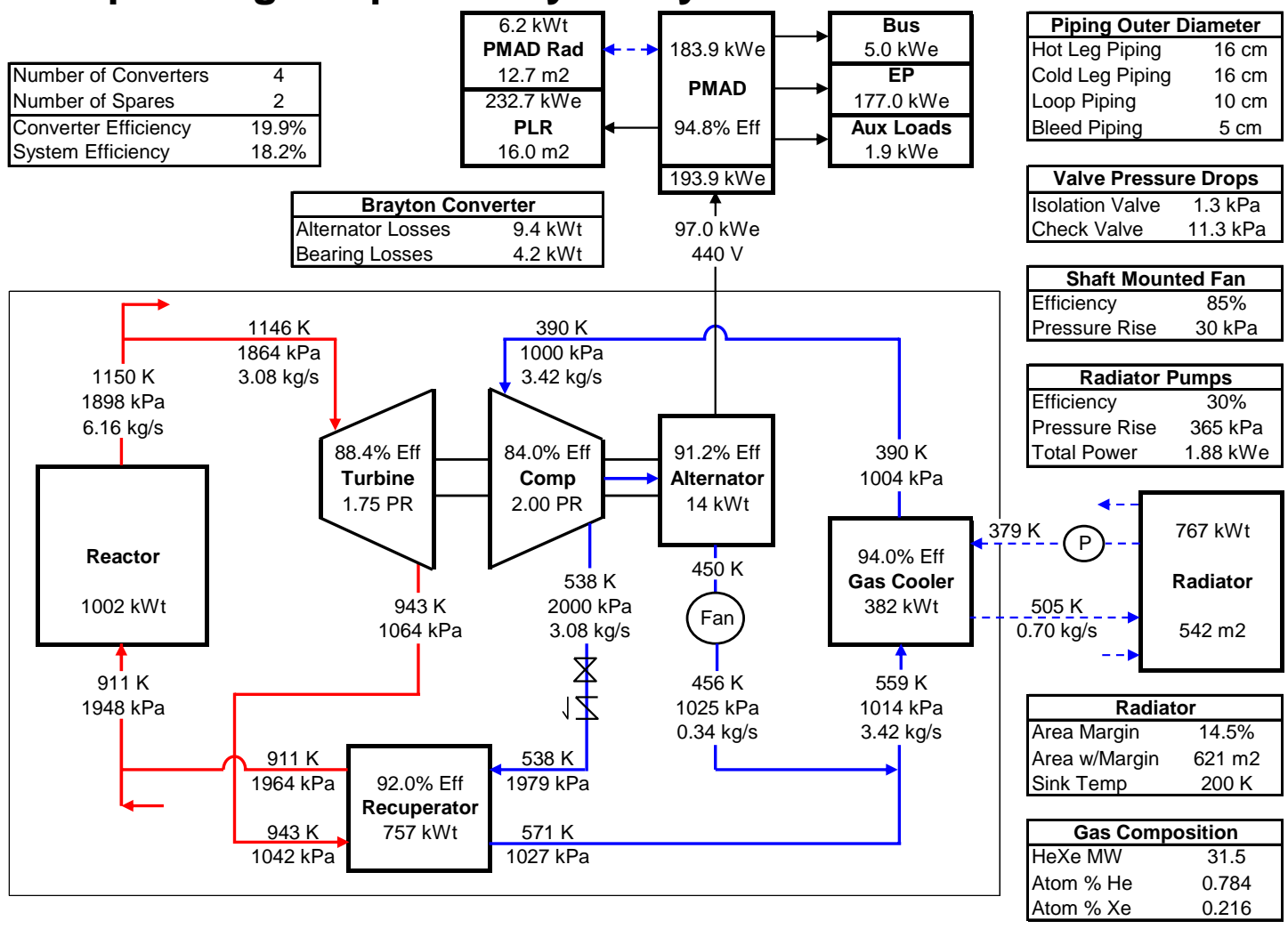


Figure 4: Range of Brayton Efficiency versus Thot for 100 and $200 \mathrm{~kW}$ units.

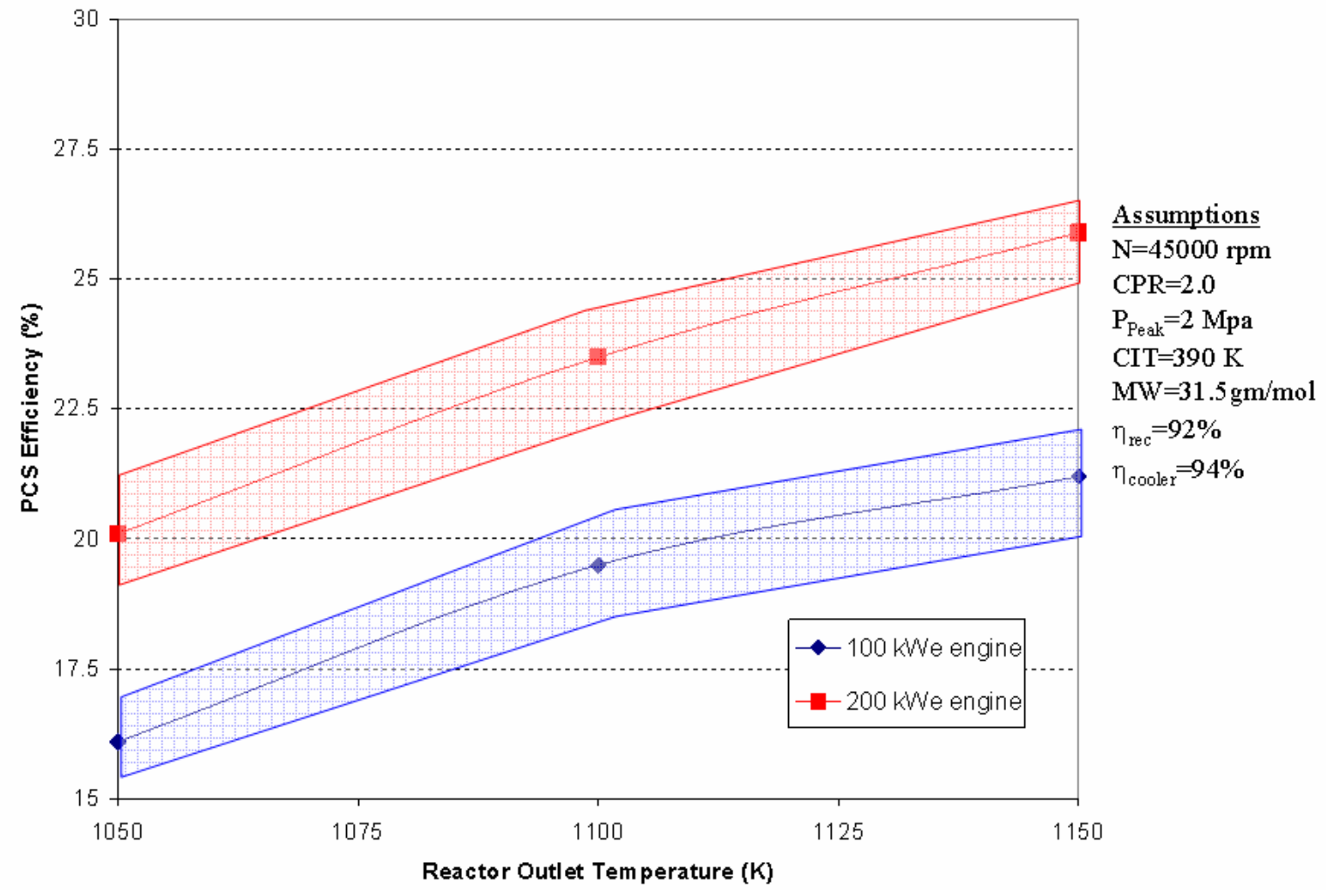

Concepts with shared heat exchangers require controllable valves in hotter portions of the loop. In order to share a recuperator and cooler, for instance, multiple valves are required to operate, as shown in Figure 5, to switch from an operational Brayton to a spare. The number of valves is further increased in this case based on the bearing and alternator cooling arrangement that draws cold gas from the compressor inlet. The hottest of these valves must operate at the turbine exit temperature $(\sim 900 \mathrm{~K})$.

Figure 5: Valve Configuration for a Share Recuperator and Cooler

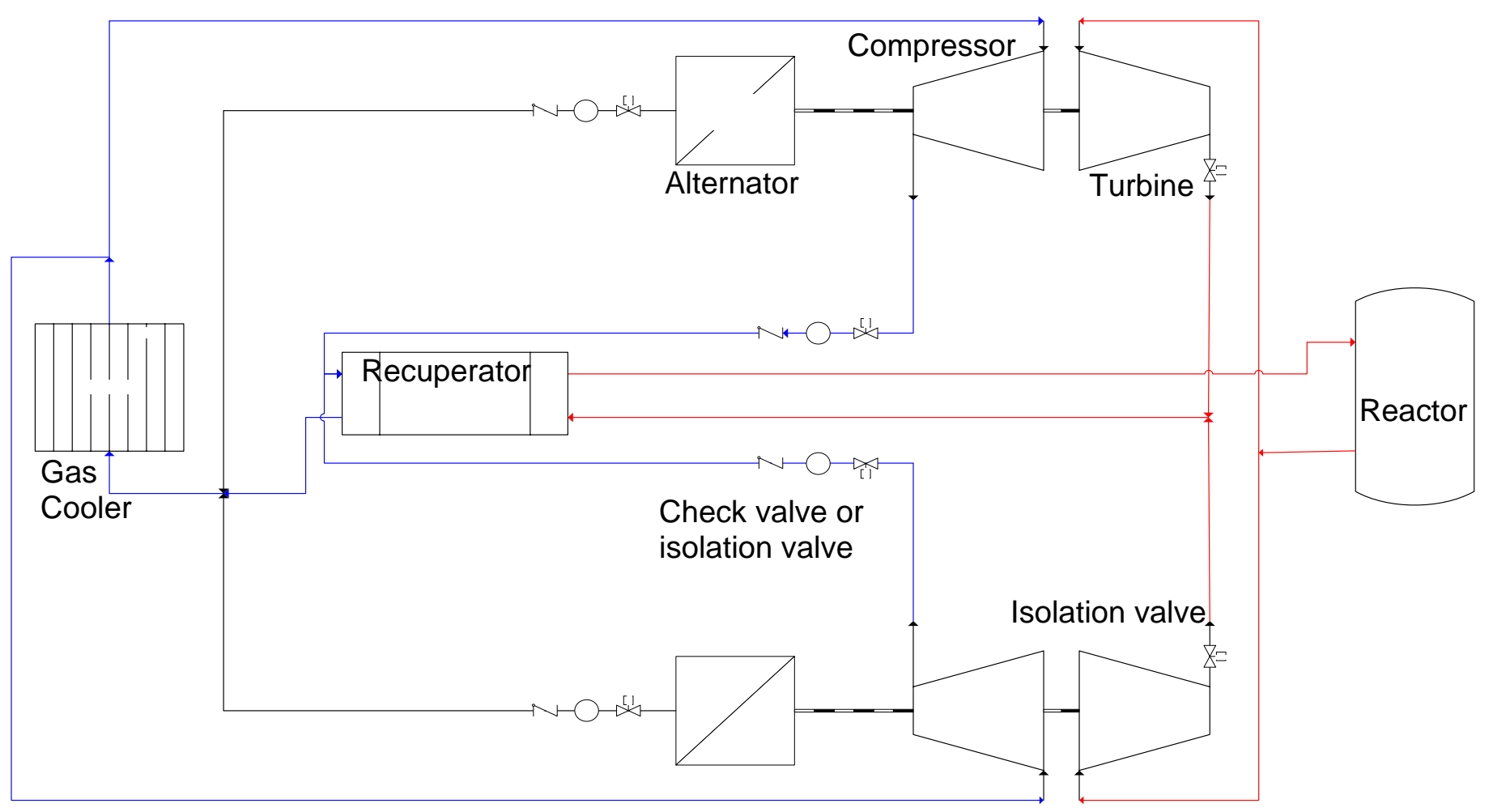




\title{
Use of Reaction Wheels
}

In the current PB1 configuration, an effort is made to eliminate the need to externally compensate for the Brayton system momentum. For instance, counter-rotating units are preferred and the orientation of the Brayton units is such that the axis of rotation is perpendicular to the long axis of the spacecraft. With a single Brayton unit, some other means of momentum compensation would be needed to counteract the Brayton unit momentum and to compensate for torque created during any Brayton speed changes. Initial mass estimates are $\sim 25 \mathrm{~kg}$ of mass penalty for a reaction wheel - small compared to the mass penalty of a spare Brayton. Momentum compensation wheels are a standard spacecraft technology and have been designed and used by the space industry. Use of reaction wheels to adequately compensate for a single Brayton unit should be further evaluated.

\section{Conclusions on Component Capability}

While there are complexities associated with use of either multiple parallel Brayton units or a single, higher power Brayton unit, the overall component capabilities appear to support either option. Key development for the single Brayton option are the turbine and alternator scale-up, while for the multiple parallel system with spares, development of reliable and large flow area valves appears to the greatest additional challenge.

\section{IMPACT ON INTERFACE SYSTEMS}

\author{
PCAD System
}

The PCAD system for the PB1 reactor concept consists of a ring bus to allow for distribution of power from each of the four Brayton units. While this provides robust continuity of power, it also requires a considerable number of circuit breakers and cabling.

Use of two independent electrical power supplies would likely provide sufficient electrical system robustness while minimizing electric system complexity. Two independent electrical systems could be provided by two Brayton units (without spares) or by one Brayton power unit with two separate alternators. Such an arrangement would have effects on the rotor dynamics and alternator and bearing cooling, and would therefore require more study. However, in principle, use of multiple alternators on the same shaft would also create some redundancy in shaft speed control, minimizing the likelihood of an overspeed event due to a loss of electric load. Each alternator and its associated electrical system would need to be sized for full power capability.

Based on the initial evaluation, the electrical system could be made to interface with any of the Brayton options envisioned.

\section{Heat Rejection System}

The heat rejection system would also need to properly interface with the Brayton units. For all of the concepts envisioned thus far, four independent fluid loops have been used for the heat rejection system to ensure ability to supply heat from the Brayton loop to the radiator heat pipes. Each section of the radiator is provided heat by two adjacent but independent cooling loops.

For a Brayton four loop system, the interface between the Brayton and the HRS loop is easily accomplished by having four independent and parallel heat rejection loops, each of which corresponds to a Brayton loop (See Figure 6, from GRC TB2 study of the liquid metal Brayton concept). This arrangement was originally envisioned by GRC in early government team studies. Operational Braytons feed operational HRS loops. Stand-by Brayton loops have heat rejection loops that are also in standby. Two loops feed each half of the radiator section so that the whole radiator is in use regardless of which Brayton units are operational. While this approach is straightforward, it necessarily links each heat rejection loop to a given Brayton loop. In so doing, a failure of a heat rejection loop (due to a micrometeroid puncture or pump failure) would preclude use of an otherwise functioning Brayton loop.

For systems with two or one Brayton units, the four heat rejection loops can interface through gas coolers arranged in series as shown in Figure 7. For a two loop plant, each loop would have a pair of cooler sections arranged in series. The upstream cooler section would be operational (with flowing coolant) while the 
downstream (colder) cooler would be isolated. For a single loop plant, four gas cooler sections, arranged in a common heat exchanger but connect to four HRS loops, would be used, with two parallel sets in series. Again, the upstream pair of coolers would be active and the downstream, colder coolers would be inactive. This arrangement does increase the flow resistance of the gas (since it must flow through a non-operational cooler as well as an operational cooler) and therefore reduces system performance marginally. However, this added pressure drop is considered manageable, particularly with the higher efficiency single Brayton system.

The three Brayton system has a hybrid interface with the four heat rejection loops. The two normally operating Braytons would each have a single $(\sim 300 \mathrm{kWt})$ heat exchanger section. The spare Brayton loop would have two heat exchange sections, one section supplying heat to each radiator half. To switch between the operating Brayton loop and the spare, the heat rejection loop pumps corresponding to the appropriate radiator would have to be energized. This three Brayton loop interface is more awkward than that corresponding interfaces for the single, two, or four-Brayton systems.

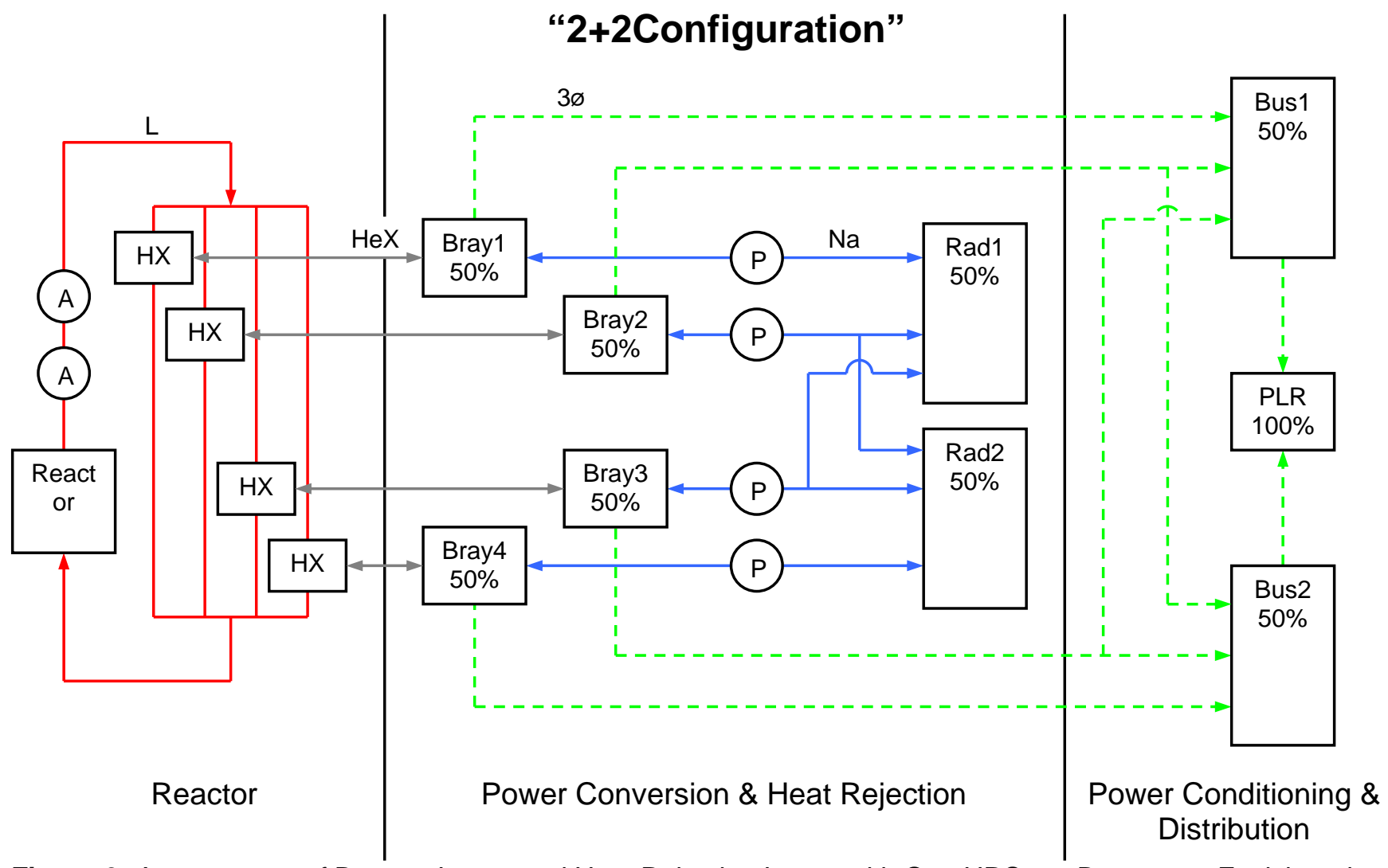

Figure 6: Arrangement of Brayton Loops and Heat Rejection Loops with One HRS per Brayton as Envisioned by GRC for the Liquid Metal Brayton System. Use of Cross-Strapping Valves Does Allow for Greater HRS Failure Tolerance 


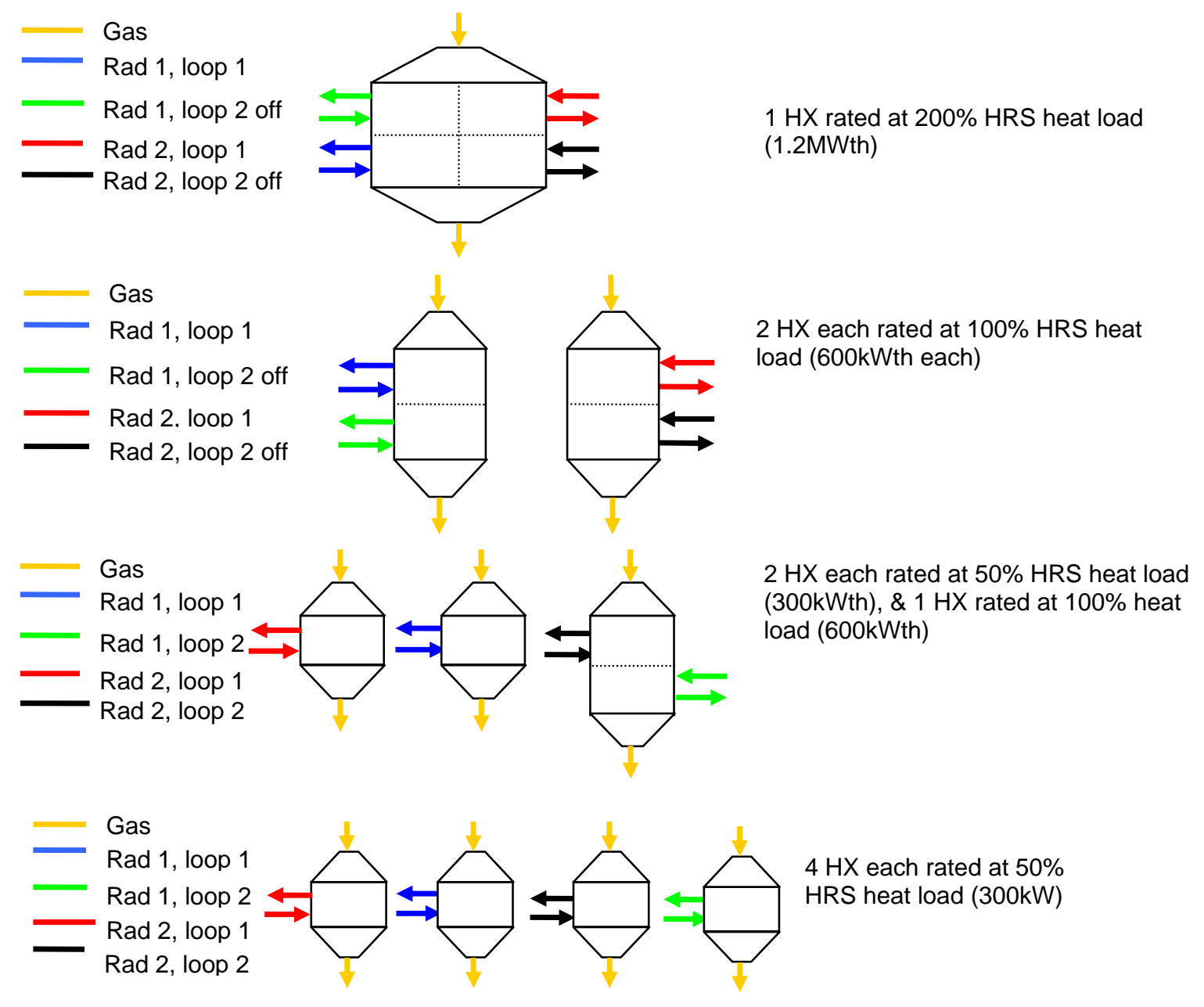

Figure 7: Heat rejection system interface options for one through four Brayton loops.

\section{OPERATIONAL CONCERNS}

Start-Up

For in-space start-up, at least one of the Brayton units must be motored using the start inverter to turn the alternator shaft and thus initiate gas coolant flow through the reactor. After this Brayton is motored, the reactor can be brought critical and warmed to higher temperature through slow movement of the control devices. Cooling flow in at least one of the heat rejection loops must be initiated to develop a cooling path for the reactor. As the heat up proceeds, the turbine work will eventually exceed the compressor power requirements and the Brayton unit will be self-sustaining. To minimize the power required from the solar array during this period of Brayton motoring, the Brayton speed is maintained low (between $20-30 \%$ of rated speed). The reactor power level continues to increase by inserting additional reactivity, raising temperature and Brayton load capacity. At some point well above self sustaining power in the first Brayton system, a second Brayton system, if used, can be started and the reactor can be slowly brought to full power by continued increase of inserted reactivity.

Starting up a Brayton requires power input to lift the bearing off the shaft and to spin the Brayton up to the minimum self-sustaining condition. The initial estimates from GRC and JPL of power required to spin the Brayton were on the order of $3 \mathrm{kWe}$. However, more recent estimates from Hamilton Sundstrand suggest that a Brayton can be started to quickly lift the shaft off the bearings and maintain a shaft speed of $\sim 30 \%$ of rated speed with less than $3 \mathrm{~kW}$ (Reference 7). Maintaining the Brayton at a minimum speed while the plant heats up is expected to require less power. Assuming that a single larger Brayton would require a bigger shaft and larger bearings, it is likely that a single Brayton system will also require a larger power level to lift the bearings. This will require further evaluation. 
Starting the second Brayton or a spare Brayton may be more challenging than starting the first unit from a reactivity control viewpoint. Lifting the shaft off the bearing in the second unit will require a minimum flow rate in that loop. The cold gas from this unheated loop will mix with the warm gas from the operational loop and reduce the average reactor inlet temperature, which in turn will increase core reactivity due to the core's negative temperature coefficient. Therefore, initiation of flow in the second Brayton will lead to a potentially large reactivity transient in the core that is not seen in starting the first unit. In addition, operating this second Brayton at low speed in a hot reactor loop will lead to rapid heat up of the recuperator in this second loop. The recuperator inlet temperature would approach the reactor exit temperature under this condition. To prevent damage to the recuperator, the second Brayton must be started when the reactor and plant are at an intermediate temperature.

Restarting a single failed Brayton during the mission life is considered significantly more challenging. Away from the sun, solar panels cannot provide sufficient power. Batteries are also expected to degrade or fail. The PB1 approach called for jettisoning the solar array and battery following reactor commissioning since the longevity of these back-up power supplies was limited. Therefore, it is likely that the shutdown of a single Brayton in a deep space mission would be a mission ending event. Multiple operating Brayton units offset this concern.

\section{Part-Power Operation}

Longer mission profiles, beyond that required for the JIMO mission, may require long term operation at part load $(\sim 50 \%)$ power output. Note that reducing power to less than $50 \%$ with the current heat rejection system technology does not seem prudent in that it will result in freezing of the water working fluid in the condenser end of the coldest heat pipes in the radiator. Long term colder operation of the reactor may also lead to core material embrittlement. NRPCT has analyzed the performance of various part-load control approaches, based on off-design operating points provided by GRC. Part load operation could be supplied by a number of means:

1) Controlling the gas inventory in the loop. Lower overall gas pressure would lead to lower thermal and electrical power output for the same shaft speed. Such a system is considered too complex and fault prone as a base case approach.

2) Controlling reactor temperature. Reducing reactor temperature reduces reactor and electrical output even at the same shaft speed and also may help to limit creep in the loop and the turbine. However, the part-load efficiency will be less than the full power efficiency.

3) Controlling Brayton speed. Developing a lower speed set point would reduce reactor power and electrical power output while maintaining closer to the full power efficiency. This would require the electrical system to be capable of the two frequency set points. If the low power mode does not require high voltage to run thrusters, this may prove practical. Speed control and temperature control could be used together as well.

4) Maintaining the reactor at full power and wasting excess electrical power through the parasitic load radiator.

5) Turning one of two operational Brayton units off during low power operations.

Figure 8 shows the options for moving from the full power operating mode to the part power operating mode for options 2 and 3. Option 2 appears to be the best option in that it reduces both reactor power level and temperature during the partload operational period, and does not require as complex an electrical system or an inventory control system.

With the exception of approach number 5 above, all of the partload control options can be accomplished with either one or two operational Brayton loops. The fifth option is likely less desirable than option 2 in that it would require unaided restart capability for the secured Brayton unit in the event that the operational unit fails. 
Figure 8: Design Space for Speed and Temperature Control of Brayton

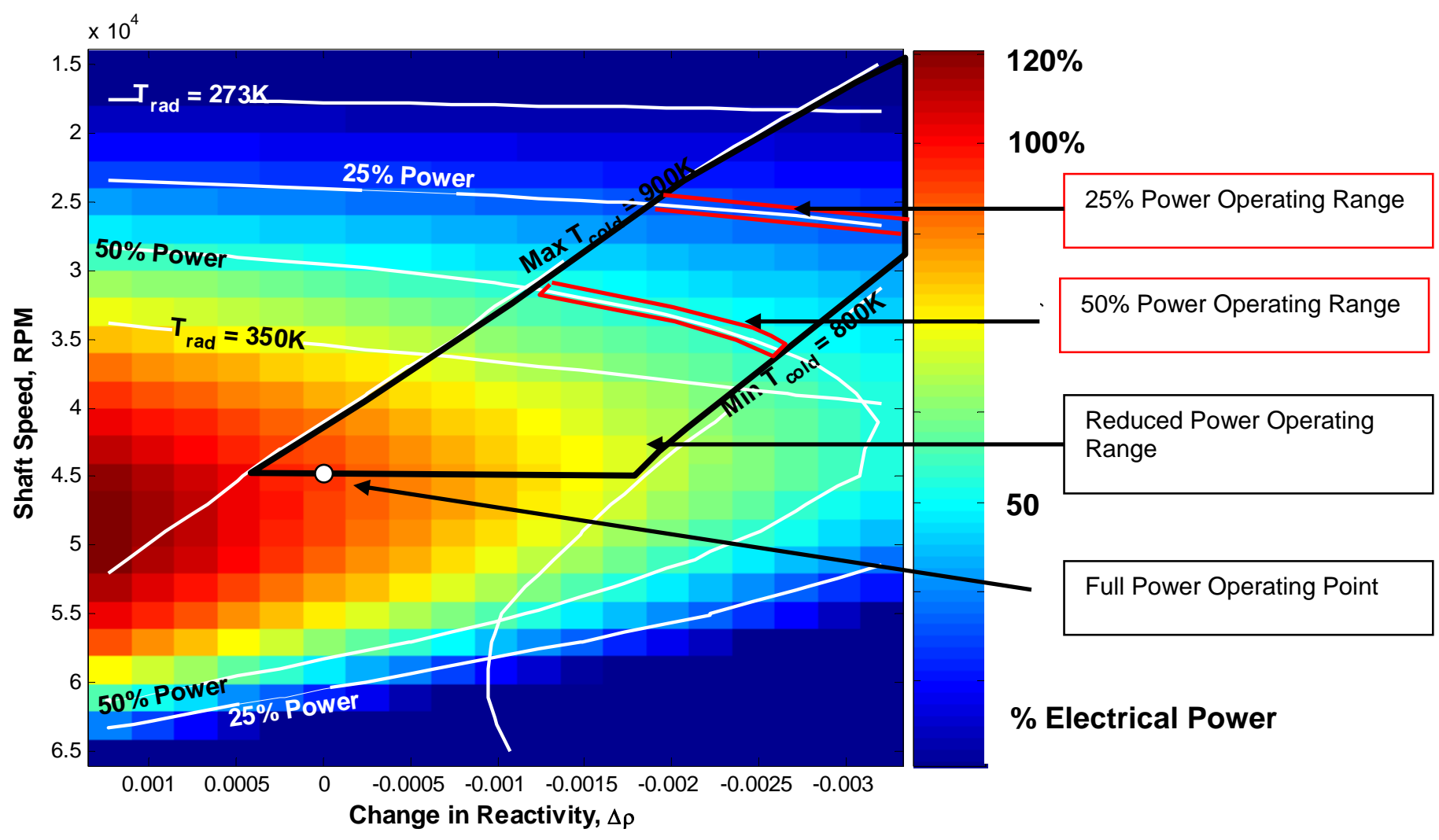

Another operational issue is the use of two Braytons in the same loop when those Braytons do not have the same operational characteristics. While such inconsistencies between like-designed parts are expected to be small, differences in the loop flow resistance, the heat exchanger effectiveness and in the turbomachinery performance will impact the relative flow in each loop and lead to off-design operation of both Braytons. In addition, any reverse flow that by-passes the check valves in the stand-by loops will result in a steady state difference in the core exit temperature and the operating turbine inlet temperature, thus reducing the fuel performance margin.

An additional study was undertaken to investigate whether systems with installed spares should utilize those spares or leave them secured. For instance, if the systems were designed for use of two Braytons to provide the full $200 \mathrm{kWe}$ load, use of three systems would allow for operation at 2/3 of rated power. This could allow for a reduction in reactor operating temperature from $1150 \mathrm{~K}$ to $\sim 1000 \mathrm{~K}$, reducing material creep concerns. However, based on the lower efficiency of this lower temperature operating point, the required reactor power increased by $\sim 30 \%$ and the required radiator area also increased by $\sim 30 \%$ relative to operating two Braytons at full power and temperature. Thus, designing the system for this operating mode leads to an overall increase in the system mass on the order of $1200 \mathrm{kgs}$. Using a combination of speed control and temperature control may allow for more efficient part-load operation which would provide some benefit for operating the spare unit. However, use of speed control requires a more complex Brayton electrical architecture. Therefore, there does not appear to be any practical benefit to designing the plant to utilize three Brayton loops at a reduced capacity.

\section{ARRANGEMENT OPTIONS}

A number of different arrangement options have been considered for the multiple Brayton system. Most of the original arrangements were done by the government and contractor teams using a liquid metal reactor assumption. The NRPCT has since developed independent arrangements based on the prior work but applicable to the gas reactor system. Options for intertwining the loops, for having loops positioned parallel to one another and for having an axially staggered modular loop arrangement have been considered. Figure 9 shows an early GRC arrangement with a liquid metal reactor and liquid metal to gas heat exchangers rather 
than direct gas cooled reactor system, and thus has smaller loop piping around the shield. Figure 10 shows the NRPCT arrangement of a four Brayton loop system. This four Brayton loop arrangement is approximately 9 meters long. This is longer than the Prometheus Baseline 1 assumptions (7 meters) and would likely have grown further as the piping size and arrangement was optimized.

Figure 11 shows the configurations with a single gas Brayton system and with two 100\% power capable Braytons. The required space behind the shield in the single Brayton case is substantially less than with multiple Braytons, there are fewer bends in the loop piping, substantially shorter loop flow lengths, and no valves in the system. This system with fewer bends, no valves, and larger loop piping leads to the improved system performance of the single Brayton system described above. Note that all the NRPCT arrangements show the large gas loop piping around the shield. Other arrangement options with spiral piping runs through the shielding have also been studied. Either approach appears feasible.

Figure 9. Parallel Loop Arrangement (NASA TB2.5 Arrangement for Liquid Metal Brayton Concept)

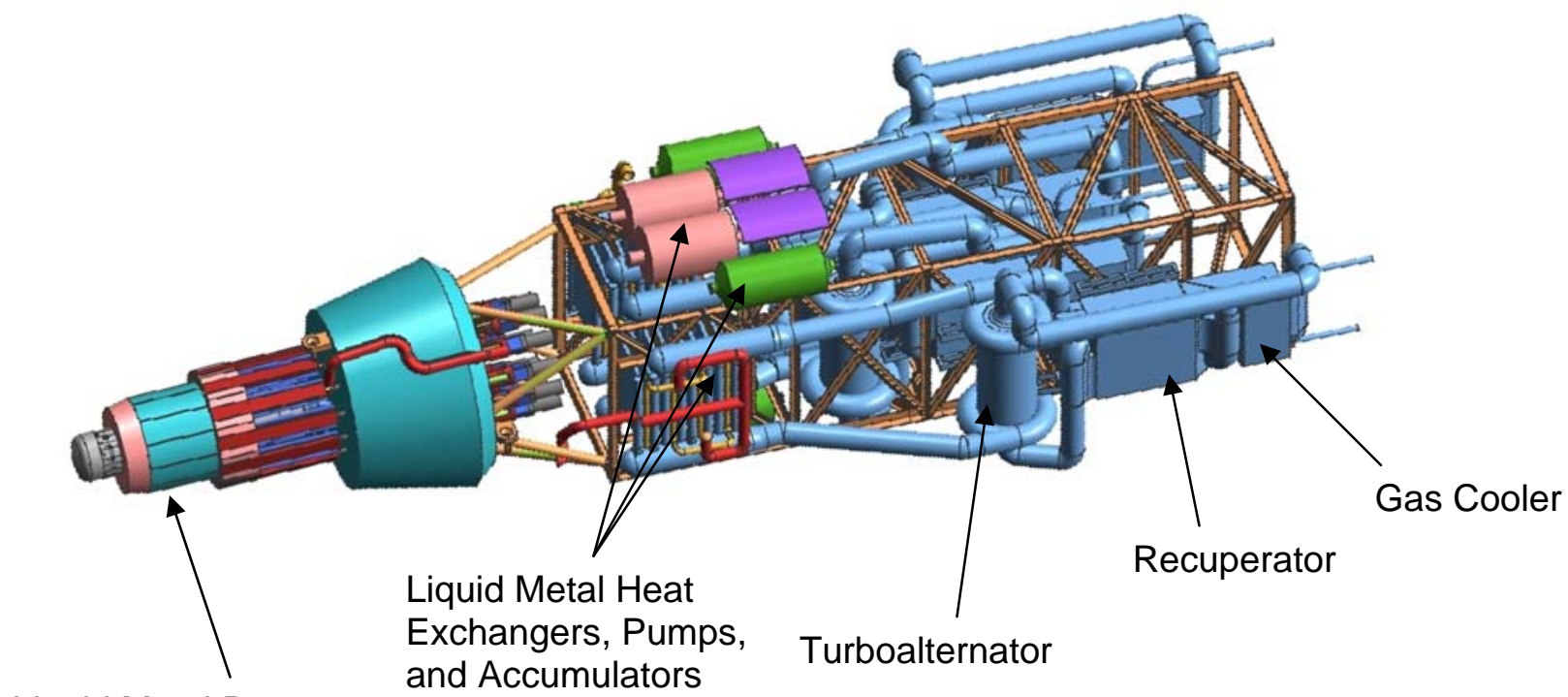

Liquid Metal Reactor

Figure 10. Gas Reactor Arrangement (Preliminary NRPCT Arrangement of 4 Units)

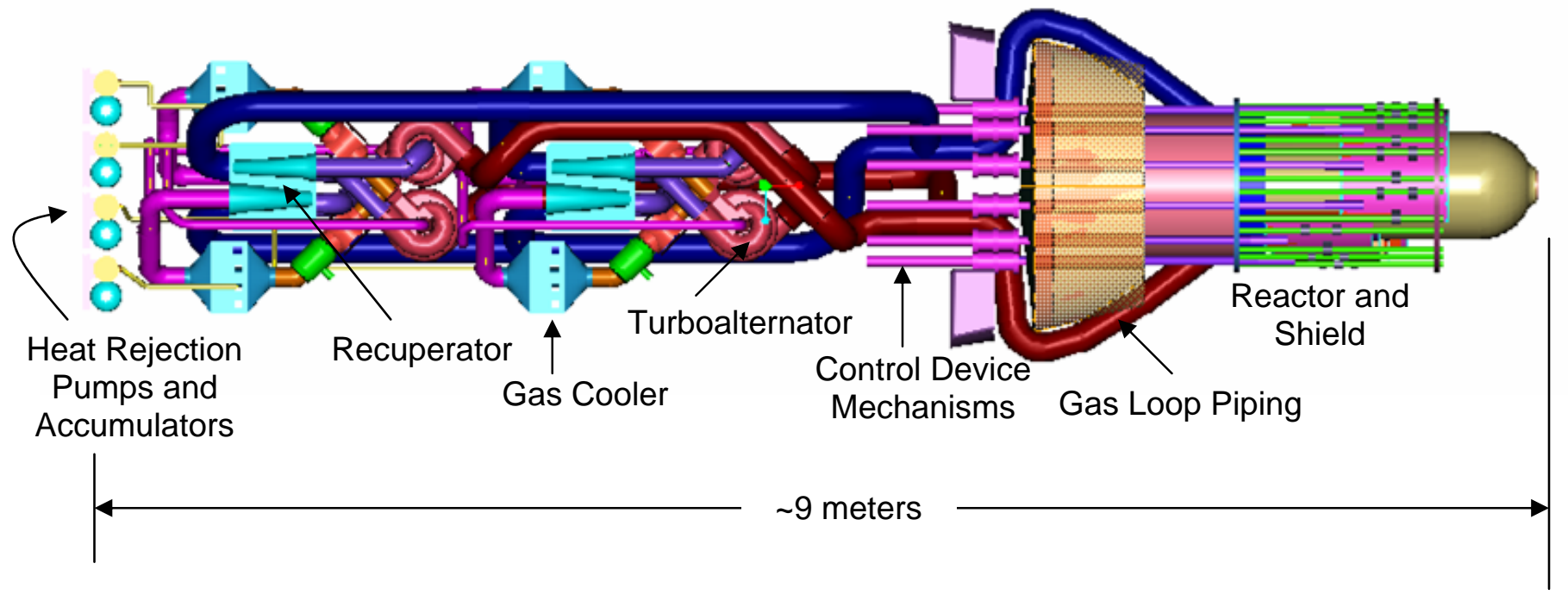


Figure 11: Single and Two Brayton Arrangements
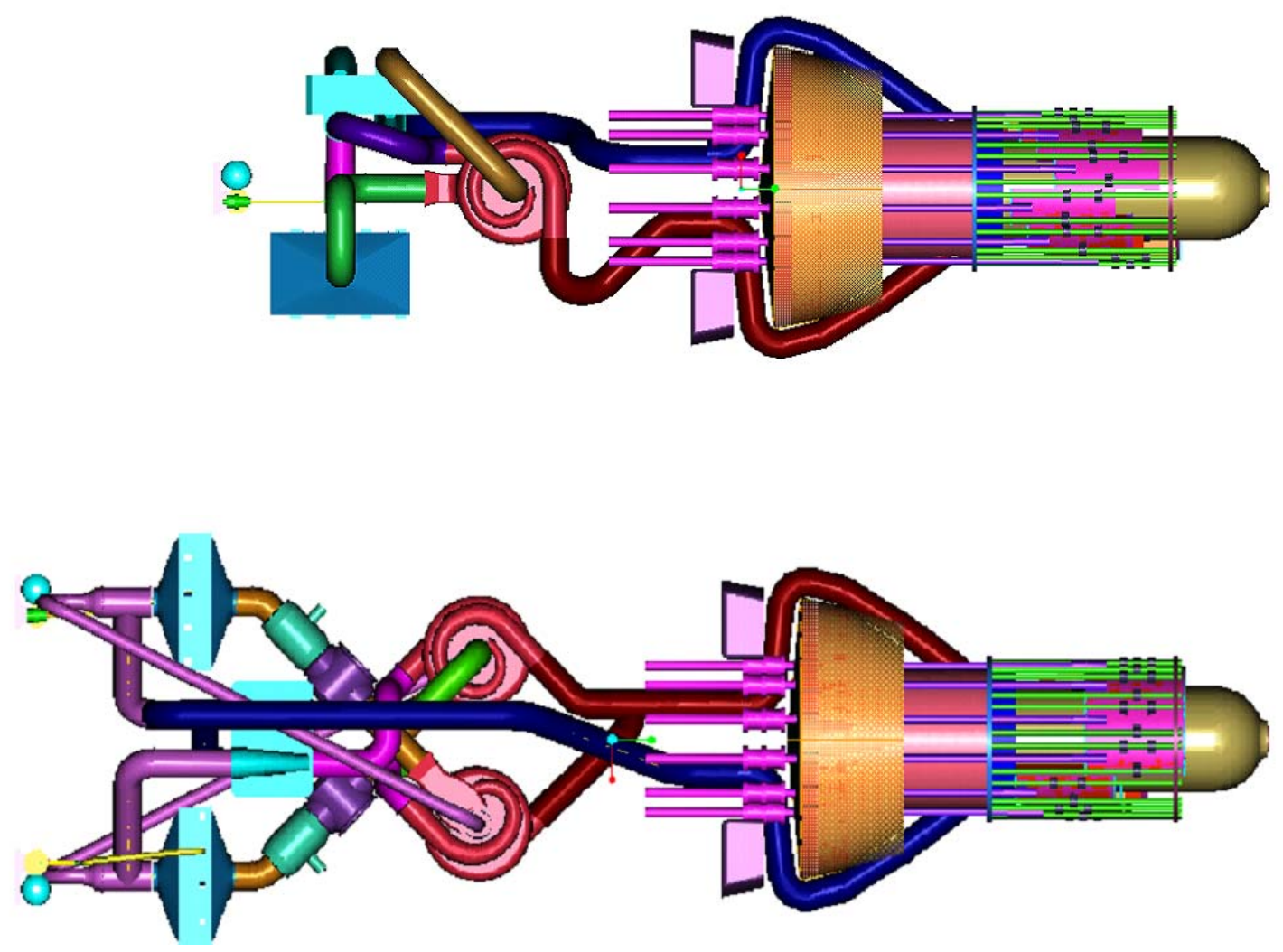

MASS COMPARISON

As stated above, preliminary estimates for the concepts with a single Brayton unit indicate the lowest overall system mass based on two factors:

1) The increase system performance associated with the larger Brayton power units, which leads to a lower mass reactor, shield and heat rejection system.

2) The elimination of the additional power conversion and loop piping mass associated with the in-line spare units and the associated valves.

Figure 12 compares the space nuclear power plant masses, including the PCAD and heat rejection system masses, for several cases. The single Brayton case is the lightest option by over $1000 \mathrm{~kg}$ 's. The two $100 \mathrm{~kW}$ Brayton case is the next lightest option, but does not provide any system redundancy. If the two 200 kWeBrayton units are each run at part-load using speed control to maintain continuity of power and system redundancy, the reactor and radiator must be sized for this less efficient condition.. This increases system mass slightly..

Note that the overall masses have considerable uncertainty. The range of reactor and shield cases, with variations of core arrangement, core materials, and shielding materials, has a range of $\sim 1000 \mathrm{~kg}$ difference from the lightest to the heaviest cases.

This mass difference between the single and multiple Brayton systems can be spent to reduce the operating temperature of the primary plant, which in turn reduces creep concerns in the fuel elements, the core structural components, the reactor vessel, the loop piping and the turbine wheel. Reducing the temperature of the plant by $100 \mathrm{~K}$ would increase the material creep capability, in terms of applied stress, by about a factor of 2 . Chemical compatibility would also be improved at this lower temperature. Evaluation of the acceptability of lower operating conditions on core material embrittlement would be required for consideration of this reduced temperature case. 
Figure 12. Comparison of space nuclear power plant system masses as a function of the number of Brayton loops and as a function of reactor type for the single Brayton case. The two $100 \mathrm{kWe}$ Case requires a higher reactor power, as noted, to accommodate the reduced system efficiency relative to a single 200 kWe Brayton. The four Brayton case requires smaller loop piping to arrange the additional equipment and, as a result, has greater loop flow resistance and larger power requirements. The two Braytons with speed control case uses two 200 kWe capable Brayton loops at half capacity. This results in a low system efficiency and a larger mass. Note that in each case, there are a range of reactor and shield options that could be considered. For the single case, the total system mass will range from less than 7000 kg's to over 8000 kg's for this range of reactor and shield designs. Note that the masses are for comparison only. System and operating parameters were not optimized.

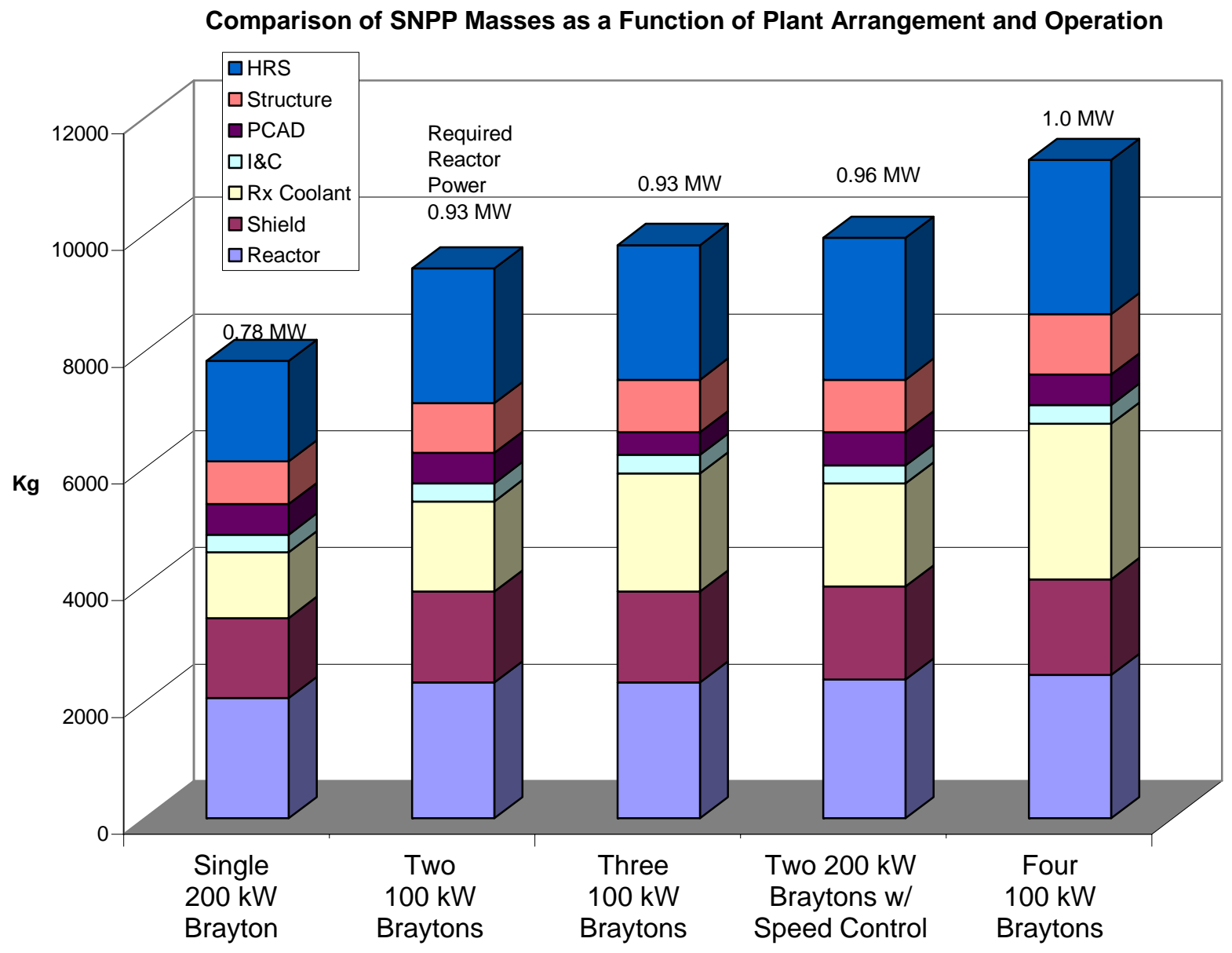




\section{RELIABILITY ASSESSMENT}

There is considerable uncertainty in projecting reliability for any component in the gas Brayton system, due to the fact that there is little relevant lifetime data. NRPCT used a combination of existing Brayton component data (e.g. from aircraft auxiliary power units), discussions with component experts, and judgment to estimate representative component reliabilities. Table 1 provides an overview of the components evaluated in the reliability assessment, along with the approach used. In order to compare reliability between the various Brayton arrangements, the values were appropriately weighted. Leakage related failures were related to the amount of piping surface area, number of welds, and penetration circumference. Brayton unit reliability data based on Garrett (now Honeywell) data are shown in Table 2. These data, from aircraft air cycle machines and auxiliary power units, suggest that individual Brayton turbine and compressor would be expected to have a reliability of about $99 \%$ for a 10 year mission. Hamilton Sundstrand performed a similar reliability review and concluded that the relatively benign (low cycle) operation of the Brayton units would have a reliability on the order of $97 \%$ (Reference 7 ).

Figures 13 and 14 compare the system reliability for cases with one, two, three, and four Brayton units with these assumed component reliabilities. The absolute values are less important than the trend of reliability with component number. The concern is that, while having spare Brayton units does increase the reliability associated with Braytons themselves, the additional complexity of the overall system to allow for this redundancy may reduce overall system reliability. The lack of ability to isolate one loop from another limits the benefit of component redundancy. Therefore, any failure of a pressure boundary is a mission ending event. Creating more Brayton loops creates more pressure boundary and therefore creates greater likelihood of failing that pressure boundary. For the overall system reliability to rise by adding Brayton components, the failure probability of the pressure boundaries themselves need to be orders of magnitude less than that of the Brayton units. The reliability comparison between a single Brayton system and systems with two, three, and four installed Braytons (Figure 14) shows that there is little potential reliability benefit for adding spare Braytons, given the uncertainties in the component reliabilities. The increased number of welds in the multi-Brayton system, to accommodate additional turbines, heat exchangers, valves, and pipe tees has the biggest impact on predicted pressure boundary reliability. Based on sensitivity studies with the component reliabilities, this trend of little benefit in system reliability for an increased number of Brayton loops holds true over a relatively wide range of assumed component reliabilities. Increased system reliability in a multi-Brayton system could only be clearly demonstrated for the two Brayton system when the Brayton turbine and compressor were assumed to have a combined reliability less than 0.97 and the combined pressure boundaries failure rate was very low.

Another potential concern for the overall system reliability is that failure of a Brayton unit could lead to a pressure boundary failure or contamination of the loop which leads to subsequent failures. If the Brayton failure results in a rupture of the pressure boundary, it would not matter whether there are spare Brayton units. Similarly, if a Brayton failure leads to introduction of debris in the loop which then affects adjacent Braytons, than redundant systems are of less value. GRC preformed a brief study of these failure scenarios and found that such failure propagation appears unlikely (Reference 8). That is, limited data shows that debris from a failed bearing stayed within the bearing cavity and was not released to the loop.

Age related failures could change the view of whether multiple Braytons could provide reliability enhancement. Given that there are age related failures due to operation of the Brayton systems, such as creep failures, wear failures, or accumulation of corrosion products in filters, having unused spare Brayton loops could be required to achieve mission lifetime. Such age related failures would have to result in degradation of the internal components without degradation of the system pressure boundaries that could lead to system failure before or after operation is transferred to the spare loops. Figure 15 depicts the classic "bathtub curve" of reliability, which suggests a likelihood of early "juvenile" failures, a low number of random midlife failures, and an increasing failure rate at end of life. The results in Figure 14 do not include the effect of aging on component reliability. With a set of spare units, life can be roughly doubled. However, forcing operation at more aggressive conditions to enable meeting mass goals with redundant components could shorten lifetime, even with in-line spare intended for life extension. Also, providing additional lifetime to the Brayton units without providing similar lifetime enhancement to the reactor, the electronics and the heat rejection loop may not be beneficial from a system reliability standpoint.

Ultimately, the reliability evaluation will need to not only account for the system architecture and the steady age related degradation, but also the accumulated impact of the plant operational transients. A more complete view of designing for enhanced reliability would take into account all the likely or foreseeable operational transients 
and casualties and their impact on the reliability of the plant components, and how to configure the plant to maximize reliability in light of those transients.

Table 1. Assumed Component Reliabilities and Scaling Sensitivities

\begin{tabular}{|c|c|c|c|}
\hline System Component & Reliability Approach & Failure Mode & $\begin{array}{c}\text { Estimated } \\
\text { Reliability per } \\
\text { unit }\end{array}$ \\
\hline $\begin{array}{l}\text { Piping Area } \\
\text { per loop }\end{array}$ & $\begin{array}{l}\text { Reliability scaled to piping length and cross-section. } \\
\text { Failures related to defects, fatigue or micrometeroid } \\
\text { strikes. }\end{array}$ & Leak to space & .9996 per loop \\
\hline $\begin{array}{l}\text { Recuperator External } \\
\text { Area }\end{array}$ & $\begin{array}{l}\text { Reliability scaled to external area. Failures related to } \\
\text { weld or braze defects, fatigue or micrometeroid strikes. }\end{array}$ & Leak to space & $\begin{array}{l}.9999 \text { per HX } \\
(.9998-200 \mathrm{~kW} \mathrm{HX})\end{array}$ \\
\hline $\begin{array}{l}\text { Recuperator Internal } \\
\text { Area }\end{array}$ & $\begin{array}{l}\text { Reliability scaled to internal area. Failures would need } \\
\text { to be sufficiently large to impact heat transfer. }\end{array}$ & $\begin{array}{l}\text { Internal leak } \\
\text { (fails) }\end{array}$ & $\begin{array}{l}.9963 \text { per HX } \\
(.9953-200 \mathrm{~kW} \mathrm{HX})\end{array}$ \\
\hline Cooler Area & $\begin{array}{l}\text { Cooler has substantial internal area. Failure estimate } \\
\text { derived from initial vendor development. Failure could } \\
\text { be caused by defects, corrosion, overpressure or } \\
\text { mircometeroid. }\end{array}$ & Leak to space & $\begin{array}{l}.9813 \text { for all } \\
\text { Coolers }\end{array}$ \\
\hline $\begin{array}{l}\text { Similar Material } \\
\text { Welds }\end{array}$ & $\begin{array}{l}\text { Weld failure rate based on expected high temperature } \\
\text { material weld challenge. } 2 \text { pipe welds assumed for } \\
\text { each component, including valves, and for tees. }\end{array}$ & Leak to space & .9996 per weld \\
\hline $\begin{array}{l}\text { Dissimilar Material } \\
\text { Welds }\end{array}$ & $\begin{array}{l}\text { Dissimilar material welds assumed for a transition from } \\
\text { superalloy to titanium pressure boundary at cooler. } \\
\text { Dissimilar welds assumed to be less reliable than } \\
\text { normal welds due to potential brittle phases. }\end{array}$ & $\begin{array}{l}\text { Crack/Leak to } \\
\text { space }\end{array}$ & .9990 per weld \\
\hline TCA Housing & Based on area and complexity of housing geometry. & Leak to space & .996 \\
\hline $\begin{array}{l}\text { Turbine \& } \\
\text { Compressor }\end{array}$ & $\begin{array}{l}\text { Research: Garrett data reflects } 0.97 \text { and Hamilton \& } \\
\text { Sundstrand's research reflects } 0.99 \text {. }\end{array}$ & $\begin{array}{l}\text { Leak to space, } \\
\text { Mechanical } \\
\text { failure }\end{array}$ & $\begin{array}{l}.95 \text { - Low estimate } \\
.97 \text { - HS estimate } \\
.99-\text { Garrett }\end{array}$ \\
\hline Rotor \& Shaft & $\begin{array}{l}\text { Mechanical failures during start-up or as a result of } \\
\text { overheating/overstressing. }\end{array}$ & $\begin{array}{l}\text { Mechanical } \\
\text { failure }\end{array}$ & .998 and .999 \\
\hline Bearing & $\begin{array}{l}\text { Educated Decision based on consultation with bearing } \\
\text { experts. Most well designed bearings fail as a result of } \\
\text { other component performance degradation. }\end{array}$ & Seize & .997 \\
\hline $\begin{array}{l}\text { Alternator Winding } \\
\text { (electrical buss) }\end{array}$ & $\begin{array}{l}\text { Estimate based on research on high temperature } \\
\text { windings. }\end{array}$ & $\begin{array}{l}\text { Loss of } \\
\text { load/Cable } \\
\text { short }\end{array}$ & .994 \\
\hline $\begin{array}{l}\text { Electrical } \\
\text { Penetration }\end{array}$ & $\begin{array}{l}\text { Based on estimated Brayton conductor size. Scaled to } \\
\text { penetration wire circumference. Failure due to fatigue, } \\
\text { material degradation, or overheating. }\end{array}$ & Leak to space & $\begin{array}{l}.997 \text { for } 100 \mathrm{~kW} \\
.994 \text { for } 200 \mathrm{~kW}\end{array}$ \\
\hline Isolation Valves & $\begin{array}{l}\text { Educated Decision, Sticking in place. Failures only } \\
\text { impact reliability if change in operating Brayton } \\
\text { needed. }\end{array}$ & $\begin{array}{l}\text { Sticking, } \\
\text { electrical failure }\end{array}$ & .98 \\
\hline Check Valves & Educated Decision. Stuck open or closed. & Sticking & .99 \\
\hline Heat Rejection Loop & $\begin{array}{l}\text { Long loop piping with many welds and flexible } \\
\text { connections. Requires deployment. Failure modes } \\
\text { include fatigue, overpressure, defects, corrosion, and } \\
\text { micrometeriods. }\end{array}$ & Leak & .97 \\
\hline Heat Rejection Pump & $\begin{array}{l}\text { Two heat rejection pumps per loop with check valves. } \\
\text { No in-space failure noted in literature associated with } \\
\text { pumped water systems. }\end{array}$ & Mechanical & .999 per loop \\
\hline
\end{tabular}

Note: No reactor, reactor vessel, or reactor control reliabilities were included because they have little effect on the number of Braytons decision. Instrumentation and Control reliability estimates were not made. 
Table 2. Garrett Data on Reliability (Reference 6)

\begin{tabular}{|l|c|c|}
\hline \multirow{2}{*}{ Component } & \multicolumn{2}{|c|}{ Failure Rate } \\
\cline { 2 - 3 } & (per hour) & (per year) \\
\hline Foil Bearings & $3 \times 10^{-8}$ & $3 \times 10^{-4}$ \\
\hline Turbine & $1 \times 10^{-8}$ & $1 \times 10^{-4}$ \\
\hline Compressor & $6 \times 10^{-8}$ & $6 \times 10^{-4}$ \\
\hline Alternator & $5 \times 10^{-8}$ & $5 \times 10^{-4}$ \\
\hline Recuperator & $3 \times 10^{-8}$ & $3 \times 10^{-4}$ \\
\hline Bleed Cooler & $9 \times 10^{-8}$ & $9 \times 10^{-4}$ \\
\hline Bellow / Ducts & $1 \times 10^{-8}$ & $1 \times 10^{-4}$ \\
\hline
\end{tabular}

Figure 13: Brayton Component Block Diagram

Brayton
"System"

\section{Single \\ Brayton System}

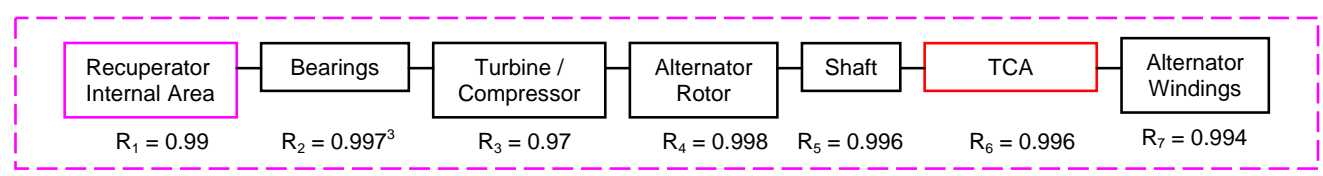

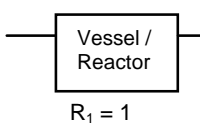
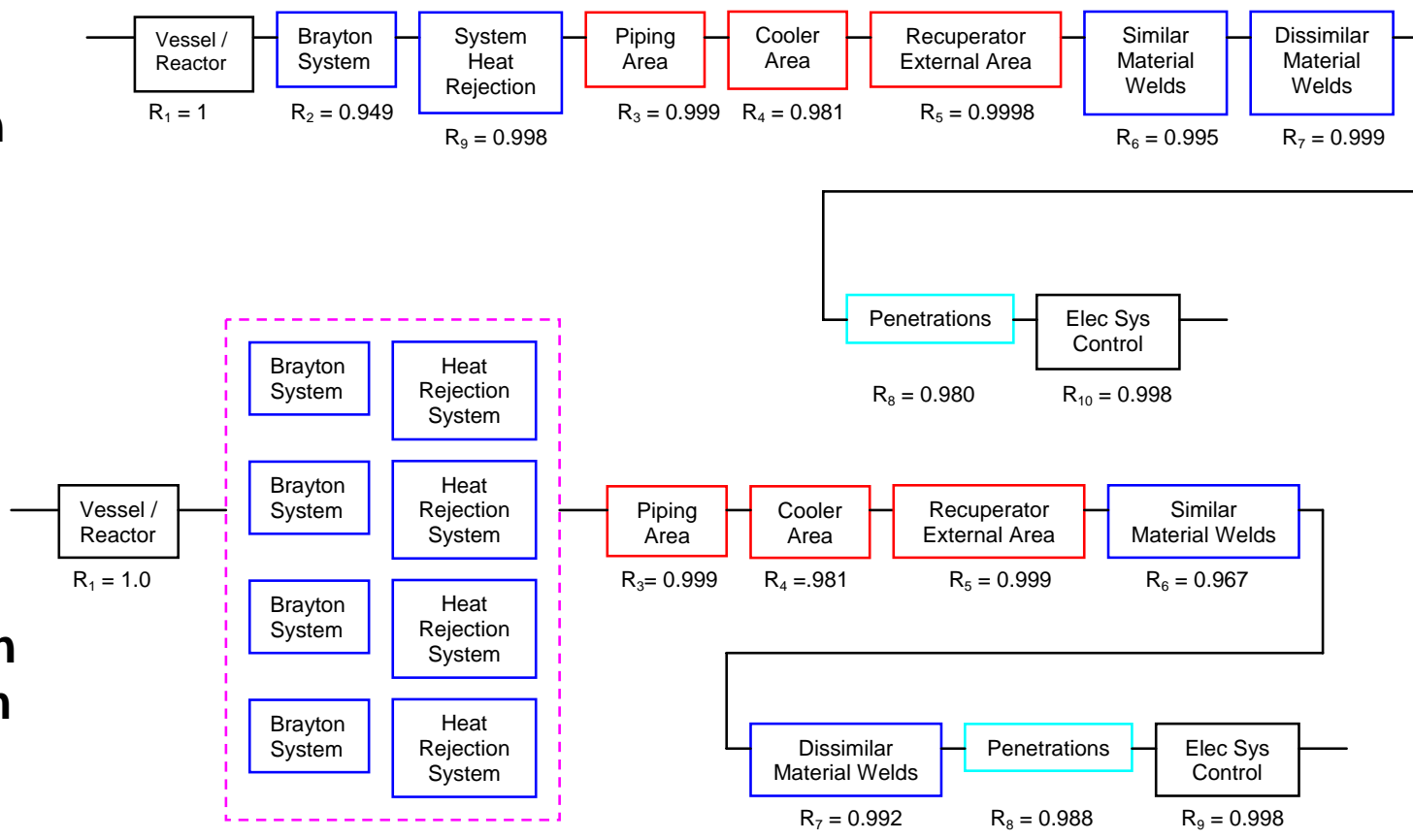
Figure 14. Comparison of System Reliability versus Number of Braytons. The figure shows four cases: A single Brayton system, a two 200 kWe Brayton system, and cases with 100 kWe Braytons with 1 or 2 spares. For each case, the turbine and compressor reliability were varied from 0.95 , to 0.97 (the Hamilton Sundstrand estimate) to 0.99 (corresponding to the Garrett Data). The results show that if the Brayton component reliability is in the range predicted by the vendors, there is little benefit to spare Braytons. Use of 3 or 4 total Brayton loops results in lower system reliability than the single Brayton case.

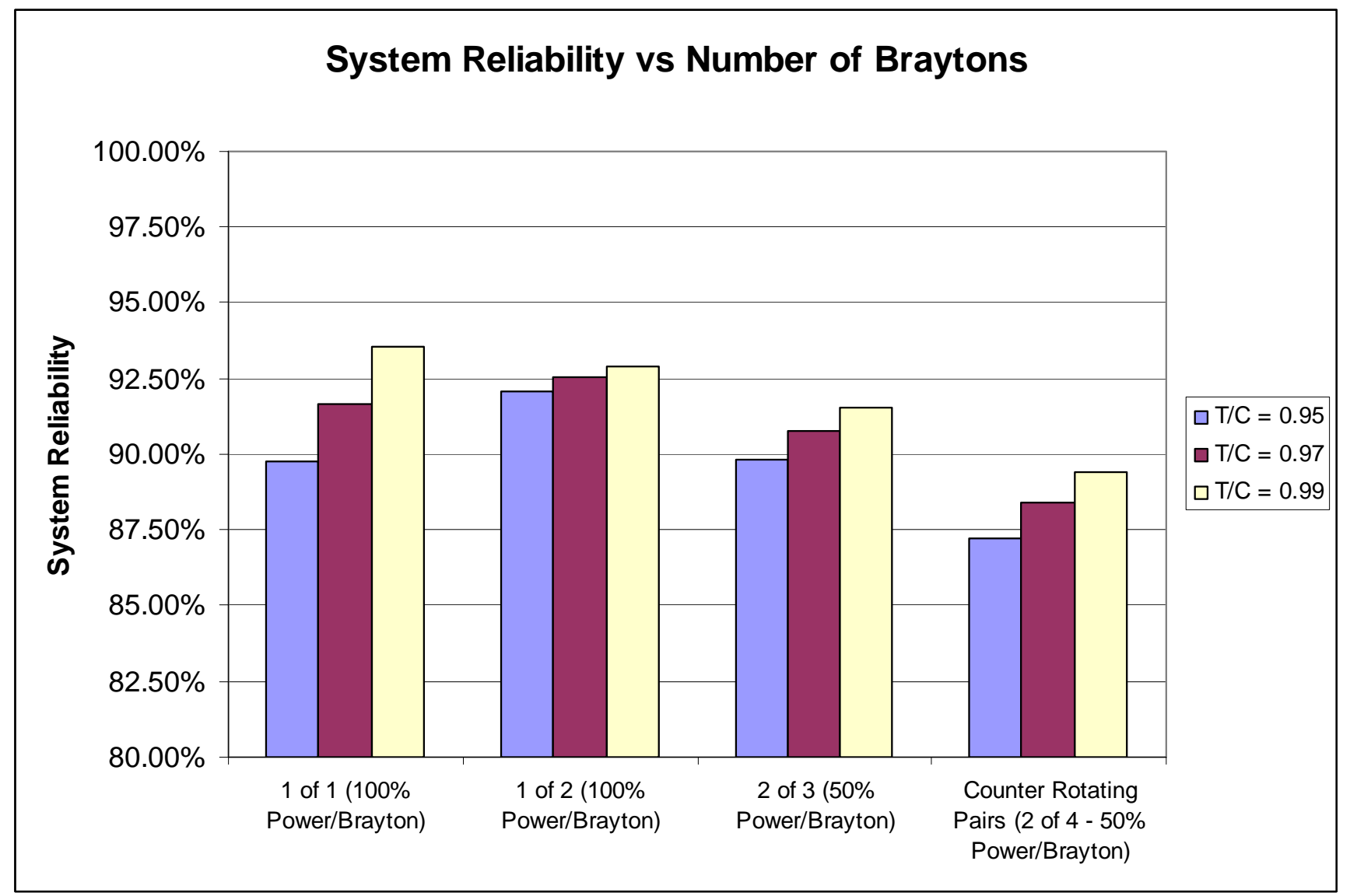

Figure 15. Depiction of Life Enhancement Benefits of Spare Units

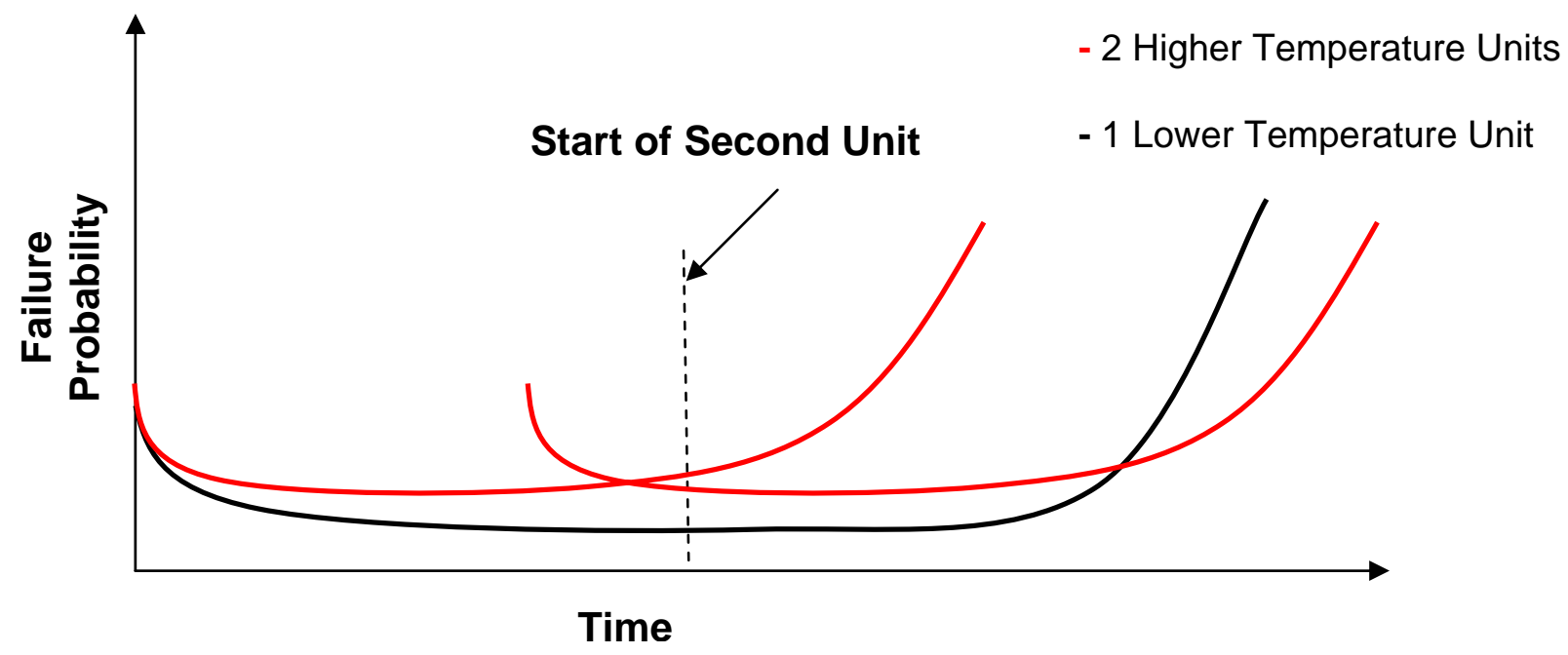




\section{MISSION FLEXIBILITY}

While the focus of the NRPCT work was associated with NEP missions, recent focus in space reactor development for Prometheus has shifted to surface missions. This surface power reactor would include nearby human habitation. Differences between a nuclear electric propulsion mission and a surface mission include:

1) Availability of alternate power supplies on surface missions reduces need for continuity of reactor power.

2) Need for momentum compensation.

3) Shield mass would increase dramatically to provide full circumferential shielding for surface missions. Thus, mass of energy conversion and heat rejection system components would be less significant. Use of indigenous shielding would reduce launched shield mass but add to the deployment complexity.

4) Reactor lifetime may not need to be $>10$ years for surface missions. Therefore, adding redundancy for increased lifetime would be less desirable.

5) Additional reactor systems may be used as the surface base grows, providing increased redundancy without additional hardware in each loop. Providing redundancy through a complete additional system accounts for faults in not only the Brayton system but the reactor system as well.

Based on these differences and others, conclusions regarding redundancy and system architecture need to be made separately for a NEP mission and a surface mission.

\section{CONCLUSIONS}

The NRPCT did not reach a conclusion regarding the reference plant architecture and arrangement for an NEP direct gas reactor mission prior to project closeout. However, the design development and analysis performed can form the basis of future decisions. Conclusions from the analysis indicate:

1) Brayton system components can be developed to provide $200 \mathrm{kWe}$ or more using existing design approaches. Use of multiple turbines will necessitate the use of check valves and/or control valves which appear feasible, but are also developmental.

2) Use of a single Brayton turbine to produce the whole electrical load results in the best system efficiency and therefore has the lowest reactor power, lowest system mass, and simplest plant arrangement. The improvement in performance in a single Brayton system can be "spent" on mass savings, reducing plant operating temperature or other parameters to improve component reliability.

3) Reactor plant start-up, and part-load operation can be accommodated with either single or multiple operating Braytons. No inherent instability associates with using multiple Braytons in a direct gas system has been found in preliminary reactor plant transient evaluations.

4) Reliability of the Brayton system includes the turbomachinery as well as the rest of the gas loop. Use of installed spares will increase system resiliency in the event of a turbine failure, but will also create additional failure modes which need to addressed in the design process. Preliminary reliability analysis suggests that there is no realizable reliability benefit to adding spare Brayton loops.

\section{REFERENCES}

1) NRPCT Document "Space Nuclear Power Plant Concept Selection, For NR Approval" Originally dated March 4, 2005. Stored in OSTI Database.

2) "Capstone C200 Beta Testing Program: Initial Results", presented at the $5^{\text {th }}$ MTG Applications Workshop, Ottawa, Canada, 25-27, 2005

3) AFRL-PR-WP-TR-2005-2018, "Integrated Power Unit (IPU) - Advanced Development Industry Version", dated $12 / 2004$

4) Howard, S., DellaCorte, C., "Gas Foil Bearings for Space Propulsion Nuclear Electric Power Generation" (NASA/TM-2006-214115)

5) Halsey, DG, Dowling, RS, Nguyen, DC, Barrett, MJ, "Closed Brayton Cycle Engine Starter/Generator Cooling", AIAA 2005, IECEC

6) Allied Signal, Garrett Fluid Systems Division, "Space Power 1991 and Beyond" p.49, 1991

7) NRPCT Document "Alternator Test Unit (ATU) Conceptual Design Meeting", April 28, 2005. Stored in OSTI Database.

8) Mason, Lee and Barrett, Michael. "Preliminary Comments on Potential Brayton Turboalternator Failure Modes." Feb. 14, 2005 
Enclosure 5 to

SPP-SEC-0039

\title{
Pressure Vessel and Reflector Temperature Sensitivity Studies of a Notional Gas-Cooled Space Reactor
}

\author{
Volk, D.R. and Robb, K.
}


This page is intentionally blank.

PRE-DECISIONAL - For planning and discussion purposes only 


\section{Pressure Vessel and Reflector Temperature Sensitivity Studies of a Notional Gas-Cooled Space Reactor}

David R. Volk and Kevin Robb

Space Reactors - Bechtel

STAIF 2006

February 2006 


\section{Background}

- Component temperatures affect several aspects of the design phase.

- Temperatures must be taken into account for material selection to ensure that thermal degradation of properties does not affect functionality.

- Temperatures play a large role in creep and stress determinations.

- Also, temperature induced deformations are of interest to the nuclear design with respect to reactivity coefficients.

- Finally, active cooling may or may not be necessary to lower component temperatures and thermal analyses can provide insight into what the most effective means are to accomplish this. 


\section{Model}

- Temperature values are derived from a 3-D FEA model in ANSYS

- ANSYS Radiation Matrix Method used

- Model creation and initial sensitivity studies were performed by Kevin Robb (2005 summer intern)

- The model is a $1 / 12^{\text {th }}$ ( $30^{0}$ "pie slice") representation of the pressure vessel and reflector assembly 


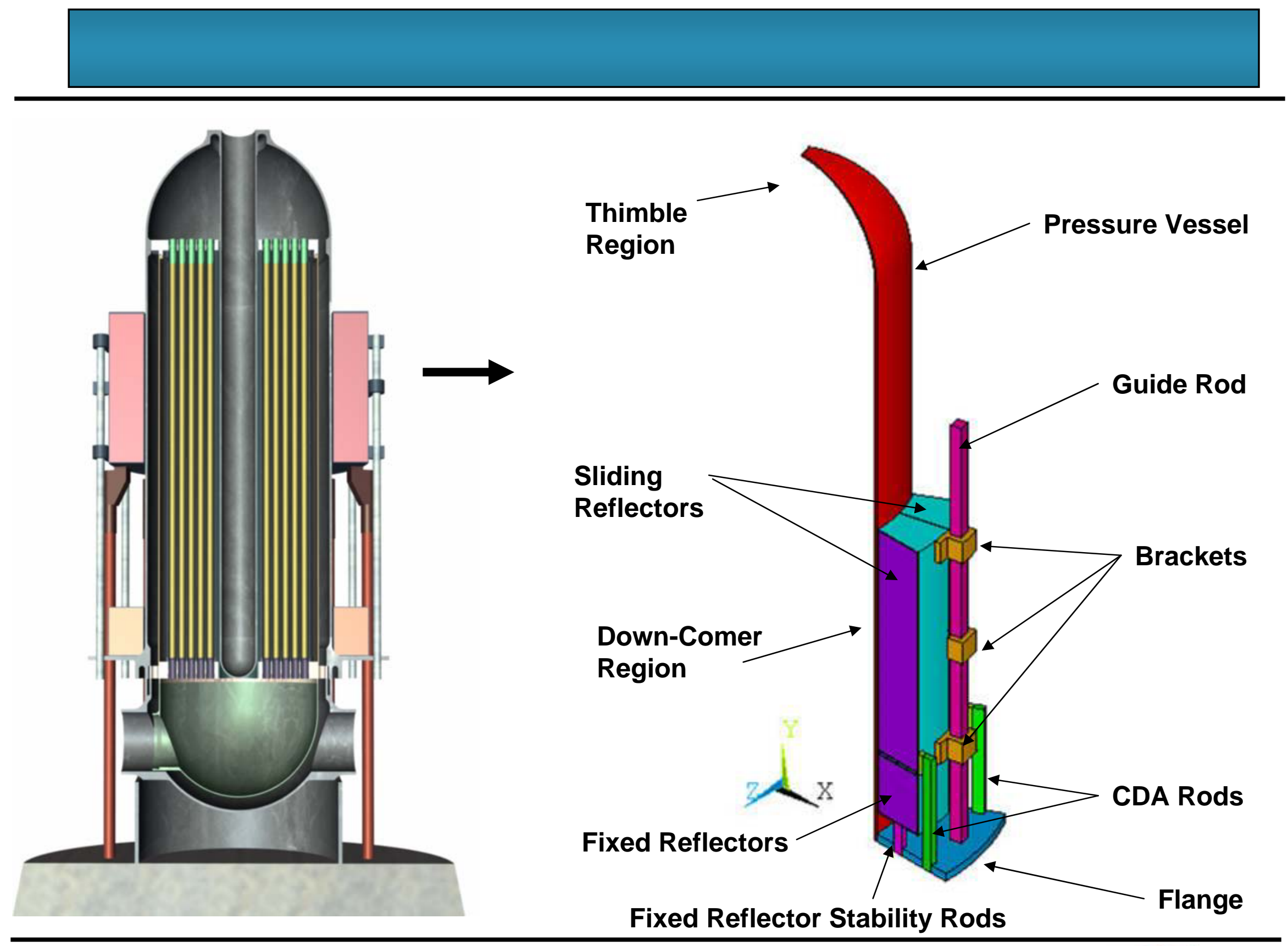

STAIF, February 2006 


\section{Model cont'd.}

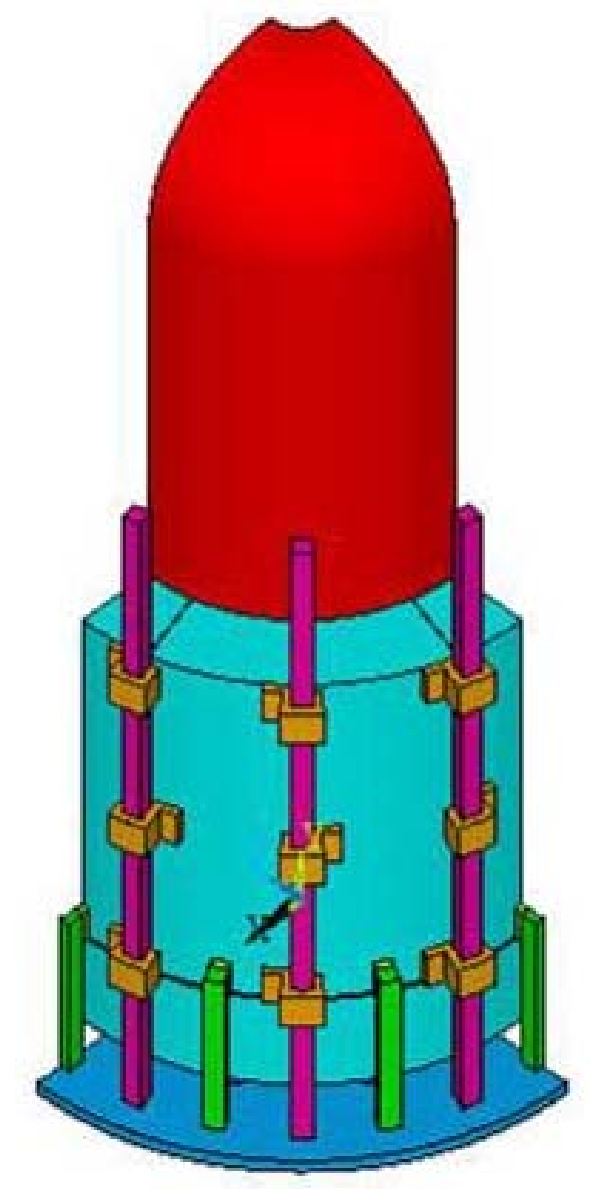

\section{Materials}

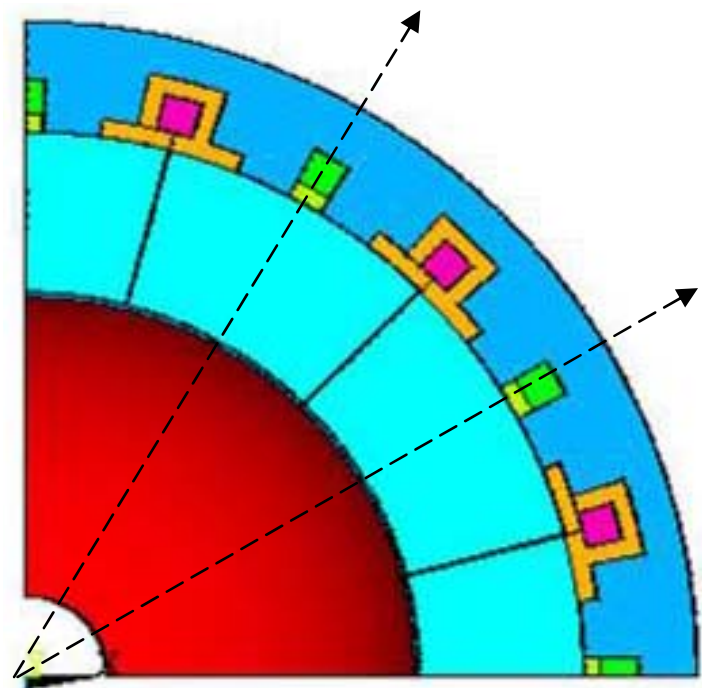

Hastelloy X - Pressure Vessel

Hastelloy X - Guide and Stability Rods

Hastelloy X - CDA Rods

Hastelloy X - Flange

BeO - Reflectors

Be - Reflector Cladding

Be - Attachment Brackets 


\section{Model cont'd.}

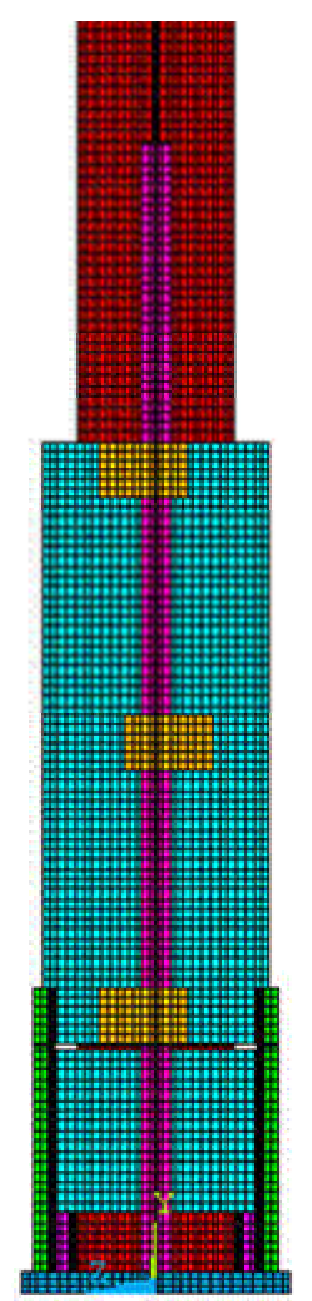

.57213 elements .273440 nodes 


\section{Baseline Loading}

- The thermal model contains convection, volumetric heat generation, and radiant heat transfer loadings. The following sections describe the baseline thermal loadings used in the analyses.

- Preload

- The initial temperature for all the components was set at 300 Kelvin. This temperature is used as the initial starting temperature for the steady state calculations.

- Convection Loading

- A convection load was applied to the down-comer region (inner surface) of the pressure vessel wall. The film coefficient is modeled as $400 \mathrm{~W} / \mathrm{m} 2 \mathrm{~K}$ and the bulk temperature is modeled as $890 \mathrm{~K}$.

- Volumetric Heat Generation Rate Loading

- Throughout the model, heat generation (energy deposition) is caused by the attenuation of neutrons and photons (gamma rays). Determining energy deposition in complicated geometry with varying materials requires specialized programs. 


\section{Baseline Loading cont'd.}

- Currently, there are no physics calculations that establish the heat generation rates for all the components of this preconceptual design. Therefore, energy deposition estimates are based, in part, on a Monte Carlo analysis of heating rates for the pressure vessel and reflector (similar rates were found in the SNAP-50 program information). Table 1 lists the baseline heat generation rates that were modeled. Rates for components other than the pressure vessel and reflectors are estimated based on distance from the model centerline and material. 


\section{Baseline Loading cont'd.}

- Table 1: Baseline Heat Generation Rates

\begin{tabular}{|l|c|r|r|r|}
\hline \multicolumn{4}{|c|}{ Heat Generation } \\
\hline Component & $\mathbf{W} /{\mathbf{~} \mathbf{m}^{\mathbf{3}}}^{\mathbf{4}} \mathbf{c m}^{\mathbf{3}}$ & $\mathbf{W} \mathbf{( 3 0}^{\mathbf{}} \mathbf{)}$ & $\mathbf{W} \mathbf{( 3 6 0}^{\mathbf{}} \mathbf{)}$ \\
\hline Pressure Vessel & 0.50 & 1144.2 & 572.1 & 6865.2 \\
\hline Flange & 0.20 & 699.0 & 139.8 & 1677.6 \\
\hline Fixed Reflector Stability Rods & 0.20 & 39.3 & 7.9 & 94.2 \\
\hline Sliding and Fixed Reflectors & 0.08 & 12625.0 & 1010.0 & 12120.0 \\
\hline Sliding and Fixed Reflector's Cladding & 0.08 & 1271.1 & 101.7 & 1220.3 \\
\hline Guide Rod & 0.04 & 696.7 & 27.9 & 334.4 \\
\hline Guide Rod Brackets & 0.04 & 304.2 & 12.2 & 146.0 \\
\hline CDA Rods and Brackets & 0.04 & 201.2 & 8.0 & 96.6 \\
\hline Total & - & 16980.7 & 1879.5 & 22554.3 \\
\hline
\end{tabular}




\section{Baseline Loading cont'd}

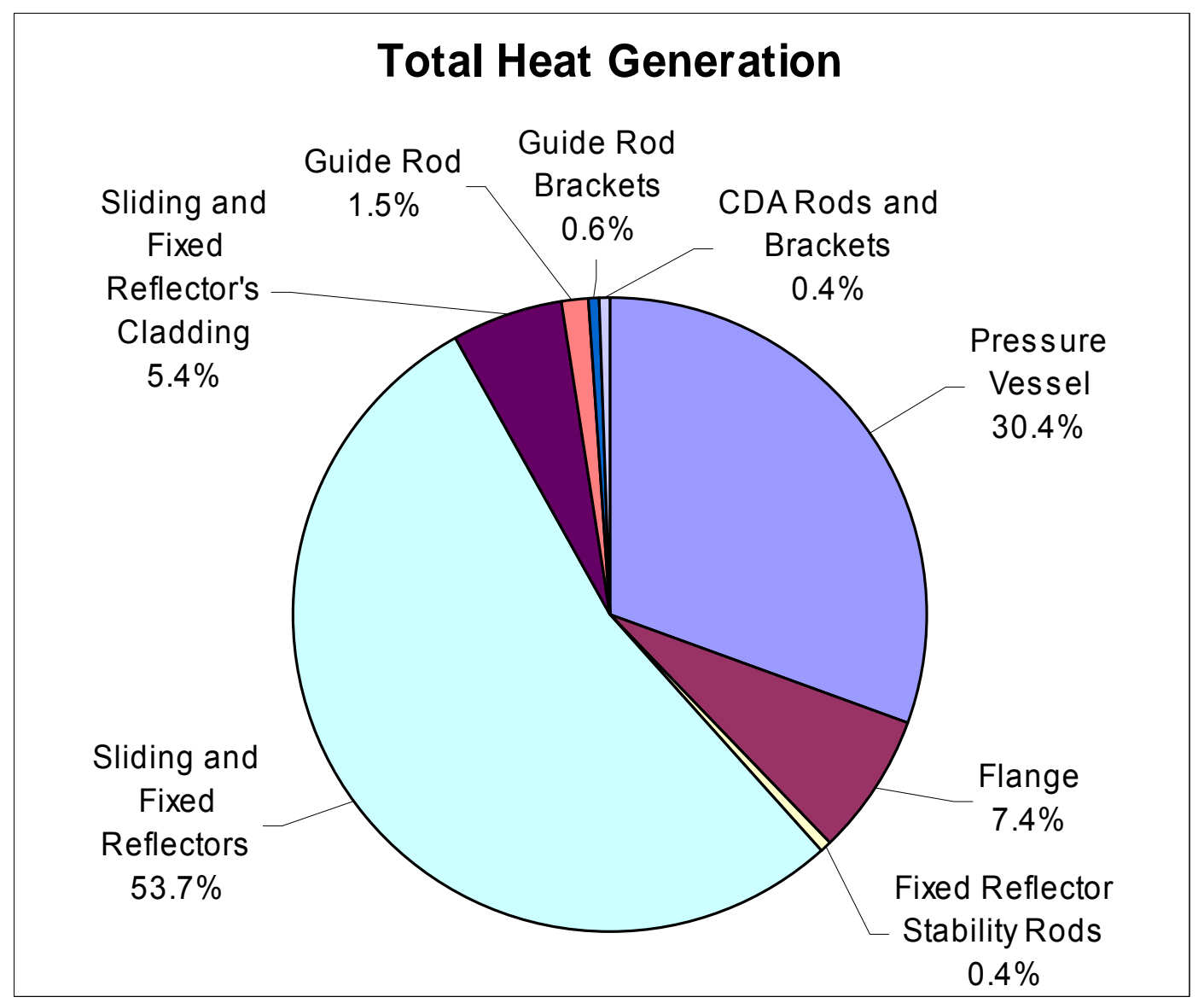




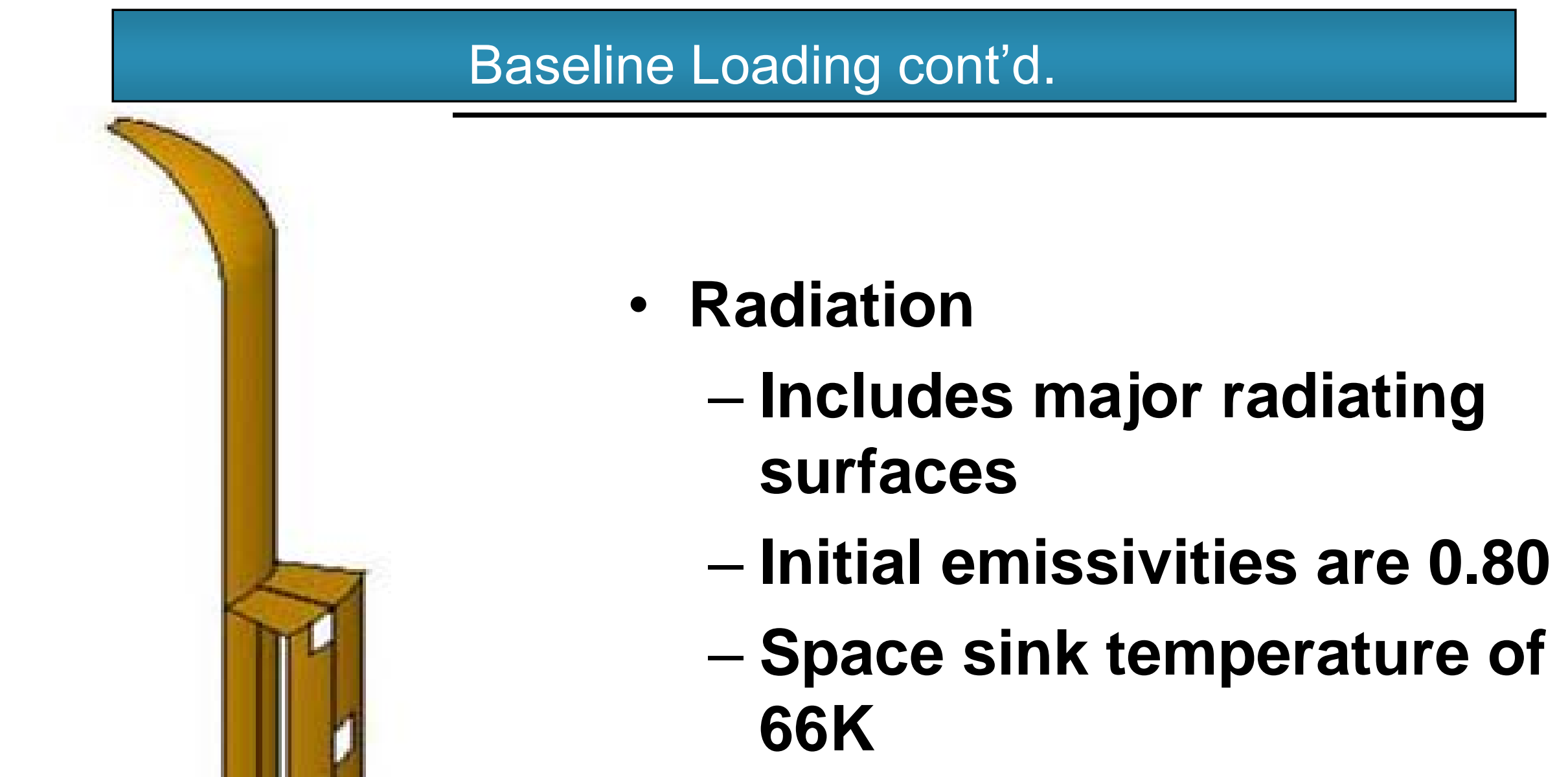

Major Radiating Surfaces 


\section{Assumptions}

- The following baseline loading assumptions were made:

- Heat generation is deposited evenly throughout a given component (no heat generation gradients within components).

- For radiating surfaces, ANSYS assumes gray diffuse surfaces (independent of wavelength and direction).

- "Cut" edges of the modeled "pie slice" are adiabatic.

- The pressure vessel and reflector structures have a cyclic symmetry every 30 degrees. There would be limited energy exchange in the hoop direction. There is currently no information on energy exchange through the top and bottom cuts of the pressure vessel. 


\section{Assumptions cont'd.}

- All components that touch one another are in full contact; no intervening thermal resistances are modeled.

- No heat flux was modeled for heat transfer from the reactor core.

All emissivities are modeled as 0.80 .

- Constant emissivities were modeled. Table 2 provides the modeled emissivities and the actual emissivities of the components (approximately). 


\section{Assumptions cont'd.}

The approximate component emissivities are evaluated at an average component temperature.

\section{Table 2 Component Emissivities}

\begin{tabular}{|l|c|c|}
\hline \multicolumn{3}{|c|}{ Component Emissivities } \\
\hline Component & $\begin{array}{c}\text { Modeled } \\
\text { Emissivity }\end{array}$ & $\begin{array}{c}\text { Approx. } \\
\text { Emissivity }\end{array}$ \\
\hline Pressure Vessel & 0.80 & 0.87 \\
Fixed and Sliding Reflectors & Non-Rad* & 0.20 \\
Fixed and Sliding Reflector's Cladding & 0.80 & $0.17-0.60^{* *}$ \\
Flange & 0.80 & 0.85 \\
Guide Rod & Non-Rad* & 0.86 \\
Guide Rod Brackets & Non-Rad* & 0.86 \\
CDA Rods and Brackets & Non-Rad* & 0.86 \\
Fixed Reflector Stability Rods & Non-Rad* & 0.86 \\
\hline
\end{tabular}

${ }^{*}$ Non-Rad components were modeled as non-radiating

** A range of emissivity values was found in the literature for Beryllium 


\section{Baseline Loading Results}

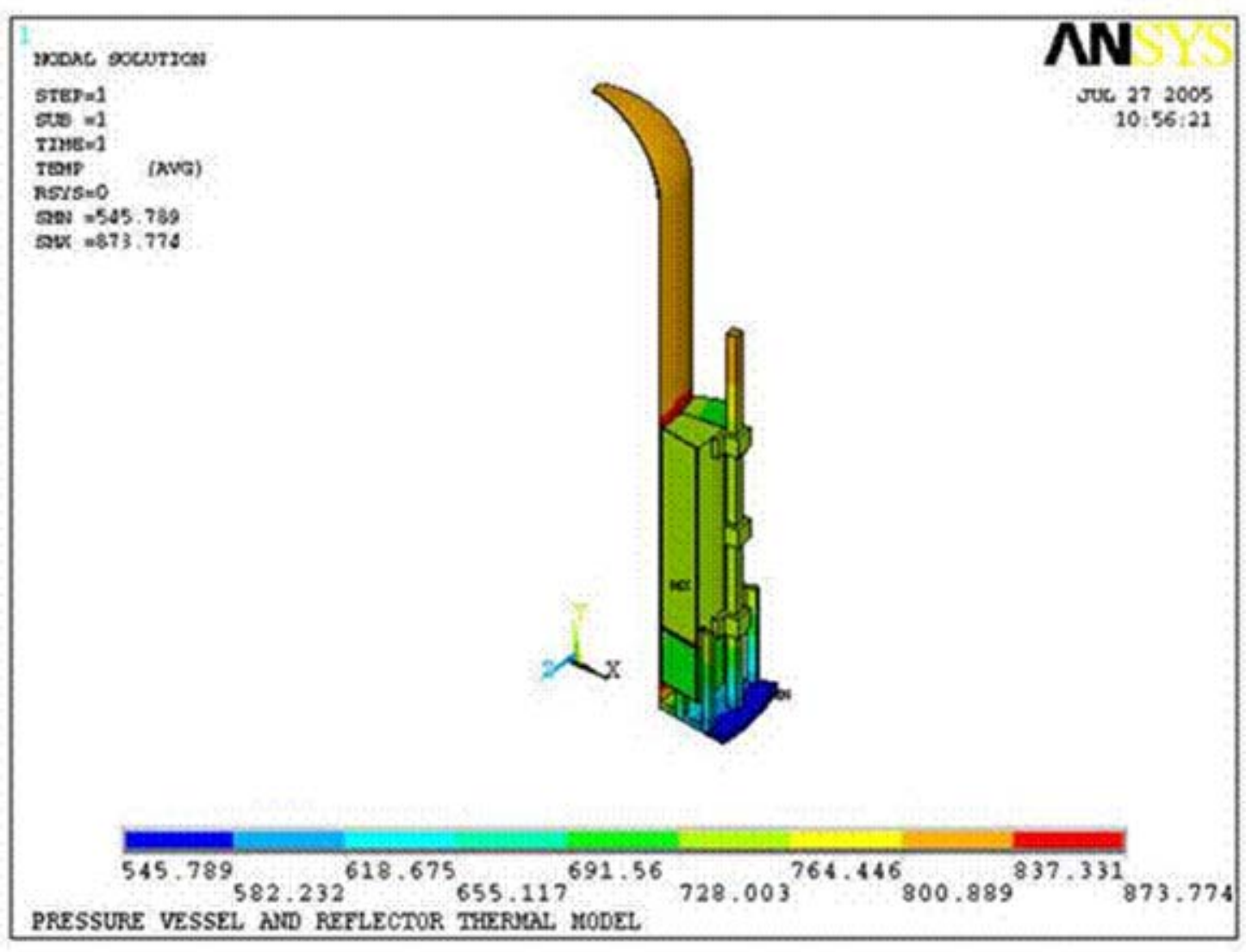




\section{Analyses}

- Initial Sensitivity analyses performed

- Peak Temperature vs. Heat Generation Rates (Reactor Power)

- Peak Temperature vs. Film Coefficient 


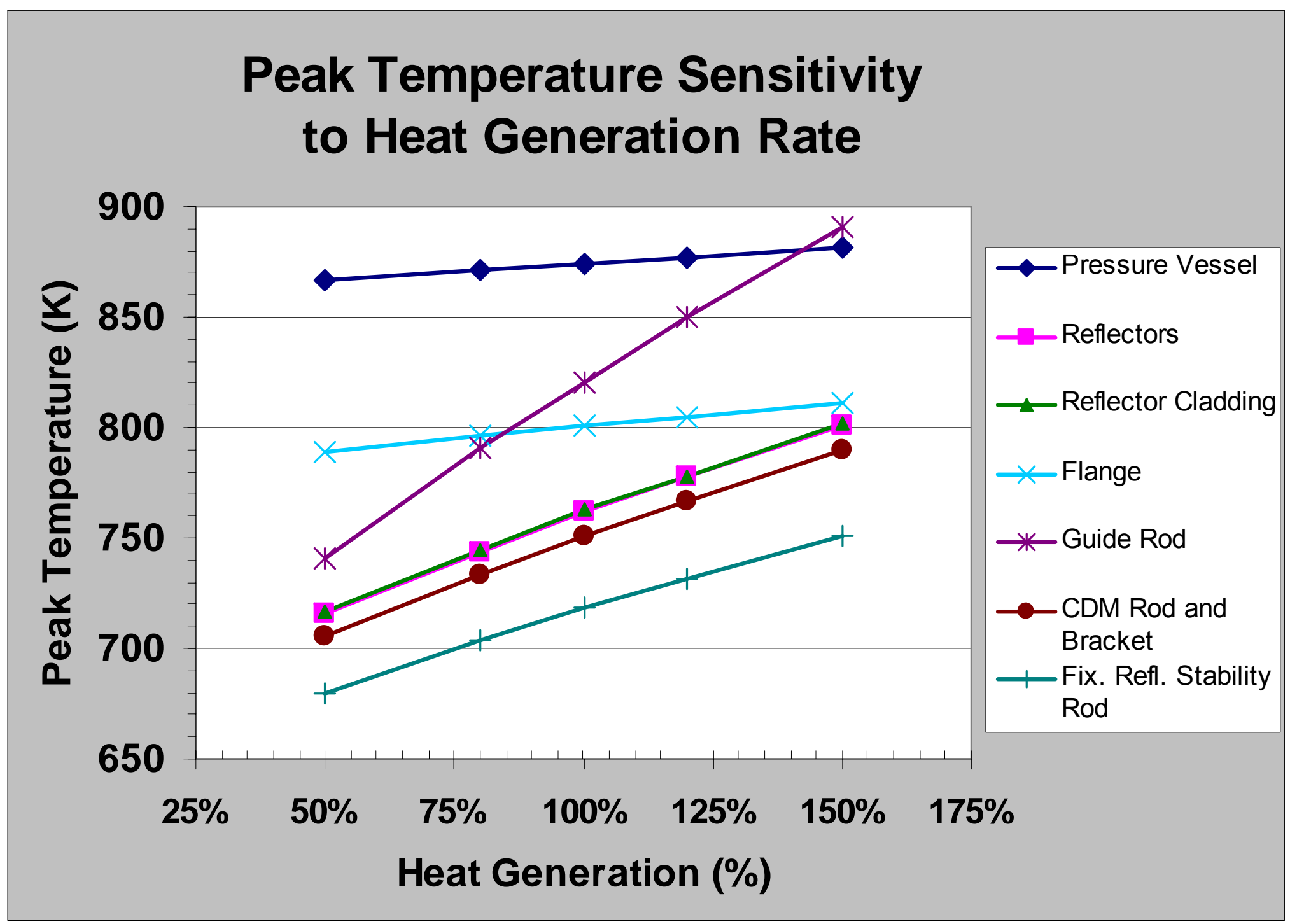




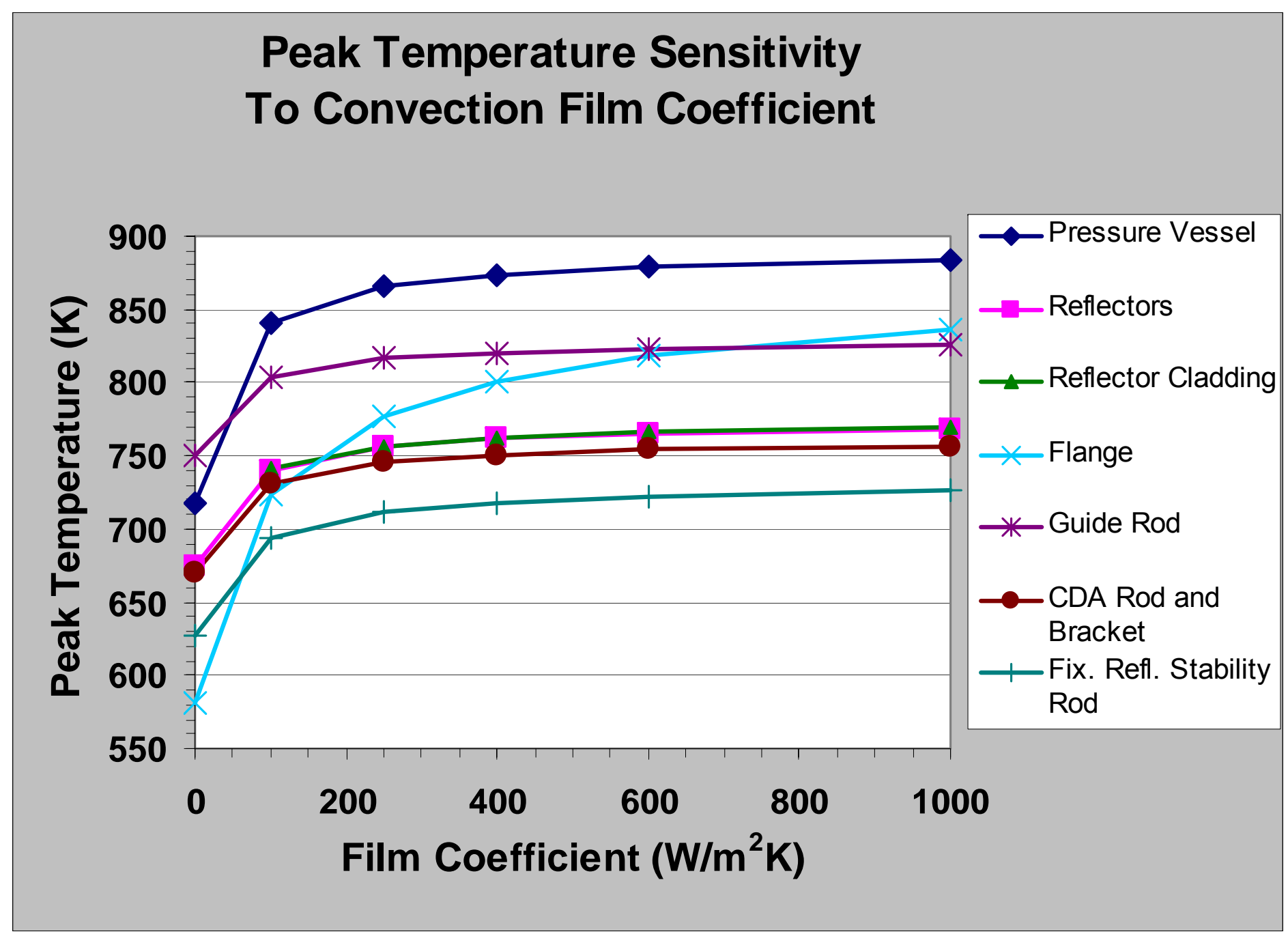




\section{Model Capabilities}

- Sensitivities (Temp vs.)

- Heat Generation Rates

- Film Coefficient

- Space Sink Temperature

- Heat Generation Distribution

- Materials and Material Properties

- Dimensions and Positions

- Down-Comer Bulk Temperature

- Readily change materials, dimensions, meshing 


\section{Further Sensitivity Studies}

- Peak temperature sensitivity analyses were performed for seven different boundary conditions variations, including the baseline case. All cases were converged to their steady state solution.

- The following is a description of the analyzed cases: 


\section{Analyzed Cases}

\begin{tabular}{|c|c|}
\hline Loading Case & Case A is the baseline case described in the text. \\
\hline A & $\begin{array}{c}\text { Description } \\
\text { B } \\
\text { reflector cladding and adjacent pressure vessel wall (INSULATED } \\
\text { "ADIABATIC" CASE). }\end{array}$ \\
\hline C & $\begin{array}{c}\text { Case C is the baseline case except the radiating surface emissivities are all } \\
\text { set equal to 0.3 (to examine the effect of modifying the surface finishes or } \\
\text { installing a thin shield to reduce emissivity or inhibit cooling to space). }\end{array}$ \\
\hline D & $\begin{array}{c}\text { Case D is the baseline case, but modeled with more realistic } \\
\text { material/temperature dependent surface emissivities than Case A. Results } \\
\text { for Case D are considered to be the most accurate because of these } \\
\text { realistic emissivities. }\end{array}$ \\
\hline E & $\begin{array}{c}\text { Case E shows the effect of raising the convection bulk temperature on Case } \\
\text { D from 890K to 942K*** }\end{array}$ \\
\hline F & $\begin{array}{c}\text { Case F shows the effect of shielding Case E from cooling to space (another } \\
\text { INSULATING "ADIABATIC" CASE). }\end{array}$ \\
\hline G & $\begin{array}{c}\text { Case G examines the effect on Case D of placing an adiabatic shield over } \\
\text { the outside of the exposed pressure vessel wall beyond the sliding reflector } \\
\text { in the direction of the thimble opening (PARTIAL INSULATING CASE). }\end{array}$ \\
\hline
\end{tabular}




\section{Results}

\begin{tabular}{|c|c|c|c|c|c|c|c|}
\hline Case & A & B & C & D & $\mathbf{E}$ & $\mathbf{F}$ & $\mathbf{G}$ \\
\hline Component & $100 \%$ & $\begin{array}{c}\text { Adiabatic } \\
100 \%\end{array}$ & $\begin{array}{c}100 \% \\
\text { Emis = } 0.3\end{array}$ & $\begin{array}{c}100 \% \\
\text { Emis=> } \\
\text { Mat Dep }\end{array}$ & $\begin{array}{c}100 \% \\
E=> \\
\text { Mat Dep } \\
\text { B.T.=942K }\end{array}$ & $\begin{array}{c}\text { Adiabatic } \\
100 \% \\
\text { E=> } \\
\text { Mat Dep } \\
\text { B.T.=942K }\end{array}$ & $\begin{array}{c}100 \% \\
\text { Emis=> } \\
\text { Mat Dep } \\
\text { 1/2PV } \\
\text { Shielded }\end{array}$ \\
\hline $\begin{array}{c}\text { Pressure } \\
\text { Vessel }\end{array}$ & 873 & 977 & 897 & $\begin{array}{c}\varepsilon=0.87 \\
897\end{array}$ & $\begin{array}{c}\varepsilon=0.87 \\
946\end{array}$ & $\begin{array}{c}\varepsilon=0.87 \\
1000\end{array}$ & $\begin{array}{c}\varepsilon=0.87 \\
897\end{array}$ \\
\hline Reflectors & 761 & 1034 & 928 & 923 & 943 & 1198 & 922 \\
\hline $\begin{array}{l}\text { Reflector } \\
\text { Cladding }\end{array}$ & 762 & 1034 & 928 & $\begin{array}{c}\varepsilon=0.17 \\
923\end{array}$ & $\begin{array}{c}\varepsilon=0.17 \\
943\end{array}$ & $\begin{array}{c}\varepsilon=0.17 \\
1199\end{array}$ & $\begin{array}{c}\varepsilon=0.17 \\
922\end{array}$ \\
\hline Flange & 800 & 1137 & 859 & $\begin{array}{c}\varepsilon=0.85 \\
800\end{array}$ & $\begin{array}{c}\varepsilon=0.85 \\
835\end{array}$ & $\begin{array}{c}\varepsilon=0.85 \\
1194\end{array}$ & $\begin{array}{c}\varepsilon=0.85 \\
800\end{array}$ \\
\hline Guide Rod & 820 & 1130 & 986 & 988 & 1005 & 1254 & 988 \\
\hline $\begin{array}{c}\text { CDA Rod } \\
\text { and Bracket }\end{array}$ & 750 & 1129 & 924 & 918 & 936 & 1199 & 918 \\
\hline $\begin{array}{c}\text { Fixed } \\
\text { Reflector } \\
\text { Stability } \\
\text { Rod } \\
\end{array}$ & 718 & 1078 & 856 & 848 & 867 & 1164 & 848 \\
\hline
\end{tabular}




\section{Conclusions}

- Convection in the downcomer heats the vessel wall for gamma/neutron heating up to approximately $1 \mathrm{~W} / \mathrm{cc}$ in the vessel wall. Beyond $1 \mathrm{~W} / \mathrm{cc}$ the downcomer starts to cool the vessel sidewall down.

- $\quad$ Outlying structures, such as the reflector guide rod, are especially sensitive to gamma/neutron heating if radiative cooling to space is hindered

- At the nominal baseline heating rates in the modeled components, isolation from the downcomer (thermal barrier, stagnant gas gap, etc) can lower peak flange temperatures by $>200 \mathrm{~K}$, the vessel sidewall by $>150 \mathrm{~K}$, the reflector/clad/CDA rods/stability rods by $90 \mathrm{~K}$, and the guide rod by $70 \mathrm{~K}$

- If the nominal baseline heating rates are close in value to the real rates, care must be exercised if external shielding for micrometeoroids is contemplated.

- A 3-dimensional model of the pressure vessel and reflector structures is required to obtain an accurate analysis which accounts for the entire 3-dimensional nature of the heat transfer environment of the components. Hand calculations are adequate on a case-basis for simplified portions of the assembly that can be sub-modeled.

- The pressure vessel outer wall temperature is strongly coupled to the bulk temperature and heat transfer coefficient of the convective flow in the downcomer, even for cases of adiabatic boundary conditions. 


\section{Conclusions cont'd.}

- $\quad$ Assuming the baseline heat generation rates modeled are accurate for a $1 \mathrm{MWth}$ gascooled space reactor, the calculated maximum working temperature of the Be reflector cladding is exceeded in all but the first case, implying that another material should be examined as a possible alternative for this component.

- Assuming the baseline heat generation rates modeled in each component are close to the actual heating rates for a $1 \mathrm{MWth}$ gas-cooled space reactor, Case $\mathrm{D}$ represents the best estimate of component temperatures from this finite element model. In this case, all modeled components except the reflector cladding exhibit peak temperatures below their estimated material maximum working temperatures (950K for nickel-based super alloys, $823 \mathrm{~K}$ for beryllium). This likely will include the guide rod, CDA rods and brackets, and stability rods, which will exhibit lower peak temperatures during sub-model analysis to include their cooling to space.

- Micrometeoroid shielding may result in a situation that increases these temperatures. However, shielding (insulating) the exposed portions of the pressure vessel beyond the reflectors will have minimal, if any, effect on the component peak temperatures.

- Since the pressure vessel and flange temperatures are closely coupled to the downcomer, increasing the inlet bulk temperature could drive the design to materials that can adequately withstand higher working temperatures (refractory metals). 


\section{Additional Work}

- In addition to the thermal sensitivity analyses described above, the nodal temperature thermal results can be mapped to a structural model and used to examine thermal deformation, thermal stress, creep, and changes in core reactivity.

- Since the present model does not include the thimble and core regions, no design conclusions are drawn from this thermal deformation analysis. This is because the thimble and core regions contribute to the thermal and structural environment of the modeled components and also provide the proper constraint locations for the deformation analyses. The methodology is presented here only to indicate one way the thermal results can be used. 


\section{Thermal Deformations}

- The following figures show the total structural deformation of the model when loaded with the Case A baseline resultant temperatures using the nodal temperature mapping technique mentioned previously. As stated previously, there are no design conclusions that can be drawn from these deformations due to the fact that the thimble and core regions are not at this time included in the finite element model. However, the figures indicate that the methodology can be successfully used for examinations of thermal distortion, creep, thermal stress and, when the thimble and core regions are included, trends in reactivity. 


\section{Color Contour Plot of Thermal Deformations - Case A}

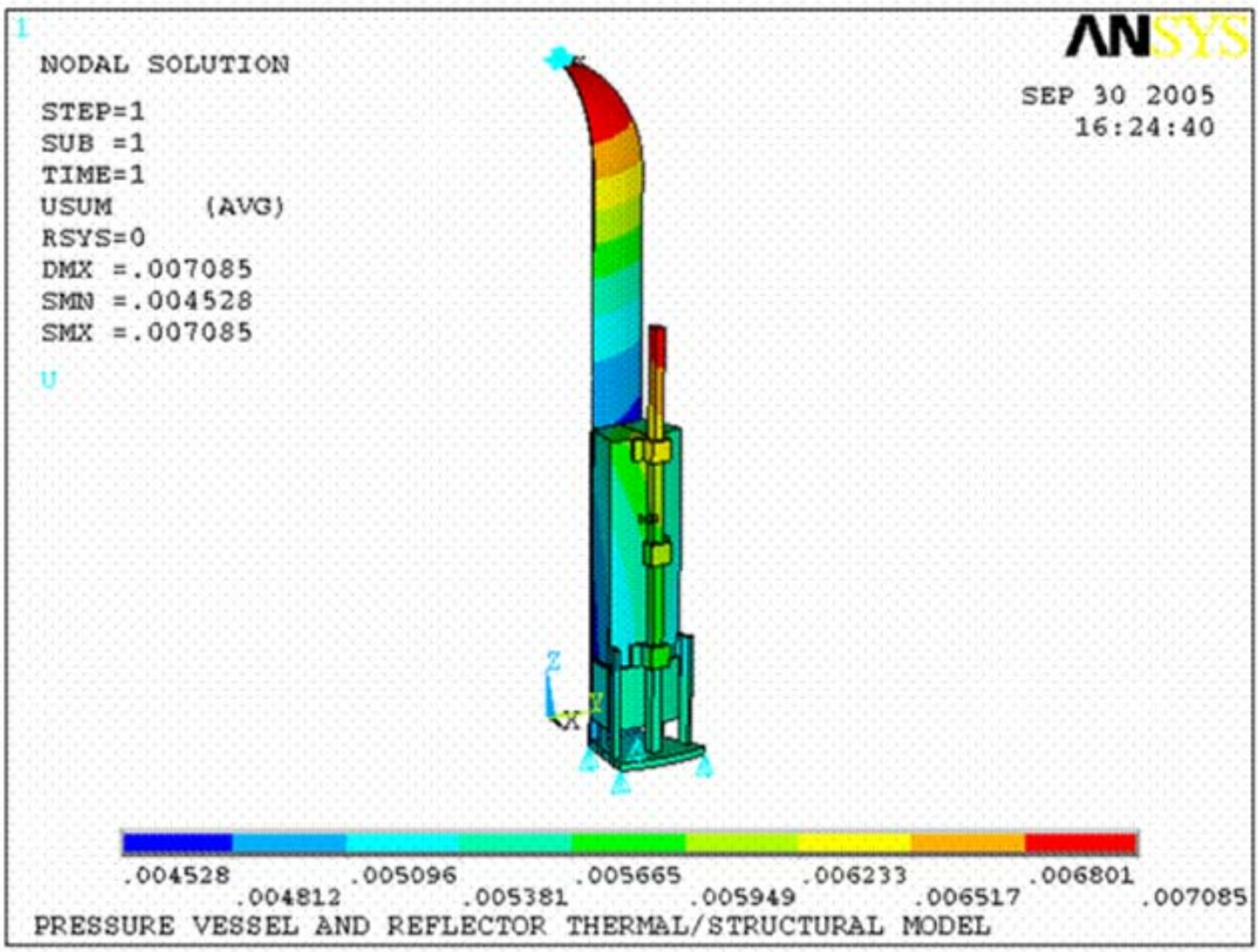




\section{Flange Assembly Thermal Deformations}

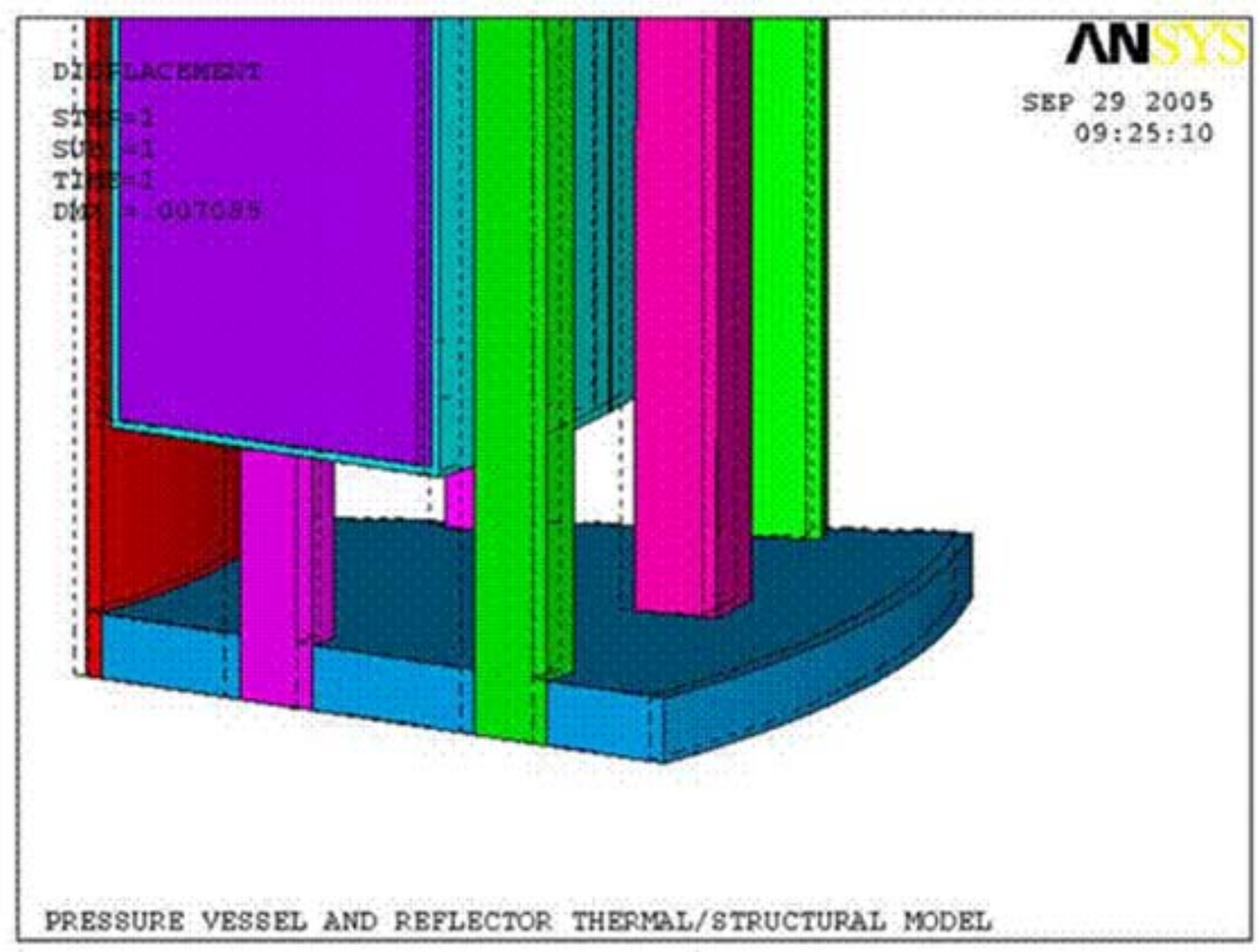




\section{Future Work}

- More accurate peak temperatures require

- more accurate heat generation rates

- more accurate convection constants modeled along the entire length of the downcomer

- Sub-modeling to capture thermal radiation of small but important components

- Complete the model in the thimble and core regions

- Extend the model to include the support skirt and shield

- Replace thermal elements with structural elements in order to:

- Find thermal stresses

- Find thermal deformations - used to study changes in reactivity

- Transient analysis (startup, off nominal events) 


\title{
Enclosure 6 to
}

SPP-SEC-0039

\section{Prometheus Hot Leg Piping Concept}

\author{
Gribik, A.M. and DiLorenzo, P.A.
}


This page is intentionally blank.

PRE-DECISIONAL - For planning and discussion purposes only 


\title{
Prometheus Hot Leg Piping Concept
}

\author{
Anastasia M. Gribik \\ Space Plant Systems - Bechtel \\ Peter A. DiLorenzo \\ Space Power Program - Lockheed Martin
}

STAIF 2006

February 2006

\section{Agenda}

- Background

- 900K Temperature Limit

- Past HTGR Hot Leg Piping Approaches

- Assumptions

- Recommended Concept Description

- Alternate Concepts

- Comparison Criteria

- Concepts Omitted from Thermal and Hydraulic Analyses

- Thermal and Hydraulic Analyses Results

- Internally Insulated Concept Advantages

- Development Efforts

- Conclusions

- Questions 


\section{Background}

- The hot leg piping from the reactor outlet to the turbine inlet contains He-Xe gas operating at $1150 \mathrm{~K}$ and between 1.4 and $4 \mathrm{MPa}$

- Baseline - 1.9 MPa

- Three Nickel superalloys are candidate materials for primary plant piping:

- Inconel 617, Haynes 230, and Nimonic PE-16

- Baseline - Inconel 617

- Pressure boundary must be maintained at $\sim 900 \mathrm{~K}$ for sufficient material strength

- Remaining plant piping operates at lower temperatures

\section{K Temperature Limit}

- Material strength of Inconel 617 is not fully known due to material test uncertainties

- Creep-fatigue interaction, strain ratcheting, irradiation effects, high temperature effects

- Inconel 617 design limit general primary membrane stress intensity is $\sim 101 \mathrm{MPa}$ at $900 \mathrm{~K}$ and 135,000 hours

- Figure depicts an exponential decrease in $\mathrm{S}_{\mathrm{mt}}$ at temperatures $>\sim 900 \mathrm{~K}$ due to creep

- At high temperatures nickel superalloys begin to decarburize if water vapor is present

- Source of contamination and weakens piping

- Cold leg piping operating temperature is $900 \mathrm{~K}$

- Advantageous to design the two major piping sections near the same temperature to minimize differential thermal expansion

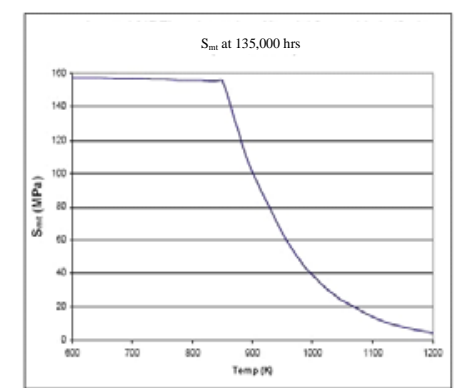

The $900 \mathrm{~K}$ maximum usage temperature provides adequate margin for a sufficient design space until these uncertainties become well defined 


\begin{tabular}{|c|c|c|c|c|c|c|}
\hline \multirow[b]{2}{*}{$\begin{array}{l}\text { Reactor Plant, } \\
\text { Country, and } \\
\text { Dates of Operation }\end{array}$} & \multirow[b]{2}{*}{$\begin{array}{l}\text { Temperature } \\
\text { Control } \\
\text { Approach }\end{array}$} & \multirow[b]{2}{*}{$\begin{array}{l}\text { Piping Materials } \\
\text { (If Applicable) }\end{array}$} & \multirow[b]{2}{*}{$\begin{array}{l}\text { Piping Dimensions } \\
\text { (cm) }\end{array}$} & \multicolumn{3}{|c|}{ Operating Parameters } \\
\hline & & & & $\begin{array}{l}\text { Power } \\
\text { (MW) }\end{array}$ & $\begin{array}{c}\text { Coolant } \\
\text { Temperature } \\
\text { (K) }\end{array}$ & $\begin{array}{c}\text { Coolant } \\
\text { Pressure } \\
\text { (MPa) }\end{array}$ \\
\hline $\begin{array}{l}\text { HTTR } \\
\text { Japan } \\
1998 \text { - Present } \\
\end{array}$ & $\begin{array}{l}\text { Counter Flow } \\
\text { with Internal } \\
\text { Insulation } \\
\end{array}$ & $\begin{array}{l}\text { Outer Pipe - SB42 (Mild Steel) } \\
\text { Inner Pipe and Liner - Hastelloy X } \\
\text { Insulation - Kaowool } \\
\end{array}$ & $\begin{array}{l}\text { Outer Pipe Diameter - } 152 \\
\text { Inner Pipe Diameter - } 36\end{array}$ & 30 & 1223 & 4 \\
\hline $\begin{array}{l}\text { Peach Bottom } \\
\text { US } \\
1966-1974\end{array}$ & $\begin{array}{l}\text { Counter Flow } \\
\text { with Internal } \\
\text { Insulation }\end{array}$ & $\begin{array}{l}\text { Outer Pipe - Carbon Steel } \\
\text { Inner Pipe - } 304 \text { Stainless Steel } \\
\text { Insulation - } 304 \text { Stainless Steel } \\
\text { Honeycomb Panels }\end{array}$ & $\begin{array}{l}\text { Outer Pipe Diameter - } 91 \\
\text { Inner Pipe Diameter } 52\end{array}$ & 115 & 998 & 2.2 \\
\hline $\begin{array}{l}\text { HTR-10 } \\
\text { China } \\
2000 \text { - Present } \\
\end{array}$ & $\begin{array}{l}\text { Counter Flow } \\
\text { with Internal } \\
\text { Insulation } \\
\end{array}$ & $\begin{array}{l}\text { Outer Pipe - Nickel Superalloy } \\
\text { Inner Pipe - Not Available } \\
\text { Insulation - Not Available } \\
\end{array}$ & $\begin{array}{l}\text { Outer Pipe Diameter - } 90 \\
\text { Inner Pipe Diameter- } 27\end{array}$ & 10 & 1000 & 3 \\
\hline $\begin{array}{l}\text { GTMHR } \\
\text { US } \\
\text { Planning Phase }\end{array}$ & $\begin{array}{l}\text { Internal } \\
\text { Insulation }\end{array}$ & $\begin{array}{l}\text { Outer Pipe - Alloy 800H (Nickel } \\
\text { Superalloy) } \\
\text { Insulation - Ceramic Fiber }\end{array}$ & $\begin{array}{l}\text { Outer Pipe Diameter }-152 \\
\text { Inner Pipe Diameter }-104\end{array}$ & 600 & 1120 & 0.7 \\
\hline $\begin{array}{l}\text { UHTREX } \\
\text { US } \\
1966-1970\end{array}$ & $\begin{array}{l}\text { Internal and } \\
\text { External } \\
\text { Insulation }\end{array}$ & $\begin{array}{c}\text { Piping - 304SS/106 Carbon Steel } \\
\text { Internal Insulation - Stainless Steel } \\
\text { Foil Reflector } \\
\text { External Insulation - Calcium Silicate }\end{array}$ & Pipe Diameter - 36 & 3 & 1590 & 3.4 \\
\hline $\begin{array}{l}\text { Dragon } \\
\text { UK } \\
1964-1989 \\
\end{array}$ & $\begin{array}{l}\text { Internal } \\
\text { Insulation }\end{array}$ & $\begin{array}{c}\text { Piping - Not Available } \\
\text { Insulation - Multilayer Nimonic } \\
\text { Liners (Nickel Superalloy) }\end{array}$ & Pipe Diameter - 19 & 20 & 1020 & 2.2 \\
\hline $\begin{array}{l}\text { Fort Saint Vrain } \\
\text { US } \\
1974-1989 \\
\end{array}$ & $\begin{array}{l}\text { Internal } \\
\text { Insulation }\end{array}$ & $\begin{array}{l}\text { Outer Pipe - Carbon Steel } \\
\text { Insulation - Ceramic Fiber }\end{array}$ & Not Available & 842 & 1050 & 4.8 \\
\hline \multicolumn{7}{|c|}{$\begin{array}{c}\text { Terrestrial Reactors Provide Guidance, but Limited Pipe Size } \\
\text { for Space Reactor Dictates New Evaluation }\end{array}$} \\
\hline
\end{tabular}

\section{Assumptions}

- Hot leg piping must travel around or through the reactor shielding

- Outer diameter limited to $16 \mathrm{~cm}$

- Constrains neutron and gamma streaming through the piping

- Space temperature - $400 \mathrm{~K}$

- NASA Glenn assumes space temperature of $200 \mathrm{~K}$

- Increase accounts for hot components in the vicinity of the hot leg piping and micrometeoroid protection

- Piping wall thicknesses

- ASME Boiler and Pressure Vessel Code

- Additional allowance for thinning due to bending

- Four hot leg piping concepts analyzed

- Internally insulated, counter flow, bypass flow, stagnant gas layer 


\section{Recommended Concept Description - Internally Insulated}

- Hot reactor outlet gas flows within a lined layer of insulation

- Slip fit liner design

- Prevents hot gas from flowing through insulation

- Either nickel superalloy or refractory metal

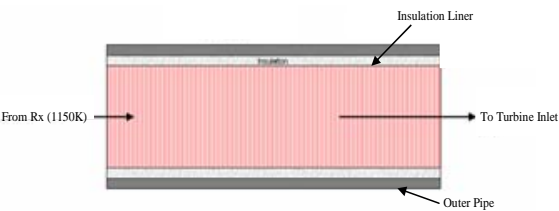

- Allows for small amount of leakage through liner slip fits to equalize pressure

- Insulation

- Must be designed to provide support between the liner and outer pipe

- Must not outgas contaminants or become friable at high temperatures

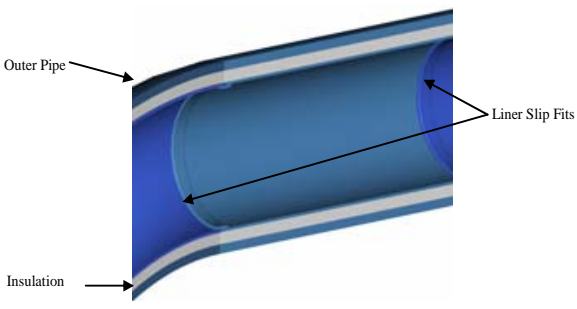

\section{Recommended Concept - Insulating Materials}

- Designed to provide sufficient support to maintain concentricity of the liner and outer pipe

- Maximum operating temperature of insulation $\sim 1150 \mathrm{~K}$

- Does not outgas contaminants or become friable at high temperatures

- Promising insulating materials are ceramic or metallic foams made of hollow bonded microspheres

- Metallic foams preferred due to compatibility with the SNPP components 


\section{Alternate Concepts - Counter Flow}

- Hot reactor outlet gas flows through inner pipe

- Cooler reactor inlet gas flows through annular space between inner pipe and outer pipe in the opposite direction

- The reactor inlet flow enters annular space from recuperator discharge

- Possible lined insulated layer between the flowing gas

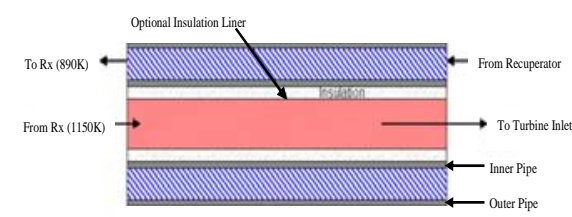
sections

- Two counter flow pipes used to reduce pressure drop

- Support structure necessary in the annular space

\section{Alternate Concepts - Bypass Flow}

- Hot reactor outlet gas flows through inner pipe

- Small quantity $(\sim 1 \%)$ of reactor inlet gas flows through annular space between inner and outer pipe in the same direction

- The bypass flow rejoins main gas flow at turbine outlet

- Possible lined insulated layer

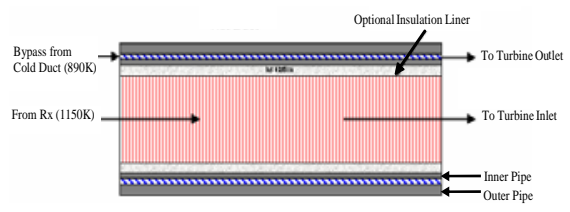
between the flowing gas sections

- Support structure necessary in the annular space 


\section{Alternate Concepts - Stagnant Gas Layer}

- Hot reactor outlet gas flows through inner pipe

- A stagnant layer of He-Xe gas contained in annular space between inner and outer pipe

- Possible lined insulated layer between the flowing gas sections

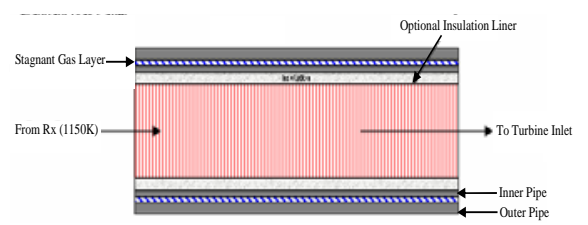

- Support structure necessary in the annular space

\section{Comparison Criteria}

- Thermal Performance

- Equalized thermal performance of the concepts by requiring that the outer pipe inner wall temperature must not exceed $900 \mathrm{~K}$

- Set heat losses per length of piping equal for flowing gas and each heat transfer path in series

- Only insulating and/or stagnant layer thicknesses varied

- Concepts could be directly compared by hydraulic performance and manufacturability

- Hydraulic Performance

- Combined pressure drops due to friction, dividing and combining flows, and pipe bends

- Updated friction factor for the effects of heat transfer

- Manufacturability

- Assembly complexity and component interface issues 


\section{Concepts Omitted from Thermal and Hydraulic Analyses}

- Counter Flow

- No insulation

- High rate of heat transfer from the hot gas to the cold gas

- Decrease in turbine entrance temperature of $\sim 150 \mathrm{~K}$

- Unacceptable decrement to cycle efficiency

- With insulation

- Increases pressure drop to an unacceptable level, $\sim 7 \% \Delta \mathrm{P} / \mathrm{P}$ for both the hot and the cold leg (versus $\sim 2 \% \Delta \mathrm{P} / \mathrm{P}$ for the internally insulated concept)

- Bypass Flow

- No insulation

- Excessive temperature increase of the cold gas causes the nickel superalloy outer pipe to exceed the temperature limit of $900 \mathrm{~K}$

- With insulation

- Insulation thickness approaches the internally insulated concept with increased manufacturing complexity

- $1 \%$ bypass flow reduces net Brayton output by $3.4 \%$ as a result of circumventing the turbine

\section{Thermal and Hydraulic Analyses Results}

- Thermal performances of the concepts analyzed were equalized; the discriminating variable between concepts was the resulting hot leg inner diameter

- Concept with the largest inner diameter will have the best hydraulic performance

- The internally insulated concept had the largest diameter as a result of having only one insulating layer

\begin{tabular}{|c|c|c|c|c|c|c|c|c|c|}
\hline \multirow{2}{*}{ Concept } & \multirow{2}{*}{$\begin{array}{c}\text { Turbine } \\
\text { Entrance } \\
\text { Temperature } \\
\text { (K) }\end{array}$} & \multirow{2}{*}{$\begin{array}{c}\text { Hot } \\
\text { Gas } \Delta \mathrm{T} \\
\text { (K) }\end{array}$} & \multicolumn{2}{|c|}{$\begin{array}{l}\text { Heat Loss Through } \\
\text { Stagnant Gas }\end{array}$} & \multirow{2}{*}{$\begin{array}{l}\text { Total } \\
\text { Heat } \\
\text { Loss } \\
(\mathrm{kW}) \\
\end{array}$} & \multirow{2}{*}{$\begin{array}{c}\text { Insulation } \\
\text { Thickness } \\
\text { (cm) }\end{array}$} & \multirow{2}{*}{$\begin{array}{c}\text { Stagnant } \\
\text { Gas } \\
\text { Thickness } \\
\text { (cm) }\end{array}$} & \multirow{2}{*}{$\% \Delta \mathrm{P} / \mathrm{P}$} & \multirow{2}{*}{$\begin{array}{c}\text { Hot } \\
\text { Leg ID } \\
(\mathrm{cm})\end{array}$} \\
\hline & & & $\begin{array}{c}\text { Conduction } \\
(\mathbf{k W})\end{array}$ & $\begin{array}{c}\text { Radiation } \\
(\mathbf{k W})\end{array}$ & & & & & \\
\hline $\begin{array}{l}\text { Stagnant Layer w/ Insulation - } \\
\text { Ni Liner }\end{array}$ & 1143.5 & 6.5 & 14.3 & 1.5 & 15.8 & 0.86 & 0.22 & 1.45 & 11.6 \\
\hline $\begin{array}{l}\text { Stagnant Layer w/ Insulation - } \\
\text { Refractory Liner }\end{array}$ & 1143.5 & 6.5 & 13.7 & 2.1 & 15.8 & 0.88 & 0.22 & 1.46 & 11.5 \\
\hline Internally Insulated & 1143.5 & 6.5 & NA & NA & 15.8 & 1.20 & NA & 1.26 & 12.1 \\
\hline $\begin{array}{l}\text { Stagnant Layer w/o Insulation - } \\
\text { Ni Liner }\end{array}$ & 1143.5 & 6.5 & 4.5 & 11.3 & 15.8 & NA & 2.77 & 4.49 & 8.4 \\
\hline $\begin{array}{l}\text { Stagnant Layer w/o Insulation - } \\
\text { Refractory Liner }\end{array}$ & 1143.5 & 6.5 & 4.5 & 11.3 & 15.8 & NA & 2.03 & 4.58 & 8.3 \\
\hline
\end{tabular}




\section{Internally Insulated Concept Advantages}

- Minimized hot leg piping pressure drop (1.3\% $\% \mathrm{P} / \mathrm{P})$

- Least complex concept to manufacture

- No stents required if insulation provides structural support between liner and outer pipe

- Liner with slip fit joints allows for differential thermal expansion of the hot liner

- One pressure boundary reduces instrumentation and control measurement issues

- Eliminating radiation heat transfer path decreases sensitivity to space temperature

Meets temperature requirements with least amount of ancillary issues

\section{Development Efforts}

- Material selection

- Outer pipe, insulation, and liner

- Manufacturability

- Material availability

- Piping assembly issues (bends and tees)

- Component interfaces

- Insulation containment

- Bimetallic joints

- Modeling and testing

- Analytical models - thermal, hydraulic, and structural

- Testing qualifies analytical models

- Turbine entrance temperature sensor placement

- Non-invasive requirement must be balanced with reactor control response time 


\section{Conclusions}

- Design features were required to allow the use of a non-refractory metal

- To maintain the hot leg piping pressure boundary at $900 \mathrm{~K}$, concepts were developed to reduce the wall temperature by adding additional layers of heat transfer resistance and/or cooling

- The hot leg piping concepts compared include internally insulated, counter flow, bypass flow, and stagnant gas layer concepts

- The internally insulated hot leg piping concept was the recommended concept

- Resulted in the least complex design and provided the largest gas flow area while maintaining the required pressure boundary temperature

- Further development efforts would have been required to overcome challenges in material selection, manufacturability, modeling, testing, and placement of the turbine entrance temperature sensor

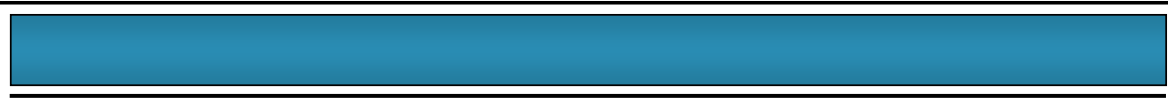

\section{Questions}




\section{Backup Slides}

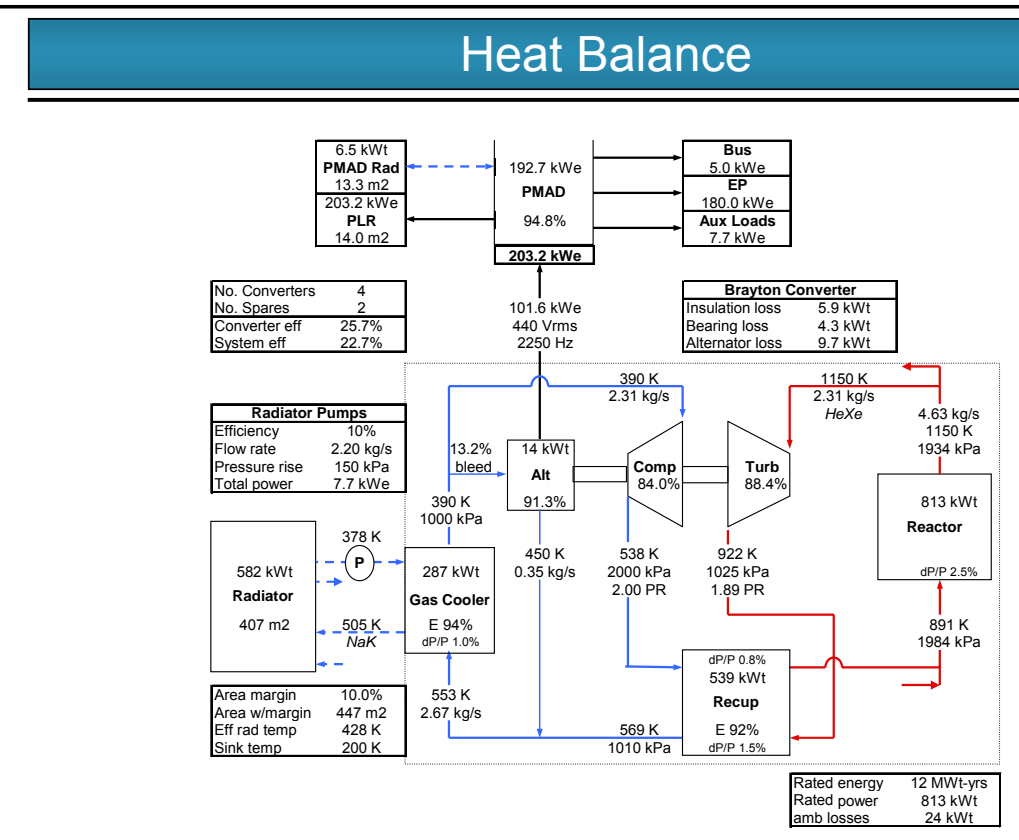




\section{Refractory Metal Disadvantages}

- Controlled environment necessary for testing refractory metals at elevated temperatures

- Increased risk of failure for long term operation of the ground test reactor due to the potential for loss of high purity vacuum

- Possibility of exposure to space-born chemical contaminates from micrometeoroid impacts and gas particles in planetary orbits which are incompatible with refractory metals

- Surface mission extensibility would be decreased since refractory metals can not be exposed to atmospheric constituents

- Bimetallic pressure boundary joint would be required between the refractory outer pipe and the cast nickel superalloy turbine housing

- Requires either the reactor pressure vessel to be refractory metal or a second bimetallic pressure boundary joint at the reactor pressure vessel to the hot leg piping interface

\section{Space Temperature Sensitivity \\ Internal Insulation versus Stagnant Gas Layer}

- $\uparrow$ space temperature requires larger thermal barrier to heat transfer

- Resistance to heat transfer of conduction path is proportional to length of conduction path

- $\downarrow$ conductive heat transfer through insulation or stagnant gas, $\uparrow$ separation between the liner and pipe

- For radiation between surfaces through a non-absorbing gas (e.g. He-Xe), surface area, rather than separating distance, impacts heat transfer

- $\downarrow$ radiant heat transfer through stagnant gas, $\downarrow$ surface area of the liner

- For stagnant gas concepts

- Radiation accounts for $\sim 75 \%$ of heat transfer

- To suppress heat transfer, area for radiation, rather than gap thickness is controlling

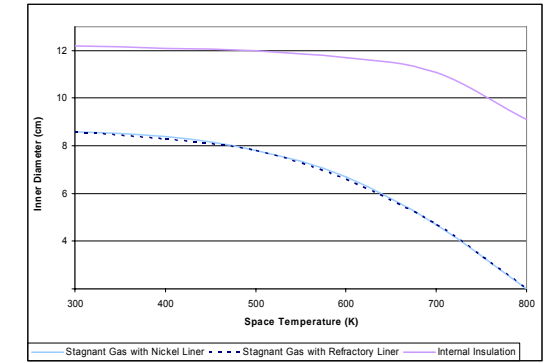

- $\uparrow$ space temperature from $200 \mathrm{~K}$ to $800 \mathrm{~K}$

_ Internally insulated concept diameter $\downarrow \sim 25 \%$

- Stagnant gas without insulation concept diameter $\downarrow \sim 77 \%$ 


\title{
Prometheus Hot Leg Piping Concept
}

\author{
Anastasia M. Gribik ${ }^{1}$ and Peter A. DiLorenzo ${ }^{2}$ \\ ${ }^{1}$ Bechtel Bettis, Inc., Bettis Atomic Power Laboratory, West Mifflin, PA 15122, USA \\ ${ }^{2}$ KAPL, Inc., Knolls Atomic Power Laboratory, Schenectady, NY 12301, USA
}

\begin{abstract}
The Naval Reactors Prime Contractor Team (NRPCT) recommended the development of a gas cooled reactor directly coupled to a Brayton energy conversion system as the Space Nuclear Power Plant (SNPP) for NASA's Project Prometheus. The section of piping between the reactor outlet and turbine inlet, designated as the hot leg piping, required unique design features to allow the use of a nickel superalloy rather than a refractory metal as the pressure boundary. The NRPCT evaluated a variety of hot leg piping concepts for performance relative to SNPP system parameters, manufacturability, material considerations, and comparison to past high temperature gas reactor (HTGR) practice. Manufacturability challenges and the impact of pressure drop and turbine entrance temperature reduction on cycle efficiency were discriminators between the piping concepts. This paper summarizes the NRPCT hot leg piping evaluation, presents the concept recommended, and summarizes developmental issues for the recommended concept.
\end{abstract}

Keywords: Gas reactor piping, internal insulation, Prometheus

PACS: 28.52.Lf

\section{BACKGROUND}

The SNPP design incorporates a piping system which circulates He-Xe gas through the reactor and closed Brayton energy conversion system. The piping is comprised of high pressure ( $\sim 2 \mathrm{MPa})$ and low pressure $(\sim 1 \mathrm{MPa})$ sections. The high pressure sections include piping from the reactor to the turbine inlet, piping from the compressor outlet to the recuperator, and piping from the recuperator to the reactor. The low pressure sections include piping from the turbine outlet to the recuperator, piping from the recuperator to the gas cooler, and piping from the gas cooler to the compressor inlet. The heat balance shown in Figure 1 was generated from the NASA Glenn space reactor power system optimization spreadsheet and depicts the nominal operating conditions for the multi-Brayton plant piping used in the hot leg piping analysis.

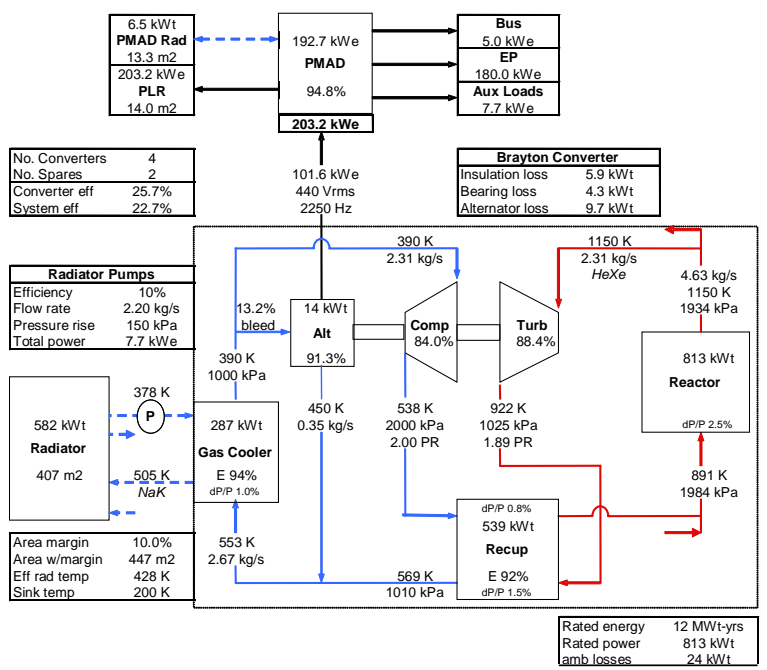

FIGURE 1. Direct Gas Concept System Schematic with Nominal Operating Conditions. 
Nominal values of operating pressure, temperature, and flow are shown in Table 1.

TABLE 1. Nominal Piping Operating Parameters.

\begin{tabular}{llccc}
\hline $\begin{array}{l}\text { Piping Run } \\
\text { From }\end{array}$ & To & $\begin{array}{c}\text { Pressure } \\
(\mathbf{M P a})\end{array}$ & $\begin{array}{c}\text { Gas Temperature } \\
(\mathbf{K})\end{array}$ & $\begin{array}{r}\text { Flow } \\
(\mathbf{k g} / \mathbf{s})\end{array}$ \\
\hline Reactor & Turbine & 1.93 & 1150 & 4.63 \\
Turbine & Recuperator & 1.02 & 922 & 2.31 \\
Recuperator & Cooler & 1.01 & 569 & 2.31 \\
Cooler & Compressor & 1.00 & 390 & 2.31 \\
Compressor & Recuperator & 2.00 & 538 & 2.31 \\
Recuperator & Reactor & 1.98 & 891 & 4.63 \\
\hline
\end{tabular}

The baseline material for the plant piping is Inconel 617, a nickel superalloy. Nickel superalloys were the primary piping material candidates due to their structural performance at high temperatures and compatibility with atmospheric constituents. The hot leg piping contains the highest temperature gas and is located in the high pressure section of the system. In the absence of a heat transfer barrier, the pipe metal temperature would approach the temperature of the gas in contact with the piping. According to currently available material test data, the thermal creep resistance of Inconel 617 decreases significantly at temperatures above $900 \mathrm{~K}$ (Bassford, 1982) and (Corum, 1991). As a result, the hot leg piping required unique design features to control pressure boundary temperature which did not apply to the rest of the piping sections. It should be noted that the turbine to recuperator piping section also contains gas at a temperature in excess of $900 \mathrm{~K}$. However, the lower gas temperature and pressure (relative to the hot leg piping) and the ability to increase the wall thickness of this piping section likely preclude the need for additional control of pressure boundary temperature.

\section{HOT LEG PIPING REQUIREMENTS}

The hot leg piping contains $\mathrm{He}-\mathrm{Xe}$ gas at a nominal operating temperature and pressure of approximately $1150 \mathrm{~K}$ and 1.9 $\mathrm{MPa}$. However, hot leg piping operating pressures from 1.4 $\mathrm{MPa}$ to $4 \mathrm{MPa}$ are being evaluated. While refractory metal alloys such as Mo-47.5Re, $\mathrm{Nb}-1 \mathrm{Zr}$, and Ta-10W offer better high temperature creep resistance than nickel superalloys, it was preferred that the piping material be a nickel superalloy to maximize mission extensibility and to minimize material compatibility issues, cost, and uncertainties associated with the development and use of refractory metals. Key challenges associated with a refractory metal hot leg pipe include:

- A bimetallic pressure boundary joint would be required between the refractory outer pipe and the cast nickel superalloy turbine housing.

- Surface mission extensibility would be decreased since refractory metals can not be exposed to atmospheric constituents.

- Refractory piping requires the reactor pressure vessel to be constructed of a refractory metal or the addition of a second bimetallic pressure boundary joint between the refractory outer pipe and the reactor pressure vessel.

- A controlled environment is necessary for testing refractory metals at elevated temperature (i.e. a high purity vacuum).

- There is an increased risk of failure for long term operation of the ground test reactor due to the potential for loss of high purity vacuum (external to the reactor primary pressure boundary).

- There is a possibility of exposure to contaminants from micrometeoroid impacts and gas particles in planetary orbits which are incompatible with refractory metals at high temperatures.

A variety of materials were considered and three wrought nickel superalloys were identified as leading candidate materials for the hot leg piping: Inconel 617, Haynes 230, and Nimonic PE-16. Inconel 617 was used as the baseline material throughout the concept evaluation to provide a common comparison; however, all three nickel superalloys 
were considered equal candidates. Inconel 617 was chosen as the baseline because significant material test data and analysis had been compiled for Inconel 617 at high temperatures in an ASME code case.

\section{Superalloy Pressure Boundary Temperature Requirement}

To maintain sufficient material strength and creep resistance with a reasonable wall thickness, analyses determined that the nickel superalloy pressure boundary should be maintained at a maximum of $\sim 900 \mathrm{~K}$. This is a reference value which could have changed as the design evolved and more material data became available. The 900K piping limit was selected as described below.

Material properties of the candidate nickel superalloy (Inconel 617) were not fully characterized due to insufficient material test data. Uncertainties in the material properties were related to creep-fatigue interaction, strain ratcheting, irradiation effects, and high temperature effects which were not quantified. There were also uncertainties with the operational conditions of the piping including cyclic and thermal stresses in addition to the piping arrangement. The 900K maximum usage temperature was judged to provide adequate margin for a sufficient design space until these uncertainties became better defined. For Inconel 617, the time dependent stress design limit $\left(\mathrm{S}_{\mathrm{mt}}\right)$ for general primary membrane stress intensity was $\sim 101 \mathrm{MPa}$, at a temperature of $900 \mathrm{~K}$ and a mission lifetime of 135,000 hours ( $\sim 15$ years), see Figure 2. This figure also depicts an exponential decrease in $\mathrm{S}_{\mathrm{mt}}$ at temperatures greater than $\sim 900 \mathrm{~K}$ as a result of thermal creep (Bassford, 1982) and (Corum, 1991).

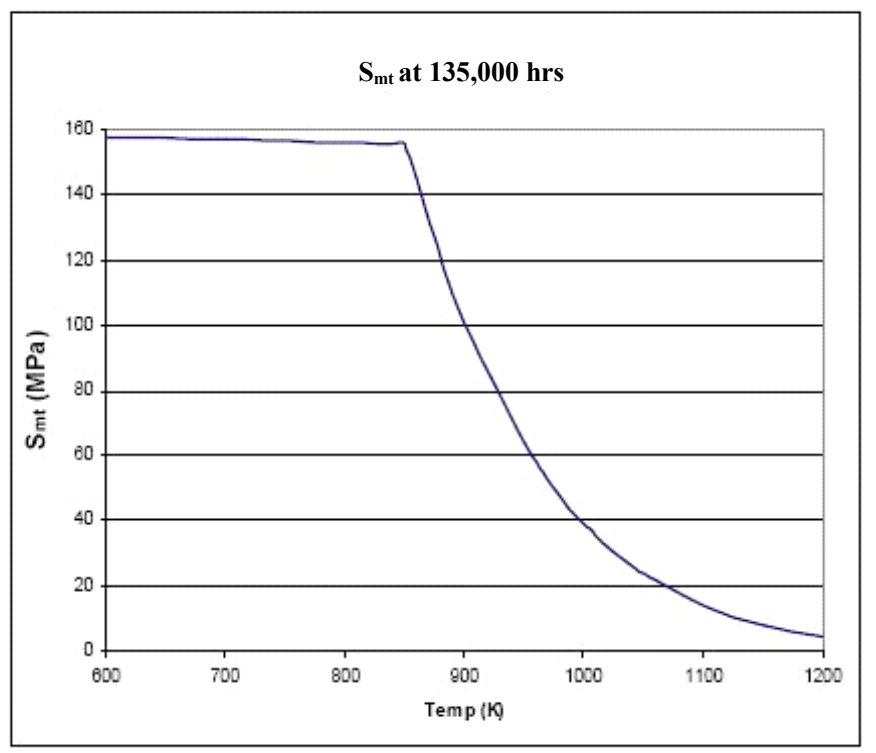

FIGURE 2. Inconel $617 \mathrm{~S}_{\mathrm{mt}}$ as a Function of Temperature at 135,000 hours.

Additionally, nickel superalloys decarburize, if water vapor is present, at elevated temperatures $(>1073 \mathrm{~K})$ which could contaminate the rest of the SNPP as well as weaken the piping (Graham, 1985). Reduction of metal temperature decreases this risk.

Another consideration is that the reactor inlet piping operates at approximately $900 \mathrm{~K}$. It may be advantageous to design the hot leg piping and reactor inlet piping to operate at or near the same temperature to minimize potential issues related to differential thermal expansion of these two piping sections.

\section{Hot Leg Pipe Sizing}

The hot leg piping must travel around or through the reactor shielding. In order to constrain neutron and gamma streaming through the piping, the piping outer diameter was limited to $16 \mathrm{~cm}$. This limit would have been revisited and optimized as the design matured. 
The nominal values of operating pressure, temperature, flow, and the piping diameter specified above were used to calculate pipe wall thicknesses. The calculated pipe wall thicknesses were used in conjunction with the operating conditions to perform thermal and hydraulic analyses of the various hot leg piping concepts.

Pipe wall thickness calculations were performed for both straight and bent piping to provide a preliminary estimate of acceptable pipe wall thicknesses. Wall thicknesses required for straight pipe were calculated based on the ASME Boiler and Pressure Vessel (B\&PV) Code (ASME, 2004). Wall thicknesses required prior to bending were estimated by multiplying the wall thicknesses required after bending, as calculated per the ASME B\&PV Code for straight pipe, by a factor to account for wall thinning caused by the bending process (Nayyar, 1992). For the thermal and hydraulic analyses, wall thicknesses were conservatively based on the pipe wall thickness prior to bending.

\section{Space Temperature Assumption}

According to the space reactor power system optimization spreadsheet, the nominal space environment temperature the Prometheus spaceship was expected to see was $200 \mathrm{~K}$. To account for hot components in the vicinity of the hot leg piping, the space temperature was increased to $400 \mathrm{~K}$ for the thermal analyses of the hot leg piping concepts. Further analysis of the thermal behavior for the entire system was needed before a more refined assumption for the space temperature could be made.

\section{HOT LEG PIPING CONCEPT DESCRIPTIONS}

In order to maintain the hot leg piping pressure boundary temperature at $900 \mathrm{~K}$, several concepts were developed which would reduce the pressure boundary temperature by adding additional layers of heat transfer resistance and/or cooling while protecting the pressure boundary from direct contact with the high temperature gas. The hot leg piping concepts compared include four main variations termed internally insulated, counter flow, bypass flow, and stagnant gas layer which are described in further detail in the following sections.

\section{Recommended Concept - Internally Insulated Hot Leg Piping}

In the internally insulated concept shown in Figure 3, the hot reactor outlet gas flows within a lined layer of ceramic or metallic insulation. The insulation is lined to prevent erosion of the insulation, to prevent the release of insulating material particulates; and to prevent the hot gas from flowing through the insulation, which would increase pressure drop by increasing the relative roughness of the piping.. The insulation liner operates at the hot leg gas temperature but does not act as a pressure boundary since small amounts of coolant flow through the liner slip fits, see Figure 4. This allows the liner material to be either a nickel superalloy or a refractory metal depending upon other material selections in the SNPP.

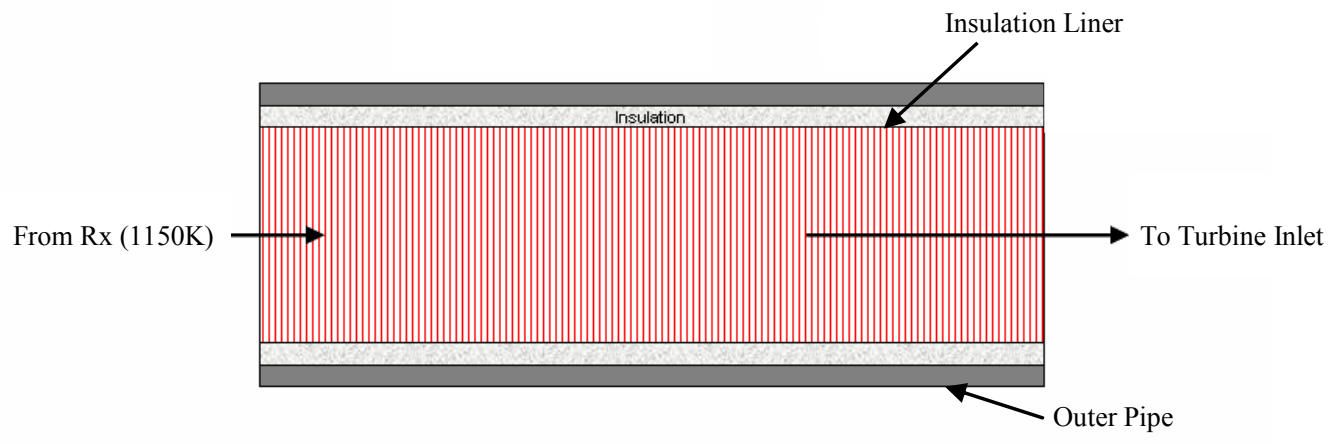

FIGURE 3. Internally Insulated Concept. 


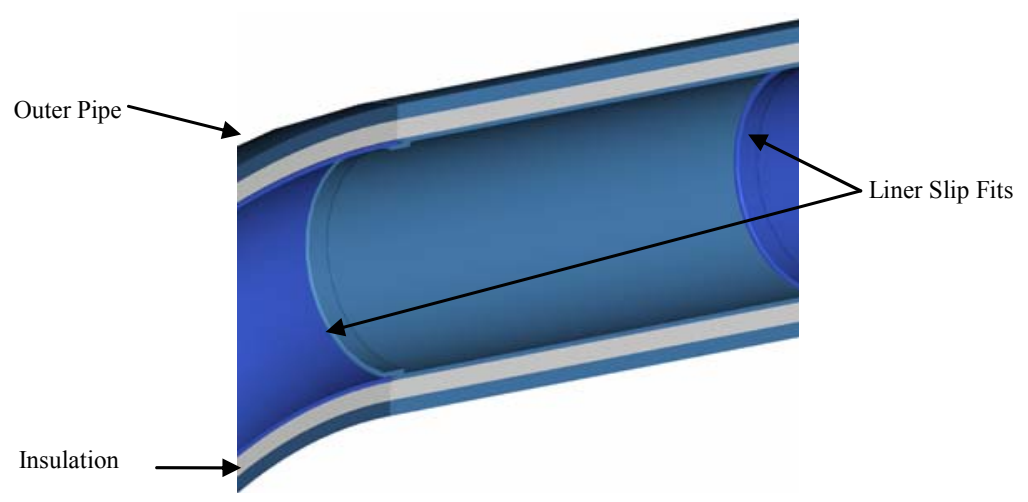

FIGURE 4. Liner Slip Fits.

Insulation is required in the internally insulated concept to maintain the temperature of the pressure boundary at or below $900 \mathrm{~K}$. This insulation would be designed to provide sufficient support to maintain concentricity of the liner and outer pipe. The maximum operating temperature of the insulation is approximately $1150 \mathrm{~K}$. In addition, it is desirable that the insulation not outgas contaminants or become friable after long periods at high temperature. With respect to these requirements, promising insulating materials for this application are ceramic or metallic foams comprised of hollow bonded microspheres. Metallic foams are preferred due to increased compatibility with other SNPP components. Figure 5 depicts Inconel 617 hollow sphere foam.

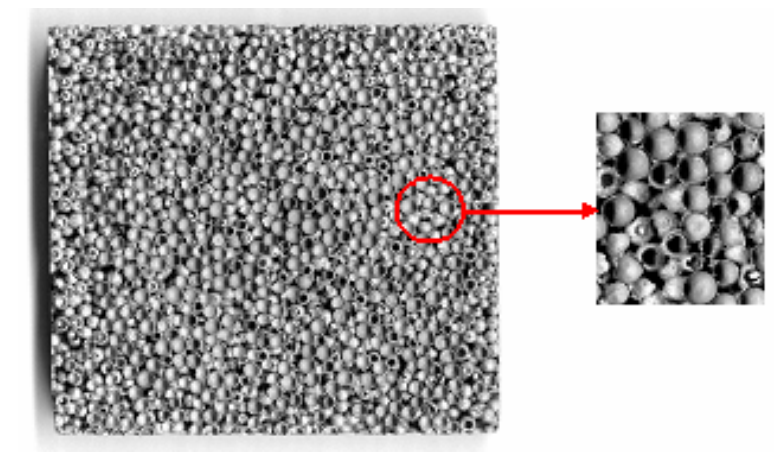

FIGURE 5. Inconel 617 Hollow Sphere Foam.

\begin{abstract}
Alternate Concepts
The other concepts evaluated were intended to reduce the pressure boundary temperature by using primary coolant or stagnant gas as a resistance layer. These concepts proved non-viable unless an insulating layer was added, similar to that used in the internally insulated hot leg concept. This would add complexity to the alternative concepts with no advantage over the internally insulated concept, while also decreasing the hot leg area for gas flow which ultimately increases pressure drop and decreases cycle efficiency.
\end{abstract}

\title{
Counter Flow Concept
}

In the counter flow concept (Figure 6), the hot reactor outlet gas flows through the inner pipe, and the cooler reactor inlet gas flows in the opposite direction from the recuperator discharge through the annular space between the inner pipe and outer pipe. Two separate counter flow hot leg pipes were used to decrease the pressure drop through the piping. There may be a lined insulation layer between the flowing gas sections. A support structure, such as stents, would be necessary in the annular spaces between the inner pipe and outer pipe to maintain concentricity. Because the inner pipe and liner are not pressure boundaries, they could be constructed from either a nickel superalloy or a refractory metal depending upon other material selections in the SNPP. 


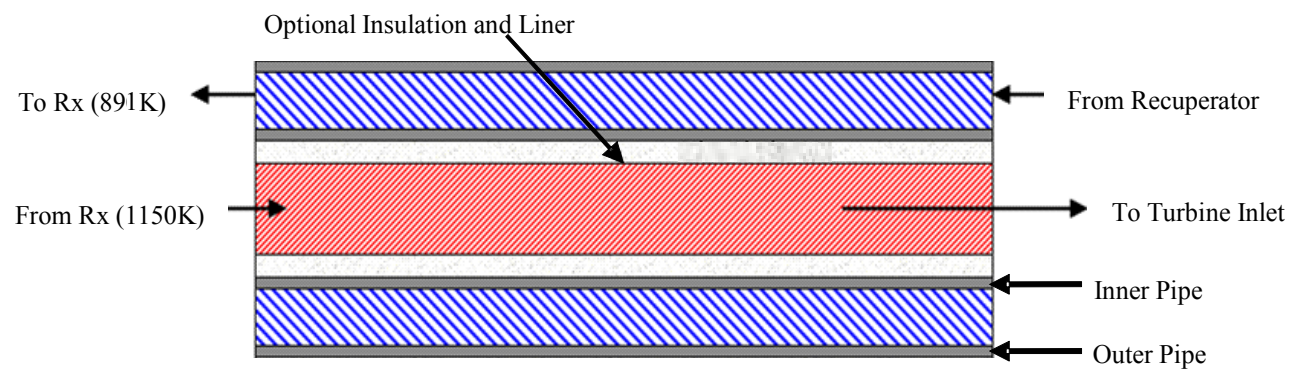

FIGURE 6. Counter Flow Concept (Pictured with Inner Insulation).

\section{Bypass Flow Concept}

In the bypass flow concept (Figure 7), the reactor outlet gas flows in the inner pipe and a small quantity ( $\sim 1 \%)$ of the cooler reactor inlet gas flows in the same direction in the annular space between the inner pipe and outer pipe. The bypass gas flow rejoins the main gas flow at the turbine outlet. There may be a lined insulation layer within the inner pipe. Some type of support structure, such as stents, would be necessary in the annular spaces between the inner pipe and outer pipe to maintain concentricity. Because the inner pipe and liner are not pressure boundaries, they could be constructed from either a nickel superalloy or a refractory metal depending upon other material selections in the SNPP.

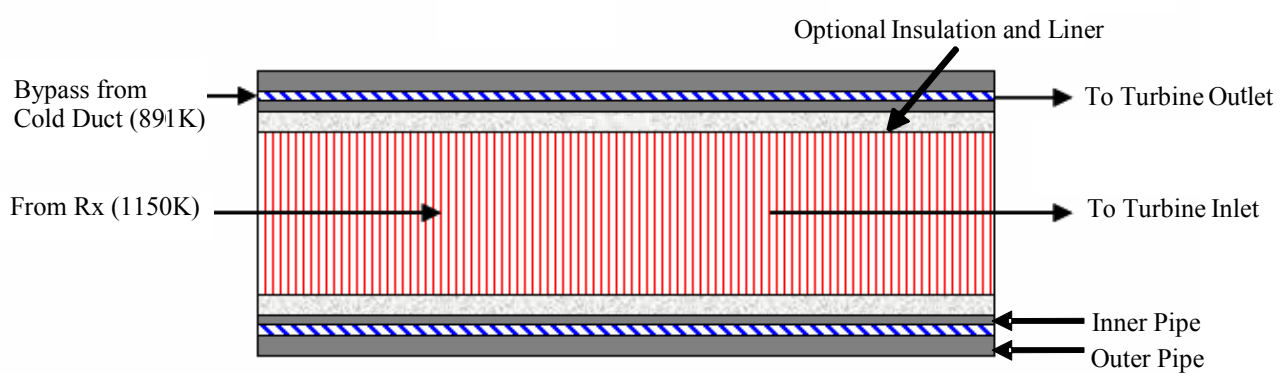

FIGURE 7. Bypass Flow Concept (Pictured with Inner Insulation).

\section{Stagnant Gas Layer Concept}

In the stagnant gas layer concept (Figure 8), the hot reactor outlet gas flows in the inner pipe and a stagnant layer of $\mathrm{He}-\mathrm{Xe}$ gas is contained in the annular space between the inner pipe and outer pipe. There may be a lined insulation layer within the inner pipe. Some type of support structure, such as stents, would be necessary in the annular spaces between the inner pipe and outer pipe to maintain concentricity. Because the inner pipe and liner are not pressure boundaries, they could be constructed from either a nickel superalloy or a refractory metal depending upon other material selections in the SNPP.

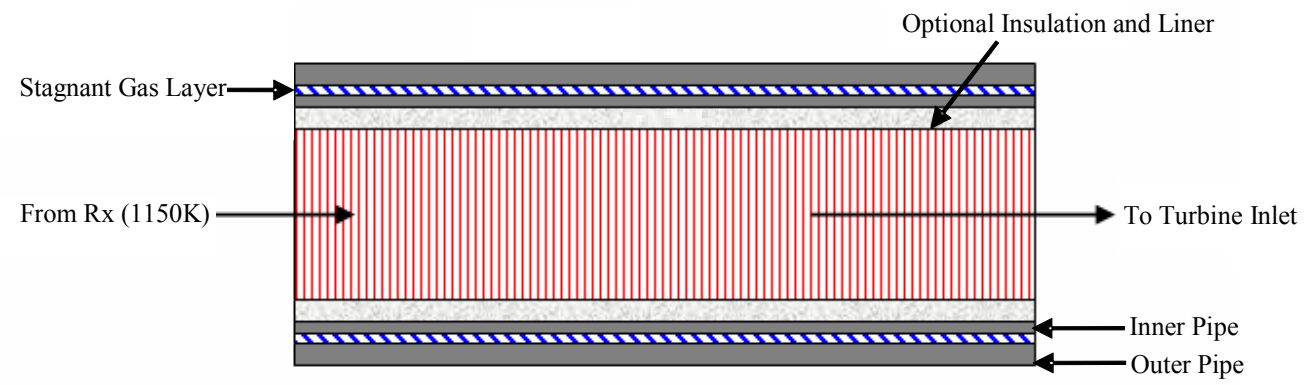

FIGURE 8. Stagnant Gas Layer Concept (Pictured with Inner Insulation). 


\section{HOT LEG PIPING CONCEPT COMPARISON}

Thermal and hydraulic analyses were performed for the internally insulated and stagnant gas layer concepts. The counter flow and bypass flow concepts were excluded as discussed below in the omitted concepts section. The analyses were performed based on an arrangement which utilized a three Brayton configuration having a shared gas cooler with two Braytons operating. The concepts were compared based on thermal performance, hydraulic performance, past HTGR practice, and manufacturing simplicity.

\section{Thermal Analysis Approach}

To assess the hot leg piping concepts, a detailed thermal analysis was performed for the internally insulated concept and the stagnant gas layer concepts (both with and without internal insulation). The thermal analysis was set up in a manner which equalized the thermal performance of the concepts by requiring that the outer pipe inner wall temperature not exceed $900 \mathrm{~K}$. As a result, only the insulating and/or stagnant gas layer thicknesses were varied, and the concepts could be directly compared by their hydraulic performance.

\section{Internally Insulated Concept}

For the internally insulated concept, there are five heat transfer paths in series:

1. Forced convection from the hot gas to the liner

2. Conduction through the liner

3. Conduction through the insulation

4. Conduction through the outer pipe

5. Radiation from the outer pipe to space

The total heat transferred through each path and from the piping to space is equal to the heat lost from the hot gas. Based on these heat transfer paths, an Excel model was developed which determined the temperature profile (axial and radial) for each resistance layer of the piping. This was accomplished by setting the heat losses per segment length of piping equal for the flowing gas and for each of the five heat transfer paths in series. The temperature profile that satisfied this requirement was calculated iteratively with the space temperature held constant at $400 \mathrm{~K}$. After the radial energy balance converged, the insulation thickness was adjusted in order to achieve an outer pipe inner wall temperature of $900 \mathrm{~K} \pm 0.5 \mathrm{~K}$, and the energy balance was recalculated. The model also automatically divided piping sections into successively smaller equal segments until the exit gas temperature from the current iteration differed by less than $0.1 \mathrm{~K}$ from the previous iteration. In addition, all gas and material properties were adjusted for temperature.

\section{Stagnant Gas Layer Concepts with Internal Insulation}

For the stagnant gas layer concepts with internal insulation, there are seven heat transfer paths in series:

1. Forced convection from the hot gas to the liner

2. Conduction through the liner

3. Conduction through the insulation

4. Conduction through the inner pipe

5. Conduction and radiation through the stagnant gas layer

6. Conduction through the outer pipe

7. Radiation from the outer pipe to space

The total heat transferred through each path and from the piping to space is equal to the heat lost from the hot gas. Based on these heat transfer paths, an Excel model was developed which determined the temperature profile (axial and radial) for each resistance layer of the piping. This was accomplished by setting the heat losses per segment length of piping equal for the flowing gas and for each of the seven heat transfer paths in series. The temperature profile that satisfied this requirement was calculated iteratively with the space temperature held constant at $400 \mathrm{~K}$. 
After the radial energy balance converged, the insulation thickness and stagnant gas layer thickness were adjusted in order to achieve an outer pipe inner wall temperature of $900 \mathrm{~K} \pm 0.5 \mathrm{~K}$, and the energy balance was recalculated. The stagnant gas layer thickness was set to be $1 / 4$ of the insulation layer thickness since insulation is more effective at limiting heat transfer than stagnant gas due to radiant heat transfer through the stagnant gas. The model also automatically divided piping sections into successively smaller equal segments until the exit gas temperature from the current iteration differed by less than $0.1 \mathrm{~K}$ from the previous iteration. All gas and material properties were adjusted for temperature.

\section{Stagnant Gas Layer Concepts without Internal Insulation}

The stagnant gas layer concepts without insulation analyses were performed using the same method presented for the internally insulated concept. However, in the stagnant gas layer concepts, convection occurs from the hot gas to the inner pipe and the heat transfer paths of conduction through the liner and insulation layers no longer exist, rather conduction and radiation occur through the stagnant gas layer. Also, instead of adjusting the insulation thickness to achieve an outer pipe inner wall temperature of $900 \mathrm{~K}$, the stagnant gas layer thickness was adjusted through iteration.

\section{Hydraulic Analysis Approach}

Pressure drop calculations were performed to provide an estimate of the percentage $\Delta \mathrm{P} / \mathrm{P}$ for the concepts analyzed. The pressure drop in the hot leg was determined, using an Excel spreadsheet analysis, by combining the pressure drops due to friction, dividing and combining flows, and pipe bends (ESDU, 1990). In addition, the effect of heat transfer on gas properties and pressure drop was taken into account. The pressure drops were then converted to a percentage $\Delta \mathrm{P} / \mathrm{P}$ by dividing the total pressure drop by the compressor inlet pressure and multiplying by 100 .

\section{Concepts Omitted from Thermal and Hydraulic Analyses - Counter Flow and Bypass Flow}

The counter flow concept with two separate pipe-in-pipe sections was eliminated as a viable concept due to the high rate of heat transfer from the hot gas to the cold gas. This heat transfer results in an unacceptable decrement to cycle efficiency. The decrease in turbine entrance temperature is $\sim 150 \mathrm{~K}$. See Table 2 for the hot gas and cold gas axial temperature profiles for a six meter pipe length divided into one meter increments.

TABLE 2. Axial Temperature Profile for the Counter Flow Concept

\begin{tabular}{lcccccccc}
\multicolumn{3}{c}{ Reactor Outlet } & \multicolumn{1}{c}{ Turbine Inlet } \\
\hline Hot Leg & $(\mathbf{K})$ & 1150 & 1123 & 1097 & 1070 & 1044 & 1017 & 991 \\
Cold Leg & $(\mathbf{K})$ & 891 & 864 & 839 & 813 & 788 & 762 & 736 \\
\hline \multicolumn{3}{c}{ Reactor Inlet } & & & & & Recuperator Outlet
\end{tabular}

If internal insulation is utilized to reduce heat transfer between the two flows, the pressure drop becomes significantly higher than in the other concepts analyzed. The combined hot and cold leg pressure drop is $\sim 7 \% \Delta \mathrm{P} / \mathrm{P}$ for the counter flow option versus $\sim 2 \% \Delta \mathrm{P} / \mathrm{P}$ for the internally insulated concept.

The bypass flow concept utilizes a fractional cooling flow ( $1 \%$ of total gas flow) in parallel with the hot leg gas. The bypass flow is supplied from the recuperator outlet and is discharged into the turbine outlet. The bypass flow concept was evaluated with and without internal insulation. The un-insulated option was not viable due to excessive cold gas temperature increase, as illustrated by the results of the counter flow thermal analysis presented above. In the un-insulated bypass flow configuration, this will cause the cold gas temperature to exceed the temperature limit of the piping material. In order to maintain an outer wall temperature of $900 \mathrm{~K}$ in the insulated bypass flow concept, the insulation thickness must approach that of the internally insulated concept. The addition of insulation will significantly increase pressure drop due to a reduction in the area available for gas flow and will also increase manufacturing complexity. 
For both the insulated and un-insulated bypass flow concepts, there is a loss of electric generation as a result of gas bypassing the turbine. At nominal operating conditions, turbine output is approximately $348 \mathrm{~kW}$. A $1 \%$ bypass flow would reduce turbine output by $\sim 3.5 \mathrm{~kW}$, thereby reducing net Brayton output ( $\sim 102 \mathrm{~kW}$ nominal) by $\sim 3.4 \%$.

\section{Thermal and Hydraulic Analysis Results}

Because the thermal performances of the concepts analyzed were equalized, the discriminating variable between concepts was the resulting hot leg inner diameter. Hydraulically, the concept with the largest inner diameter will have the best performance. The internally insulated concept had the largest inner diameter as a result of having only one insulating layer. A summary of the thermal and hydraulic performance of the analyzed concepts is presented in Table 3.

TABLE 3. Thermal and Hydraulic Analysis Results.

\begin{tabular}{|c|c|c|c|c|c|c|c|c|c|}
\hline \multirow{2}{*}{ Concept } & \multirow{2}{*}{$\begin{array}{c}\text { Turbine } \\
\text { Entrance } \\
\text { Temperature } \\
\text { (K) }\end{array}$} & \multirow{2}{*}{$\begin{array}{c}\text { Hot } \\
\text { Gas } \Delta \mathrm{T} \\
\text { (K) }\end{array}$} & \multicolumn{2}{|c|}{$\begin{array}{c}\text { Heat Loss Through } \\
\text { Stagnant Gas }\end{array}$} & \multirow{2}{*}{$\begin{array}{l}\text { Total } \\
\text { Heat } \\
\text { Loss } \\
(\mathrm{kW})\end{array}$} & \multirow{2}{*}{$\begin{array}{c}\text { Insulation } \\
\text { Thickness } \\
\text { (cm) }\end{array}$} & \multirow{2}{*}{$\begin{array}{l}\text { Stagnant } \\
\text { Gas } \\
\text { Thickness } \\
\text { (cm) }\end{array}$} & \multirow[b]{2}{*}{$\% \Delta \mathrm{P} / \mathrm{P}$} & \multirow{2}{*}{$\begin{array}{c}\text { Hot } \\
\text { Leg ID } \\
(\mathrm{cm})\end{array}$} \\
\hline & & & $\begin{array}{c}\text { Conduction } \\
(\mathbf{k W})\end{array}$ & $\begin{array}{c}\text { Radiation } \\
(\mathrm{kW})\end{array}$ & & & & & \\
\hline $\begin{array}{l}\text { Stagnant Layer w/ Insulation - } \\
\text { Ni Liner }\end{array}$ & 1143.5 & 6.5 & 14.3 & 1.5 & 15.8 & 0.86 & 0.22 & 1.45 & 11.6 \\
\hline $\begin{array}{l}\text { Stagnant Layer w/ Insulation - } \\
\text { Refractory Liner }\end{array}$ & 1143.5 & 6.5 & 13.7 & 2.1 & 15.8 & 0.88 & 0.22 & 1.46 & 11.5 \\
\hline Internally Insulated & 1143.5 & 6.5 & NA & NA & 15.8 & 1.20 & NA & 1.26 & 12.1 \\
\hline $\begin{array}{l}\text { Stagnant Layer w/o Insulation - } \\
\text { Ni Liner }\end{array}$ & 1143.5 & 6.5 & 4.5 & 11.3 & 15.8 & NA & 2.77 & 4.49 & 8.4 \\
\hline $\begin{array}{l}\text { Stagnant Layer w/o Insulation - } \\
\text { Refractory Liner }\end{array}$ & 1143.5 & 6.5 & 4.5 & 11.3 & 15.8 & NA & 2.03 & 4.58 & 8.3 \\
\hline
\end{tabular}

\section{Supplemental Results - Space Temperature Sensitivity}

A space temperature sensitivity analysis was performed for the analyzed concepts in order to assess the impact of increasing space temperature on the hot leg inner diameter. As the space temperature increases, a larger thermal barrier to heat transfer is required to maintain the pressure boundary temperature at $900 \mathrm{~K}$. The increase in the thickness of the insulation and/or the stagnant gas layer decreases the diameter of the inner pipe for a fixed outer diameter.

The internally insulated concept continues to have the largest flow area of the analyzed concepts as the space temperature is increased. This is because, with other parameters fixed, the resistance to heat transfer of a conduction path is directly proportional to the length of the conduction path. To reduce the conductive heat transfer through the insulation or stagnant gas layer, the separation between the liner and pipe must be increased.

In contrast, for radiation between surfaces through a non-absorbing gas (e.g. He-Xe), the surface areas, rather than the separating distance, impact heat transfer. To reduce the radiant heat transfer through the stagnant gas layer between the inner pipe and outer pipe, the surface area of the inner pipe must be reduced. For the stagnant gas layer without insulation concepts, radiation accounts for approximately 70 to 75 percent of the heat transfer; therefore, in order to suppress heat transfer, the area for radiation, rather than the thickness of the gap is controlling. For the stagnant gas layer with insulation concepts, the insulating layer reduces the inner pipe wall temperature, thereby reducing the amount of radiant heat transfer between the inner pipe and outer pipe.

As a result, the internally insulated and the stagnant layer with internal insulation concepts are less sensitive to increases in space temperature. However, the internally insulated concept is the least sensitive of all the analyzed concepts. See Figure 9 for a comparison of the space temperature sensitivity for the analyzed concepts. Increasing space temperature from $200 \mathrm{~K}$ to $800 \mathrm{~K}$ causes the inner diameter of the internally insulated concept to decrease by $\sim 25 \%$ versus $\sim 30 \%$ for the stagnant gas with insulation concepts and $77 \%$ for the stagnant gas without insulation concepts. 


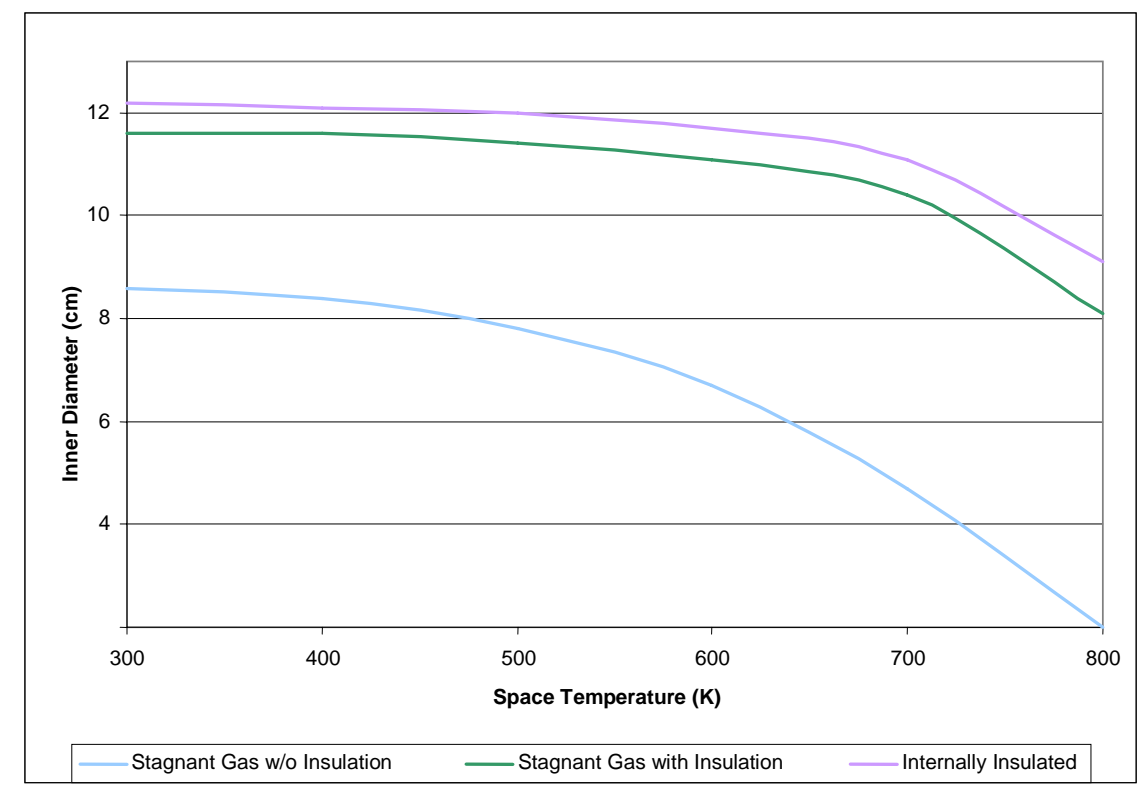

FIGURE 9. Inner Diameter as a Function of Space Temperature.

\section{HTGR Practice}

HTGRs have used a number of engineering techniques to maintain desired pressure boundary temperature in the hot leg piping. Table 4 summarizes these approaches, as well as piping materials, piping dimensions, and plant operating parameters. These reactors either utilized counter flow or internal insulation as the method for maintaining the pressure boundary temperature. However, the concepts which utilized the counter flow approach had significantly larger piping diameters than the SNPP. It should be noted that there are HTGRs not presented in this table due to insufficient primary piping information.

TABLE 4: HTGR Approaches for Maintaining Pressure Boundary Temperature.

\begin{tabular}{|c|c|c|c|c|c|c|}
\hline \multirow[b]{2}{*}{$\begin{array}{l}\text { Reactor Plant, } \\
\text { Country, and } \\
\text { Dates of Operation }\end{array}$} & \multirow[b]{2}{*}{$\begin{array}{l}\text { Temperature } \\
\text { Control } \\
\text { Approach }\end{array}$} & \multirow[b]{2}{*}{$\begin{array}{l}\text { Piping Materials } \\
\text { (If Applicable) }\end{array}$} & \multirow[b]{2}{*}{$\begin{array}{l}\text { Piping Dimensions } \\
\text { (cm) }\end{array}$} & \multicolumn{3}{|c|}{ Operating Parameters } \\
\hline & & & & $\begin{array}{l}\text { Power } \\
\left(\mathbf{M W}_{\mathrm{t}}\right)\end{array}$ & $\begin{array}{c}\text { Coolant } \\
\text { Temperature } \\
\text { (K) }\end{array}$ & $\begin{array}{c}\text { Coolant } \\
\text { Pressure } \\
\text { (MPa) }\end{array}$ \\
\hline $\begin{array}{l}\text { HTTR } \\
\text { Japan } \\
1998 \text { - Present }\end{array}$ & $\begin{array}{l}\text { Counter Flow } \\
\text { with Internal } \\
\text { Insulation }\end{array}$ & $\begin{array}{l}\text { Outer Pipe - SB42 (Mild Steel) } \\
\text { Inner Pipe and Liner - Hastelloy X } \\
\text { Insulation - Kaowool }\end{array}$ & $\begin{array}{l}\text { Outer Pipe Diameter - } 152 \\
\text { Inner Pipe Diameter - } 36\end{array}$ & 30 & 1223 & 4 \\
\hline $\begin{array}{l}\text { Peach Bottom } \\
\text { US } \\
1966-1974\end{array}$ & $\begin{array}{l}\text { Counter Flow } \\
\text { with Internal } \\
\text { Insulation }\end{array}$ & $\begin{array}{c}\text { Outer Pipe - Carbon Steel } \\
\text { Inner Pipe - 304 Stainless Steel } \\
\text { Insulation - 304 Stainless Steel } \\
\text { Honeycomb Panels }\end{array}$ & $\begin{array}{l}\text { Outer Pipe Diameter - } 91 \\
\text { Inner Pipe Diameter } 52\end{array}$ & 115 & 998 & 2.2 \\
\hline $\begin{array}{l}\text { HTR-10 } \\
\text { China } \\
2000-\text { Present }\end{array}$ & $\begin{array}{l}\text { Counter Flow } \\
\text { with Internal } \\
\text { Insulation }\end{array}$ & $\begin{array}{l}\text { Outer Pipe - Nickel Superalloy } \\
\text { Inner Pipe - Not Available } \\
\text { Insulation - Not Available }\end{array}$ & $\begin{array}{c}\text { Outer Pipe Diameter-90 } \\
\text { Inner Pipe Diameter- } 27\end{array}$ & 10 & 1000 & 3 \\
\hline $\begin{array}{l}\text { GTMHR } \\
\text { US } \\
\text { Planning Phase }\end{array}$ & $\begin{array}{l}\text { Internal } \\
\text { Insulation }\end{array}$ & $\begin{array}{c}\text { Outer Pipe - Alloy } 800 \mathrm{H} \text { (Nickel } \\
\text { Superalloy) } \\
\text { Insulation - Ceramic Fiber }\end{array}$ & $\begin{array}{l}\text { Outer Pipe Diameter - } 152 \\
\text { Inner Pipe Diameter - } 104\end{array}$ & 600 & 1120 & 0.7 \\
\hline $\begin{array}{l}\text { UHTREX } \\
\text { US } \\
1966-1970\end{array}$ & $\begin{array}{l}\text { Internal and } \\
\text { External } \\
\text { Insulation }\end{array}$ & $\begin{array}{c}\text { Piping - 304SS/106 Carbon Steel } \\
\text { Internal Insulation - Stainless Steel } \\
\text { Foil Reflector } \\
\text { External Insulation - Calcium Silicate }\end{array}$ & Pipe Diameter - 36 & 3 & 1590 & 3.4 \\
\hline $\begin{array}{l}\text { Dragon } \\
\text { UK } \\
1964-1989\end{array}$ & $\begin{array}{l}\text { Internal } \\
\text { Insulation }\end{array}$ & $\begin{array}{c}\text { Piping - Not Available } \\
\text { Insulation - Multilayer Nimonic } \\
\text { Liners (Nickel Superalloy) }\end{array}$ & Pipe Diameter - 19 & 20 & 1020 & 2.2 \\
\hline $\begin{array}{l}\text { Fort Saint Vrain } \\
\text { US } \\
1974-1989\end{array}$ & $\begin{array}{l}\text { Internal } \\
\text { Insulation }\end{array}$ & $\begin{array}{l}\text { Outer Pipe - Carbon Steel } \\
\text { Insulation - Ceramic Fiber }\end{array}$ & Not Available & 842 & 1050 & 4.8 \\
\hline
\end{tabular}




\section{HTGR References}

HTTR, Peach Bottom, and Dragon (Simnad, 1991) and (Brey, 2001); HTR-10 (Xu, 2000), GTMHR (Potter, 1996); UHTREX (Simnad, 1991) and (Simnad, 1971); and Fort Saint Vrain (Simnad, 1991), (Brey, 2001), and (IAEA, 2001).

\section{Manufacturability Assessment}

All of the concepts considered would have required some level of manufacturing development for the assembly process of the internal insulation and/or concentric piping/liner within the outer pipe. However, the internally insulated concept was the most straightforward to manufacture. This concept has only one outer pressure boundary and internal insulation with a slip fit liner. The remaining concepts utilize concentric welded pipes with an optional lined insulation layer. The process to fabricate concentric welded pipes would require significant development. Additionally, multiple concentric pipes make examination of the piping welds more difficult and increase component interface complexity.

\section{Concept Comparison Discussion}

Hydraulic performance, thermal performance, and manufacturability proved to be the major concept discriminators between the four concepts under comparison. Given the constraint of a fixed maximum allowable hot leg pipe outer diameter, the internally insulated hot leg piping concept had significant advantages over the other concepts considered. The counter flow and bypass flow concepts were eliminated due to inferior thermal and hydraulic performance. The un-insulated stagnant gas layer concept achieved equivalent thermal performance to the internally insulated concept, but with a pressure drop penalty. The insulated stagnant gas layer concept achieved equivalent thermal and hydraulic performance to the internally insulated concept, but with a manufacturability penalty. Table 5 presents a summary of the primary grounds for concept elimination.

TABLE 5: Eliminated Concepts.

\begin{tabular}{lcc}
\hline Eliminated Concept & Primary Reason for Elimination & Secondary Reason for Elimination \\
\hline Counterflow without Insulation & Decrease in Cycle Efficiency & Manufacturing Complexity \\
Counterflow with Insulation & Pressure Drop & Manufacturing Complexity \\
Bypass Flow without Insulation & Decrease in Cycle Efficiency & Manufacturing Complexity \\
Bypass Flow with Insulation & Decrease in Cycle Efficiency & Manufacturing Complexity \\
Stagnant Gas Layer without Insulation & Pressure Drop & Space Temperature Sensitivity \\
Stagnant Gas Layer with Insulation & Manufacturing Complexity & N/A \\
\hline
\end{tabular}

Hydraulic calculations, based on early arrangement studies, indicated that pressure losses within the SNPP piping system were significant enough to have a major impact on cycle efficiency. Although the results were based on preliminary piping arrangements, the magnitude of the calculated losses indicated that piping pressure drops would continue to be a major driver in arrangements and system design and performance. The internally insulated concept provided the largest design space, since it resulted in the lowest pressure drop while maintaining the required pressure boundary surface temperature of $900 \mathrm{~K}$. In addition, there is greater fabrication complexity with the alternate designs with no benefits.

\section{DEVELOPMENT EFFORTS}

The internally insulated nickel superalloy hot leg concept presented a number of significant development issues including: material selection, manufacturability, modeling and testing, and placement of the turbine entrance temperature sensor. The following sections briefly describe the development efforts that the NRPCT would have focused on to deliver the internally insulated hot leg piping concept. 


\section{Material Selection}

In order for the internally insulated hot leg piping concept to have adequately performed hydraulically, thermally, and structurally, appropriate materials would need to have been selected. In addition, the chosen materials would need to have met all system requirements and constraints. Final selection of the reactor plant materials would not have occurred for several years due to radiation testing and other long term materials testing; however, preliminary material selection would have been required in the near term to support conceptual design and proof of principal testing. Material development efforts would have been required for the outer pipe, insulation, and liner.

\section{Manufacturability}

The purpose of a manufacturability study would have been to determine the feasibility of acquiring and assembling the hot leg piping. Manufacturability issues for the internally insulated nickel superalloy hot leg piping include material availability, piping assembly, and component interfaces which include insulation containment and issues associated with joining the hot leg piping to both the turbine inlet and reactor pressure vessel outlet.

\section{Modeling and Testing}

Analytical models would have been utilized to further develop the internally insulated nickel superalloy hot leg piping concept. Testing would have been used to qualify these analytical models. The initial testing would have focused solely on a straight section of piping, followed by introducing bends and tees into the test section. Thermal, hydraulic, and structural modeling would have been qualified by these tests.

\section{Turbine Entrance Temperature Sensor Placement}

The temperature of the gas in the hot leg piping may have to have been monitored to supply feedback for reactor control. It was desired that the sensors making this measurement be as non-invasive as possible in order to minimize flow disruptions and discontinuities in the pressure boundary. The inherent response times of all sensors which were under consideration for measuring the coolant are on the order of several milliseconds. Placing them outside the gas stream would have introduced a finite delay time for the temperature at the sensor location to reach equilibrium during a transient. This delay time would have depended primarily on the heat transfer properties of the piping configuration and would dominate the response time of the hot leg temperature sensor.

The non-invasive requirement for the hot leg temperature sensor must therefore be evaluated against impacts on reactor control response time. Other factors affecting sensor placement include sensor accuracy and resolution, temperature tolerance, sensor size, and feasible attachment methodologies. The sensor technologies under consideration for measuring the hot gas temperature were ultrasonics, thermocouples, resistance temperature devices (RTDs), optical pyrometry, and fiber Bragg grating.

\section{CONCLUSIONS}

The baseline SNPP incorporates a piping system which circulates He-Xe coolant through the reactor and closed Brayton energy conversion system. Due to the elevated gas temperature in the section of piping between the reactor and the turbine, the hot leg piping, additional design features were required to allow the use of a non-refractory metal pressure boundary. In order to maintain the hot leg piping pressure boundary temperature at $900 \mathrm{~K}$, several concepts were developed which would reduce the pressure boundary temperature by adding additional layers of heat transfer resistance and/or cooling while protecting the pressure boundary from direct contact with the high temperature gas. The hot leg piping concepts compared include four main variations termed internally insulated, counter flow, bypass flow, and stagnant gas layer.

The hot leg piping concepts were compared based on thermal and hydraulic performance and manufacturing complexity. Based on these comparison criteria, the NRPCT recommended continued development of a nickel superalloy pipe with lined insulation on the inner surface of the piping. The internally insulated hot leg piping 
concept proved equivalent or superior to the other concepts considered, with respect to the selection criteria. This concept resulted in the least complex design and the largest gas flow area while maintaining the required pressure boundary temperature. However, further development efforts would have been required to overcome challenges in material selection, manufacturability, modeling and testing, and the placement of the turbine entrance temperature sensor for the recommended hot leg piping concept.

\section{NOMENCLATURE}

$\mathrm{S}_{\mathrm{mt}}=$ Time dependent stress design limit

$\Delta \mathrm{P} / \mathrm{P}=$ Piping pressure drop divided by the compressor outlet pressure

\section{ACKNOWLEDGMENTS}

The NRPCT acknowledges the support received from NASA Glenn Research Center.

\section{REFERENCES}

ASME, ASME Boiler and Pressure Vessel Code, Section III, Division 1, Subsection NB, The American Society of Mechanical Engineers, New York, 2004, pp. 114-116.

Bassford, T.H., "Inconel Alloy 617 Data Package," INCO Alloys International, Huntington, 1982.

Brey, H.L., "Development History of the Gas Turbine Modular High Temperature Reactor" in IAEA-TECDOC-gtpc, edited by Dutch Uselton, International Atomic Energy Agency, Vienna, 2001, pp. 25-44.

Corum, J.M., "Rules for Design of Alloy 617 Nuclear Components to Very High Temperatures," in PVP, Vol. 215 (1991).

ESDU, Engineering Sciences Data, Fluid Mechanics, Internal Flow, Vol. 2 Bends, Branches, and Junctions, London, 1990, Items 73022,73023 , and 83037.

Graham, L.W. "High Temperature Corrosion in Impure Helium Environments," in High Temperature Technology, Vol. 3 , No. 1 (1985).

IAEA, "The HTTR and HTR-10 Test Reactors" in IAEA-TECDOC-1198, edited by IAEA, International Atomic Energy Agency, Vienna, 2001, pp. 115-140.

Nayyar, M.L., Piping Handbook, McGraw-Hill, Inc., New York, 1992, pp. A305.

Potter, R.C., Gas Turbine-Modular Helium Reactor (GT-MHR) Conceptual Design Description Report, General Atomics, San Diego, 1996, pp. 4.1-4.164.

Simnad, M.T., Fuel Element Experience in Nuclear Power Reactors, Gordon and Breach, New York, 1971.

Simnad, M.T., "Early History of High Temperature Helium Gas-Cooled Nuclear Power Reactors," in Energy, Vol. 16, No. 1/2 (1991),

Xu, Y., High Temperature Gas Cooled Reactor Programme in China, Institute of Nuclear Energy Technology - Tsinghua University, Beijing, 2000, pp. 1-7. 
Enclosure 7 to

SPP-SEC-0039

\section{Reactor Instrumentation and Control: Systems and Sensors}

Loomis, K.C.

Boyle, J.A.

Robare, D.J. 
This page is intentionally blank.

PRE-DECISIONAL - For planning and discussion purposes only 


\title{
Space Nuclear Power Plant
}

\section{Reactor Instrumentation and Control System and Sensors}

Kent Loomis, John Boyle

Space Electrical Systems - Lockheed Martin

\author{
Darren Robare \\ Space I\&C - Bechtel
}

STAIF 2006

February 2006 


\section{Sensing System Architecture}

-Expected I\&C architecture uses point to point wiring and no multiplexer

-A trade study was conducted on use of a multiplexer behind the shield - results showed significant mass penalty $(>250 \mathrm{~kg})$

-Point to point approach more tolerant to part and cable failures

-Places additional burden on electronics due to $50 \mathrm{~m}$ cable length 


\section{Sensing System Environments}

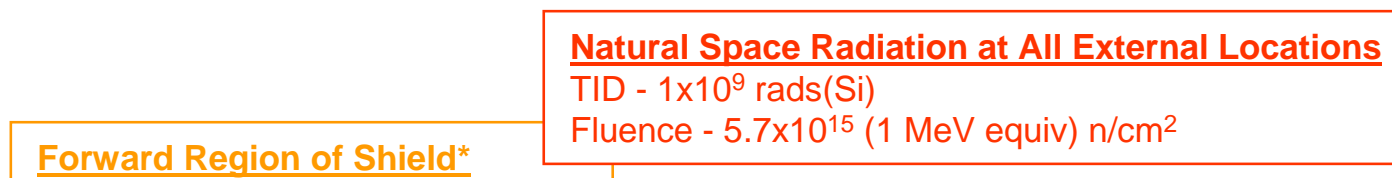

Forward Region of Shield*

$<800 \mathrm{~K}$ Interior Shield

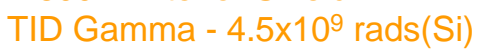

Fluence Neutron $-3.8 \times 10^{19} \mathrm{n} / \mathrm{cm}^{2}$

*Reactor contribution only

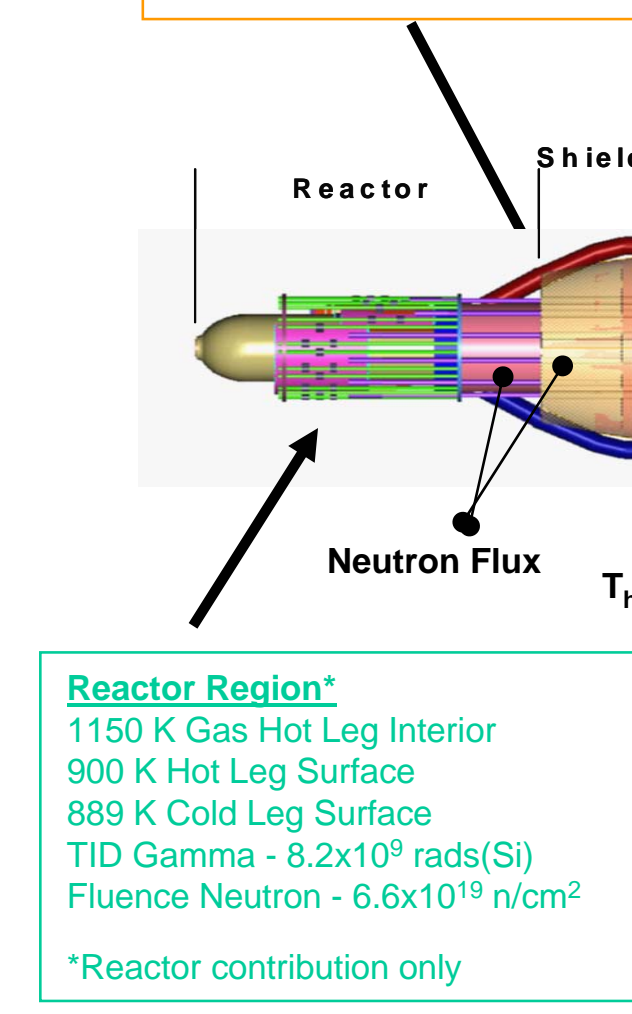
Neutron Flux

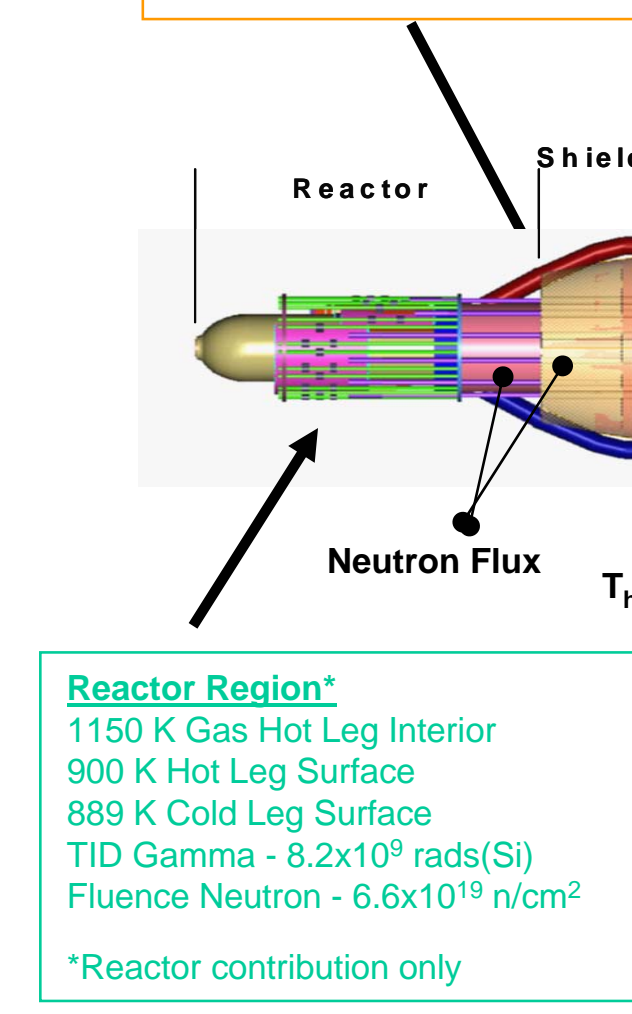

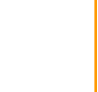

CDM/Power Conversion Region*

$900 \mathrm{~K}$ Hot Leg Surface

$400 \mathrm{~K}$ conduit for cables

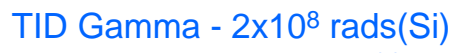

Fluence Neutron - $6 \times 10^{14} \mathrm{n} / \mathrm{cm}^{2}$

${ }^{*}$ Reactor contribution only

Power Conversion CDM 's
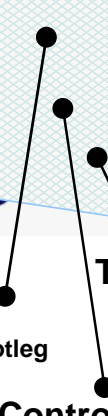

Control Element

Position

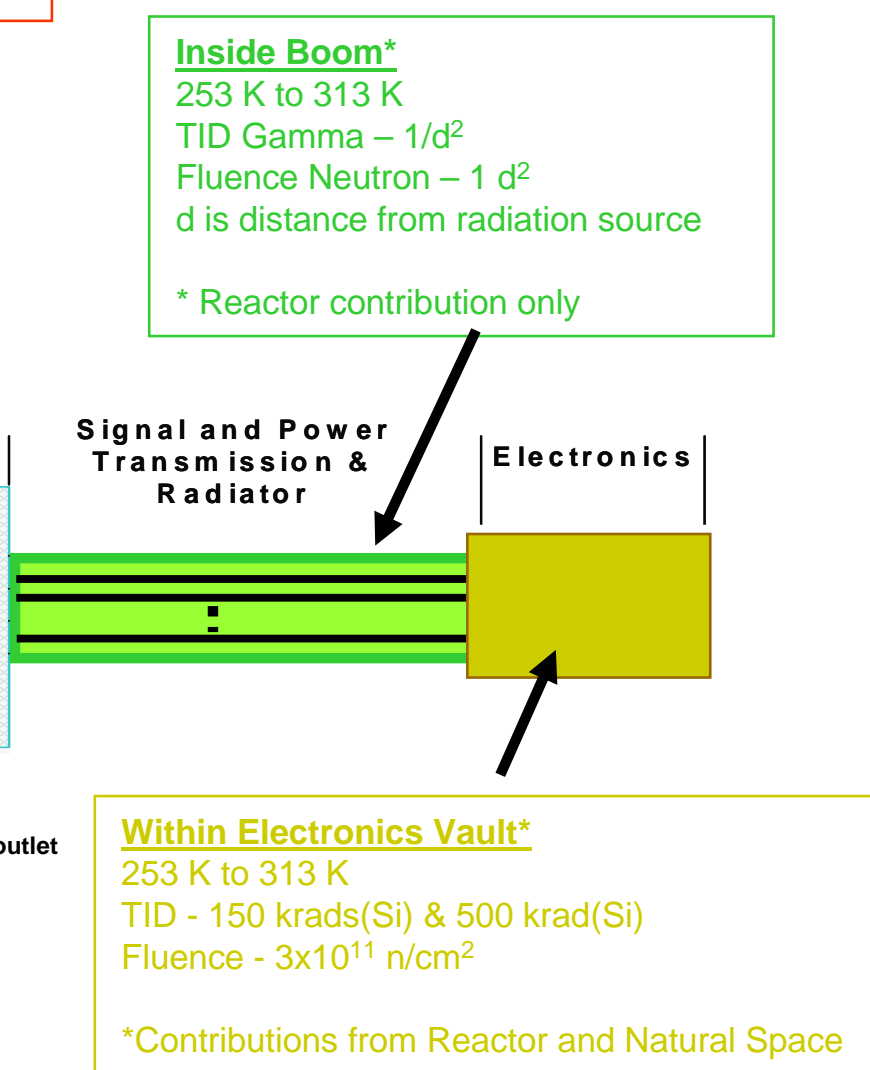




\section{Spacecraft System Architecture}

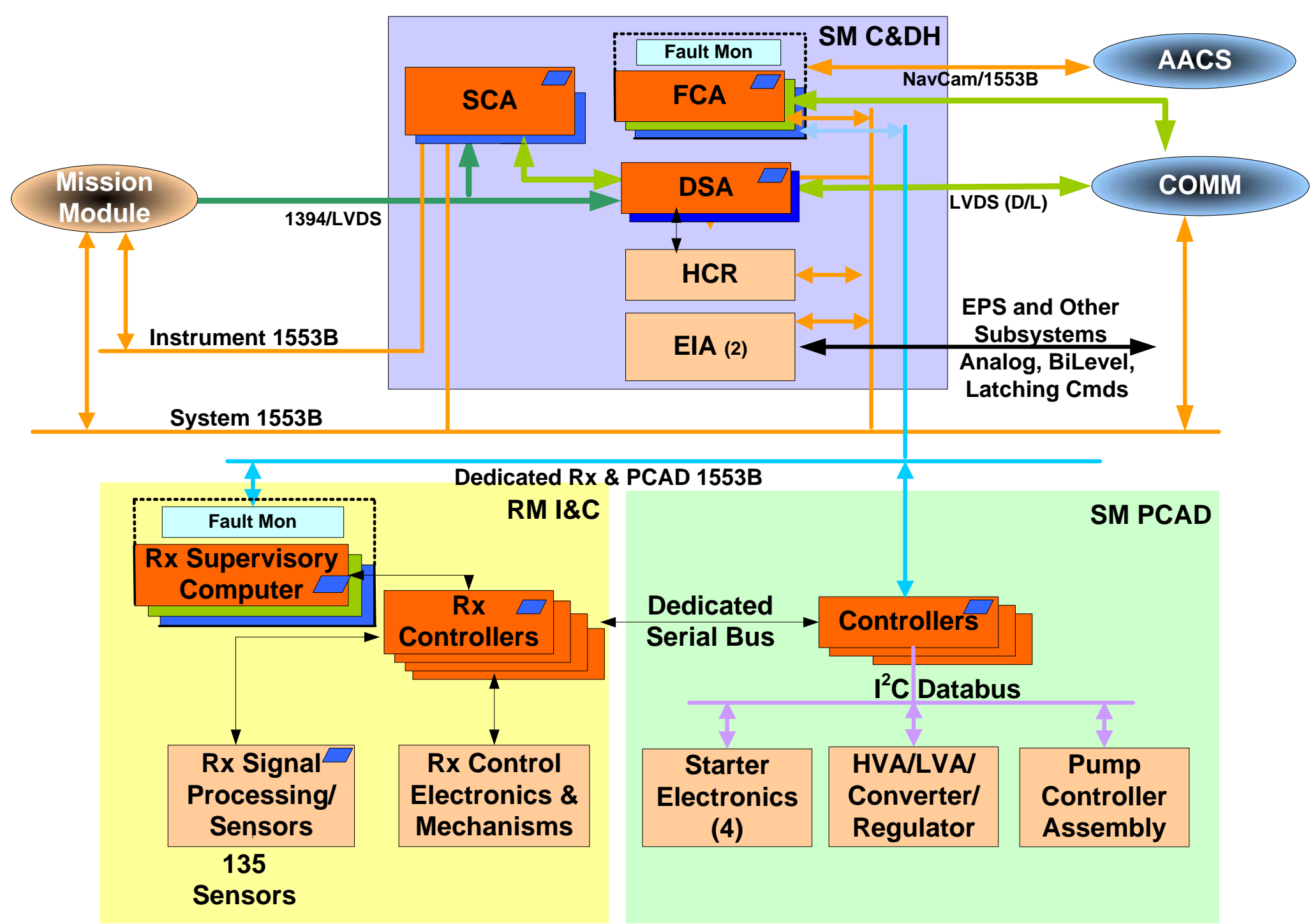




\section{Reactor I\&C Architecture}

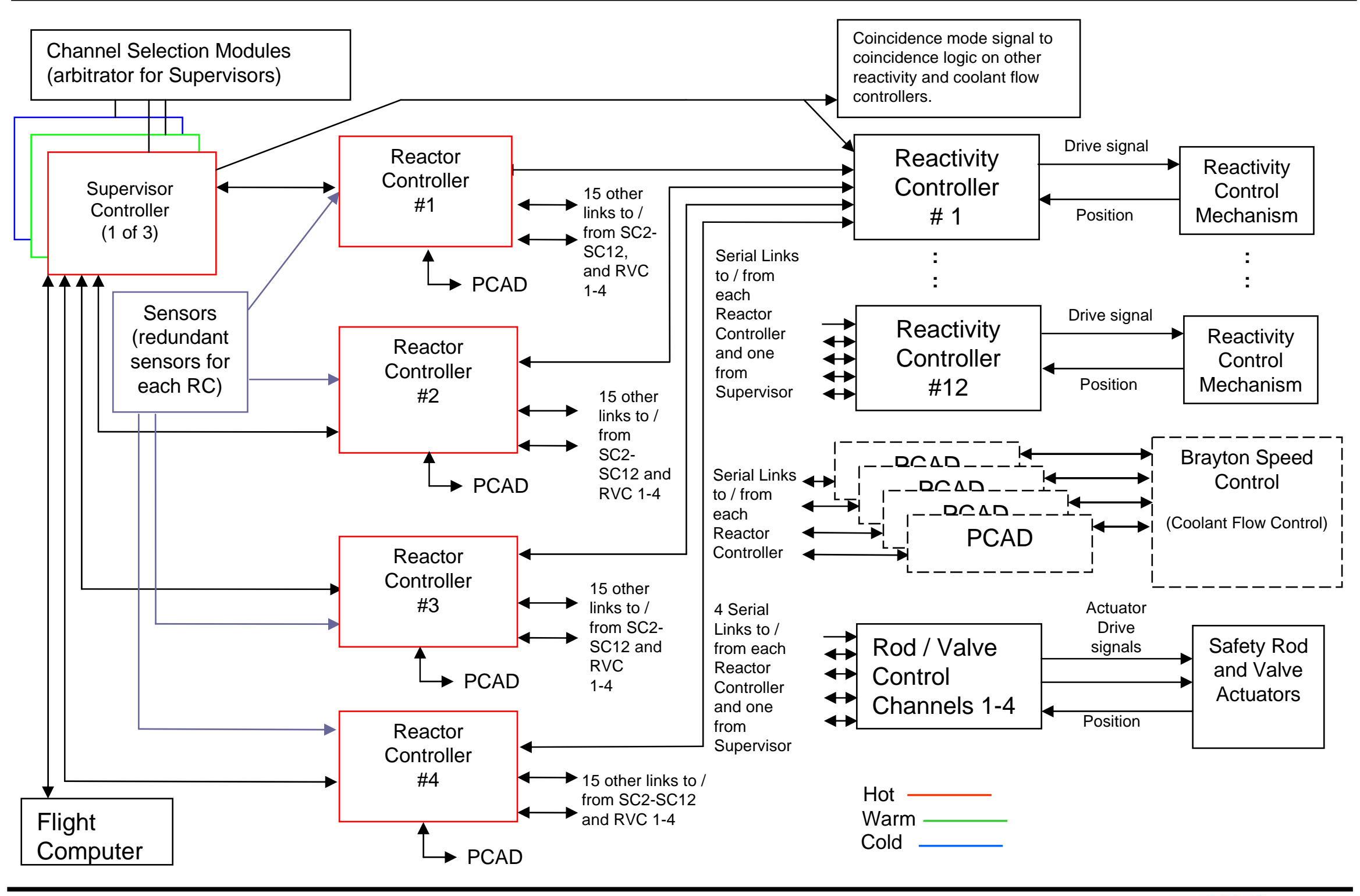

STAIF, February 2006 


\section{Sensing Needs}

- Reactor

- Temperature

- Primary state variable for reactor control

- Pressure

- Indicator of gas inventory

- Flow

- Indicator of abnormal flow conditions

- Mechanism Position

- Reactor startup

- Diagnostics for stuck mechanism

- Nuclear

- Reactor startup

- Indication of abnormal/unexpected reactor transients

- PCAD

- Electric Power, Current, Voltage, Frequency

- Brayton Speed/Voltage Primary state variable for PLR control

- HRS Temperatures, Flow 


\section{Reactor Coolant Temperature}

- Measure reactor coolant temperatures for plant and component control

- "Considered the most desirable of the reactor parameters for control."

- Range of measurements:

- Reactor Hot Leg - $1150 \mathrm{~K}$

- Compressor Inlet - $390 \mathrm{~K}$

- Reactor Cold Leg - 890K

- Plant performance desires good accuracy $\sim+/-5 \mathrm{~K}$.

- Larger uncertainties introduce severe mass penalties on plant

- Hot leg temperature is the most challenging sensor problem

- Most demanding accuracy, reliability, response, durability and integrity requirements in most severe sensor environment

- Range of measurement $250 \mathrm{~K}-1200 \mathrm{~K}$

- Drift characteristics problematic for conventional sensors (RTDs, T/Cs)

- Difficult to fixture:

- Insulated non-refractory pipe

- May require well for adequate response time

- Most Promising Technologies

- Optics (Fiber Bragg Grating)

- Ultrasonics

- High Temperature RTD 


\section{Fiber Bragg Grating Temperature}

- Obtain Temperature from a shift in reflected wavelength

- Applicable to sensing in extreme environments

- Wavelength encoded

- Sensor system can withstand radiation induced attenuation in fiber

- Gratings written on Sapphire fiber*

- Tested to $1800 \mathrm{~K}$

- Issues with radiation hardness of electronics, ie. Optical detector
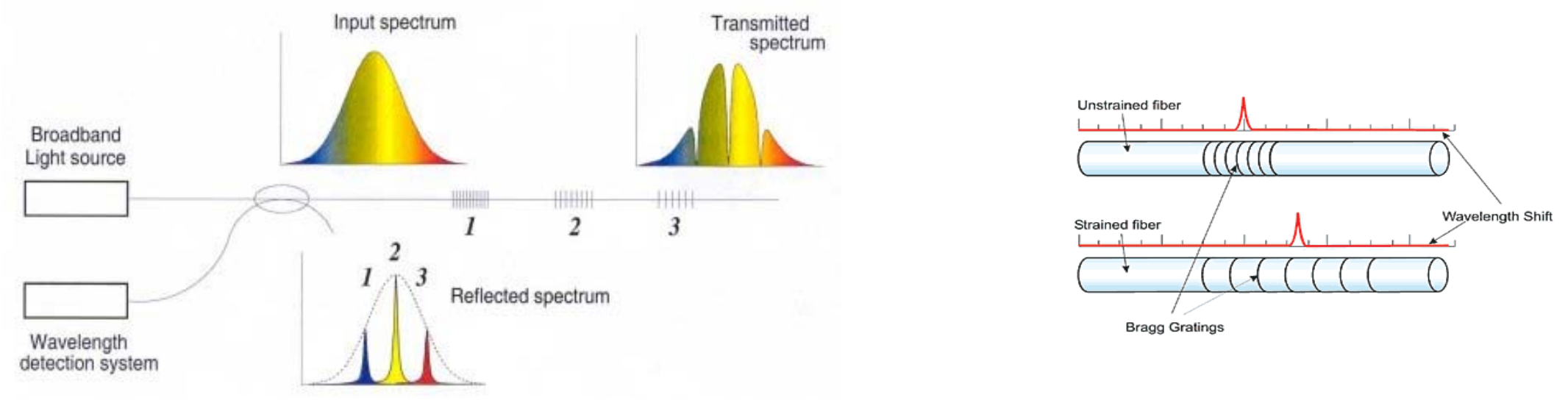

*IEEE Photonics Technology Letters, 16, no. 11, 2004 


\section{Ultrasonic Temperature}

- Measures the Time of Flight of an acoustic wave in a notched wire waveguide.

- Obtain temperature by calculating the speed of sound in the tip.

- Applicable to sensing in extreme environments (high radiation fields, high temperatures, corrosive, etc.). Typically a research tool.

- Capable of transmitting through pressure boundaries

- Issues with interfering signals and signal-to-noise ratio

- New as an power plant operational temperature sensing technology
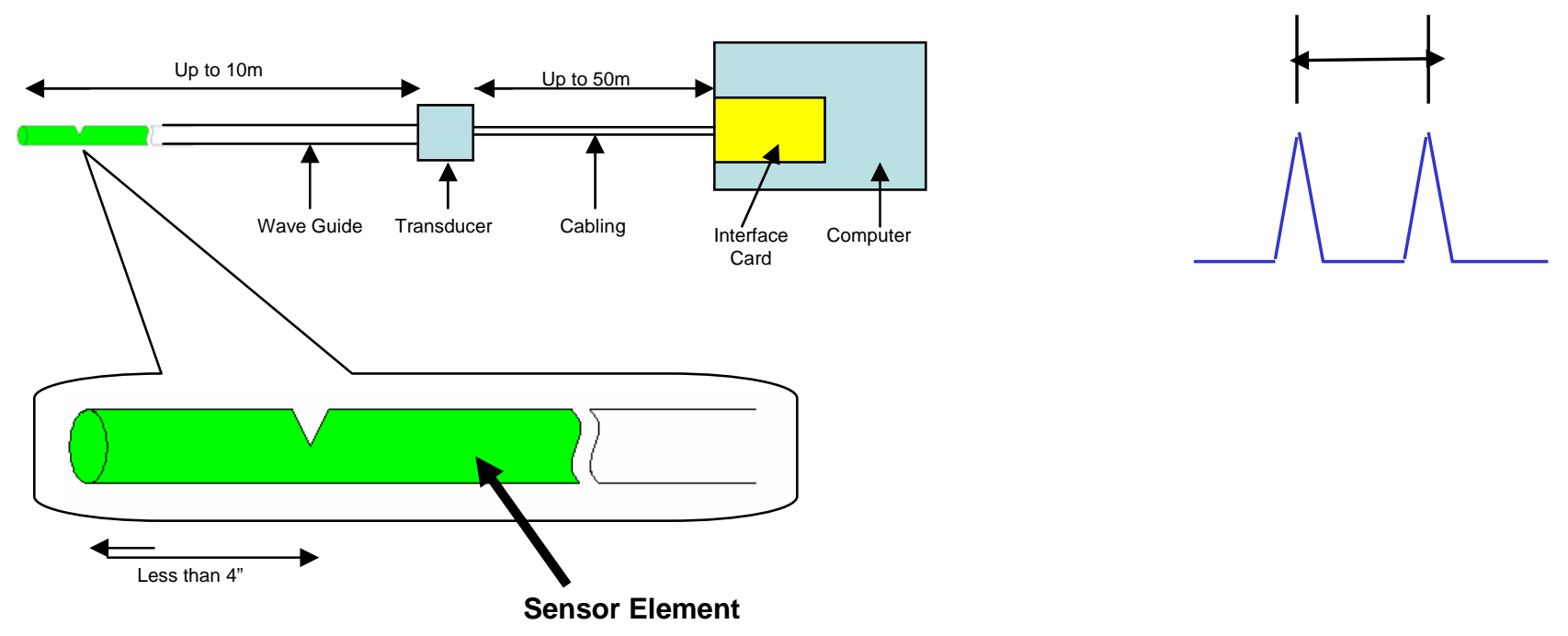


\section{High Temperature RTD}

- RTD conventional technology choice

- Use in lower temperature portions of plant straightforward

- Platinum elements good to approximately $\sim 600 \mathrm{~K}$

- Platinum elements not suitable for higher temperature service due to recrystallization and grain growth

- Possible choices for higher temperature elements:

- Pt-Ir alloy

- Refractory metals

- Ceramic elements

- Insulators appear to be available (Alumina, Beryllia, etc.)

- Calibration

- Johnson noise calibrate feasible, but very challenging

- Low signal level

- Distance to electronics

- EMI from power system 


\section{Nuclear}

- Measure full range of neutron flux from reactor with a single detector

- Fission Counter

- Well known technology

- High temperature capability to $800 \mathrm{~K}$

- Good Lifetime

- Relatively low voltage (500V)

- $\quad$ Silicon Carbide

- Lower mass

- Developmental - issues with sensitivity and lifetime

- Very low bias voltage (30V - 200V)

- Both technologies may permit simple pulse counting signal process for power calculation

- Integration of detector in shield or reflector minimizes mass, size, and other impacts

- Forward of shield in Fixed Reflector

- No high temperature detector technology available

- Location has excellent sensitivity over full range and core life with no major effects to mass or other systems

- In-Shield

- Moderate temperature - detector technologies exist

- Location has good sensitivity, but potential impacts to shielding and other system designs

- Aft of Shield

- Moderate temperature - commercial detector technology adequate

- Inadequate sensitivity for startup

- Fission Counter Considered Best Choice for Spacecraft Reactor 


\section{Reactor Coolant Pressure}

- Measure maximum reactor coolant gas pressure for reactor and Brayton machine control

- Gas cooled reactor plant demands non-invasive measurements

- Possible Choices

- Ultrasonic Gas Resonance

- More developmental

- Some use in simple high pressure gas systems (100-300 MPa)

- Moderate pressure (1-3 MPa ), complicated systems not demonstrated

- Ultrasonic with Bellows or Diaphragm

- Capture method provides leak barrier

- Time of flight method

- Within capabilities of available technologies

- Could also use LVDT (Linear Variable Differential Transformer) with Bellows

- Location of sensor in cold portion of system greatly reduces it risk and development costs. 


\section{Reactor Coolant Flow}

- Reactor volumetric flow during startup, normal operations, and unusual events for plant control.

- Ultrasonics only technology considered

- Non-invasive

- Low temperature coolant loop location preferable

- Examples currently applied in gas industry

- Three possible methods

- Vortex shedding

- Count vortices shed by blunt body in flow stream

- Cross correlation

- Match upstream flow pattern at time $t$ with downstream pattern at time $t+\delta t$

\section{$L=$ Flight Path in Gas \\ $D=$ Inside Diameter \\ $x=$ Axial Flow Path}

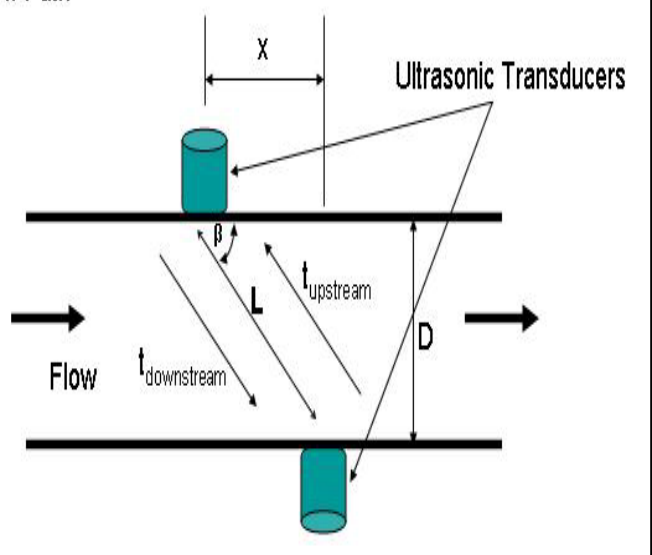

$\beta=$ angle between the acoustic path and the direction of flow

- Time of flight

- Velocity inferred from difference between upstream and downstream propagation times

- Best approach - Time of flight

- No blunt body in flow stream

- Simplest signal processes 


\section{Reflector Position}

- Absolute position measurement and motion verification

- Control Drum - Rotary Position Sensor

- Ultrasonic, resolver, Hall effect, capacitance, ..., considered

- Resolver best approach - Size, Range, Robustness, Maturity

- Slider Control Element - Linear Position Sensor

- Ultrasonic, LVDT, and capacitance considered

- Ultrasonic best approach - Size and weight

- LVDT feasible, but higher mass and size

- Attached to Control Drive Mechanism

- If temperature $<400 \mathrm{~K}$, sensor material selection greatly simplified.

- Sensor size a significant impact on plant arrangement aft of shield 


\section{Conclusions}

- I\&C System Architecture

- SNPP I\&C System Architecture Conceptual Design Established to Meet Prometheus (JIMO) Requirements

- Software Rich Control System to Enable In-Flight Modifications and Ease in Development with an Aggressive Schedule

- Sensors

- Hot leg temperature sensor feasible, but most challenging

- Remaining plant sensors (flow, pressure, cold leg temperatures) may be more reliable (certainly more feasible) and may provide alternative plant control opportunities

- Position and Nuclear sensors feasible

- Optical approach allows many sensors on one fiber

- Ultrasonic methods allow single interface card for several sensor types 
Enclosure 8 to

SPP-SEC-0039

\title{
Fuel for Thought: Considerations for a Space Nuclear Reactor
}

\author{
Simonson, S., et al
}


This page is intentionally blank.

PRE-DECISIONAL - For planning and discussion purposes only 


\section{Fuel for Thought: Considerations for a Space Nuclear Reactor}

\author{
Dan Barnes \\ John Beale \\ Brian Campbell \\ Monchao Chen \\ Barri Gurau \\ John Hack \\ Shay Harrison
}

Cathy Jordan

Lynne Kolaya

Emanuel Lewis

Beth Lugert

Robert Mulford

James Nash

Ryan Nelson

George Newsome
David Noe

Michael Petranka

Barbara Pratt

Chris Regan

Stefanie Ricca

Scott Simonson

James Vollmer

Naval Reactors Prime Contractor Team

STAIF February 2006 


\section{Prometheus-1 Mission}

\begin{tabular}{|c|c|}
\hline Power & $\sim 1 \mathrm{MW}_{\text {th }} \sim 185 \mathrm{~kW}_{\mathrm{e}}$ \\
\hline Life & 20 Years \\
\hline Energy & $12-15$ years at full power \\
\hline Temperatures & $\begin{array}{c}\sim 900-1150 \mathrm{~K} \text { reactor coolant } \\
<1700 \mathrm{~K} \text { fuel }\end{array}$ \\
\hline Transients & $\begin{array}{c}\text { Startup, Up-Power \& Down- } \\
\text { Power }\end{array}$ \\
\hline Shielding & $\begin{array}{c}\text { To protect Power Plant } \\
\text { Equipment and Science } \\
\text { Package Instruments }\end{array}$ \\
\hline $\begin{array}{c}\text { Launch/Re- } \\
\text { entry Casualty }\end{array}$ & $\begin{array}{c}\text { To fit launch fairing } \\
\text { Size }\end{array}$ \\
\hline Mass & $\begin{array}{c}\text { Integrated plant mass } \\
\text { minimized }\end{array}$ \\
\hline
\end{tabular}

\section{Selection Criteria}

\section{Deliverability, Capability, Reliability, Cost, Schedule, Safety}




\section{Reactor Design}

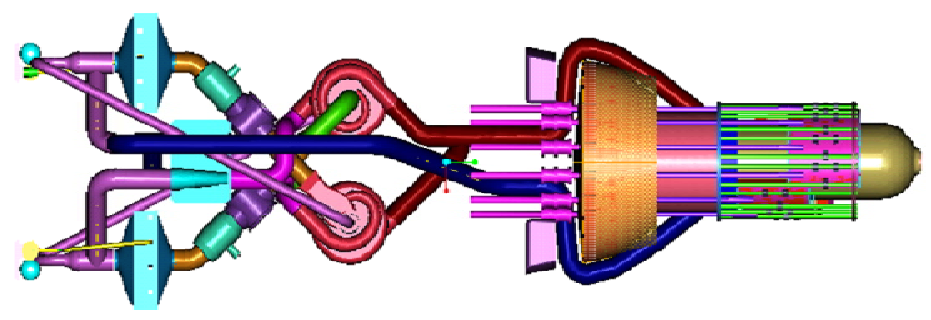

- Direct Gas Reactor Selected Because it Met Performance Requirements, Minimized Development Challenges and was Most Readily Tested
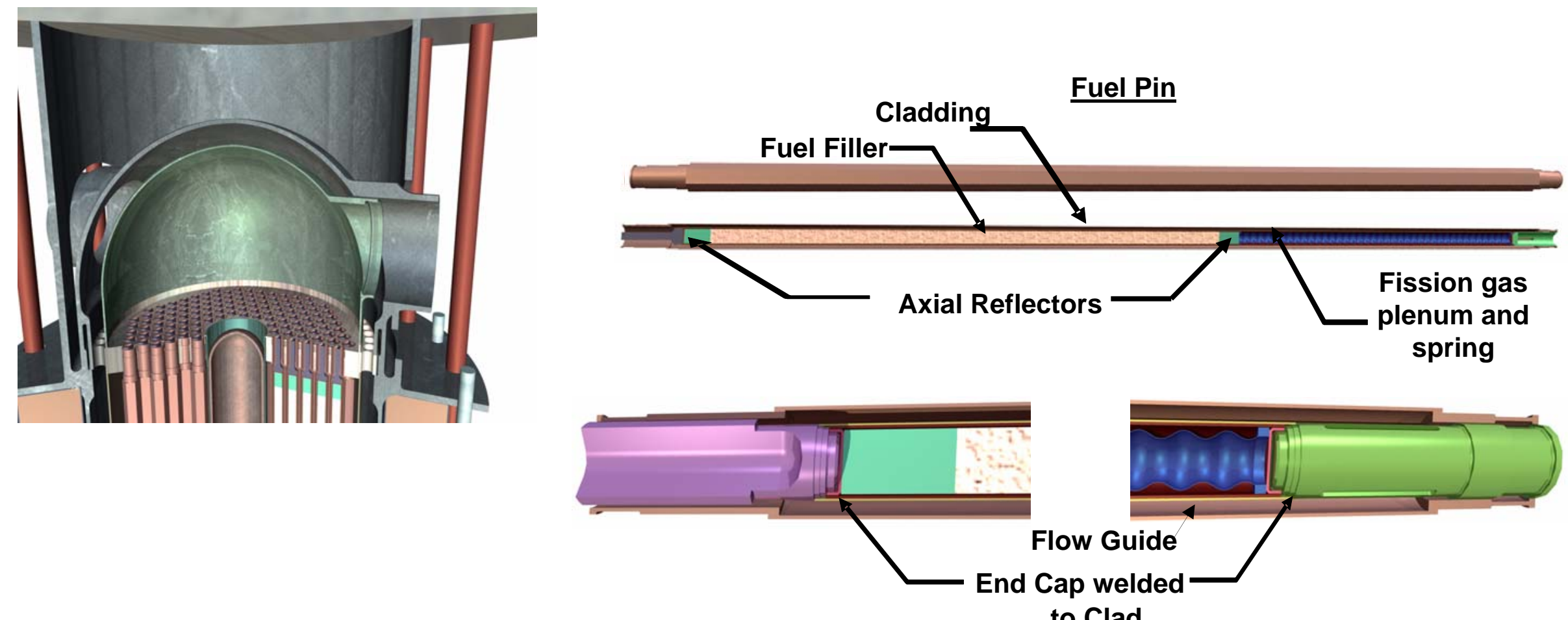

to Clad 


\section{NRPCT Fuel Achievements}

- Selected $\mathrm{UO}_{2}$ Fuel for a Prometheus Reactor

- Investigated performance of $\mathrm{UO}_{2}$

- Fission gas release and swelling

- Fission product retention

- Fuel restructuring

- Consolidated and interpreted UN database

- Teamed with LANL to re-establish UN fabrication

- Predicted irradiated thermal conductivity for UN

- Formulated novel irradiation testing designs

- Temperature accuracy

- Measure creep forces

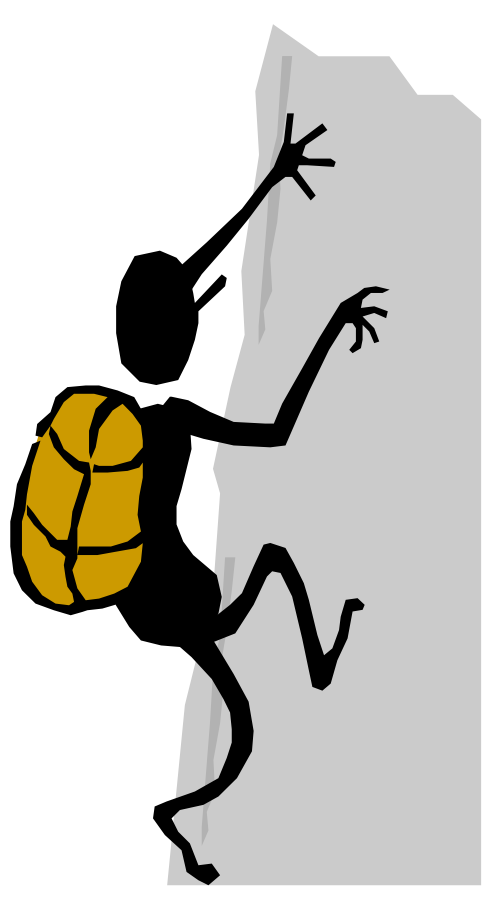




\section{Initial Fuel Consideration}

- $\mathrm{UO}_{2}$

- Best known performance of uranium-containing fuels

- Large commercial database, know correlations, fabricating and handling infrastructure established

- UN

- $40 \%$ higher $\mathrm{U}$ density than $\mathrm{UO}_{2}$

- Unirradiated and calculated irradiated thermal conductivity $10 \mathrm{x}$ higher than $\mathrm{UO}_{2}$

- Fission gas release rates lower than $\mathrm{UO}_{2}$

- $\mathrm{UC}_{\mathrm{UUC}}$

- $34 \%$ higher $\mathrm{U}$ density than $\mathrm{UO}_{2}$

- Unirradiated thermal conductivity 4-5x higher than $\mathrm{UO}_{2}$

- Thermally stable

- Other

- Hydrides

- Alloys

- Molten or gaseous phases 


\section{UC/UC ${ }_{2}$ Fuel}

- High swelling

- High gas release

- Poor thermodynamic stability of fission products (like UN)

- Poor rare-earth fission product retention

- Carbides not stable

- Eutectic formation

- Chemical attack
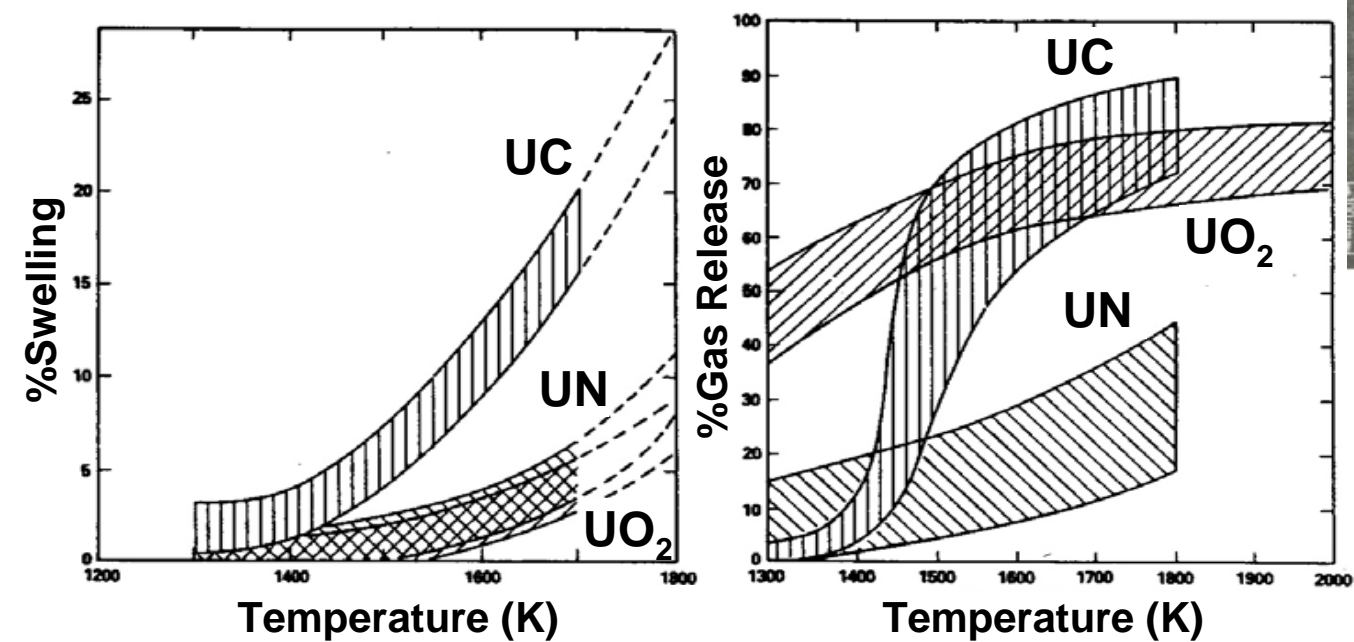

SiC coating failure

upon chemical attack

El-Genk and Hoover, Eds., "Space Nuclear Power Systems." 1984

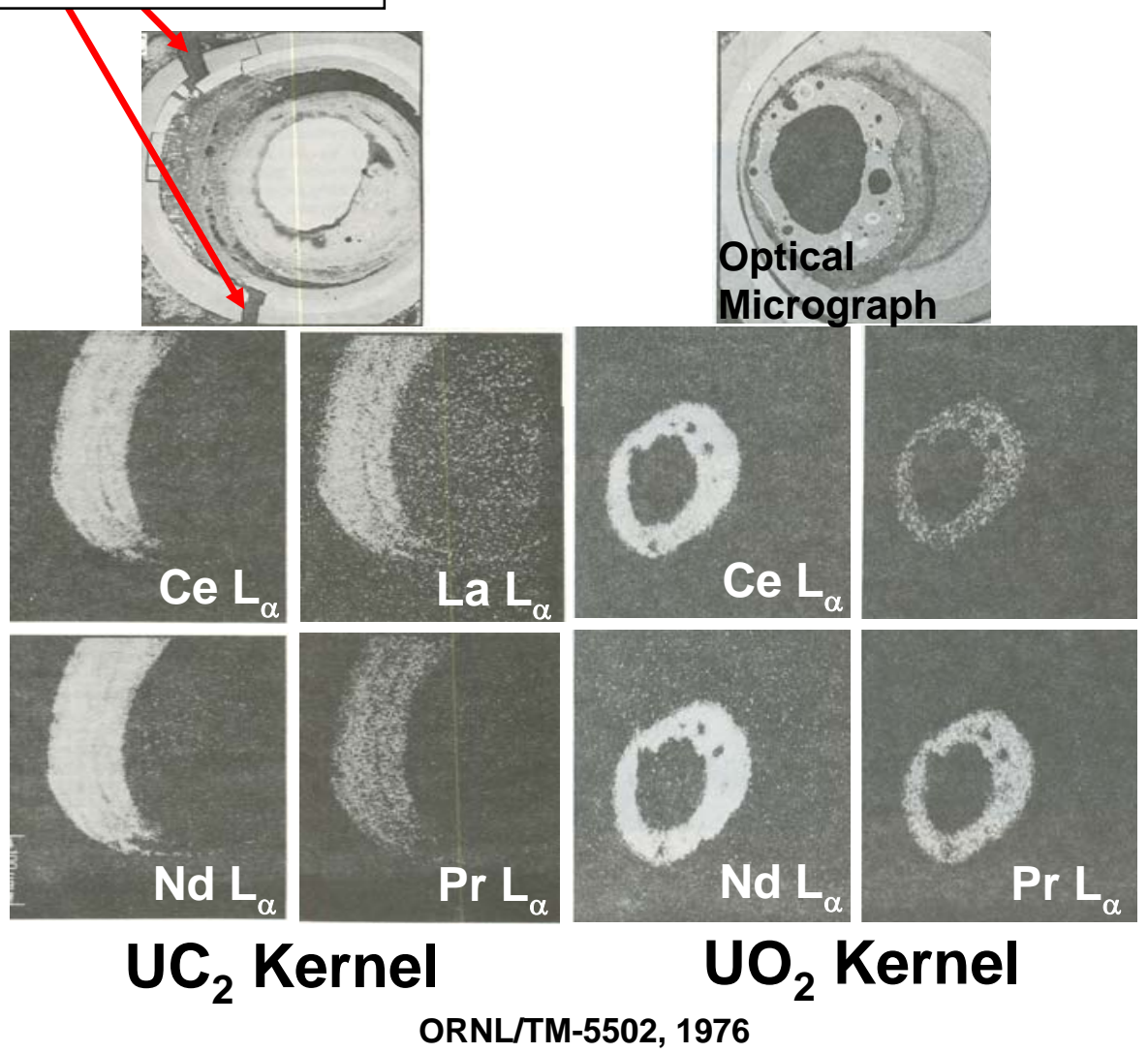

\section{Rapidly Narrowed Selection} Down To UN And $\mathrm{UO}_{2}$ 


\section{Technical Issues/Uncertainties}

\begin{tabular}{|l|l|}
\hline \multicolumn{1}{|c|}{ UN } & \multicolumn{1}{|c|}{$\mathbf{U O}_{\mathbf{2}}$} \\
\hline Chemical compatibility with clad/liner materials & $\begin{array}{l}\text { Fission gas release (including long term diffusive } \\
\text { gas release) at low burnup rate - insufficient data }\end{array}$ \\
\hline $\begin{array}{l}\text { Swelling (constrained and unconstrained) vs. } \\
\text { temperature and burnup }\end{array}$ & $\begin{array}{l}\text { Constrained swelling and mechanical behavior at } \\
\text { low burnup rate - insufficient data }\end{array}$ \\
\hline Unknown transient behavior & $\begin{array}{l}\text { Transient behavior: } \mathrm{UO}_{2} \text { pellets almost always } \\
\text { crack during temperature changes in commercial } \\
\text { reactors }\end{array}$ \\
\hline $\begin{array}{l}\text { Lack of experimental data collected for } \\
\text { irradiated thermal conductivity (verify or } \\
\text { disprove theoretical calculations) }\end{array}$ & $\begin{array}{l}\text { May be less suitable for accelerated irradiation } \\
\text { testing since this would push the fuel into a } \\
\text { restructuring regime }\end{array}$ \\
\hline $\begin{array}{l}\text { Effect of loss of hermeticity on chemical } \\
\text { stability }\end{array}$ & \\
\hline $\begin{array}{l}\mathrm{N}_{2} \text { overpressure thermodynamically predicted } \\
\text { to be unnecessary; kinetics unknown }\end{array}$ & \\
\hline
\end{tabular}




\section{SP-100 UN Fission Gas Release}

- Fission gas calculations based on design fuel temperature

- Test capsule design complex

- Data only report cladding temperatures estimated from reactor coolant temperature

- Fuel bowed and gap closed

- Uncertain about true fuel temperature

- Use of SP-100 fuel design temperature under predicts both fission gas release and swelling

- Recalculated with design clad temperature $+100 \mathrm{~K}$ (same as swelling)
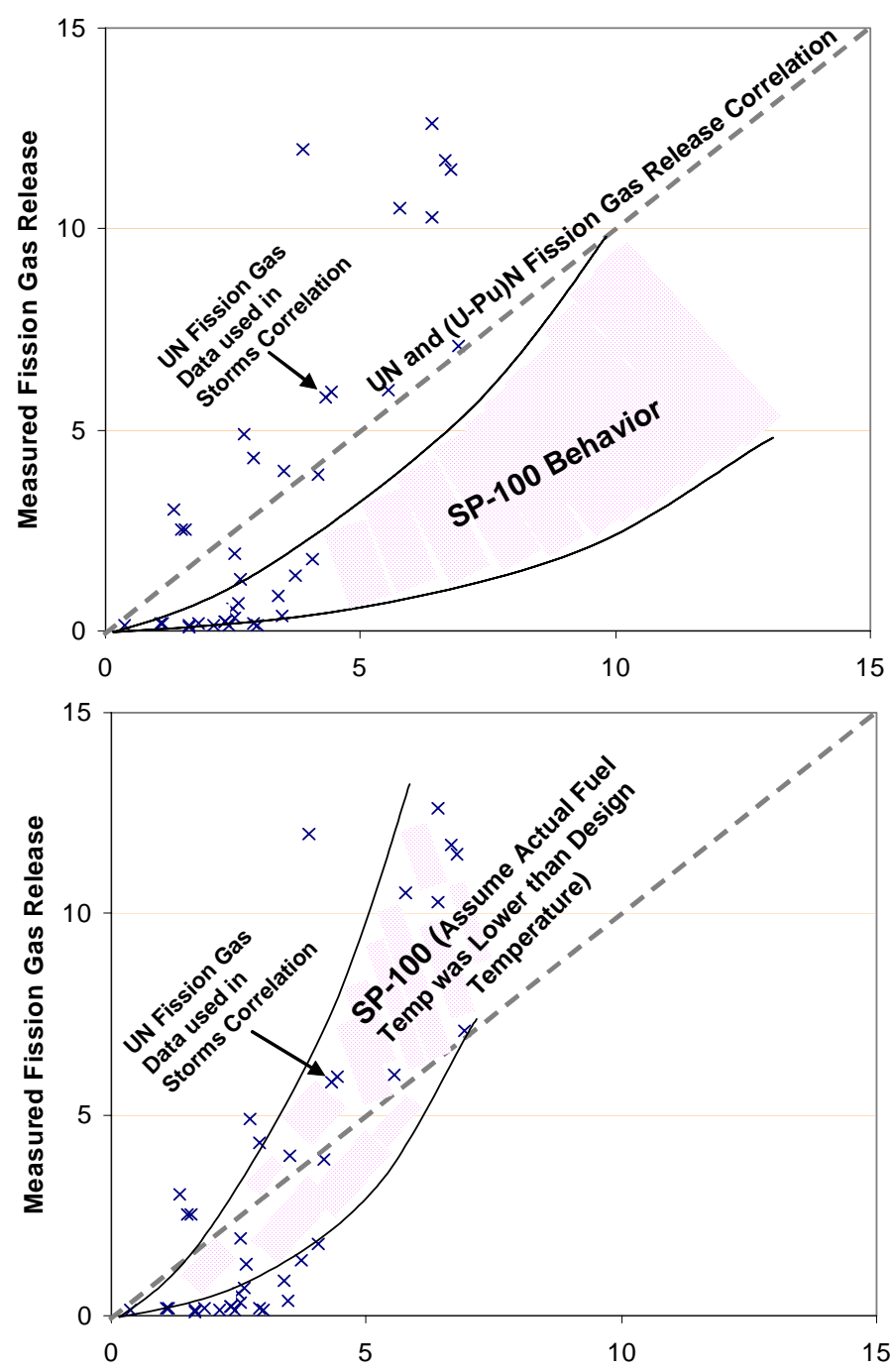

Storms Predicted Fission Gas Release

R. B. Matthews. Podolsk-Moscow, Russia, September (1993).

$x$ Storms UN Data

SP-100 Data 


\section{UN Swelling}

\section{SP-100 Swelling}

Assume SP-100 Fuel Temp 170K Below Design Temp

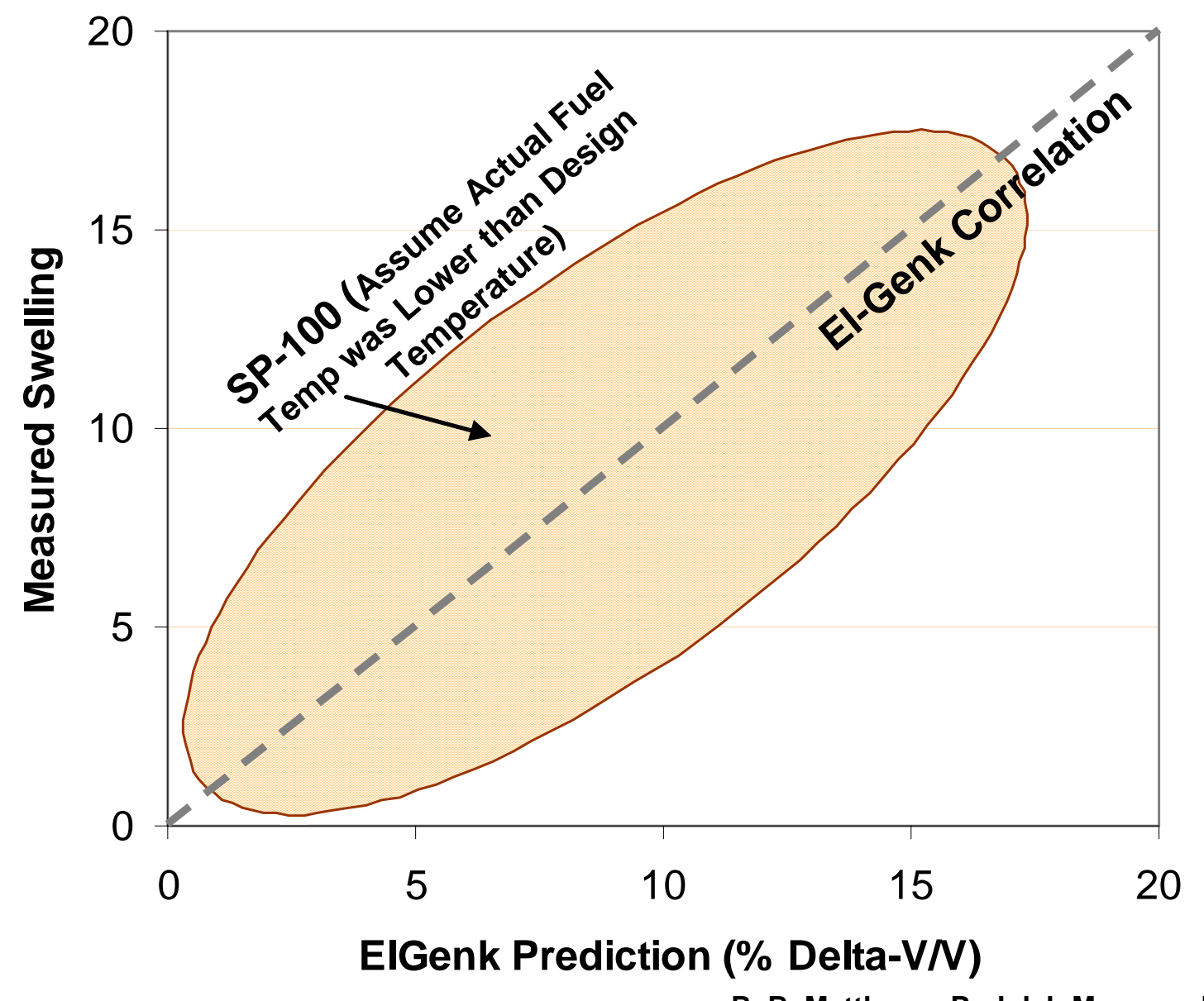

R. B. Matthews. Podolsk-Moscow, Russia, September (1993). Ross, El-Genk, and Matthews. 1990. J. Nucl. Materials, 170:169-177 


\section{UN Thermal Conductivity $(\kappa)$}

- Predicted thermal conductivities of $95 \%$ dense $\mathrm{UO}_{2}$ and $\mathrm{UN}$, irradiated to $3 \%$ FIMA

- Irradiated UN thermal conductivity much higher than $\mathrm{UO}_{2}$ at same burnup

High $\kappa$ Reduces $\Delta \mathrm{T}$ Across UN:

- Lowers PCT

- Minimizes Diffusion Of Fission Products

- Little Or No Fuel Restructuring Reported

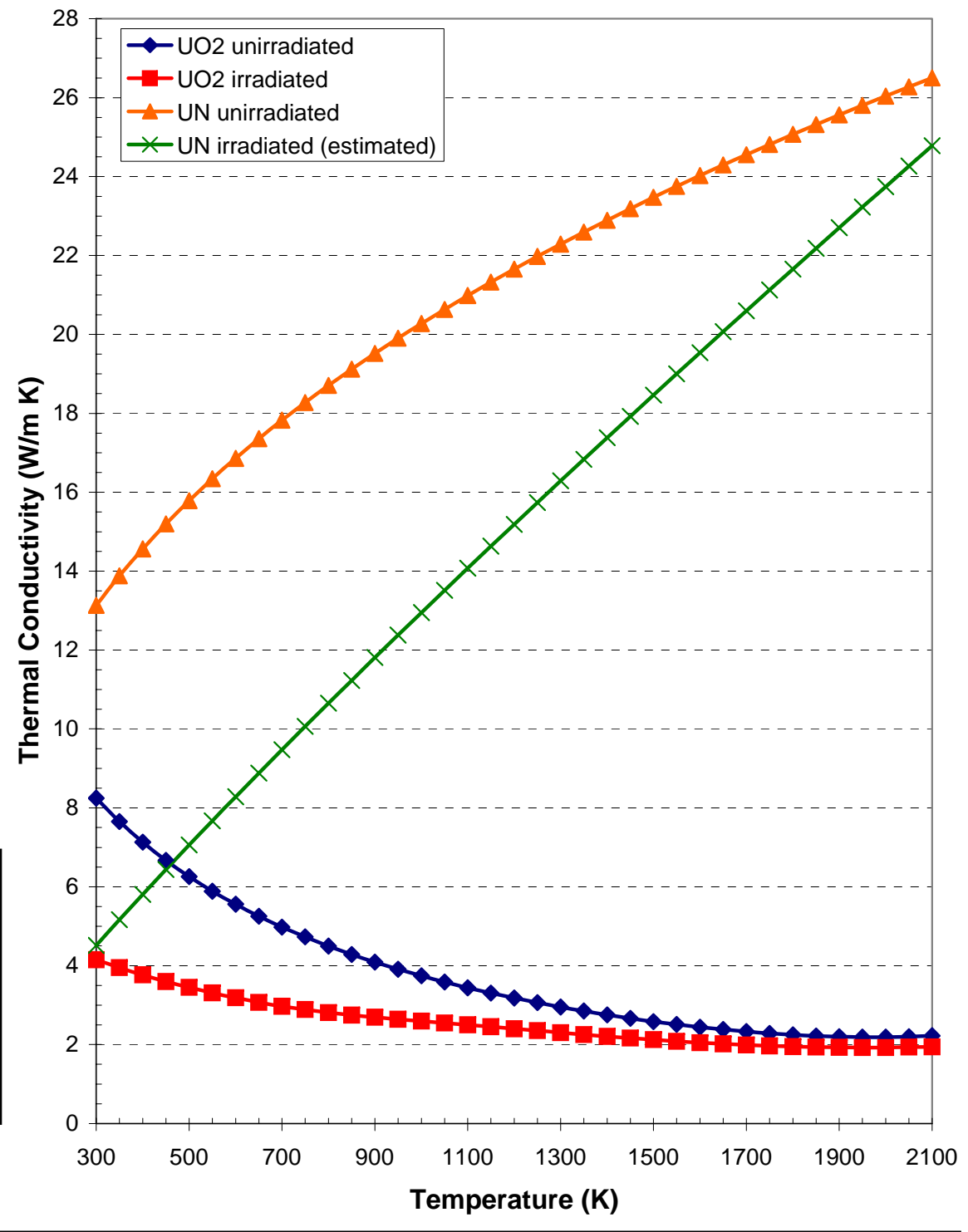




\section{UN Fuel Elements}

- Compatibility concerns at long times

- Literature evidence:

- Irradiated fuel test results dominated by chemical attack

- Nb, Nb-Zr, Mo-Re, and W clad attack with irradiated UN fuel

- Thermodynamics predict few fission product ternary compounds will form in fuel

- Nitrides less energetically stable than equivalent oxide compounds

- Unreacted fission product species diffuse out of fuel body and interact with other fuel element materials

- However, there are concerns that this is just due to the limitation of the available databases

- Little data to assess UN in a Silicon Carbide system.

Compatibility Concerns/Uncertainties At Long Times Conservative Properties Add Reactor Mass 


\section{$\mathrm{UO}_{2}$ Fuel Chosen}

- $\mathrm{UO}_{2}$ chosen because of likelihood of retiring unknowns on Prometheus schedule

- Well-known chemical, thermal, and mechanical properties

- Fission product species are retained; less concern for interaction with clad/liner

- More viable fuel element materials systems than UN

- Larger irradiation performance database

- Existing fabrication infrastructure 


\section{Limited Data for Design}

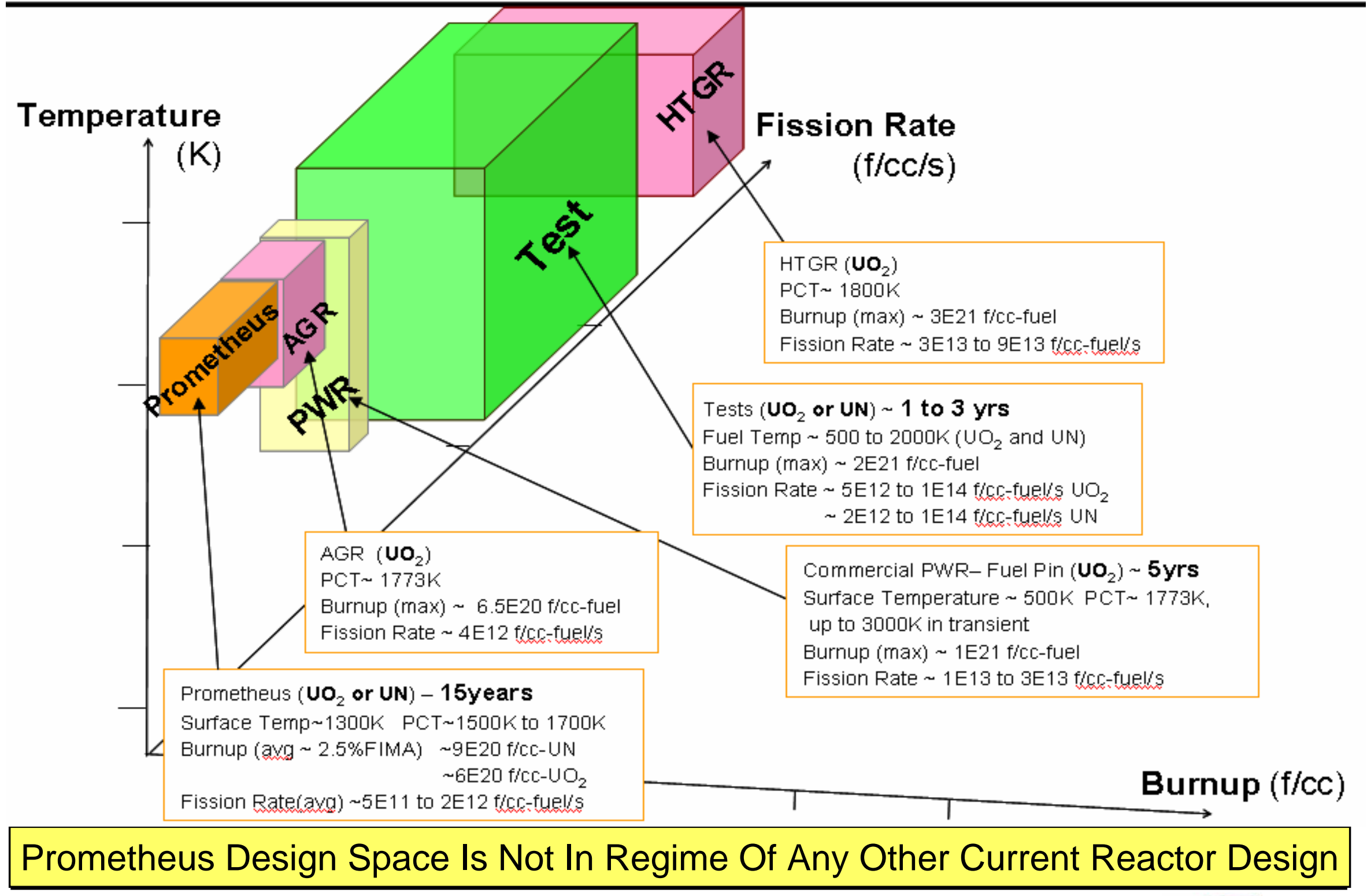

PRE-DECISIONAL - For planning and discussion purposes only 


\section{$\mathrm{UO}_{2}$ : Prometheus vs. Commercial}

- Some common problems seen with pellets in commercial reactors are not expected to occur for most Prometheus Reactor designs

- Temperature and temperature gradient too low for columnar grain growth

- Burnups are below the normal local threshold of $\sim 6.3 \%$ FIMA for Rim Formation

- Pellets may still crack, swell, or have high fission gas release

Prometheus Design Space Is Outside Restructuring Problems

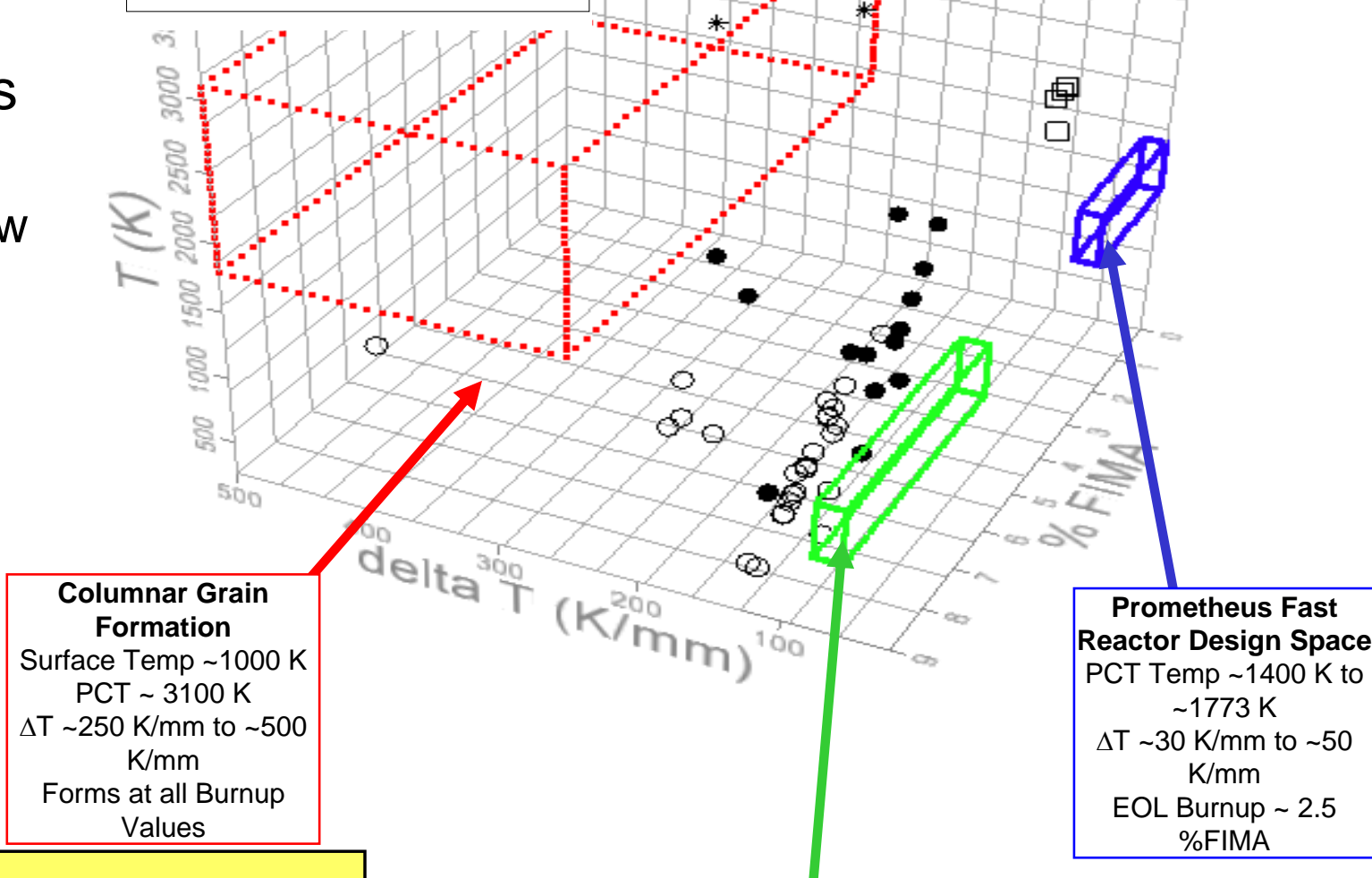

\section{Pre-Conceptual Design Operating Conditions} $\square$ Columnar Grains Not Observed * Columnar Grains Observed

O Rim Formation Not Observed

- Rim Formation Observed

Irradiation-Induced Rim Formation

Surface Temp $800-1400 \mathrm{~K}$

Local $\Delta \mathrm{T} \sim 60 \mathrm{~K} / \mathrm{mm}$ to $\sim 80 \mathrm{~K} / \mathrm{mm}$ Forms in Burnup Range $\sim 4.5$ to $\sim 9 \%$ FIMA 


\section{$\mathrm{UO}_{2}$ Design Correlations}

- Preliminary Fuel materials design information compiled

- Provide material property correlations to use for design

- Utilized commercial fuel performance models and existing data

- No models and/or data exist that meet all Prometheus conditions

- Burnup rate, temperature, and materials

- Models are stated to be applicable for Prometheus temperature range, but were verified using commercial reactor data

- Higher burnup, lower temperature data 


\section{Design Implications}

- Designing to PCT limit NOT necessarily best practice

- Want to be colder

- Minimizes diffusion and compatibility issues

- Flatter $\Delta \mathrm{T}$

- No restructuring, lowers fuel stresses, reduced odds of cracking

- Data uncertainties

- Want to keep below maximum temperature

Higher temperatures result in larger, heavier designs 


\section{Options to Resolve Unknowns}

- Modeling

- Compare ability of $\mathrm{UN}$ and $\mathrm{UO}_{2}$ to retain fission gases

- Calculate thermo-chemical properties of ternary nitrides

- PIE of existing Fuel

- JNC/JAERI Fuels and possibly AGR fuel

- Out of reactor testing

- For compatibility of fuel and fission products with clad/liner

- Irradiation testing

- Test Prometheus conditions of $\Delta T$, temperature, and fission rate in Advanced Test Reactor (ATR)

- Note: Accelerated testing could be a problem for $\mathrm{UO}_{2}$ due to low thermal conductivity

- Faster fission rates may push you into a restructuring regime

First Three May Influence Design, Last One Is Confirmatory 


\section{Testing UN in ATR}

\section{Test Objectives:}

- Verify performance against SP-100 fuel

- Gas Release, Swelling, Stability, etc

- Thermal conductivity after irradiation

- Thermal Transient Performance

- Small temperature uncertainty

Concerns about resolving unknowns:

- Uncertainty may still be high

- Small Sample set

- Test duration is short

\begin{tabular}{|c|c|}
\hline $\begin{array}{c}\text { Power } \\
\left(\mathrm{W} / \mathrm{cm}^{3}\right)\end{array}$ & $\begin{array}{c}\text { Burnup } \\
\text { (f/cc) }\end{array}$ \\
\hline 500 & $6.7 \times 10^{20}$ \\
\hline 750 & $10.1 \times 10^{20}$ \\
\hline
\end{tabular}

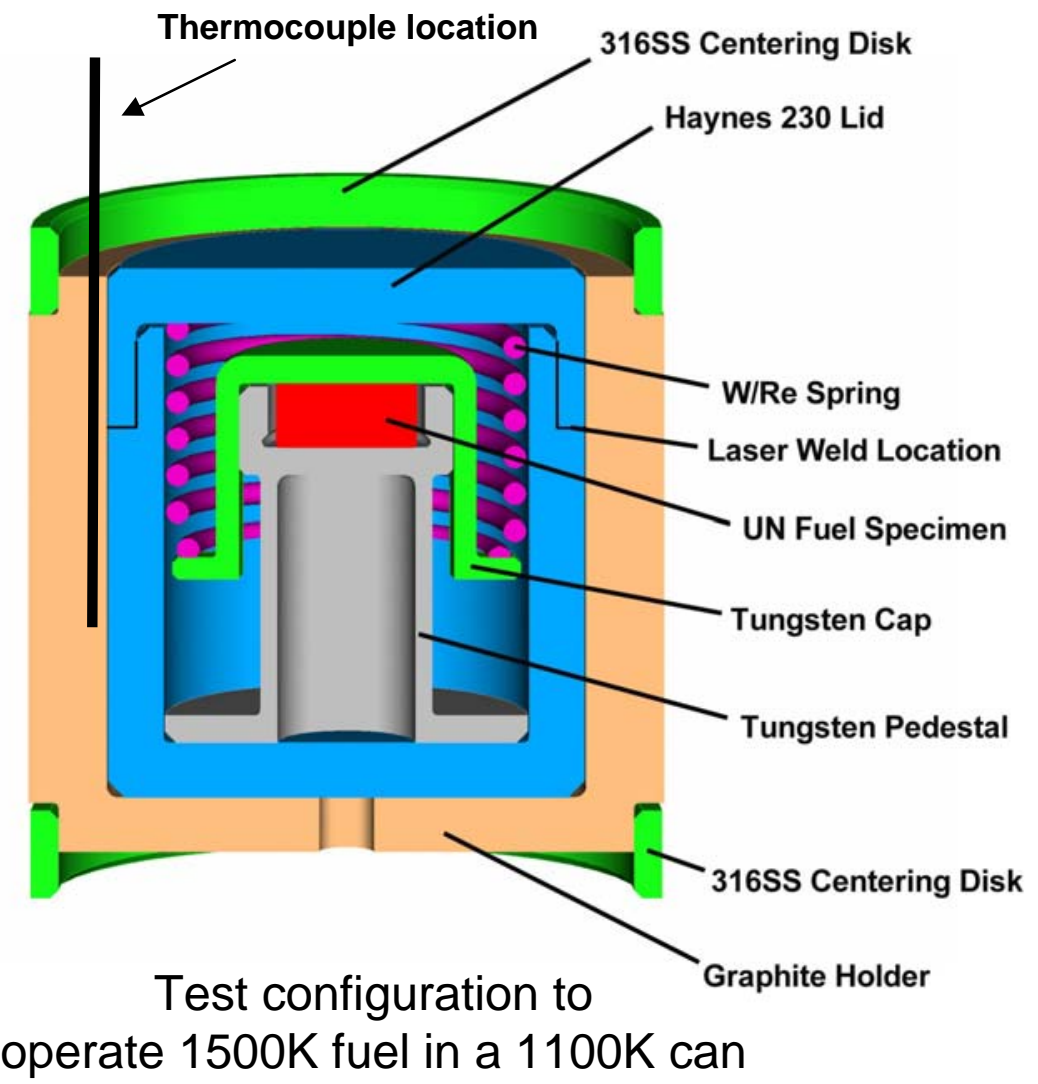

Small Temperature Uncertainty = Accurate Data 


\section{Conclusions}

- Considered several fuel system designs

- Chose $\mathrm{UO}_{2}$ fuel

- UN material compatibility issues

- $\quad \mathrm{UC} \mathrm{UC}_{2}$ gas release and compatibility issues were not outweighed by performance benefit

- Successful UN fabrication re-established

- Some phenomena which affect commercial reactors will not be of concern for current Prometheus reactor designs

- Insufficient data to support design of a Prometheus reactor

- Fuel properties recommended to design

- Specific tests are needed

- Existing data used to size elements and size core

- Uncertainties in fuel performance have large impact on reactor design element

- e.g., fission gas release and swelling of $\mathrm{UO}_{2}$

- The conclusions might have been different if the schedule allowed for additional time for fuel system development 


\section{References}

F.J. Homan, E.L. Long, Jr. "Irradiated Performance of HTGR Recycle Fissile Fuel." ORNL/TM-5502, 1976.

C.M Cox, D.S. Dutt, and R.A. Karnesky, "Fuel Systems for Compact Fast Reactors" in Space Nuclear Power Systems. Eds. M.S. El-Genk and M.D. Hoover. Orbit Book Company, 1984.

R. B. Matthews. "Irradiation Performance of Nitride Fuels", Specialist Conference on Space Nuclear Power and Propulsion Technologies - Materials and Fuels", Podolsk-Moscow, Russia, September, 1993.

R. Matthews. Ceramic Bulletin, 71(1992) pp. 96-101.

Ross, El-Genk, and Matthews. 1990. J. Nucl. Materials, 170:169-177

Nogita et al. Journal of Nuclear Materials, 248 (1997) pp 196-203.

Ray et al. Journal of Nuclear Materials, 188 (1992) pp 90-95.

Spino et al. Journal of Nuclear Materials, 256 (1998) pp 189-196.

Une et al. Journal of Nuclear Materials, 278, (2000) pp 54-63.

Une et al. Journal of Nuclear Materials, 188, (1992) pp 65-72.

Walker et al. Journal of Nuclear Materials, 188, (1992) 73-79.

Yagnik et al. Journal of Nuclear Materials, 270 (1999) pp 65-73.

D.T. Hagrman, ed. "SCDAP/RELAP5/MOD3.1 Code Manual Volume IV: MATPRO-A Library of Materials Properties for Light Water Reactor Accident Analysis". Idaho National Engineering Laboratory, November, 1993.

A.H. Booth and G.T. Rymer. "Determination of the Diffusion Constant of Fission Xenon in $\mathrm{UO}_{2}$ Crystals and Sintered Compacts". Atomic Energy of Canada Limited. AECL-692, 1958.

Minato et al. Journal of Nuclear Materials, 246 (1997) pp 215-222.

D.D. Lanning, C.E. Beyer, and K.J. Geelhood. NUREG-/CR-6534, Volume 4, PNNL-11513, dated May, 2005.

LANL 2005 UN Fabrication Campaign, Actinide and Fuel Cycle Technologies, NMT Division, Los Alamos National Laboratory, 2005. 


\section{Backup Slides}




\section{Acknowledgments}

Bechtel - Bettis Atomic Power Laboratory

Los Alamos National Laboratory

Lockheed Martin - Knolls Atomic Power Laboratory 


\section{$\mathrm{UO}_{2}$ Pellet Rim Restructuring}

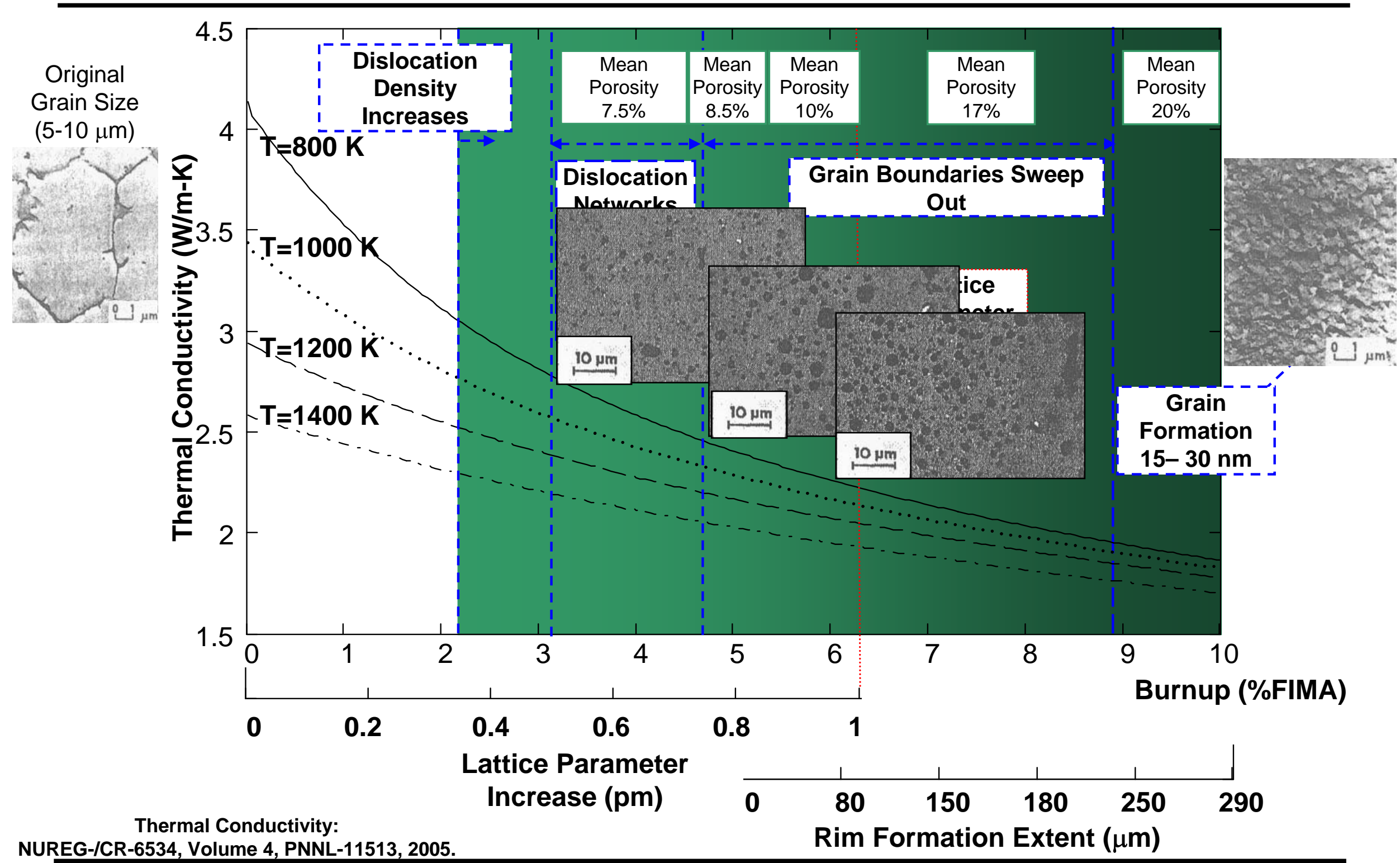

PRE-DECISIONAL - For planning and discussion purposes only 


\section{$\mathrm{UO}_{2}$ Fission Gas Release}

- Uncertainty as to diffusion coefficient of $\mathrm{UO}_{2}$

- No diffusion data for Prometheus conditions

- Diffusion sensitive to fission rate

- Fission gas release mechanisms sensitive to fission rate

- Maintenance-free lifetime is unprecedented

- Simplistic Booth model chosen

- Gives a conservative estimate

- Assuming $100 \%$ gas release at end of life

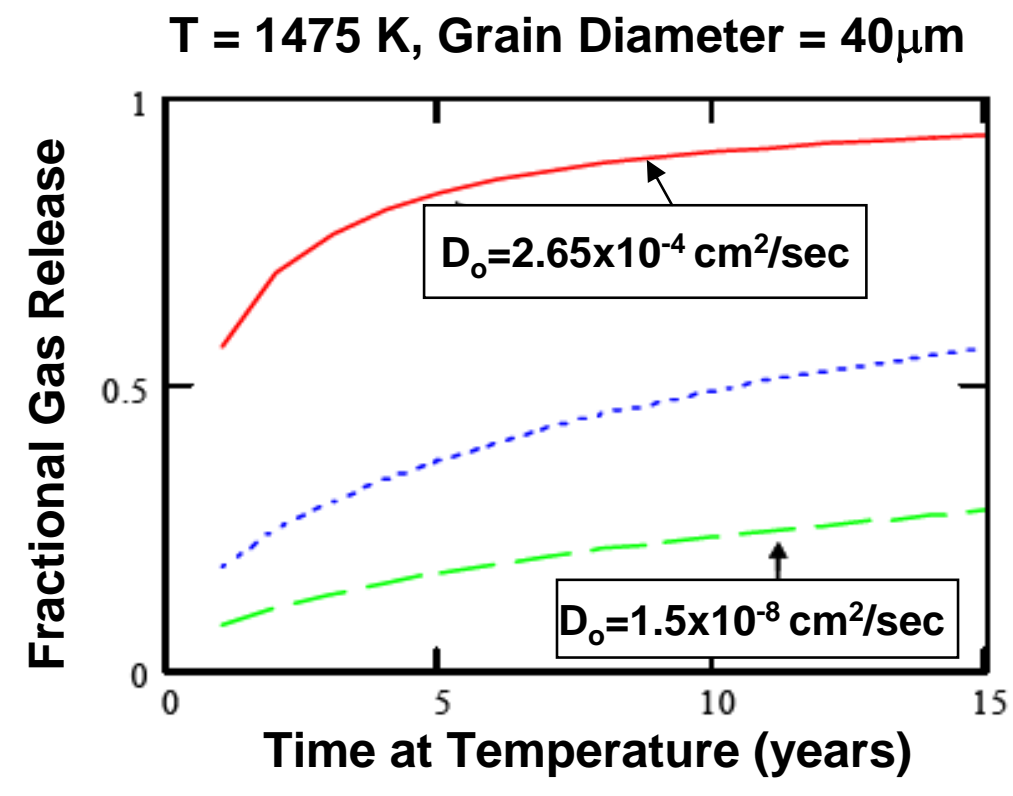

Causes Design To Be More Conservative So Mass Increases

- Impacts Cladding Thickness And Plenum Sizing 


\section{Unresolved: $\mathrm{UO}_{2}$ Swelling}

- Solid and gaseous fission product swelling

- Swelling important in design calculations

- Inaccurate swelling predictions causes uncertainty in design gap

- Results in uncertainty in temperature

- No clear model to predict Prometheus swelling

- Models based on commercial PWR data

- Lower surface temperature and larger temperature gradient

- Most do not include gaseous

Comparison of Temperatures Used for UO2 Swelling Equation From FRAPCON/MATPRO

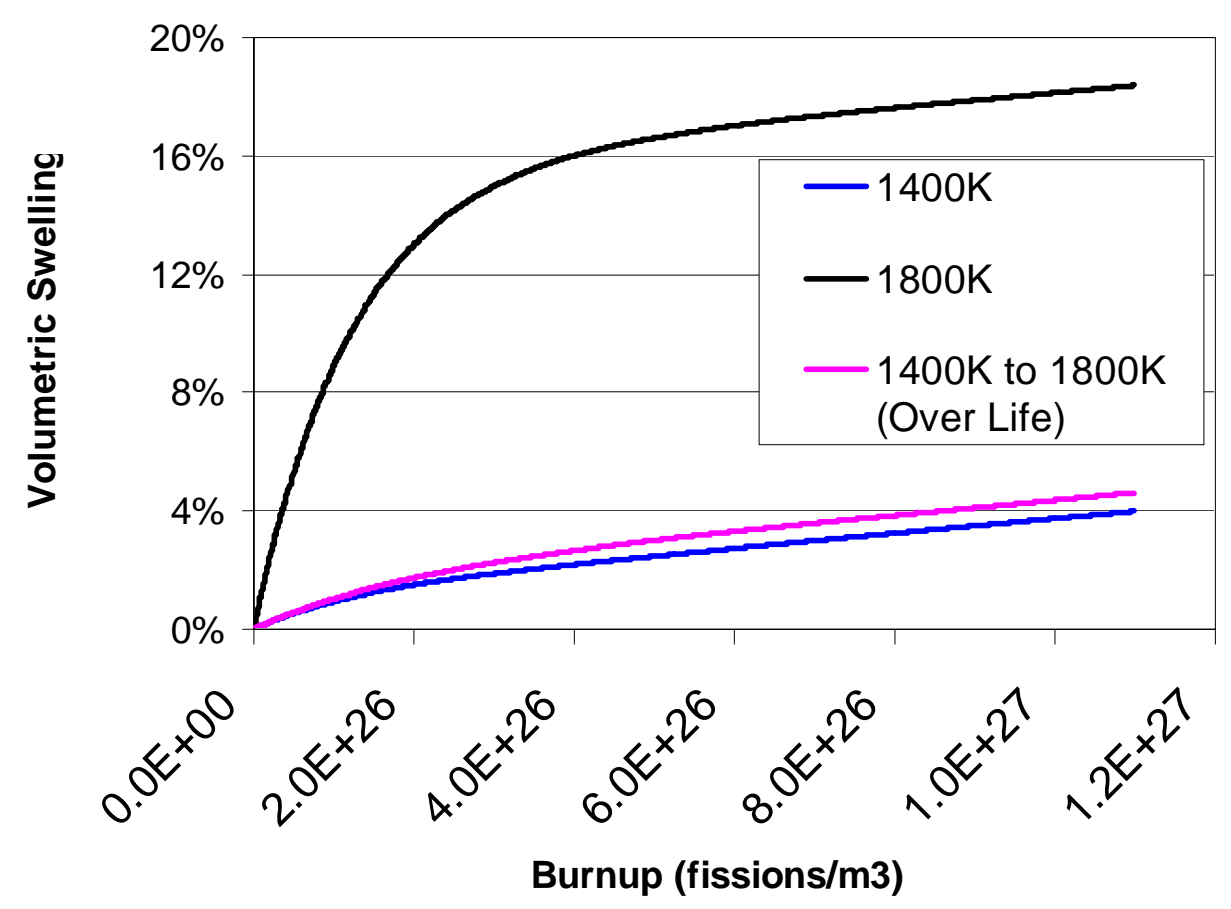
contribution

\section{Uncertainty In How Swelling Affects Gap Design in Fuel Element}

- Gap Width Underestimated $=$ Pellet/Clad Interaction

- Gap Overestimated = Poor Heat Conduction 


\section{Predicted Fission Product Yields}

- Fast neutron energy calculations using RACER code

- Several other sets of data available:

- GE calculated yields for a fast spectrum in late '70s

- Evaluation using thermal spectrum

- Important to note:

- Xe 10X more than $\mathrm{Kr}$

- Cs 8X more than $\mathrm{Rb}$ and $\mathrm{Te}$

\begin{tabular}{|c|c|c|c|}
\hline$\underline{\mathrm{Zr}}$ & $13.00 \%$ & $\underline{\mathrm{Kr}}$ & $1.37 \%$ \\
\hline$\frac{\mathrm{Nd}}{\mathrm{Xe}}$ & $12.86 \%$ & $\underline{\mathrm{Te}}$ & $1.37 \%$ \\
\hline$\underline{\mathrm{Cs}}$ & $12.50 \%$ & $\underline{\mathrm{Rh}}$ & $1.36 \%$ \\
\hline$\underline{\mathrm{Ce}}$ & $7.60 \%$ & $\underline{\mathrm{Pd}}$ & $1.18 \%$ \\
\hline$\underline{\mathrm{Mo}}$ & $7.65 \%$ & $\underline{\mathrm{Pm}}$ & $0.64 \%$ \\
\hline$\underline{\mathrm{Ru}}$ & $5.11 \%$ & $\underline{\mathrm{Sn}}$ & $0.32 \%$ \\
\hline$\underline{\mathrm{Ba}}$ & $4.74 \%$ & $\underline{\mathrm{Eu}}$ & $0.13 \%$ \\
\hline$\underline{\mathrm{La}}$ & $3.89 \%$ & $\underline{\mathrm{Cd}}$ & $0.10 \%$ \\
\hline$\underline{\mathrm{Pr}}$ & $3.58 \%$ & $\underline{\mathrm{Sb}}$ & $0.06 \%$ \\
\hline$\underline{\mathrm{Sr}}$ & $3.23 \%$ & $\underline{\mathrm{Ag}}$ & $0.05 \%$ \\
\hline$\underline{\mathrm{Tc}}$ & $2.64 \%$ & $\underline{\mathrm{Gd}}$ & $0.02 \%$ \\
\hline$\underline{\mathrm{Sm}}$ & $2.31 \%$ & $\underline{\mathrm{Nb}}$ & $0.02 \%$ \\
\hline$\underline{\mathrm{Y}}$ & $1.84 \%$ & $\underline{\mathrm{In}}$ & $0.02 \%$ \\
\hline$\underline{\mathrm{Rb}}$ & $1.39 \%$ & & \\
\hline
\end{tabular}




\section{Fission Product Impact in $\mathrm{UO}_{2}$}

- Soluble oxides in $\mathrm{UO}_{2}$ matrix

- Rare earths, Y, Zr, Mo

- Intermetallics

- Ru, Rh, Tc, Mo, Pd

- Insoluble precipitates

- $\mathrm{BaZrO}_{3}, \mathrm{SrZrO}_{3}$

- 6 main species of concern, gas or volatile

- Xe, Kr, I, Cs, Rb, Te

- Clad attack by Pd

- No evidence at low burnup but some at high burnup
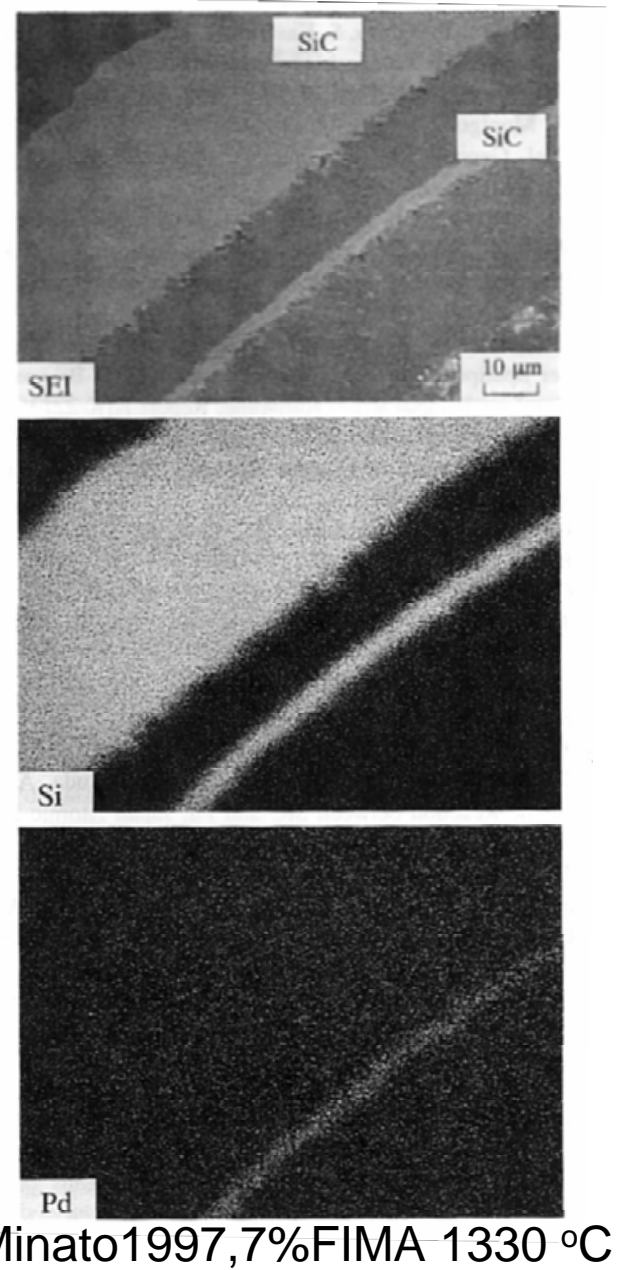

Gaseous/Volatile Fission Products Need To Be Managed 


\section{UN Fabrication Re-Established}

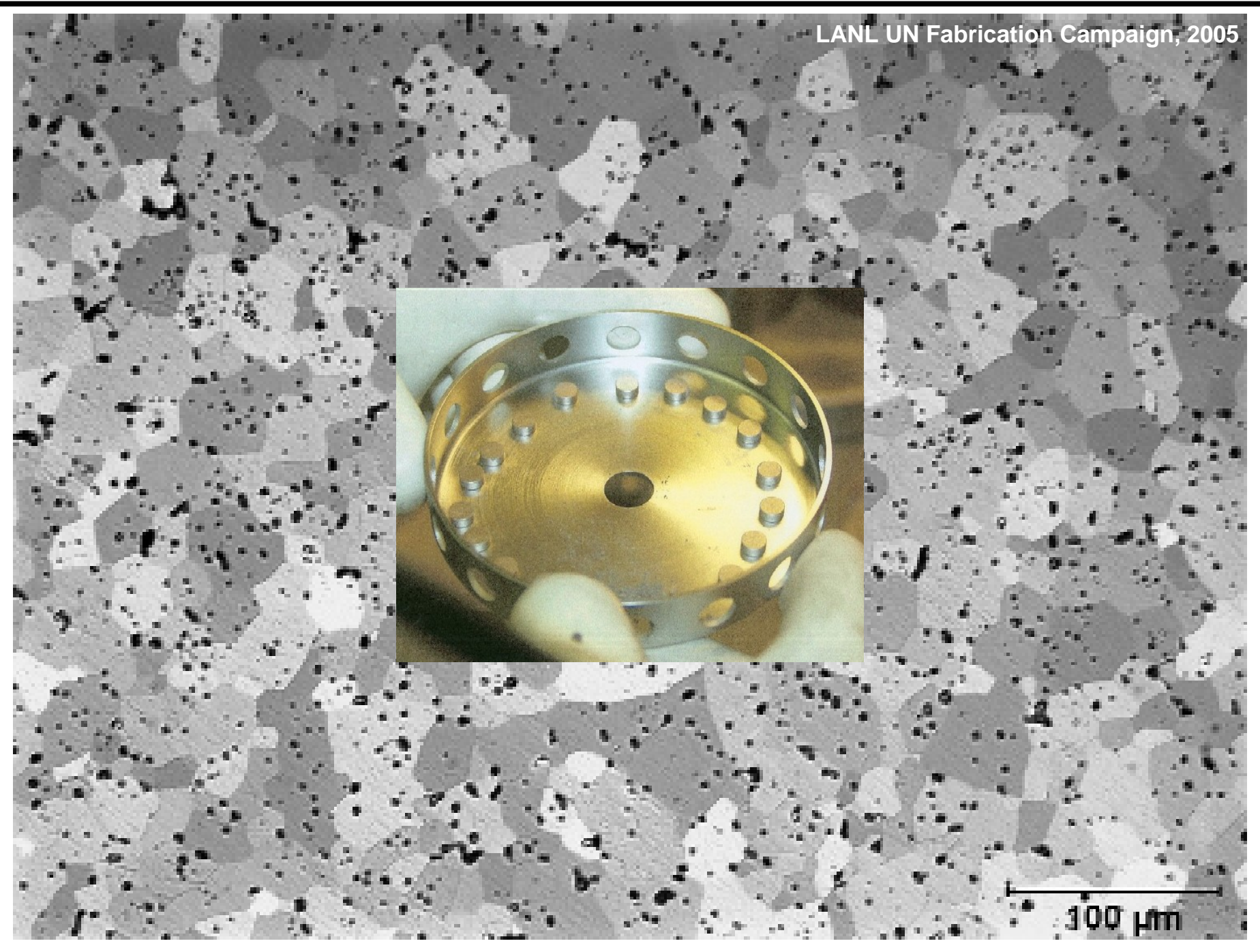

Fabrication Of UN Not Viewed As A First-Order Issue 


\section{UN: Nitrogen Overpressure}

\section{SNAP-50 Experimental Data}

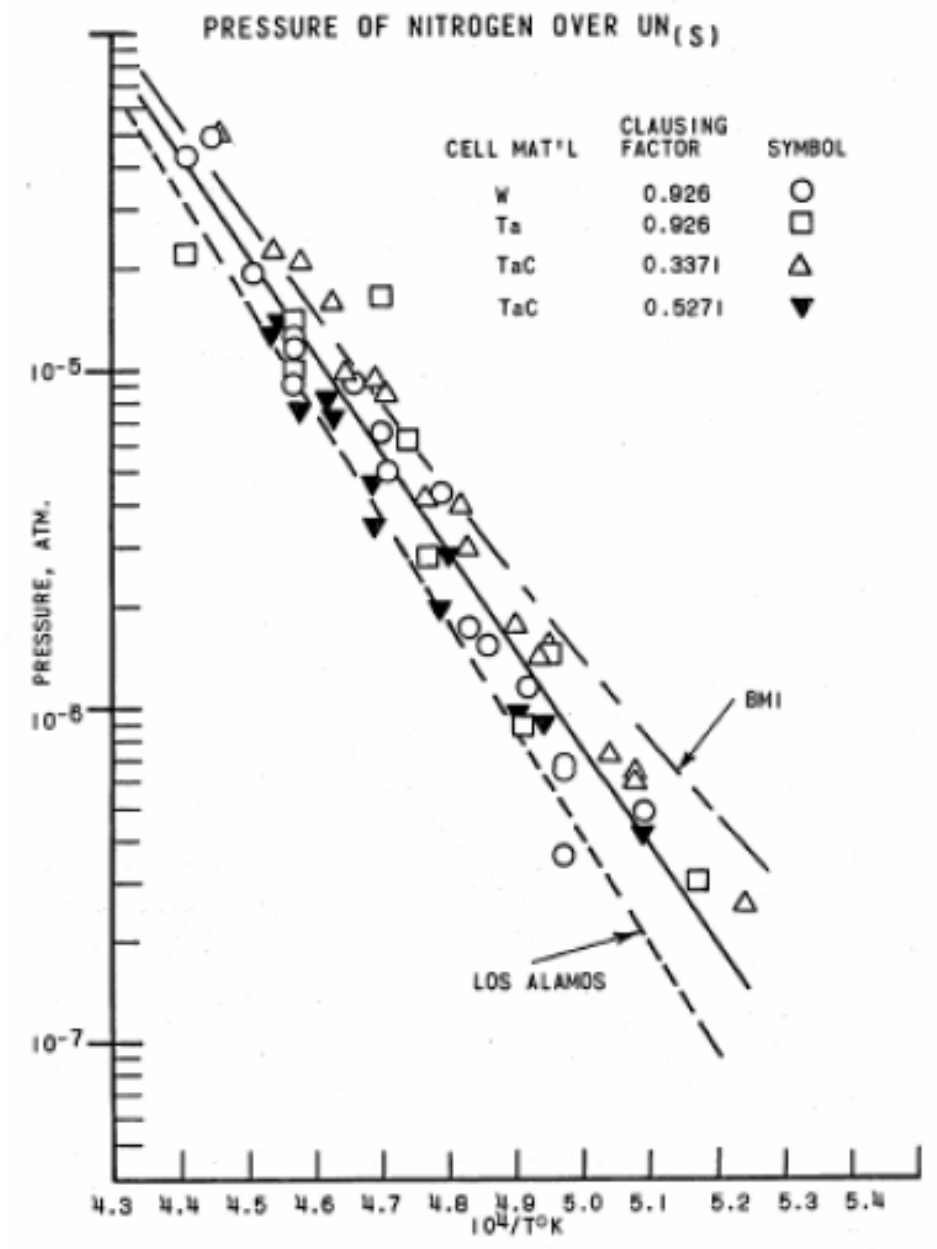

\section{Thermodynamic Calculations}

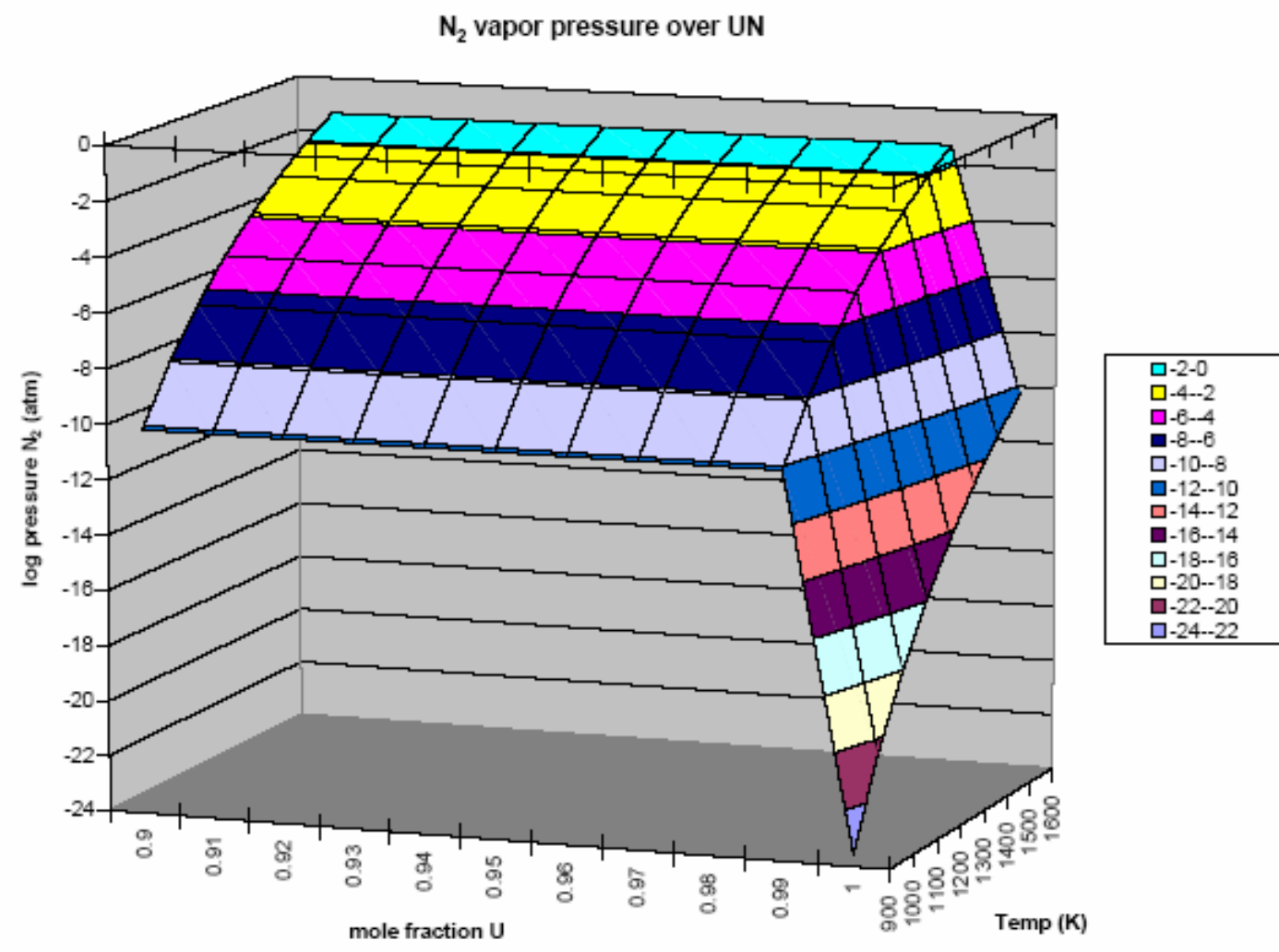

Believe That Small Clad Breach And Loss Of $\mathrm{N}_{2}$ Not An Issue 


\section{$\mathrm{UO}_{2}$ Fission Gas Release (2)}

- Diffusion-based fractional gas release during irradiation - Booth model

- Evaluate to Determine the Effect of Properties such as Temperature and Grain Size

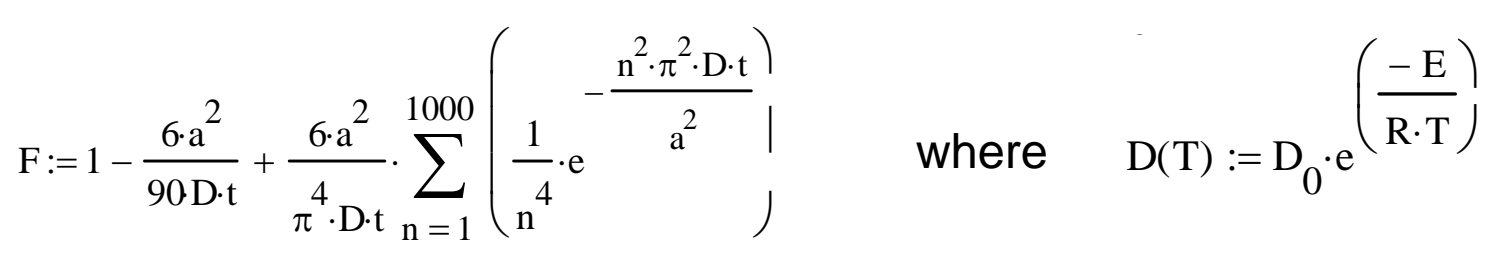

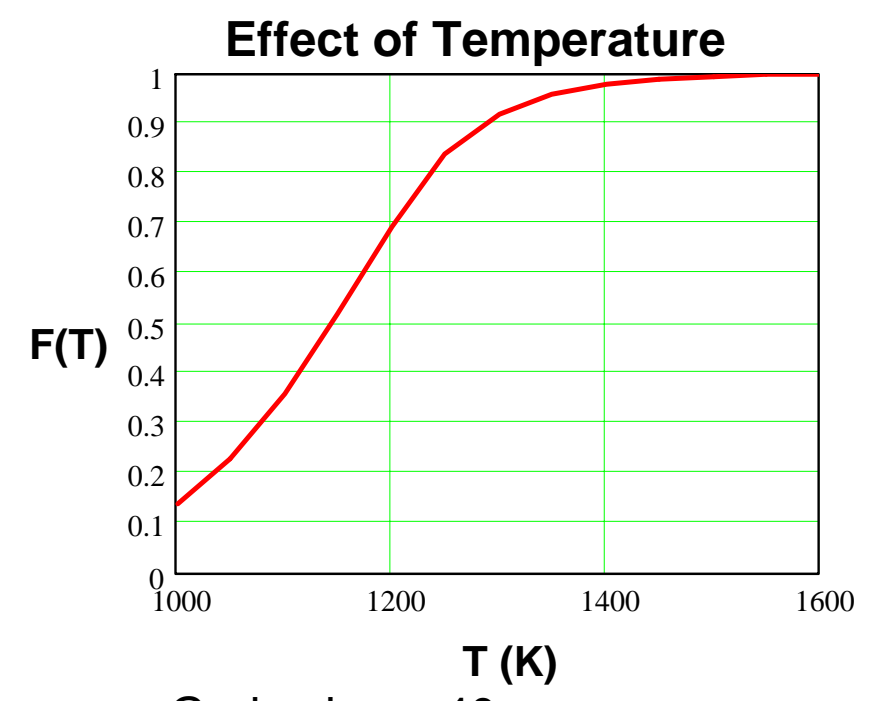

Grain size $=40 \mu \mathrm{m}$

Time $=15$ years

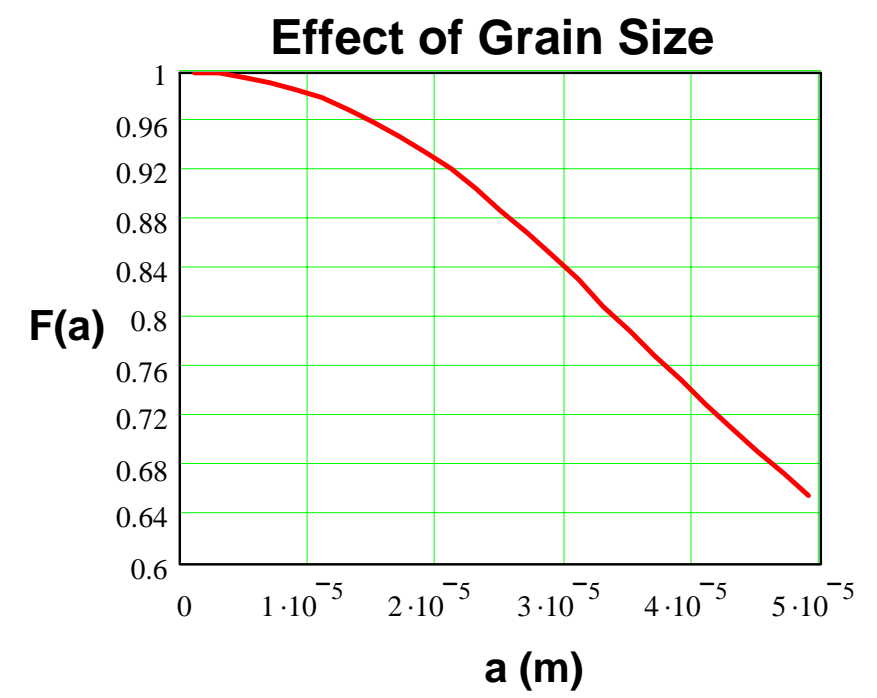

Temperature $=1600 \mathrm{~K}$ Time $=15$ years

Designing To PCT Not Always Best

A.H. Booth and G.T. Rymer. AECL-692, 1958. 


\section{Existing Irradiated Fuel}

- $\mathrm{UO}_{2}$

- Blanket Fuel

- EBR-II (MOX)

- FFTF (U-Pu alloy)

- Shippingport Atomic Power Station

- JNC/JAERI Fuel

- Mk-I UO $\mathrm{O}_{2}$ Blanket Fuel

- Mk-II Depleted $\mathrm{UO}_{2}$ Fuel Pins

- JOYO Type B8 Fuel Pins

- Mk-III Insulator Pellets

- NFD Fuel

- Commercial BWR Fuel Pin

- SP-100 Fuel

- Not Easily Retrievable

- AGR

- May be Available
- UN

- JNC/JAERI Fuel

- Mk-II Insulator Pellets

- SP-100 Fuel

- Not Easily Retrievable
AGR $\cup_{2}$ Fuel Is The Only Available Fuel That Is Close To Prometheus Conditions. 


\section{Plans to Fill Technical Gaps}

\section{Conduct testing in Advanced Test Reactor (ATR)}

- Provide high temperature, low burnup, low power performance data by 2008

- Softer neutron spectrum and lower fuel enrichment than Prometheus

- Fission product distribution will be different but performance should be similar

- Goal of lower temperature uncertainty compared to previous tests

- In capsule thermocouples

- Tight tolerances

- PIE evaluations to back calculate temperature

$\mathrm{UO}_{2}$ Test Parameters (18 pellets total)

\begin{tabular}{|c|c|c|c|}
\hline $\begin{array}{c}\text { Power } \\
\left(\mathrm{W} / \mathrm{cm}^{3}\right)\end{array}$ & $\begin{array}{c}\text { PCT } \\
(\mathrm{K})\end{array}$ & $\begin{array}{c}\text { Burnup } \\
(\mathrm{f} / \mathrm{cc})\end{array}$ & $\begin{array}{c}\text { Time } \\
(\text { Days })\end{array}$ \\
\hline 150 & 1600 & $2.4 \times 10^{20}$ & 500 \\
\hline
\end{tabular}

UN Test Parameters

(3 pellets for each condition)

\begin{tabular}{|c|c|c|c|}
\hline $\begin{array}{c}\text { Power } \\
\left(\mathrm{W} / \mathrm{cm}^{3}\right)\end{array}$ & $\begin{array}{c}\text { PCT } \\
(\mathrm{K})\end{array}$ & $\begin{array}{c}\text { Burnup } \\
(\mathrm{f} / \mathrm{cc})\end{array}$ & $\begin{array}{c}\text { Time } \\
(\text { Days })\end{array}$ \\
\hline 500 & 1500 & $6.7 \times 10^{20}$ & 500 \\
\hline 750 & 1500 & $10.1 \times 10^{20}$ & 500 \\
\hline
\end{tabular}

Add Insight Into Temperature Uncertainty In Previous Data 


\section{Testing $\mathrm{UO}_{2}$ in ATR}

\section{Test Objectives:}

- Gas release and swelling for unconstrained fuel

- Performance differences between grain sizes

- Restrained swelling and force at low fission rate

- Thermal Transient Performance

- Small temperature uncertainty

Same concerns as UN test

\begin{tabular}{|c|c|c|c|}
\hline $\begin{array}{c}\text { Grain } \\
\text { Size }\end{array}$ & Condition & $\begin{array}{c}\text { Power } \\
\left.\text { (W/cm }^{3}\right)\end{array}$ & $\begin{array}{c}\text { Burnup } \\
\text { (f/cc) }\end{array}$ \\
\hline $10 \mu \mathrm{m}$ & $\begin{array}{l}\text { Constrained and } \\
\text { Unconstrained }\end{array}$ & 150 & $2.4 \times 10^{20}$ \\
\hline $40 \mu \mathrm{m}$ & $\begin{array}{l}\text { Constrained and } \\
\text { Unconstrained }^{*}\end{array}$ & 150 & $2.4 \times 10^{20}$ \\
\hline
\end{tabular}

*Unconstrained case does not have Moly divider plate and restraint tubes

Small Temperature Uncertainty = Accurate Data

Novel Test To Measure Fuel Viscosity/Creep

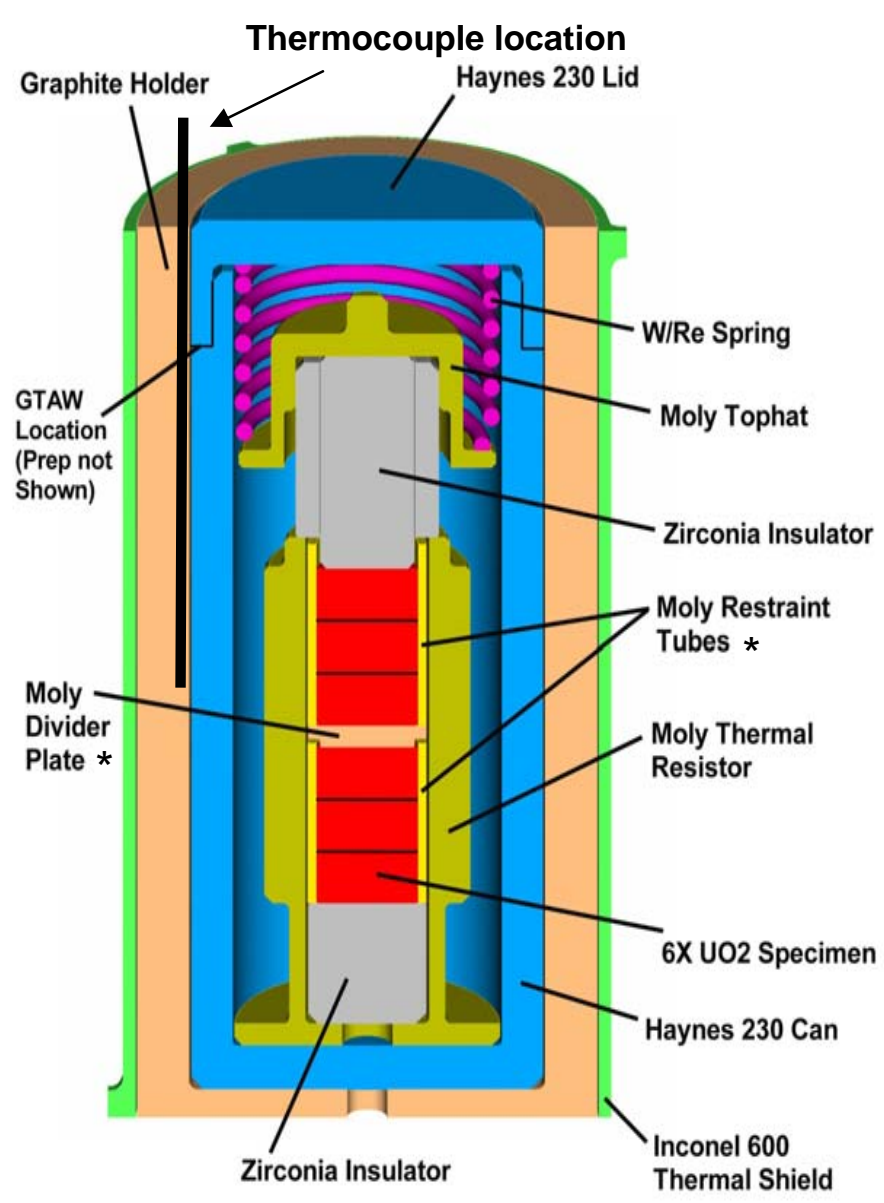

Test configuration to operate $1600 \mathrm{~K}$ fuel in a $1100 \mathrm{~K}$ can 


\section{Restructuring: The Rest of the Story}

- Moderated core case (15 year

\section{Pre-Conceptual Design Operating Conditions} pellet design) pushes burnups to $7.5 \%$ FIMA but the peaking factor is 2.4

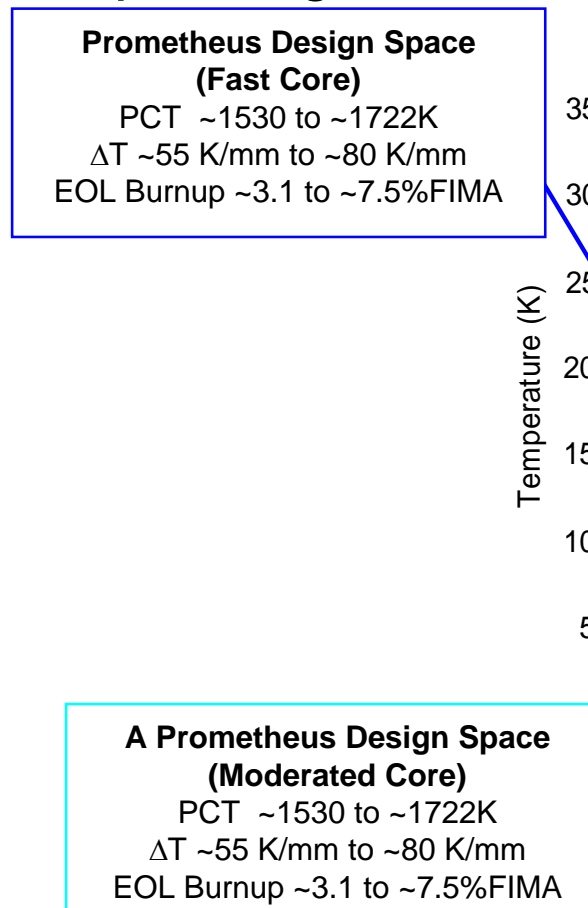

$\square$ Columnar Grains Not Observed * Columnar Grains Observed o Rim Formation Not Obsenved

$$
3500 \quad \text { Rim Formation Observed }
$$

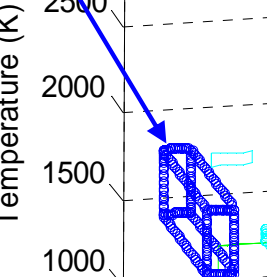

500

2

Burnup (\%FIMA)

$$
\begin{gathered}
\text { All rectangles on the } 2 D \\
\text { planes of the plot are } \\
\text { projections of design } \\
\text { space having the same } \\
\text { color. }
\end{gathered}
$$

Surface Temp $\sim 1000 \mathrm{~K}$ $\mathrm{PCT} \sim 3100 \mathrm{~K}$

$\Delta \mathrm{T} \sim 250 \mathrm{~K} / \mathrm{mm}$ to $\sim 500 \mathrm{~K} / \mathrm{mm}$ Forms at all Burnup Values
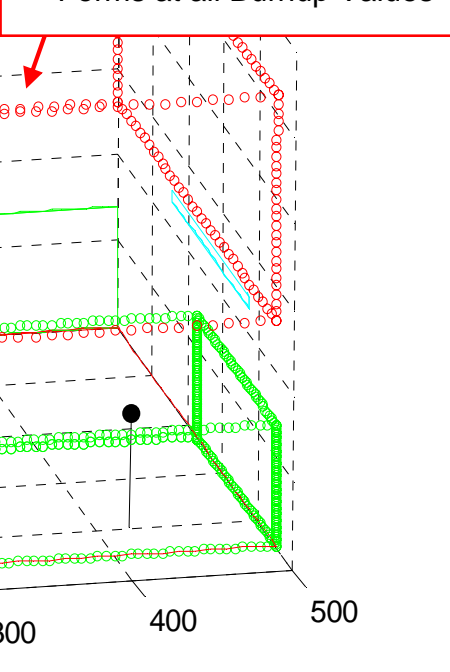

200

Temperature Gradient $(\mathrm{K} / \mathrm{mm})$

Irradiation-Induced Rim Formation

Surface Temp $800-1400 \mathrm{~K}$

$\Delta \mathrm{T} \sim 60 \mathrm{~K} / \mathrm{mm}$ to $\sim 80 \mathrm{~K} / \mathrm{mm}$

Forms in Burnup Range $\sim 4.5$ to $\sim 9 \%$ FIMA 


\section{Conservatism in Design}

- Trade-off exists between swelling and gas release

- Larger grains means slower gas release, slower release means more swelling

- Correlations utilized give conservative estimates in

- Fission gas release

- Swelling

- Over/under predicted swelling can lead to more uncertainties

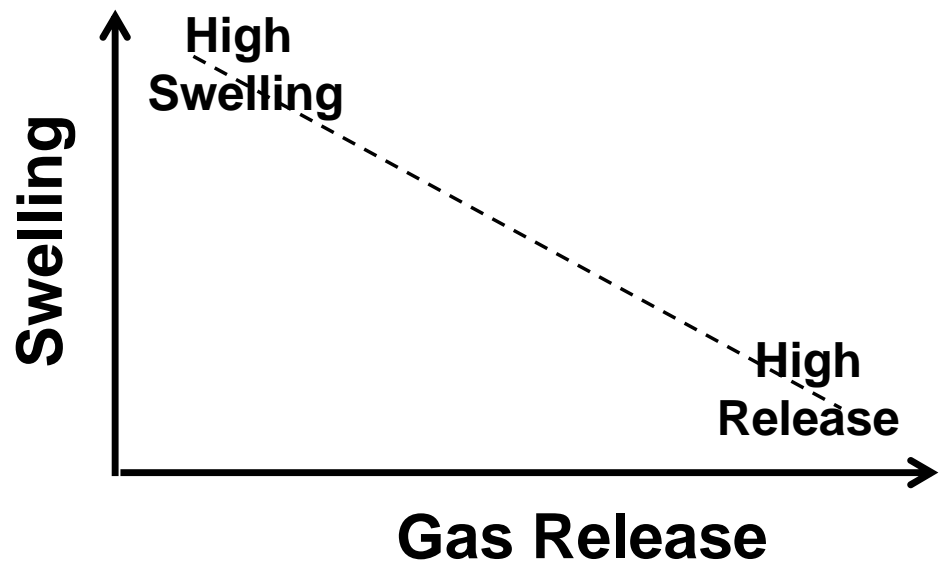

Swelling And Gas Release Are Accommodated By Increasing Cladding Thickness And Providing Plenum Volume 
Enclosure 9 to

SPP-SEC-0039

\title{
Summary of Structural Material Considerations for Prometheus Space Nuclear Power
}

\author{
Angeliu, T., et al
}


This page is intentionally blank.

PRE-DECISIONAL - For planning and discussion purposes only 


\section{Summary of Structural Material Considerations for Prometheus Space Nuclear Power}

\section{Tom Angeliu} Youssef Ballout Rita Baranwal Jessica Bump Matt Frederick
Amitava Guha John Hack Nikki Johnson Erik Mader Craig McCann George Newsome
Ryan Nelson Dave Noe Wayne Ohlinger Tymm Schumaker Scott Simonson
Naval Reactors Prime Contractor Team

Jeremy Busby, Keith Leonard Steve Zinkle, Oak Ridge National Lab Ivan Locci, Jim Nesbitt, Frank Ritzert, NASA-Glenn Research Center

Jerry Gould, Edison Welding Institute

\section{STAIF, February 2006}




\section{Jupiter Icy Moon Orbiter Mission}

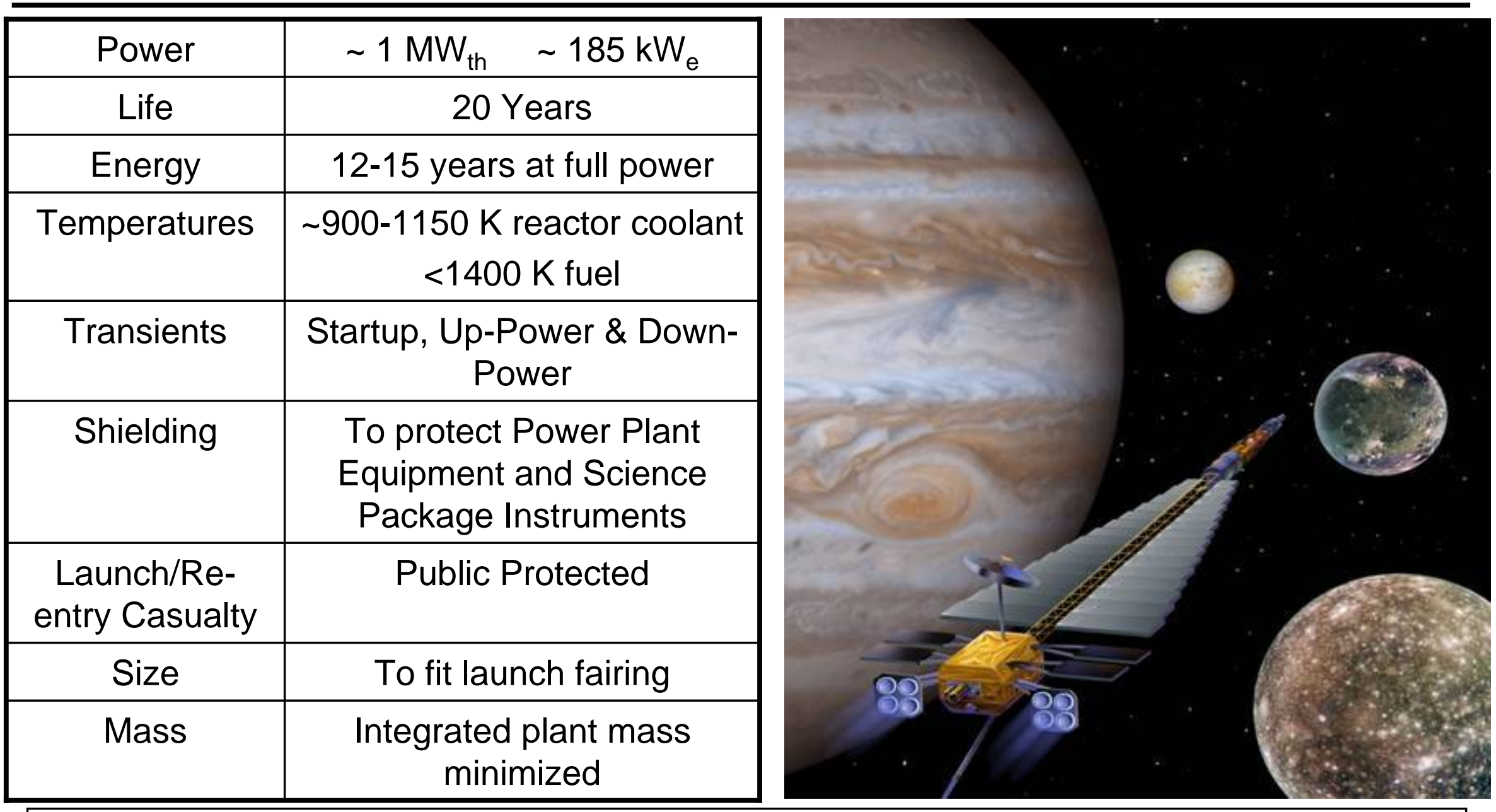

\section{Selection Criteria}

Deliverability, Capability, Reliability, Cost, Schedule, Safety 


\section{Prometheus Space Reactor System}

\section{Energy Conversion}

$300 \mathrm{~K}$ to $1150 \mathrm{~K}$

Space Vacuum

$\mathrm{He} / \mathrm{Xe}$ (impure)

$<10^{15} \mathrm{n} / \mathrm{cm}^{2}(\mathrm{E}>0.1 \mathrm{MeV})$

$\mathrm{Ni}$ and Ti-base, Stainless steels

$\frac{\text { Shielding \& }}{\text { Reflectors }}$
$<700 \mathrm{~K}$
Space Vacuum
Shielding Materials
$<4 \times 10^{19} \mathrm{n} / \mathrm{cm}^{2}(\mathrm{E}>0.1 \mathrm{MeV})$
$\mathrm{W}, \mathrm{Ni}-$ base $, \mathrm{Be}, \mathrm{B}_{4} \mathrm{C}, \mathrm{LiH}$
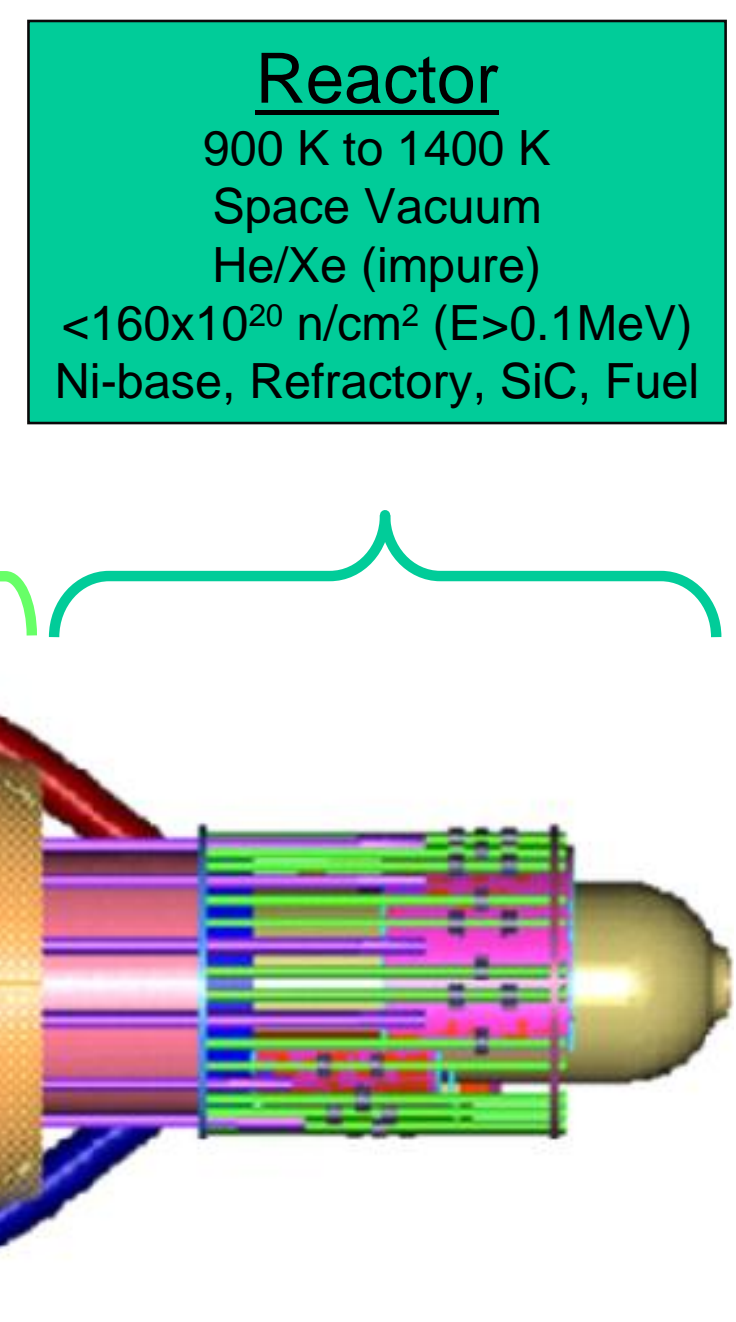

Many different materials are required 


\section{Reactor and Plant Materials}

Primary Material Issues Thermal Creep

Radiation Damage

Environmental Effects

Joints

\section{Primary Materials Refractory Metal Alloys}

$\mathrm{SiC}$

Ni-Base Alloys

Ti Alloys

Stainless Steels

$\mathrm{BeO} / \mathrm{LiH}$

Magnets

Organics / Oxides

Bearing Coatings

Many complex interactions are expected Significant materials testing and development were required 


\section{Reactor Environment - Thermal Creep}

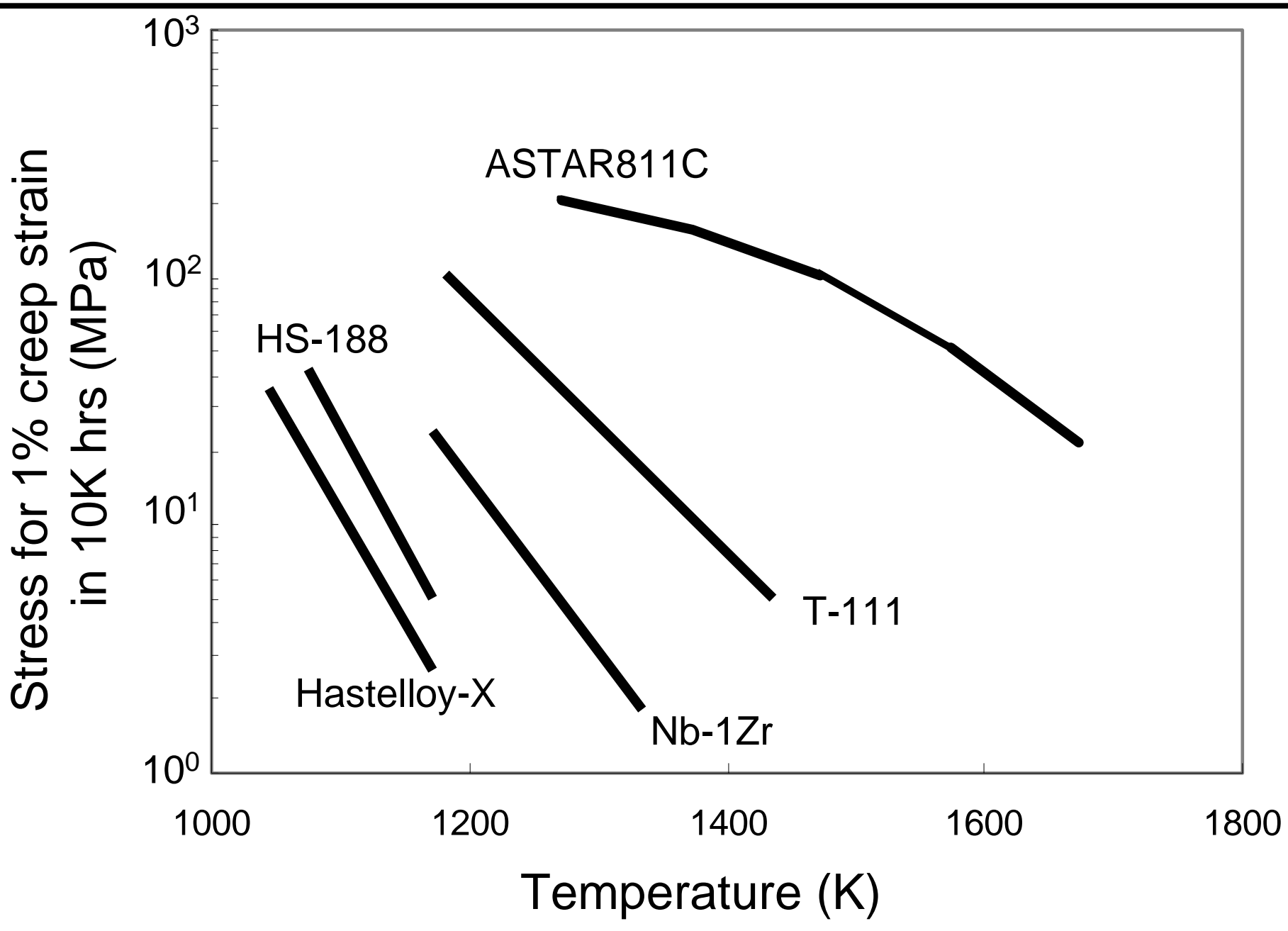

Refractory metal alloys have superior creep and high temperature strength.

Ni-base alloys may be good enough for pressure vessel. 


\section{Pressure Vessel}

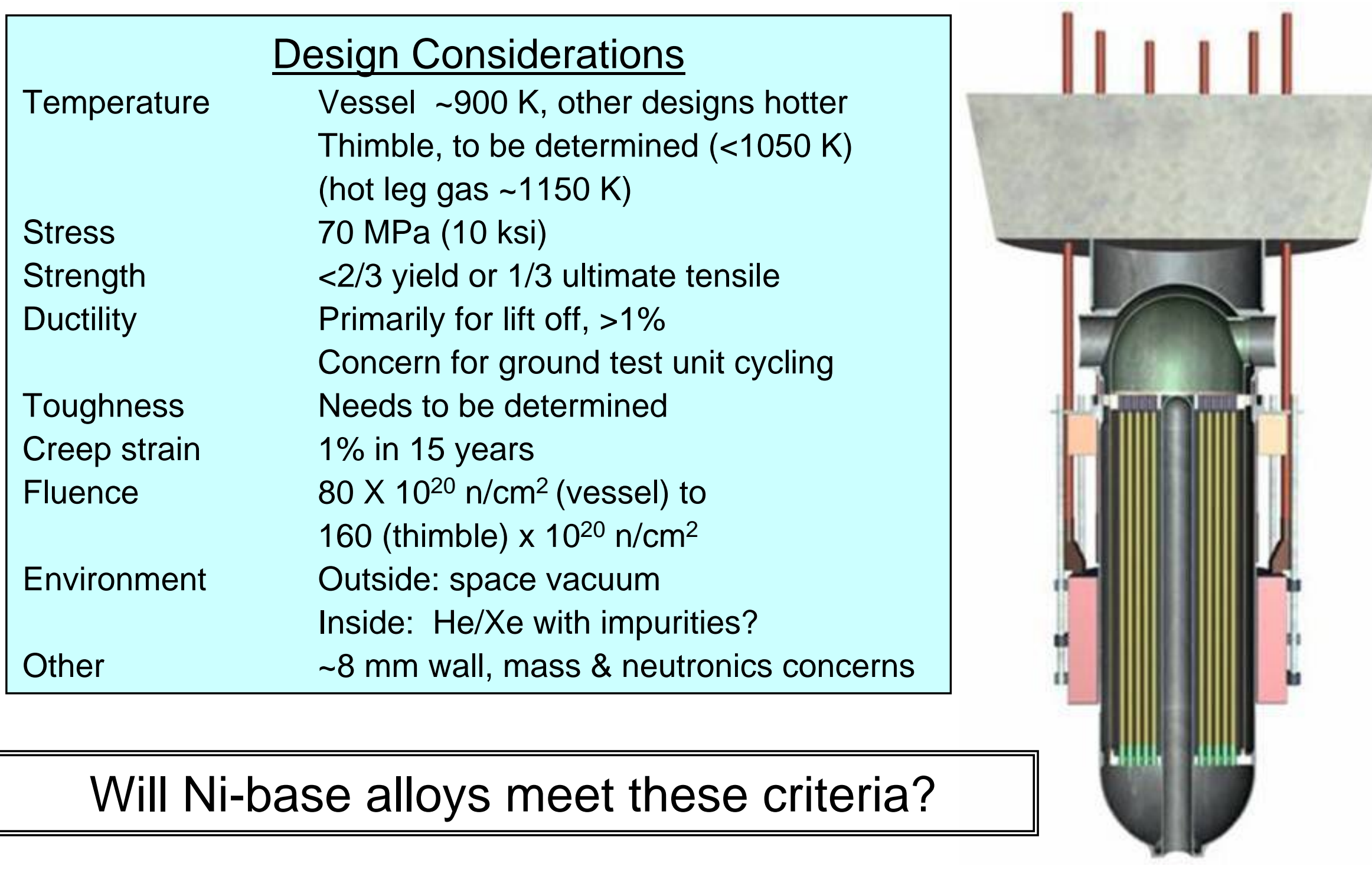




\section{Ni-base Thermal Creep}

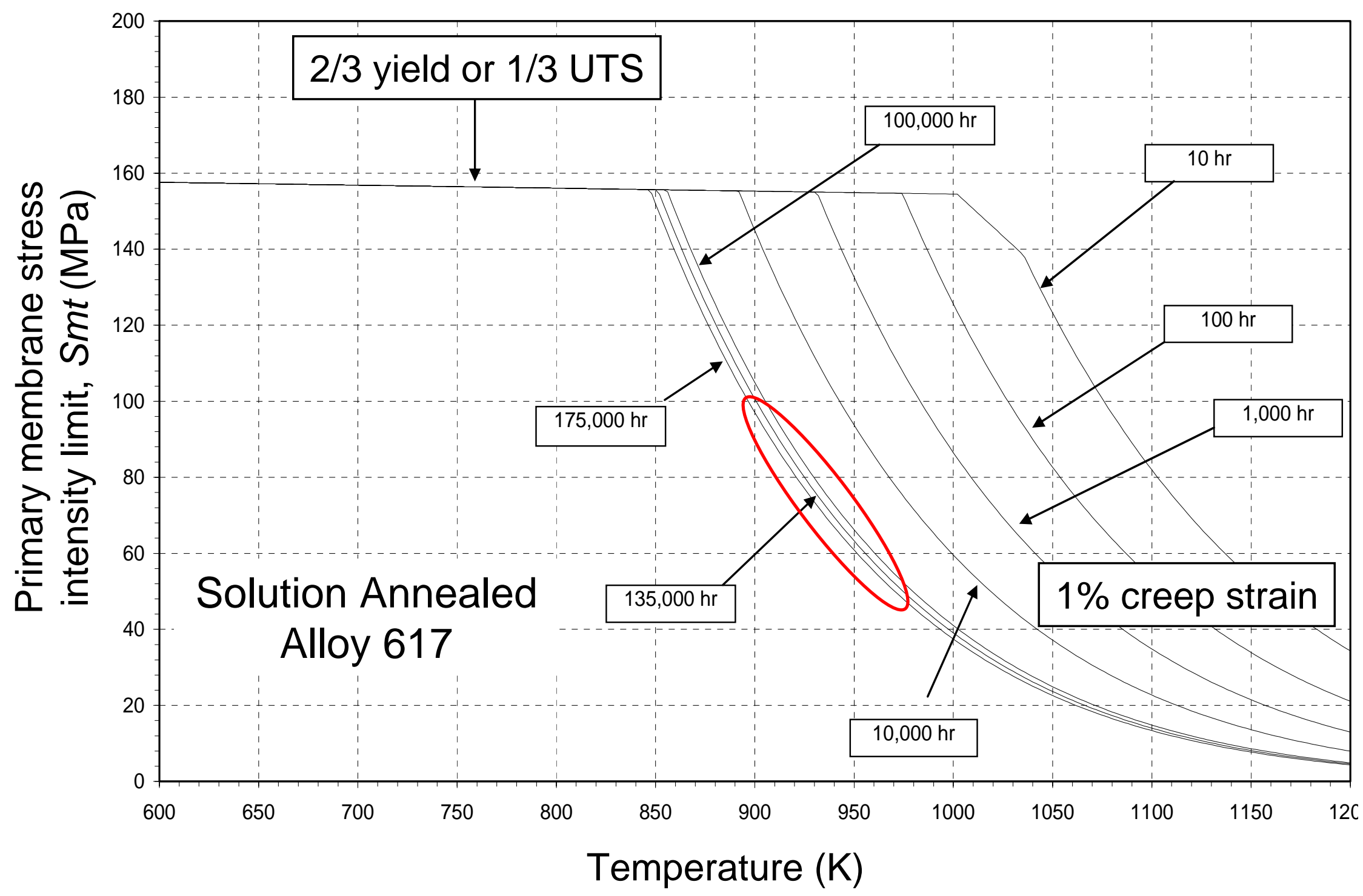




\section{Thermal Creep Comparison}

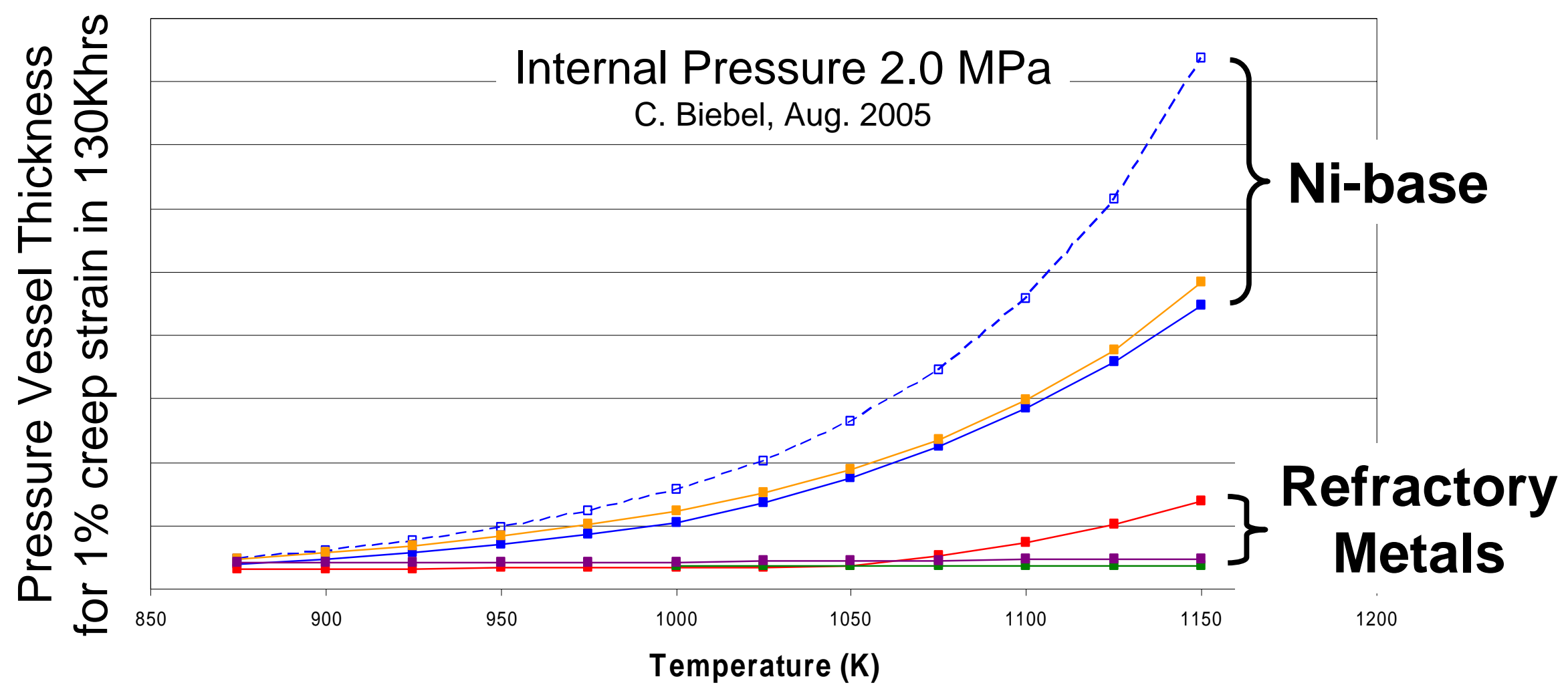

$0.76 \mathrm{~cm}$ Ni-base vessel wall at $925 \mathrm{~K}$, highly sensitive to $\mathrm{T}$ Refractory metal alloys are much less sensitive to $T$ 


\section{Reactor Core - Radiation Damage}

Refractory Metal Alloys

Radiation damage is limiting at lower $\mathrm{T}$ Creep and coolant interactions limit high $\mathrm{T}$

\section{Ni-base Alloys}

Radiation damage and creep are high $\mathrm{T}$ limits

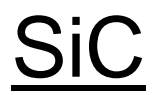

Radiation damage on mechanical properties saturate

\section{All materials have} radiation damage issues

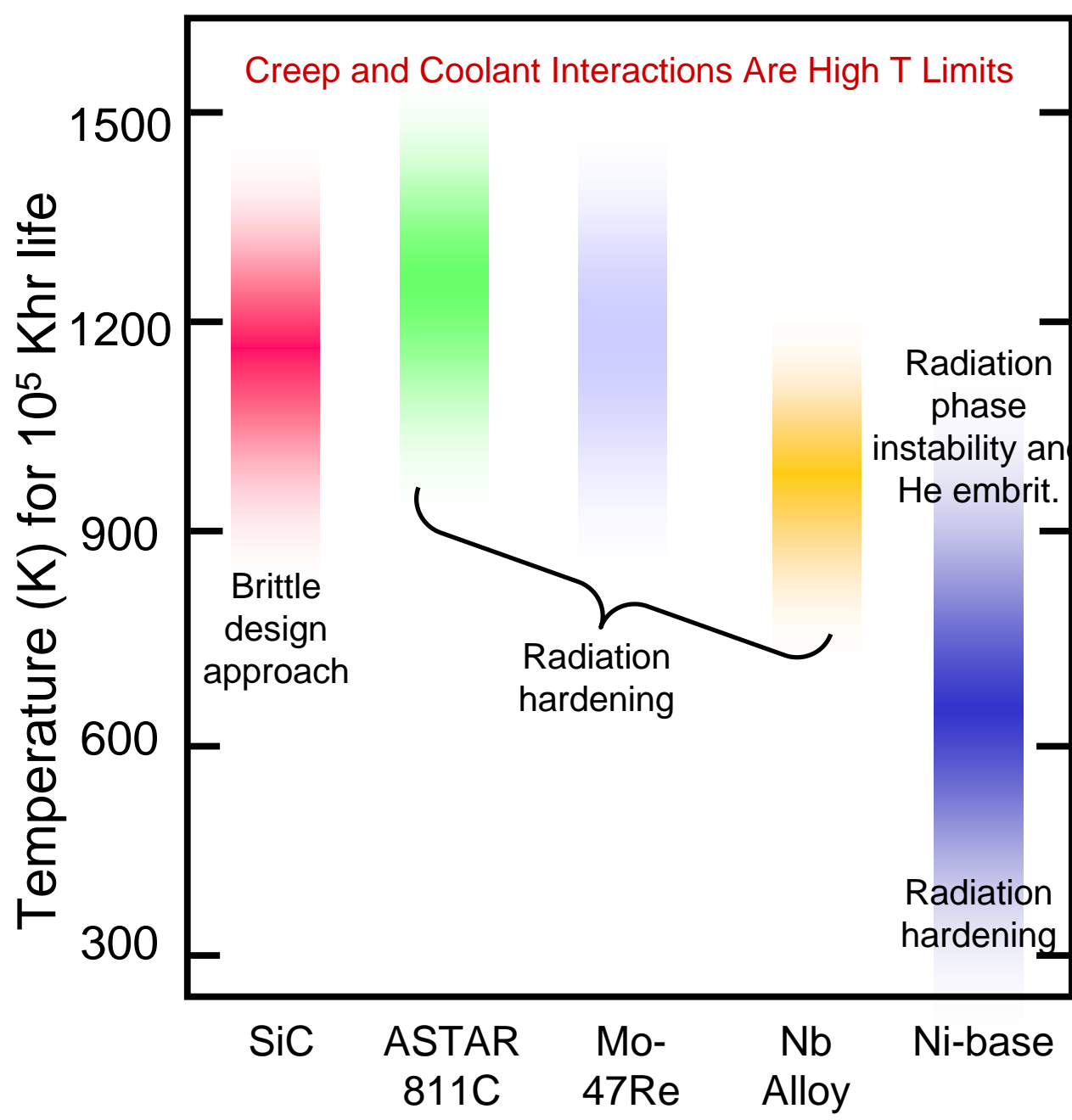

Adapted from S. Zinkle and N.M. Ghonium, Fusion Eng \& Design, 51-51 (2000) 55-71. 


\section{Radiation Damage in Ni-base Alloys}

Phase instability $\left(\sim 0.3-0.6 \mathrm{~T}_{\mathrm{m}}\right)$

Segregation of $\mathrm{Al}, \mathrm{Ti}, \mathrm{Nb}$, Si to grain boundaries Formation of brittle phases

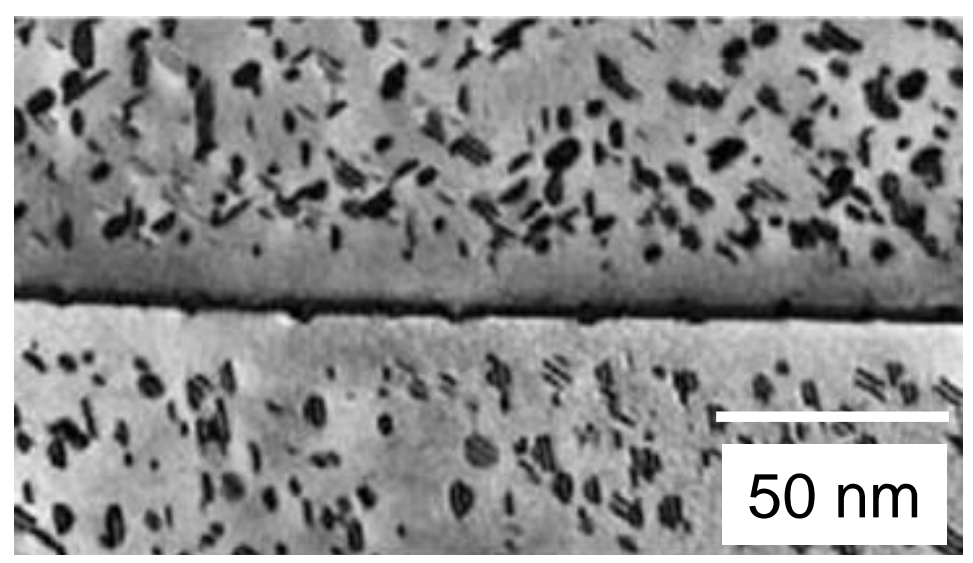

S. Zinkle, ASM-TMS Spring Sym, Niskayuna, NY (2005).

Radiation-induced embrittlement may be minimized by composition

Specification of nuclear grade alloys (low Al, Ti, Nb, Si, ${ }^{10} \mathrm{~B}$ )
He embrittlement $\left(>0.5 \mathrm{~T}_{\mathrm{m}}\right)$

$\mathrm{Ni}$ and ${ }^{10} \mathrm{~B}$ transmutate to $\mathrm{He}$ Bubbles form at grain boundaries

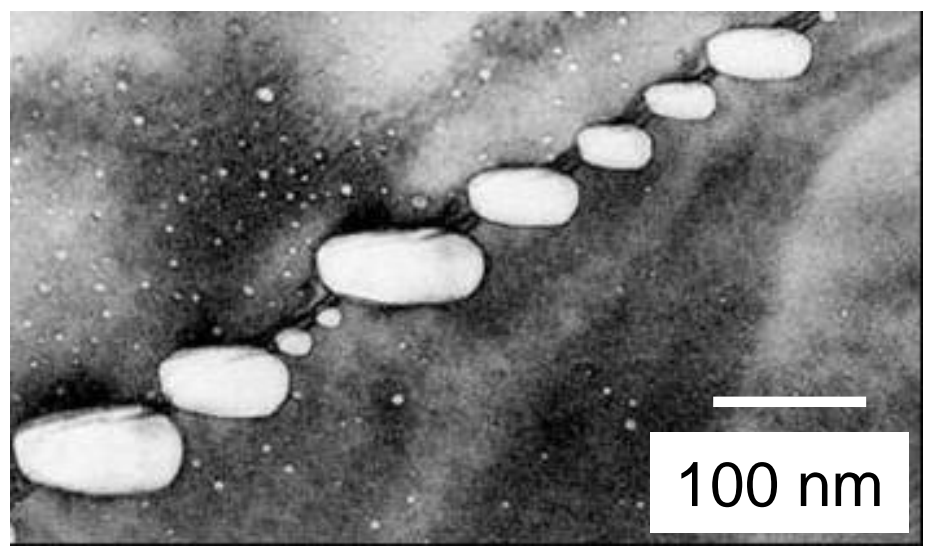

S. Zinkle, ASM-TMS Spring Symp, Niskayuna, NY (2005)

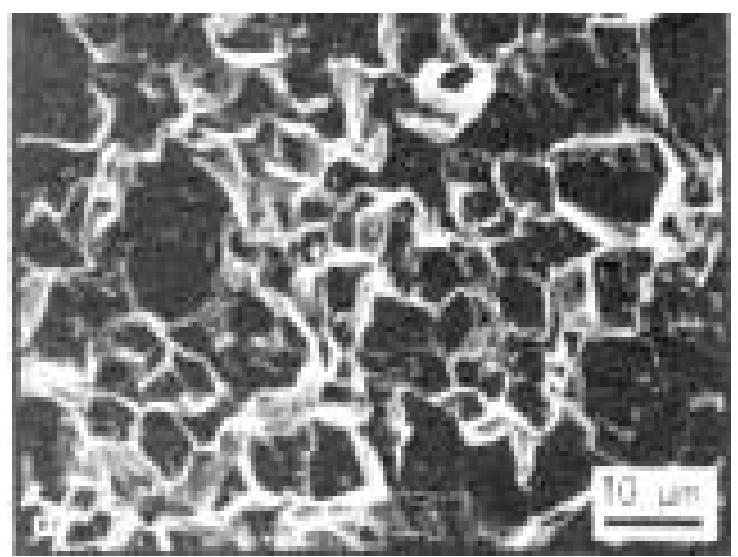

Intergranular fracture is bad 


\section{Radiation Damage in Refractory Metals}

\section{Radiation hardening and embrittlement}

Generally pronounced for $\mathrm{T}_{\text {irr }}<0.3 \mathrm{~T}_{M}$

Concern for transients and ground-based testing

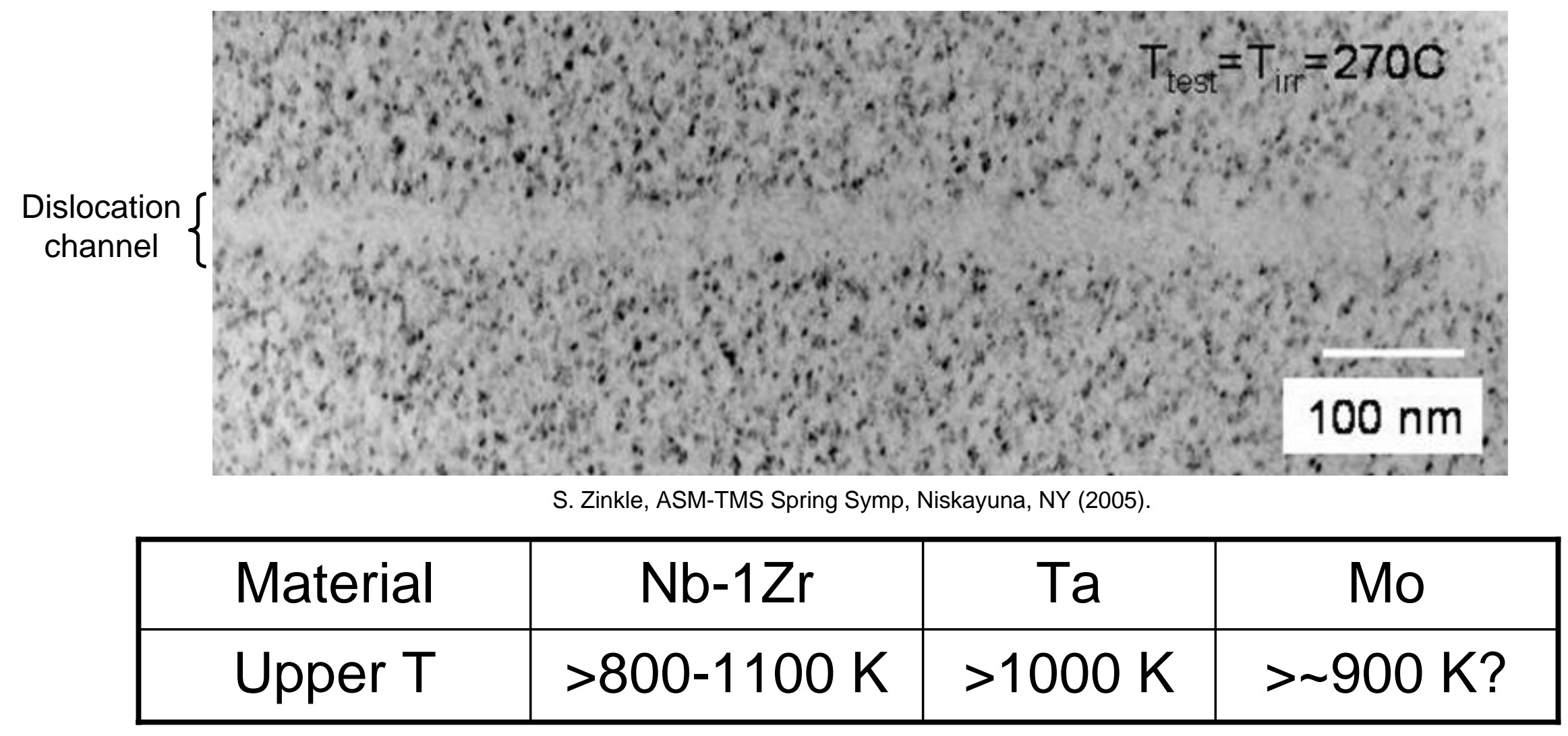




\section{Radiation Damage Experiments}

\section{Material stability under neutron exposure at elevated temperatures is required}

Freedom from phase transformations (thermal and/or irradiation-induced)

Freedom from radiation-induced segregation, creep, swelling, hardening and embrittlement

\section{Multiple programs to obtain these data}

Irradiation in a mixed neutron spectrum (HFIR, Oak Ridge National Lab)

Thermal aging studies to support the irradiation study (ORNL)

Irradiation in a fast neutron spectrum (JOYO-1 not summarized in this presentation)

\begin{tabular}{|c|c|c|c|c|c|c|c|c|c|}
\hline & Alloy & $\underline{\mathrm{Nb}}$ & $\underline{\mathrm{Zr}}$ & $\underline{\mathbf{W}}$ & $\underline{\mathrm{Ta}}$ & $\underline{\mathrm{Hf}}$ & $\underline{\mathbf{R e}}$ & Mo & $\underline{\mathrm{C}}$ \\
\hline \multirow{5}{*}{ Prometheus } & Mo-47.5Re & & & & & & 47.5 & Bal. & \\
\hline & Mo-41Re & & & & & & 41 & Bal. & \\
\hline & ASTAR811C & & & 8 & Bal. & 0.7 & 1 & & 0.025 \\
\hline & $\mathrm{T}-111$ & & & 8 & Bal. & 2 & & & \\
\hline & FS-85 & Bal. & 1 & 10 & 28 & & & & \\
\hline SP-100 Benchmark & $\mathrm{Nb}-1 \mathrm{Zr}$ & Bal. & 1 & & & & & & \\
\hline
\end{tabular}




\section{Radiation Damage Experiments}

\section{Thermal Exposure}

Vacuum aging at 1098, 1248 and $1398 \mathrm{~K}$ for $1100 \mathrm{hrs}$ (+25K of estimated HFIR irradiation T)

\section{Neutron Exposure}

High Flux Isotope Reactor (HFIR at ORNL, J.T. Busby, K.J. Leonard, J.R. Mayotte, D.T. Hoelzer, K.A. Thomas, J.W. Jones and S.J. Zinkle)

- Thermal spectrum leads to non-prototypic transmutation

20 and $40 \times 10^{20} \mathrm{n} / \mathrm{cm}^{2}$ (E>0.1MeV), Prometheus up to $200 \times 10^{20} \mathrm{n} / \mathrm{cm}^{2}$ (E>0.1MeV) 1073, 1223 and 1373K (nominal) for 1 or 2 cycles (552 or 1104 hours)

\section{Characterization}

Electrical resistivity

Microhardness

Density (swelling)

Tensile testing (strength, ductility)

Fractography

Chemical analysis

Metallography

Transmission electron microscopy

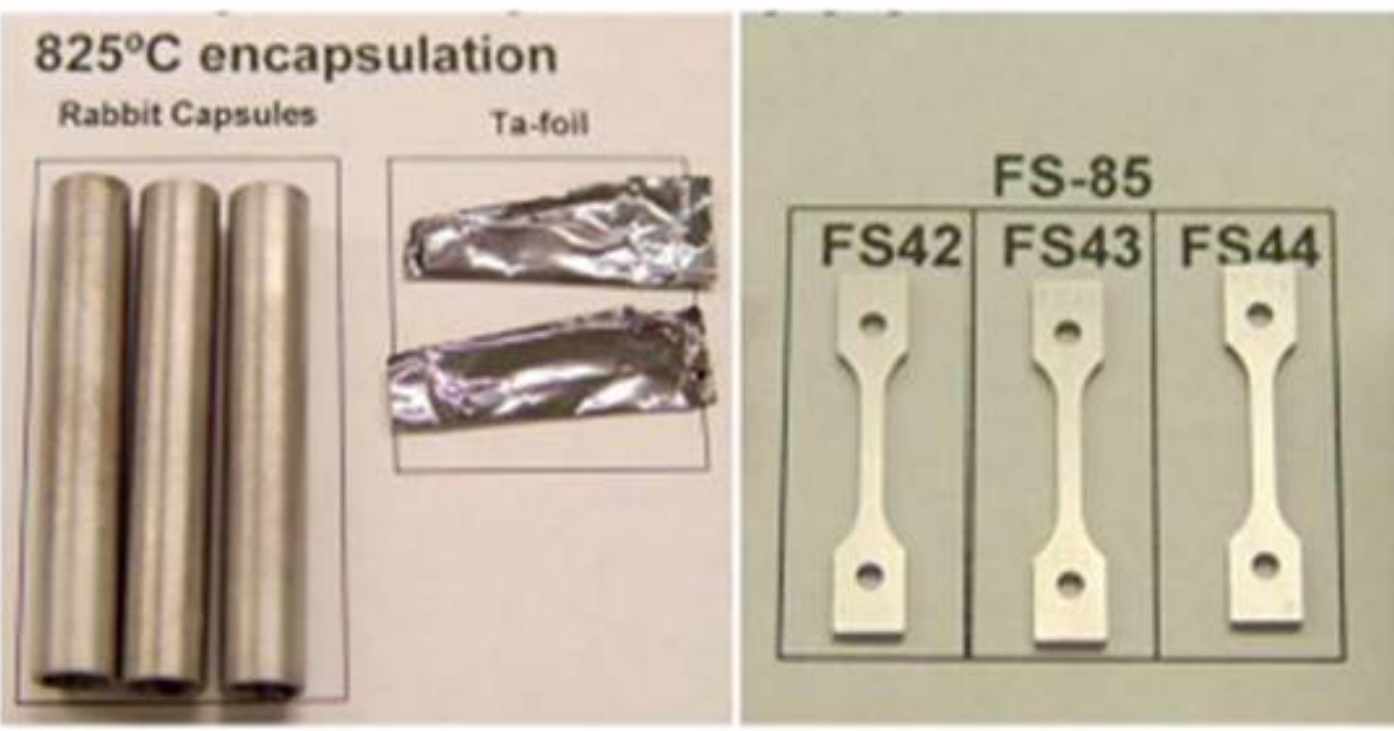




\section{Radiation Damage Refractory Metal Alloys}

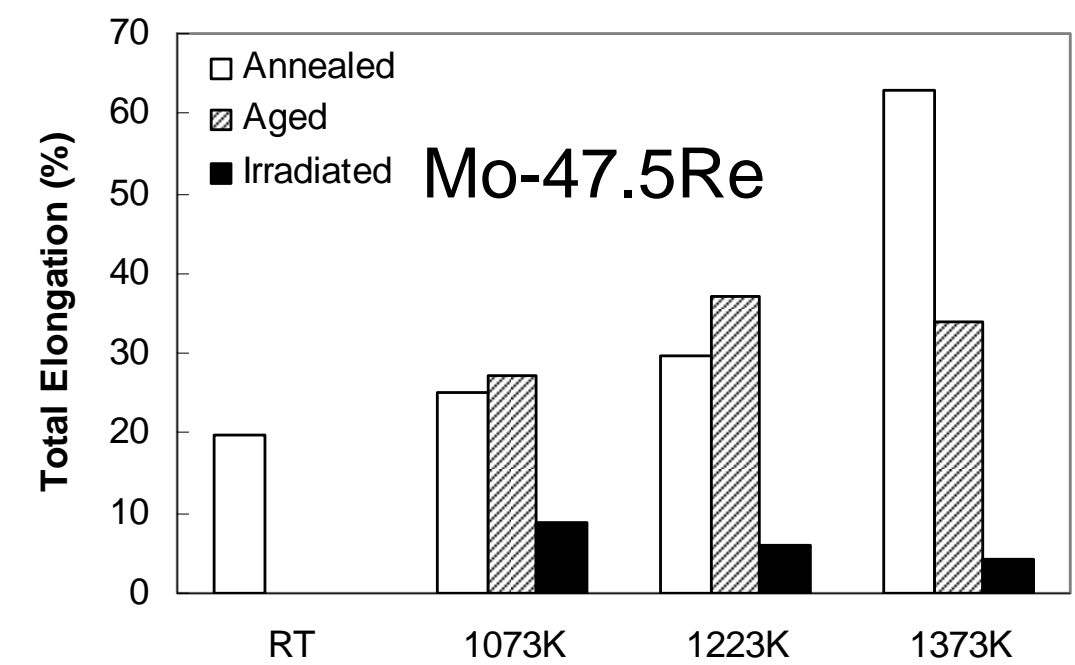

\section{High Flux Isotope Reactor (HFIR)}

Aged to $\sim 1 \%$ of mission life, irradiated to $10 \& 20 \%$ of mission fluence Comparing annealed to aged to irradiated Tensile testing - total elongation Mo-Re alloys exhibit radiation-induced embrittlement FS-85 needs additional investigation
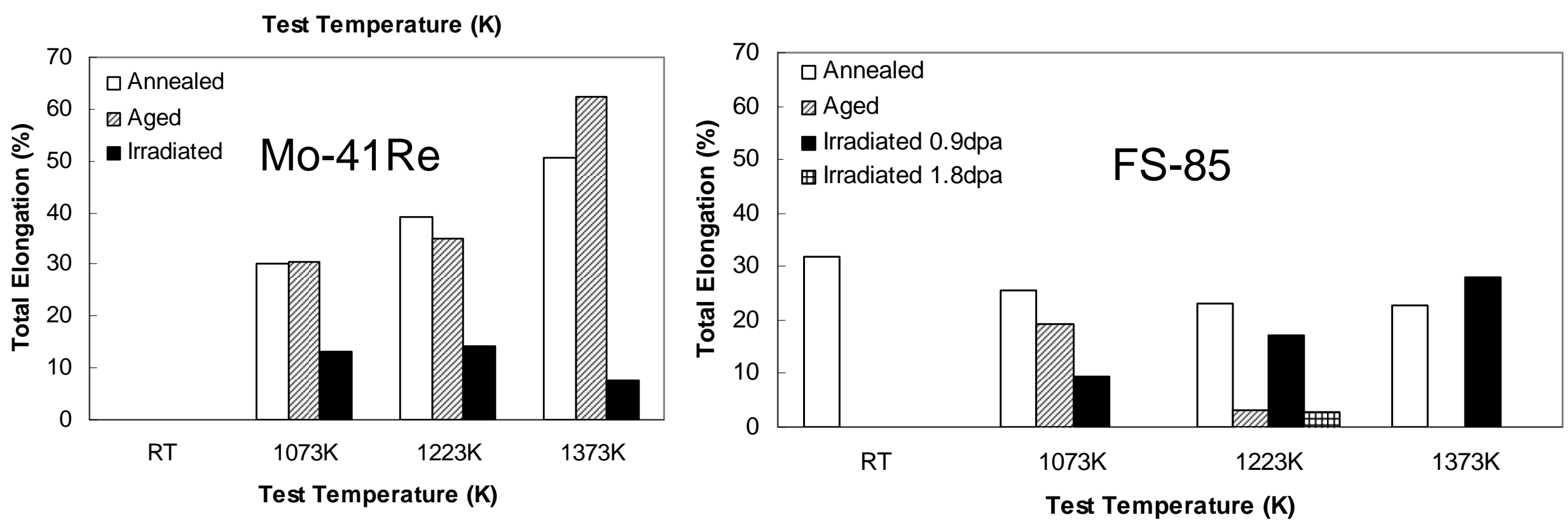


\section{Mo-41Re}

\section{$1248 \mathrm{~K}$ \\ aged}

No precipitation after thermal aging

Slight Re enrichment at grain boundaries ( $\sim \%$ increase)

\section{Mo-47.5Re}

Sigma phase after $1773 \mathrm{~K} / 1 \mathrm{hr}$ solution anneal

Sigma \& chi phases after thermal aging
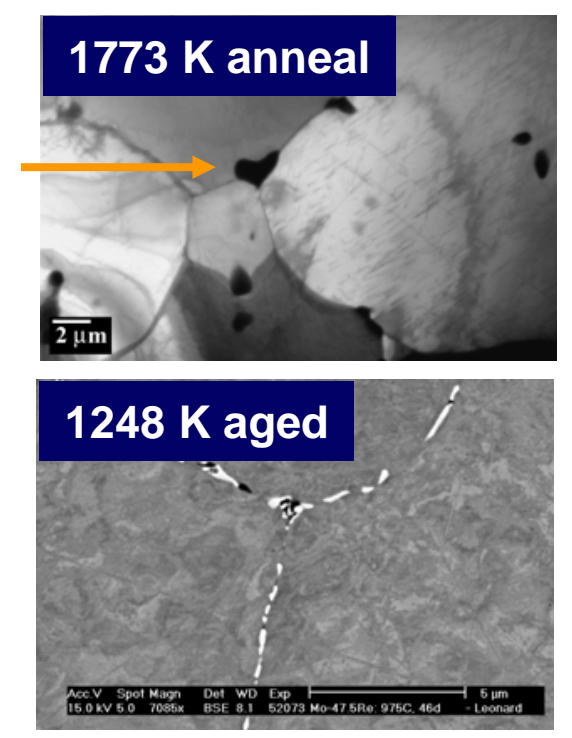

国地

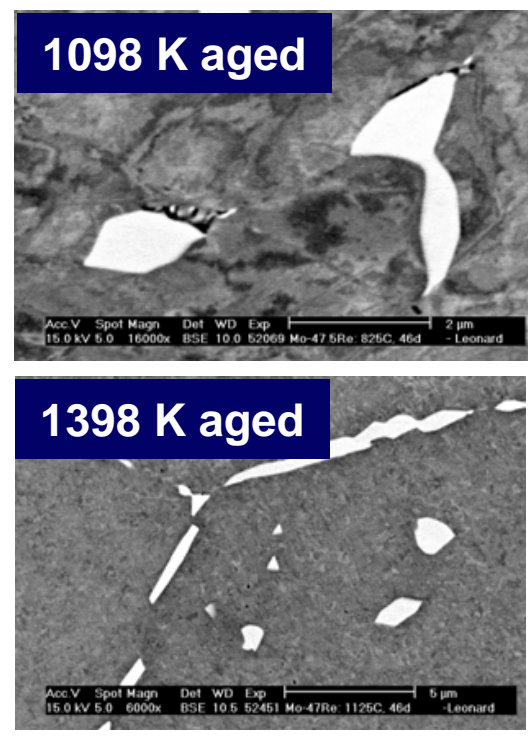

K. Leonard, ORNL (2005).

Sigma and chi are apparently not detrimental to the tensile behavior

Sigma and chi may contribute to irradiation strengthening No microstructural analysis of irradiated materials was conducted 


\section{Environmental Effects}

\section{Fission Products}

Nuclear fission creates a wide range of elements

Some of these elements are very detrimental to structural materials

\section{Fuel Cladding}

If fission products are not oxidized in the fuel, they can react with the cladding

$\mathrm{Cd}, \mathrm{Te}, \mathrm{Cs}, \mathrm{I}$ and others

Cadmium and tellurium are associated with liquid metal embrittlement

\section{Reactor and Plant Components}

If fission products are not contained by the fuel cladding, then they may be released as a vapor

Liquid metal embrittlement is a concern where these elements condense

\section{Fission product interactions need to be established}




\section{Degradation in Impure He/Xe}

\section{Refractory Metal Alloys}

$\mathrm{Ta}$ and $\mathrm{Nb}$ alloys do not form a protective oxide.

Mo alloys form a volatile oxide at low and very high oxygen levels.

Interstitial Embrittlement Interstitials ( $\mathrm{C}$ and $\mathrm{O}$ ) are readily absorbed to strengthen the matrix and decrease the ductility.

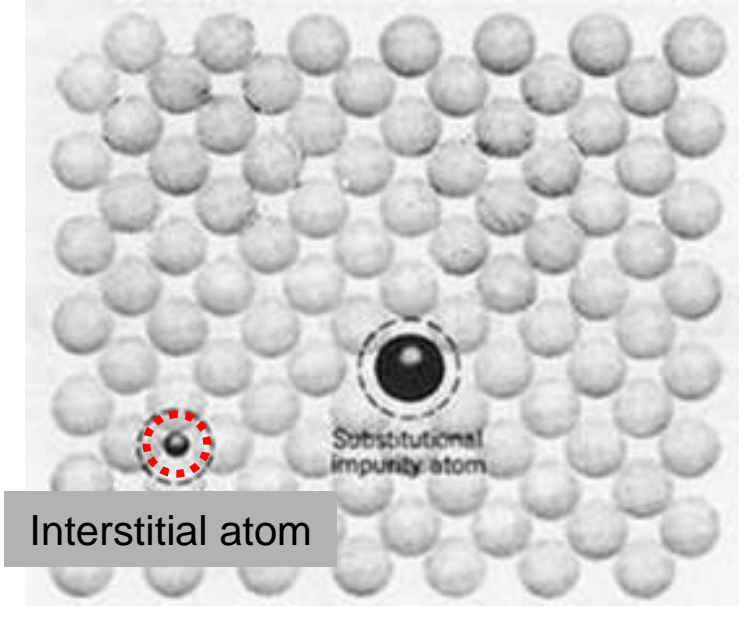

Temperature / kinetics are important to determine degradation rates Can refractory metal and Ni-base alloys co-exist in the same coolant loop? 


\section{Dissimilar Metal Joints}

Refractory metal to Ni-base alloy and refractory metal alloy to refractory metal alloy joints can form intermetallic phases which embrittle boundaries. Dependent on time, $T \&$ composition.

Cannot fusion weld due to intermetallic formation.

\section{Solid-State Joining Feasibility Studies}

Inertia Welding, Edison Welding Institute, J. Gould

Ni-base (Hastelloy $X$ ) to Ta-based (T-111)

Good bonding when both materials deform
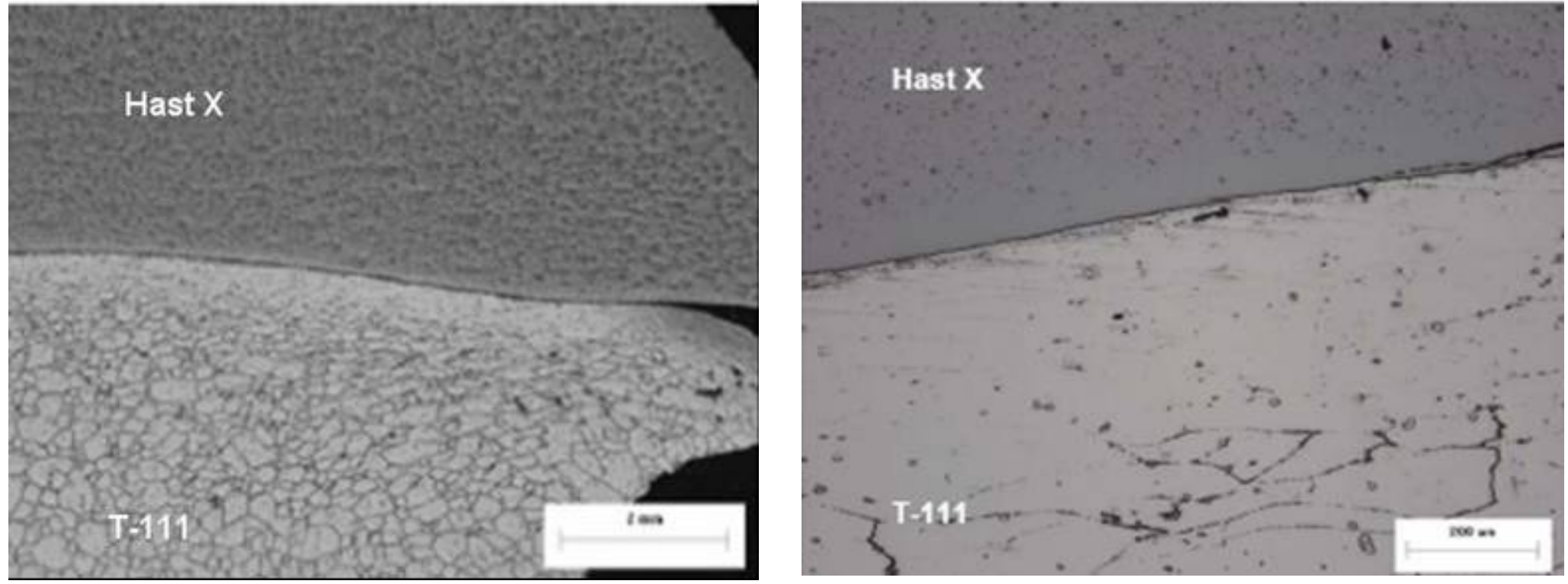


\section{Dissimilar Metal Joints}

\section{Diffusion Studies}

$>12 \mu \mathrm{m}$ ( 0.5 mils) of intermetallic promotes embrittlement, $<1 \%$ tensile ductility Recommended use of an interlayer to hinder diffusion. (Buckman \& Goodspeed, 1969)

NASA-GRC (I. Locci, J. Nesbitt, F. Ritzert)

Ni-base to Mo-Re $1150 \mathrm{~K} / 4 \mathrm{hr}$

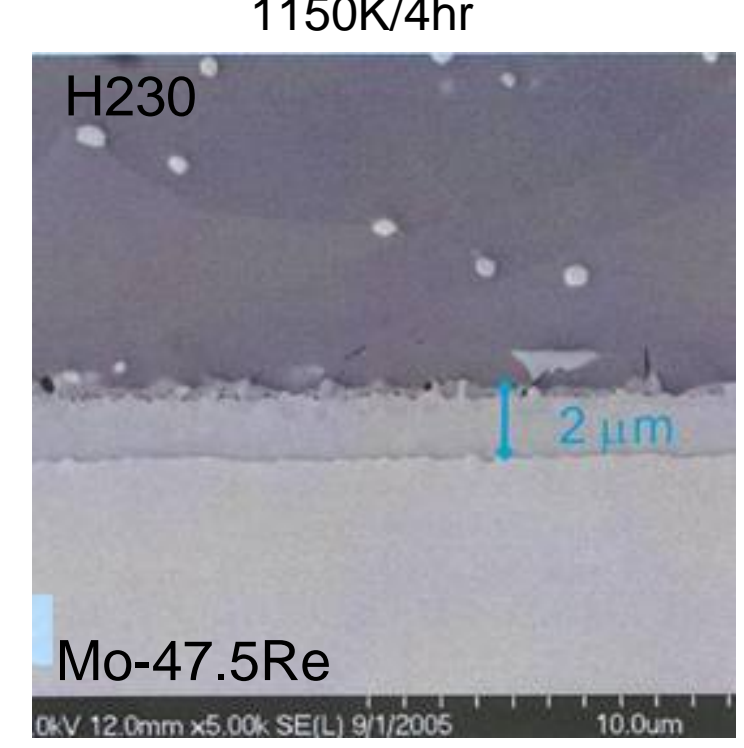

Ni-base to Mo-Re

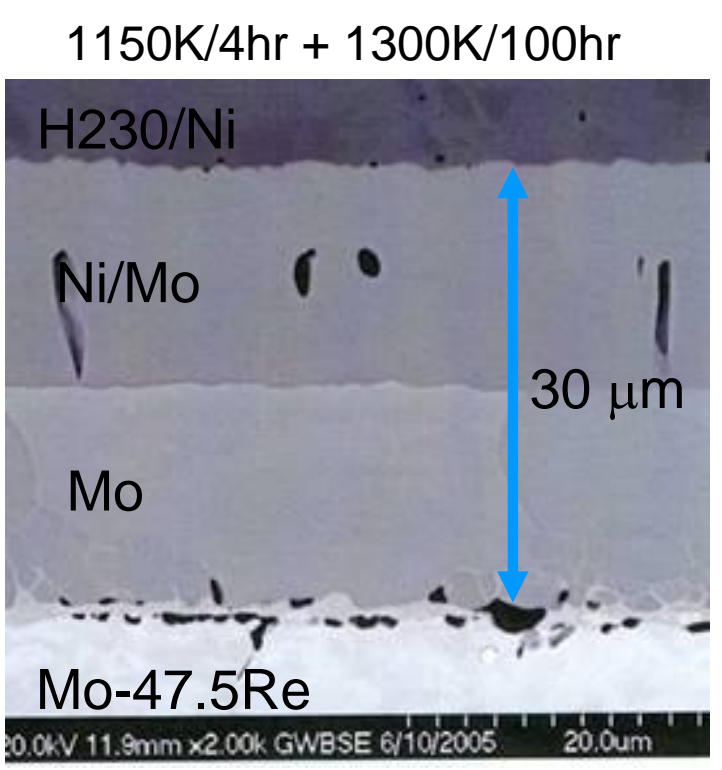

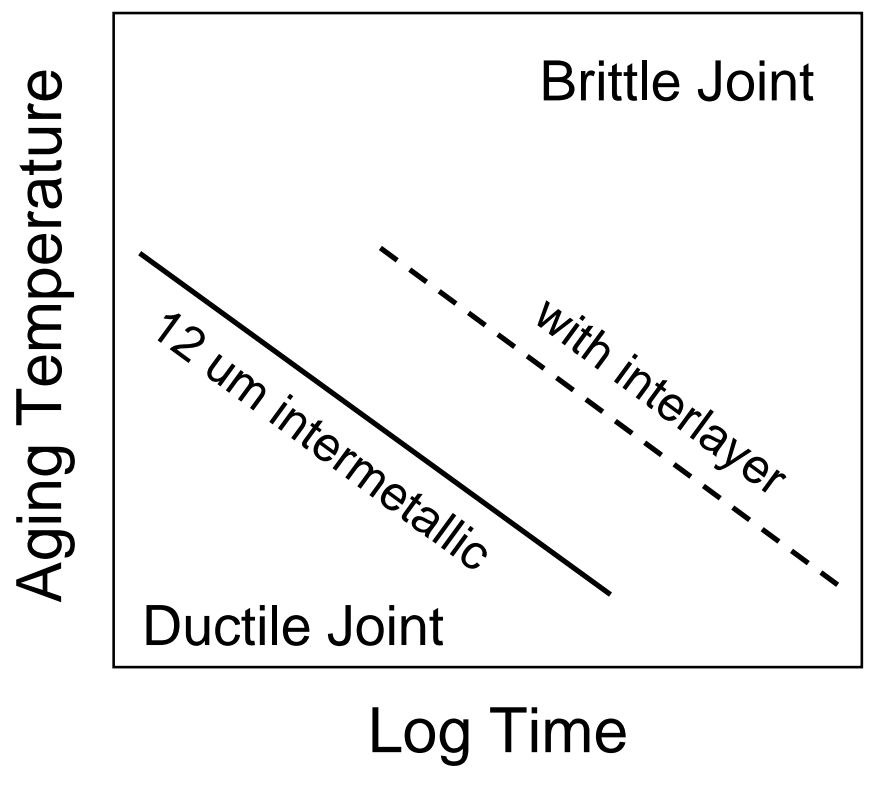

Dissimilar metal joints in the vessel are not recommended Pursue interface layers to inhibit intermetallic formation 


\section{Plant Components and Materials}

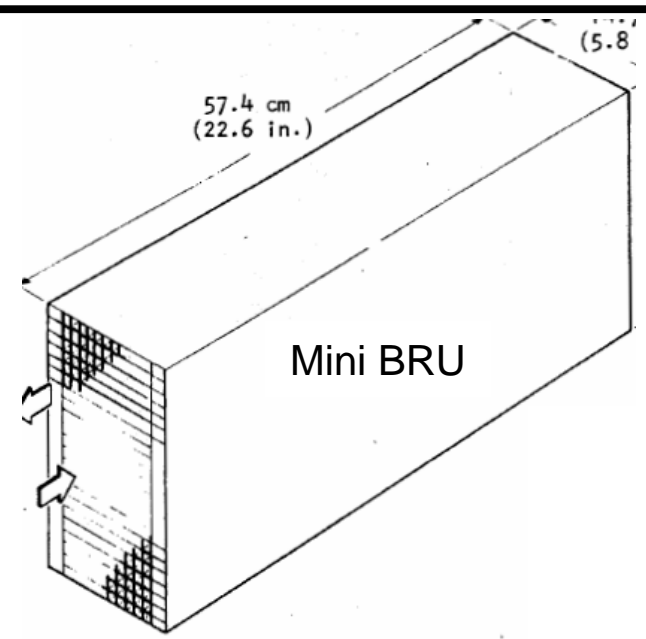

Recuperator

High surface area

(plate \& fin), $\sim 140 \mathrm{~m}^{2}$

IN625 wrought

Various braze materials

Ni-based (Si, B, Cu, Mn)

Precious metal (Pd-Co, Ni-Pd-Si-B)
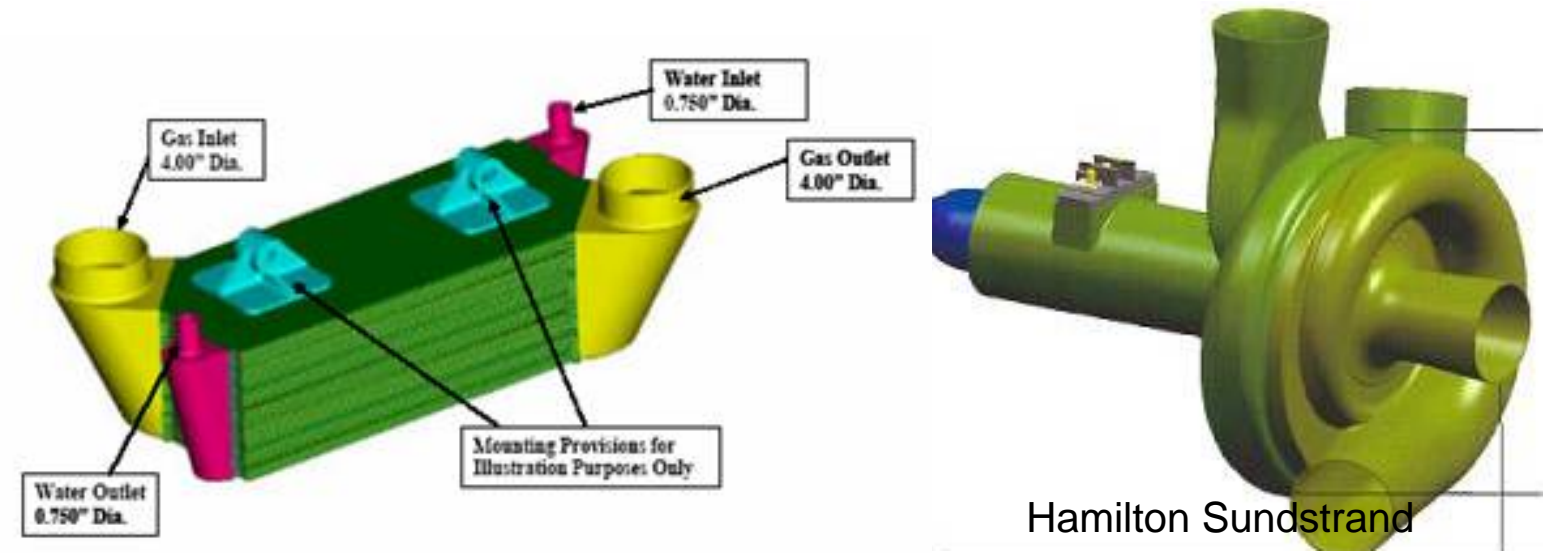

Gas Cooler Alloys 625, 690
Turbine Casing (at $\mathrm{T}_{\text {Hот }}$ ) Ti6Al4V (compressor only) MAR-M247 (turbine only)

Turbine Wheel/Blades MAR-M-247 (cast superalloy) IN792 (cast superalloy)

\section{Compressor} Wheel/Blades Ti6Al4V, stainless steel 


\section{Turbine and Ducting}

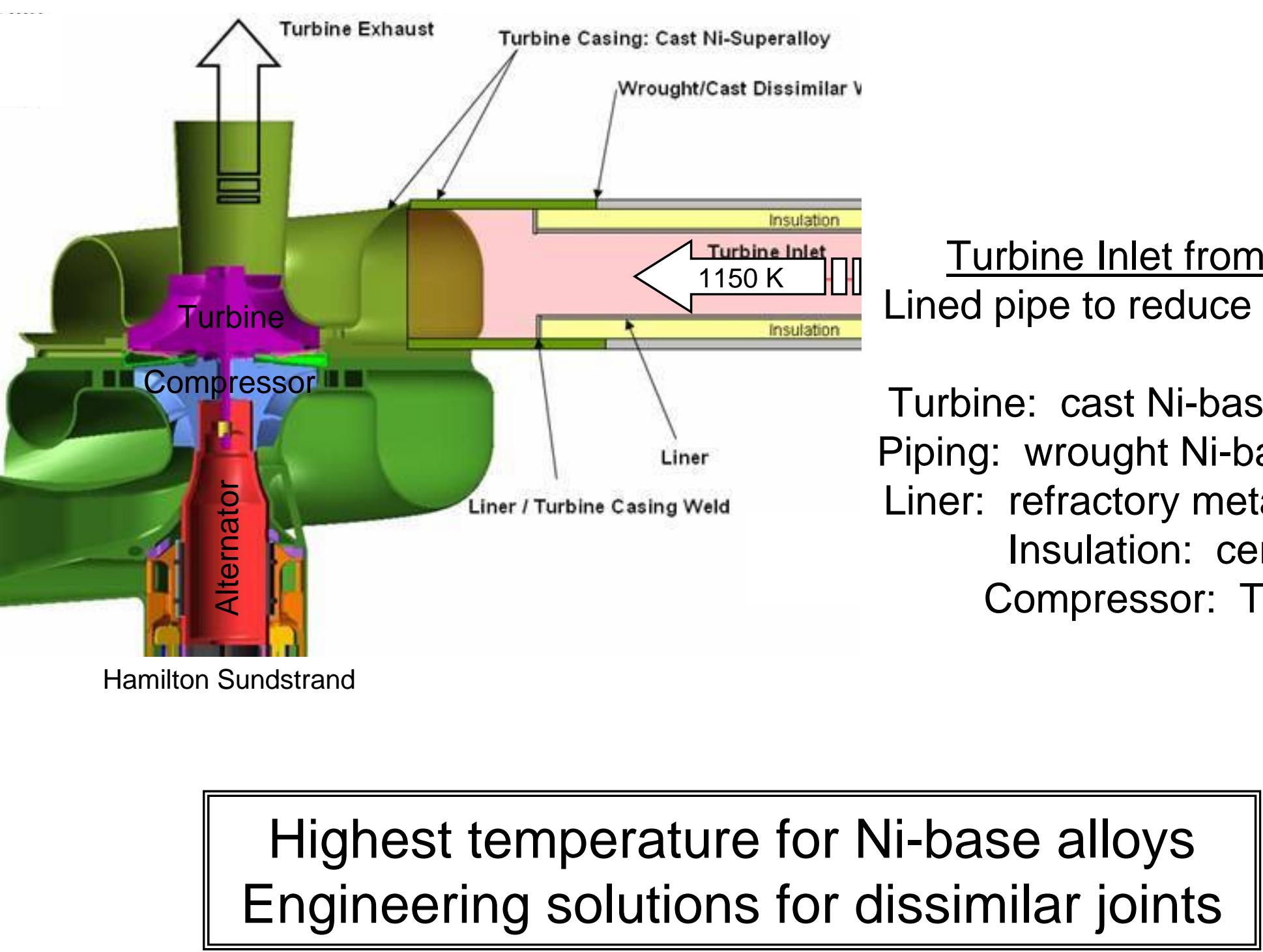




\section{Alternator and Bearings}

Contains many different materials

Windings (CuNi)

Insulation (polyamide-KAPTON)

Magnets (SmCo)

Lamination (FeCo)

Foil bearings - solid lubricants- $\mathrm{CaF}_{2}, \mathrm{BaF}_{2}, \mathrm{AgNi}_{2} \mathrm{Cr}_{2} \mathrm{O}_{3}$

Potting material - epoxy
$13 \%$ of $\mathrm{He} / \mathrm{Xe}$ working fluid bleeds through the alternator assembly

Concerns with impurity transfer and fission product radiation damage

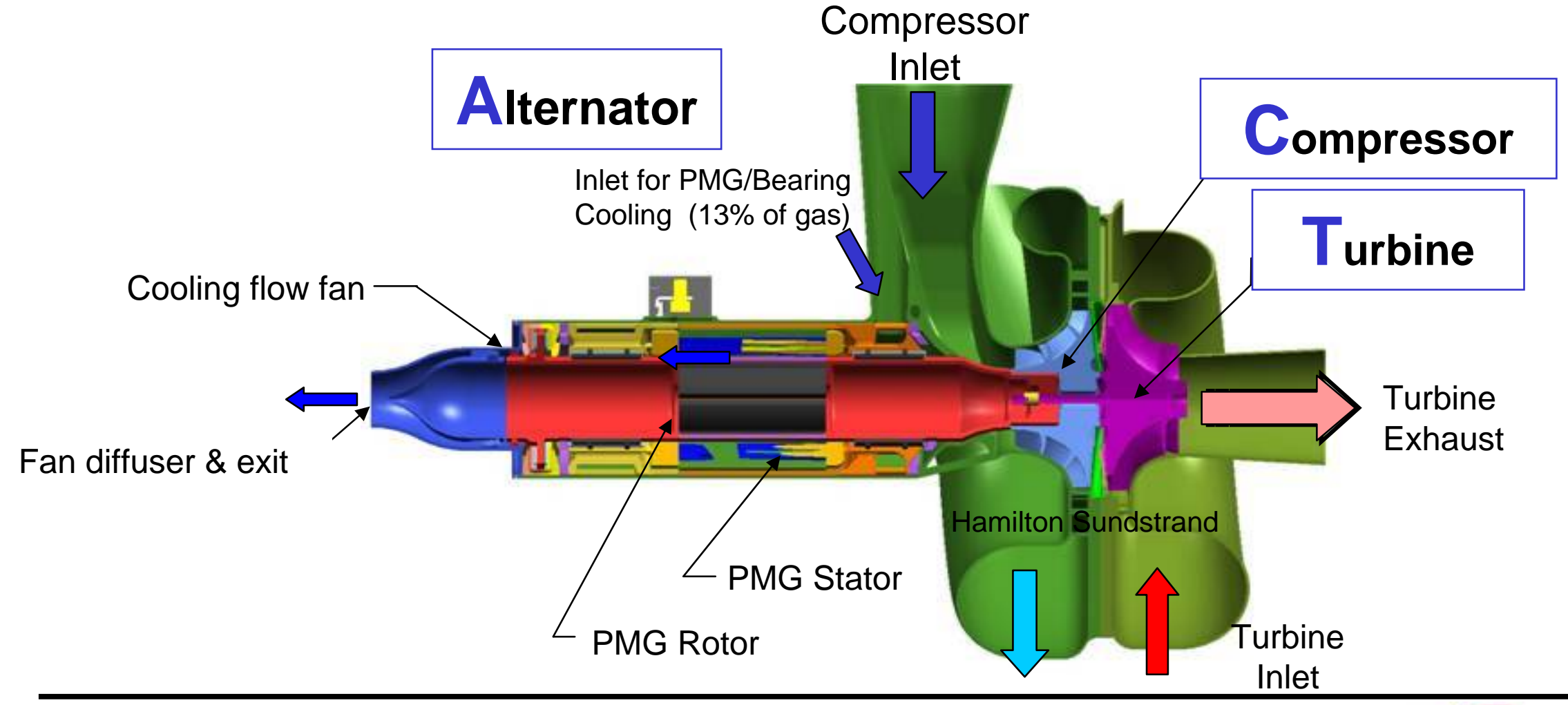




\section{Materials Test Programs}

\section{Thermal Creep and Creep Fatigue}

Confirm previous data and fill holes in the database, especially creep fatigue

Long term data were especially needed

\section{Radiation Embrittlement}

Very limited data for all materials in the temperature and neutron fluence regimes of interest Limited options for exposing materials in representative neutron spectrum (no domestic)

\section{Environmental Effects}

Prototypical environment needs to be established, may use HTGR experience Many degradation mechanisms: interstitial embrittlement, decarburization, fission products

\section{Joints}

Dissimilar metal joints would likely require solid state joining process development and incorporation of an interface layer

Very limited data on radiation effects on joints

\section{Multi-year materials test programs were required}




\section{Conclusions}

\section{Refractory metal alloys}

More than adequate thermal creep

Must manage lower temperatures to avoid radiation hardening, embrittlement

Coolant may need to be ultra-clean or vessel coated to avoid interstitial embrittlement

\section{Ni-base superalloys}

Likely adequate thermal creep

Susceptible to radiation-induced He embrittlement and solute segregation

Coolant may need to be oxidizing to prevent decarburization $>1173 \mathrm{~K}$

\section{$\mathrm{SiC}$}

More than adequate thermal creep

Brittle design criteria must be developed

Low activation with saturation of mechanical properties with radiation damage

\section{Dissimilar Metal Joints}

$\mathrm{Ni}$-base vessel may have cast to wrought $\mathrm{Ni}$-base joint at turbine, development needed

Refractory metal alloy vessel may have a refractory metal to Ni-base alloy joint

Technically challenging at higher temperatures

\section{Significant materials testing and development programs are required}


Bechtel - Bettis Atomic Power Laboratory

Edison Welding Institute

Hamilton Sundstrand

Lockheed Martin - Knolls Atomic Power Laboratory

NASA - Glenn Research Center

Oak Ridge National Lab

Pittsburgh Materials Technology, Inc.

Rhenium Alloys Inc 
Enclosure 10 to

SPP-SEC-0039

\title{
Mass Transport Modeling and Supporting Experimental Tasks for the Prometheus Space Reactor System
}

\author{
Schumaker, T. and Ohlinger, W.
}


This page is intentionally blank.

PRE-DECISIONAL - For planning and discussion purposes only 


\title{
Mass Transport Modeling and Supporting Experimental Tasks for the Prometheus Space Reactor System
}

\author{
Tymm Schumaker \\ Youssef Ballout \\ Knolls Atomic Power Laboratoryl Naval Reactors Prime Contractor Team \\ Wayne Ohlinger \\ Bettis Atomic Power Laboratoryl Naval Reactors Prime Contractor Team \\ Peter Tortorelli, Steve Pawel, Dane Wilson, B. Radhakrishnan, John Vitek, Chad Duty \\ Oak Ridge National Lab
}

\section{STAIF, February 2006}




\section{Agenda}

* Background

* Overview of Environmental Issues for Prometheus

* Preliminary Mass Transport Model - Equilibrium Approach (with results)

* Finite Element Model (the Burden Model)-Dynamic Approach

*xperimental Testing to Support Modeling Effort * Summary 


\section{Major Materials Issues}

\section{Environmentally Assisted Degradation:}

$t>$ Gas Corrosion

$>$ Fission Products $\}$ Mass Transport Issues

>Space Vacuum Evaporation 


\section{Definition of Gas Corrosion Issues}

* Dissimilar materials thermodynamically coupled in a high temperature re-circulating helium loop

* Large volume of impure HeXe acts as a common: $\longrightarrow$ Reactor Coolant * Large temperature differential across core and plant: $\sim 390$ - $1400 \mathrm{~K}$

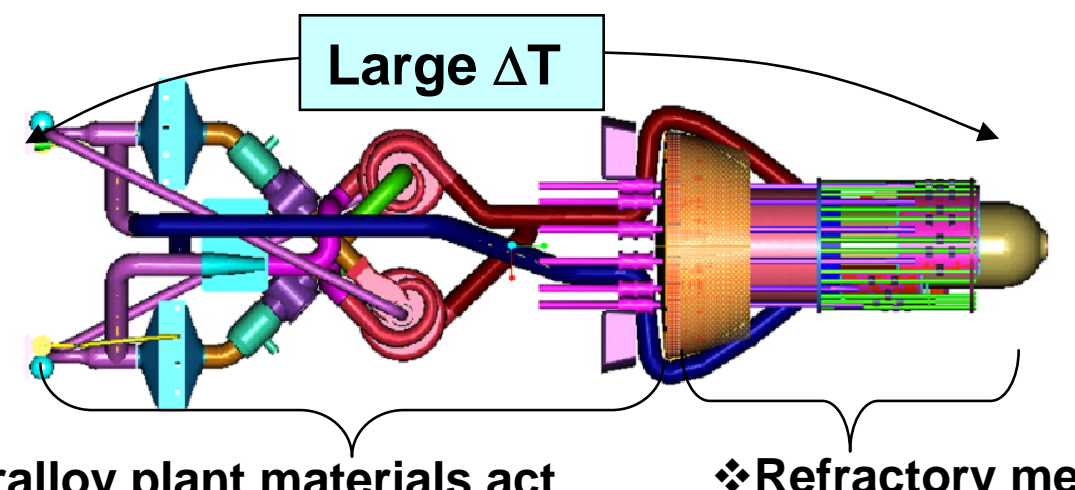

* Ni-base superalloy plant materials act * Refractory metal core alloys act as "sources" for impurities as "sinks" for impurities
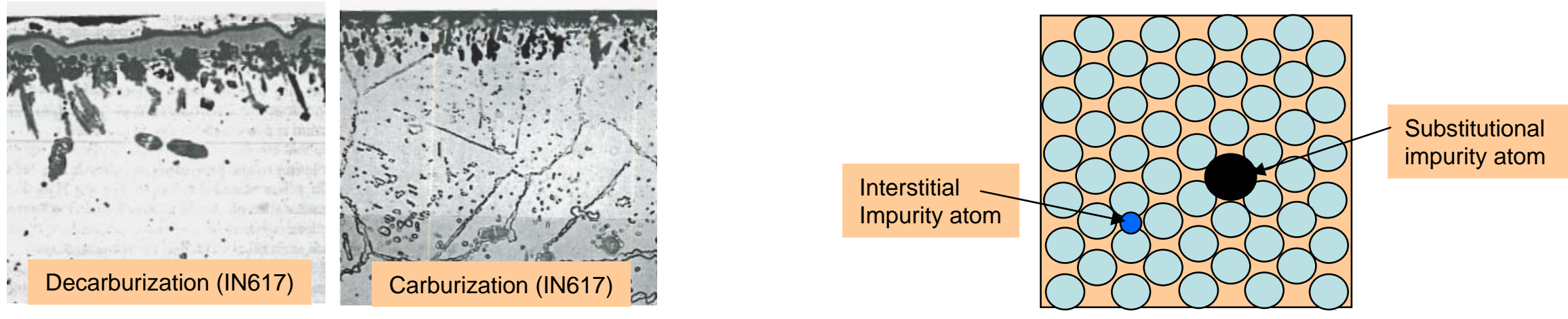

Superalloy Degradation

Refractory Metal Degradation 


\section{Refractory Metal Alloy Interstitial Embrittlement Threshold}

\section{Embrittlement Threshold}

*At temperature $(T)$, threshold below which the refractory metal alloy candidate will not be adversely affected by interstitial embrittlement (increase in strength, decrease in ductility)

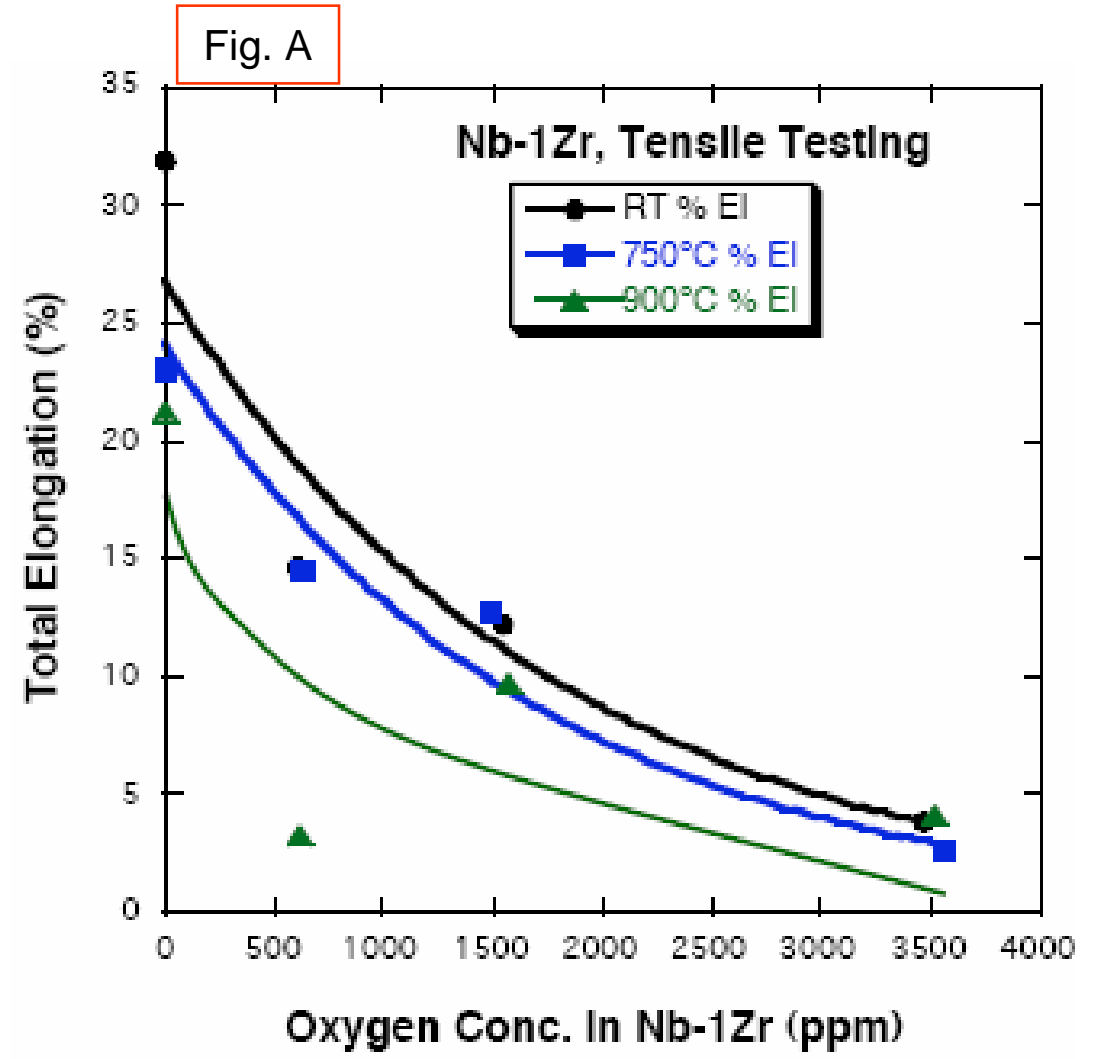

DiStefano \& Chitwood

J. Nuclear. Materials., 2001

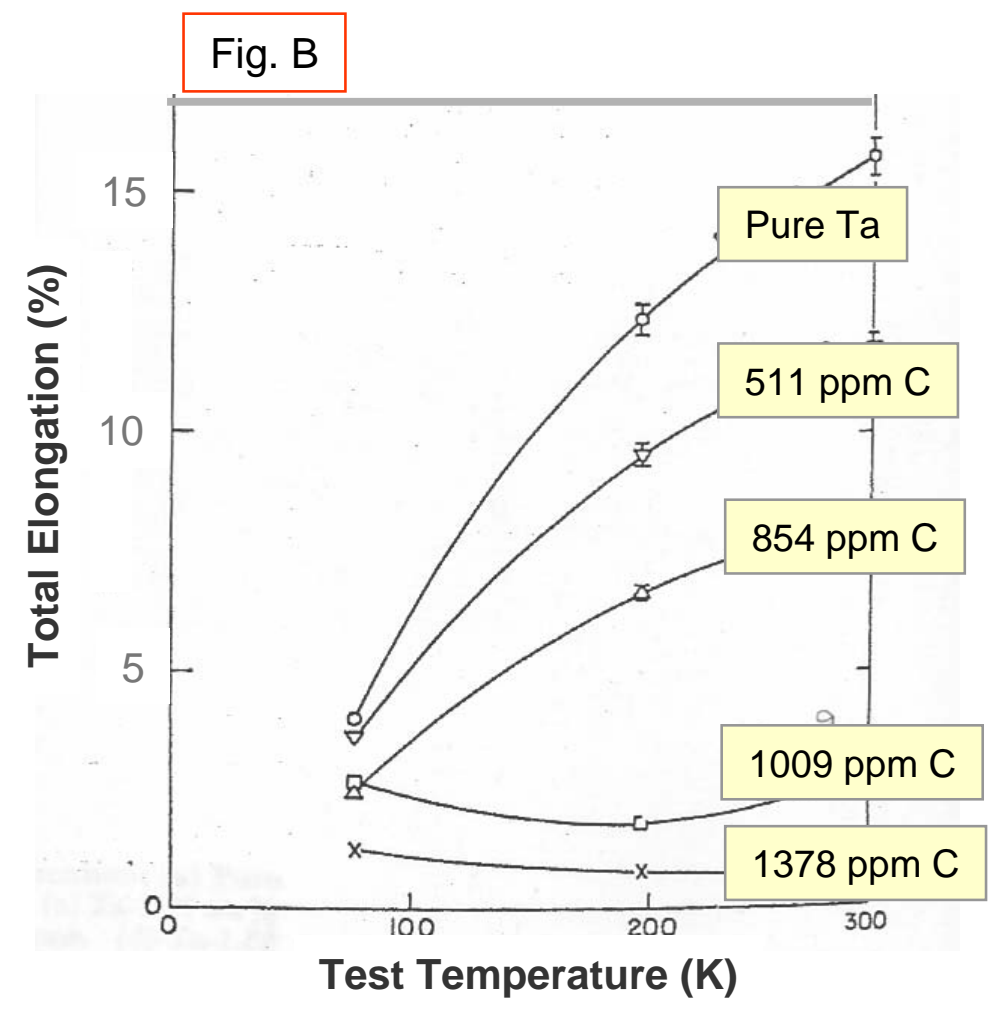

Atomic Percent Carbon in Tantalum

Rao \& Thomas

Acta Metallurgica., 1975 


\section{Direct Gas Brayton: Complex Impurity Contributions}

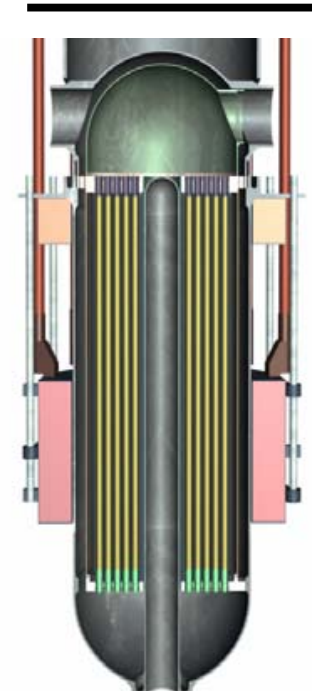

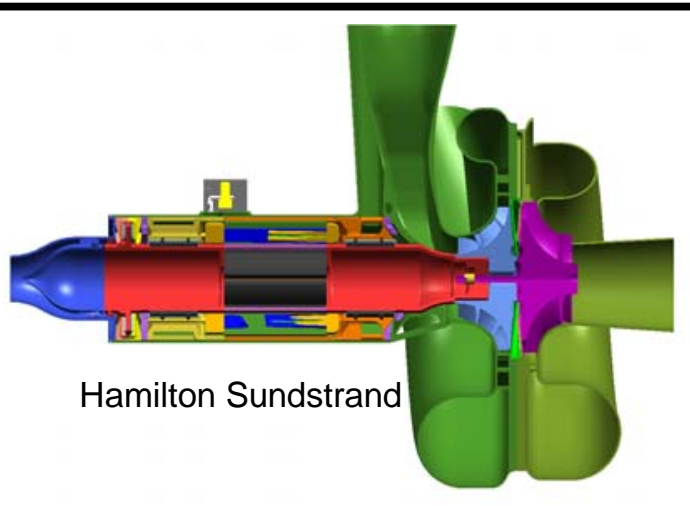

Turbo-alternator Assembly -Wide range of materials

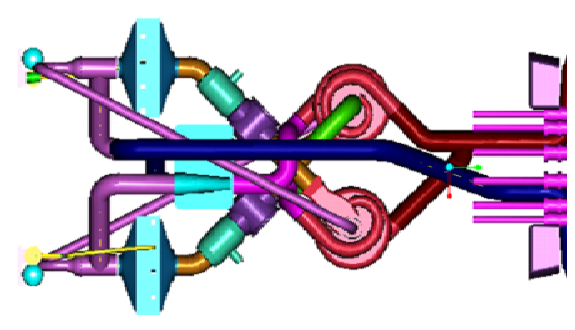

Piping / Ducting Wrought Ni-base Superalloy

\section{Core-Ni-based}

Superalloy Vessel

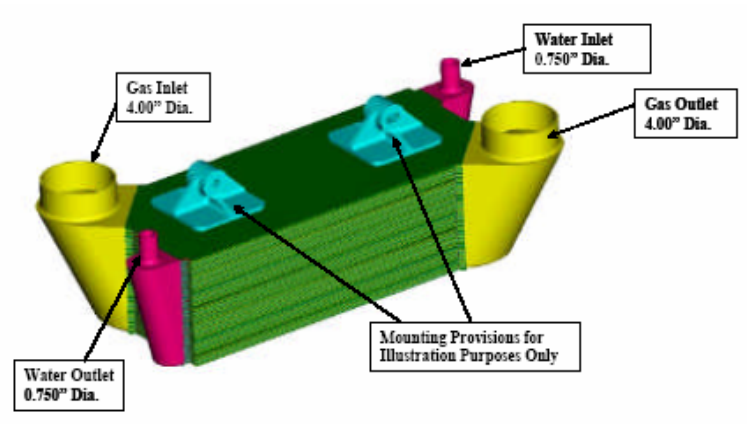

Gas Cooler Titanium-Lower Temp

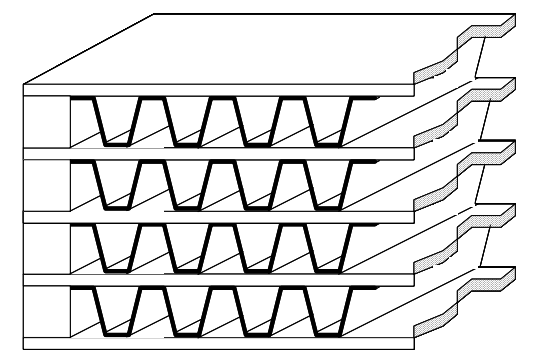

Recuperator -IN625 wrought -High acreage Various braze materials Ni-based (Si, B, Cu, Mn) Precious metal (Pd-Co, Ni-Pd-Si-B

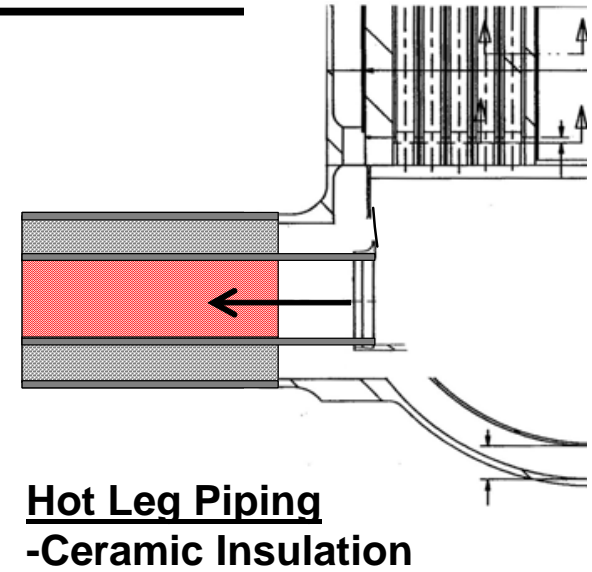

-Ceramic Insulation

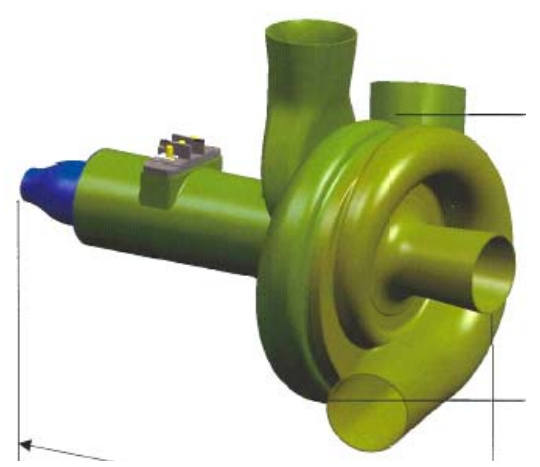

Hamilton Sundstrand

Turbine/Compressor

-Cast Superalloy (MAR-M-247) -Ti6Al4V 


\section{Mass Transport Modeling Overview}

\section{Modeling Effort for Prometheus}

$>$ Equilibrium Approach - Preliminary Mass Transport Model (Oak Ridge Nat'l Lab)

D Dynamic (Kinetic) Approach - Finite Element Approach (Burden Model)

\section{Experimental Support}

$>$ Acquisition of equilibrium and kinetic data

$>$ Confirmation of modeling predictions

-Capsules

-Flowing Gas Loops

-Helium Corrosion Loop 


\section{Equilibrium Approach}

Preliminary Mass Transport Model 


\section{Preliminary Mass Transport Model}

Equilibrium Approach: Worst Case - No Limited Kinetic Data Required

Objective: To determine maximum load of impurities from source materials to sink materials over predetermined mission life ( 120,000 hours).

\section{Assumptions:}

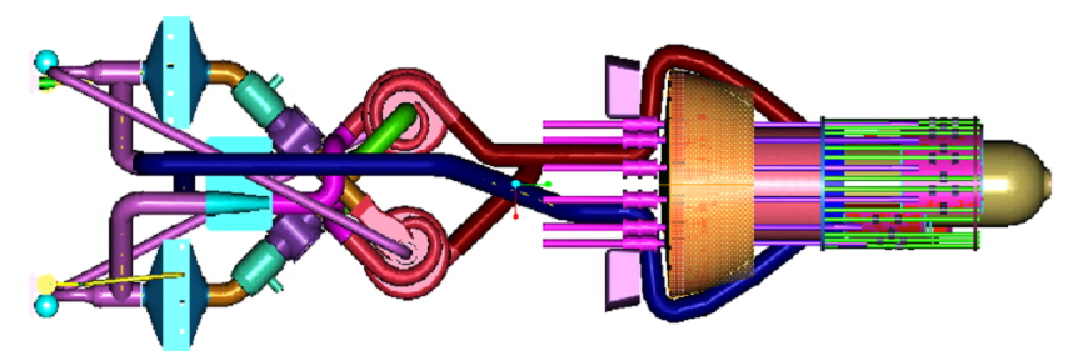

(1) Equilibrium has been reached for each reactant species in the helium gas-all reactions proceed to completion

(2) The only impurity species accounted for are O, N, and C

(3) Impurity contributions only considered at temperatures $>800 \mathrm{~K}$

(4) Reactor coolant/plant working fluid treated only as a conduit for impurities, not a contributor

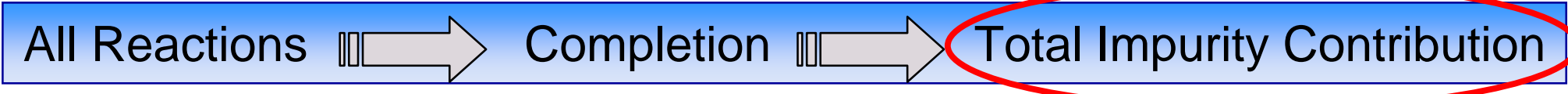




\section{1) Design Specific Data:}

$>$ Mass, Material Type (impurity contribution), Surface Area, Temperature

\section{2) Limited Kinetic Data:}

Estimate of a solid state diffusion distance over component lifetime

\section{3) Limited Thermodynamic Data:}

$>$ Estimate of elemental activity in various system componentsidentifies which components will act as impurity "sources" or "sinks"

*Design, kinetic and thermodynamic data gathered as input for the Preliminary Mass Transport Model will be used for the more comprehensive Burden Model until experimental data becomes available 


\section{Design Input for Preliminary Mass Transport Model}

\section{1) Design Specific Data Required}

\section{Key Design Parameters}

needed to support the model:

$>T>800 \mathrm{~K}$

$>$ Surface Area

$>$ Mass

\begin{tabular}{|c|c|c|c|c|c|}
\hline No. & & Description & $\begin{array}{l}\text { Temp. } \\
\text { (K) }\end{array}$ & $\begin{array}{l}\text { SA } \\
\left(m^{2}\right)\end{array}$ & $\begin{array}{l}\text { Mass } \\
(\mathrm{kg})\end{array}$ \\
\hline 1 & & Reactor & & & \\
\hline & $a$ & outer vessel & 950 & 2.6 & 226 \\
\hline & $\mathrm{b}$ & thimble & 1160 & 0.6 & 28 \\
\hline & c & clad & 1220 & 20.4 & 177 \\
\hline & $d$ & block & 1160 & 26.6 & 542 \\
\hline & $\mathrm{e}$ & inner baffle & 1160 & 1.1 & 5 \\
\hline & $f$ & outer baffle & 1160 & 3.1 & 14 \\
\hline & $\mathrm{g}$ & inner dome & 1160 & 0.9 & 4 \\
\hline 2 & & Duct to turbine & 1150 & 4.2 & 296 \\
\hline 3 & & Turbine & & & \\
\hline & $a$ & wheel - stage 1 & 1030 & 0.04 & 0.4 \\
\hline & $\mathrm{b}$ & wheel - stage 2 & 900 & 0.04 & 0.4 \\
\hline & c & wheel - stage 3 & 800 & 0.04 & 0.4 \\
\hline & $d$ & wheel - stage 4 & 700 & 0.04 & 0.4 \\
\hline & $\mathrm{e}$ & housing - stage 1 & 1088 & 0.06 & 2.5 \\
\hline & $f$ & housing - stage 2 & 963 & 0.06 & 2.5 \\
\hline & $\mathrm{g}$ & housing - stage 3 & 838 & 0.06 & 2.5 \\
\hline & $\mathrm{h}$ & housing - stage 4 & 713 & 0.06 & 2.5 \\
\hline 4 & & $\begin{array}{l}\text { Duct to high T } \\
\text { recuperator }\end{array}$ & 922 & 0.8 & 38 \\
\hline 5 & & High T recuperator & & & \\
\hline & $a$ & inlet & 834 & 34.0 & 35 \\
\hline & $\mathrm{b}$ & outlet & 642 & 34.0 & 35 \\
\hline 6 & & Duct to gas cooler & 569 & 1.2 & 52 \\
\hline 7 & & Gas cooler & & & \\
\hline 8 & & Duct to compressor & 390 & 1.0 & 45 \\
\hline 9 & & Compressor & & & \\
\hline 10 & & $\begin{array}{l}\text { Duct to low T } \\
\text { recuperator }\end{array}$ & 538 & 0.7 & 30 \\
\hline 11 & & Low $\mathrm{T}$ recuperator & & & \\
\hline & $a$ & inlet & 627 & 34.0 & 35 \\
\hline & $\mathrm{b}$ & outlet & 803 & 34.0 & 35 \\
\hline 12 & & Duct to reactor & 891 & 5.6 & 398 \\
\hline
\end{tabular}




\section{Kinetic Data Have Been Compiled from Literature and DICTRATM}
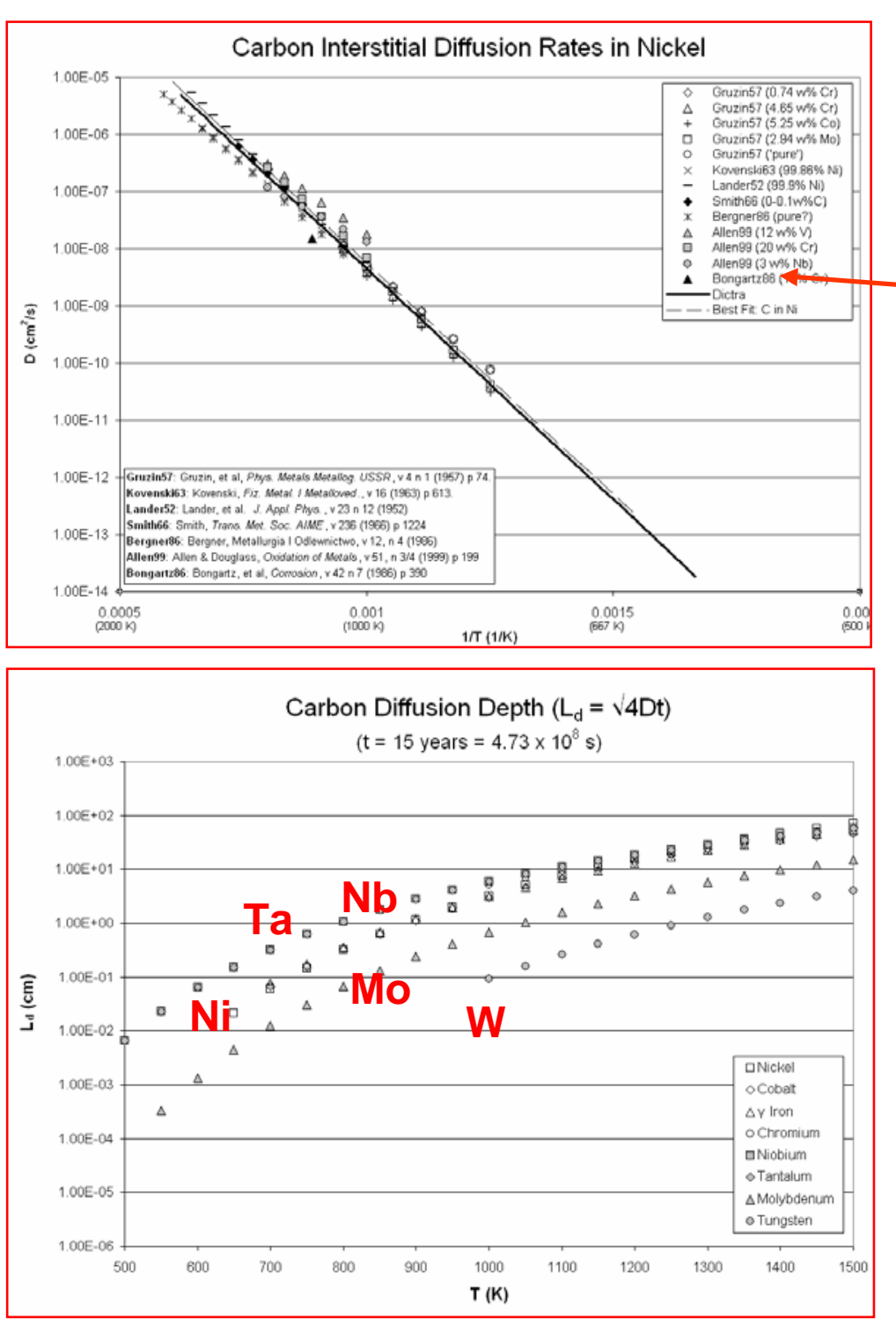

\section{2) Limited Diffusion Data Required}

$>$ Need to calculate a diffusion length to estimate "volume" of each component participating in impurity transfer over mission life Compare empiricalmeasurements to DICTRA ${ }^{\mathrm{TM}}$ database

$>$ Diffusion coefficients for $\mathrm{C}, \mathrm{O}$ and $\mathrm{N}$ documented as a function of $\mathrm{T}$ for ( $\mathrm{Nb}, \mathrm{Ta}, \mathrm{Mo}, \mathrm{W}, \mathrm{Ni}, \mathrm{Co}, \mathrm{Fe}$, and $\mathrm{Cr}$ )

Example for carbon diffusion depth $>$ Near upper end of operating temperature, diffusion depth of carbon calculated to be $\sim 1-10 \mathrm{~cm}$ over mission life - 15 years.

Most components have section thicknesses $<1 \mathrm{~cm}$. Conservative approach - entire volume of each component will participate in the transfer of impurities.

Put Upper Bound on Source Contribution over Lifetime 


\section{Thermodynamic Calculations for Carbon and Oxygen Activity in Nb}

3) Limited Thermodynamic Data Required
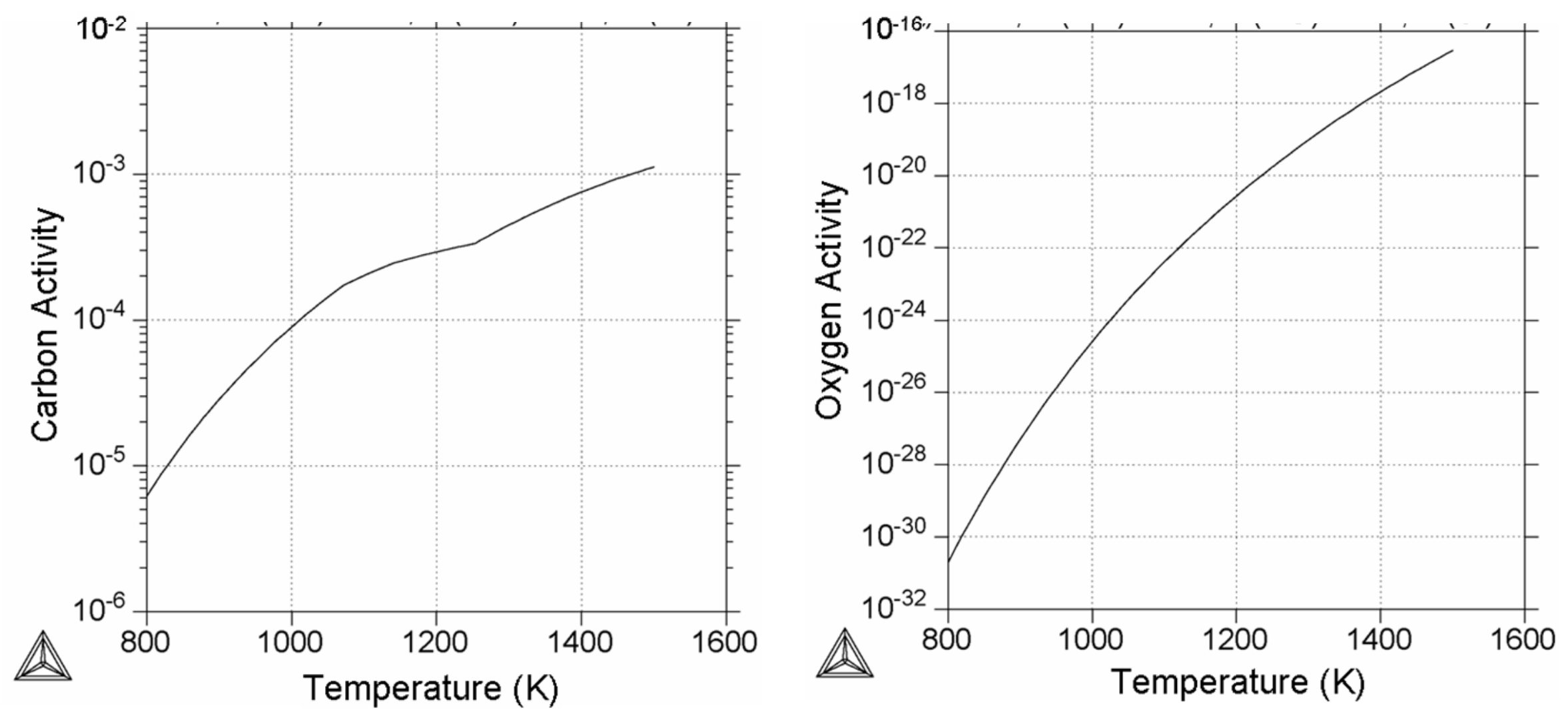

Used to Identify which components act as a "Source" or a "Sink" 


\section{Two Cases Were Considered}

\begin{tabular}{|c|c|c|c|}
\hline \multicolumn{4}{|c|}{$\begin{aligned} & \text { SA = Superalloy } \\
\mathrm{RM}= & \text { Refractory metal alloy }\end{aligned}$} \\
\hline Component & Description & Case I & Case II \\
\hline 1 & Reactor & & \\
\hline & outer vessel & RM & $\mathrm{SA}$ \\
\hline & thimble & RM & SA \\
\hline & clad & RM & RM \\
\hline & block & RM & $\mathrm{SA}$ \\
\hline & inner baffle & RM & $\mathrm{SA}$ \\
\hline & outer baffle & RM & $\mathrm{SA}$ \\
\hline & inner dome & $\mathrm{RM}$ & $\mathrm{SA}$ \\
\hline 2 & Duct to turbine & $\mathrm{SA}$ & $\mathrm{SA}$ \\
\hline 3 & Turbine & & \\
\hline & wheel - stage 1 & SA & $\mathrm{SA}$ \\
\hline & wheel - stage 2 & SA & SA \\
\hline & wheel - stage 3 & $\mathrm{SA}$ & $\mathrm{SA}$ \\
\hline & wheel - stage 4 & $\mathrm{SA}$ & SA \\
\hline & housing - stage 1 & SA & SA \\
\hline & housing - stage 2 & SA & $\mathrm{SA}$ \\
\hline & housing - stage 3 & $\mathrm{SA}$ & SA \\
\hline & housing - stage 4 & SA & $\mathrm{SA}$ \\
\hline 4 & Duct to hi T recup & SA & SA \\
\hline 5 & Hi T recup & & \\
\hline & inlet & SA & $\mathrm{SA}$ \\
\hline 6 & Lo T recup & & \\
\hline & outlet & $\mathrm{SA}$ & $\mathrm{SA}$ \\
\hline 7 & Duct to reactor & SA & SA \\
\hline
\end{tabular}

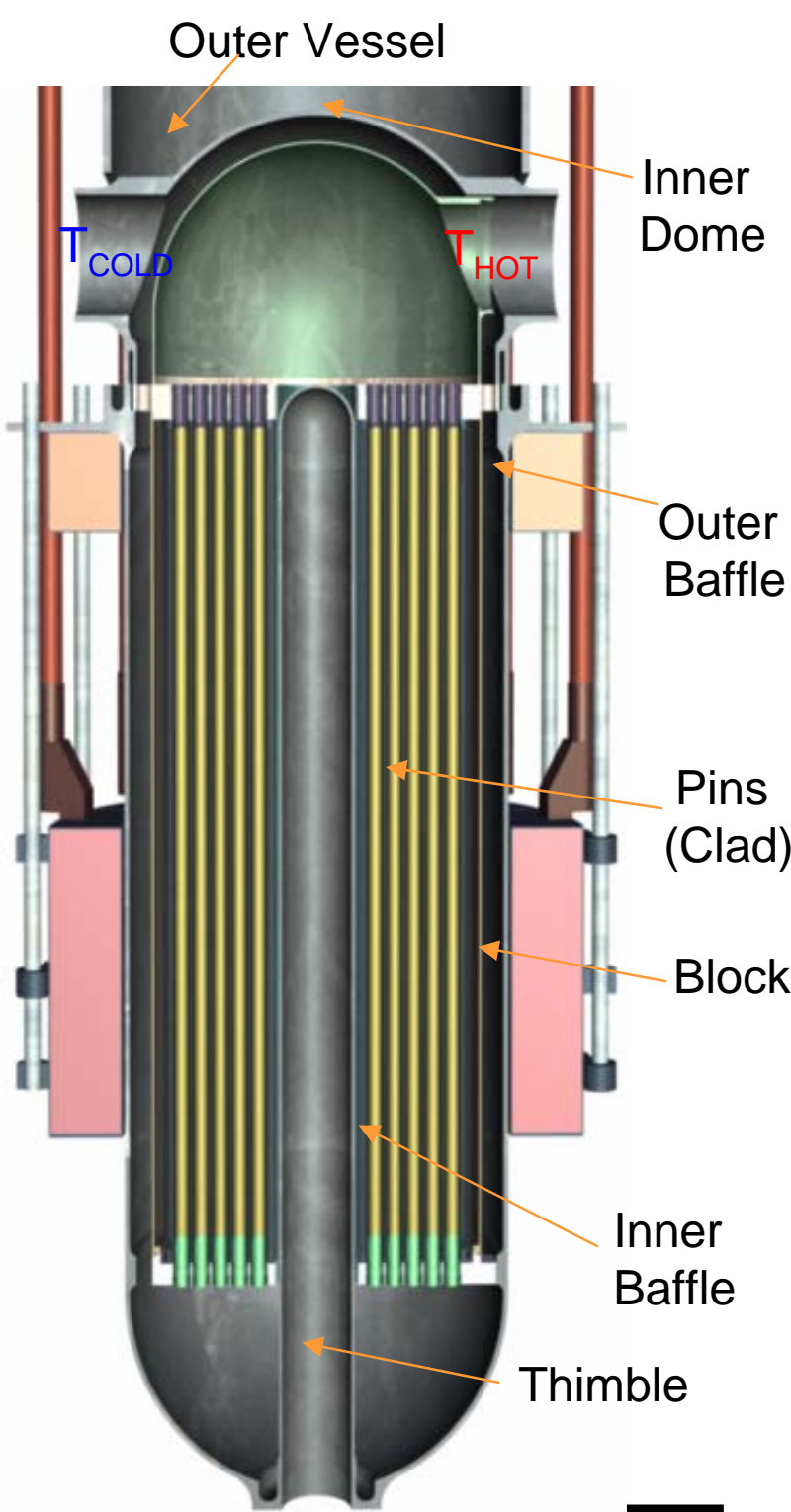


Divide System into Components/Subcomponents: e.g., turbine casing-range of temps

$>$ Assign a material to each component (Haynes 230, IN792, Nb)

$>$ Assign temperatures to each component or subcomponent

$>$ Determine source or sink behavior of each component or subcomponent for particular species (carbon or oxygen) using Thermocalc to estimate activities in the alloys

$>$ Compile diffusion coefficient data for species (carbon or oxygen)

$>$ Calculate approximate amount of mass of species released over 15 years

$>$ Deliver impurities to sinks and calculate changes in concentrations 


\section{Case I : Carbon Transfer in Superalloy/Refractory Metal System}
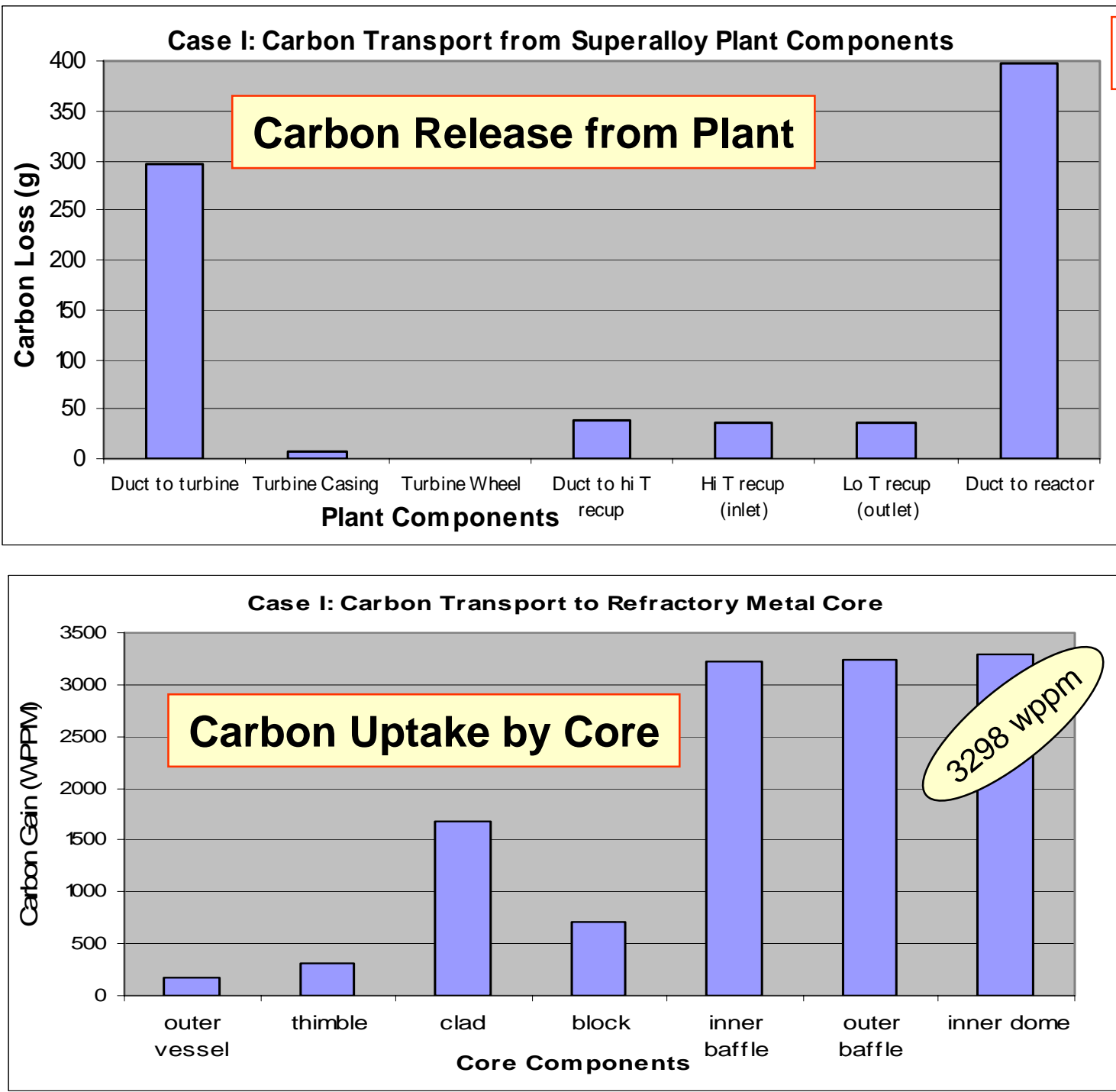

Larger impurity "sink" surface area

\begin{tabular}{|l|l|l|}
\hline Description & Case I & Case II \\
\hline Reactor & & \\
\hline outer vessel & RM & SA \\
\hline thimble & RM & SA \\
\hline clad & RM & RM \\
\hline block & RM & SA \\
\hline inner baffle & RM & SA \\
\hline outer baffle & RM & SA \\
\hline inner dome & RM & SA \\
\hline
\end{tabular}

RM = Refractory metal alloy SA = Superalloy

$>$ Sum carbon loss from superalloys $810 \mathrm{~g}$

$>$ Plant ducting was largest contributor

$>$ Inner dome saw largest uptake of carbon 3298 wppm 


\section{Case II : Carbon Transfer in Superalloy/Refractory Metal System}

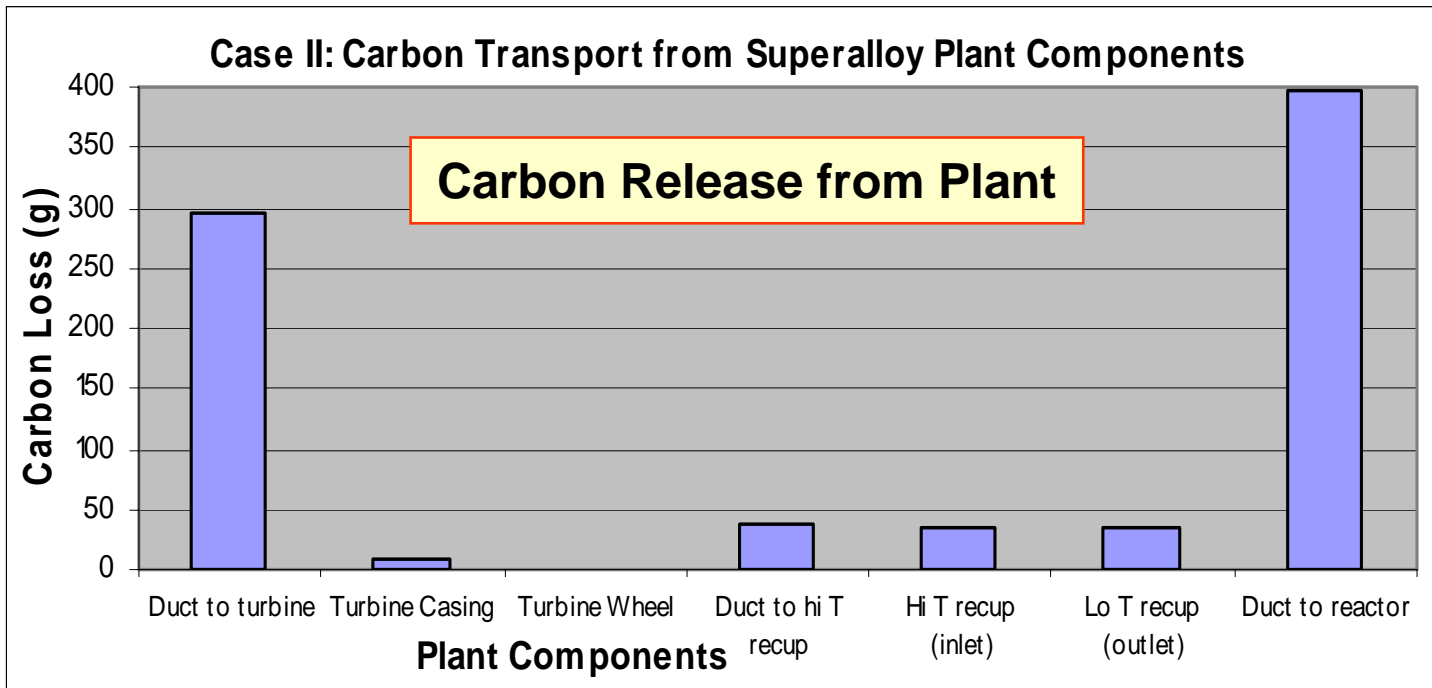

\begin{tabular}{l}
\multicolumn{2}{|c|}{ Refractory Metal Alloy Clad Only } \\
\begin{tabular}{|l|l|l|}
\hline Description & Case I & Case II \\
\hline Reactor & & \\
\hline outer vessel & RM & SA \\
\hline thimble & RM & SA \\
\hline clad & RM & RM \\
\hline block & RM & SA \\
\hline inner baffle & RM & SA \\
\hline outer baffle & RM & SA \\
\hline inner dome & RM & SA \\
\hline
\end{tabular}
\end{tabular}

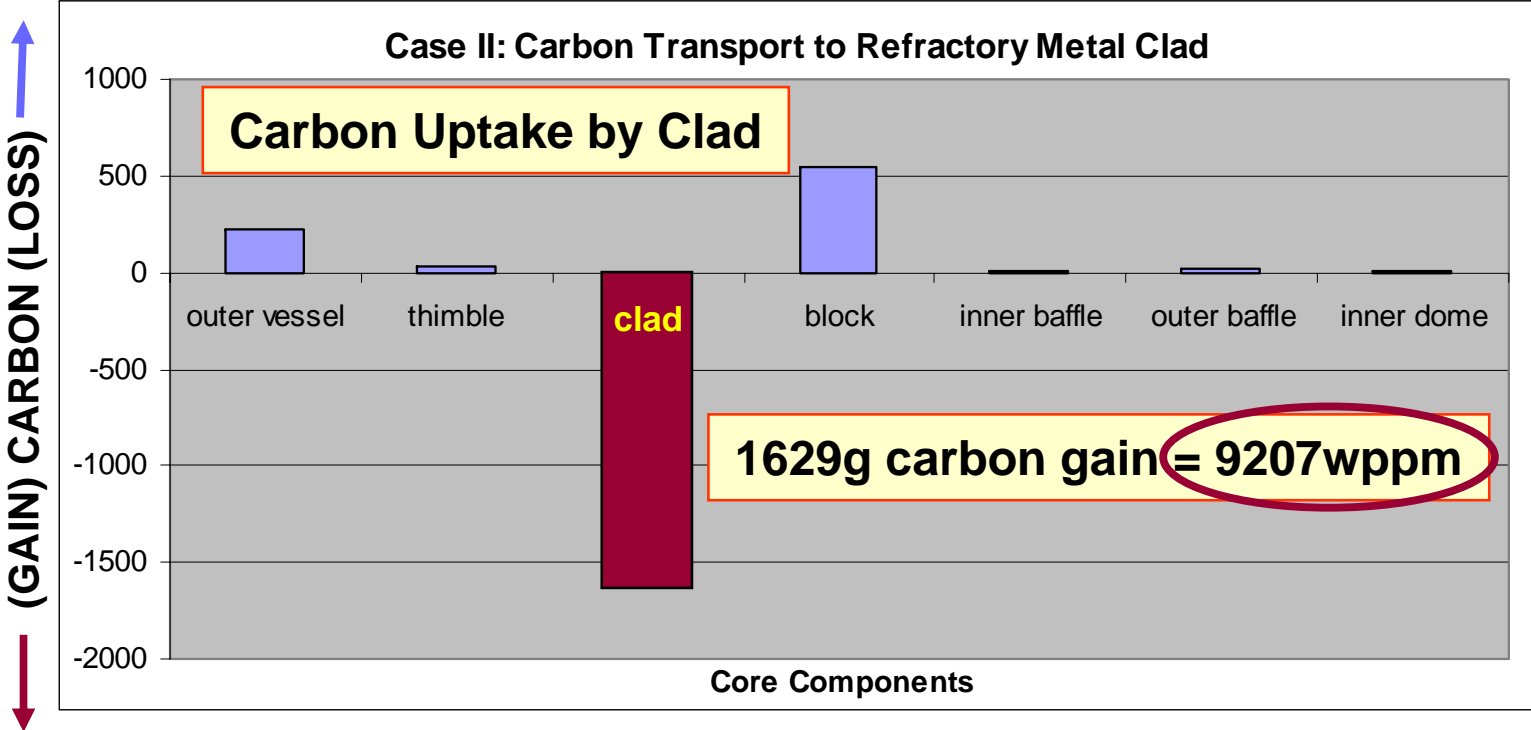

RM = Refractory metal

SA $=$ Superalloy

Sum carbon loss from superalloy has doubled:1629g

Superalloy core block is now largest contributor

$>$ Transport strongly dependent on surface area ratio 


\section{Case I : Oxygen Transfer in Superalloy/Refractory Metal System}
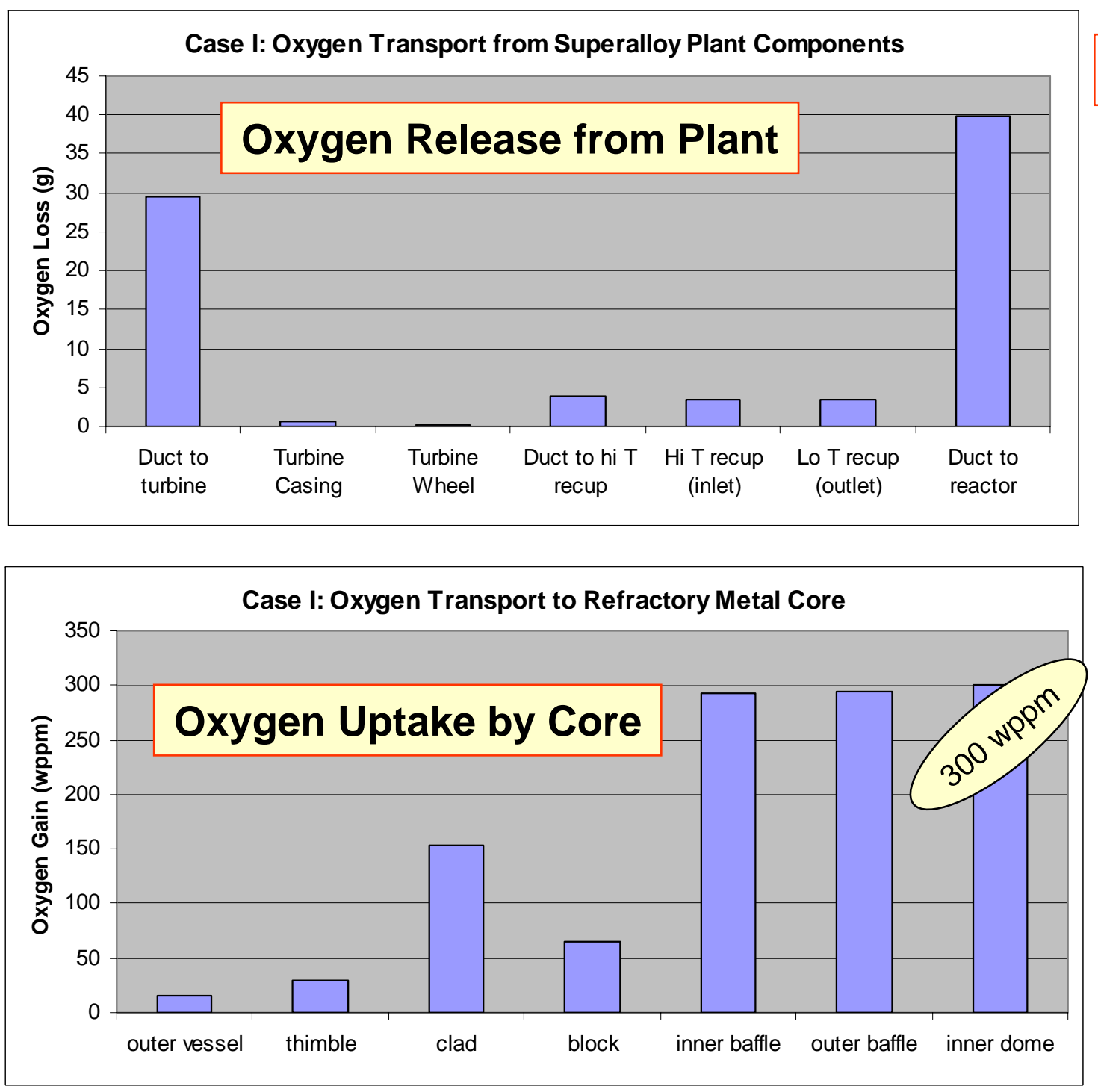

\section{Larger impurity "sink" surface area}

\begin{tabular}{|l|c|c|}
\hline Description & Case I & Case II \\
\hline Reactor & & \\
\hline outer vessel & RM & SA \\
\hline thimble & RM & SA \\
\hline clad & RM & RM \\
\hline block & RM & SA \\
\hline inner baffle & RM & SA \\
\hline outer baffle & RM & SA \\
\hline inner dome & RM & SA \\
\hline
\end{tabular}

$$
\text { RM = Refractory metal alloy }
$$
SA = Superalloy

\section{$>$ Sum oxygen loss much lower:73.8g}

$>$ For oxygen case, embrittlement threshold was not exceeded 


\title{
Dynamic Approach
}

\author{
Burden Model \\ (finite element)
}




\section{Finite Element Model (Burden Model)}

\section{Dynamic Approach: Kinetic Data Required}

Objective: Calculate overall contaminants available from Space Power Plant system components, predict rate of change of composition and residence of contaminants, determine the associated impact on structural material properties and predict a system lifetime.

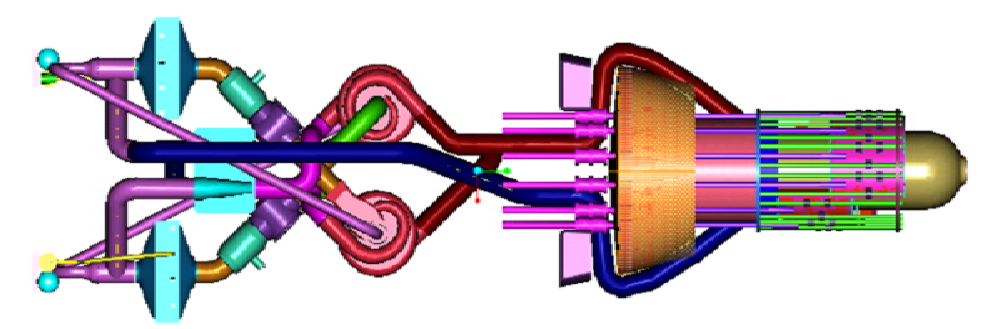

\section{Advantages of kinetic approach over equilibrium approach:}

1) Determines slowest rate controlling step for transport in superalloy, gas or refractory.

2) Provides information on time dependency of reactions to provide a lifetime prediction.

3) Allows impact of system/component geometry to be rigorously included in calculation.

4) Provides ability to make parametric changes in system - perform sensitivity analysis - change materials, design parameters and recalculate lifetime.

$$
\text { Experimental Testing }
$$




\section{Input Required for Burden Calculations}

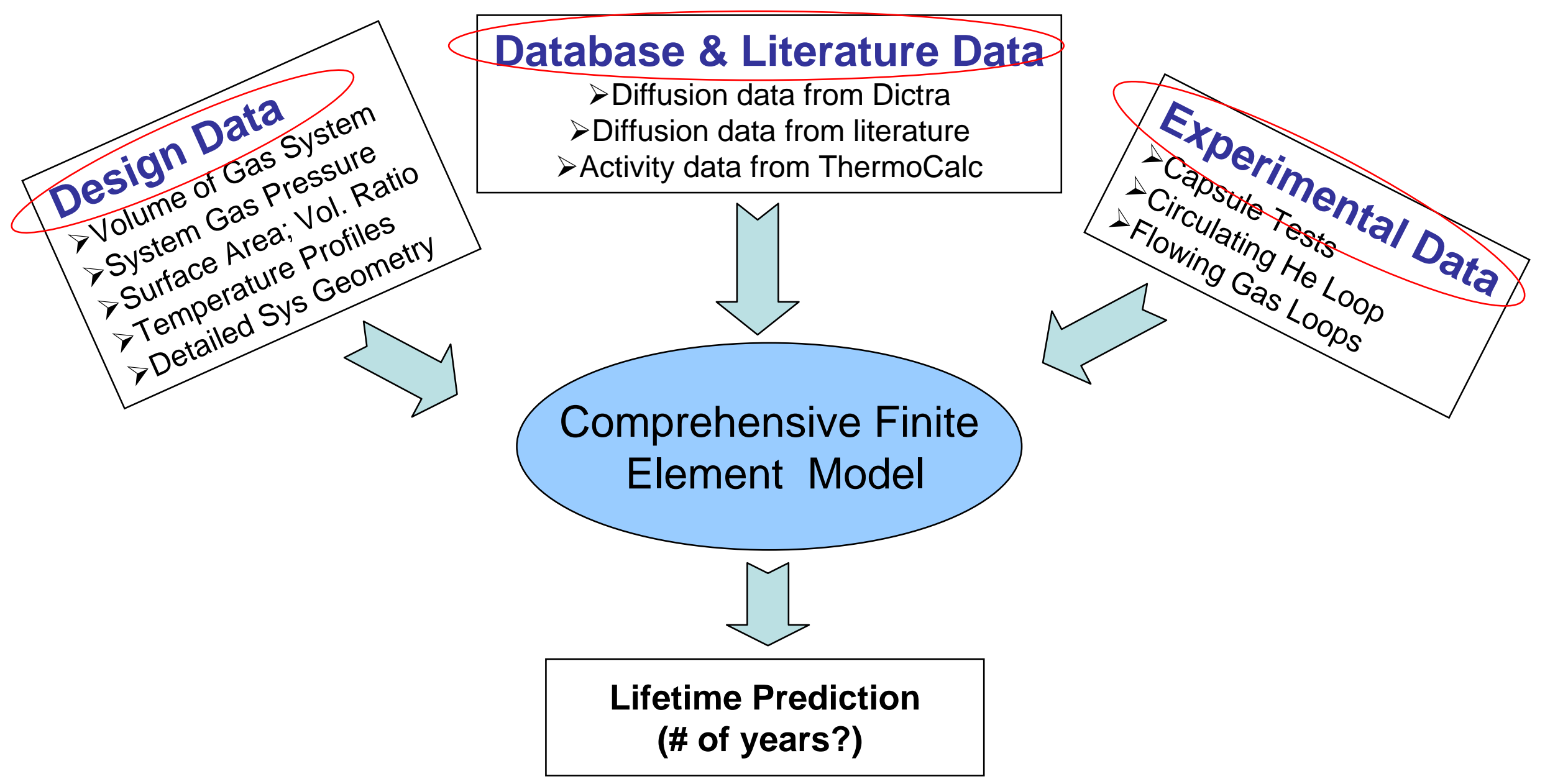

*Design estimates, and kinetic and thermodynamic data gathered as input for the Preliminary Mass Transport Model will be used for the more comprehensive Burden Model until experimental data becomes available 


\section{Finite Element Analysis using Fluent ${ }^{\mathrm{TM}}$ Flow Code}

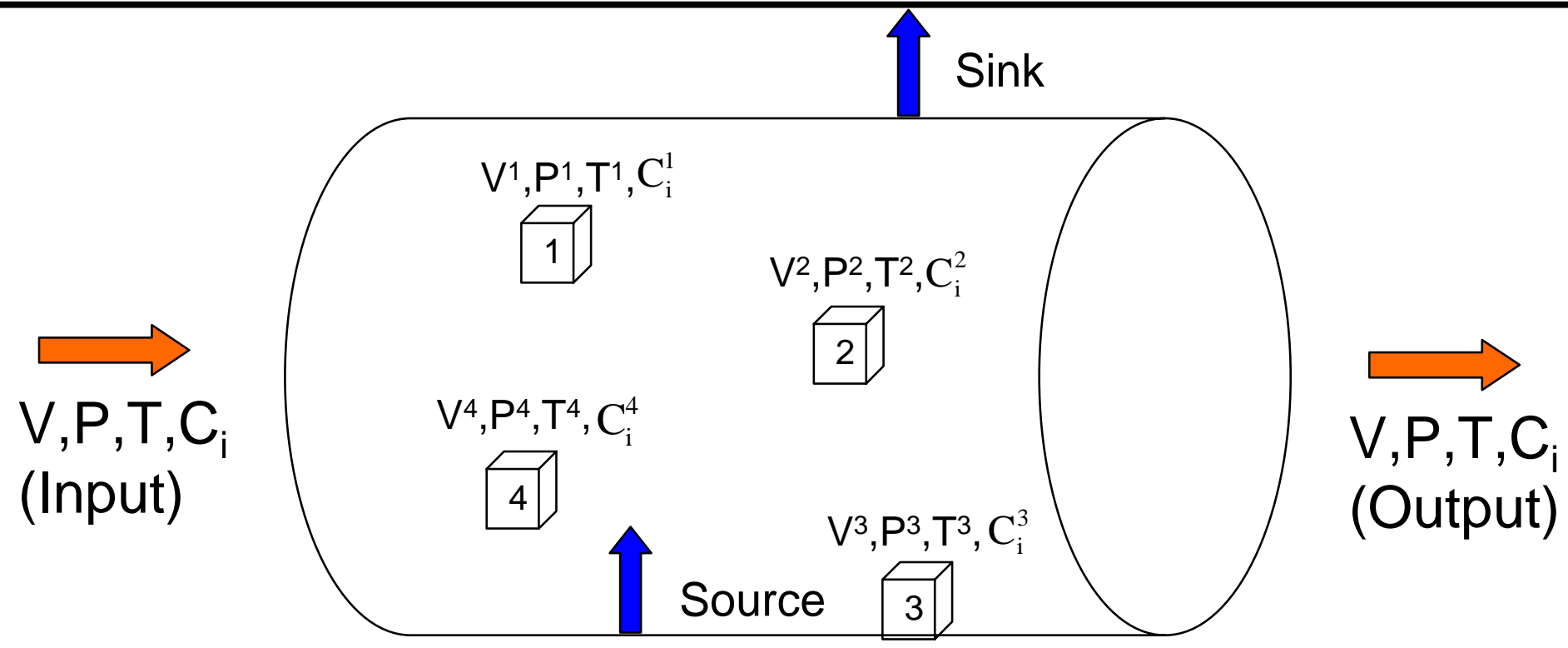

\section{-Turbulent flow}

-Transient sources of solids and gases (due to debris formation or degassing of system) -Reactions between gaseous species

- Surface reactions including adsorption and desorption

-Deviations from equilibrium due to surface films (oxides or carbides)

Tracking net composition change per unit area and volume around the gas circuit 


\section{Experimental Testing Support}

\section{Materials Testing \& Evaluation}




\section{$>$ Capsule Testing}

$>$ Flowing Gas Loop Testing

$>$ Helium Corrosion Loop Testing

Testing at Oak Ridge National Laboratory \& Bettis 


\section{Capsule Testing}

\section{Scoping experiments}

$>$ Bound interaction temperature

$>$ Surface area ratio variations

$>$ Gas chemistry variations

$>$ Fission product interactions

$>$ Test mitigation techniques:

$>$ Coatings

$>$ Getters

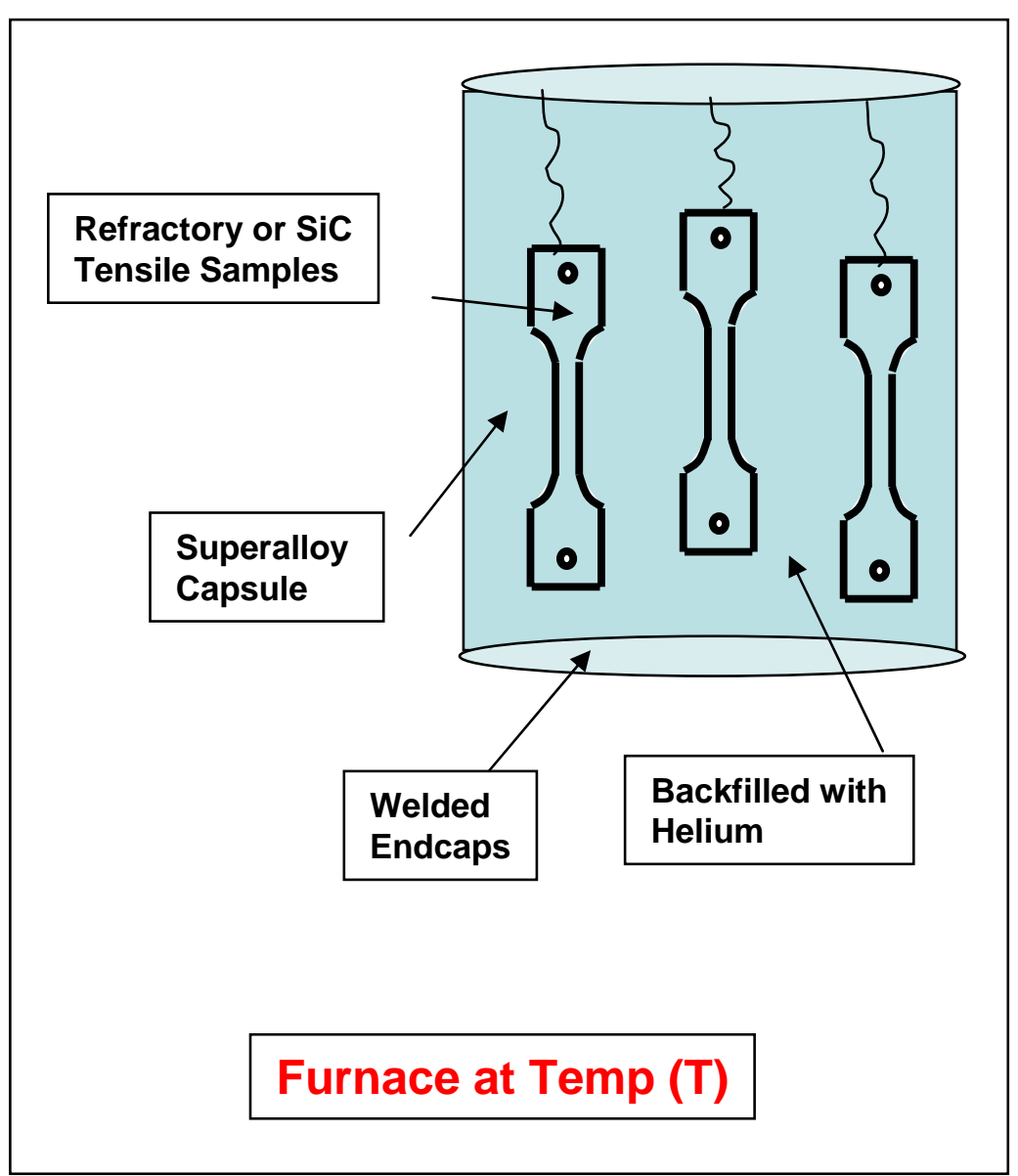




\section{Flowing Gas Loops}

Refractory metal test loop
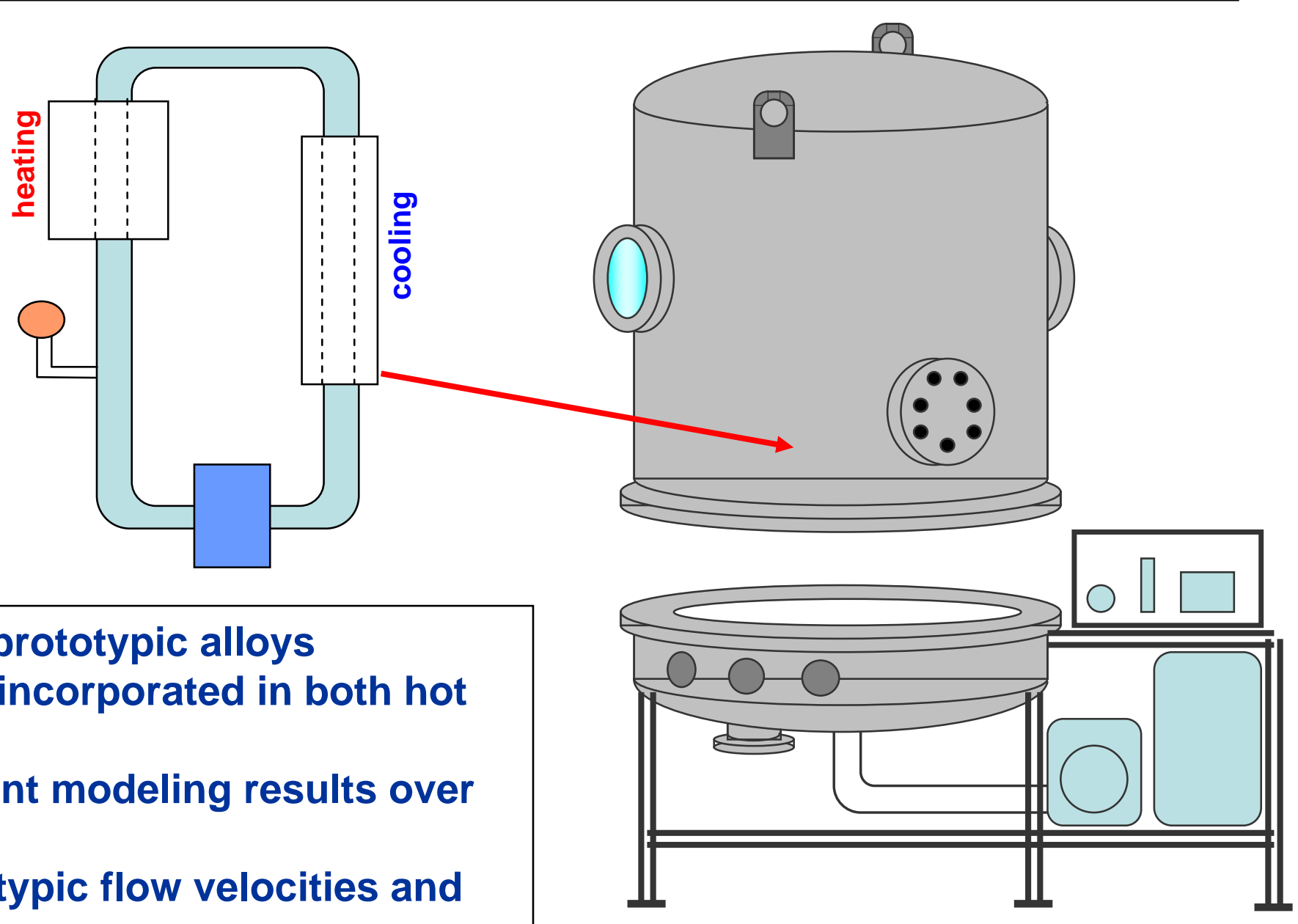

Vacuum Chamber

Manufactured from prototypic alloys

Material specimens incorporated in both hot and cold legs

$>$ Validate finite element modeling results over long times

$>$ Testing under prototypic flow velocities and test temperatures

Vacuum conditions (external to loop)

Characterize effect of temperature differential 


\section{Circulating Helium Loop Testing}

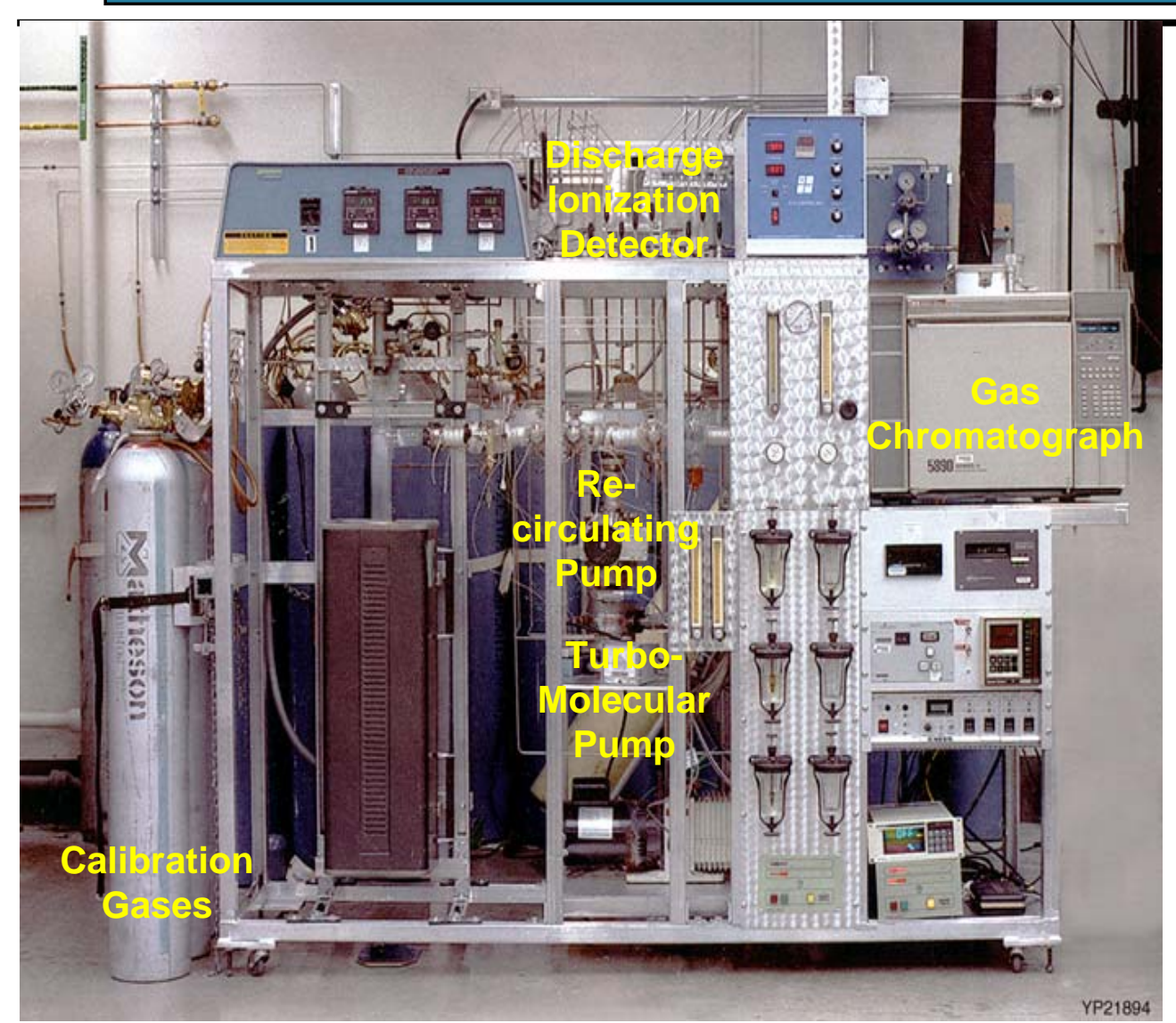

\section{Provides precise kinetic data}

required for a lifetime prediction

Circulating He Loop

$\rightarrow$ Quartz loop

$>$ Single specimen material

$>$ Vary time

$>$ Fixed temperature

$>$ Quantitative on-line gas analysis

$>$ Vary impurity concentration

$>$ Kinetic data

$>$ Mechanical properties

* Supplies data on rate of uptake of impurities by refractories

* Will define baseline composition of helium that will embrittle refractory alloy of choice * Will define alteration of gas composition due to release of impurities from superalloys * Tensile specimens used to understand if mechanical properties significantly impacted 


\section{Summary}

\section{Preliminary Mass Transport Model}

\section{Basis for Model Calculations}

$$
\begin{aligned}
& >\text { ThermoCalc }^{\mathrm{TM}} \text { (activity data) } \\
& >\text { DICTRA }^{\mathrm{TM}} \text { (diffusion data) }
\end{aligned}
$$

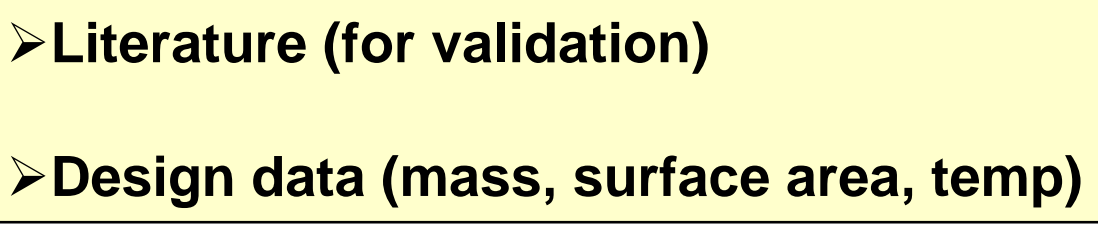

\section{Calculated Results:}

-Carbon transfer from source to sink surpassed the minimum impurity level for refractory metal embrittlement.

- Oxygen transport did not exceed the threshold for embrittlement in unalloyed $\mathrm{Nb}$.

-Plant piping was the largest contributor to impurity transfer due to the large surface area.

-Impurity transport was strongly dependent on surface area indicating that design changes could have a large impact on mass transport.

-Calculations for nitrogen indicated little or no transport (due to uncertainties in database). 


\section{Summary}

\section{The Burden Model}

The methodology for a comprehensive finite element model had been established:

-Generation of thermodynamic and thermochemical data provided the basis for the Burden model until experimental data were available.

-Identified CFD code for model

-Outlined experimental tasks

$>$ Isothermal capsule

$>$ Flowing gas loops

$>$ Re-circulating helium loop

-Understanding of how design data impacts the system 


\section{Acknowledgments}

Bechtel - Bettis Atomic Power Laboratory

Hamilton Sundstrand

Lockheed Martin - Knolls Atomic Power Laboratory

NASA - Glenn Research Center

Oak Ridge National Lab 


\section{Background}

March 2004: Naval Reactors assigned responsibility for reactor and primary plant design for Project Prometheus
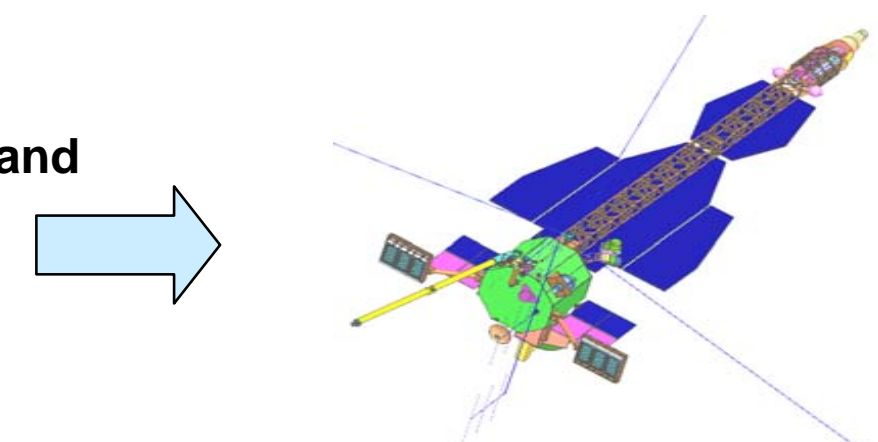

April 2004: NRPCT Formed (Naval Reactors Prime Contractor Team)

Preliminary definition of Long-lead test programs

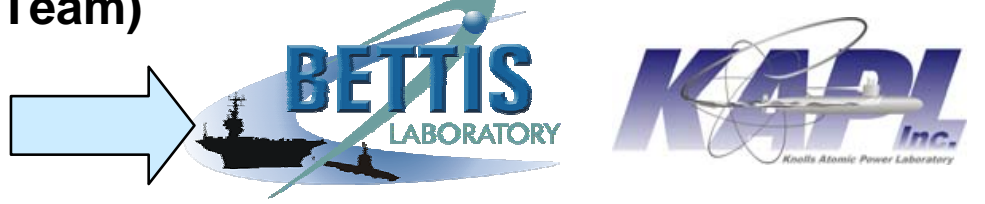

Extensive material reviews

February 2005: NRPCT Decision Teams formed

Compiled information and evaluated concept options

Chose Direct Gas Brayton Concept

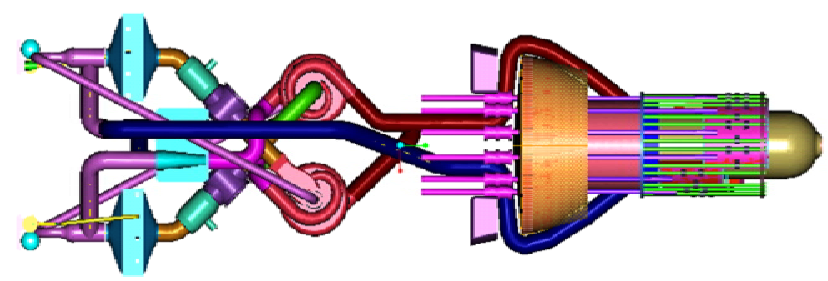


Enclosure 11 to

SPP-SEC-0039

\title{
Compatibility of SNPP Materials in an Inert He/Xe Working Gas Containing Reactive Impurities
}

\author{
Hall, M.M.
}


This page is intentionally blank.

PRE-DECISIONAL - For planning and discussion purposes only 


\title{
Compatibility of SNPP Materials in an Inert He/Xe Working Gas Containing Reactive Impurities
}

Applications of Equilibrium Thermochemistry

\author{
M. M. Hall, Jr.
}

Bechtel Bettis, Inc.

STAIF 2006

February 2006 


\section{Compatibility of SNPP Materials}

- Compatible Materials and Environments:

- Combinations of candidate reactor core and Brayton Unit materials and environments that promote passive (or immune) corrosion behavior

- Analysis Approach:

- Equilibrium thermochemical analyses used to determine corrosion oxidation and carburization potentials for environments that assure long term compatibility of all materials in contact with the environment 


\section{Limitations and Applicability of Equilibrium Analyses}

- Equilibrium thermochemistry analyses

- can identify reactions that may and may not occur

- cannot identify the reactions that necessarily will occur

- Application

- conservatively determine compatible materials and environments

- Risk

- exclusion of materials and environments that could be considered compatible due to very slow reaction rates

- Advantages

- simpler than kinetic analyses

- provide early information regarding conservative constraints for SNPP materials selection

- provide guidance for test objectives and test environments for SNPP materials qualification testing 


\section{Outline}

- Sources of SNPP working gas impurities

- Environmental effects on material properties

- Environments compatible with candidate core and Brayton Unit materials

- Analysis assumptions and methods

- Results

- Conclusions 


\section{Sources of SNPP Impurities}

\section{Based on Graphite Core - HTGR Experience}

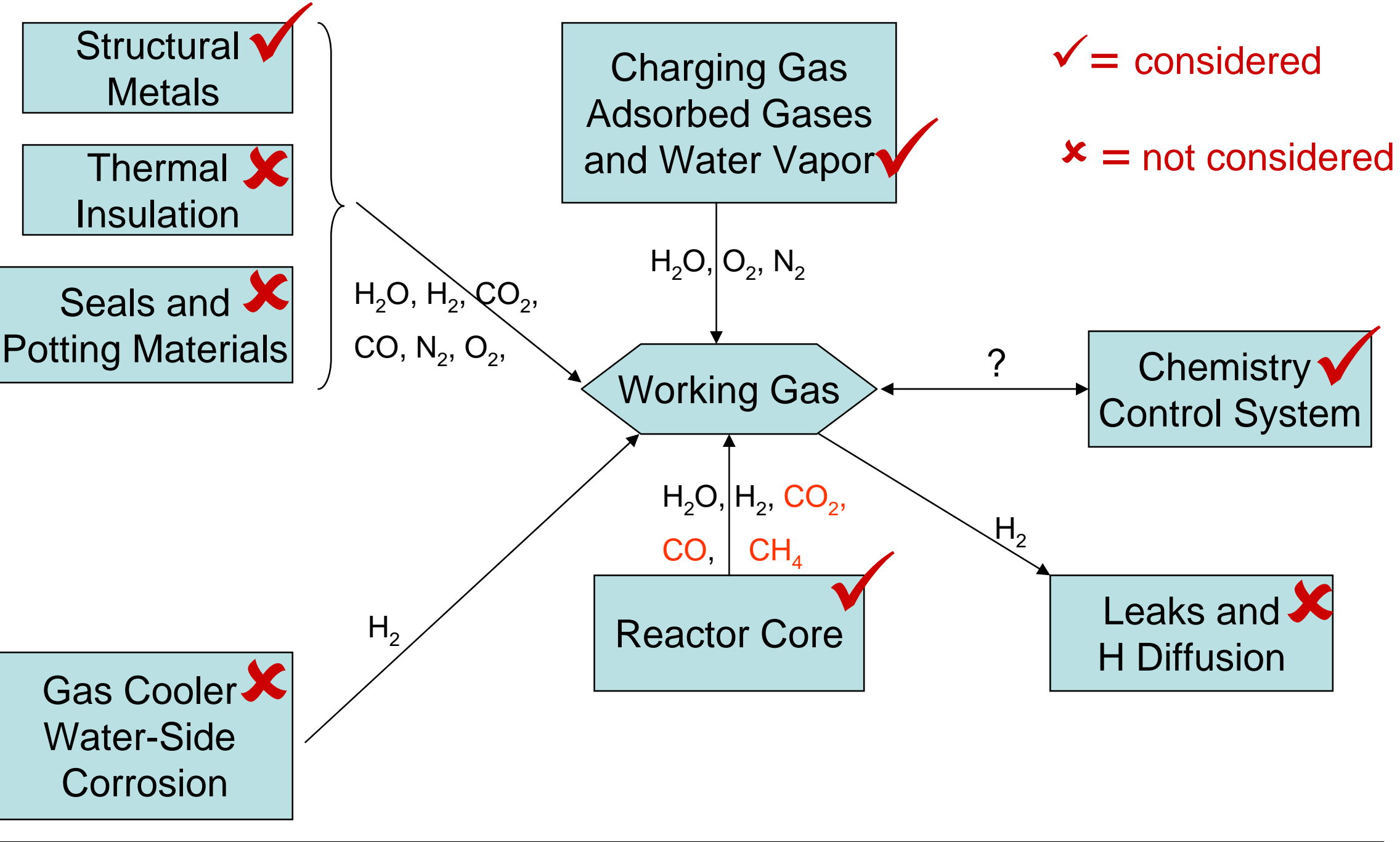




\section{Environmental Effects on SNPP Materials}

- Time-temperature-flux dependent changes in microstructure/properties

- Oxidation/Carburization due to reactive impurities

- $\mathrm{H}_{2} \mathrm{O}(\mathrm{g}) \Rightarrow$ oxidation and decarburization

- $\mathrm{CO}(\mathrm{g}) \Rightarrow$ oxidation and carburization

- $\mathrm{CH}_{4}(\mathrm{~g}) \Rightarrow$ carburization

- $\mathrm{H}_{2}(\mathrm{~g}) \Rightarrow$ oxide reduction

- Formation of surface oxides and carbides

- Internal oxidation, carburization and decarburization

- Depletion of alloying elements 


\section{Environmental Effects on SNPP Materials}

- Impact on oxidation/carburization on mechanical properties

- $\mathrm{Nb}, \mathrm{Ta}, \mathrm{V}$ refractory metal alloys severely embrittled by absorption of $\mathrm{C}, \mathrm{O}, \mathrm{N}$

- Mo, W refractory metal alloys less susceptible to embrittlement low solubility for $\mathrm{O}, \mathrm{N}$, and tolerant of low concentrations of $\mathrm{C}$

- $\mathrm{Al}_{2} \mathrm{O}_{3}$ and $\mathrm{Cr}_{2} \mathrm{O}_{3}$ surface oxides may be protective

- $\mathrm{Nb}, \mathrm{Ta}, \mathrm{V}$ oxides not protective; Mo, $\mathrm{W}$ dioxides may be

- Internal oxidation and carburization embrittle superalloys

- Decarburization and dealloying reduce creep strength of superalloys 


\section{Compatible Environments - Superalloys}

\section{Oxidation - Carburization Potentials}

Traditional Phase Stability Diagrams $\mathrm{Cr}_{2} \mathrm{O}_{3}$ - Former Superalloy Example

$\mathrm{Cr}-\mathrm{C}-\mathrm{O}, 1150 \mathrm{~K}$

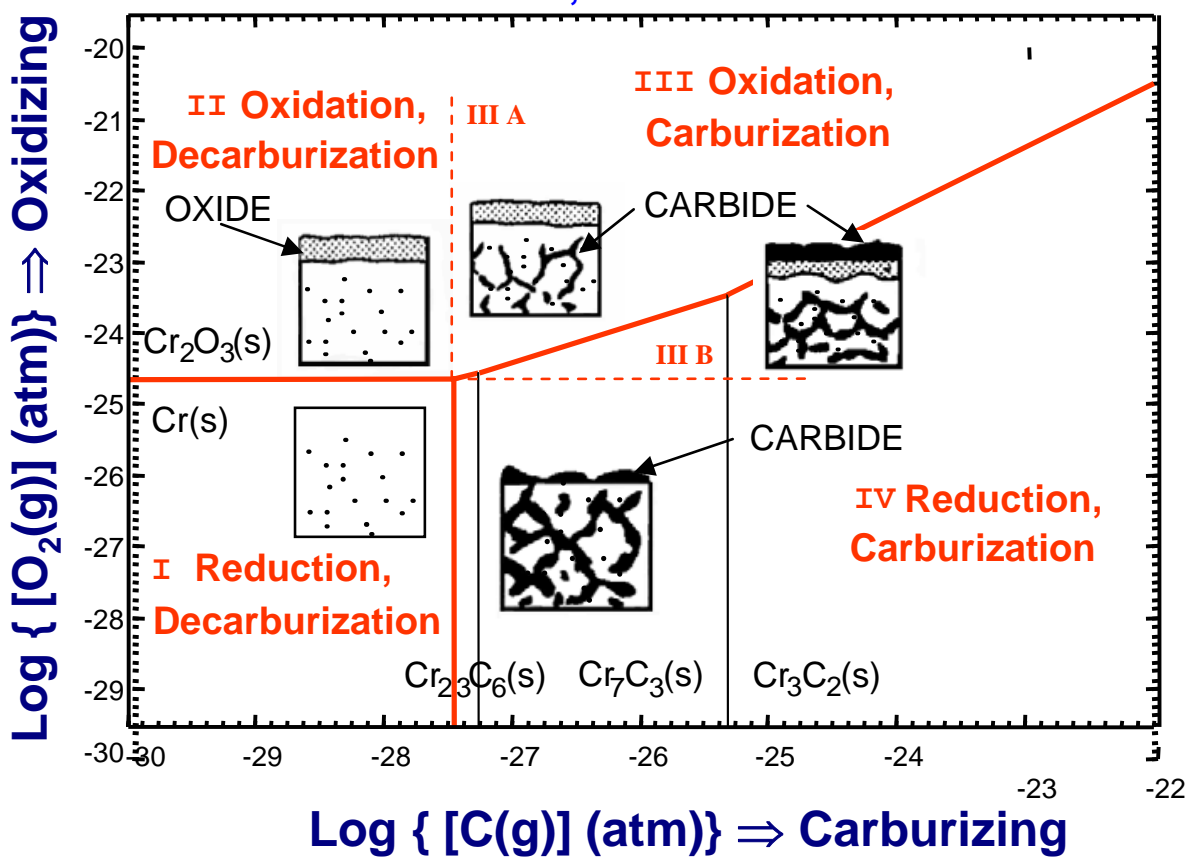

- Oxidation-carburization potential regions II and III A form protective surface oxides for $\mathrm{Cr}_{2} \mathrm{O}_{3}$ - former superalloys - thereby avoiding excessive carburization and decarburization

- $\mathrm{Al}_{2} \mathrm{O}_{3}$ - former superalloys similar to $\mathrm{Cr}_{2} \mathrm{O}_{3}$ - former superalloys but require much lower oxygen potentials to form protective oxides 
- $\mathrm{Nb}, \mathrm{Ta}, \mathrm{V}$ alloys $\Rightarrow$ Region I

- Avoid interstitial absorption

- Mo, W Alloys $\Rightarrow$ Region I

- Avoid formation of volatile Mo oxides

- $\mathrm{SiC} \Rightarrow$ Region III A

- Form protective $\mathrm{SiO}_{2}$ - avoid formation of volatile $\mathrm{SiO}(\mathrm{g})$

- Region IV $\Rightarrow$ should be avoided

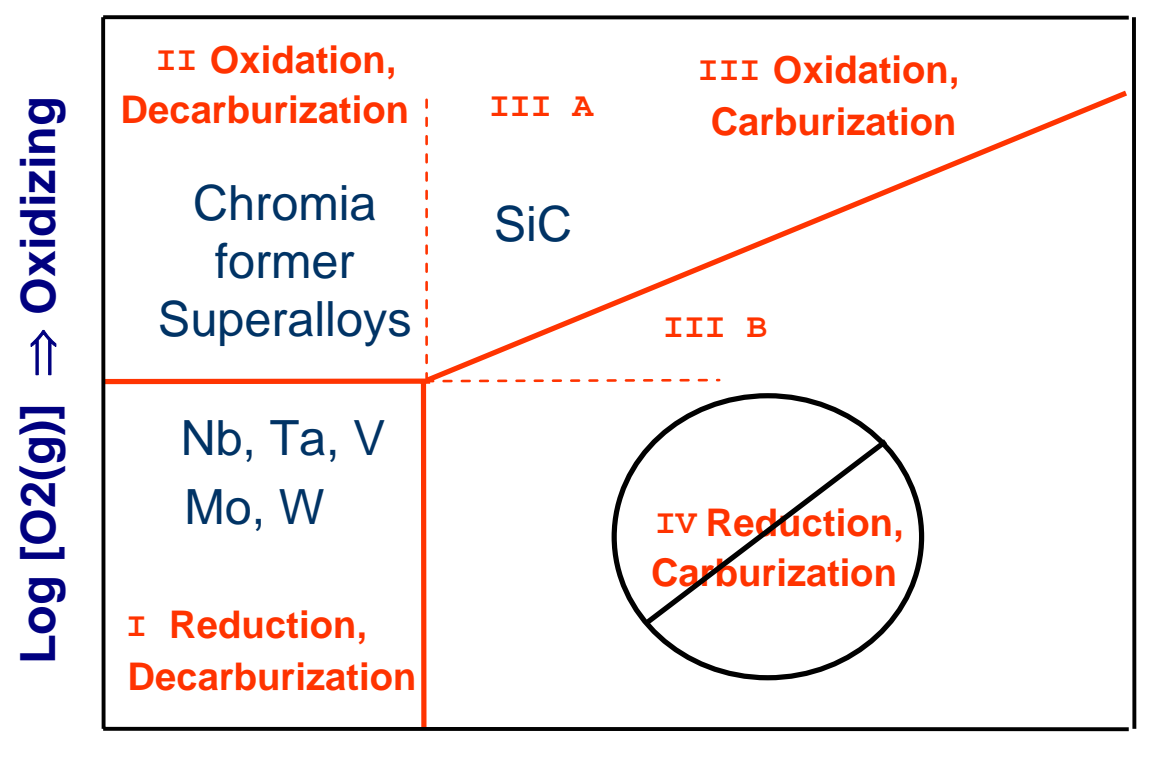

$\log [\mathrm{C}(\mathrm{g})] \Rightarrow$ Carburizing 


\section{SNPP Schematic - Heat Balance}

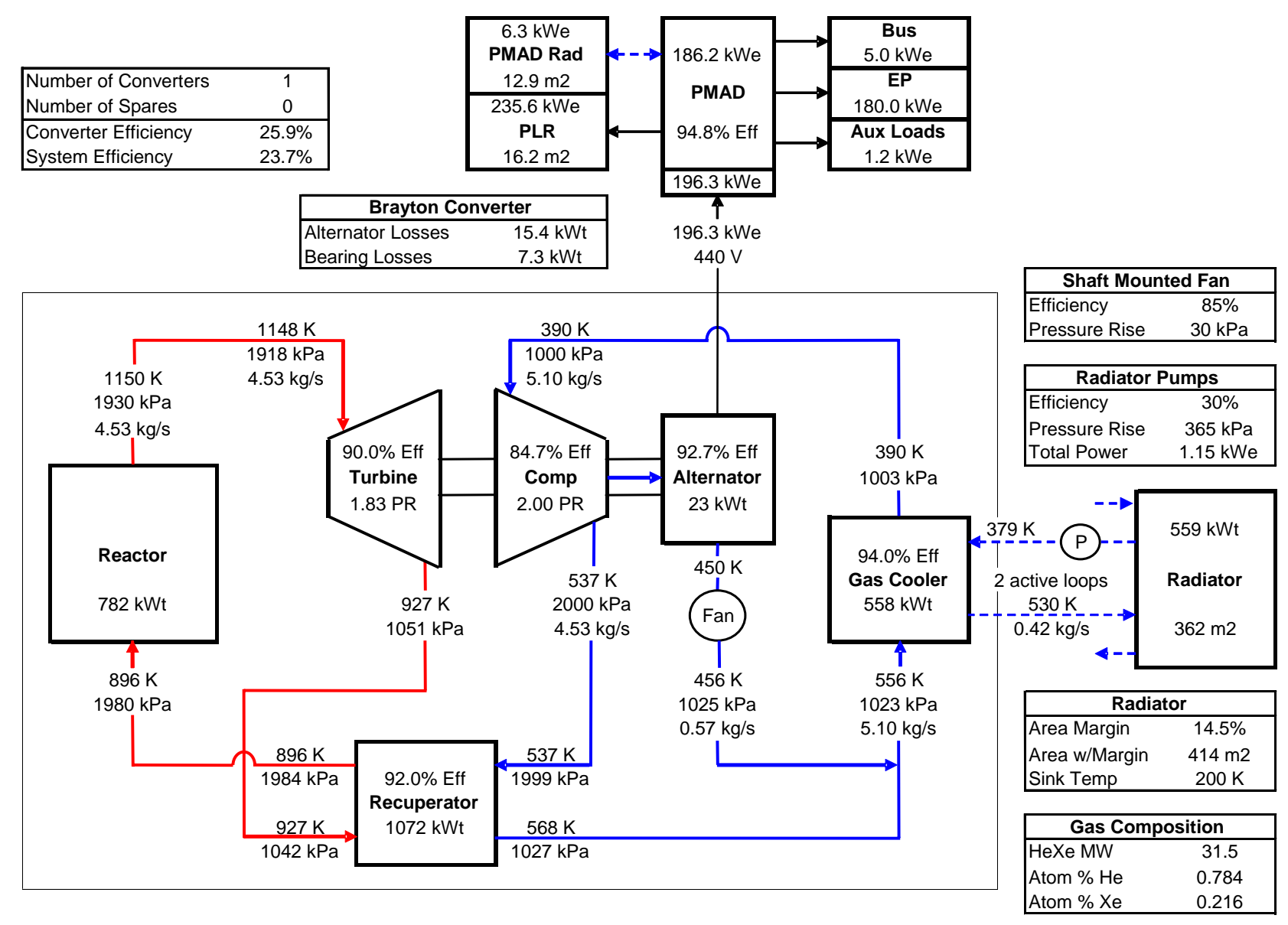




\section{Analysis Assumptions and Methods}

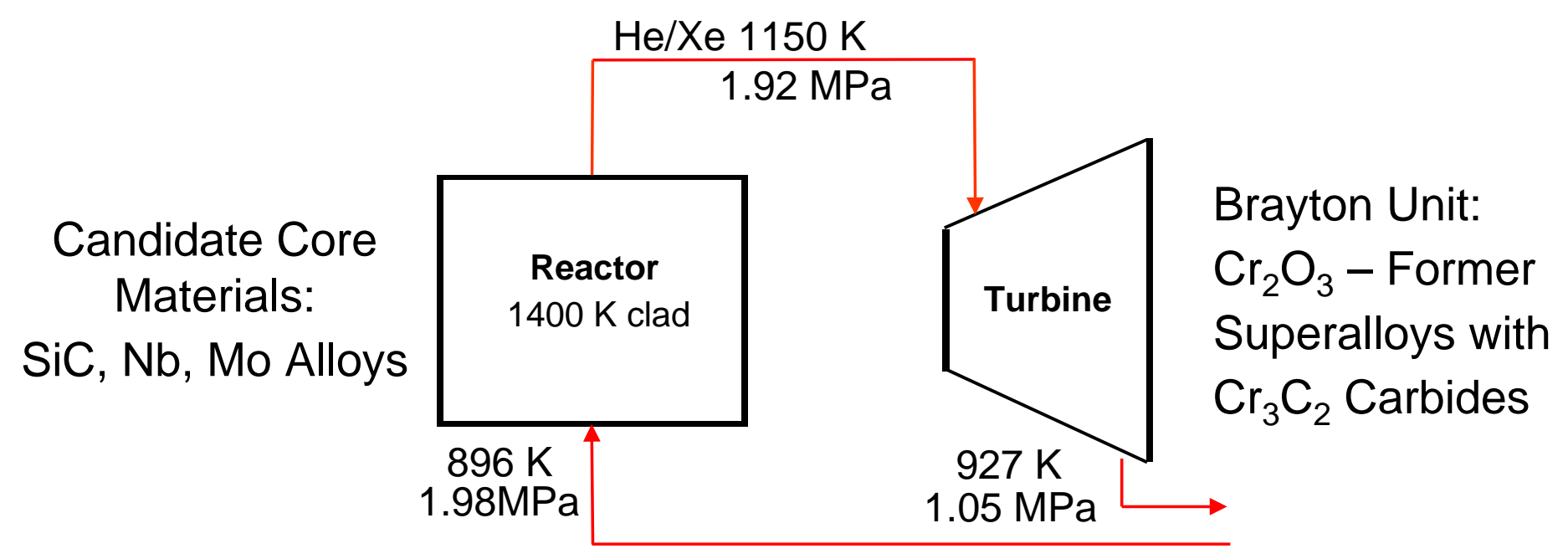

- Equilibrium thermochemistry assumed

- Gibbs energy minimization method (HSC Chemistry)

- Adsorbed water vapor $\mathrm{H}_{2} \mathrm{O}(\mathrm{g})$ assumed principal impurity at startup

- $\mathrm{H}_{2} \mathrm{O}(\mathrm{g})$ reactions with $\mathrm{Cr}_{3} \mathrm{C}_{2}$ and $\mathrm{SiC}$ only source of $\mathrm{CO}, \mathrm{H}_{2}, \mathrm{CH}_{4}$

- Assume $\mathrm{SiC}, \mathrm{Cr}, \mathrm{Cr}_{3} \mathrm{C}_{2}, \mathrm{Mo}, \mathrm{Nb}$ in excess of equilibrium amounts

- Calculate reaction products as function of one independent input variable, that is, the $\mathrm{H}_{2} \mathrm{O}(\mathrm{g})$ burden

$>$ which fully defines the $\mathrm{O}-\mathrm{C}$ potentials of the working gas environment 


\section{Analysis Assumptions and Methods}

Assumption that Water Burden is Only Independent Variable Fully Defines $O-C$ potentials: SiC example

Alternate Oxidation and Carburization Potential Variables:

$$
\begin{aligned}
& 2 \mathrm{H}_{2}(g)+\mathrm{O}_{2}(g)=2 \mathrm{H}_{2} \mathrm{O}(g) ; \Rightarrow\left[\mathrm{O}_{2}\right]=\frac{1}{K_{1}}\left(\frac{\left[\mathrm{H}_{2} \mathrm{O}\right]}{\left[\mathrm{H}_{2}\right]}\right)^{2} \\
& 2 \mathrm{H}_{2}(g)+\mathrm{C}(\mathrm{g})=\mathrm{CH}_{4}(g) ; \Rightarrow[\mathrm{C}]=\frac{1}{K_{2}} \frac{\left[\mathrm{CH}_{4}\right]}{\left[\mathrm{H}_{2}\right]^{2}}
\end{aligned}
$$

Reaction of SiC with $\mathrm{H}_{2} \mathrm{O}$ to form $\mathrm{SiO}_{2}$ :

$$
\mathrm{SiC}+2 \mathrm{H}_{2} \mathrm{O}(\mathrm{g})=\mathrm{SiO}_{2}+\mathrm{CH}_{4}(\mathrm{~g}) ; \Rightarrow \frac{\left[\mathrm{H}_{2} \mathrm{O}\right]}{\left[\mathrm{H}_{2}\right]}=\frac{1}{K_{3}^{1 / 2}}\left(\frac{\left[\mathrm{CH}_{4}\right]}{\left[\mathrm{H}_{2}\right]^{2}}\right)^{1 / 2}
$$

- Conclude O - C potentials are co-variables each dependent on the $\mathrm{H}_{2} \mathrm{O}$ burden of the system 


\section{Thermochemical Stability of SiC @ 1400 K}

- $\mathrm{H}_{2} \mathrm{O}(\mathrm{g})$ burden greater than 2.6E-6 mol frac required to

- form protective $\mathrm{SiO}_{2}$ oxide

- avoid volatile $\mathrm{SiO}(\mathrm{g})$ phase

- Free carbon C(s) "dust" forms for $\mathrm{H}_{2} \mathrm{O}(\mathrm{g})$ burden > 6.1E-4 mol frac

$>$ Concern for gas flow-induced erosion of SiC

$>$ Impact on heat transfer unknown

- Conclude max and min controls required on system oxidation potential (water burden)

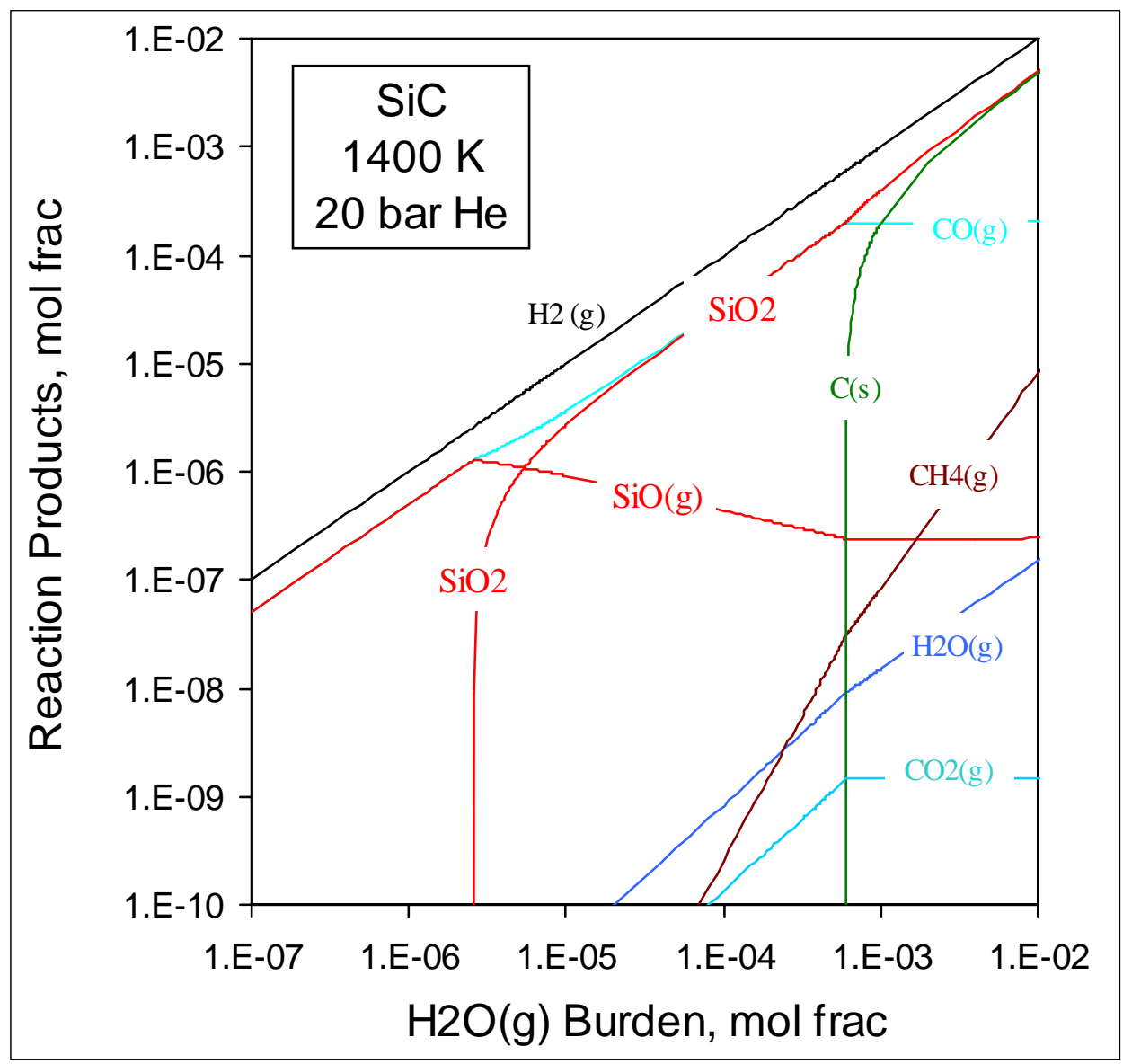




\section{Thermochemical Stability of $\mathrm{Cr}_{3} \mathrm{C}_{2} @ 1150 \mathrm{~K}$}

\section{Analysis representative of the chromia-former superalloys}

- $\mathrm{H}_{2} \mathrm{O}(\mathrm{g})$ burden greater than 2.8E$8 \mathrm{~mol}$ frac required to

$>$ form protective $\mathrm{Cr}_{2} \mathrm{O}_{3}$ oxide

$>$ avoid volatile $\mathrm{Cr}(\mathrm{g})$ phase (dealloying) and decarburization

- Free carbon $\mathrm{C}(\mathrm{s})$ forms for $\mathrm{H}_{2} \mathrm{O}(\mathrm{g})$ burden > 2.1E-3 mol frac $>$ interferes with formation of protective $\mathrm{Cr}_{2} \mathrm{O}_{3}$ oxide

$>$ accelerated decarburization and loss of mechanical strength

- Conclude max and min controls required on system oxidation potential (water burden)

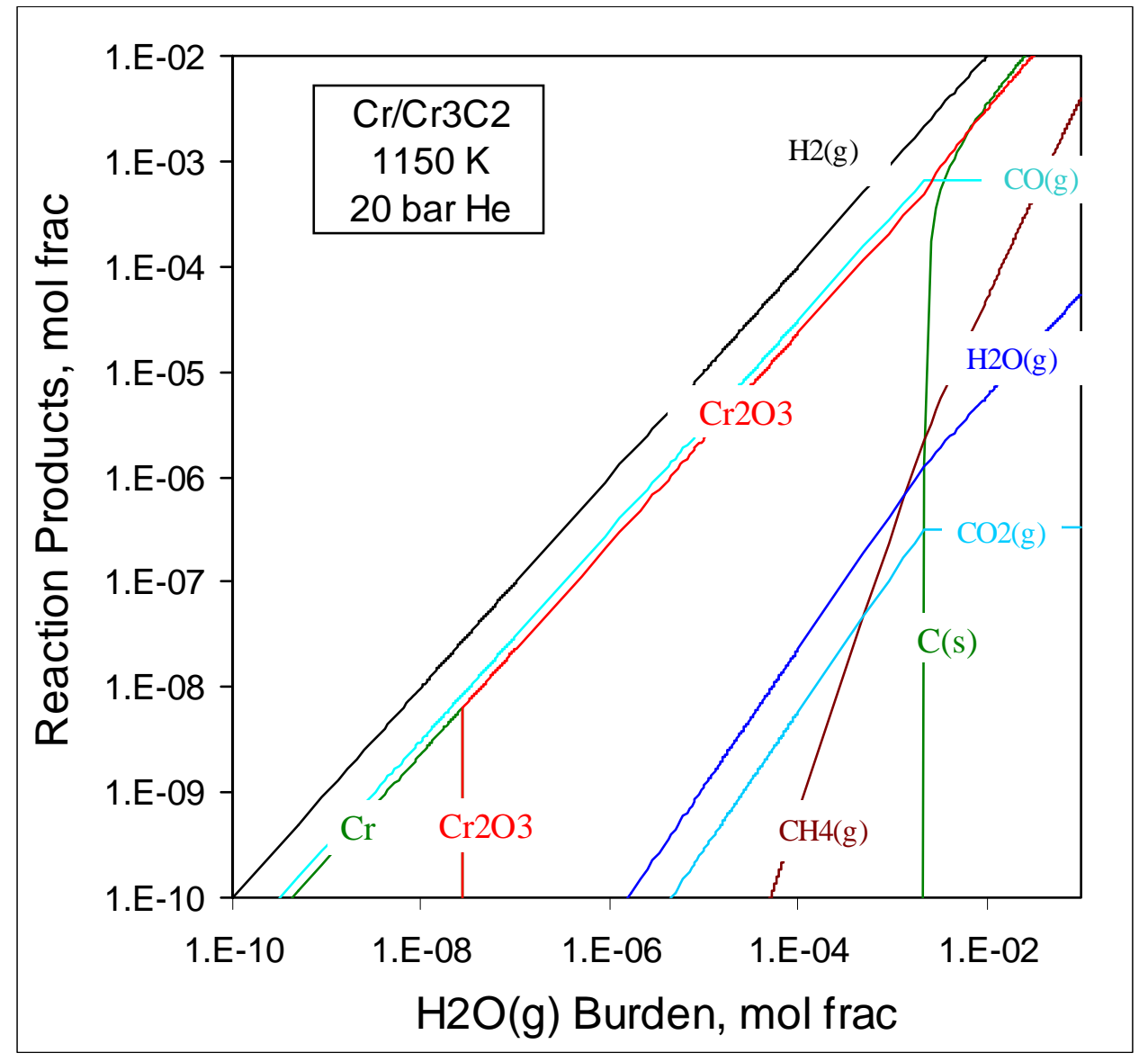




\section{Thermochemical Stability of Nb @ 1400 K}

- $\mathrm{H}_{2} \mathrm{O}(\mathrm{g})$ burden less than $3.2 \mathrm{E}-9 \mathrm{~mol}$ frac required to avoid oxidation and carburization of $\mathrm{Nb}$

- Lower $\mathrm{H}_{2} \mathrm{O}(\mathrm{g})$ burden required to prevent $\mathrm{Nb}$ embrittlement

- Conclude that protective coatings must be used at higher oxidation potentials

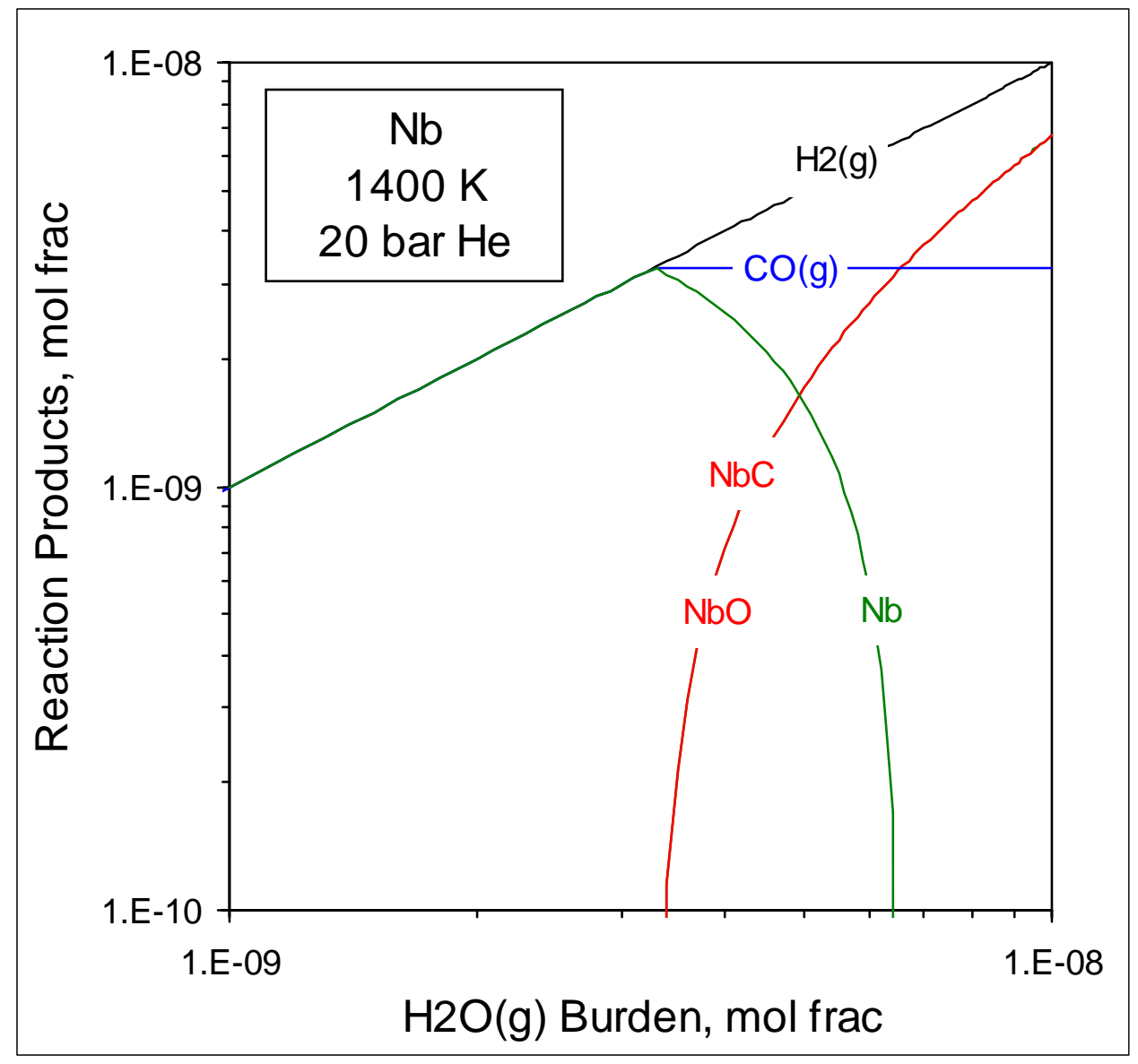




\section{Thermochemical Stability of Mo @ 1400 K}

- $\mathrm{H}_{2} \mathrm{O}(\mathrm{g})$ burden less than 0.13 mol frac required to avoid oxidation of Mo

$>$ protective $\mathrm{Cr}_{2} \mathrm{O}_{3}$ oxide can form without oxidizing Mo

- $\mathrm{H}_{2} \mathrm{O}(\mathrm{g})$ burden less than 2.3E-6 mol frac required to avoid carburization of Mo

$>$ protective $\mathrm{Cr}_{2} \mathrm{O}_{3}$ oxide can form without carburizing Mo

- Conclude max and min controls required on system oxidation potential (water burden)

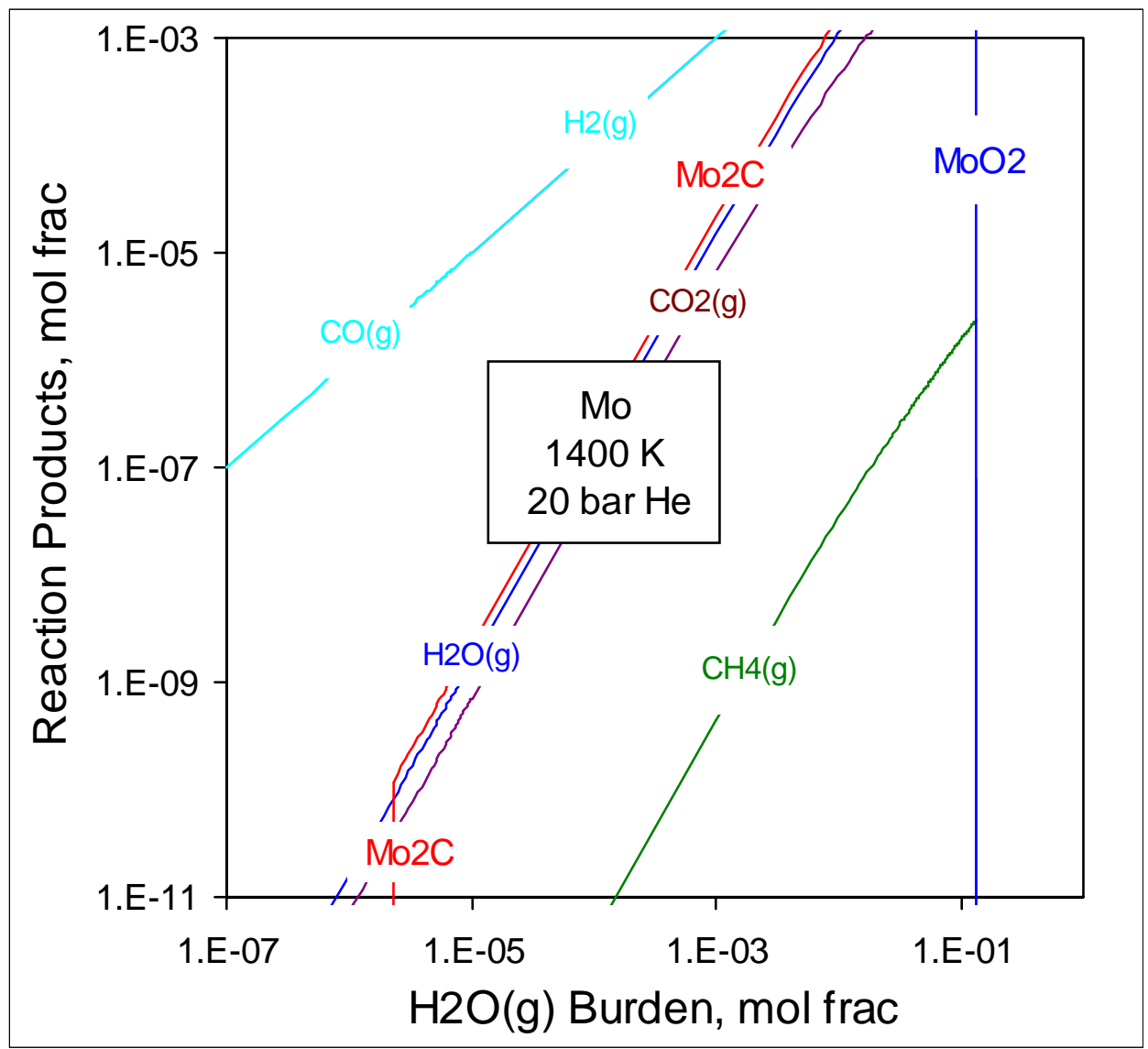




\section{Compatibility of SNPP Candidate Materials}

- At $\mathrm{H}_{2} \mathrm{O}(\mathrm{g})$ burden needed to form protective $\mathrm{Cr}_{2} \mathrm{O}_{3}$

$>\mathrm{Nb}$ will oxidize and be embrittled

$>\mathrm{MoO}_{2}$ and higher potential volatile Mo oxides will not form

> Relatively narrow range $\mathrm{H}_{2} \mathrm{O}(\mathrm{g})$ burden (100X) to form $\mathrm{Cr}_{2} \mathrm{O}_{3}$ and avoid $\mathrm{Mo}_{2} \mathrm{C}$

- At $\mathrm{H}_{2} \mathrm{O}(\mathrm{g})$ burden needed to form protective $\mathrm{SiO}_{2}$

$>$ protective $\mathrm{Cr}_{2} \mathrm{O}_{3}$ oxide is stable

$>$ Relatively narrow range $\mathrm{H}_{2} \mathrm{O}(\mathrm{g})$ burden (200X) to form $\mathrm{Cr}_{2} \mathrm{O}_{3}$ and avoid concern for erosion of SiC

- Conclude that

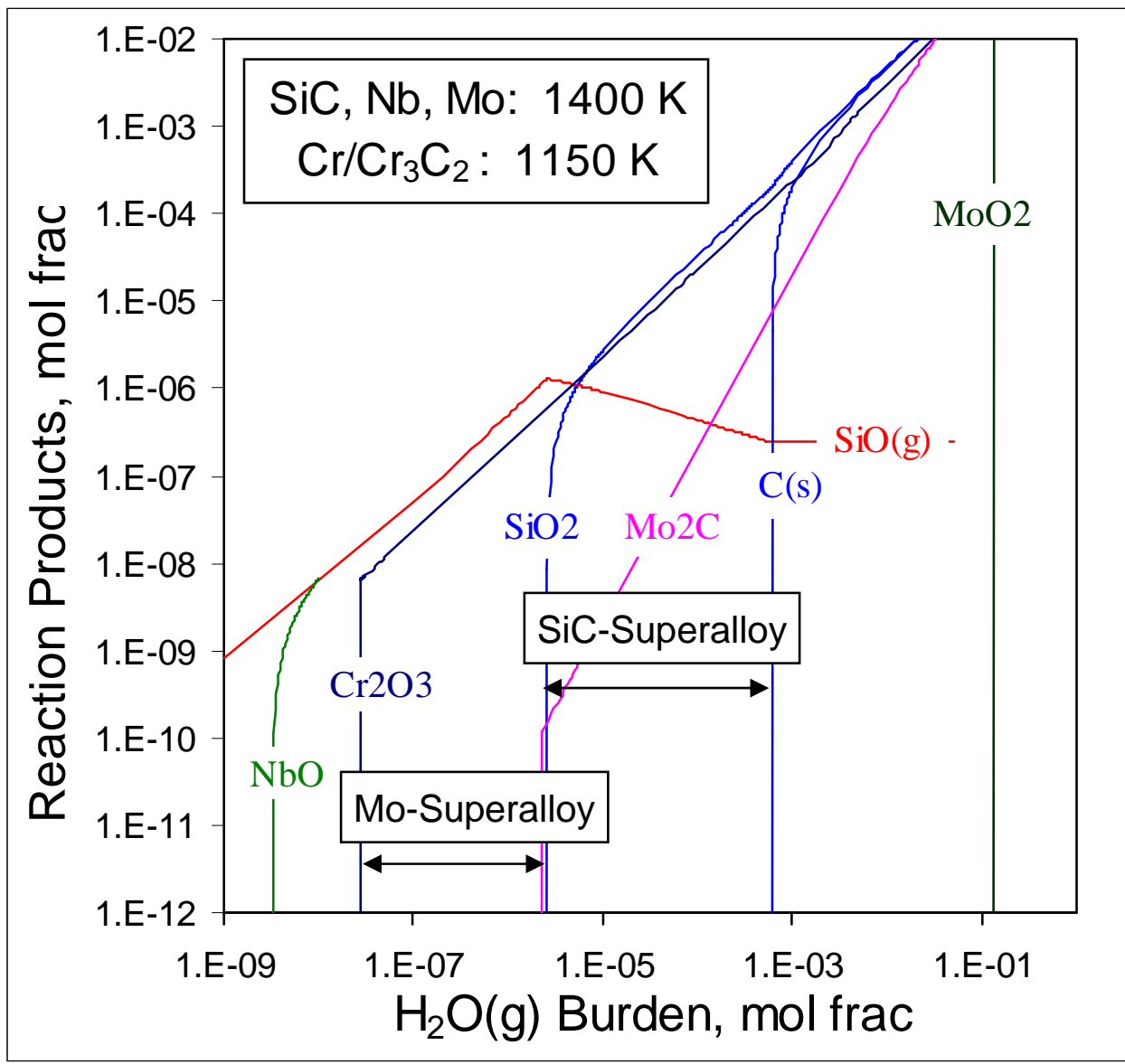

$>$ Protective coatings are required for $\mathrm{Nb}, \mathrm{Ta}, \mathrm{V}$ alloy applications

$>$ Mo alloys and $\mathrm{SiC}$ are both compatible with $\mathrm{Cr}_{2} \mathrm{O}_{3}$ - former superalloys 


\section{Conclusions}

- Minimum SNPP oxidation potentials must be established to form protective oxides on superalloy Brayton unit materials and $\mathrm{SiC}$ core materials

- minimum oxidation potentials required for $\mathrm{Al}_{2} \mathrm{O}_{3}$ - former alloys very low and not limiting when used with $\mathrm{Cr}_{2} \mathrm{O}_{3}$ - formers

- Maximum oxidation potential limits may be required to avoid excessive oxidation of $\mathrm{Cr}_{2} \mathrm{O}_{3}$ - former superalloys, carburization of Mo and gas flow-induced erosion of SiC

- Protective coatings are required for use of $\mathrm{Nb}, \mathrm{Ta}, \mathrm{V}$ alloys

- Mo alloys without coatings and SiC fuel clad are both compatible with $\mathrm{Cr}_{2} \mathrm{O}_{3}$ - former Brayton Unit superalloys provided that minimum and maximum oxidizing potentials can be controlled 


\section{QUESTIONS ?}


Enclosure 12 to

SPP-SEC-0039

\title{
Use of RELAP5-3D for Dynamic Analysis of a Closed- Loop Brayton Cycle Coupled to a Nuclear Reactor
}

\author{
McCann, L.D.
}


This page is intentionally blank.

PRE-DECISIONAL - For planning and discussion purposes only 


\section{Dynamic Analysis of a Closed- Loop Brayton Cycle Coupled to a Nuclear Reactor

\author{
Larry McCann \\ Space Plant Systems - Bechtel
}

STAIF 2006

February 2006 
- Introduction

- Code Improvements

- Input Model Development

- Steady State Results

- Transient Results

- Summary 


\section{Introduction}

- NRPCT has been working on design of a nuclear reactor for the NASA Jupiter Icy Moons Orbiter (JIMO).

- The JIMO mission would have required $100-300 \mathrm{~kW}_{\mathrm{e}}$ to propel the spacecraft to the outer planets, orbit the moons, and perform scientific investigations from lunar orbit.

- A gas-cooled fast reactor (GFR) directly connected to one or more closed-loop Brayton cycles was chosen as the best candidate to meet the mission requirements based on current technology.

- A RELAP5-3D model of the reactor and closed-loop Brayton cycle has been developed and used to perform dynamic analysis of the JIMO reactor plant.

- The RELAP5-3D computer code is used at Bechtel and widely in the commercial nuclear industry for dynamic analysis of nuclear reactor plants.

- The Idaho National Laboratory (INL) made changes to the RELAP5-3D code so it could be used to model the closed-loop Brayton cycle.

- The remainder of this presentation discusses the code changes, input model development, and results. 


\section{Spacecraft Reactor Plant Overview}

- Gas coolant is $22 \%$

Xenon, $78 \%$ helium b: mole fraction

- To maximize system efficiency $(\sim 23 \%)$ reactor outlet temperature is $1150 \mathrm{~K}$

- There are 4 Brayton loops installed in parallel with 2 require for $100 \%$ power.

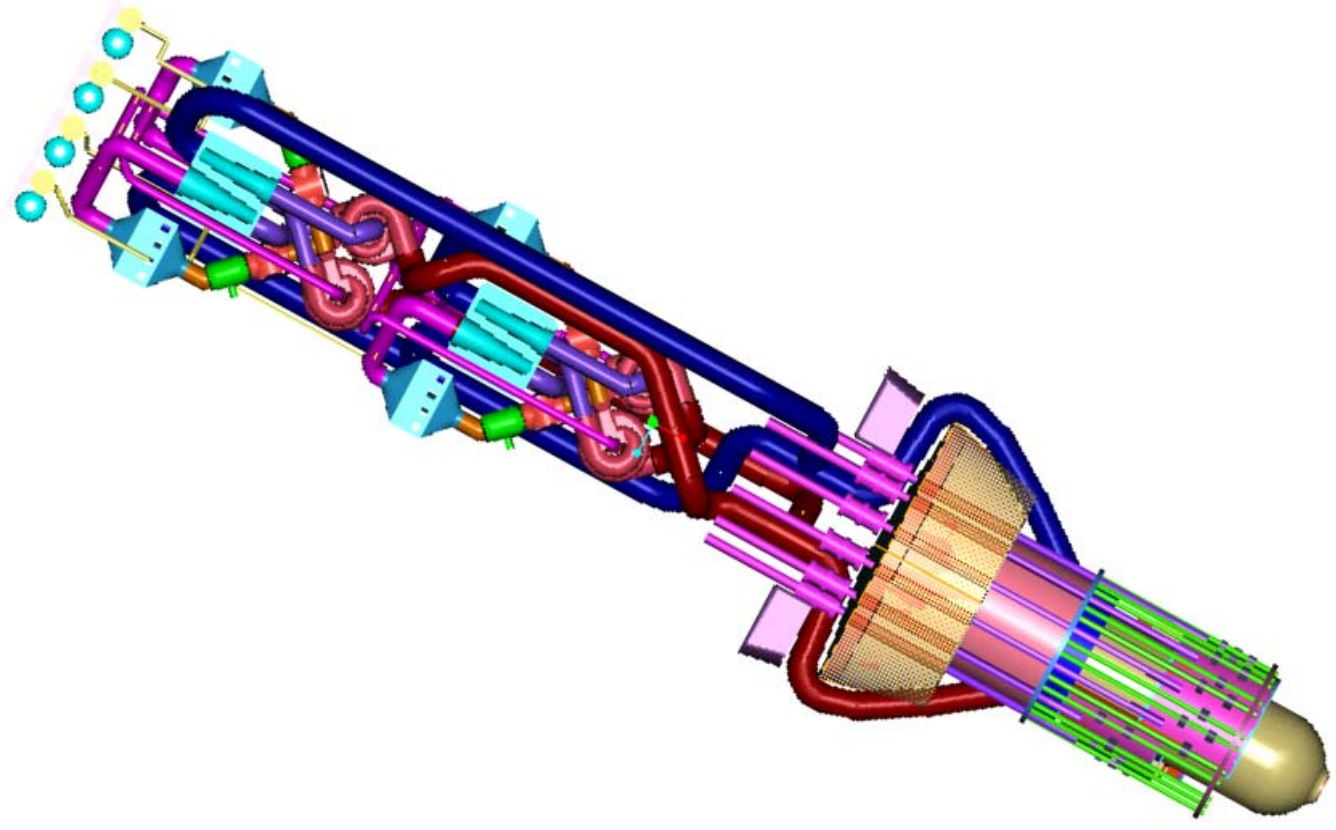




\section{RELAP5-3D Code Improvements}

- The INL was contracted to make the necessary code improvements so RELAP5-3D could be used for dynamic analysis of the JIMO concept:

- Properties for the desired helium-xenon mixture were added to the code.

- A compressor component was developed and included in the code.

- Bechtel Bettis enhanced the turbine model

- The appropriate turbine performance maps can now be explicitly represented.

- The enhanced turbine model has been provided to INL for their inclusion in a future version of RELAP5-3D. 
- The reactor model is similar to other RELAP5-3D reactor models.

- There are two closed-loop Brayton systems operating in parallel.

- A turbine and compressor share the same shaft with the alternator which generates the electric power for the spacecraft.

- There are also a recuperator and a gas cooler in each Brayton loop.

- The gas cooler transfers excess energy to the heat rejection system.

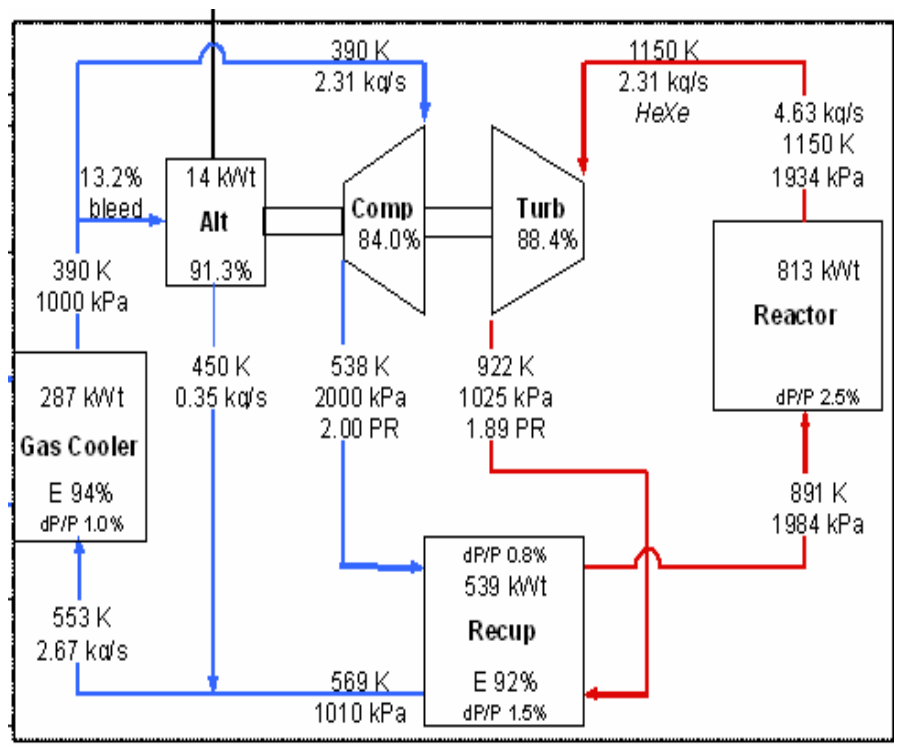

- Jacob Crittenden will present a separate discussion of his novel solution to modeling compact heat exchangers.

- The bleed path was not included in this pre-decisional model. 


\section{Turbine and Compressor Performance}

- NASA Glenn Research Center (GRC) provided generic compressor and turbine performance maps for use in the dynamic analysis.

- The RELAP5-3D code changes made it possible to use the maps directly.

- GRC also provided their method for determining off-design conditions.

- For transients that operate far from the design condition, it was necessary to extrapolate the maps for the transient calculations. If JIMO were pursued, performance maps would be required for a wider range of mass flow rates and shaft speeds.

- In RELAP5-3D, the shaft speed is calculated by balancing the torques of the compressor, turbine, and alternator plus any additional losses.

- Shaft speed is controlled by a control system which transfers load to or from a parasitic load resistor (PLR). The control system operates fast enough that the nuclear reactor is unaffected by it. 


\section{Steady State Results}

\begin{tabular}{|c|c|c|c|c|}
\hline \multirow{2}{*}{ Location } & \multicolumn{2}{|c|}{ Design Point Heat Balance } & \multicolumn{2}{c|}{ RELAP5-3D } \\
\cline { 2 - 5 } & Temperature (K) & Pressure (kPa) & Temperature (K) & Pressure (kPa) \\
\hline Turbine Inlet & 1150 & 1934 & 1149 & 1933 \\
\hline Turbine Exit & 522 & 1025 & 927 & 1051 \\
\hline $\begin{array}{c}\text { Recuperator } \\
\text { Low } \\
\text { Pressure } \\
\text { Side Exit }\end{array}$ & 390 & 1010 & 553 & 1036 \\
\hline \begin{tabular}{c} 
Gas Cooler Exit \\
\hline $\begin{array}{c}\text { Compressor Exit } \\
\text { Romperator }\end{array}$
\end{tabular} & 538 & 2000 & 526 & 1026 \\
\hline $\begin{array}{c}\text { Recuph } \\
\text { Pressure } \\
\text { Side Exit }\end{array}$ & 891 & 1984 & 892 & 1987 \\
\hline
\end{tabular}


- This transient causes the shaft speed in the affected loop to increase.

- The back torque on the shaft from the alternator is suddenly lost.

- For this transient to occur, it is assumed that loss of electrical load and loss of the PLR occur simultaneously.

- A new higher shaft speed is reached based mostly on the alternator and compressor torques.

- The temperature at the compressor inlet increases requiring more torque to turn the compressor, while the temperature at the turbine inlet is fairly constant, balancing the torques at a higher shaft speed.

- Significant interpolation of the compressor performance maps is required for this transient. More detailed maps would be desirable if the design effort were to continue. 


\section{Loss of Electrical Load from One of Two Alternators}

- Shaft speed approaches the upper limit of performance data (1.4).

- Reactor power increase causes the core hot spot temperature to increase about 50K.

- Results are driven by performance maps, so these would need to be refined to further the design.

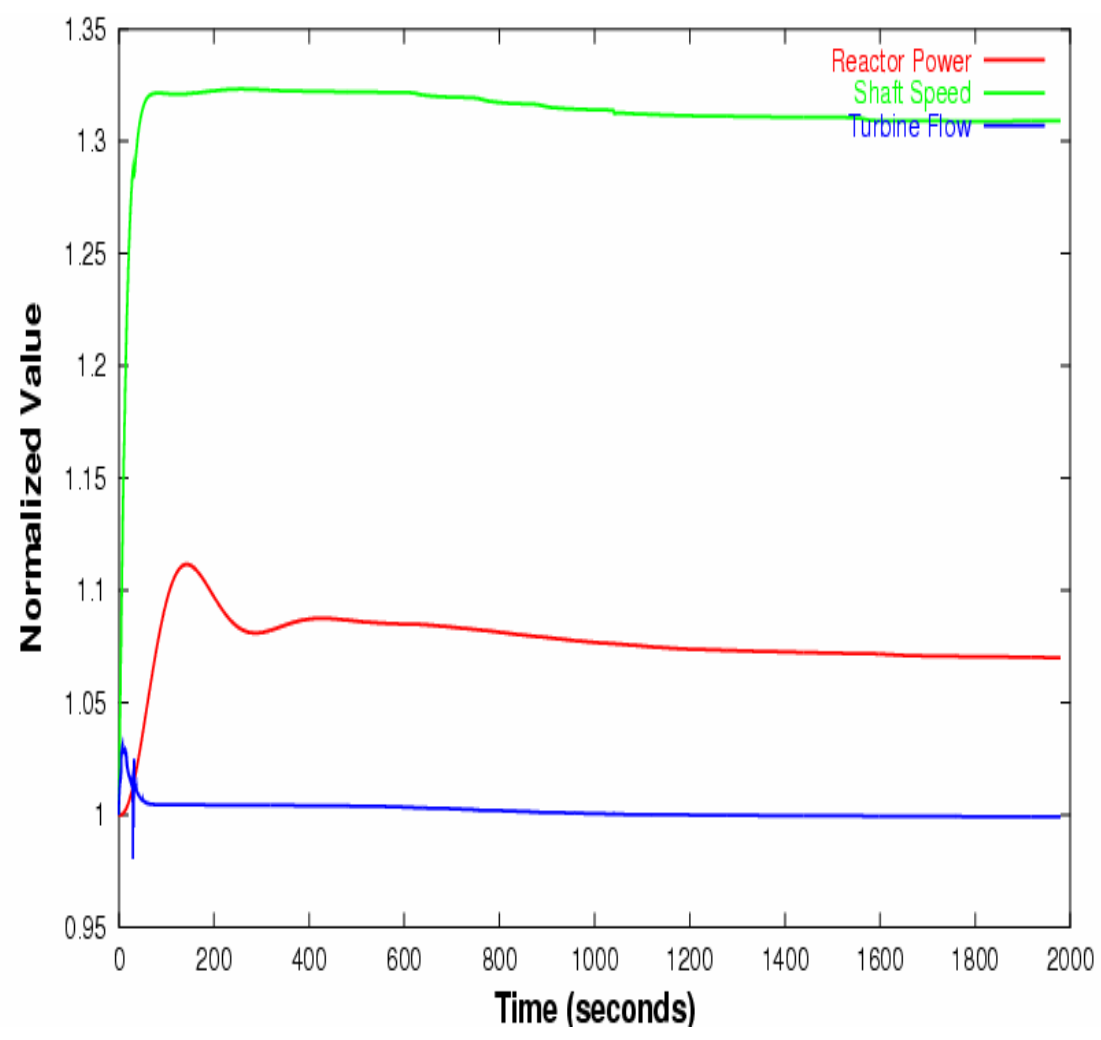


- This is highly assumption dependent. The assumed initial conditions are:

- Initially the heat rejection system (HRS) loops and the gas loops are all at $400 \mathrm{~K}$.

- The reactor has previously been taken critical and power increased to $1 \%$.

- During startup the HRS removes heat at a reduced rate. When the $\mathrm{CBC}$ are at operating temperature and shaft speed, the HRS heat removal rate is increased to normal.

- Both turbines are initially motored at $25 \%$ of design shaft speed to preclude bearing damage using energy from solar collectors and/or batteries. 
- The transient assumptions are:

- Increase gas temperature and the shaft speed of one of the two turbines simultaneously at a rate that results in the desired reactor outlet temperature and shaft speed on one turbine in 2.5 hours (Note that a much slower transient would be more likely to be used, but the trends should be similar).

- After the first turbine is at operating speed, start increasing the second turbine at a rate to reach operating speed in 2.5 hours.

- Once a turbine reaches self-sustaining (turbine torque exceeds compressor torque) shaft speed is allowed to increase until operating speed is reached.

- After the temperature and shaft speed are at operating conditions at about 5 hours, bring the HRS loops up to full flow. 


\section{Start-up Transient}

- Even at high rates of heat-up and shaft speed increase, the reactor power does not exceed $100 \%$.

- The first turbine is selfsustaining at about $67 \%$ and the second at about $56 \%$, because the inlet temperature to the second turbine is hotter.

- Negative electric power indicates power is required to motor the turbines before reaching self-sustaining.

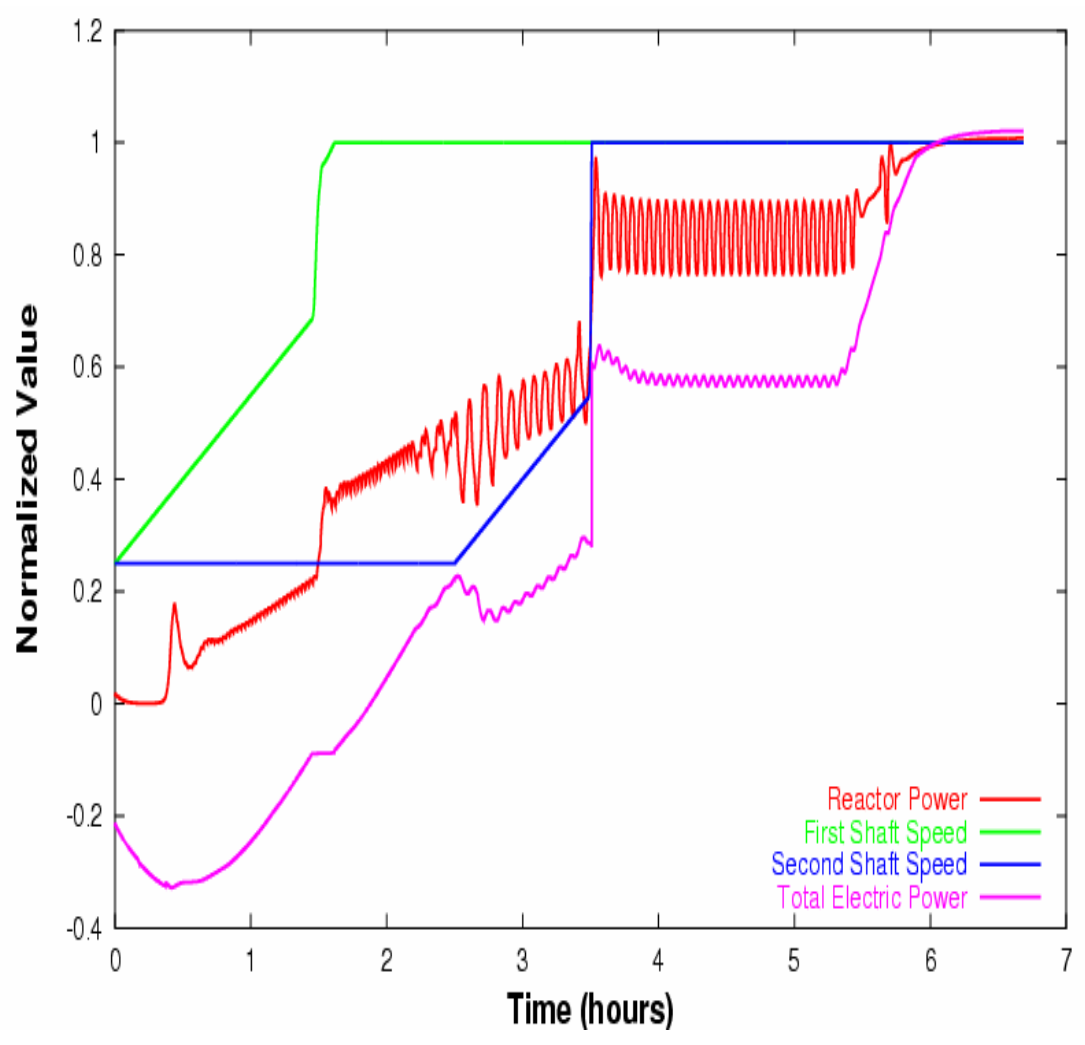


- $\quad$ The heat-up is accomplished by moving the sliders as follows:

- Move the sliders a short time then hold position.

- Repeat the above steps as necessary to match the heat-up goal.

- Reactor outlet temperature is compared to the heat-up goal.

- This can result in some oscillations, since the times are pre-determined. A method with reduced oscillations could be developed.

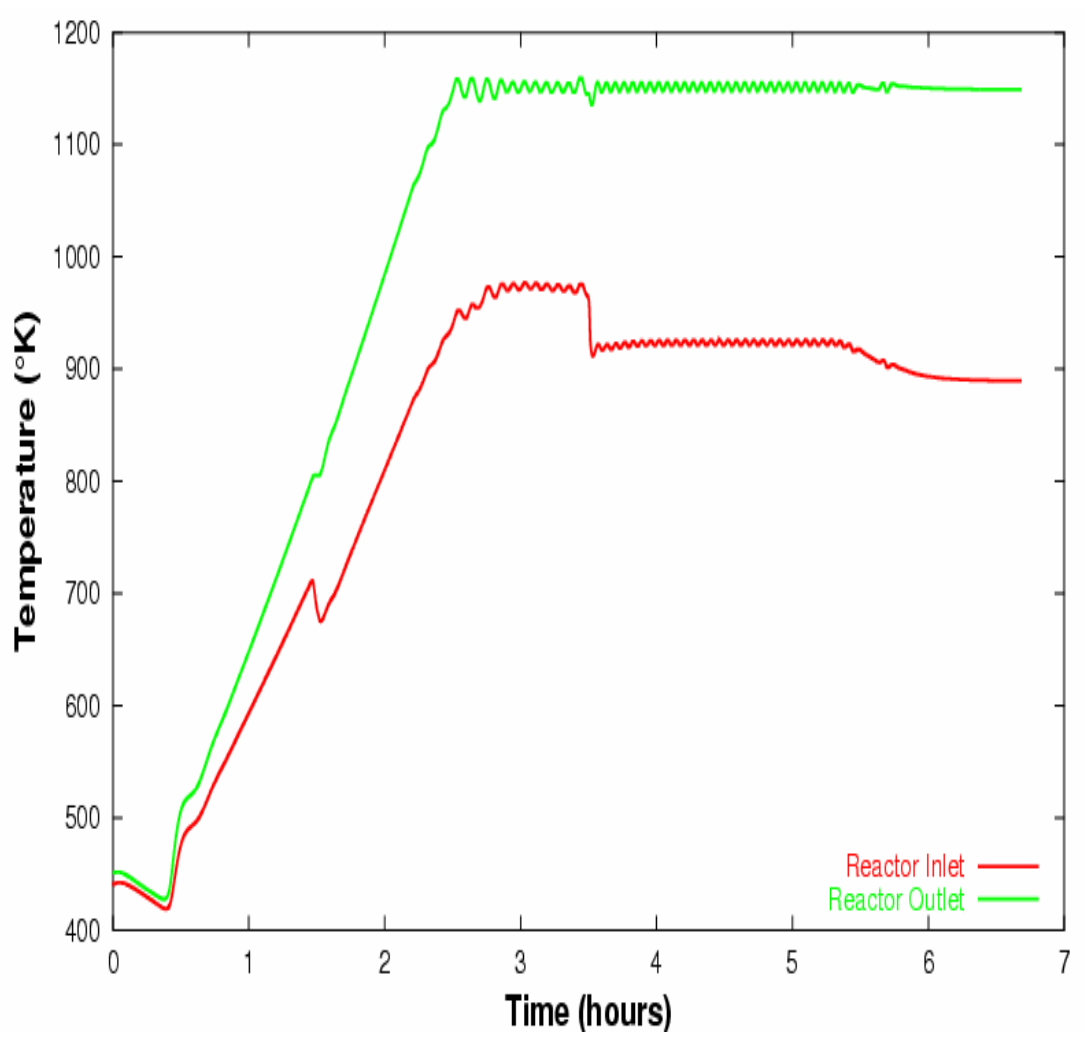


- Models predict stable operation and self-correcting response to component failures.

- RELAP5-3D can be used to represent a GFR directly connected to a parallel pair of closed-loop Brayton systems.

- Steady state results are consistent with a steady state heat balance for the reactor plant.

- Turbine and compressor performance maps beyond the normal range of operations are required to represent some extreme transients.

- Transient response seems reasonable for the transients analyzed.

- Validation of the RELAP5-3D input modeling procedure is required against test data or a validated transient analysis code.

- It is judged that RELAP5-3D could have been successfully validated for transient analysis of this JIMO reactor plant. 


\title{
Use of RELAP5-3D for Dynamic Analysis of a Closed- Loop Brayton Cycle Coupled To a Nuclear Reactor
}

\author{
Larry D. McCann \\ Bechtel Bettis, Incorporated \\ Bettis Atomic Power Laboratory \\ PO Box 79 \\ West Mifflin, PA 15122-0079 \\ 412-476-5066 mccannld@bettis.gov
}

\begin{abstract}
This paper describes results of a dynamic system model for a pair of closed Brayton-cycle (CBC) loops running in parallel that are connected to a nuclear gas reactor. The model assumes direct coupling between the reactor and the Brayton-cycle loops. The RELAP5-3D (version 2.4.1) computer program was used to perform the analysis. Few reactors have ever been coupled to closed Brayton-cycle systems. As such their behavior under dynamically varying loads, startup and shut down conditions, and requirements for safe and autonomous operation are largely unknown. The model described in this paper represents the reactor, turbine, compressor, recuperator, heat rejection system and alternator. The initial results of the model indicate stable operation of the reactor-driven Brayton-cycle system. However, for analysts with mostly pressurized water reactor experience, the Brayton cycle loops coupled to a gas-cooled reactor also indicate some counter-intuitive behavior for the complete coupled system. This model has provided crucial information in evaluating the reactor design and would have been further developed for use in developing procedures for safe start up, shut down, safe-standby, and other autonomous operating modes had the plant development cycle been completed.
\end{abstract}

\section{INTRODUCTION}

The Naval Reactors Prime Contractor Team (NRPCT) has evaluated nuclear reactor designs for the Prometheus Program and its envisioned initial mission, Jupiter Icy Moons Orbiter (JIMO). The purpose of JIMO was to use a nuclear electric propulsion spacecraft to explore three moons of Jupiter and to provide nuclear power technology extensible to future missions. This mission required the development of a highpower (100-300 kWe ) Nuclear Electric Propelled (NEP) spacecraft capable of propelling itself to the outer planets and then orbiting its moons. Closed-loop gas turbine power conversion systems were judged to be the best candidates for these high-power spacecraft based of the state of current technology. Figure 1 shows one concept considered. This particular concept shown has four closed-loop Brayton Systems, two of which are required to develop full power and the other two available as spares should one or two of the systems fail during the mission.

A RELAP5-3D model has been developed to analyze both steady-state and dynamic behavior of a reactor coupled to a parallel pair of closed-loop Brayton-cycle systems. Figures 2 and 3 contain schematics of the input model. A brief description of this model and some steady state and transient results are described. If the design effort had continued, it is judged that RELAP5-3D with the appropriate input procedure could have been used to answer many of the Gas-Brayton design and operational questions.

\section{REACTOR MODEL}

This reactor model is within the range of concepts studied by NRPCT (Project Prometheus Reactor Module Final Report, 2006). Figure 2 contains the schematic of the RELAP5-3D input model for a representative gas reactor. Some of the features of this reactor concept are summarized in Table 1. The reactor core model is composed of 354 fuel pins of diameter $1.777 \mathrm{~cm}$. Each fuel pin passes through a cylindrical core block with an annular flow channel between the pin and the core block. Each fuel pin has a gas plenum to accommodate fission products. The reactor vessel has both the inlet and outlet nozzles at one end of the 
reactor vessel. The incoming coolant flows between the exterior of the core block and the vessel wall to the inlet plenum at the opposite end of the reactor vessel. The coolant then flows through the flow channels to the outlet plenum where it exits through the outlet nozzle. The flow channels are represented with five annuli approximately equally dividing the total core flow area. There is a sixth flow channel in the model which represents the hottest channel in the core. Reactivity is controlled with neutron-reflecting sliders on the exterior of the reactor vessel that surround the circumference of the vessel and can be moved axially.

One feature typical of the fast reactors considered is that a significant contributor to temperature feedback is the geometry change that results from reactor fuel and structural material temperature changes. Unlike water cooled reactors, the coolant is an insignificant contributor to reactivity feedback. RELAP5-3D has the capability to represent the effect of fuel temperature change on reactivity. In order to account for the reactivity change due to changing structural material temperatures, a change to the RELAP5-3D code was made which adds a reactivity feedback coefficient based on geometry temperature change. The total feedback is of the order of -0.002 dollars $/ \mathrm{K}$, as noted in Table 1 . If the design effort would have continued, studies based on detailed reactor kinetics models and testing would have been performed to refine the kinetics feedback model in the dynamic analysis.

\section{CLOSED-LOOP BRAYTON SYSTEM}

Figure 3 contains the schematic of one of the two RELAP5-3D input models of the closed Brayton Cycle (CBC) system. The parallel system is identical. Each of these systems contains a turbine, recuperator, a gas cooler, a compressor, and a shaft connecting the compressor, alternator, and turbine. The gas cooler transfers excess energy to a heat rejection system (HRS) which contains $\mathrm{NaK}$ as its working fluid and radiates the energy to space.

Recent improvements have been made to the RELAP5-3D computer code by the Idaho National Laboratory (INL) to facilitate modeling the closed-loop Brayton system. A compressor component is now available which can represent the expected performance maps of the compressor (Fisher et al., 2005). Also, the turbine component has been expanded to accept variable inlet irrecoverable loss factor and efficiency values to ensure the turbine performance follows the desired performance maps. This code change to the turbine component was completed internally at Bechtel Bettis, Inc. The turbine component changes have been provided to the INL for incorporation into a future release of RELAP5-3D.

The heat transfer across the compact cross-flow heat exchangers provides a unique challenge in modeling in RELAP5-3D. An input model method was used which gives both accurate results and acceptable computational speed for the compact counter-flow heat exchangers.

The following sections discuss the more important features considered in the modeling of the shaft, compressor, turbine, and alternator components.

\section{Shaft Component}

The turbine, alternator, and compressor are all connected to one shaft. Thus, these components all operate at identical shaft speeds. RELAP5-3D determines shaft speed by balancing the torques on the shaft imposed by the components plus any parasitic losses. The equation for the load balance on the shaft is (RELAP5-3D, 2003):

$\mathrm{I} \mathrm{d} \omega / \mathrm{dt}=\tau_{\mathrm{T}}-\tau_{\mathrm{C}}-\tau_{\mathrm{A}}-\tau_{\mathrm{P}}$ 


\section{Turbine and Compressor}

The performance maps for the turbine and compressor are generic performance maps that were developed by NASA Glenn Research Center and provided to Bechtel Bettis, Inc. The maps were developed using the procedure described by Converse and Giffin (Converse and Giffin, 1984). These data are input to the compressor and turbine models in RELAP5-3D to represent the performance of these components.

Among the transients analyzed are an overspeed transient and startup. These transients result in mass flow rates and shaft speeds outside the ranges in the performance maps provided. To model transients that extend beyond the range covered by the performance maps, extrapolations to both lower and higher mass flow rates were performed. In addition, extrapolations to lower and higher shaft speeds were also included in the input model. Simple linear extrapolation was used. Use of these extrapolations demonstrates the system behavior trends and the ability of the computer code to provide reasonable calculations. If the JIMO project would have continued, more explicit performance maps for flow rates and shaft speeds beyond those currently available would have been required.

\section{THERMODYNAMIC STATE POINTS FOR CBC SYSTEM}

The steady-state state-points in Figure 4 for one of the closed-loop Brayton systems considered shows the approximate state points (temperatures, pressures, and flow rates) for a $101.6 \mathrm{~kW}_{\mathrm{e}}$ system, more recent NRPCT evaluations (Ashcroft, 2006) show slightly different state points based on increased loop flow resistance. These state-points are presented because they are the "target" values that were selected for the design of the dynamic model. The fluid is 78 percent mole fraction of Helium and 22 percent mole fraction of Xenon. The RELAP5-3D properties for helium and xenon and the mixture are based on the NIST Database (Lemmon et al., 2002).

Table 2 compares the state point data with the RELAP5-3D model calculations for the direct Brayton loop cooled gas reactor. Further code improvements that were planned for future work included improved representation of temperature to more accurately represent the temperature gradient across heat exchangers. Even without this change, the RELAP5-3D results are comparable to the calculated design point. The Brayton loop flow rate is $2.28 \mathrm{~kg} / \mathrm{s}$ compared to the $2.31 \mathrm{~kg} / \mathrm{s}$ design point flow rate. Since the RELAP5-3D input model does not represent heat loss to ambient (24 $\mathrm{kW}_{\mathrm{t}}$ in Table 2), the reactor power is $801 \mathrm{~kW}_{\mathrm{t}}$ compared to $813 \mathrm{~kW}_{\mathrm{t}}$ in the state point. A future update to the model would have incorporated ambient heat losses. With the same ambient heat loss, the predicted reactor power would be $825 \mathrm{~kW}_{\mathrm{t}}$. In addition, the bleed flow is not represented and that affects the comparison as well. Overall, the model results are in good agreement with the state point with areas identified that could improve that agreement.

\section{TRANSIENTS}

The RELAP5-3D input model has been used to analyze several JIMO transients. The three of most interest are:

1. Complete loss of electrical load, resulting in shaft speed increasing significantly

2. Sudden stoppage of one of the two turbines due to mechanical failure

3. Start-up transient

Each of these transients is discussed in the following sections. 


\section{Loss of Electrical Load from One Alternator}

The turbine, alternator, and compressor are all connected to one shaft. Thus, these components all operate at identical shaft speeds. The shaft speed is determined by a balance of the torques on the shaft imposed by the components plus any parasitic losses as noted previously and described by equation (1).

When the alternator load is suddenly removed there is a net positive torque on the turbine shaft resulting in an increased rotational speed. Note that a control system to regulate shaft speed was envisioned for Prometheus. If working properly, excess power would be transferred to a parasitic load resistor (PLR) by the shaft speed control system maintaining the same load on the alternator and the transient successfully averted. This transient assumes that a multiple component failure results in loss of the electrical connections to the load and to the PLR.

The increased shaft speed causes the compressor to force a higher mass flow rate through the loop. The shaft speed stabilizes at a new higher speed where the compressor and any parasitic loads are balanced by the torque produced by the turbine. In order for the shaft to stabilize at a new speed, rather than increase indefinitely, the magnitude of the compressor torque must approach that of the turbine torque. The equations for compressor and turbine torque are indicated below.

$\tau_{\mathrm{T}}=\eta_{\mathrm{T}} \mathrm{m} \Delta \mathrm{P}_{\mathrm{T}} / \rho_{\mathrm{T}} \omega$

$\tau_{\mathrm{C}}=\mathrm{m} \Delta \mathrm{P}_{\mathrm{C}} / \eta_{\mathrm{C}} \rho_{\mathrm{C}} \omega$

At higher shaft speeds, both the turbine and compressor efficiencies decrease. That tends to reduce the difference in the turbine and compressor torques as can be seen from the equations for torque above. In addition, while the temperature entering the turbine is fairly constant, the temperature entering the compressor increases as shaft speed increases. Compressor inlet temperature increases indirectly as a result of the increased shaft speed. The increased shaft speed increases the compressor exit pressure which increases the compressor exit temperature. That hotter gas at the compressor exit provides less cooling of the hot gas flowing through the recuperator from the turbine. That results in hotter gas at the compressor inlet. The hotter gas has a lower density resulting in more torque required to turn the compressor, as seen in equation (3). The final shaft speed is the one where the compressor torque balances the turbine torque.

Figures 5 and 6 show the responses of shaft speed and Brayton loop mass flow rates during the over speed transient. The shaft speed in the normally operating loop is held constant. This is consistent with the shaft speed control that would be employed. The shaft speed in the loop losing its electrical load accelerates from 45,000 rpm to about 59,000 rpm (Figure 5). Mass flow rate in that loop increases slightly at the start of the transient then falls slightly below the normally operating loop mass flow rate (Figure 6). Although the shaft speed has increased by 30 percent, mass flow rate ends at about the same value as at the start. This is because the density at the compressor has decreased by 20 percent because pressure downstream of the turbine is lower.

Figures 7 and 8 compare reactor power and core hot spot temperature. Reactor power peaks at approximately 111 percent and hot spot temperature increases by $50 \mathrm{~K}$ before approaching steady state values of around 107 percent power and $40 \mathrm{~K}$ above the starting temperatures.

Figure 9 shows the temperatures through the Brayton loop are affected by the loss of electrical load. Since more energy is used by the turbine to operate at higher speed, the turbine outlet and reactor inlet temperatures gets cooler.

\section{Loss of One Turbine}

This transient considers the potential impact of one of the two Brayton turbines stopping rapidly. This could be caused by bearing failure. This is represented in RELAP5-3D by disconnecting the turbine from the shaft component. The result of disconnecting the turbine is that the shaft quickly stops without the turbine torque to keep it rotating. Shaft speed is plotted in Figure 10. As the shaft stops, the compressor 
pumps less gas causing the mass flow rate to drop to zero. Mass flow rates in the two Brayton loops are plotted in Figure 11.

As a result of this transient, the flow to the reactor is reduced by about 50 percent. Some of the flow from the operating Brayton loops would flow backward through the idle Brayton loop if reverse flow were not prevented, reducing the reactor flow to less than 50 percent. To prevent an idle turbine from rotating in the reverse direction, check valves were expected to be installed in each Brayton loop. This model represents those check valves, so there is no reverse flow in the idle loop.

The reactor power drops by about the same amount as the flow through the reactor, approximately 50 percent, due to temperature feedback from the increasing core temperatures. Reactor power is shown in Figure 12. Core hot spot temperature is plotted in Figure 13.

Figures 14 plots the temperatures through the Brayton loop with the idle turbine. Temperatures immediately start to increase. The temperature at the Brayton loop inlet increases because the flow through the core decreases before power starts to decrease, heating the gas to a higher outlet temperature. The idle loop cold leg temperature also increases because less energy is removed from the gas in the idle loop as the turbine stops. One final reason for the temperatures to increase is that pressure approaches the loop inlet pressure throughout the CRC as flow stops. Once the shaft is completely stopped in the idle loop, temperatures remain essentially constant because flow has stopped.

Figure 15 plots the electrical power produced. The electrical power on the idle loops drops immediately to zero. The electrical power produced in the operating loop increases about 10 percent. The electric power produced in the operating loop increases because the fluid entering the loop from the reactor is hotter and the fluid entering the compressor stays at about the same temperature. From Equations (2) and (3), that means the torque generated by the turbine increases because density is lower, while the torque required by the compressor is essentially unchanged. That leaves more torque to drive the alternator, as is seen in Equation (1).

\section{Start-Up}

Figures 16 through 22 are calculated parameter values during a plant start-up transient. Start-up transients are contingent on the assumptions made. The scenario modeled was based on initial formulated control actions. More recent and integrated procedures were subsequently developed by NRPCT (Project Prometheus Reactor Module Final Report, 2006). For the start-up analyzed here, it was assumed that the entire plant starts at $400 \mathrm{~K}$ and the reactor is critical at the point of adding heat, 1percent $\left(8 \mathrm{~kW}_{\mathrm{t}}\right)$ power. During start-up the HRS removes heat at a reduced rate. The heat rejection method used in this model is non-physical, but it achieves the desired effect. The heat sink for the radiator in the input model is held at $400 \mathrm{~K}$ during startup instead of the normal value of $200 \mathrm{~K}$. Once operating temperature and shaft speed are reached in both $\mathrm{CBCs}$, the HRS heat removal rate is restored to normal by reducing sink temperature to $200 \mathrm{~K}$. To provide reactor flow, both turbines are initially motored at the minimum speed, 25 percent shaft speed $(11,250 \mathrm{rpm})$ to preclude damage to turbine bearings. Shaft speed is shown in Figure 16. The resulting mass flow rates are shown in Figure 17. The sliders are moved as required to heat the reactor outlet temperature to $1150 \mathrm{~K}$ in 2.5 hours $(300 \mathrm{~K} / \mathrm{hr}$ ). Figure 18 plots the resulting reactor power and Figure 19 plots the reactor core inlet, outlet and average temperatures. In parallel, the motor speed of one turbine is increased at 13,500 rpm per hour until it is self-sustaining (the turbine torque exceeds compressor torque), then shaft speed is allowed to be dictated by the turbine and compressor torques until it reaches 45,000 rpm. This is shown in Figure 16, where self-sustaining occurs for the first turbine at about 1.5 hours and at about 3.5 hours for the second turbine. Slider motion is simulated by moving the sliders at 0.5 $\mathrm{cm} /$ minute for 8 seconds then holding for 100 seconds. After the hold period, the slider motion process is repeated if required in order to maintain reactor outlet temperature within $1 \mathrm{~K}$ of the heat up goal. Note that the oscillations in reactor power and other parameters are caused by the stair-step slider motion. During the design, the method to heat-up the plant would have been refined to preclude this oscillation.

During the first 2.5 hours, the reactor power increases to between 40 percent and 50 percent and reactor outlet temperature increases to $1150 \mathrm{~K}$, as shown in Figures 18 and 19. After 2.5 hours the motor speed of 
the second turbine is increased at 13,500 rpm per hour until it is self-sustaining, as seen in Figure 16. At that point, since the temperature entering the Brayton loop is at $1150 \mathrm{~K}$, the second turbine reaches selfsustaining at a lower shaft speed. The combination of increased coolant flow rate resulting from the second Brayton loop and the colder gas entering the reactor causes reactor power to peak at about 100 percent and then level off at between 80 percent and 90 percent power. Since the HRS heat removal rate is reduced (by increasing the radiator sink temperature), the power levels off below 100 percent. For the same reason, the total electrical loads level off at a total of about $130 \mathrm{~kW}_{\mathrm{e}}$, which is about 60 percent of full electrical power. The HRS heat removal rate is restored to normal after temperature and shaft speed reach operating levels in both CBCs. Both reactor power and electric power reach $100 \%$ at that time.

This transient demonstrates the approximate response of this notional start-up and indicates that it is not an excessively severe transient. More careful control plus use of the shaft speed controller even after selfsustaining turbine conditions are reached could make the start-up even less severe. It is expected that startup would occur over a much longer period which would reduce any power overshoot. The shaft speed would not likely increase simultaneously with temperature. Shaft speed and temperature would be increased alternately. The second loop would need to be brought up to speed before any temperature limits are violated in the loop components, which may require starting the loop before the first one reaches normal operating conditions. The electrical power required to motor the shaft indicated in Figure 22 (the negative power values) is approximately an order of magnitude larger than expected. This is because the compressor and turbine maps in the RELAP5-3D input model had to be extrapolated to perform this transient. If the work would have continued, compressor and turbine data would have been incorporated into the model to cover the range of all transients performed.

\section{SUMMARY AND CONCLUSIONS}

A RELAP5-3D model of a conceptual gas cooled reactor directly connected to a pair of closed-loop Braytons systems in parallel has been developed. The model is shown to give reasonable agreement with a steady-state heat balance calculation. There are no dynamic analysis data to compare against, but the results appear reasonable. The model predicts stable operation and self-correcting response to component failures. Further work would have included several test programs to validate the ability to model closed loop Braytons systems with RELAP5-3D. It is expected that this code combined with a modeling procedure developed by comparison to test data would have been an effective tool in refining the design of the Prometheus reactor plant and establishing procedures for its operation. 


\section{NOMENCLATURE}

$\tau_{\mathrm{C}}=$ compressor torque (nt-m)

$\tau_{\mathrm{T}}=$ turbine torque (nt-m)

$\tau_{\mathrm{A}}=$ torque imposed by the alternator (nt-m)

$\tau_{\mathrm{P}}=$ torque imposed by parasitic losses (nt-m)

I = shaft moment of inertia $\left(\mathrm{kg}-\mathrm{m}^{2}\right)$

$\eta_{\mathrm{T}}=$ turbine efficiency

$\mathrm{m}=$ mass flow rate $(\mathrm{kg} / \mathrm{s})$

$\Delta \mathrm{P}_{\mathrm{T}}=$ turbine differential pressure (Pascals)

$\rho_{\mathrm{T}}=$ average fluid density in the turbine $\left(\mathrm{kg} / \mathrm{m}^{3}\right)$

$\omega=$ shaft speed $(\mathrm{rad} / \mathrm{s})$

$\eta_{\mathrm{C}}=$ compressor efficiency

$\Delta \mathrm{P}_{\mathrm{C}}=$ compressor differential pressure (Pascals)

$\rho_{\mathrm{C}}=$ average fluid density in the compressor $\left(\mathrm{kg} / \mathrm{m}^{3}\right)$

\section{AKNOWLEDGMENTS}

The author thanks Cliff Davis at the Idaho National Laboratory for assistance in making RELAP5-3D code changes to the compressor component to facilitate modeling two closed-loop Brayton systems for the first time ever with this code. Thanks to Paul Johnson at the NASA Glenn Research Center for providing much information about the closed-loop Brayton systems.

\section{REFERENCES}

Project Prometheus Reactor Module Final Report, SPP-67110-0008, January 31, 2006.

Fisher, James E., Davis, Cliff B., and Weaver, Walter L., Idaho National Laboratory, "RELAP5-3D@ Compressor Model", Proceedings of the Space Nuclear Conference 2005, San Diego, California, June 5-9, 2005, Paper 1115

RELAP5-3D C Code Manual: Volume I: Code Structure, System Models and Solution Methods, INEEL-EXT-9800834, Revision 2.2, October 2003.

Converse, G. L. and Giffin, R. G., "Extended Parametric Representation of Compressor Fans and Turbines", NASA CR 174645, NASA Lewis Research Center, Cleveland, Ohio, 1984.

Ashcroft, J. M. and Eshleman, C. D., "Summary of NR Program Prometheus Efforts", STAIF 2006

Lemmon, E. W., McLinden, M. O., and Huber, M. L., "REFPROP Reference Fluid Thermodynamic and Transport Properties," NIST Standard Reference Database 23, Version 7.0 Beta Version, National Institute of Standards and Technology, June 2002. 
TABLE 1. RELAP-3D Model Reactor Parameters

\begin{tabular}{|l|r|}
\hline \multicolumn{1}{|c|}{ Parameter } & Value \\
\hline Number of fuel pins & 354 \\
\hline Fuel pin diameter $(\mathrm{cm})$ & 1.777 \\
\hline Fuel height $(\mathrm{cm})$ & 66.4 \\
\hline Gas plenum height $(\mathrm{cm})$ & 14 \\
\hline Core diameter $(\mathrm{cm})$ & 57.5 \\
\hline Vessel OD $(\mathrm{cm})$ & 63.58 \\
\hline Channel thickness $(\mathrm{cm})$ & 0.269 \\
\hline Total kinetics feedback coefficient $(\$ / \mathrm{K})$ & -0.002 \\
\hline
\end{tabular}

Table 2. Steady State Comparison of RELAP5-3D Calculations to the Heat Balance Calculations

\begin{tabular}{|l|c|c|c|c|}
\hline \multirow{2}{*}{ Location } & \multicolumn{2}{|c|}{ Design Point } & \multicolumn{2}{c|}{ RELAP5-3D } \\
\cline { 2 - 5 } & Temperature (K) & Pressure (kPa) & Temperature (K) & Pressure (kPa) \\
\hline Turbine Inlet & 1150 & 1934 & 1149 & 1933 \\
\hline Turbine Exit & 922 & 1025 & 927 & 1051 \\
\hline $\begin{array}{l}\text { Recuperator Low } \\
\text { Pressure Side Exit }\end{array}$ & 569 & 1010 & 553 & 1036 \\
\hline Gas Cooler Exit & 390 & 1000 & 380 & 2003 \\
\hline Compressor Exit & 538 & 2000 & 526 & 1987 \\
\hline $\begin{array}{l}\text { Recuperator High } \\
\text { Pressure Side Exit }\end{array}$ & 891 & 1984 & 892 & 1026 \\
\hline
\end{tabular}


Figure 1. Prometheus Concept with Direct Gas-Cooled Reactor and Four Parallel Closed Brayton Loops

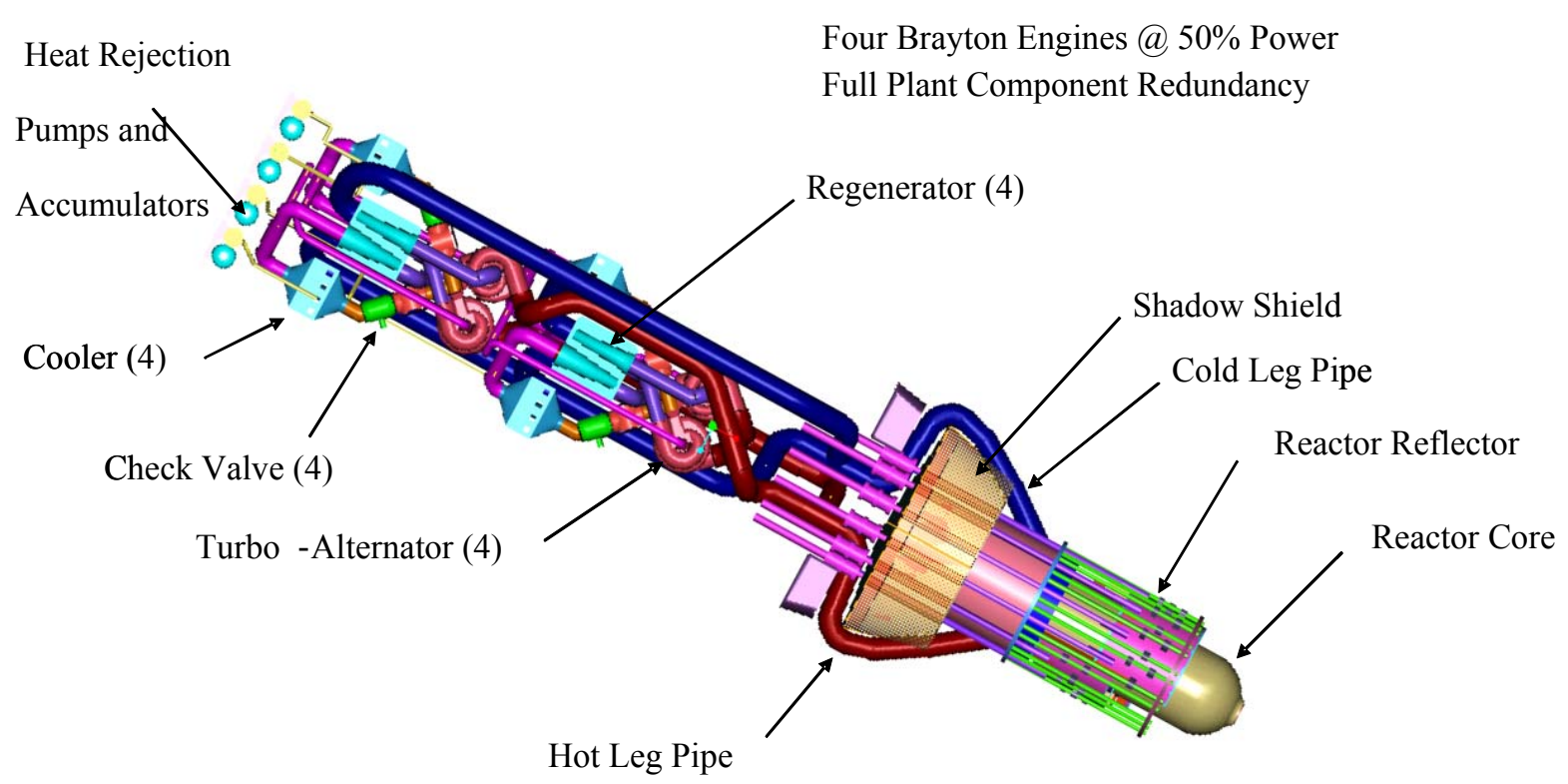


Figure 2. RELAP5-3D Input Model Schematic of the Gas Cooled Reactor Concept

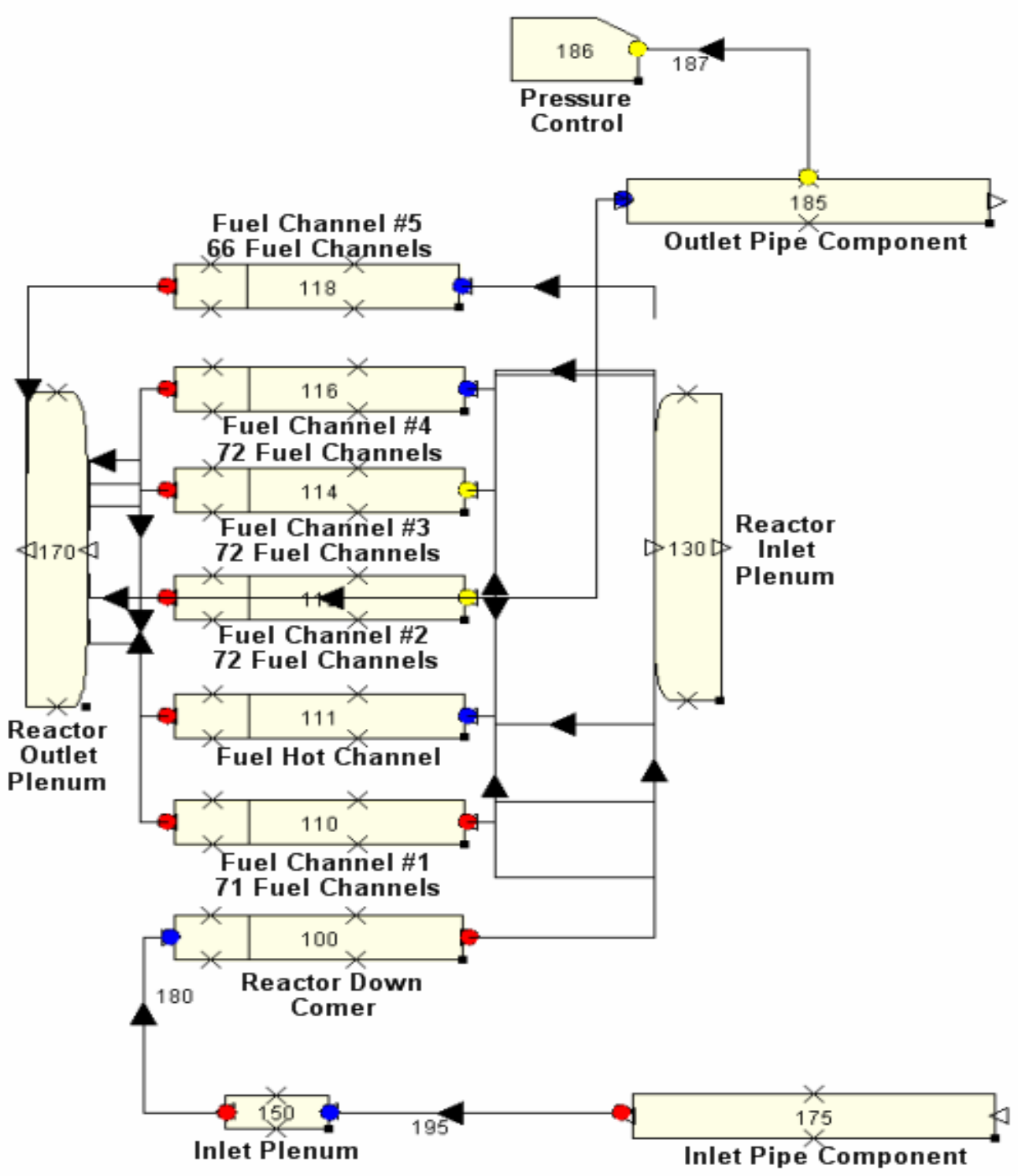


Figure 3. RELAP5-3D Input Model Schematic of One of the Two Identical Closed Loop Brayton System and Corresponding Heat Rejection System
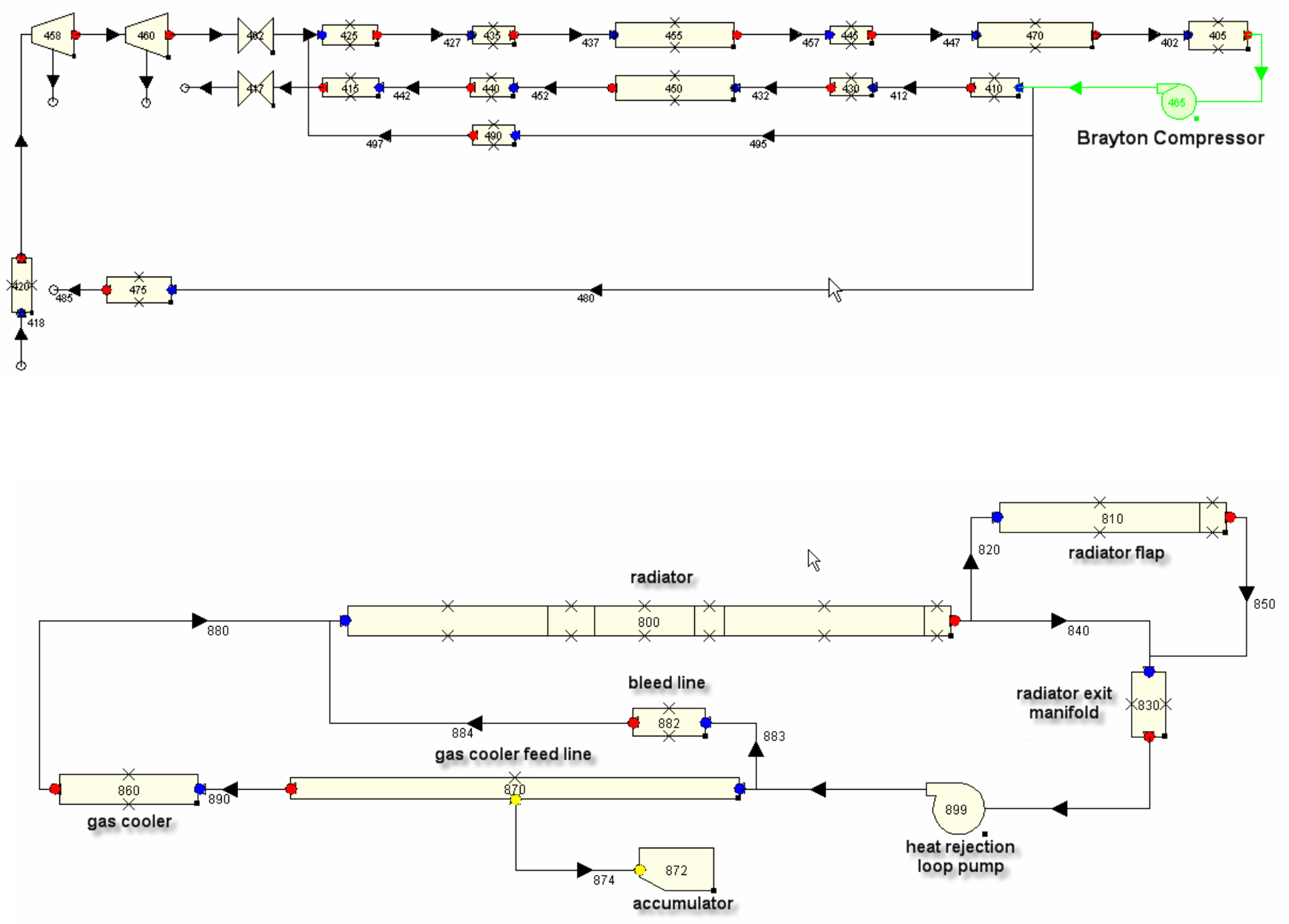
Figure 4: State-points for temperature, pressure, and mass flow rate for a Prometheus Pre-Conceptual Design closedBrayton-cycle system

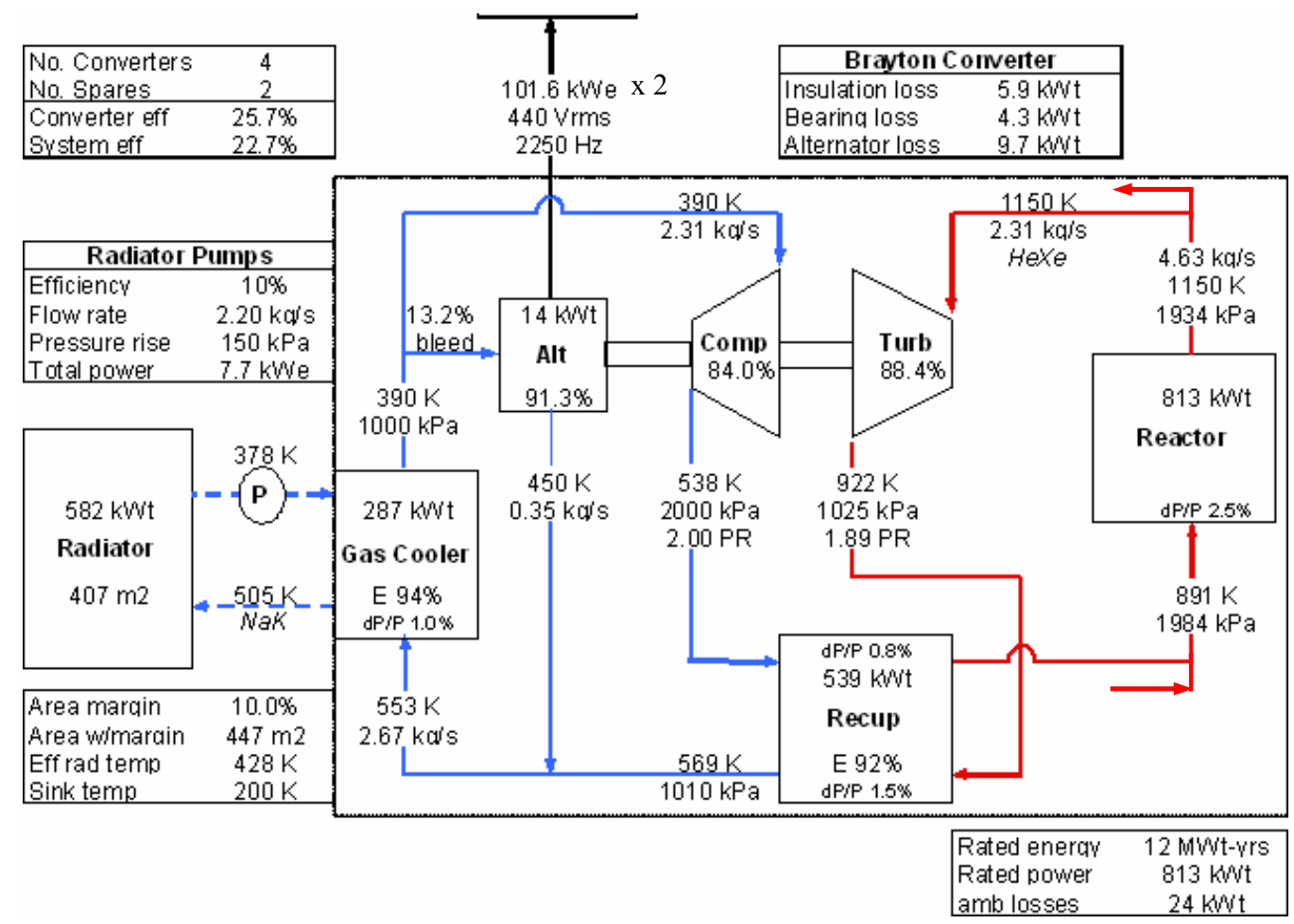


Figure 5. Shaft Speed Response to Loss of the Electrical Load from One of Two Alternators

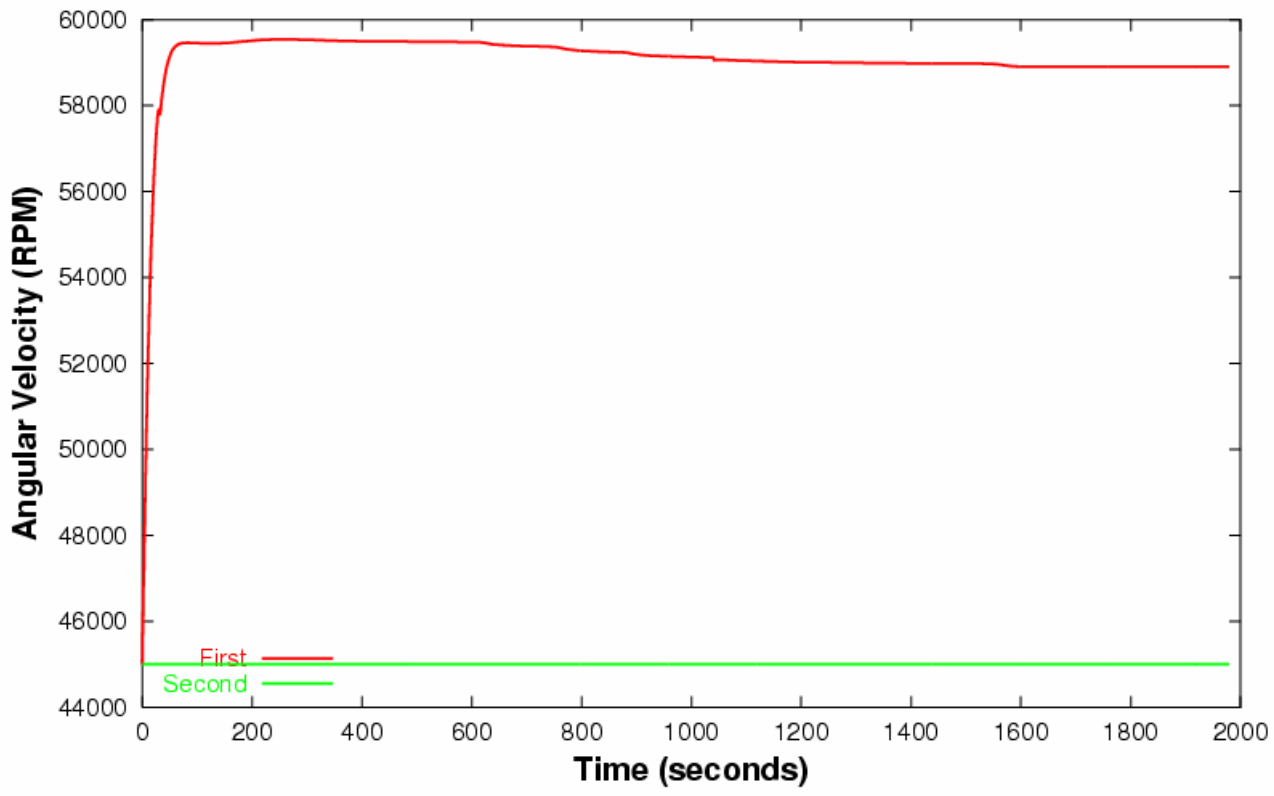

$1123050: 10$

Figure 6. Brayton Loop Mass Flow Rate Response to Loss of the Electrical Load from One of Two Alternators

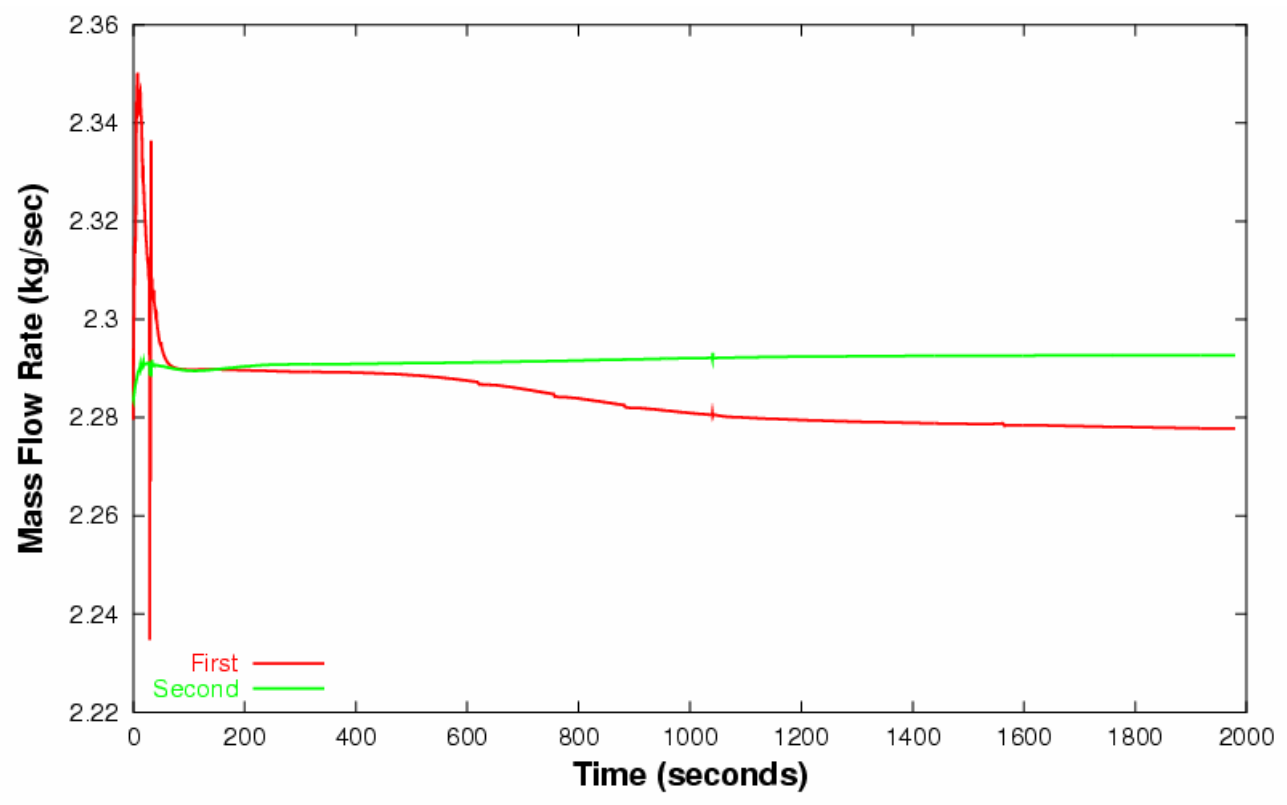

112305 6::10 
Figure 7. Reactor Power Response to Loss of the Electrical Load from One of Two Alternators

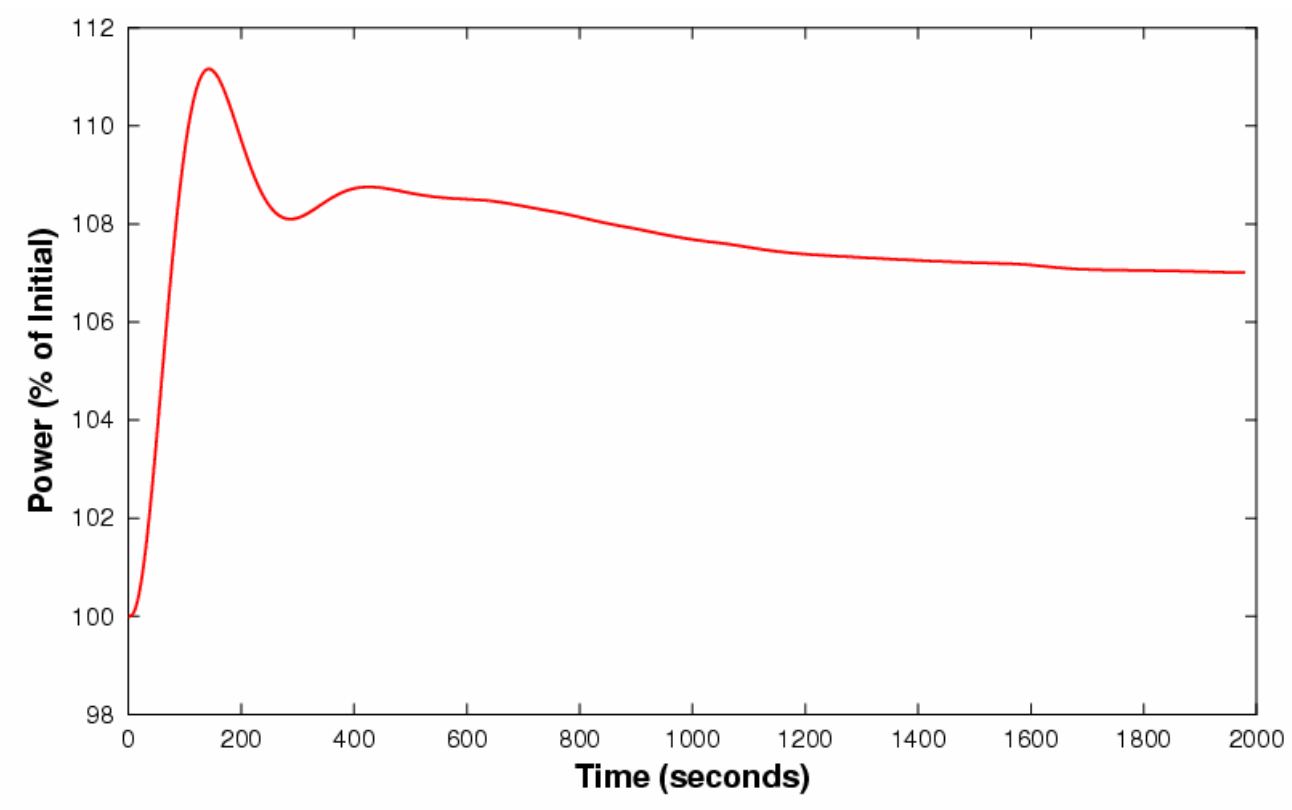

112305 6 : :18

Figure 8. Reactor Hot Pin Hot Spot Temperature Change during Loss of the Electrical Load from One of Two Alternators

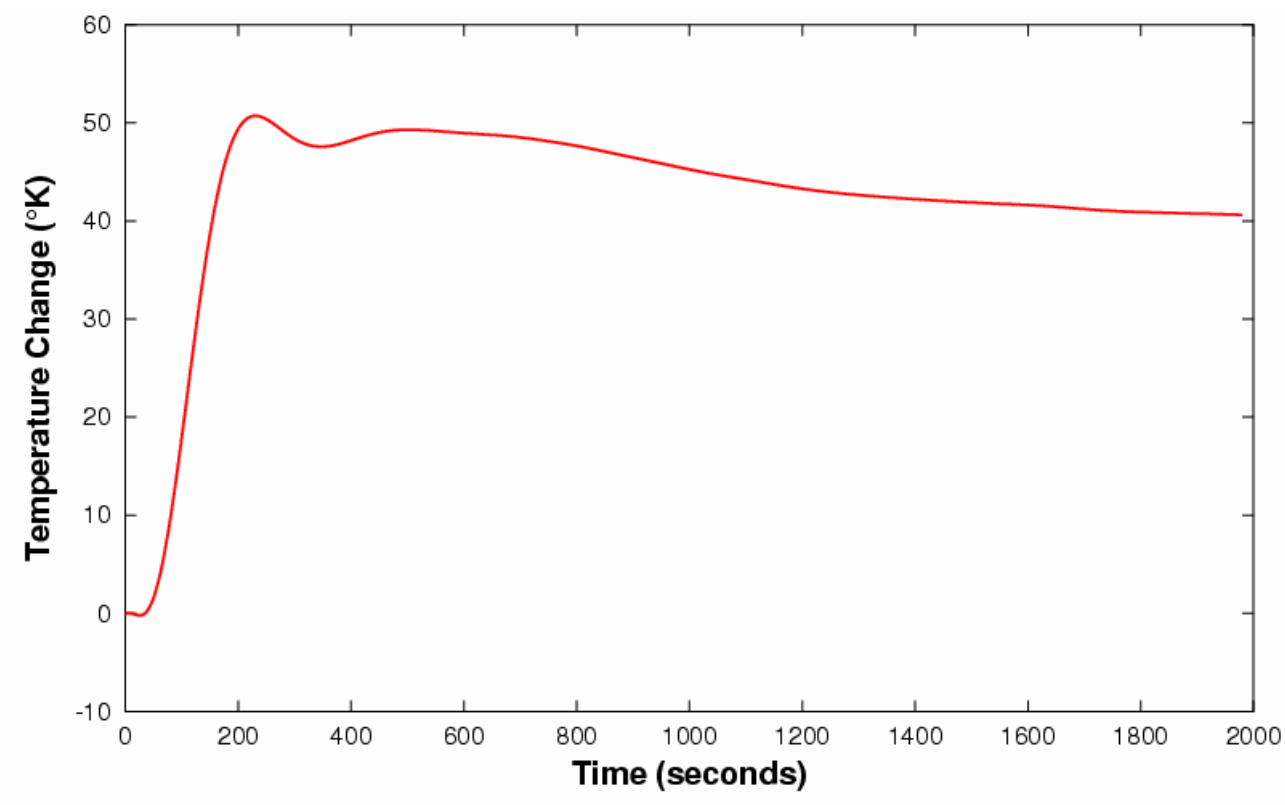

${ }_{1120050: 18}$ 
Figure 9. Affected Brayton Loop Temperature Response to Loss of the Electrical Load from One of Two Alternators

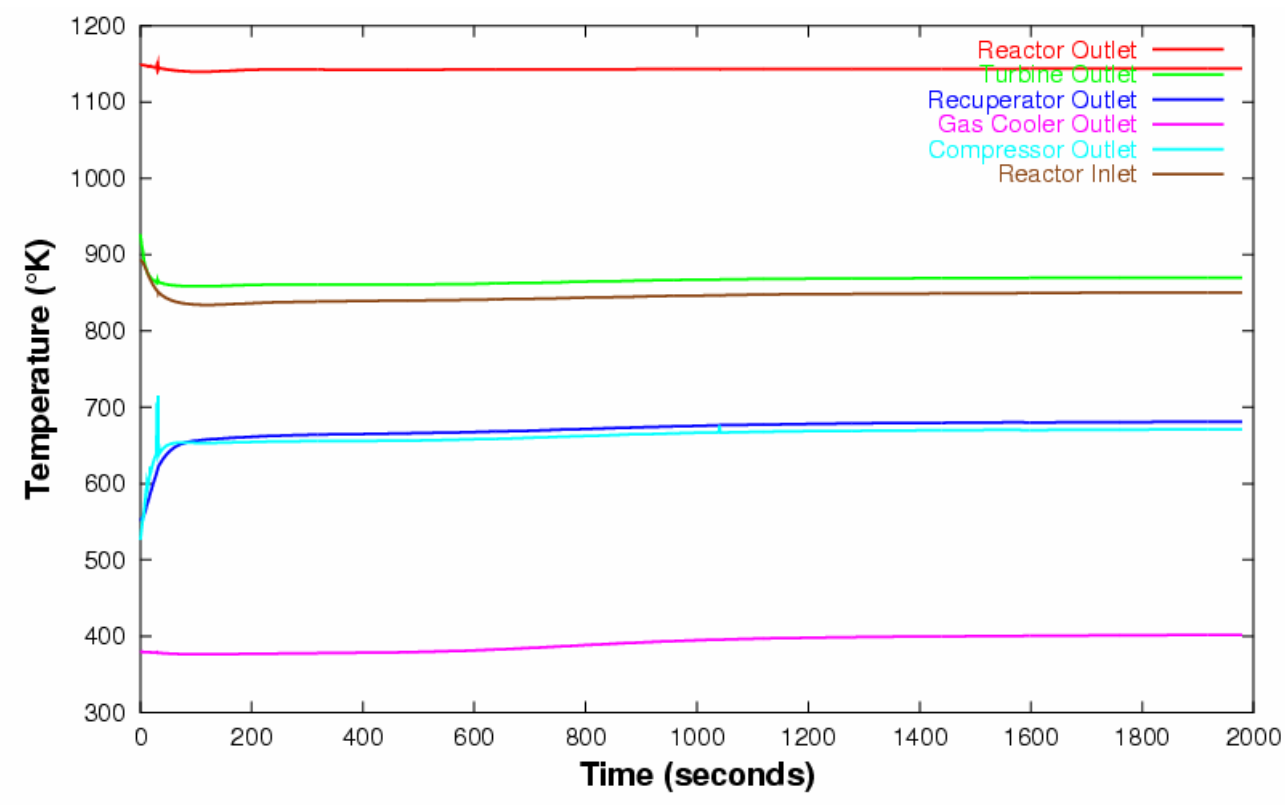

1123050200

Figure 10. Shaft Speed Response to Loss of One of Two Turbines

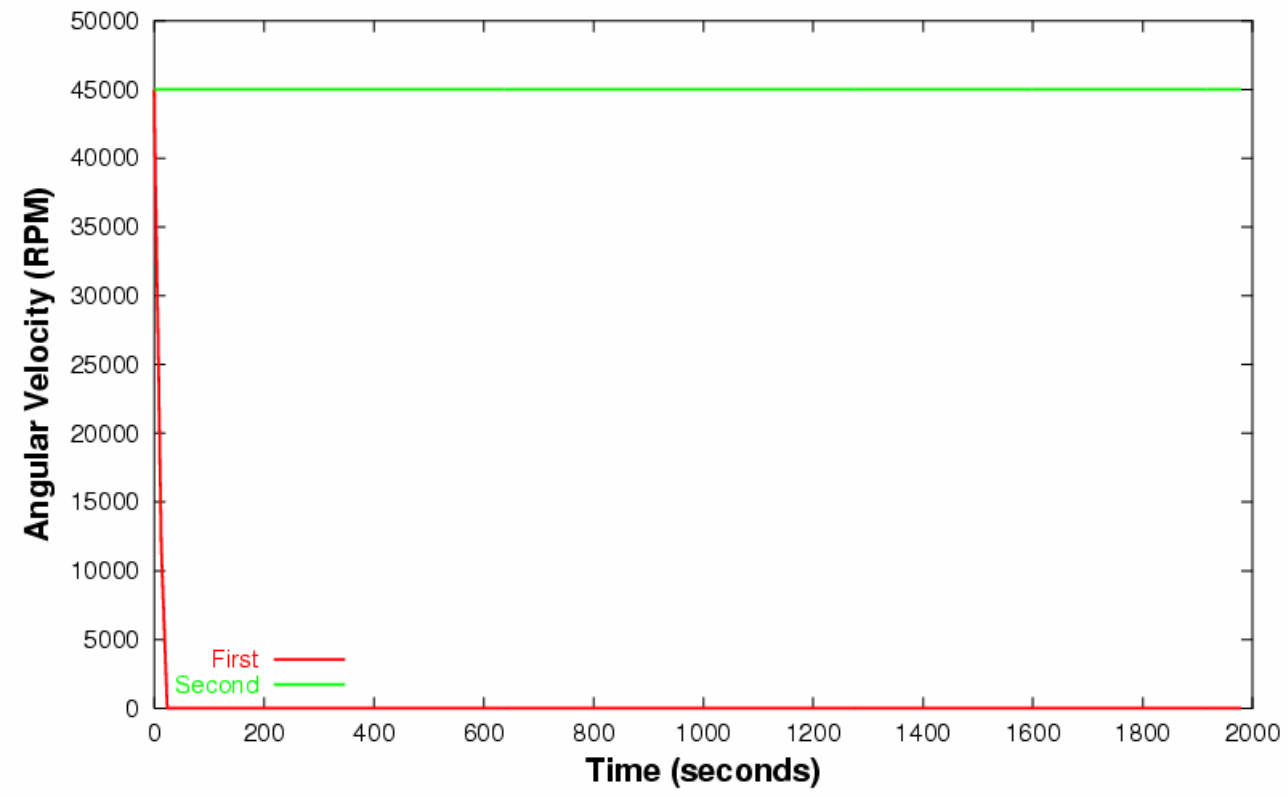


Figure 11. Loop Mass Flow Rates during Loss of One of Two Turbines

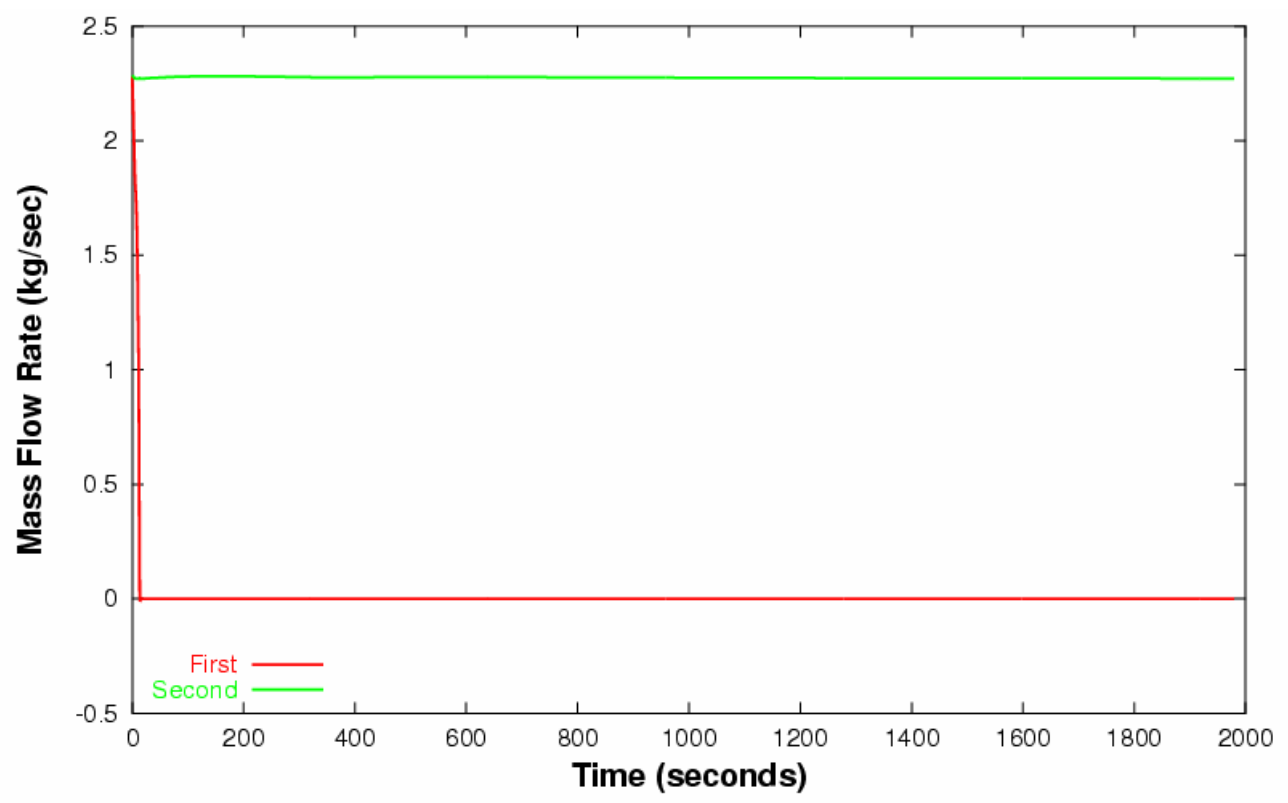

1122050005

Figure 12. Reactor Power Response to Loss of One of Two Turbines

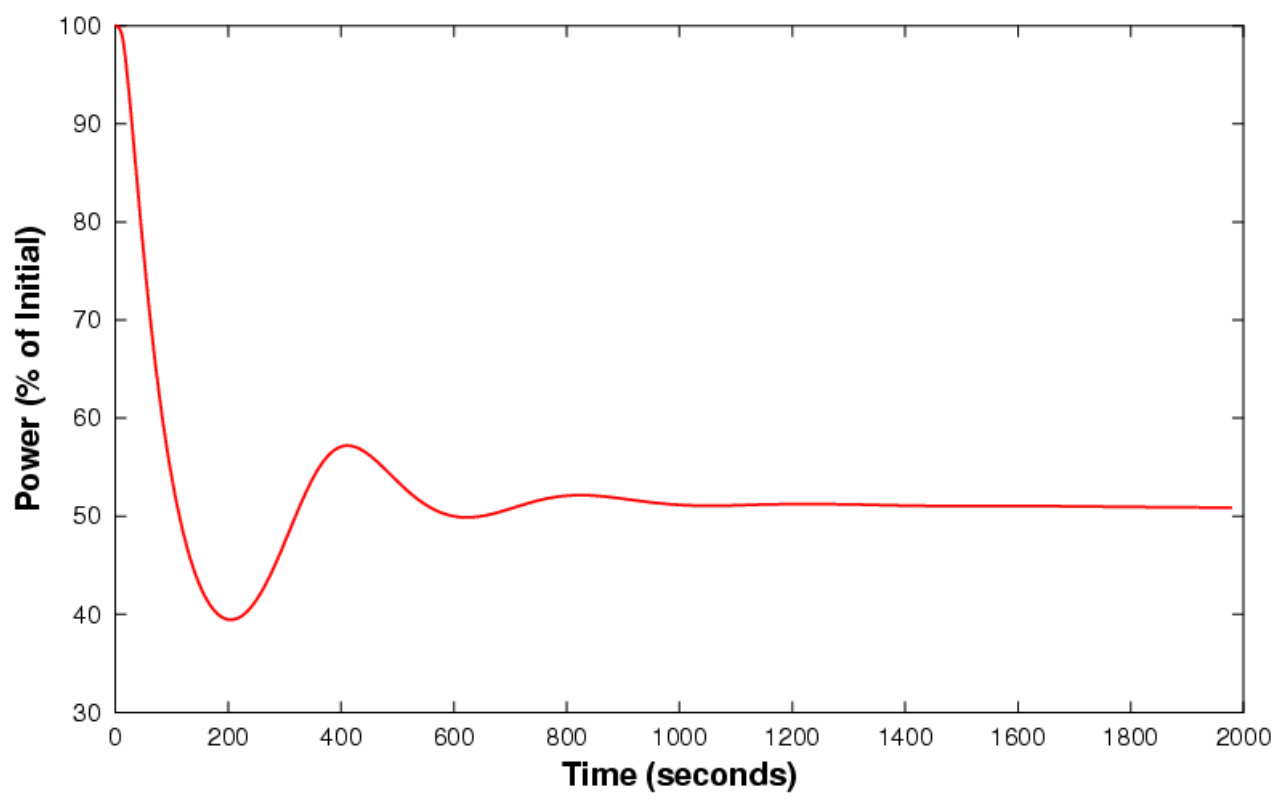

112205 v04 
Figure 13. Reactor Hot Pin Hot Spot Temperature Change during Loss of One of Two Turbines

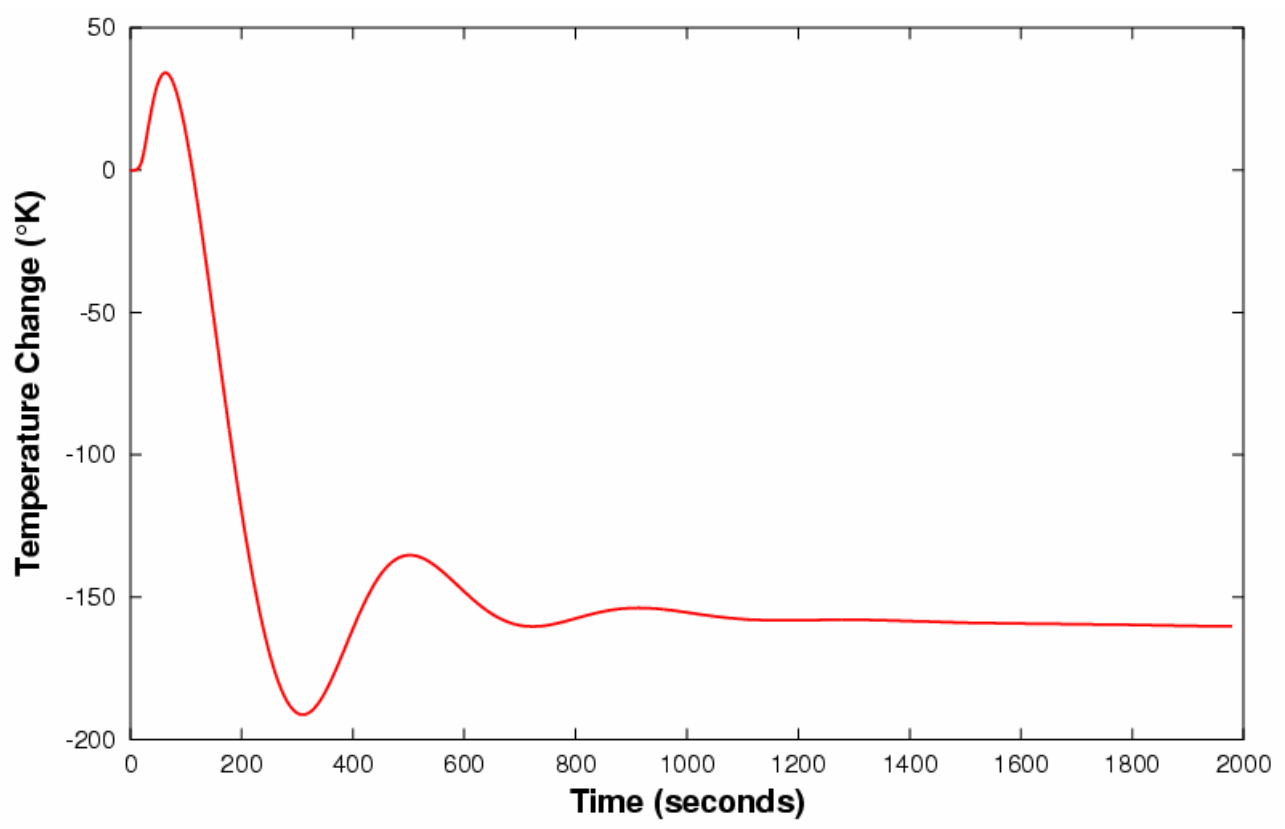

112205 vol

Figure 14. Affected Brayton Loop Temperature Response to Loss of One of Two Turbines

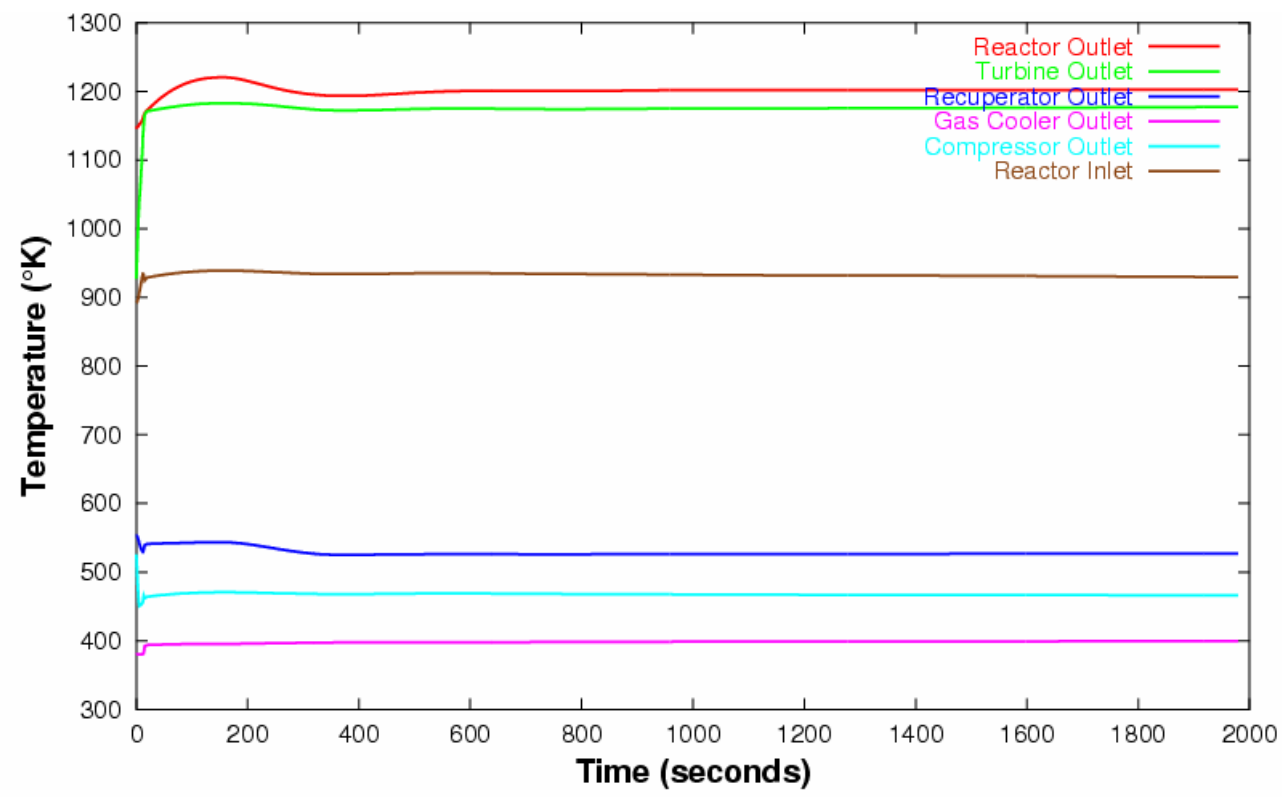

112305 b.66 
Figure 15. Electrical Loads for the Loss of One of Two Turbines

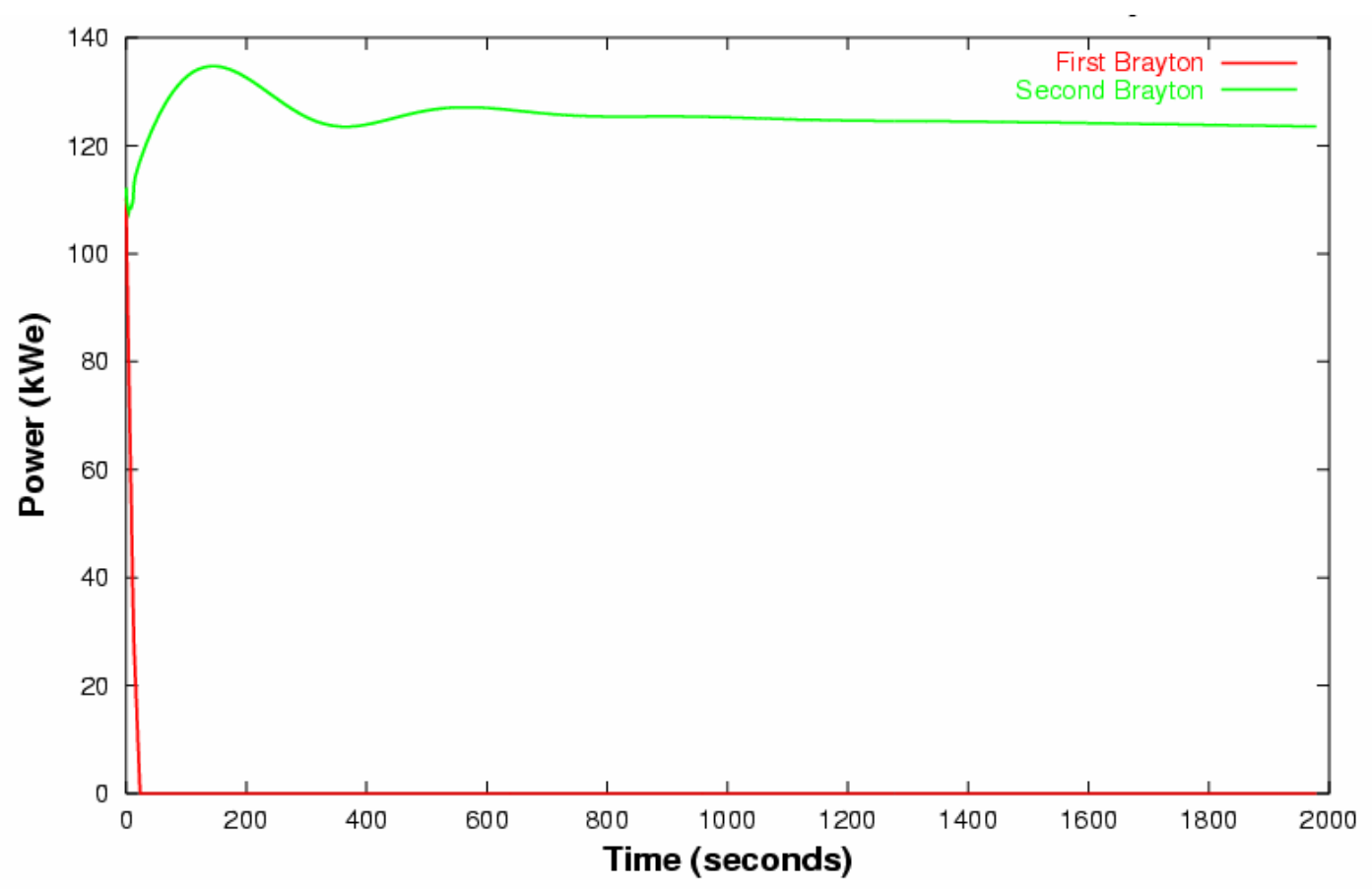

Figure 16. Shaft Speed Response during Start-up

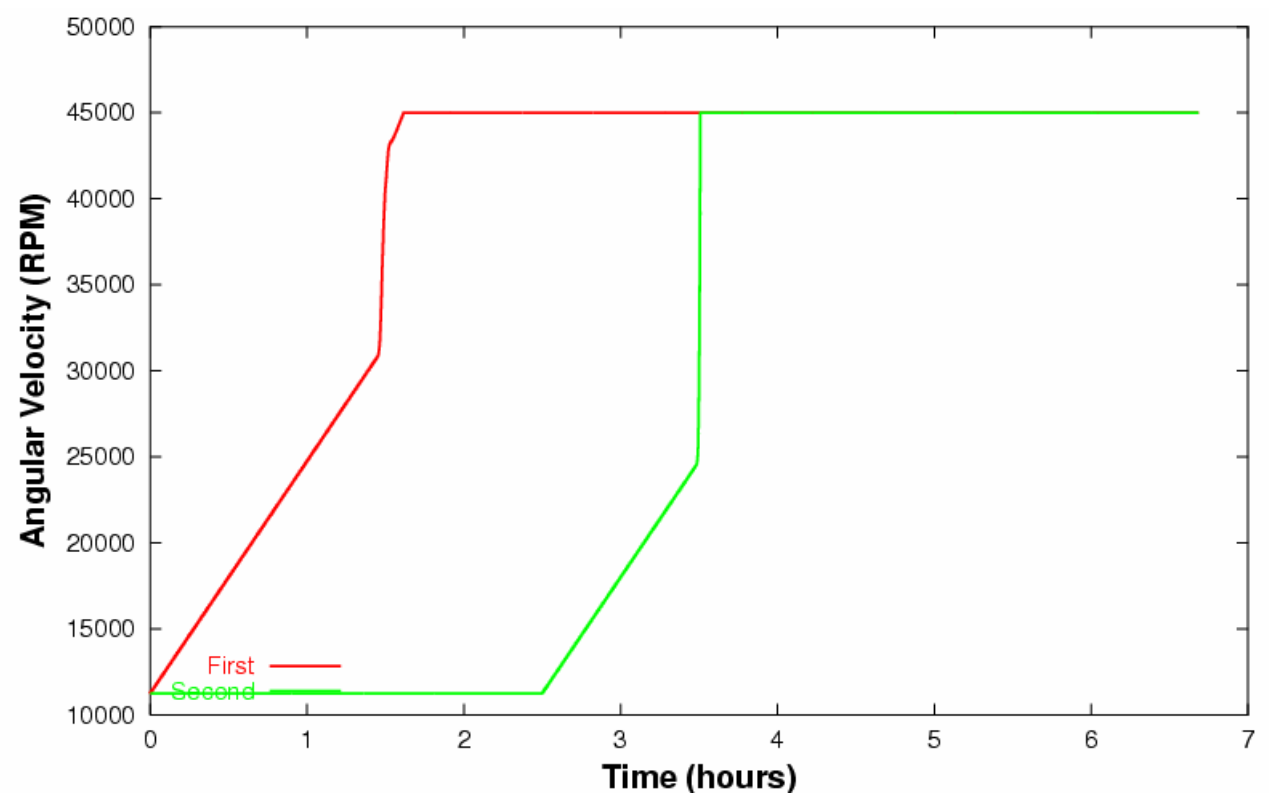


Figure 17. Loop Mass Flow Rates during Start-Up

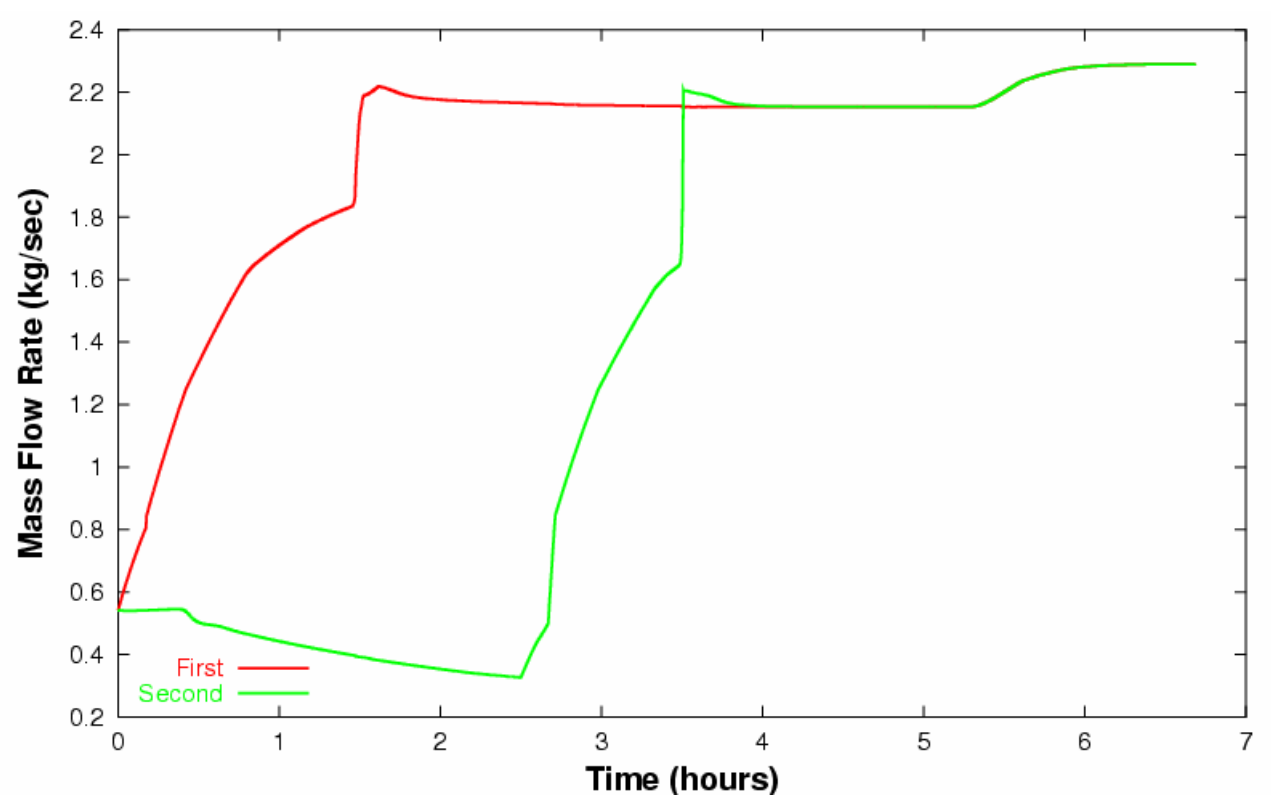

Figure 18. Reactor Power during Start-Up

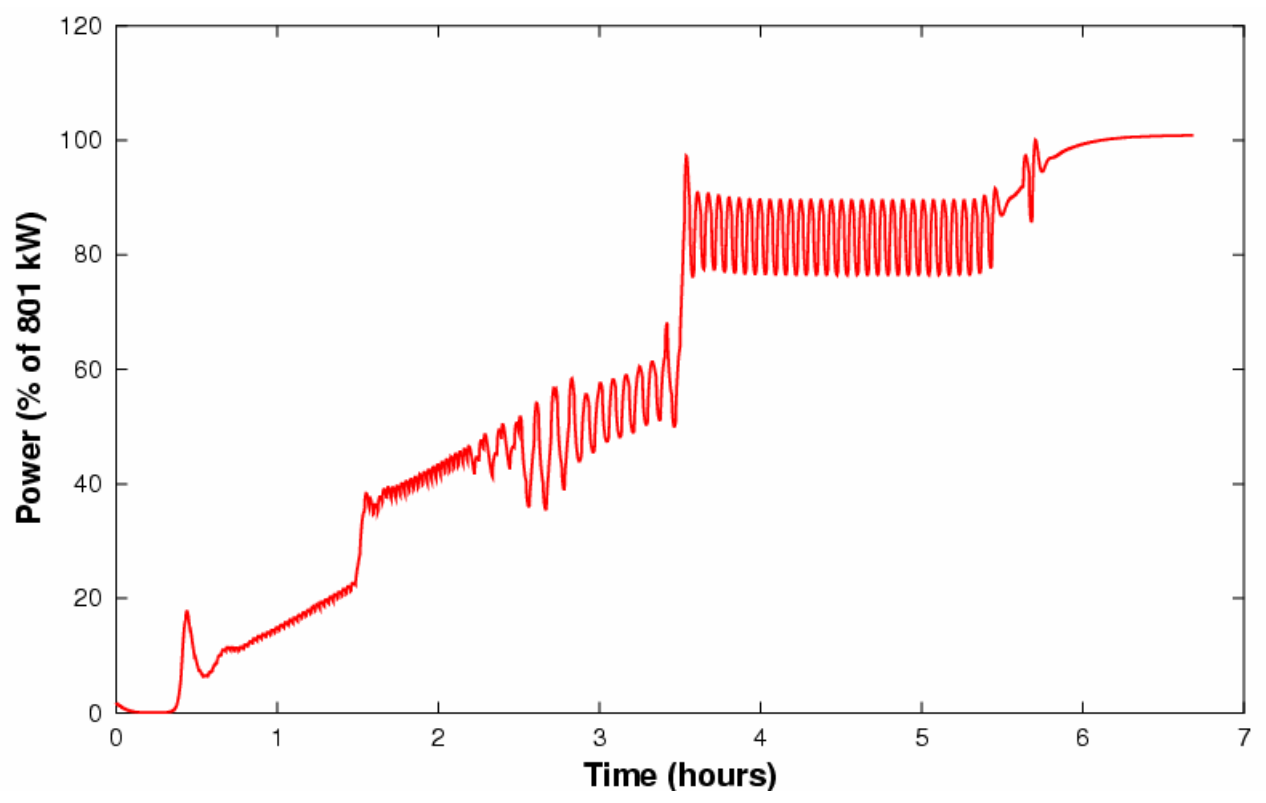


Figure 19. Reactor Temperatures during Start-Up

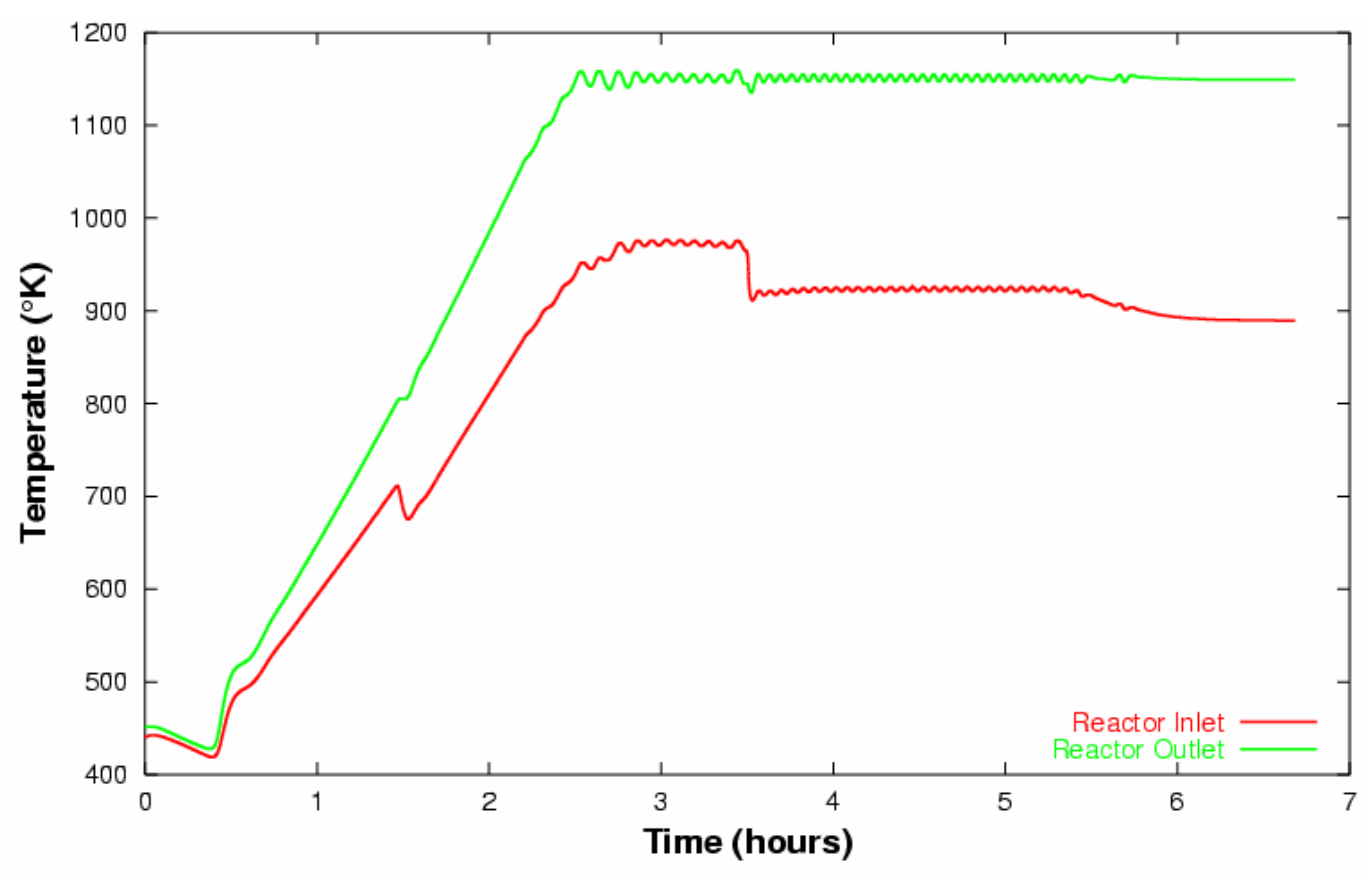

11:aosizas

Figure 20. First Brayton Loop Temperature Response during Start-Up

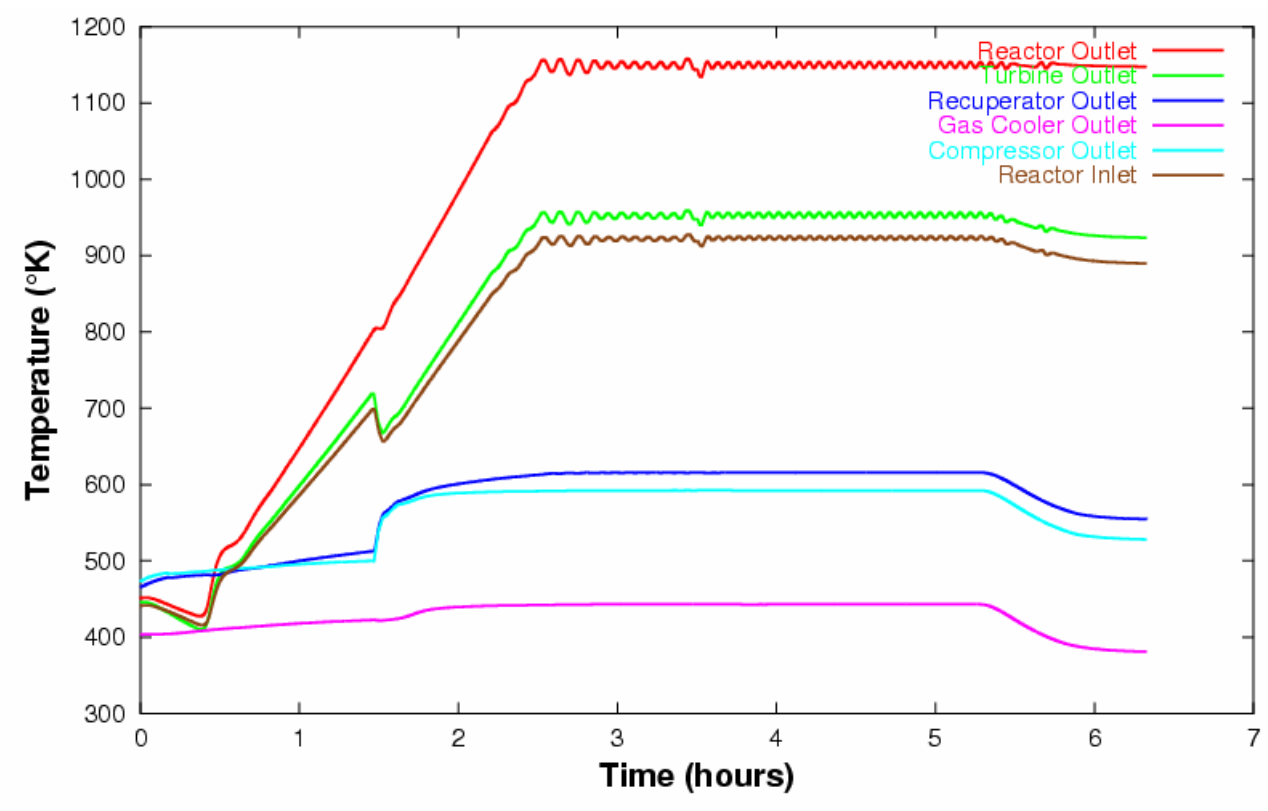

$112005 \times 26$ 
Figure 21. Second Brayton Loop Temperature Response during Start-Up

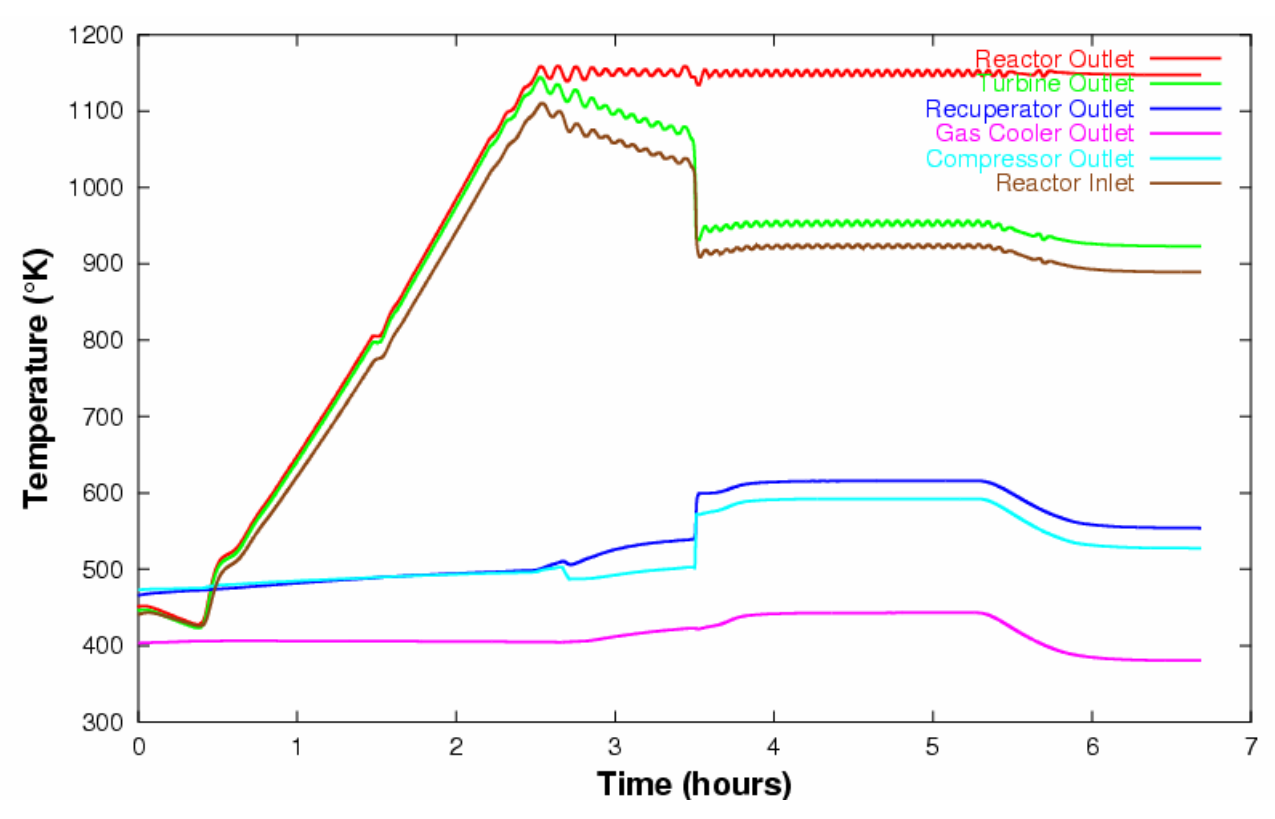

Figure 22. Electrical Loads during Start-Up

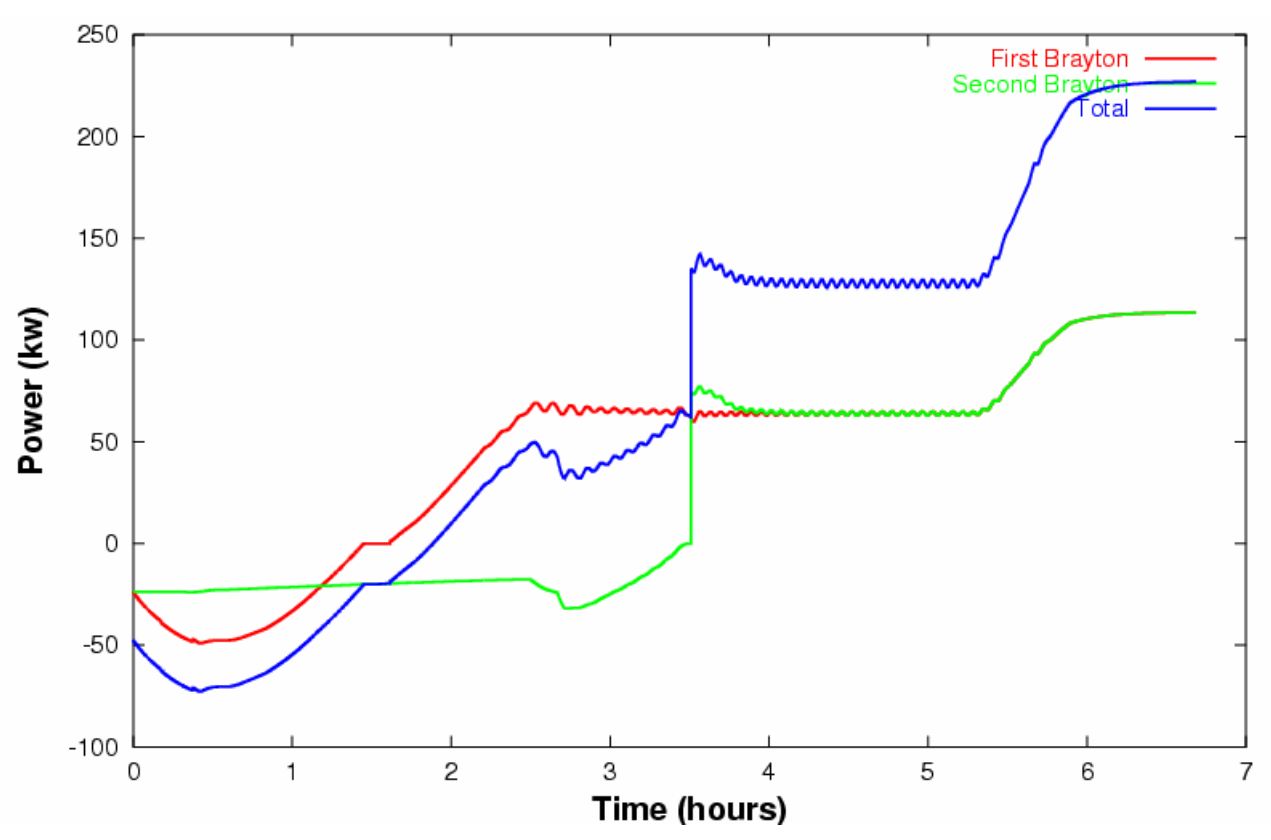


Enclosure 13 to

SPP-SEC-0039

\title{
Ex-Core CFD Analysis Results for the Prometheus Gas Reactor
}

\author{
Lorentz, D.G.
}


This page is intentionally blank.

PRE-DECISIONAL - For planning and discussion purposes only 


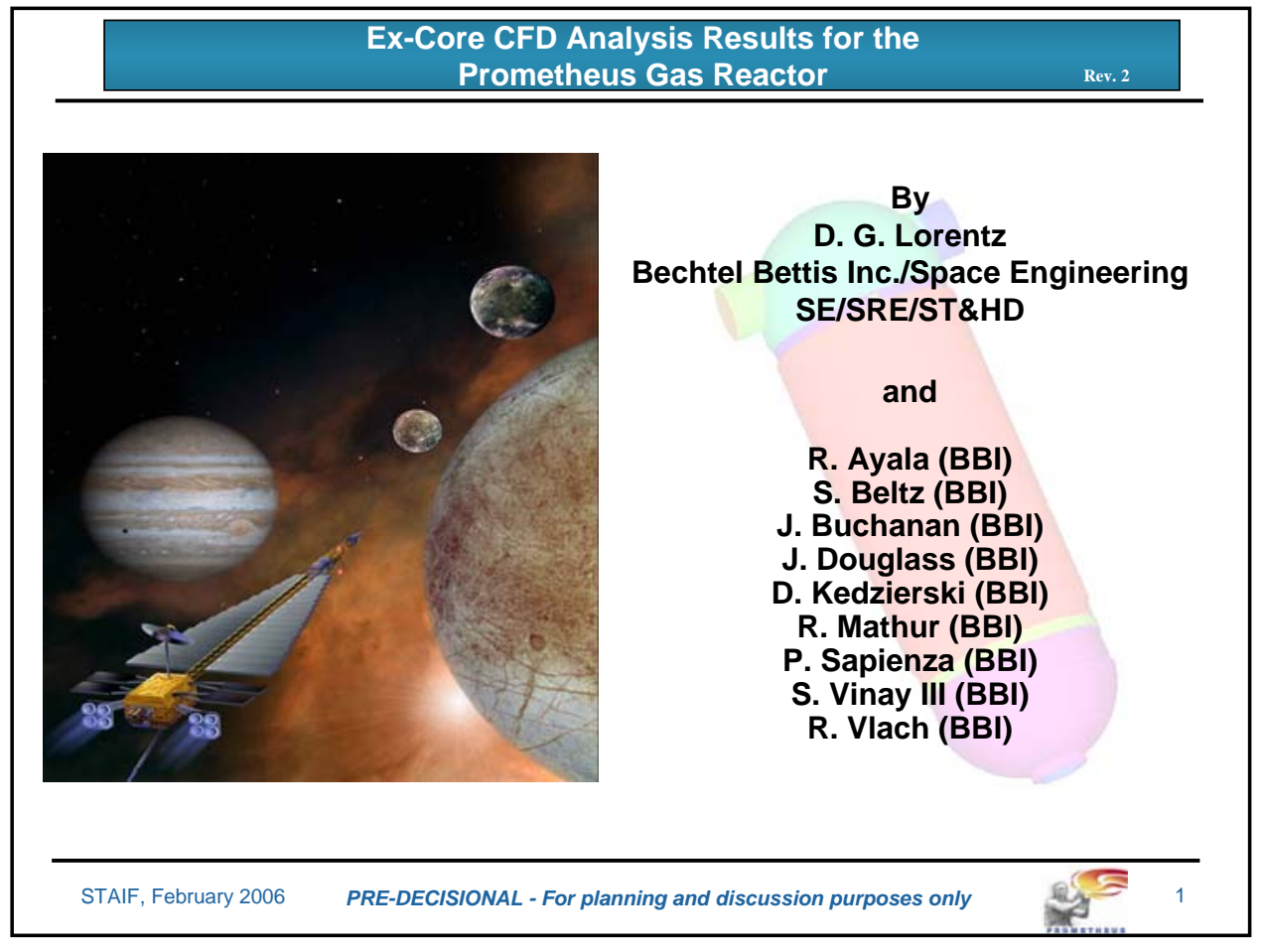

\section{CFD Progress Overview}

- Introductions \& Motivations

- Goals for Ex-core Analyses

- Modeling results

- Nozzle-to-nozzle Model

- Isothermal at $\mathrm{T}_{\text {ave }}\left(1050 \mathrm{~K}, \mathrm{P}_{\text {ave }}\right)$

- $w / 38.1 \mu \mathrm{m}$ in rough surfaces

- w/inlet velocity profiles

- Segmented models

- Upper discharge head model

- Lower plenum model

- Lessons, issues \& resolution

- Future plans

Nozzle-to-Nozzle Model

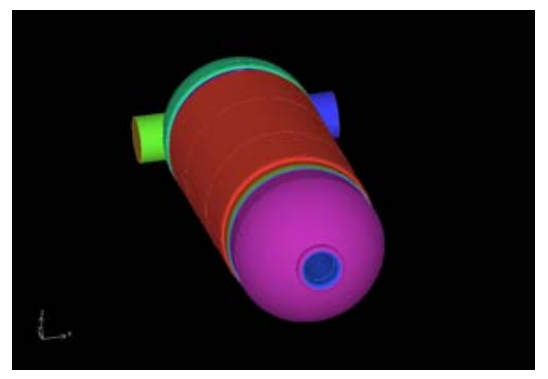




\section{A Design Cycle: Evolutions per Quarter?}

Will it properly interface with the balance of plant (BOP) design?

Will it meet shielding design requirements?

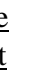

Manufacturability: can we make it?

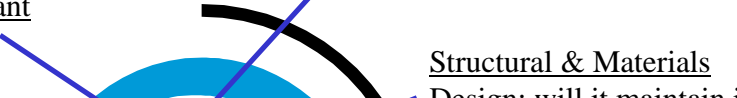
Design; will it maintain its structural integrity during service?

Will it meet the thermal/hydraulic design basis?

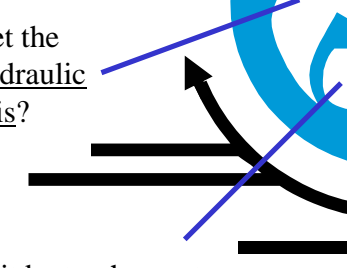

Will it be too heavy to send into orbit?

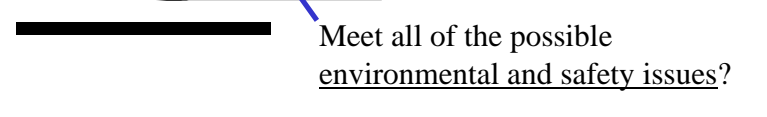

\section{I conclude...}

- There is much to be concerned about...

- In this presentation, I only want to address the issues related to the delivery of coolant to the core.

- And l'll explain what we have accomplished to date

- Where we were headed just prior to the time of project cancellation

- And some lessons learned for the next major reactor design project

- However, I was concerned about "keeping up" with the design cycle. 
- CFD, in general, refers to the science (or art) of using numerical methods to obtain a solution of the governing equations over a given flow field of interest.

- Fluid motion (flow) is governed by the three conservation laws:

- Conservation of mass,

- Momentum, and

- Energy.

- These laws are held together with an equation of state and appropriate constitutive relationships.

\section{OK, Just remember this...}

- A successful CFD analysis defines a flow field

- For a given set boundary conditions (BCs)

- For a particular geometry and

- The resolved flow field should address modeling criteria

- A flow field is defined by:

- Velocity and if non-isothermal, thermal gradients

- These gradients can be categorized (examples)

- Vortices

- Recirculation zones

- Levels of turbulence (laminar, transition, turbulent)

- A successful CFD analysis should be independent of grid size and configuration

- It should meet basic mass \& energy balances

- And it should meet basic mesh sizing issues "at the wall" 

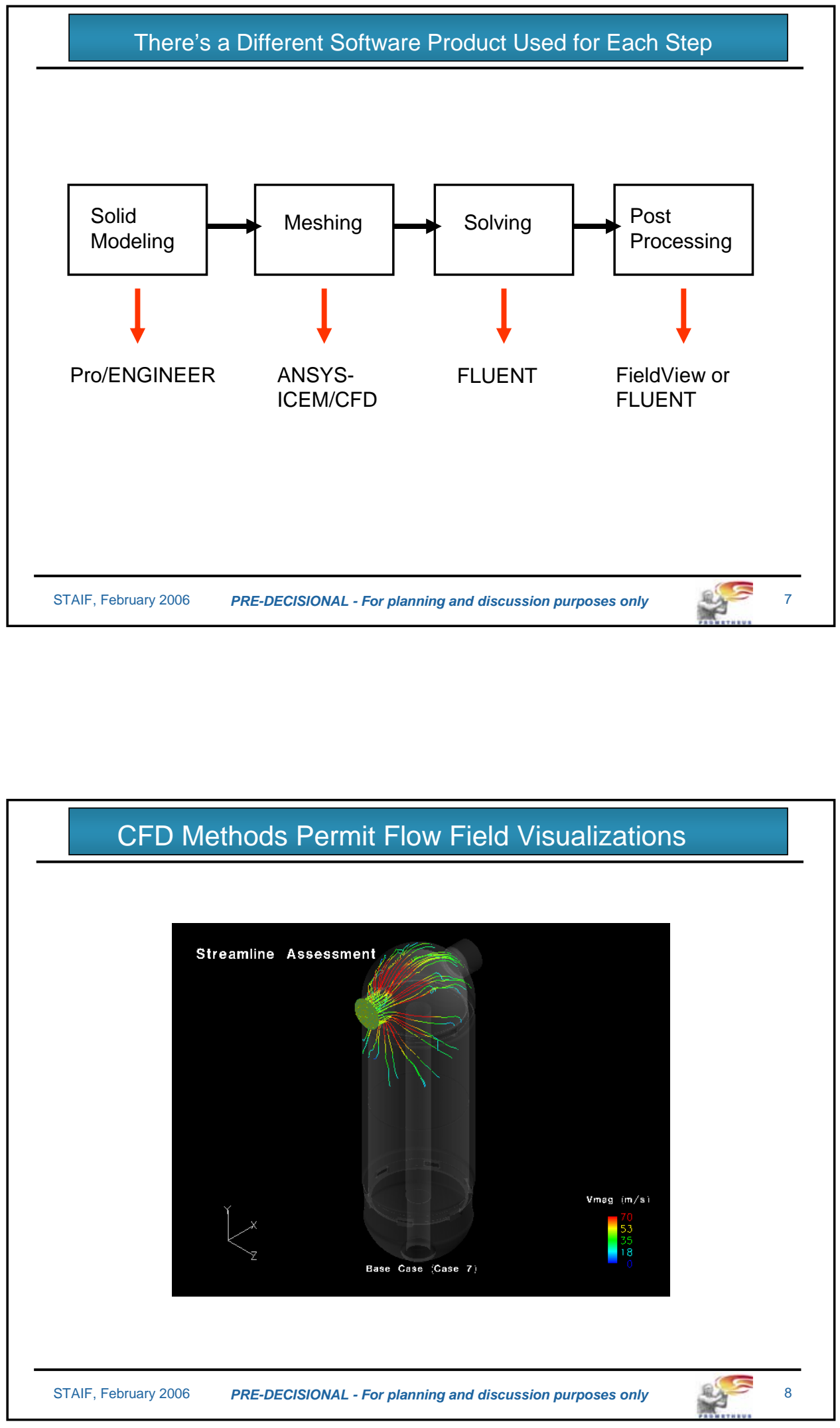


\section{References, Clarification, \& Definitions}

- "Downcomer" is defined as a flow path and a volume occupied between the reactor vessel's inside wall surface and the core wrapper's outer surface.

- And it is bounded by the reactor's upper and lower vents

- Porous volumes were used to mockup known (or assumed) resistance in the core. The core was modeled using 3 radial porous volumes.

- Modeled Cartesian Coordinate Orientation:

$-\quad+Y$ is pointed UP thru the centerline of the model.

$-\quad+X$ is pointed thru the centerline of the inlet nozzle.

- $\quad \mathrm{Y}^{+}$is a dimensionless variable used in the mesh sizing work to model the turbulence near-the-wall.

- A vortex is fluid flow rotating around a central axis (e.g., whirlpool or tornado).

- A vortex core is a locus of points where vorticity and velocity are aligned, that usually identifies the center of the vortex.

- Wetted surfaces are those surfaces in contact with the reactor coolant.

\section{Goals for Ex-core CFD Analysis Work}

- Minimize the pressure drop across the reactor vessel.

- Assess reactor vessel ability to deliver appropriate reactor coolant flow to the core inlet

- Appropriate is defined by:

- Desired mass flow

- Distributed in a defined manner

- Defined by our in-core designers

- Develop alternative methods for distributing flow to the core's inlet

- Address various analysis assumptions

- Surface roughness

- Inlet boundary conditions 


\section{Summary: Basic Design Issues Address}

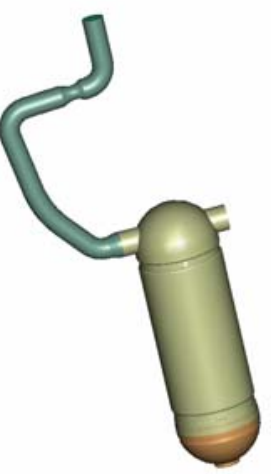

- Assess Overall Nozzle-tonozzle dP loss

- dP contributions from annuli

- Frictional loss contribution

- Upstream effects

- Assess Flow Maldistribution

- Identify \& quantify

- Downcomer (up-stream of reactor core inlet)

- At reactor core inlet

\section{Design Cycle Strategy}

- Use Nozzle-to-nozzle CFD model results to "feed" smaller models

- Use in developing boundary conditions for smaller models

- Develop smaller CFD models (segmented models)

- For use in assessing detailed models

- Design features can be quickly added or modified

- Re-meshed and solved

- Segmented models can be solved in a timely manner

- Solved in weeks, not months 


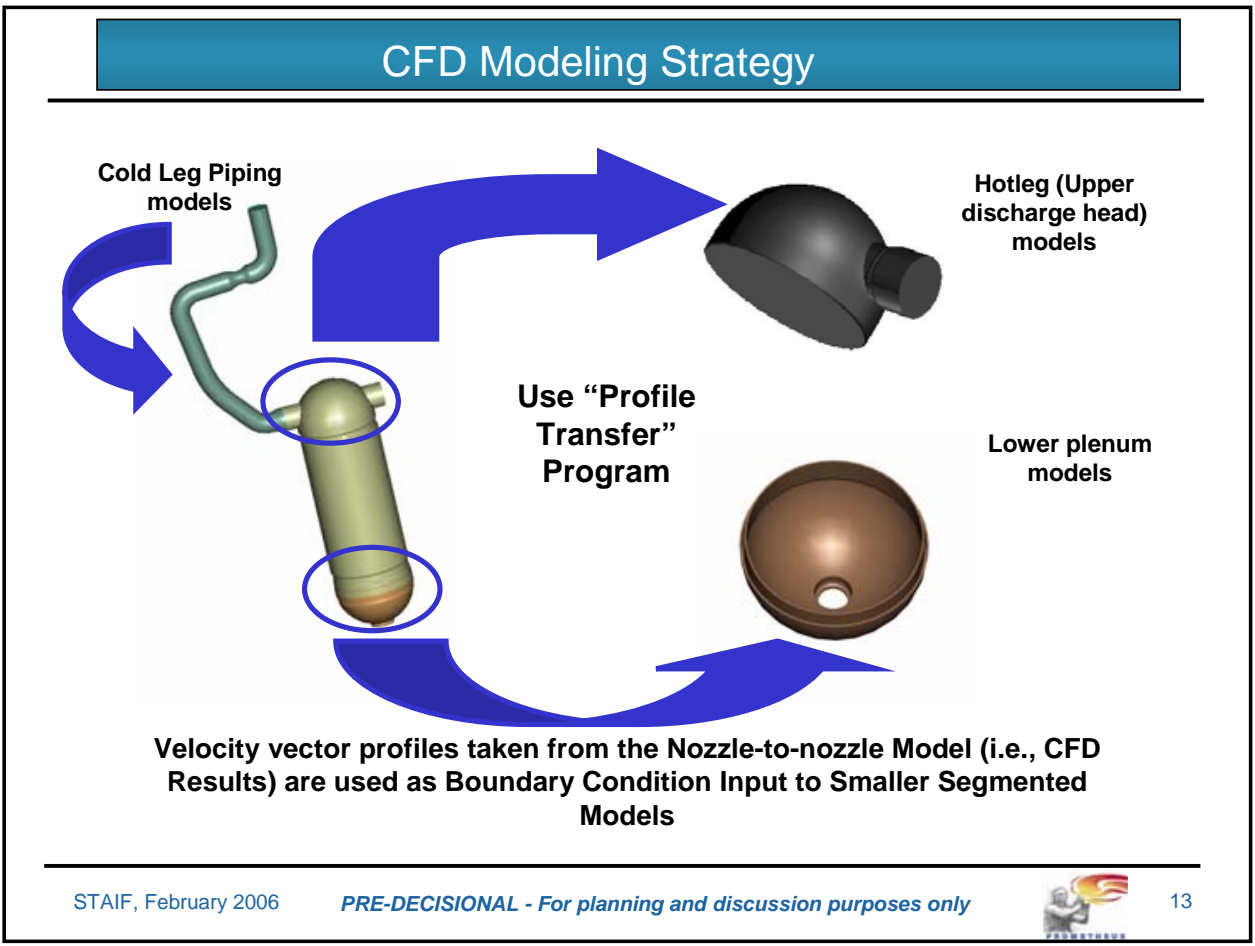

\section{Work started in March 2005}

- Using the 3/2005 Space Core Mechanical Design's reactor design

- Model featured

- Opposing $17.78 \mathrm{~cm}$ ID inlet \& outlet nozzles

- A vessel design that attempted to maintain vessel interior wall temperatures at roughly $\mathrm{T}_{\text {cold }}(880 \mathrm{~K})$

- 3 upper annulus vents \& 6 lower annulus vents

- Upper \& lower hemispherical heads

- Inner discharge hemispherical head

- Block reactor core design

- Model assessed at $7.12 \mathrm{~kg} / \mathrm{s}(1 \mathrm{MW})$

- Equates to $44.05 \mathrm{~m} / \mathrm{s}$ uniform inlet velocity at $T_{\text {ave }}$

- Assumed 0.7177/0.2823 He/Xe mole fraction $\rightarrow 39.94 \mathrm{~g} / \mathrm{mole}$ 


\section{Technical Approach for Designing Nozzle-to-nozzle Mesh}

- Divided model into 7 material zones

- 4 ex-core material zones

- 3 porous material zones for the core

- Technical basis for He/Xe gas properties

- NASA/Glenn's CEA2 (chemical equilibrium with applications) data base (Ref. 1)

- Available off of their web site

- Data supports our range of T, P conditions

- For isothermal conditions, used only density \& viscosity data

- Other thermodynamic and transport properties are available

- Interrogated 3/2005 design for flow areas \& wetted perimeters

- Provided $D_{h}$ for the various regions

- And noted turbulent conditions in all ex-core material zones

- Computer usage: initially 8 processors, now 16 on FY05 LINUX cluster

- Solved using $\mathrm{k}-\varepsilon$ solver using standard wall function

- Elected to a use tetrahedral and prism hybrid meshing method

Ref. 1 - CEA manuals NASA RP-1311 Part I, 1994, and NASA RP-1311 Part II, 1996.

\section{Modeling basics}

- Surface reference terminology:

- Inlet = reactor vessel inlet nozzle

- Upper vents (3 vents)

- Lower vents (6 vents)

- Reactor core inlets 1, 2 \& 3

- Reactor core outlets 1,2 \& 3

- Outlet $=$ reactor vessel outlet nozzle
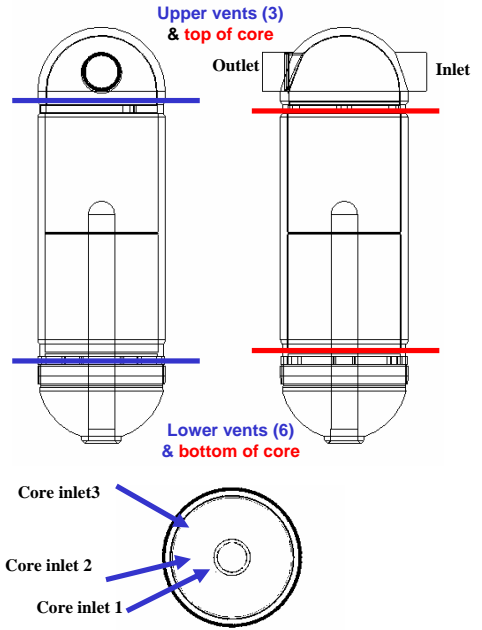


\section{Views of Upper Vents}

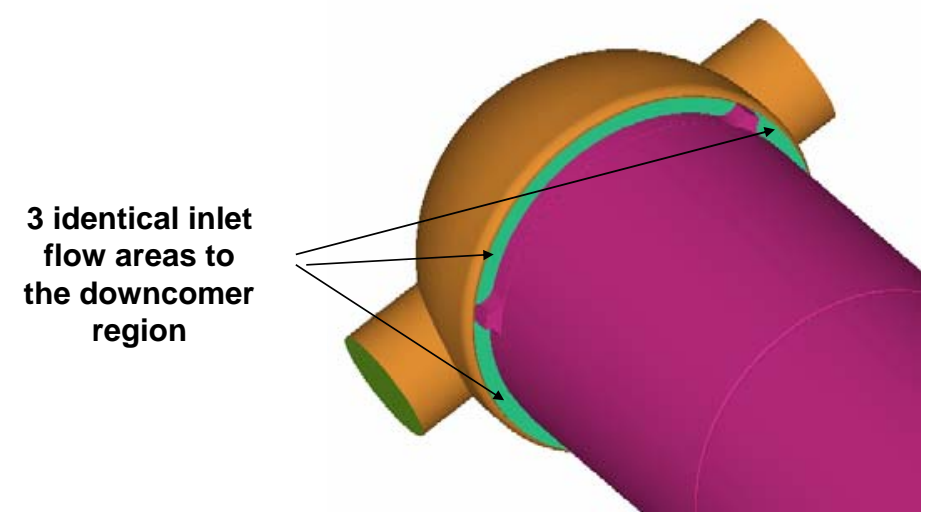

Alpha version of Rx Model circa 3/05

\section{View of Lower 6 Vents}

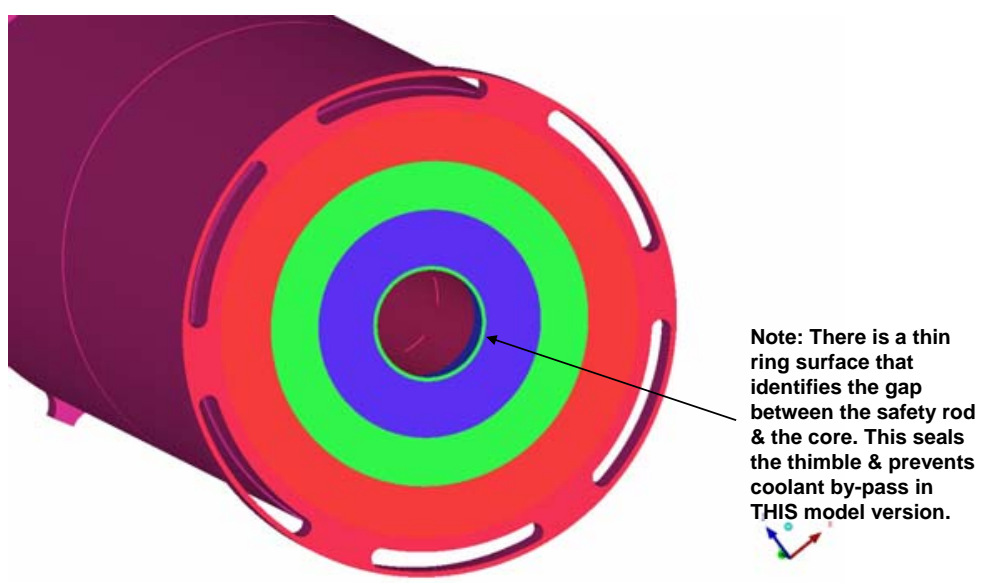

Alpha version of Rx Model circa 3/05 


\section{Modeling basics (continued)}

- Reactor vessel Nozzle-to-nozzle volume divided into 7 zones

- "mat u" = volume includes nozzle \& annular space between the upper hemispheres

- "mat_a" = the downcomer volume

- "mat_l" = lower hemisphere volume

- "mat c1, c2 \& c3" = the 3 inner to outer concentric radiaT core regions

- "mat d" = the core discharge volume that includes the hemisphere above the core plus the outlet nozzle

- Segmented Models

- Cold leg model $\left(880 \mathrm{~K}, \mathrm{P}_{\text {ave }}\right)$

- Mat_a

- Mat u

- Mat I

- Hot leg models $\left(1150 \mathrm{~K}, \mathrm{P}_{\text {ave }}\right)$

- Mat_d

- Lower plenum model $\left(1015 \mathrm{~K}, \mathrm{P}_{\mathrm{ave}}\right)$

- Mat_I

- Preliminary Coldleg Piping (1015 K, $\left.\mathrm{P}_{\text {ave }}\right)$

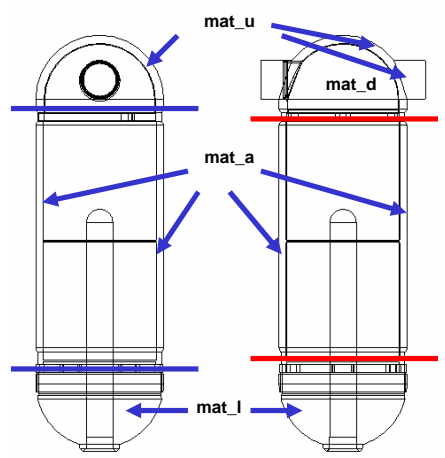

\section{CFD Nozzle-to-nozzle Model Validation}

- Define adequate mesh density in the model ( $12 \mathrm{M}$ cells)

- Meet basic mass balance requirement (<1E-04 kg/s)

- Meet $\mathrm{Y}^{+}$goal (30 to 300) for wetted surfaces for $k-\varepsilon$ solver (ave. $\mathrm{Y}^{+} \sim 63$ )

- Establish core's porous volume dP $(\sim 1.6$ psid $)$ 
- Isothermal conditions (fluid material properties) at $\mathrm{T}_{\text {ave }}$

- Smooth surfaces

- 3 radial core zones

- Uniform velocity profile at the reactor's nozzle inlet

- Expect this: we'll be reminded of "what happens upstream impacts downstream performance"

- = Base Case

\section{Cases Completed - To Date}

\begin{tabular}{|l|c|c|c|}
\hline & Case \# & Roughness & Inlet Nozzle BC \\
\hline "Base Case" & 7 & Smooth & Uniform \\
\hline $38.1 \mu$ m Case & 8 & Rough & Uniform \\
\hline Experimental CL Pipe & 9 & Smooth & Non-Uniform \\
\hline 6" CL Pipe & 10 & Smooth & Non-Uniform \\
\hline 8" CL pipe & 11 & Smooth & Non-Uniform \\
\hline
\end{tabular}




\section{CFD Case Study Results Summary}

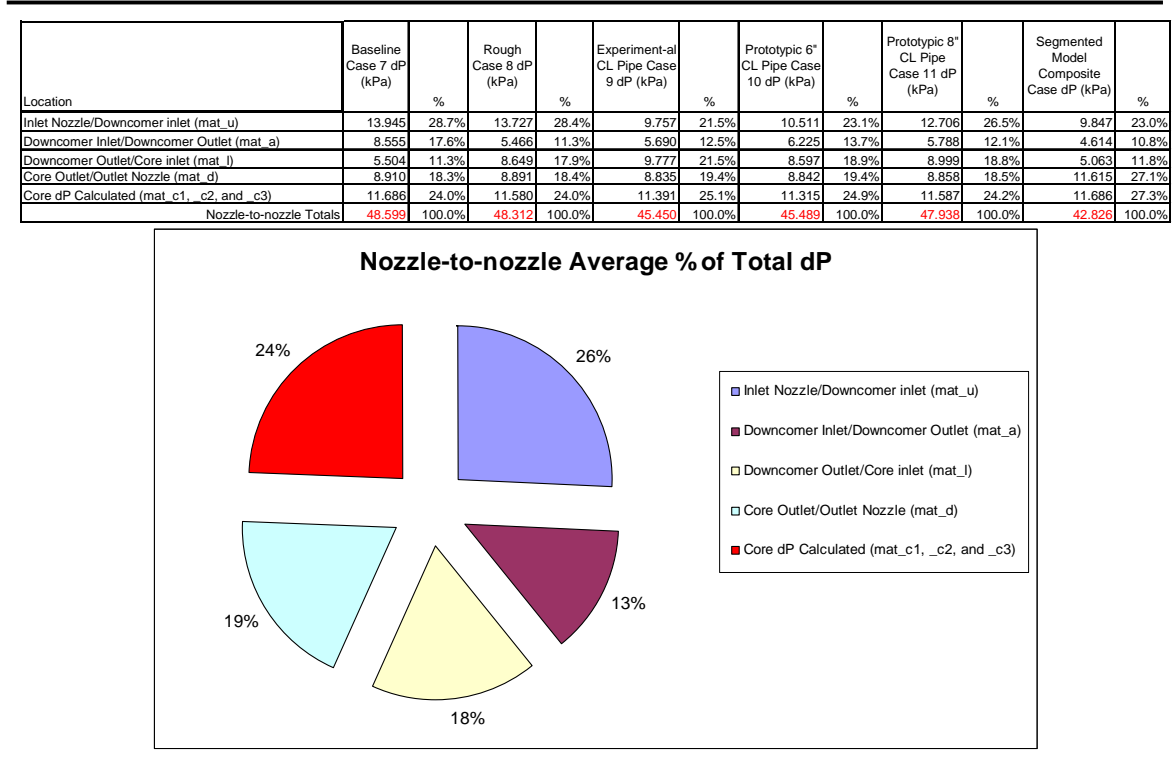

\section{Things to Remember from "Summary Slide"}

1. Nozzle-to-nozzle models consistently predicted dP between 42.82 to $48.60 \mathrm{kPa}$

2. Composite segmented model case predicted lowest $\mathrm{dP}$

- Added dP from a coldleg \& hotleg models

- Did not utilize velocity profile BC information

- Instead shared average mass flow input

- Segmented models OK for predicting detailed behavior

- But could loose big-picture accuracies

- Improvements to comparability should be expected when velocity profile are transferred as BCs

3. The "devil-is-in-the-details"

- Additional review of post-processing results reveal more about the numbers 


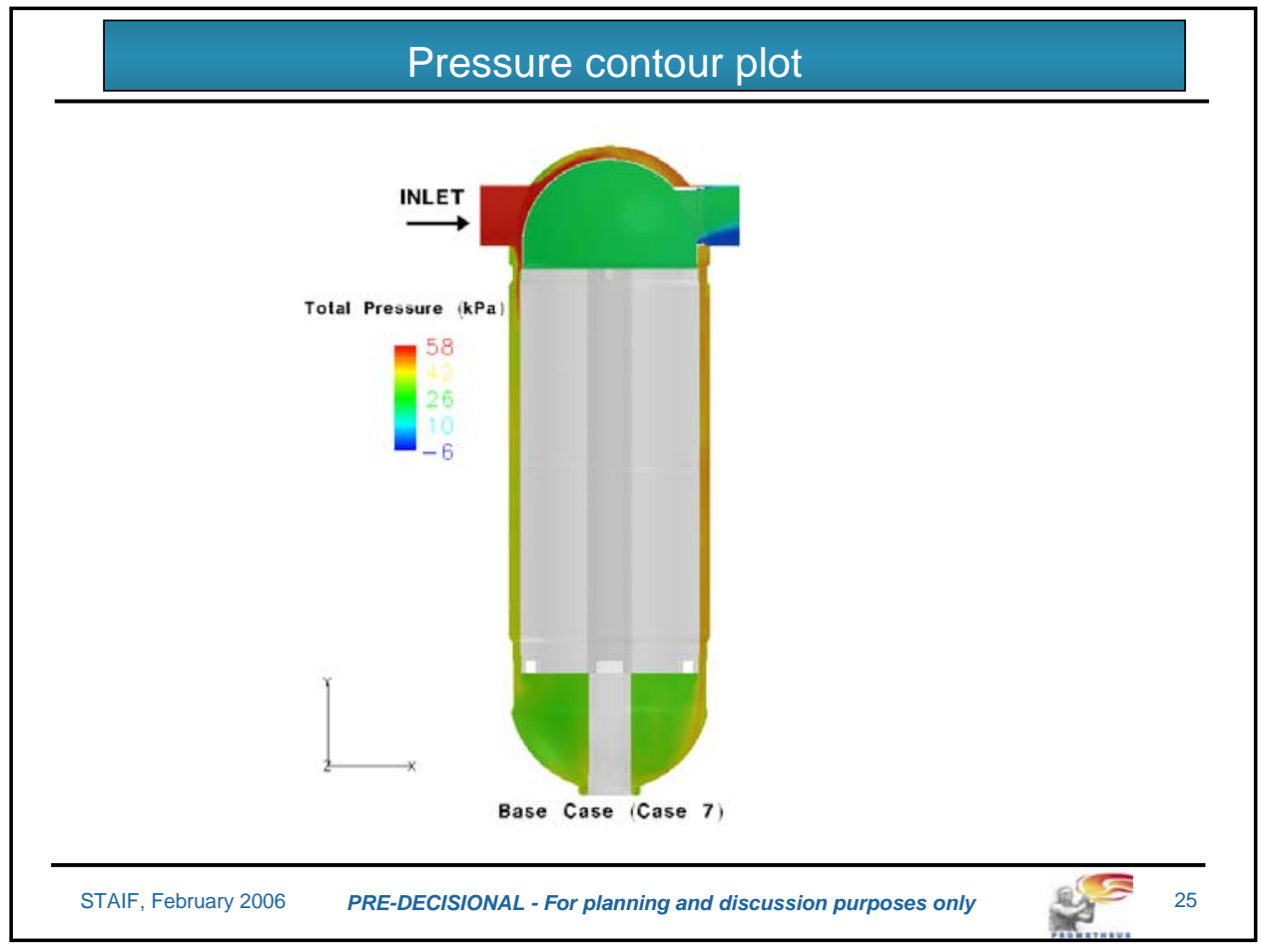

Streamlines Illustrate The Overall Flow Path

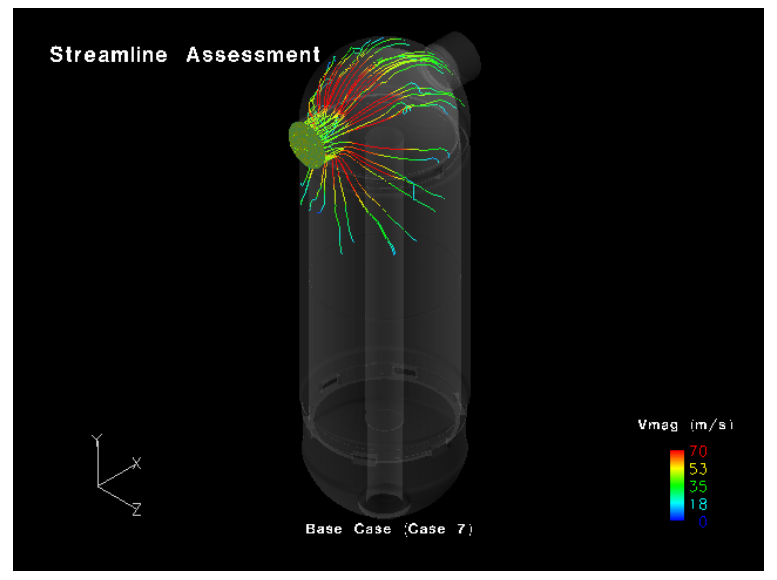




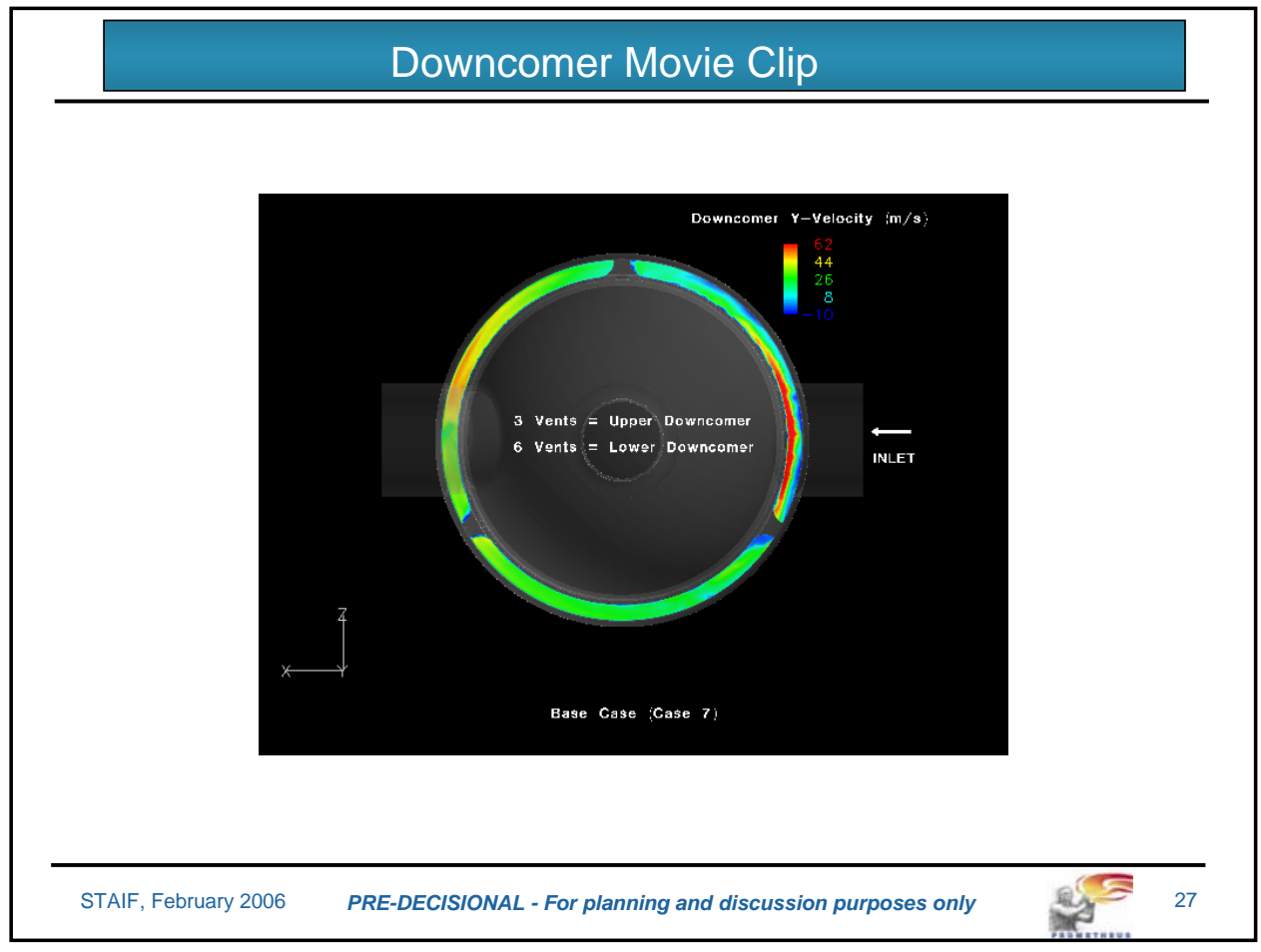

\section{Isometric View of Downcomer}

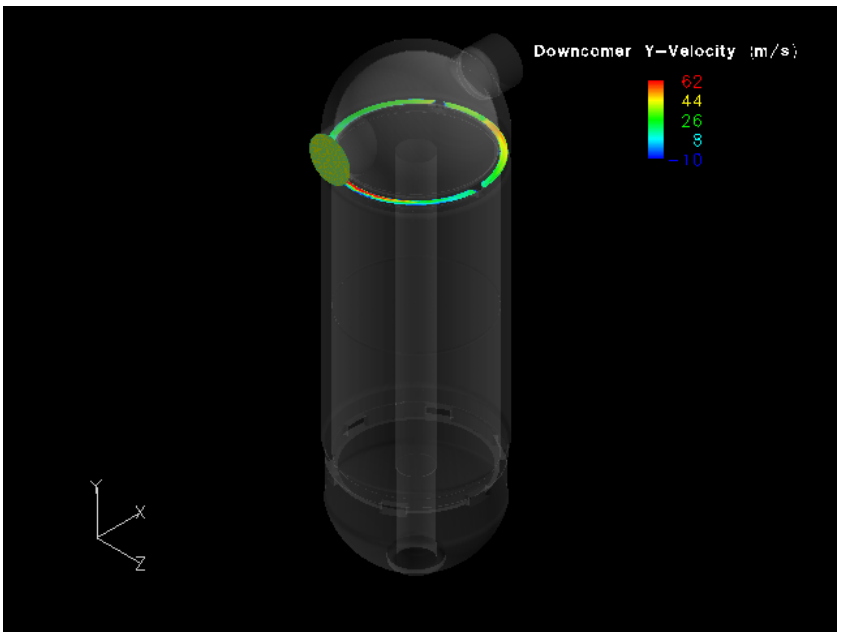



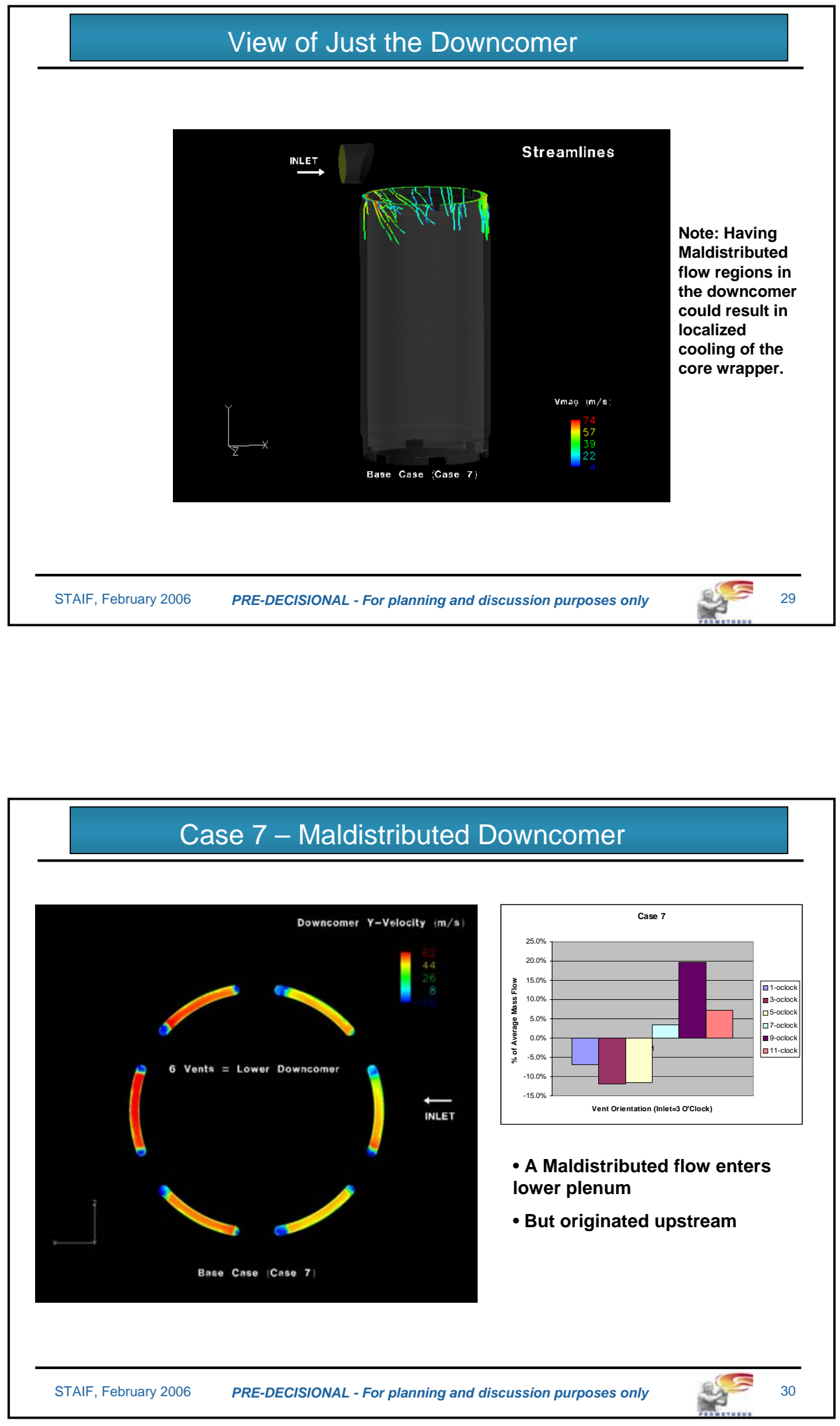


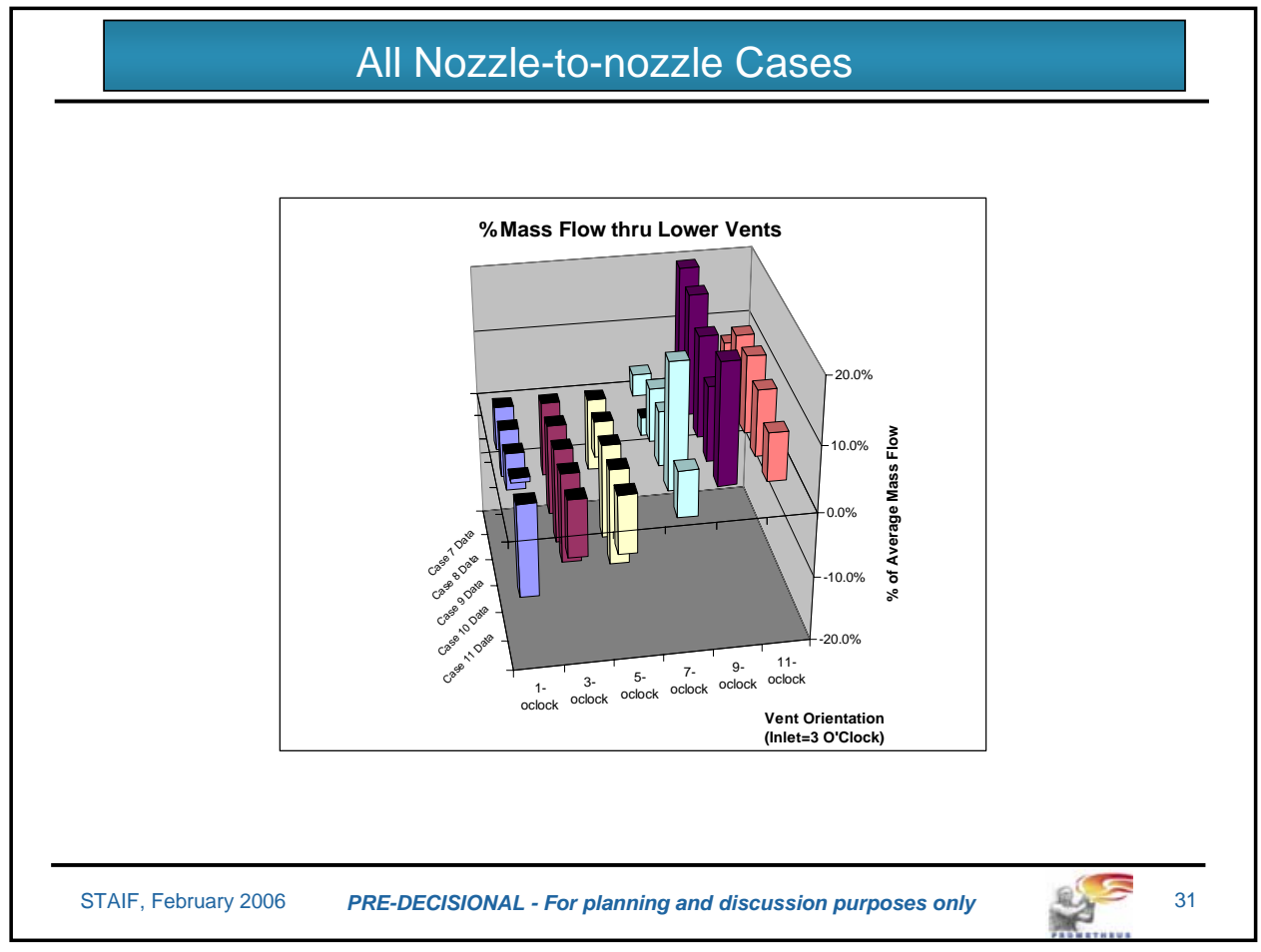

Focus on the Lower Plenum

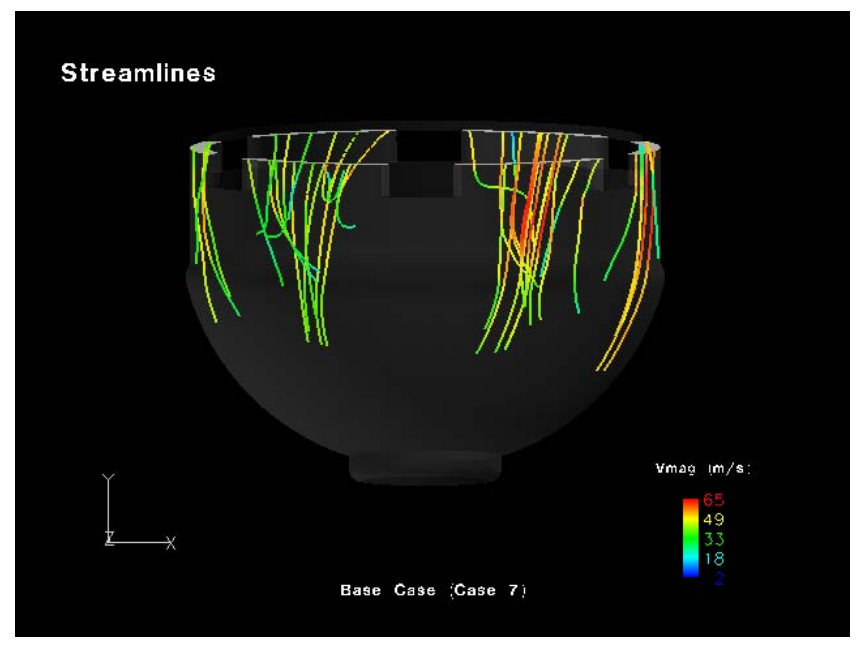



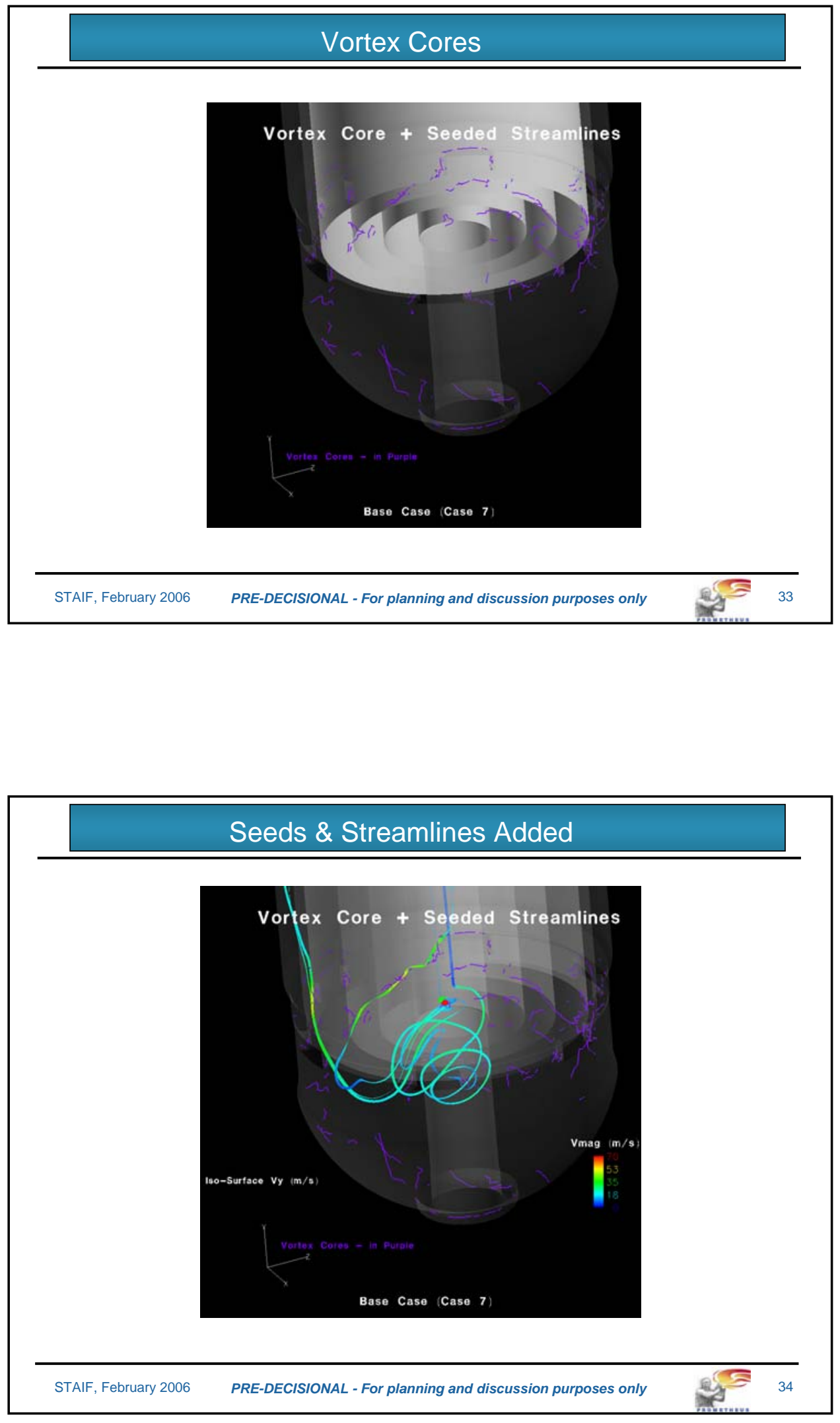

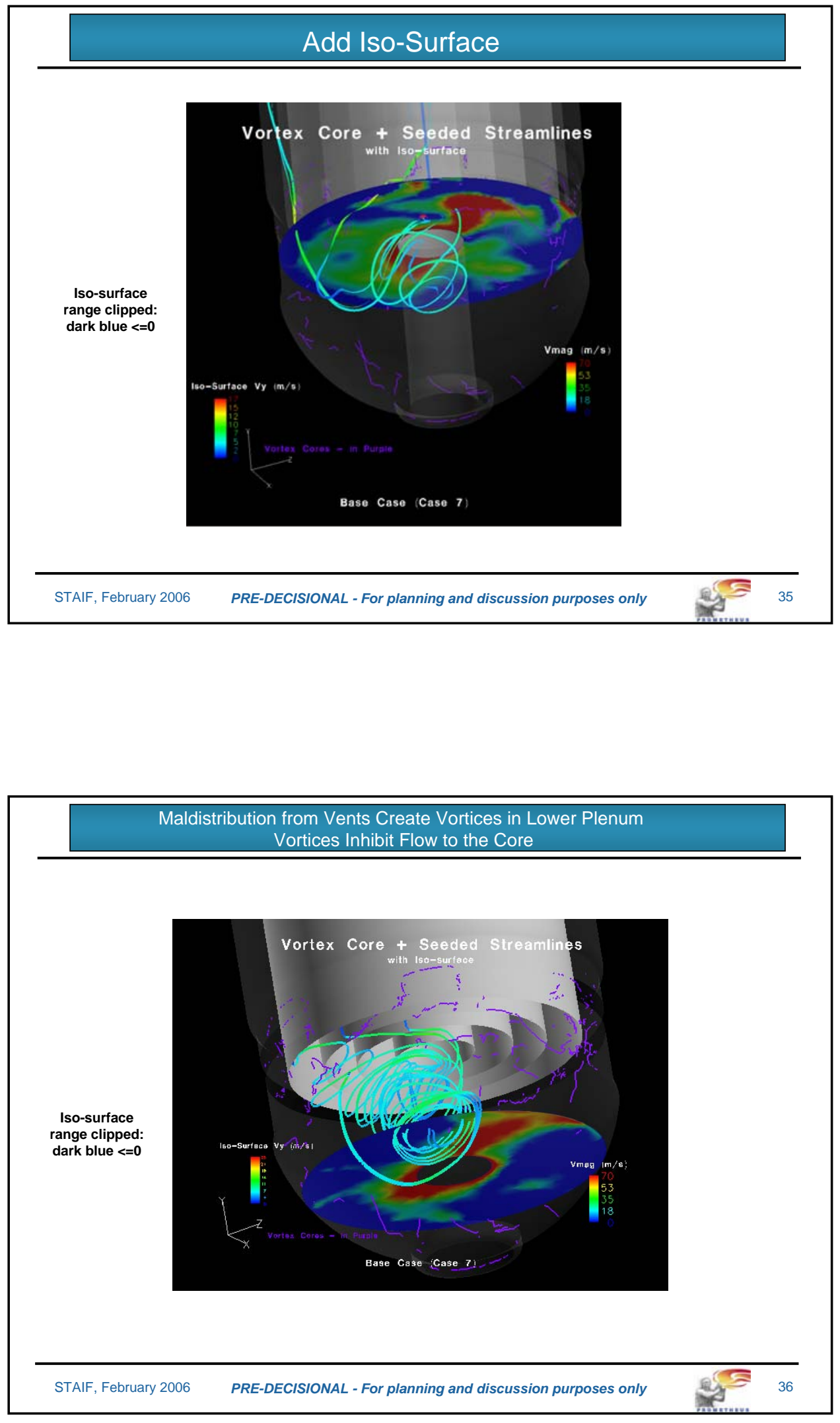

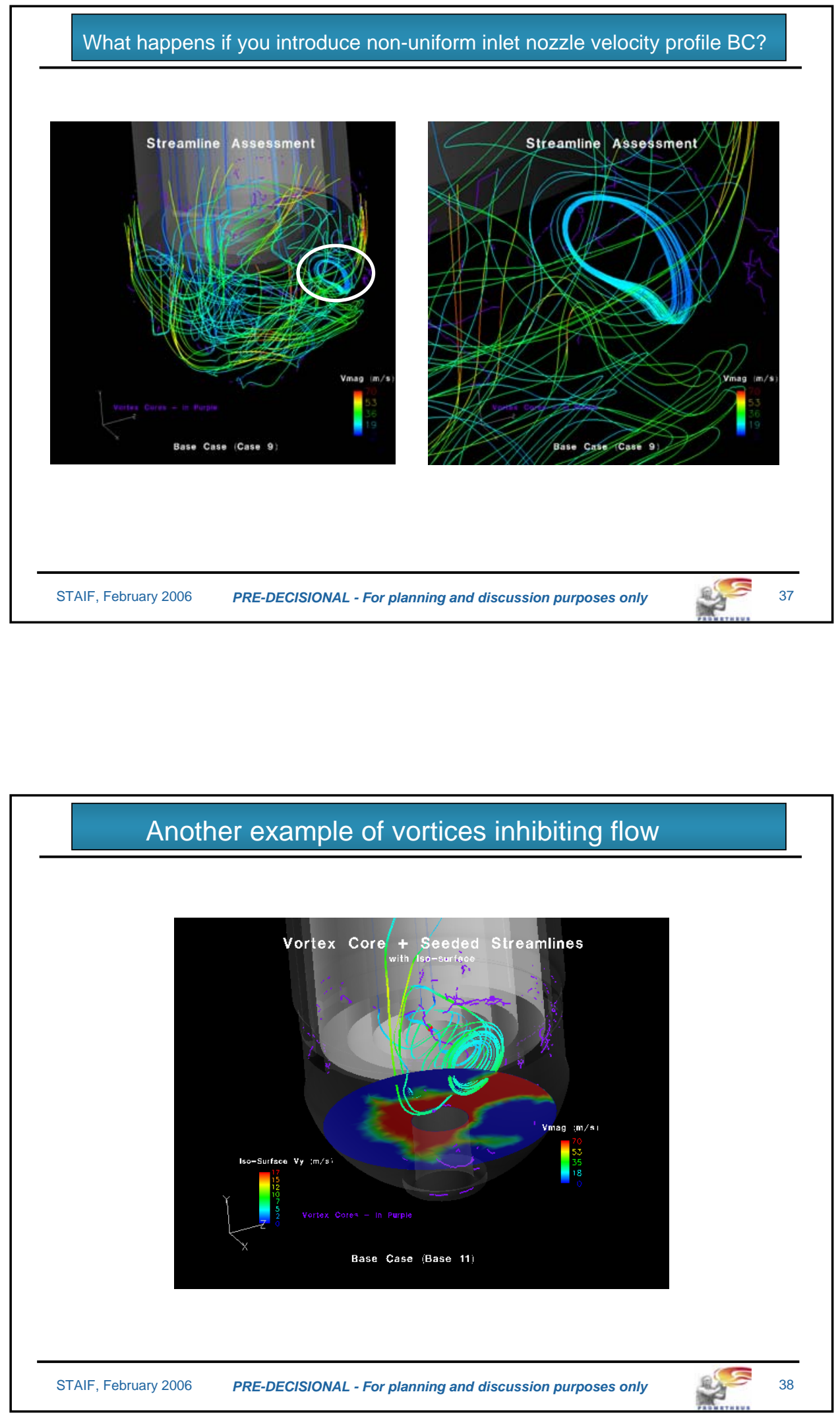


\section{Core Inlet Flow Profile}

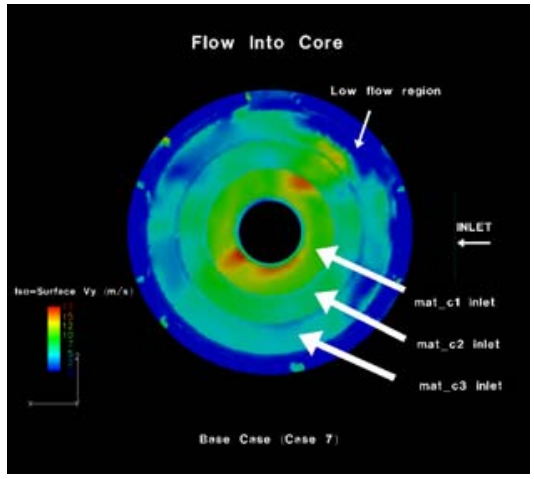

As Calculated Core Inlet Distribution Nearly Inverted

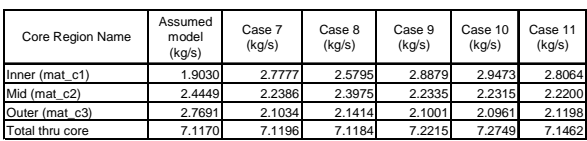

- "Assumed" modeled flow distribution to the core was nearly inverted to that of as calculated distribution using Nozzle-tonozzle models

Less flow to the outer core region

- Strongly reinforces plans to perform reacto vessel air test program

- Also reinforces CFD modeling plans to assess different flow re-distribution concepts

\section{Pressure \& $V_{y}$ Plots of Core Inlet Compared}
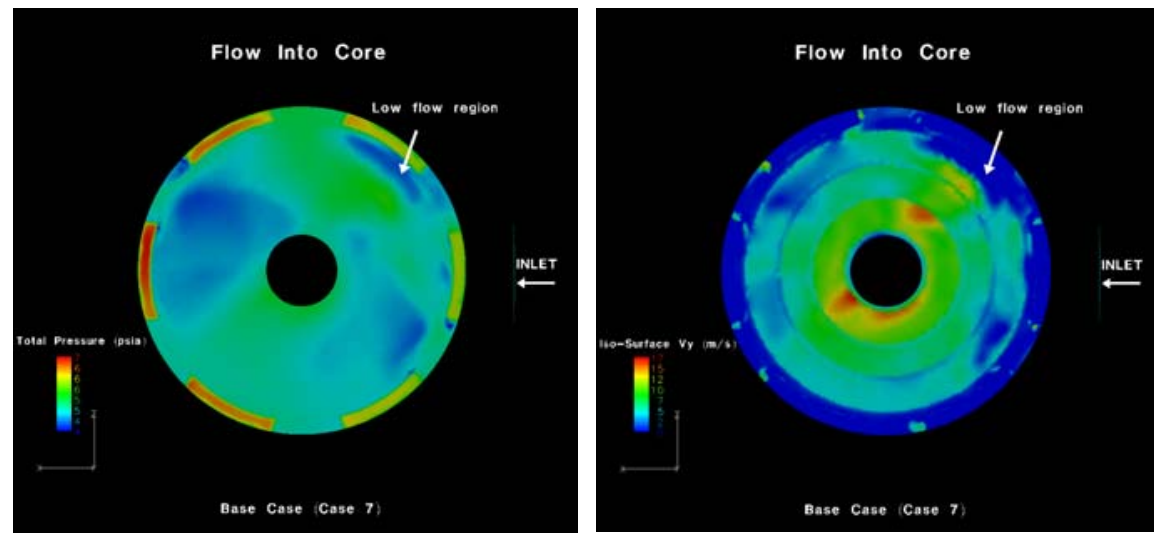

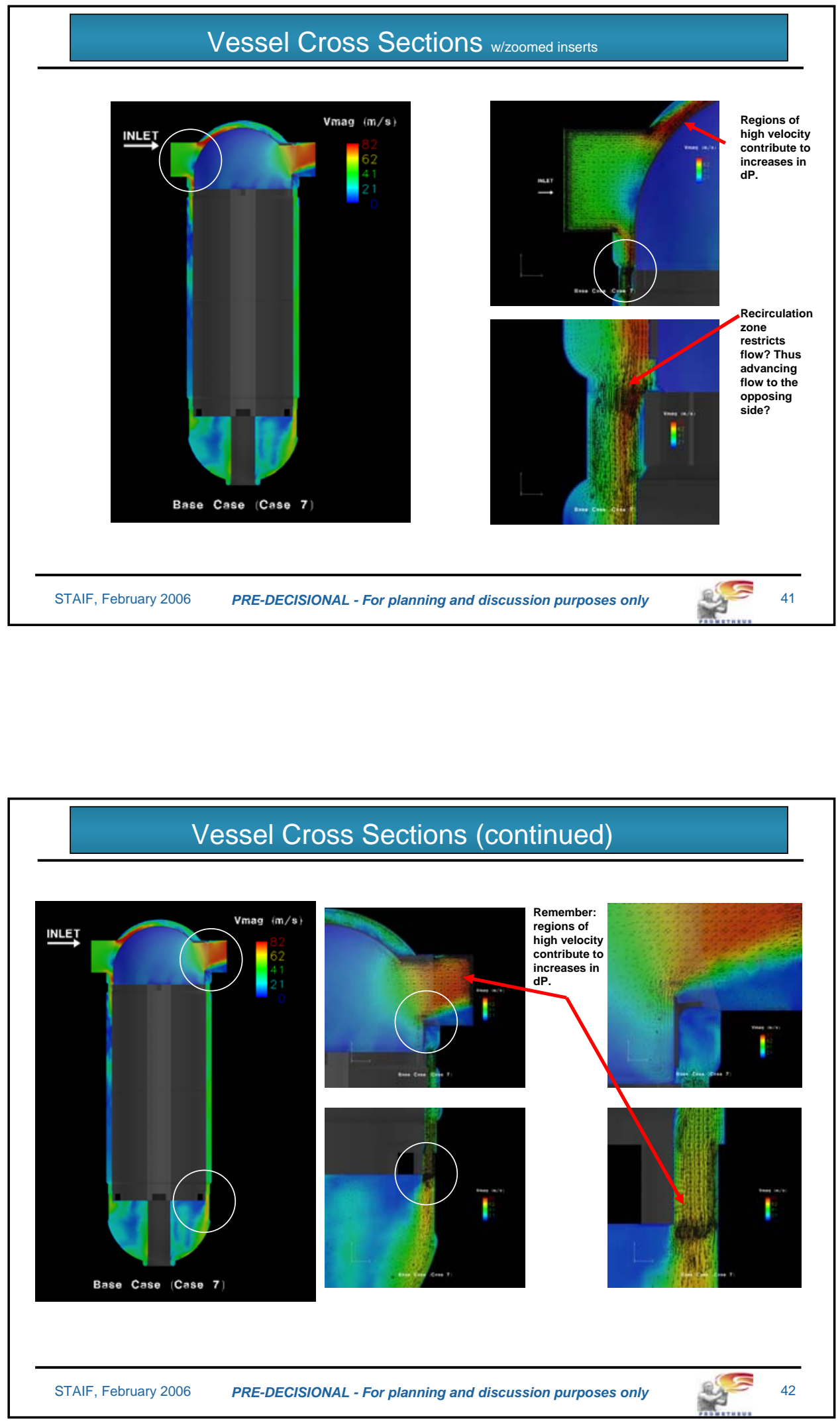


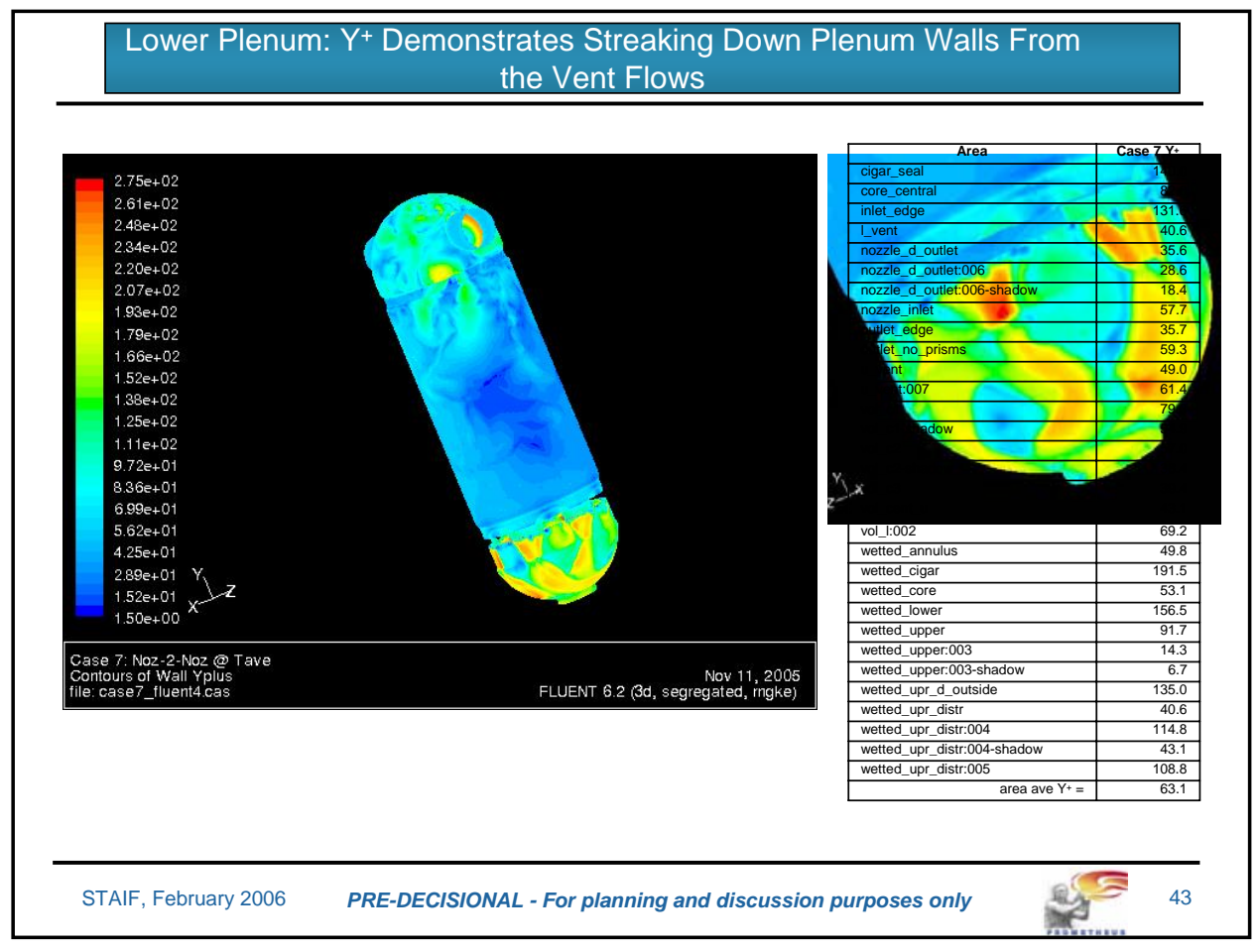

Shear Stress At The Wall Shows The Same Thing

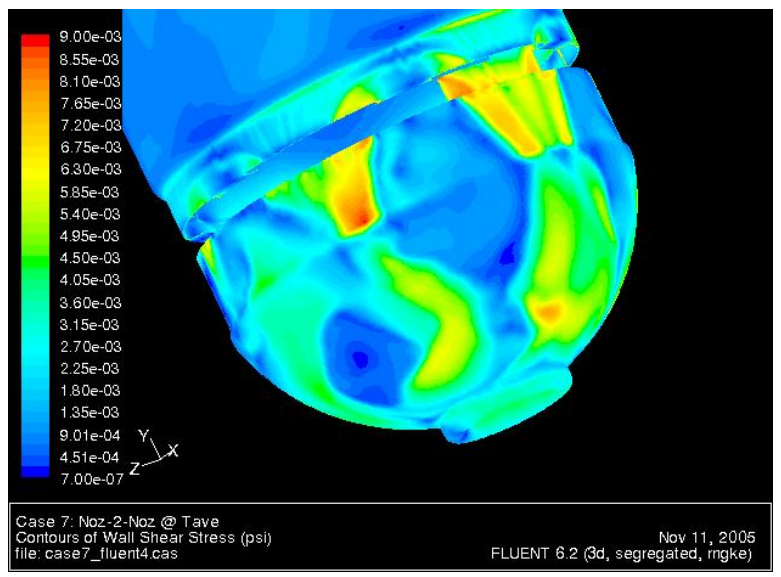




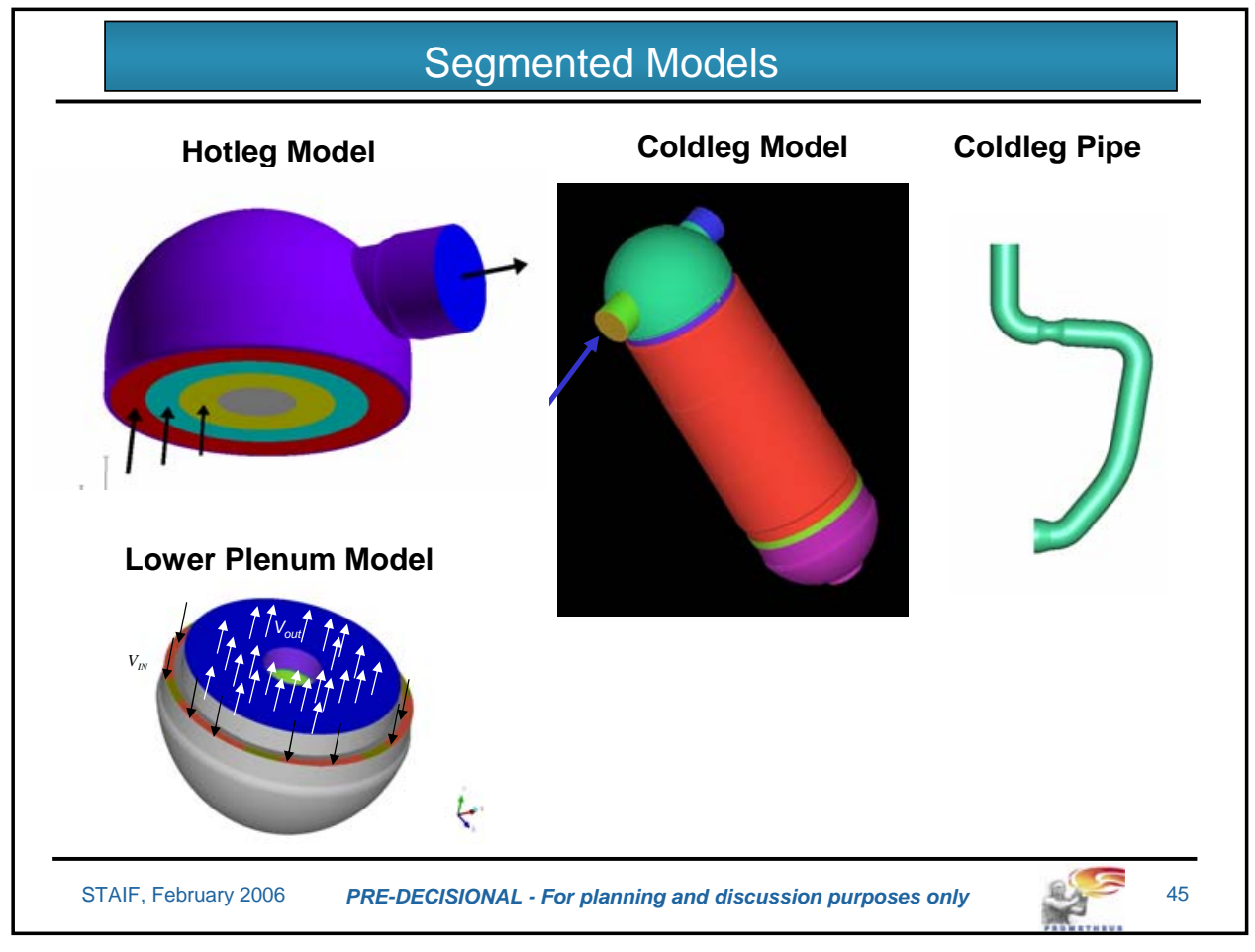

\section{Lower Plenum Segmented Models (R. Vlach)}

- Modeled the flow distribution in the lower plenum region

- Main interest was to assess flow distribution entering the core

- Method used: import Inlet BCs from the Nozzle-to-nozzle model

- As an inlet velocity BC

- Compare to a perfectly distributed flow to the lower plenum

- Assess different flow re-distribution concepts

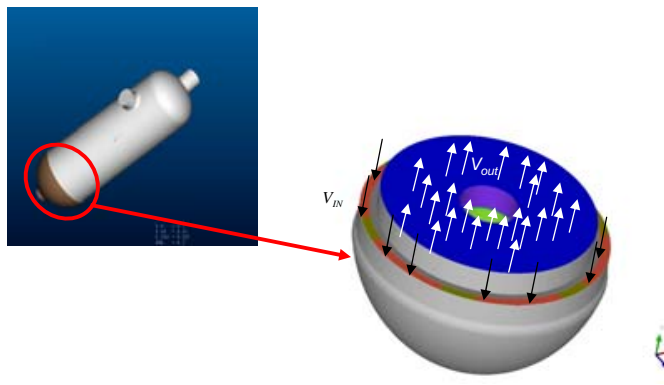



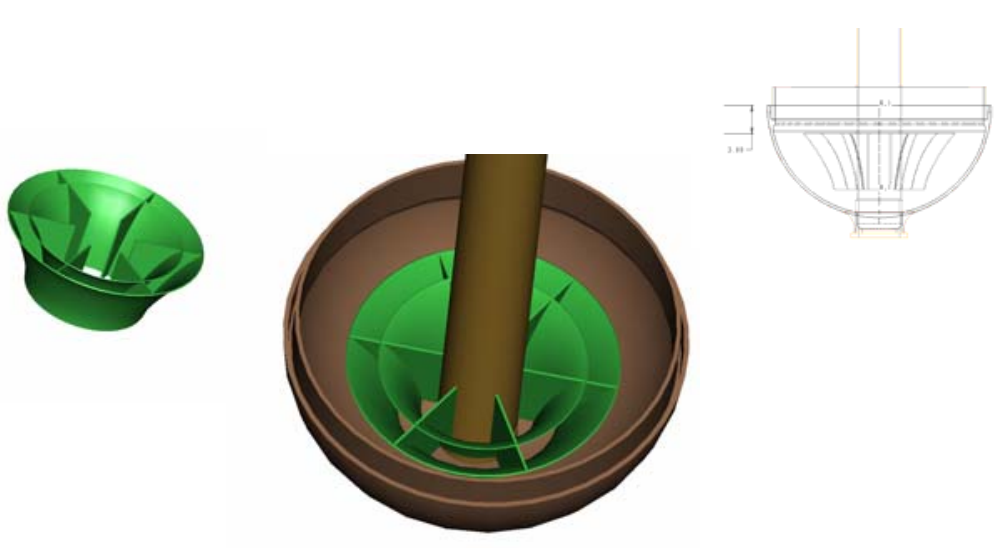

\section{Segmented Models (R. Mathur)}

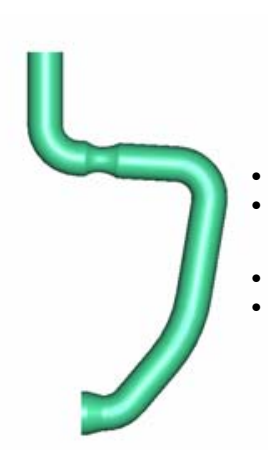

\section{Cold Leg Piping} Models

Modeled using Pro/Pipe Module Original models extracted from 4

Brayton model

- File Ref: ..14 Brayton- Piping around the Shieldizemo-5b.asm

- Added fittings to avoid CRDMs

- Assured clearance of support structure \& shielding

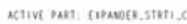

"Six-Inch" Pipe

Model
“Eight-Inch" Pipe

Model 


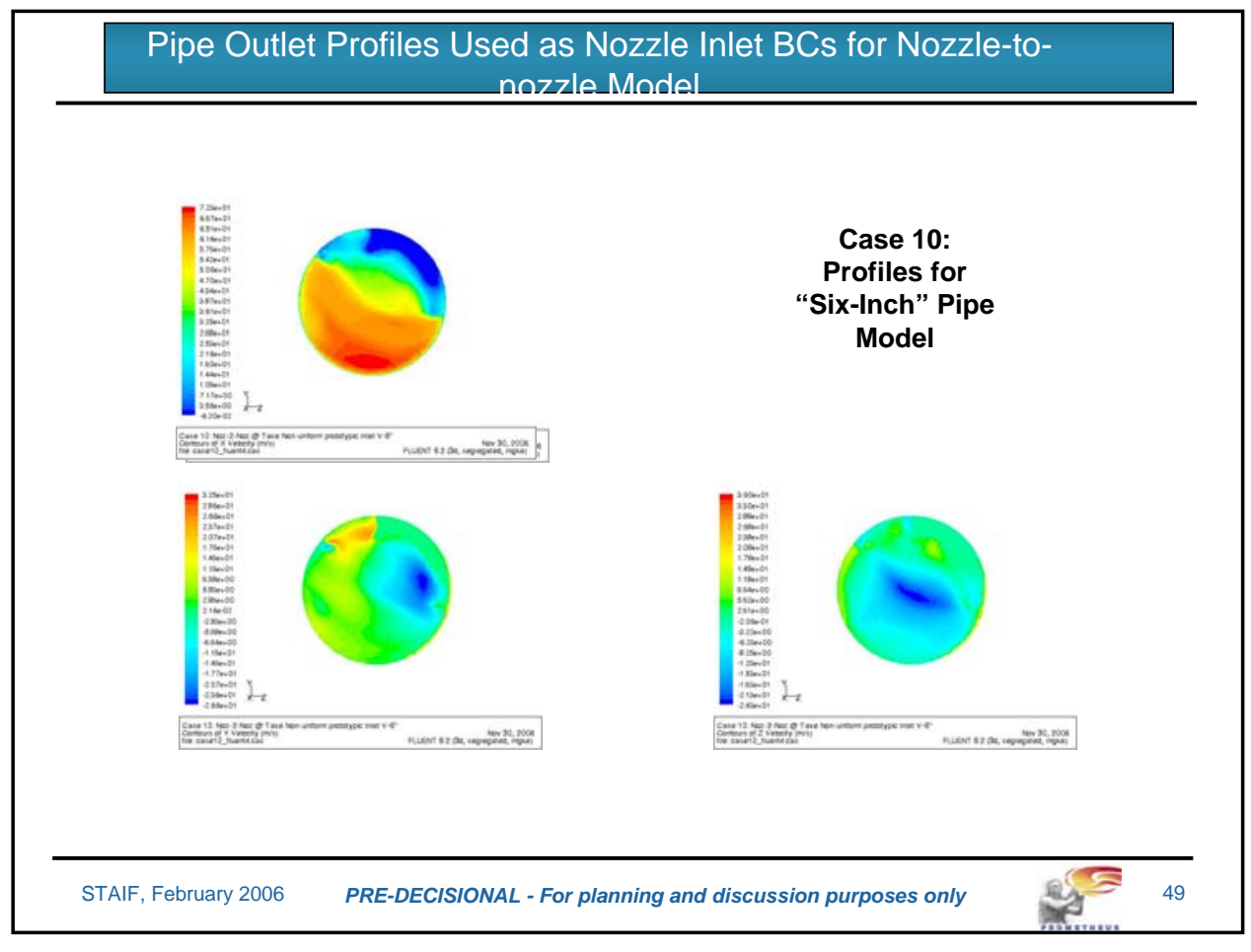

\section{Pipe Outlet Profiles Used as Nozzle Inlet BCs for Nozzle-to-nozzle Model}

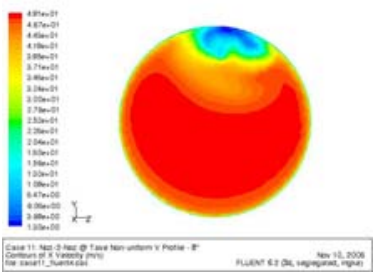

Case 11:

Profiles for

"Eight-Inch"

Pipe Model
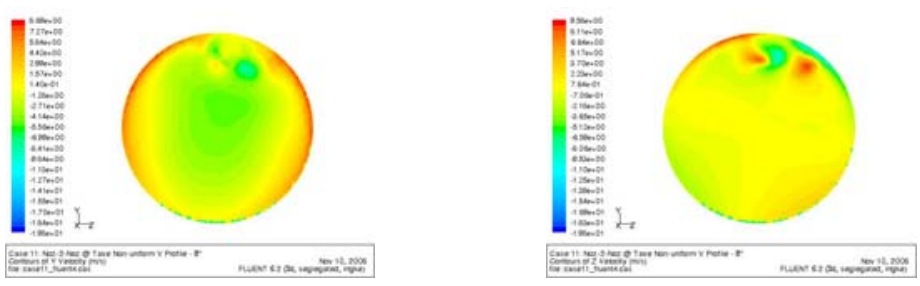

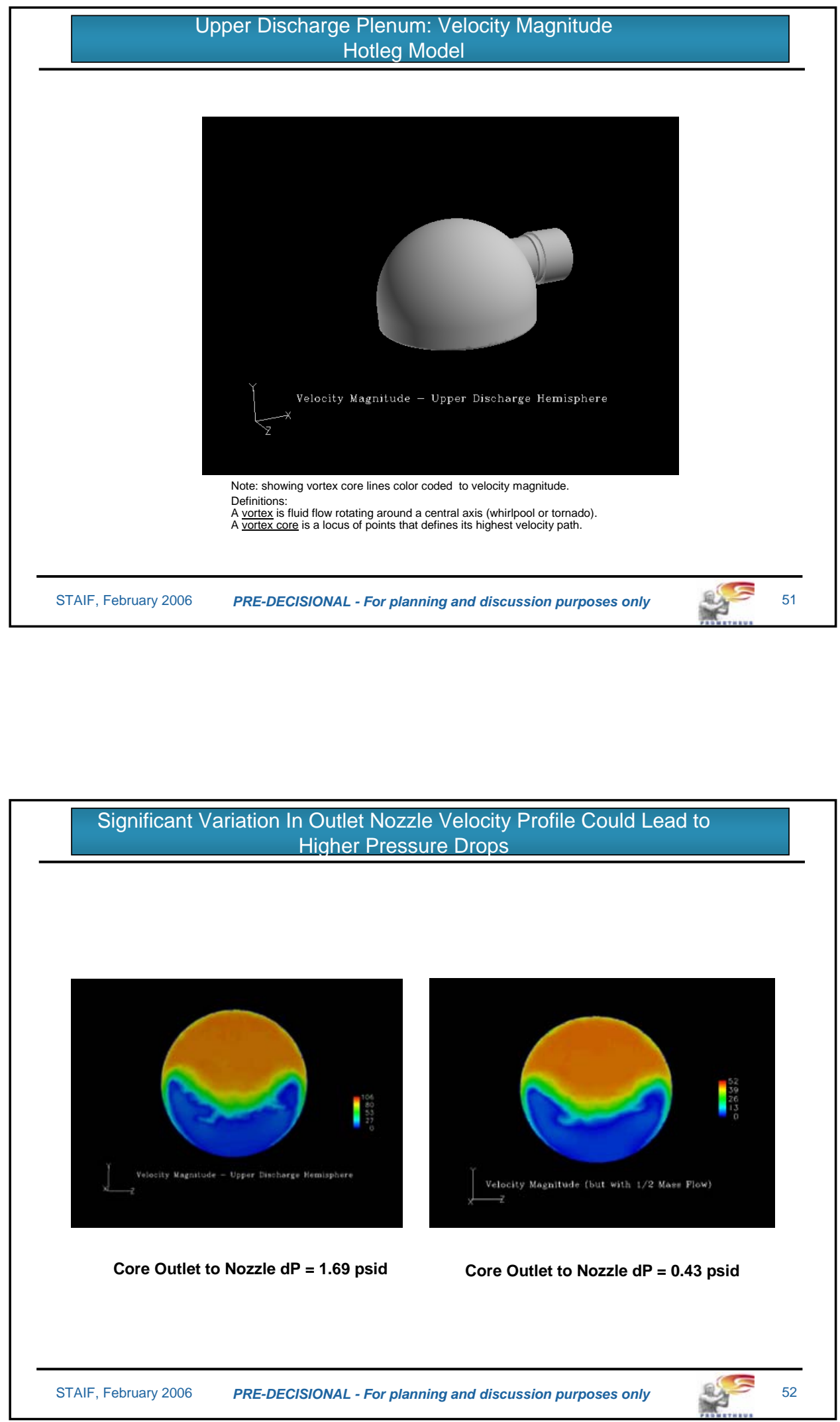


\section{Major Issues Observed}

- The March 2005 reactor design did not meet $34.82 \mathrm{kPa}$ pressure drop goal

- Off by $\sim 13.78 \mathrm{kPa}$

- Observed high velocity in local regions

- Maldistribution of flow was observed in downcomer

- Noted that up-stream issues maldistribute flow in the downcomer

- Also influence lower plenum's flow patterns \& create vortices

- Observed maldistribution of flow at core's inlet

- Observed vortices in lower plenum that inhibit flow to core's inlet

- Concluded that eliminating maldistributed flow is good goal

\section{What we've learned, so far:}

- We successfully constructed \& solved Nozzle-to-Nozzle models

- Developed a viable "production" model

- Results to date have passed our CFD modeling criteria

- Solve first-order: converged $<3,000$ iterations (less than 2 days)

- Second-order solution: $<5,000$ additional iterations ( 2 weeks or more)

- To date, convergence of Nozzle-to-nozzle models is very good

- Established dP across the reactor

- Assuming a uniform velocity profile

- Assuming a rougher surface finish

- Assuming non-uniform velocity profiles

- Successfully developed \& ran segmented models for detailed design assessments

- Developed software tool that transfer Nozzle-to-nozzle results to the segmented models

- For use as BCs

- Segmented models have been helpful at defining localized effects \& assessing alternative design features 


\section{Actual N-2-N Time-Line of Effort}

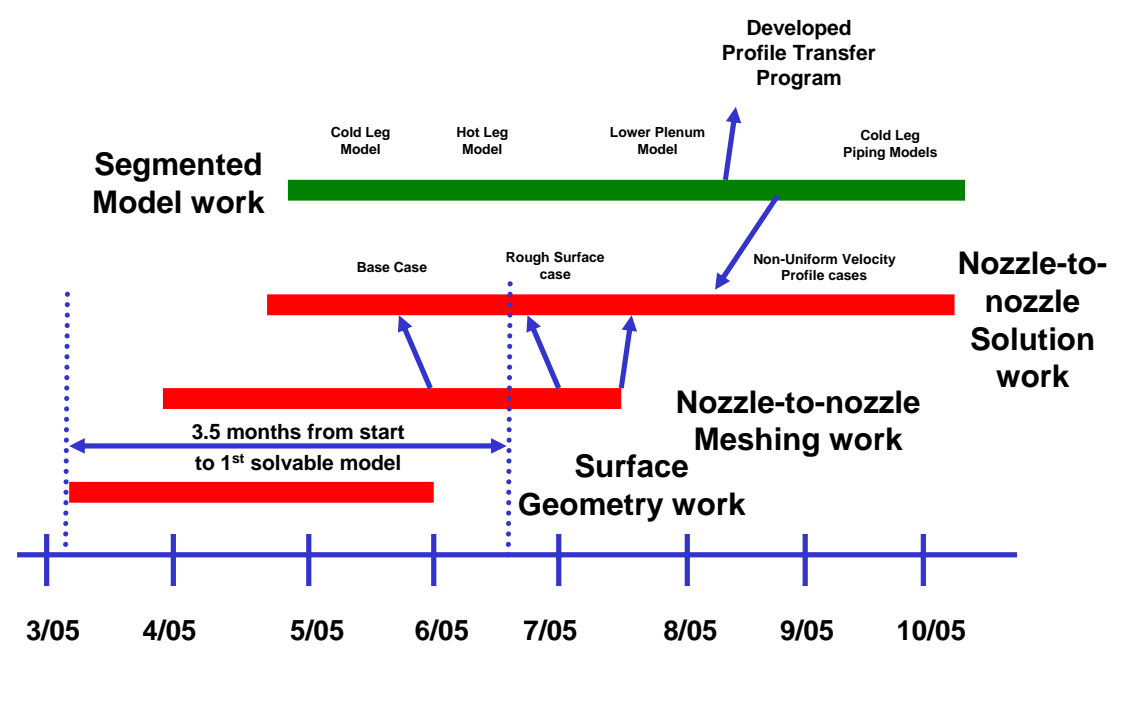

\section{Expected Benefits from Lessons Learned}

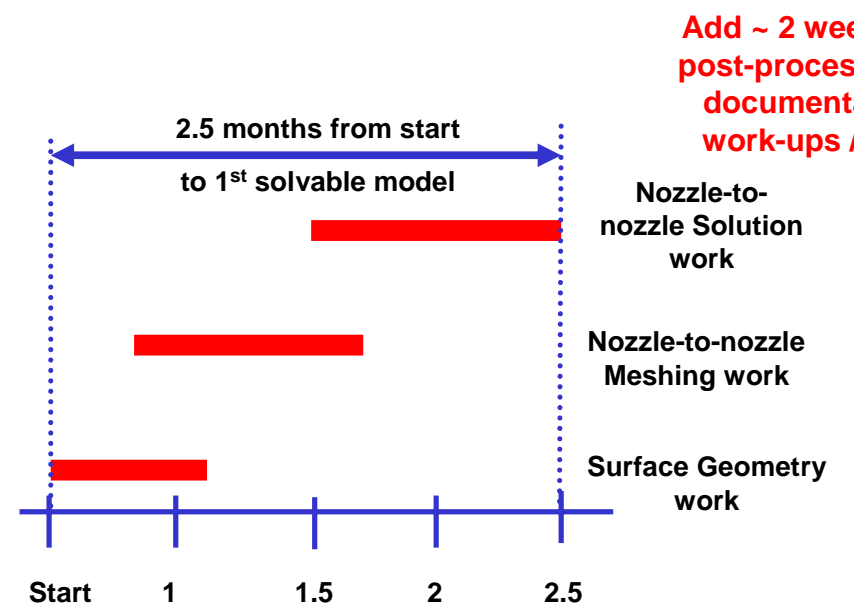




\section{Where were we headed? - Part 1}

- First priority: address flow distribution to the core

Having no or dramatically low flow to regions of the core is not acceptable

Need to supply a known flow distribution to the core

- $\quad$ Second priority: reduce Nozzle-to-nozzle pressure drop

Reduce high velocity regions in the vessel

- Inlet and outlet nozzles

- Upper annulus regions

- Vent regions

Develop new segmented modeling strategy Initially focused on lower plenum flow designs

Initially focused on lower plenum flow designs

- Fixes to maldistribution were under consideration at the time of project termination

- An upper orifice plate to replace the three upper vents

An inverted "I ale shative to an orifice plate

(bon thimble)

(a whistle?)

( \& outlet nozzle) \& their orientation

Pursue other significant reactor design issues

Vent sizing \& orientation

Downcomer \& upper annuli dimensioning

Perform additional surface roughness sensitivity studies on Nozzle-to-nozzle model

General "stream-lining" design issues

- Note: fixing maldistribution can result in additional dP loss
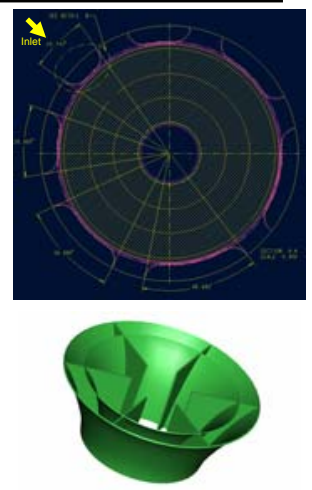

\section{Where were we headed? - Part 2}

- As design concept evolved, perform QA work-up

- Mesh/grid sensitivity studies would have increased model size $2 X$

- Important to note: with evolving vessel design, maintaining QA is still a necessity

- Develop a non-isothermal Nozzle-to-nozzle model on next design iteration

- BTW: the current mesh was designed to be solved non-isothermally

- Incorporate lessons learned into future Nozzle-to-nozzle models

- Further improve mesh for enhanced compute performance

- Add porous volume features to simulate the thimble bypass flow

- Compare air test program's results to CFD results

- Feedback results from CFD to test program 


\section{Big Picture Issues}

- The reactor vessel pressure drop to $34.82 \mathrm{kPa}$ ( -5.1 psid) goal

- Was based on hand calculations

- Pressure losses in the reactor are tied to Brayton Cycle \& BOP heat rejection issues

- Hand calculations could not account for non-uniform \& high velocity flow regimes

- In localized areas

- CFD based calculations were going to be supported \& remaining issues resolved by an air-flow test program

- Given that long lead "heavy equipment" prototype manufacturing was 2 to 3 years away

- We were on target to both perform the CFD analysis \& test work to support

- Future work could have included transient \& accident conditions scenario assessments 


\title{
"Ex-Core CFD Analysis Results for the Prometheus Gas Reactor”
}

\section{Donald G. Lorentz \\ Space Engineering, Bechtel Bettis, Inc. West Mifflin, PA 15122 USA \\ Telephone: 412-476-6160, email: lorentzd@bettis.gov}

\begin{abstract}
This paper presents the initial nozzle-to-nozzle (N2N) reactor vessel model scoping studies using computational fluid dynamics (CFD) analysis methods. The N2N model has been solved under a variety of different boundary conditions. This paper presents some of the basic hydraulic results from the N2N CFD analysis effort. It also demonstrates how designers were going to apply the analysis results to modify a number of the design features. The initial goals for developing a preliminary CFD $\mathrm{N} 2 \mathrm{~N}$ model were to establish baseline expectations for pressure drops and flow fields around the reactor core. Analysis results indicated that the averaged reactor vessel pressure drop for all analyzed cases was $46.9 \mathrm{kPa}$ ( $6.8 \mathrm{psid}$ ). In addition, mass flow distributions to the three core fuel channel regions exhibited a nearly inverted profile to those specified for the in-core thermal/hydraulic design. During subsequent design iterations, the goal would have been to modify or add design features that would have minimized reactor vessel pressure drop and improved flow distribution to the inlet of the core.
\end{abstract}

\section{INTRODUCTION}

In the overall reactor design process, the underlying goal for the ex-core computational fluid dynamics (CFD) analysis work was to quickly and thoroughly advance the system's hydraulic design through its preliminary design stages by evaluating the reactor vessel design as an entire entity, nozzle inlet-to-nozzle outlet. The term "ex-core" means that the analysis work explicitly defined all fluid volumes between the reactor's inlet and outlet nozzles but implicitly defined the fluid volume inside core. The resulting CFD model was referred to as the nozzle-to-nozzle (N2N) model; it became the basis of a "CFD scoping study" description. Within this project's structure, the CFD analysis work would focus on two basic design attributes: 1) the overall pressure drop across the reactor vessel nozzle-to-nozzle and 2) coolant flow distribution to the core.

Prior to the time of developing the N2N model, the targeted pressure drop across the reactor was $2.5 \%$ of system inlet pressure; thus a $34.8 \mathrm{kPa}$ (5.1 psid) pressure drop became a preliminary design goal. Given that the $2.5 \%$ of system inlet pressure goal was an estimate based upon average flow velocities in system components, it was anticipated that the calculated estimate would not account for local flow regime effects that would influence pressure drop (e.g., in high velocity regions). Thus, it was anticipated that design methods (to lower velocities) would be to be applied to those regions in order to minimize the pressure drop.

The core's inlet coolant flow distribution was also a concern since maldistributed flow could create hot spots in the core. Thus, a prediction of local core inlet velocities and their comparisons to ideal inlet core flow conditions was necessary. A design goal was to develop vessel design features that would establish properly distributed flow to the core regions.

\section{METHODOLOGY}

The N2N model was developed from the 1 MW (thermal) March 2005 reactor design. Additional CFD work on alternative vessel designs did not take place due to project cancellation. The March 2005 reactor vessel design featured opposing $17.78 \mathrm{~cm}$ (7 in) ID inlet \& outlet nozzles, a vessel design that attempted to maintain vessel exterior wall temperatures at roughly $\mathrm{T}_{\text {cold }}(880 \mathrm{~K})$, three upper annulus vents and six lower annulus vents, upper \& lower hemispherical heads, an inner discharge hemispherical head (that created a annular gap between the upper and discharge hemispherical heads), and a "block reactor" core design. The mass flow rate through the vessel was assigned at $7.12 \mathrm{~kg} / \mathrm{s}$ for a $1 \mathrm{MW}$ (thermal) design; this equates to $44.1 \mathrm{~m} / \mathrm{s}$ uniform inlet velocity at $\mathrm{T}_{\text {ave }}(1015 \mathrm{~K})$. The reactor coolant was an inert gas mixture with a $0.7177 / 0.2823 \mathrm{He} / \mathrm{Xe}$ mole fraction; this equated to a molecular weight for the gas mixture of $39.94 \mathrm{~g} / \mathrm{mole}$.

The overall vessel volume was divided into seven material volumes or zones. The material volumes permitted local control over mesh density and represented convenient "breaks" in the total ex-core reactor volume that corresponded to anticipated $\mathrm{T}_{\text {cold }}$ or $\mathrm{T}_{\text {hot }}$ conditions. As noted, the reactor core was modeled implicitly using 3 radial core regions 
(areas with inlets to multiple fuel regions); each region was assigned a porous volume resistance to approximate an $11 \mathrm{kPa}$ (1.6 psid) pressure drop across the core. The four ex-core material volumes were assigned to: 1 ) the inlet nozzle and hemispherical annulus, 2) the downcomer annulus, 3) the lower plenum, and 4) the upper discharge plenum and outlet nozzle.

For the purpose of sizing the 3-D mesh, flow areas and wetted perimeters were extracted and ex-core related boundary conditions (BC) were established at key locations within the reactor; this information provided hydraulic diameters. With the projected local velocities and hydraulic diameters, local Reynolds numbers and Mach numbers were calculated that in-turn permitted the mesh to be sized. A 12 million cell (4 million nodes) hybrid N2N mesh was created in ICEM/CFD (V5.1) and written out for use in FLUENT (V6.2.16), a commercial CFD solver.

The basic BC setup for the first two cases, Case 7 and 8, assigned the reactor nozzle inlet a "velocity inlet" BC while the reactor's outlet nozzle assigned a pressure outlet BC of 0 psig. The only variation to this basic BC arrangement was that in Cases 9, 10 and 11, the velocity inlet BCs were changed from being a constant or uniform velocity (of $44.1 \mathrm{~m} / \mathrm{s}$ ) to a variable velocity profile defined by velocity vector $(\mathrm{x}, \mathrm{y}, \mathrm{z})$ fields. Compared to Cases 9 , 10, and 11 , Cases 7 and 8 effectively modeled a flow straightened condition imposed by the uniform velocity profile BC. All cases assessed included hydraulically smooth surfaces except for Case 8, which had all of its wetted surfaces assigned an arithmetically averaged (AA) surface roughness of $4.19 \mu \mathrm{m}$ (165 $\mu \mathrm{in})$. All of the models were solved with material properties taken at $\mathrm{T}_{\text {ave }}(1015 \mathrm{~K})$.

\section{PRELIMINARY RESULTS}

Once solved, leading indications established that the mesh easily met all of the wall function $\mathrm{Y}^{+}$criteria and that it had solved with mass balances of $<1 \mathrm{E}-04 \mathrm{~kg} / \mathrm{s}$. Analysis data representing local N2N velocity profiles, core inlet velocities, and vessel pressure contour plots were extracted from the large $\mathrm{N} 2 \mathrm{~N}$ model. Additional data was acquired from the model in order to establish quantifiable pressure drops and mass flows at the material "break points.” This process was repeated for all 5 analysis models.

Solution results indicated the following:

1. The base case model (Case 7) produced the maximium pressure drop of $48.6 \mathrm{kPa}$ ( $\sim 7 \mathrm{psid}$ ). Thus the target was missed by $13.8 \mathrm{kPa}(\sim 2.0$ psid $=7.0$ - 5.0). The average pressure drop for all five cases was $46.9 \mathrm{kPa}$ ( 6.8 psid). CFD N2N vessel pressure drop allocations and average pressure drops for all 5 of the N2N cases solved are listed in Table 1. Figure 1 compares the ex-core average pressure drop (percent of total) across the reactor, as analyzed by CFD, to the goals established for ex-core pressure losses.

2. From Table 2, mass flow distributions to the three core inlets exhibit (see Figure 2) a nearly inverted profile to those specified for the in-core thermal/hydraulic design. That is, more flow is going to the innermost fuel region of the core than was assumed by the in-core analysis), leaving the outer region with less flow.

3. A contour plot (Figure 3) of the inlet velocity to the core (using Case 7 as typical results) illustrates considerable variation in axial velocity entering the core. The large secondary flows in the lower plenum create high flow regions near the spindle and low flow regions towards the periphery. Figures 4a, b, c, \& d identify the flow structures that can inhibit flow to the core region. The velocity entering the lower plenum is highly skewed towards the side opposite the inlet nozzle (see Figure 6). That, combined with the configuration which requires the downcomer flow to turn $180^{\circ}$, leads to the lower flow through the outer core region. On the outlet side of the core, which the downcomer velocity skews towards, most of the recirculation is clustered towards the top of the lower plenum as shown by the vortex cores in the upper right of Figure $4 \mathrm{~b}$ and detailed in Figure $4 \mathrm{~d}$. These tight recirculation vortices are generated by the high shear region locally where the jetting downcomer flow cannot turn into the core. On the inlet side of the lower plenum which has preferentially lower velocities, in addition to the recirculation clustered near the inlet to the core region, there is a larger separation zone lower in the plenum which will starve the flow locally from this side and redistribute it to lateral core regions, details of which are shown in Figure 4c.

4. Reactor cross-section contour plots of total system pressure (Figure 5) and of velocity magnitude (Figure 6) identify regions of the reactor vessel with high velocities and correspondingly high pressure losses. As 
noted previously, because of the way that flow discharges from the inlet nozzle and impinges on the upper head hemisphere, the velocity preferentially redistributes to the outlet side of the downcomer.

Table -1. Pressure Drop Allocations for All 5 Cases

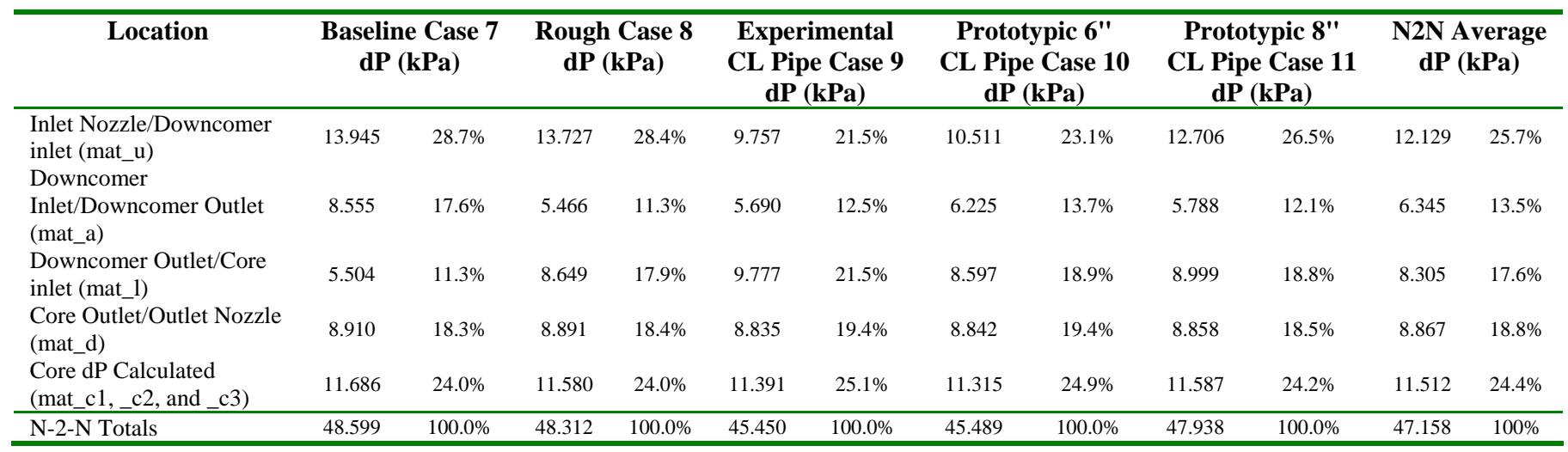

Table -2. Mass Flow Distributions to the Three Core Region Inlets For All Five Cases

\begin{tabular}{lcccccc}
\hline \multicolumn{1}{c}{ Channel Name } & $\begin{array}{c}\text { Assumed Model } \\
\mathbf{( k g / s )}\end{array}$ & $\begin{array}{c}\text { Case 7 } \\
\mathbf{( k g / s )}\end{array}$ & $\begin{array}{c}\text { Case 8 } \\
\mathbf{( k g / s )}\end{array}$ & $\begin{array}{c}\text { Case 9 } \\
\mathbf{( k g / s )}\end{array}$ & $\begin{array}{c}\text { Case 10 } \\
\mathbf{( k g / s )}\end{array}$ & $\begin{array}{c}\text { Case 11 } \\
\mathbf{( k g / s )}\end{array}$ \\
\hline Inner (mat_c1) & 1.9030 & 2.7777 & 2.5795 & 2.8879 & 2.9473 & 2.8064 \\
Mid (mat_c2) & 2.4449 & 2.2386 & 2.3975 & 2.2335 & 2.2315 & 2.2200 \\
Outer (mat_c3) & 2.7691 & 2.1034 & 2.1414 & 2.1001 & 2.0961 & 2.1198 \\
\hline Total through core & 7.1170 & 7.1196 & 7.1184 & 7.2215 & 7.2749 & 7.1462 \\
\hline
\end{tabular}

\section{CONCLUSIONS}

1. CFD analyses of the March 2005 reactor design indicated that the design did not meet the $34.8 \mathrm{kPa}$ (5.1 psid) pressure drop goal. The CFD results indicated that the design was off targeted goals by $13.8 \mathrm{kPa}(\sim 2.0$ psid $=7.0-5.0)$. This may be attributed to the target calculation's traditional method for estimating pressure drop (that utilized mass and flow-area based averaged velocities). In contrast and by its very nature, the CFD analyses accounted for variations in hydraulic diameters and flow areas within the system that led to variations in velocities observed within the reactor model (see Figure 6). There are ideas to improve (lower) this pressure drop by reducing local high velocity regions in the reactor vessel. Specifically, this would be accomplished by:

a. Rounding all incoming-flow-edges at nozzles \& vents.

b. Modifying inlet and outlet nozzle designs (i.e., tapering the nozzle internal surfaces) as well as the upper hemisphere.

c. And if a) and b) failed to meet vessel pressure drop goals, then the widening of flow areas in the regions of high velocity would be necessary.

2. Eliminating maldistributed flow in the reactor vessel is a goal. Maldistribution of flow can lead to local hot spots inside the core and potentially to fuel failures. Maldistribution of flow in the downcomer is a product of many design issues. In general, the origins are upstream sources:

a. Maldistributed flow was observed both up-stream and down-stream of the inlet nozzle and in the hemispherical annulus. This contributed to maldistributed flow inside the downcomer and this maldistribution continued into the lower plenum, making the flow in the lower plenum even more chaotic.

b. Maldistribution at the core inlet may be traced to the development of "vortex cores" or secondary flow structures that were observed in lower plenum to inhibit flow to the fuel inlet.

3. Surface roughness, in general, is an important contribution to pressure drop. However at this stage in our 
investigations, the rough surface model (Case 8 with $4.19 \mu \mathrm{m}$ (165 $\mu$ in) AA roughness) provided about the same pressure drop as the corresponding smooth case (Case 7). It was observed that the pressure drops around the Case 8's reactor vessel were re-distributed from those observed in Case 7, but when totaled, they approximated the smooth case's pressure drop. Additional surface roughness assessments are necessary before materials selections are finalized.

\section{FUTURE WORK}

Future CFD modeling work should incorporate new reactor core (i.e., in-core) and vessel designs. However, models of the new core designs would have likely continued to model the core implicitly in order to reduce the overall mesh cell count. The new in-core designs could have also included an increased number of material volumes dedicated to model fuel regions. Many other design attributes could have influenced the overall reactor and balance of plant designs in a way that could have, in turn, influenced the thermal/hydraulic design. For example, implementing a higher system pressure and $\mathrm{T}_{\text {ave }}$ were being discussed. Also, the use of a higher helium-to-xenon ratio in the reactor coolant, leading to an average molecular weight of $\sim 30 \mathrm{~g} / \mathrm{mole}$, was under discussion. The use of refractory materials for the reactor vessel and internals was under review. The above design changes and others not mentioned here were going to make the March 2005 design "a starting point" for future CFD analysis work. The lessons learned from the March 2005 design did not "marry" the project to one specific reactor core design type; thus the basic CFD process was flexible to advance to the next in-core design iteration. Still, the future CFD ex-core work had its priorities and the first two (discussed below) would have been on the top of the list of things to work on during the next major reactor vessel design iteration.

1. Having dramatically low flow to regions of the core is not acceptable. It is necessary to have a flow distribution to the core that meets in-core cooling design requirements for the core channels or regions. The current ideas to fix maldistribution to the core include:

a. An upper orifice plate to replace the three upper vents. (A proposed alternative to an orifice plate had been developed that featured sizing and orienting the vents for optimized uniform flow to the downcomer).

b. An inverted "lamp shade" positioned in lower plenum that would have broken up vortices in the lower plenum and directed flow to the regions of the core in the desired mass flow fractions.

c. A colander plate positioned just upstream of the core with the same objective as b).

d. Redesigning inlet and the outlet nozzles and their orientation in order to re-distribute flow and thereby lower the velocities in the discharge areas that lead to the downcomer.

2. Clearly, the March 2005 reactor vessel design did not meet the $34.8 \mathrm{kPa}$ (5.1 psid) pressure drop goal and thus design modifications would be required to reduce N2N pressure drop.

a. To accomplish a pressure drop reduction, lowering flow conditions in the high velocity regions within the vessel is necessary. Specifically there are three regions:

i. Inlet and outlet nozzles,

ii. Upper annulus regions defined by the upper hemispherical head and the hemispherical discharge head (e.g., see Figure 6)

iii. Up-stream and down-stream of the vent regions.

b. If the design activity noted in a) failed to meet vessel pressure drop design goals, then widening flow areas would have been investigated with its implied impact of a larger and heavier reactor vessel.

More design work was anticipated in the lower plenum in order to remediate the maldistribution at the core's inlet. Although a detailed investigation of the lower plenum using segmented models had already been conducted, the need was identified to develop a new segmented modeling strategy (using small CFD models with $<2$ million cells) that could quickly investigate a variety of current and new ideas to improve flow distribution to the core. Work was planned to perform the N2N CFD analysis non-isothermally. It was strongly held that performing a mesh grid sensitivity analysis on this CFD "scoping study" was a necessity. It was also anticipated that CFD analysis work would have been closely linked to a test program for both design and interpretation of results. 


\section{ACKNOWLEDGMENTS}

The author would like to extend his appreciation to the US Department of Energy, US Naval Reactors, and the National Aeronautics and Space Administration for supporting the Prometheus Project.

\section{REFERENCES}

NASA Technical Memorandum 4513, CEA2, "Chemical Equilibrium Program”, "Coefficients for Calculating Thermodynamic and Transport Properties of Individual Species", ca. 1993 (89 pages in all) 

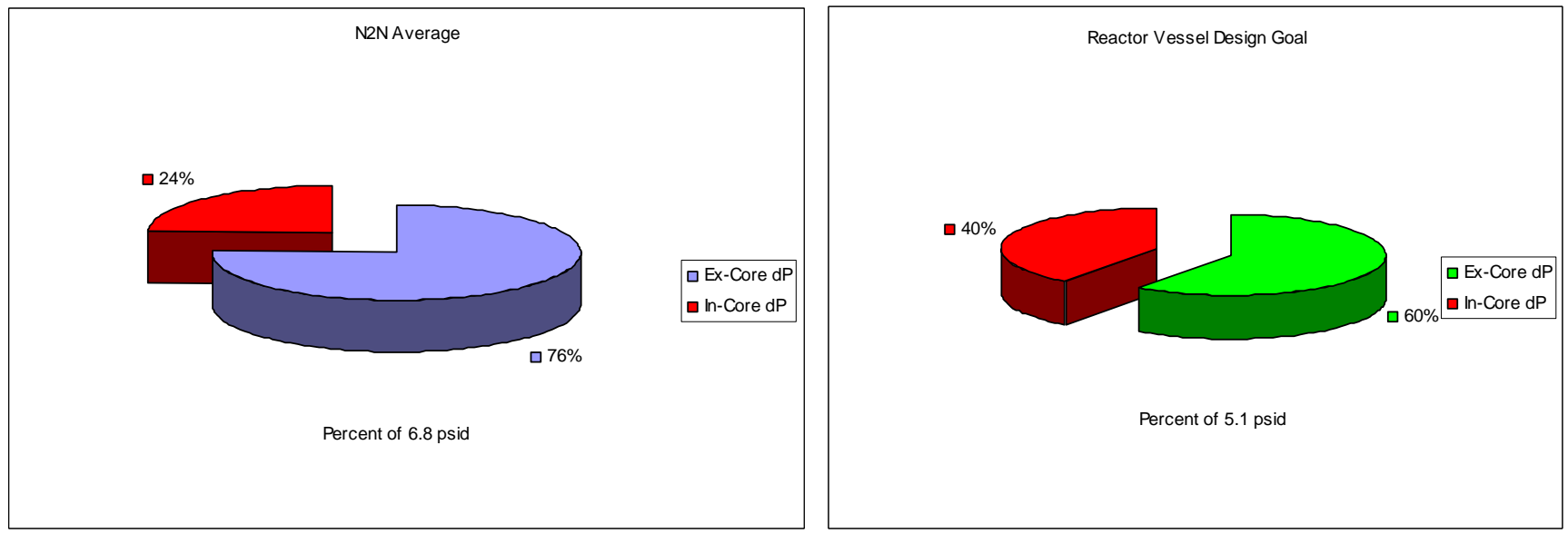

Figure 1. Average N2N Pressure Drop Across the ReactorVessel, as Analyzed by CFD, As Compared to the Hand Calculations Estimates

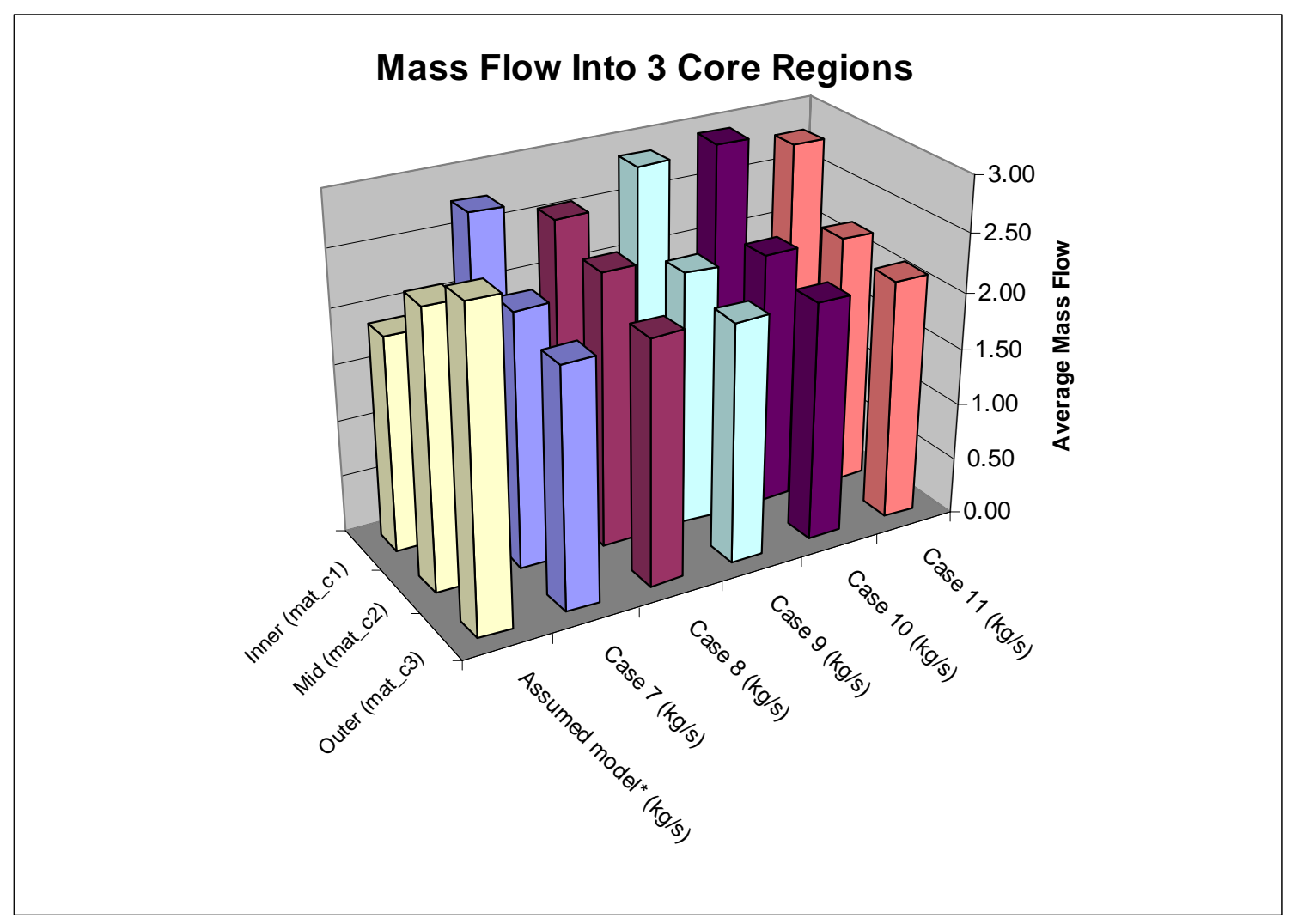

Figure 2. Inverted Core Inlet Mass Flows,as analyzed by CFD, as Compared to the Assumed Distribution 


\section{Flow Into Core}

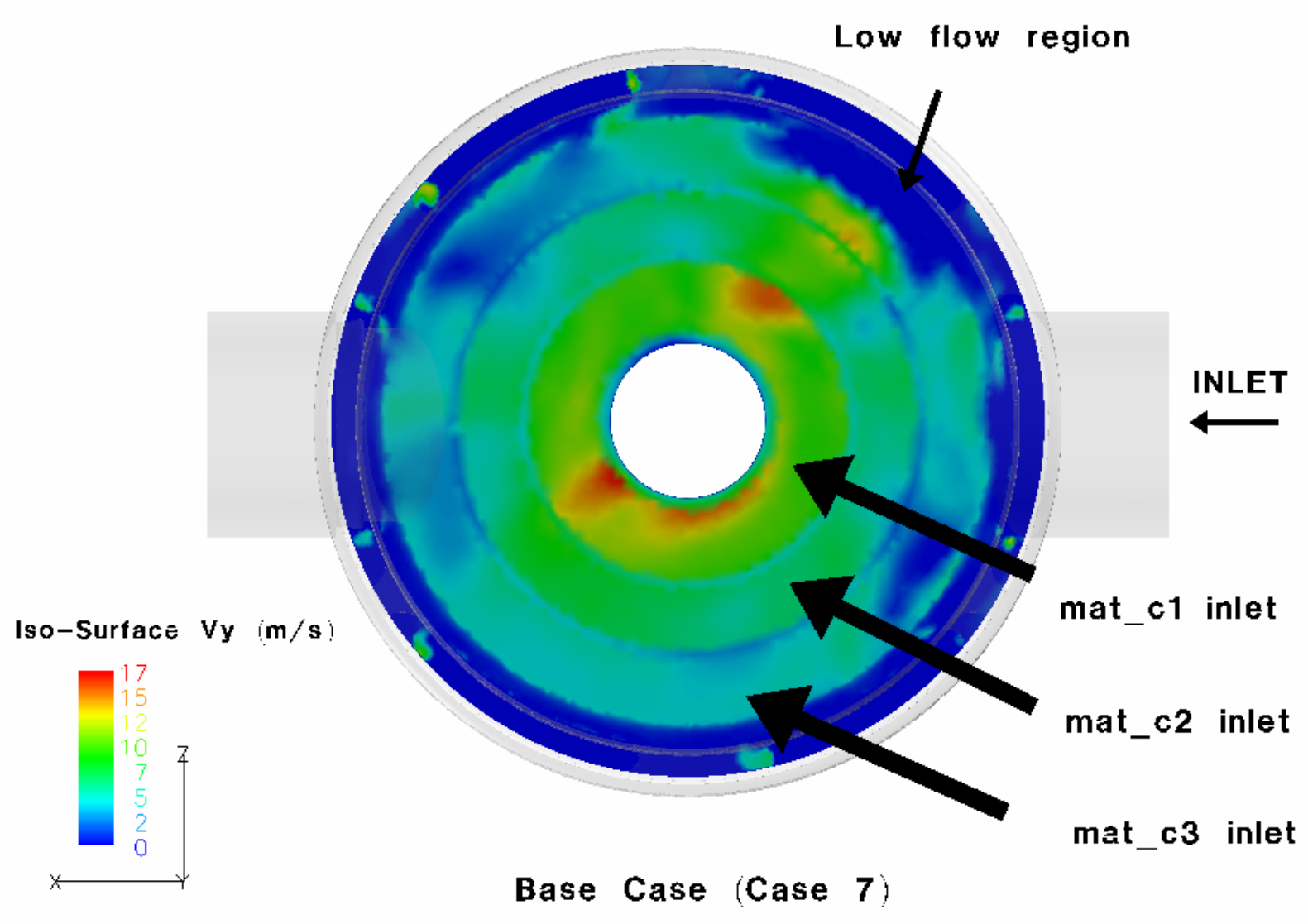

Figure 3. Inlet Velocity to the Core (Case 7, typical) 


\section{Flow Into Core}
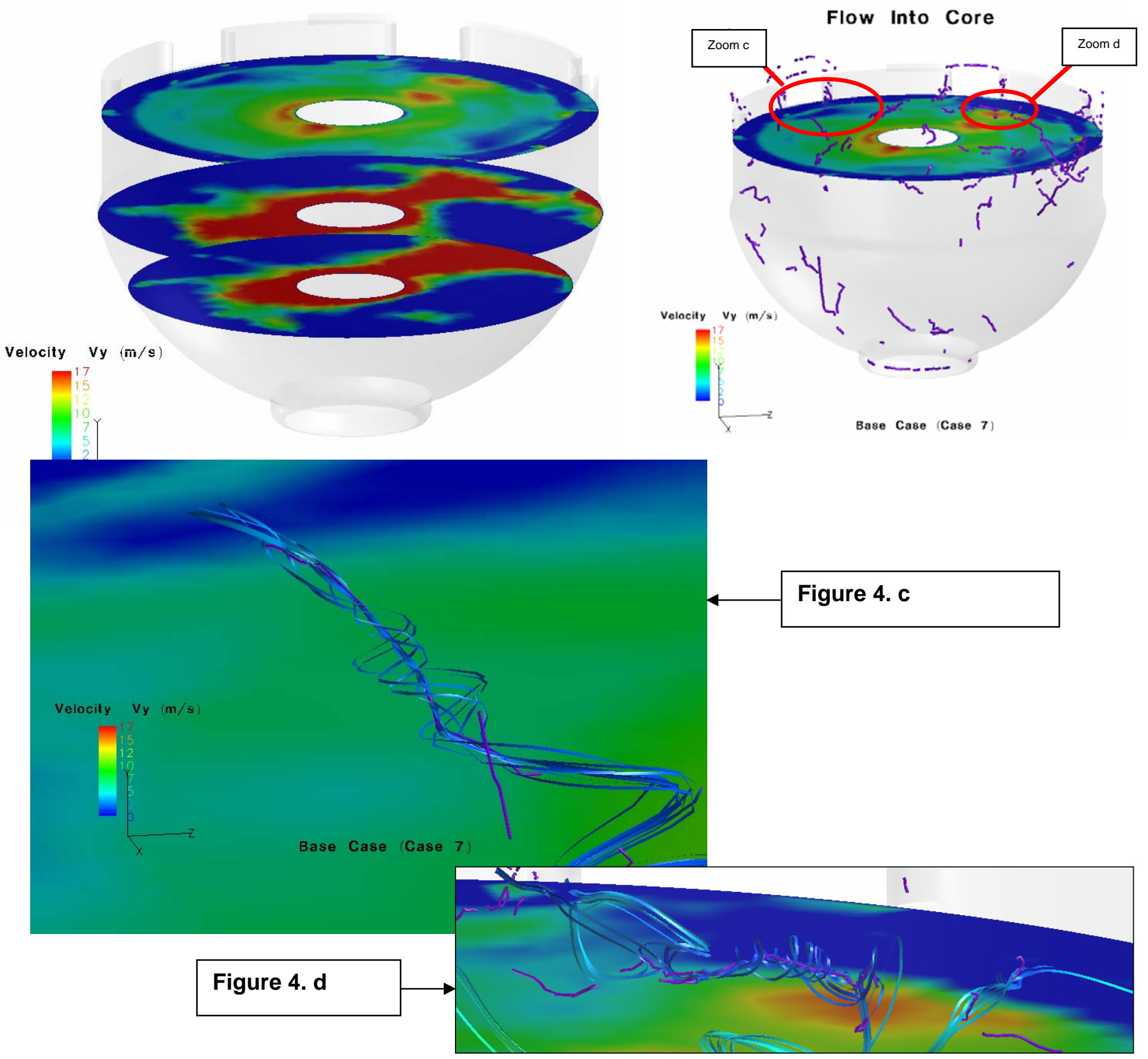

Figure 4. a Three Iso-Surfaces Contour Plots of Y-Velocity (m/s); Upper Most = Inlet to Core Figure 4. b Vortex Cores in Lower Plenum with Core Inlet Contour Plot

Figure 4. c \& d Zoom-in of Seeded Vortex Cores in Lower Plenum Illustrating Their Ability to Inhibit Flow into theCore 


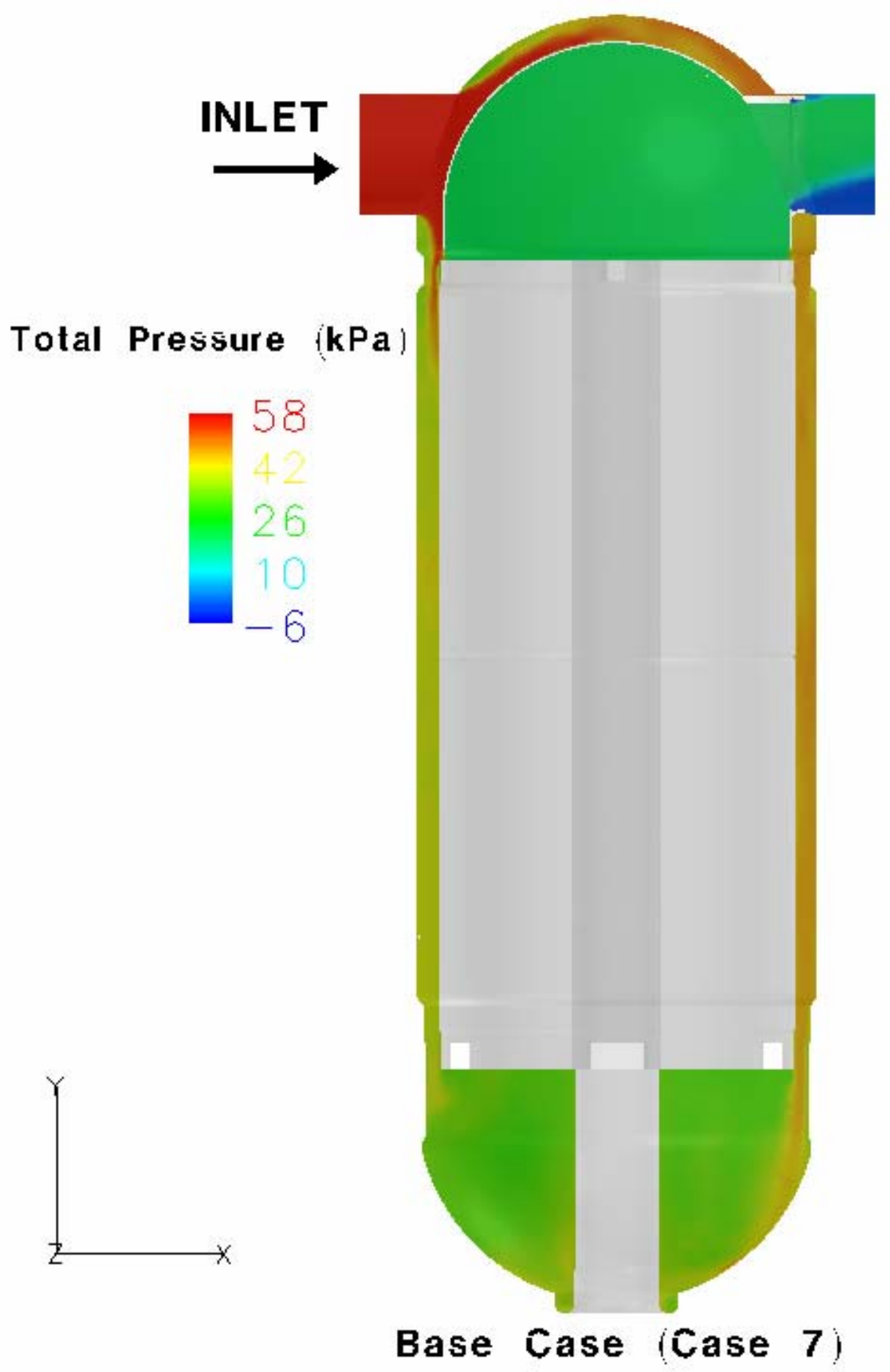

Figure 5. Reactor Cross-Section Contour Plots of Total System Pressure 


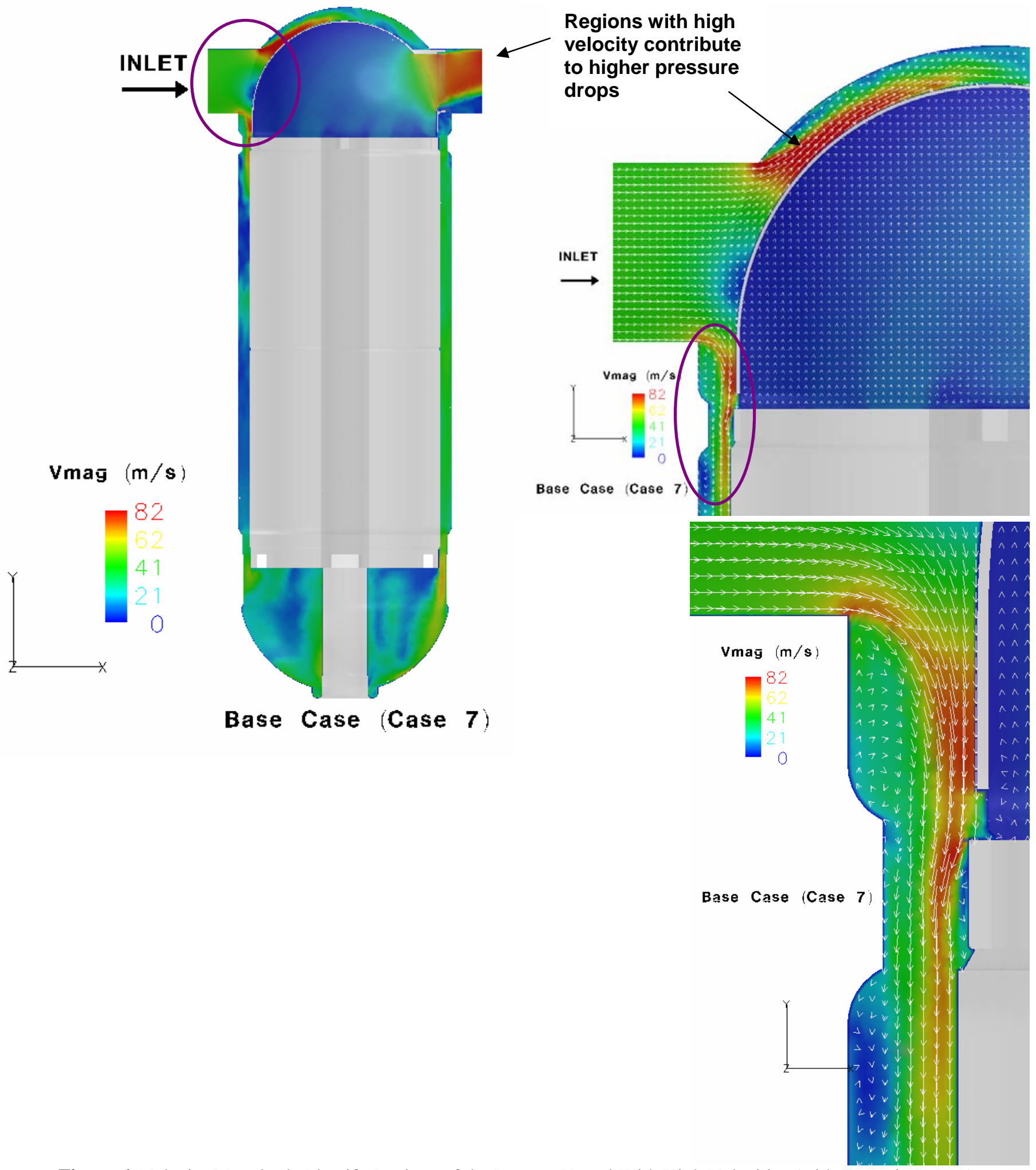

Figure 6. Velocity Magnitude Identify Regions of the Reactor Vessel With High Velocities (with Zoom-in Inserts) 


\title{
Enclosure 14 to
}

SPP-SEC-0039

\section{Review of Helium and Xenon Pure Component and Mixture Transport Properties and Recommendation of Estimating Approach for Project Prometheus}

\author{
Haire, M.A. and Vargo, D.D.
}


This page is intentionally blank.

PRE-DECISIONAL - For planning and discussion purposes only 
Review of Helium and Xenon Pure Component and Mixture Transport Properties and Recommendation of Estimating Approach for Project Prometheus

Melissa A. Haire and David D. Vargo Space Engineering - Bechtel Bettis, Inc.

STAIF 2006

February 2006 


\section{Agenda}

- Significance

- Pure Component Options

- Pure Component Data Plots

- Mixture Options

- Mixture Data Plots

- Future Work

- Summary 


\section{Significance}

- Selected coolant and working fluid for Project Prometheus

- Temperature range from $390 \mathrm{~K}$ to $1150 \mathrm{~K}$ for mix (up to $\sim 1500 \mathrm{~K}$ for helium in fuel element at BOL)

- Impacts pressure drop (affects laminar flow more than turbulent) and heat transfer calculations

- Reynolds number $=\rho \vee D / \mu$

- Prandtl number $=\mathrm{Cp} \mu / \mathrm{k}$

- Nusselt number $=\mathrm{h} \mathrm{D} / \mathrm{k}$

- Pressure drop $=f$ (friction factor) $=f(R e)$

- Convective heat transfer coefficient $h=f(R e, P r, k)$

- Overall heat transfer coefficient $=f(h)$

- Heat transfer and temperature profile of stagnant gas (pipe in pipe stagnant gas concept and fuel element gap $)=f(k)$

- Discrepancies in transport property values = discrepancies in results 
- Empirical Data

- National Institute of Standards and Technology (NIST)

- Online database (webBook)

- Tabular data

- Helium - data to $1500 \mathrm{~K}$

- Xenon - data to $800 \mathrm{~K}$

- Design Institute for Physical Property (DIPPR) Data Compilation

- Equations provided by DIPPR that were curve fit to empirical data

- Helium - data to $2000 \mathrm{~K}$

- Xenon - data to $1500 \mathrm{~K}$

- Theoretical/Semi-empirical (kinetic theory)

- Chapman and Enskog 


\section{Pure Component Viscosity}

Pure Component Viscosity vs. Temperautre

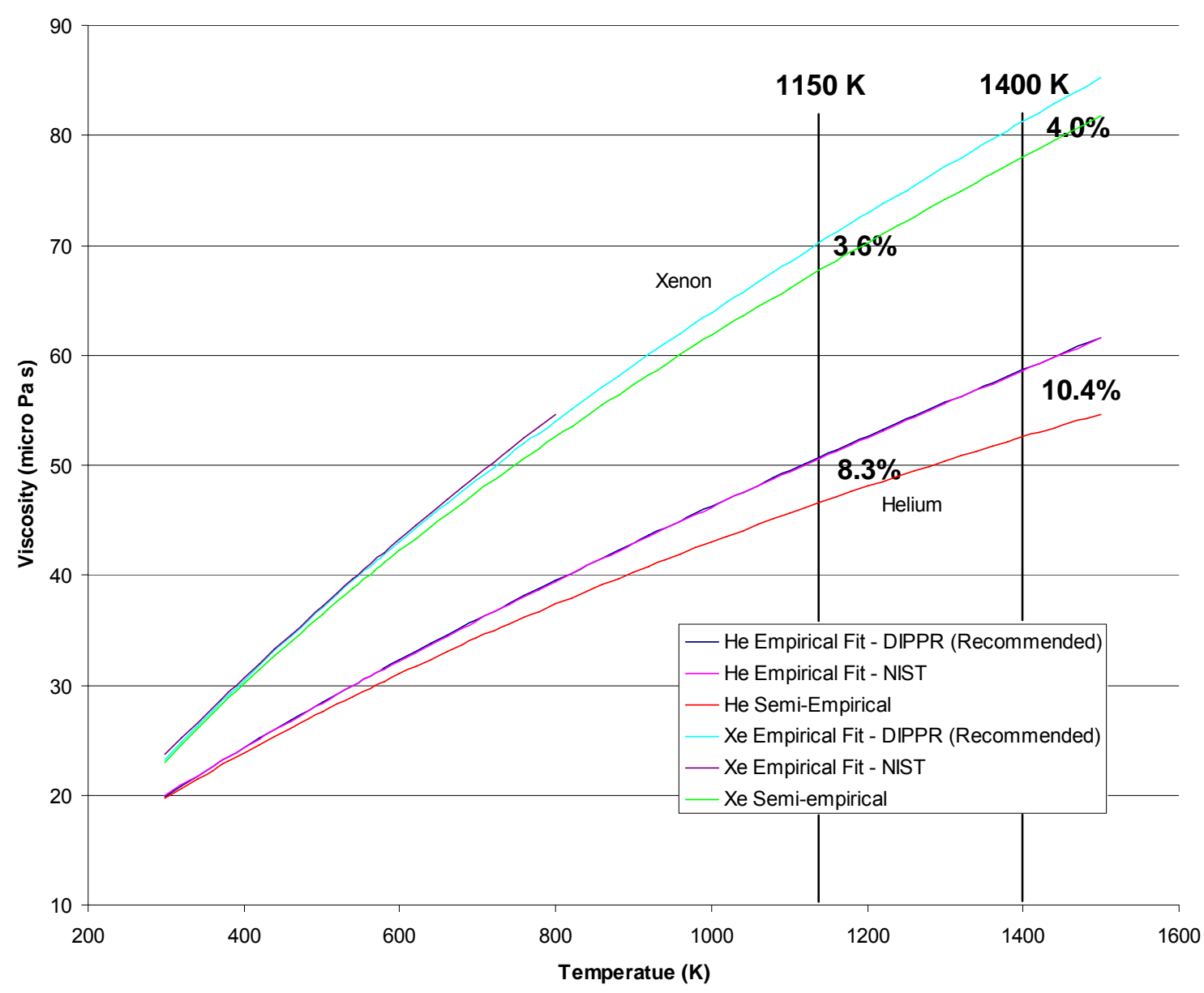




\section{Pure Component Thermal Conductivity}

Pure Component Thermal Conductivity vs. Temperature

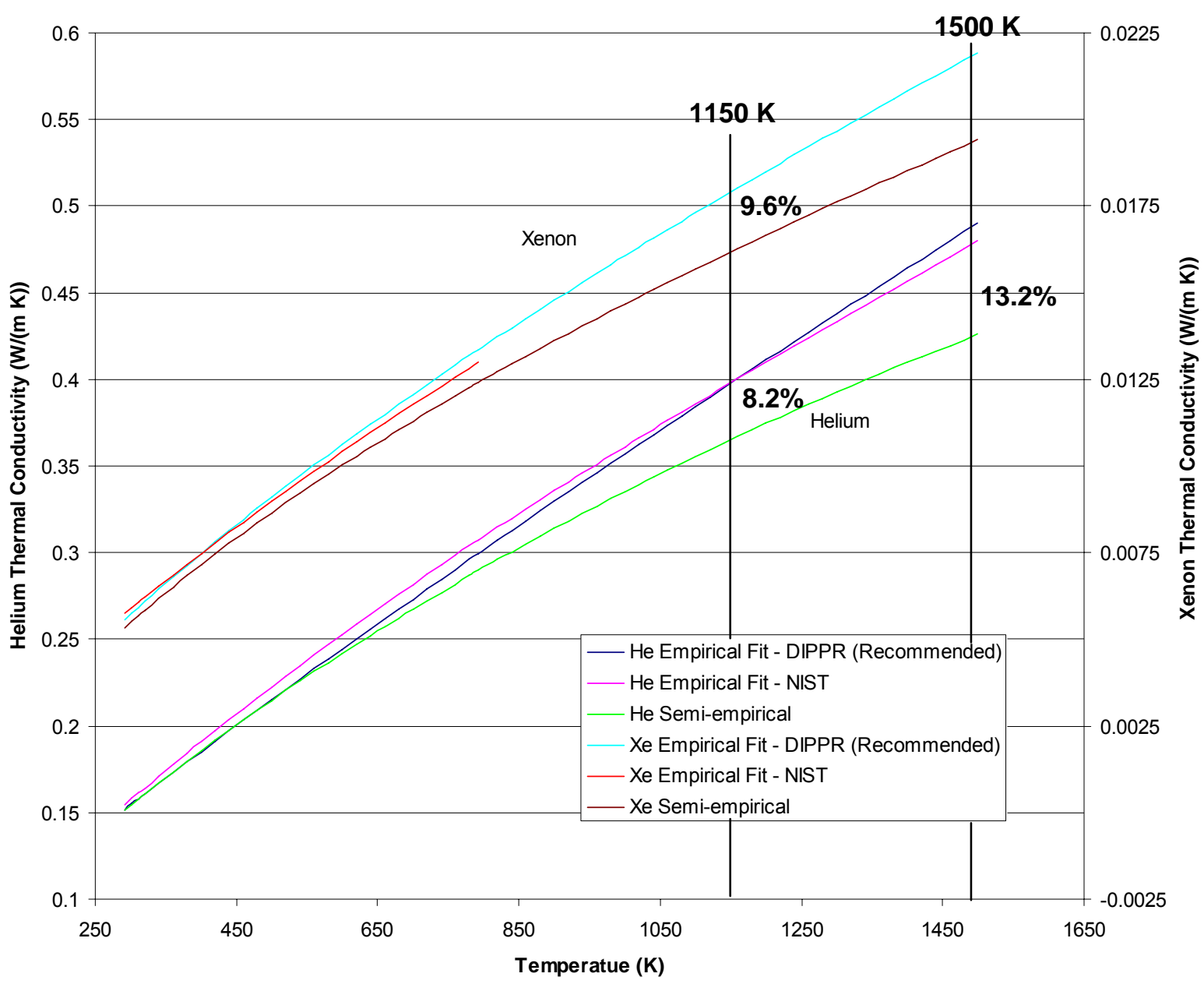


- Empirical

- INL has performed a literature search for data and has provided results

- Limited data compared to pure component

- Theoretical/Semi-empirical

- Most are based on the kinetic theory but vary in level of simplification relative to the most rigorous formulation (Chapman and Enskog)

- Corresponding states methods eliminate the need for pure component data, but are subsequently less accurate

- Extension beyond binary (e.g. for fuel element helium + fission gases) 


\section{HeXe Viscosity}

HeXe Viscosity vs. Temperature at $13.1 \%$ Xenon (at\%)

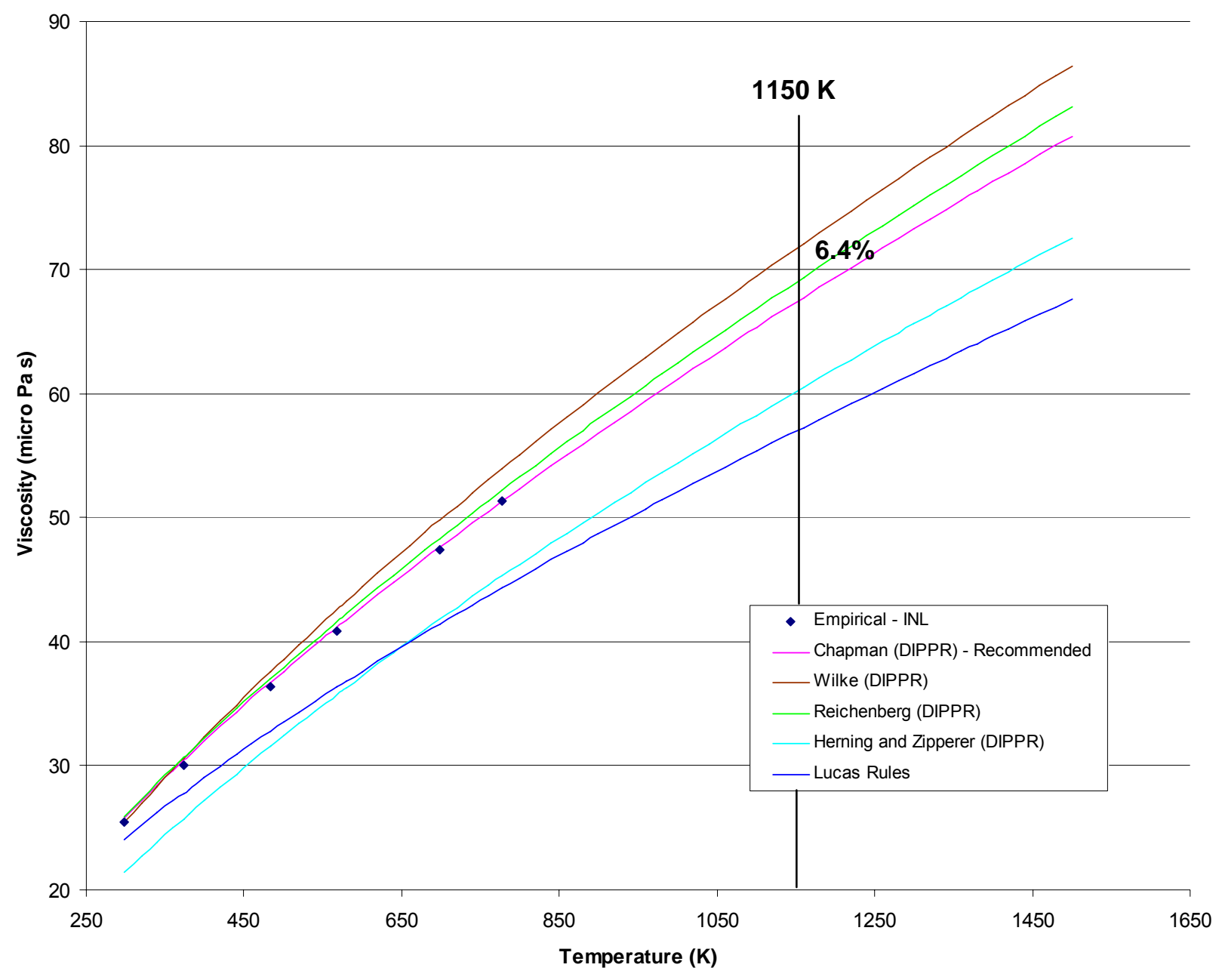




\section{HeXe Thermal Conductivity}

HeXe Thermal Conductivity vs. Temperature at $21.6 \%$ Xenon (at\%)

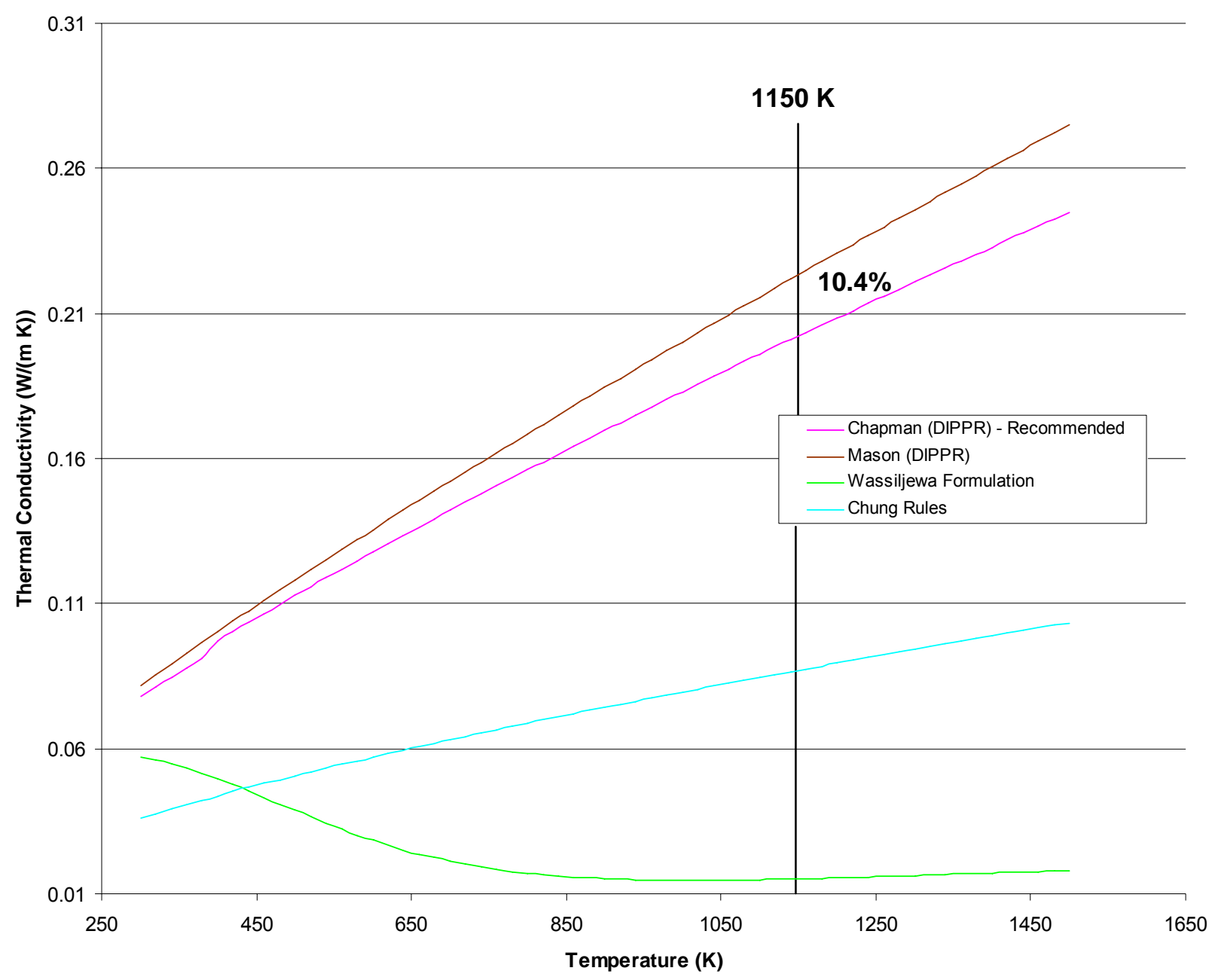




\section{HeXe Thermal Conductivity}

\begin{tabular}{|r|r|r|r|}
\hline \multicolumn{5}{|c|}{ \% Discrepancy Compared to Empirical Data } \\
\hline Temperature $(\mathrm{K})$ & $\begin{array}{l}\text { Xenon Mole } \\
\text { Fraction }\end{array}$ & Mason (DIPPR) & $\begin{array}{l}\text { Chapman (DIPPR) - } \\
\text { Recommended }\end{array}$ \\
\hline 291.2 & 0.139 & 8.37 & 4.95 \\
\hline 291.2 & 0.201 & 10.34 & 5.92 \\
\hline 291.2 & 0.304 & 4.73 & 0.03 \\
\hline 291.2 & 0.401 & 5.53 & 0.61 \\
\hline 302.2 & 0.213 & 4.86 & 0.34 \\
\hline 302.2 & 0.283 & 7.04 & 1.98 \\
\hline 311.2 & 0.1139 & 2.93 & 0.42 \\
\hline 311.2 & 0.2603 & 4.87 & 0.17 \\
\hline 311.2 & 0.346 & 7.60 & 2.10 \\
\hline 793.2 & 0.213 & 1.77 & 5.67 \\
\hline 793.2 & 0.283 & 3.44 & 5.17 \\
\hline 1500 & 0.1 & 3.76 & 3.12 \\
\hline 1500 & 0.1 & 10.42 & 3.10 \\
\hline 1500 & 0.3 & 17.89 & 2.89 \\
\hline Rus of Discrepancies & & $\mathbf{9 3 . 5 5}$ & $\mathbf{3 6 . 4 7}$ \\
\hline Sum of Discrepancies & 7.80 & $\mathbf{3 . 3 3}$ \\
\hline
\end{tabular}


- Viscosity and thermal conductivity

- Pressure impact on pure component

- Several semi-empirical methods have been identified

- NIST source code - semi-empirical per INL

- NIST references include elevated pressure

- Significantly greater impact on Xe than He

- Pressure impact on mixture

- Impacts greater at lower $\mathrm{T}$, higher $\mathrm{P}$, and higher $\mathrm{Xe}-<1 \%$ at current Prometheus conditions

- No experimental data at $>1 \mathrm{~atm}$. 
- Compressibility Factor (Z) - Second Virial Coefficient B

- $P V_{\text {actual }}=Z R T$

$-Z=V_{\text {actual }} / V_{\text {ideal }}=1+B / V$

$-\mathrm{B}_{\text {mix }}=\mathrm{x}_{1}^{2} \mathrm{~B}_{1}+2 \mathrm{x}_{1} \mathrm{x}_{2} \mathrm{~B}_{12}+\mathrm{x}_{2}^{2} \mathrm{~B}_{2}$

- Pure component $B$ as $f(T)$ from DIPPR

- Pure component $B$ as $f(T)$ from INL

- Cross component $B$ as $f(T)$ from INL

- Cross component B semi-empirical from Prausnitz

- $\mathrm{Cp}$

$$
C_{P}(p, T)=C_{P 0}-T p\left(x_{1}^{2} \frac{\partial^{2} B_{1}}{\partial T^{2}}+2 x_{1} x_{2} \frac{\partial^{2} B_{12}}{\partial T^{2}}+x_{2}^{2} \frac{\partial^{2} B_{2}}{\partial T^{2}}\right)
$$


- Helium and Xenon viscosity and thermal conductivity values impact pressure drop and heat transfer calculations

- Temperature and composition are the primary variables

- Pressure impact within the range being considered for Prometheus would need to be investigated in future work

- Deviation from ideal gas behavior would need to be investigated in future work

- Additional HeXe mixture data are needed, and the recommendation reflects the most accurate method in comparison to available data

- Pure component recommendation - DIPPR pure component values obtained from the provided equations

- HeXe mixture recommendation - Chapman and Enskog rigorous kinetic theory (first order for viscosity, third order for thermal conductivity) 


\title{
Review of Helium and Xenon Pure Component and Mixture Transport Properties and Recommendation of Estimating Approach for Project Prometheus (Viscosity and Thermal Conductivity)
}

\author{
Melissa A. Haire ${ }^{1}$ and David D. Vargo ${ }^{1}$ \\ ${ }^{1}$ Bechtel Bettis, Inc., Bettis Atomic Power Laboratory, P.O. Box 79, West Mifflin, PA 15122, USA \\ (412)476-6654; hairema@bettis.gov \\ (412)476-6668,vargodd@bettis.gov
}

\begin{abstract}
The selected configuration for the Project Prometheus Space Nuclear Power Plant was a direct coupling of Brayton energy conversion loop(s) to a single reactor heat source through the gas coolant/working fluid. A mixture of helium $(\mathrm{He})$ and xenon $(\mathrm{Xe})$ gas was assumed as the coolant/working fluid. Helium has superior thermal conductivity while xenon is added to increase the gas atomic weight to benefit turbomachinery design. Both elements have the advantage of being non-reactive. HeXe transport properties (viscosity and thermal conductivity) were needed to calculate pressure drops and heat transfer. HeXe mixture data are limited, necessitating the use of semi-empirical correlations to calculate mixture properties. Several approaches are available. Pure component properties are generally required in the mixture calculations. While analytical methods are available to estimate pure component properties, adequate helium and xenon pure component data are available. This paper compares the sources of pure component data and the approaches to calculate mixture properties. Calculated mixture properties are compared to the limited mixture data. Based on the results of these comparisons, approaches are recommended to calculate both pure component and mixture properties. Given the limited quantity of HeXe mixture data (all at one atmosphere), additional testing may have been required for Project Prometheus to augment the existing data and confirm the selection of mixture property calculation method.
\end{abstract}

Keywords: Transport properties, Helium, Xenon

PACS: 51.20.+d

\section{BACKGROUND}

HeXe was the assumed coolant and working fluid for initial engineering work on the Project Prometheus Space Nuclear Power Plant (SNPP). The recommended method to calculate the viscosity and thermal conductivity of pure helium and pure xenon is to use equations provided by the Design Institute for Physical Property Data (DIPPR) (Daubert et al., 1992). These equations are produced from curve fits of empirical data. The recommended method to calculate the viscosity and thermal conductivity of HeXe mixtures is the theoretical approach described by Hirschfelder (Hirschfelder, Curtiss, and Bird, 1954) with the addition of two higher order thermal conductivity correction factors described by Kestin (Kestin et al., 1984) and Singh (Singh, Dham, and Gupta, 1992).

Accurate and consistent methods to calculate helium and xenon pure component and mixture viscosity and thermal conductivity were needed for reactor, plant, and materials studies and design work. This paper addresses the binary mixture of helium and xenon. Extension to mixtures beyond two components (e.g. fuel pin helium and fission gas) is not addressed. 


\section{PURE COMPONENT RESULTS}

The methods compared for determining pure component transport properties are as follows:

- $\quad$ DIPPR - Empirical data compilation project (Daubert et al., 1992)

- National Institute of Standards and Technology (NIST) - On-line WebBook (Linstrom and Mallard, 2005)

- Chapman and Enskog's kinetic theory (Hirschfelder, Curtiss, and Bird, 1954)

\section{Design Institute for Physical Properties (DIPPR)}

The Design Institute for Physical Properties (DIPPR) data compilation project was initiated in 1980 under American Institute of Chemical Engineers (AIChE) guidance with Pennsylvania State University as the contractor. There were 42 industrial sponsors including the National Institute of Standards and Technology (NIST). According to the AIChE website, "The mission of the Design Institute for Physical Properties is to develop the world's best source of critically evaluated thermophysical and environmental property data".

DIPPR provides a reliability estimate with each equation. This value represents the average reliability of data plus error from regression. DIPPR indicates less than 3\% error for helium and xenon vapor viscosity and less than 5\% error for helium and xenon vapor thermal conductivity. To avoid unsatisfactory weighting of data, not all of the accepted references were used in developing the regression curves. The DIPPR database can be acquired through Brigham Young University.

\section{National Institute of Standards and Technology (NIST)}

The National Institute of Standards and Technology has created an on-line database to provide pure component thermodynamic and transport properties. The on-line database returns transport properties based on input temperature and pressure. The on-line database extends to $1500 \mathrm{~K}$ for helium and $800 \mathrm{~K}$ for xenon. Tabular pure component viscosity and thermal conductivity data obtained from the on-line database were used directly in the mixture property correlations. Tabular data from NIST can be accessed from http://WebBook.nist.gov or a more advanced version can be purchased.

\section{Chapman and Enskog}

The theory proposed by Chapman and Enskog uses the rigorous kinetic theory of monatomic gases and expresses the transport properties in terms of intermolecular potential energy $\varphi(r)$, where $r$ is the distance between a pair of molecules undergoing a collision. The expression for $\varphi(r)$ is most closely represented by the Lennard-Jones (6-12)

potential, $\varphi(r)=4 \varepsilon\left[\left(\frac{\sigma}{r}\right)^{12}-\left(\frac{\sigma}{r}\right)^{6}\right]$. The Lennard-Jones parameters for $\sigma$ (collision diameter) and $\varepsilon$ (maximum energy of attraction between a pair of molecules) have been determined empirically for many molecules, including helium and xenon. The energy of attraction is usually expressed as a ratio with the Boltzman constant as $\varepsilon / \mathrm{k}$. If the values for Lennard-Jones potentials are unknown, they can be estimated through corresponding states methods of critical temperature, pressure, and volume. The transport properties are also based on the collision integrals, the details of the paths the molecules take during a binary collision, and the distance traveled by a molecule between successive collisions, which accounts for the intermolecular forces (weak attractions at large separations and strong repulsions at small separations) (Bird, Stewart, and Lightfoot, 2002). The collision integrals $\left(\Omega^{(1, s)^{*}}\right)$ are a function of a dimensionless parameter of temperature $\left(\mathrm{T}^{*}\right)$, Lennard-Jones Potential parameter $\varepsilon$, and the Boltzman constant k. Data have been taken for the collision integrals and provided by Hirschfelder (Hirschfelder, Curtiss, and Bird, 1954). The resulting equations for viscosity $(\eta)$ and thermal conductivity $(\lambda)$ of a pure monatomic gas are (Hirschfelder, Curtiss, and Bird, 1954):

$$
[\mu]_{1} \times 10^{7}=266.93 \frac{\sqrt{M T}}{\sigma^{2} \Omega^{(2,2)^{*}}}(\mathrm{~g} / \mathrm{cm} \mathrm{sec})
$$




$$
[\lambda]_{1} \times 10^{7}=1989.1 \frac{\sqrt{T / M}}{\sigma^{2} \Omega^{(2,2)^{*}}}(\mathrm{cal} / \mathrm{cm} \mathrm{sec} \mathrm{K})
$$

where:

$$
\begin{aligned}
& {[\mu]_{1}=\text { viscosity }(\mathrm{g} / \mathrm{cm} \mathrm{s})} \\
& {[\lambda]_{1}=\text { thermal conductivity }(\mathrm{cal} / \mathrm{cm} \mathrm{s} \mathrm{K})} \\
& \mathrm{T}=\text { absolute temperature }(\mathrm{K}) \\
& \mathrm{T}^{*}=\text { reduced temperature }=\mathrm{T} /(\varepsilon / \mathrm{k}) \\
& \mathrm{M}=\text { molecular weight } \\
& \sigma=\text { collision diameter }(\AA) \\
& \varepsilon / \mathrm{k}=\text { potential parameter }(\mathrm{K}) \\
& \Omega^{(2,2)^{*}}=\text { collision integral }
\end{aligned}
$$

\section{Comparison}

There are substantial quantities of pure component data for helium and xenon, which are represented by the DIPPR equations and NIST tabular data. DIPPR and NIST bound the temperature range for which their empirical fits are reliable. The DIPPR temperature range extends to $2000 \mathrm{~K}$ for helium and $1500 \mathrm{~K}$ for xenon, while the on-line NIST database extends to $1500 \mathrm{~K}$ for helium and $800 \mathrm{~K}$ for xenon. DIPPR provides the references of experimental data used for the formulation of their curve fits (Daubert, 1992).

DIPPR equations and NIST tabular data produce very similar results for the viscosity and thermal conductivity of pure helium and pure xenon and are within DIPPR's error band. The empirically fitted equations of DIPPR are recommended for pure component use over those of NIST due to the NIST temperature limitation $(800 \mathrm{~K})$ for xenon in the on-line database. SNPP design operating temperatures exceed $800 \mathrm{~K}$ in much of the system.

The curves outlined in the pure component graphs (Figure 1 through Figure 4) are as follows:

- Empirical Fit - DIPPR (Recommended) - Equations resulting from curve fits of experimental data and presented by DIPPR (Daubert et al., 1992)

- Empirical Fit - NIST - Tabular data provided by the NIST chemistry WebBook (Linstrom and Mallard, 2005)

- Semi-Empirical Theory - Semi-empirical theory refers to the first order approximation of Chapman and Enskog pure component theory (Hirschfelder, Curtiss, and Bird, 1954) with a curve fit of collision integral data provided in (Hirschfelder, Curtiss, and Bird, 1954)

\section{Helium Viscosity}

Figure 1 graphically represents the results of the helium viscosity comparison and shows the deviation of the semiempirical method of calculating helium viscosity from the empirically derived DIPPR curve fit recommended in this paper. Figure 1 shows that NIST results track well with DIPPR results. Helium semi-empirical values deviate from DIPPR values by as much as $10.4 \%$ at $1400 \mathrm{~K}$ (fuel clad surface temperatures in contact with HeXe may approach $1400 \mathrm{~K})$. 


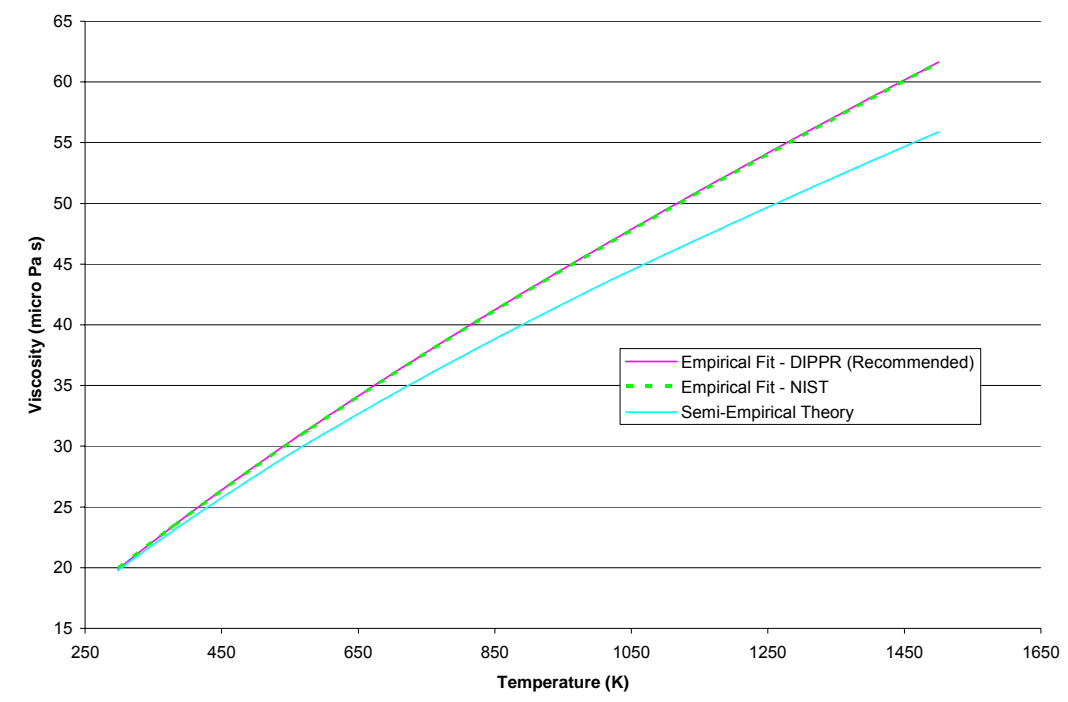

FIGURE 1. Helium Viscosity as a Function of Temperature.

\section{Xenon Viscosity}

Figure 2 graphically represents the results of the xenon viscosity comparison and shows the deviation of the semiempirical method of calculating xenon viscosity from the empirically derived DIPPR curve fit recommended in this paper. Figure 2 shows that NIST results track well with DIPPR results. Xenon semi-empirical values deviate from DIPPR values by as much as $4.0 \%$ at $1400 \mathrm{~K}$.

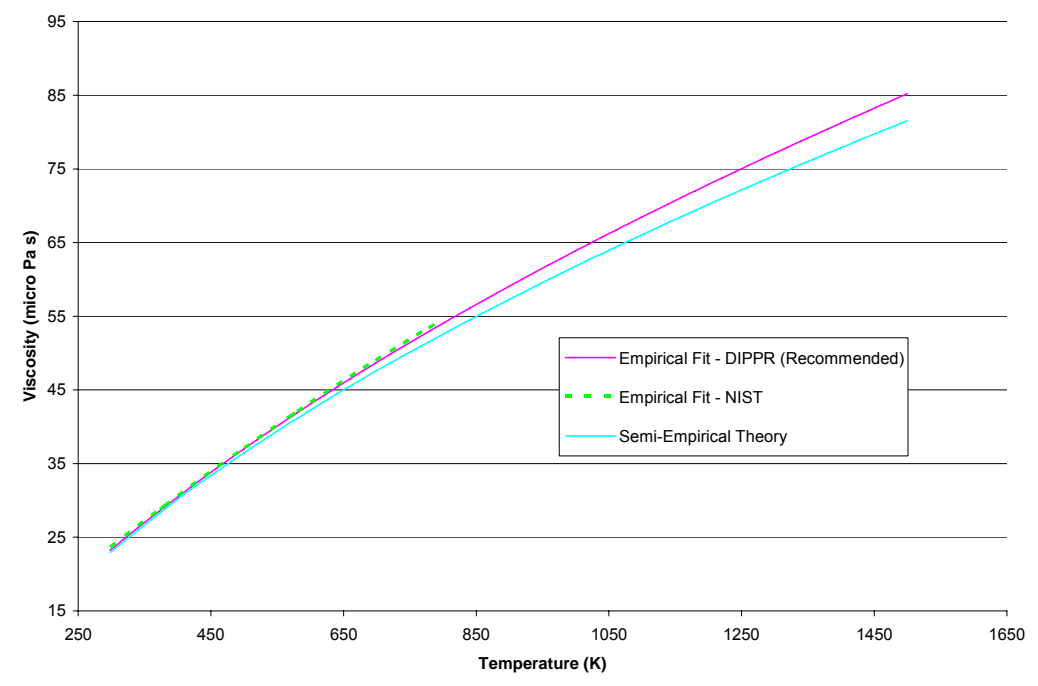

FIGURE 2. Xenon Viscosity as a Function of Temperature.

\section{Helium Thermal Conductivity}

Figure 3 graphically represents the results of the helium thermal conductivity comparison and shows the deviation of the semi-empirical method of calculating helium thermal conductivity from the empirically derived DIPPR curve fit recommended in this paper. Figure 3 shows that NIST results track well with DIPPR results. At $1500 \mathrm{~K}$ (fuel pin 
helium temperatures may approach $1500 \mathrm{~K}$ at beginning of life) the semi-empirical approach deviates from the empirically derived DIPPR value by $13.2 \%$.

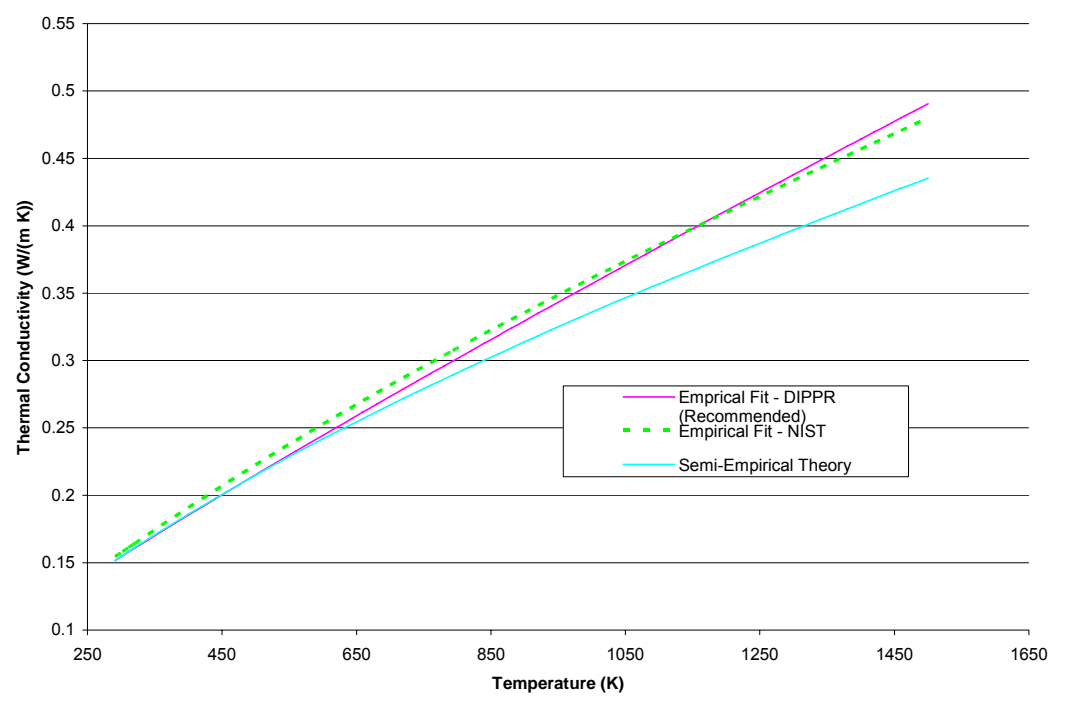

FIGURE 3. Helium Thermal Conductivity as a Function Temperature.

\section{Xenon Thermal Conductivity}

Figure 4 graphically represents the results of the xenon thermal conductivity comparison and shows the deviation of the semi-empirical method of calculating xenon thermal conductivity from the empirically derived DIPPR curve fit recommended in this paper. Figure 4 shows that NIST results track well with DIPPR results. At $1150 \mathrm{~K}$ (reactor outlet gas temperature) the semi-empirical approach deviates from the empirically derived DIPPR value by $9.6 \%$.

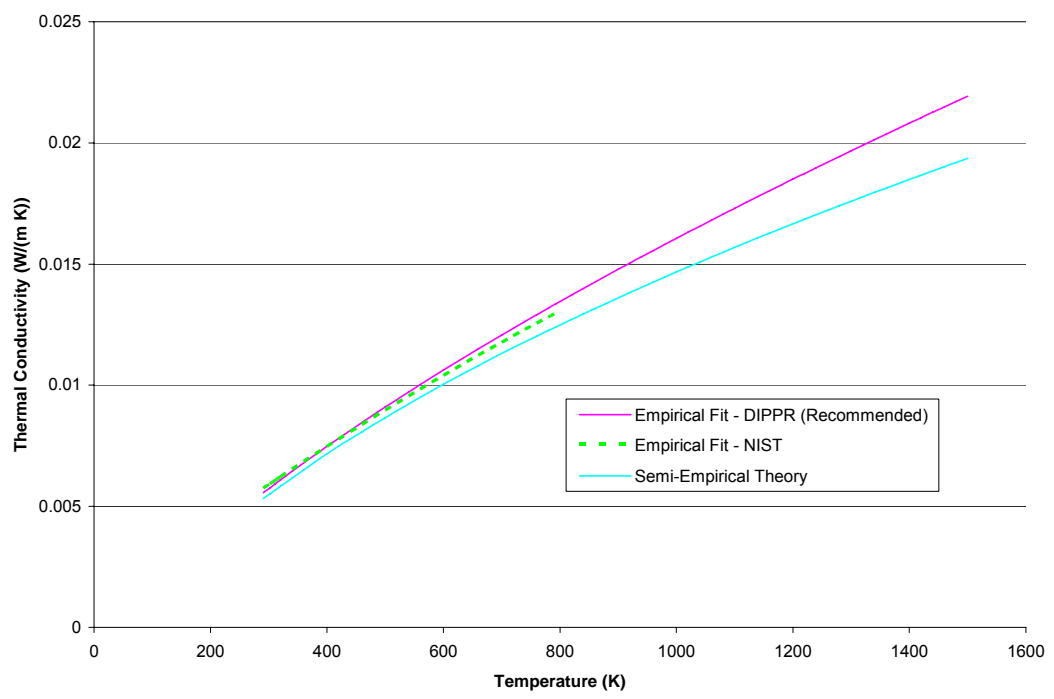

FIGURE 4. Xenon Thermal Conductivity as a Function of Temperature.

The work done by DIPPR and NIST includes a comprehensive analysis of pure component transport properties. The goal of these projects was to provide users with reliable, empirically derived transport properties. NIST and DIPPR compare well, validating pure property results for each organization. DIPPR was recommended over NIST as a result of the on-line NIST xenon temperature upper bound $(800 \mathrm{~K})$. While the semi-empirical approach is a valid 
method for determining pure component transport properties in the absence of experimental data, DIPPR and NIST empirically derived curve fits alleviate the need for a semi-empirical approach and provide better accuracy, particularly at higher temperatures.

\section{MIXED GAS RESULTS}

The empirical data used as points of comparison for HeXe mixed gas transport property estimates were obtained by a literature search performed by Idaho National Laboratory (INL). Only a limited amount of empirical mixture data has been found, especially for HeXe thermal conductivity.

\section{Viscosity}

The methods used to estimate gas mixture viscosity are as follows:

- Chapman and Enskog, (Hirschfelder, Curtiss, and Bird, 1954)

- Reichenberg, (Poling, Prausnitz, and O’Connell, 2001)

- Wilke, (Poling, Prausnitz, and O'Connell, 2001)

- Herning and Zipperer, (Poling, Prausnitz, and O’Connell, 2001)

- Lucas, (Poling, Prausnitz, and O’Connell, 2001)

\section{Chapman and Enskog}

The rigorous kinetic theory of Chapman and Enskog was described previously and is extended to include the binary interactions of molecules for the mixture viscosity. The Chapman and Enskog theory was derived by solving the Boltzman equation using the Sonine polynomial expansion. Due to rapid convergence of the Sonine polynomial, an accurate representation of the mixture viscosity coefficient can be acquired by including only the first term in the expansion. Chapman and Enskog define binary gas viscosity as (Hirschfelder, Curtiss, and Bird, 1954):

$$
\begin{gathered}
{\left[\mu_{m i x}\right]_{1}=\frac{1+Z_{\mu}}{X_{\mu}+Y_{\mu}} \quad(P a \cdot s)} \\
X_{\mu}=\frac{x_{1}^{2}}{\left[\mu_{1}\right]_{1}}+\frac{2 x_{1} x_{2}}{\left[\mu_{12}\right]_{1}}+\frac{x_{2}^{2}}{\left[\mu_{2}\right]_{1}} \\
Y_{\mu}=\frac{3}{5} A_{12}^{*}\left\{\frac{x_{1}^{2}}{\left[\mu_{1}\right]_{1}}\left(\frac{M_{1}}{M_{2}}\right)+\frac{2 x_{1} x_{2}}{\left[\mu_{12}\right]_{1}}\left(\frac{\left(M_{1}+M_{2}\right)^{2}}{4 M_{1} M_{2}}\right)\left(\frac{\left[\mu_{12}\right]_{1}^{2}}{\left[\mu_{1}\right]_{1}\left[\mu_{2}\right]_{1}}\right)+\frac{x_{2}^{2}}{\left[\mu_{2}\right]_{1}}\left(\frac{M_{2}}{M_{1}}\right)\right\} \\
Z_{\mu}=\frac{3}{5} A_{12}^{*}\left\{x_{1}^{2}\left(\frac{M_{1}}{M_{2}}\right)+2 x_{1} x_{2}\left[\left(\frac{\left(M_{1}+M_{2}\right)^{2}}{4 M_{1} M_{2}}\right)\left(\frac{\left[\mu_{12}\right]_{1}}{\left[\mu_{1}\right]_{1}}+\frac{\left[\mu_{12}\right]_{1}}{\left[\mu_{2}\right]_{1}}\right)-1\right]+x_{2}^{2}\left(\frac{M_{2}}{M_{1}}\right)\right\} \\
{\left[\mu_{12}\right]_{1}=2.6693 \times 10^{-6} \frac{\sqrt{2 M_{1} M_{2} T /\left(M_{1}+M_{2}\right)}}{\sigma_{12}^{2} \Omega_{12}^{(2,2)^{*}}} \quad(P a \cdot s)}
\end{gathered}
$$

where:

$\left[\mu_{\text {mix }}\right]_{1}=$ the binary mixture viscosity of the species 1 and 2 (Pa s) 
$X_{\mu}, Y_{\mu}, Z_{\mu}=$ parameters that account for the interaction of the gas molecules

$\mathrm{x}_{1}, \mathrm{x}_{2}=$ mole fractions of species 1 and 2

$\mathrm{M}_{1}, \mathrm{M}_{2}=$ molecular weights of species 1 and 2

$\mathrm{A}_{12}{ }^{*}=$ ratio of collision integrals that are functions of $\mathrm{T}_{12}{ }^{*}$

$\mathrm{T}_{12} *=$ dimensionless parameter of the binary mixture defined by $\mathrm{T}_{12} *=\mathrm{T} /\left(\varepsilon_{12} / \mathrm{k}\right)$

$\mathrm{T}=$ temperature $(\mathrm{K})$

$\varepsilon_{12} / k=\sqrt{\varepsilon_{1} / k \cdot \varepsilon_{2} / k}$, parameter in the potential function characteristic, of 1-2 interaction (K)

$\left[\mu_{1}\right]_{1}=$ the pure component viscosity of species $1(\mathrm{~Pa} \mathrm{~s})$

$\left[\mu_{2}\right]_{1}=$ the pure component viscosity of species $2(\mathrm{~Pa} \mathrm{~s})$

$\left[\mu_{12}\right]_{1}=$ coefficient of viscosity of a hypothetical pure substance, the molecules of which have a molecular weight of $2 M_{1} M_{2} /\left(M_{1}+M_{2}\right)$

\section{Reichenberg Method}

The method of Reichenberg is based on the rigorous kinetic theory of Chapman and Enskog with corresponding states methodology to obtain certain parameters. It is a simplified version compared to Chapman and Enskog and is considered the most accurate of the kinetic theory simplifications. The method of Reichenberg utilizes temperature, composition, pure component viscosity, critical temperature, critical pressure, molecular weight, and the dipole moment of each component. The pure component values used for this correlation were obtained from the DIPPR database. Due to the simplification of the kinetic theory, an assumption is made that $\mathrm{A}^{*}$; a collision integral ratio of a first order pure component interaction, is $5 / 3$. This assumption drops the effects of intermolecular forces in certain interactions. Polarized and ionized atoms/molecules are impacted by this assumption, and accounted for by a polar correction factor in the method of Reichenberg. This assumption simplified the equations by dropping several values in the $\mathrm{H}$ matrix of the kinetic theory to zero.

\section{Wilke Method}

The method of Wilke is a further simplified form of Chapman and Enskog and neglects second order effects. The same assumption of $\mathrm{A}^{*}$ being equal to $5 / 3$ is made in the method of Wilke, but a polar correction factor is not used to account for this assumption. This assumption drops the effects of intermolecular forces in certain interactions. Additional assumptions include that the ratios of collision integrals of the 1-2 to 2-2 interactions and 1-2 to 1-1 interactions are 1. This assumes that all molecules have the same hard sphere cross section (are the same size). Helium and xenon have a large size difference, possibly contributing to the discrepancy compared to the Chapman and Enskog method, which accounts for size differences. The method of Wilke is frequently utilized because of ease of calculation combined with adequate accuracy for many gas mixtures and temperature ranges.

\section{Herning and Zipperer Method}

The method of Herning and Zipperer is analogous to the method of Wilke. The only difference is in the determination of the interaction parameter, which is used to account for the interaction of molecules with respect to each other. Herning and Zipperer further simplified the calculation of this parameter to be the square root of the 
ratio of molecular weights. This method still gives relatively good results for non-polar mixtures, but additional accuracy is lost with the simplification of the interaction parameter.

Lucas Rules

The Lucas rules are based on corresponding states methods. This approach estimates pseudocritical and other mixture properties from pure component properties, the composition of the mixture, and mixing and combining rules defined by Lucas. The Lucas approach is the first of the correlations considered that is not interpolative, it will not result in the pure component viscosity if the mole fraction of one component is 1 and the mole fraction of the other component is 0 . The methods utilizing corresponding states are not as accurate as those based on the kinetic theory, but provide an advantage in the lack of necessity of having pure component data.

\section{Gas Mixture Viscosity Comparisons}

The empirical data obtained by INL for HeXe gas mixture viscosity are provided for a temperature range of approximately $300 \mathrm{~K}$ to $800 \mathrm{~K}$ at various mole fractions. The correlation methods described above were all computed using the DIPPR pure component equations, with the exception of the Lucas Rules, which do not utilize pure component values. This allows a consistent comparison of methods. The methods used for the comparison in Figure 5 and labeled as such are as follows:

- Empirical - HeXe mixture data literature search (Hashimoto, Matsunaga, Nagashima, and Mito, 1992; Kestin, Khalifa, and Wakeham, 1978; Mason and Von Ubisch, 1960; Mastovsky, 1977; and Saxena and Gandhi, 1963)

- Chapman (DIPPR) - Recommended - This is the method of Chapman and Enskog (Hirschfelder, Curtiss, and Bird, 1954) using DIPPR pure component values (Daubert et al., 1992) and collision integral curve fits of collision integral data provided in (Hirschfelder, Curtiss, and Bird, 1954)

- Wilke (DIPPR) - This is the Wilke mixture viscosity method (Poling, Prausnitz, and O'Connell, 2001) using DIPPR pure component values (Daubert et al., 1992) with no collision integrals required

- Reichenberg (DIPPR) - This is the method of Reichenberg (Poling, Prausnitz, and O'Connell, 2001) using DIPPR pure component values (Daubert et al., 1992) with no collision integrals required

- Herning and Zipperer (DIPPR) - This is the method of Herning and Zipperer (Poling, Prausnitz, and O’Connell, 2001) using DIPPR pure component values (Daubert et al., 1992) with no collision integrals required

- Lucas Rules - This is the method of Lucas (Poling, Prausnitz, and O'Connell, 2001) with no pure component properties or collision integrals required

The results of the correlations for gas mixture viscosity all compare well, with the exception of the method of Herning and Zipperer, and the Lucas Rules, which were expected to produce the least accurate results (Poling, Prausnitz, and O'Connell, 2001). All other correlations stayed within 5.2\% discrepancy in comparison to INL experimental mixture data (up to $800 \mathrm{~K}$ only). It should be noted that as temperature is increased, the Wilke simplification shows greater deviation from the full Chapman and Enskog theory. At $1150 \mathrm{~K}$ (reactor outlet gas temperature), the Wilke method deviates from the recommended method (Chapman and Enskog) by $6.4 \%$ for the mole fraction represented in Figure 5. The recommended method is Chapman (DIPPR), as it produces results with the least amount of discrepancy (1.2\% maximum) in comparison to the empirical mixture data.

When the Chapman and Enskog method is extended beyond binary mixtures (fission gas release), it becomes significantly more difficult to implement. This is caused by the need to take the determinants of larger matrices whose sizes are determined by an $(\mathrm{n}+1)$ by $(\mathrm{n}+1)$ matrix and an (n) by (n) matrix (Hirschfelder, Curtiss, and Bird, 1954), where $\mathrm{n}$ is the number of elements in the mixture. A potential solution to the added difficulty is to utilize programs that have built in functions to perform matrix calculations. 


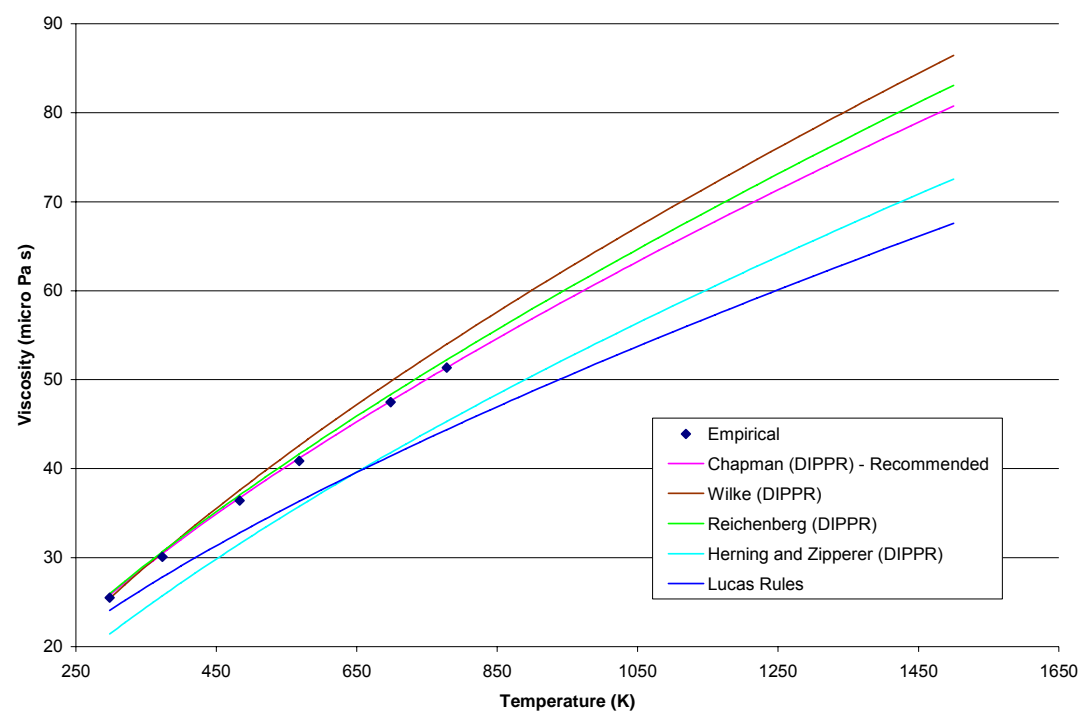

FIGURE 5. HeXe Viscosity as a Function of Temperature at 13.1 Atom \% Xenon.

\section{Thermal Conductivity}

The methods used to estimate gas mixture thermal conductivity are as follows:

- Chapman and Enskog (Hirshfelder, Curtiss, and Bird, 1954) including higher order correction factors (Kestin et al., 1984 and Singh, Dham, and Gupta, 1992)

- Mason and Saxena (Poling, Prausnitz, and O'Connell, 2001)

- Wassiljewa formulation (Poling, Prausnitz, and O'Connell, 2001)

- Chung (Poling, Prausnitz, and O’Connell, 2001)

The methods used to estimate gas mixture thermal conductivity are less accurate as compared to empirical data than those used to estimate gas mixture viscosity. Thermal conductivity is more susceptible to variations in the size of the molecules, variations in mass, concentration dependence, and temperature dependence (Singh, Dham, and Gupta, 1992). Additionally, the kinetic theory assumes a single average of the mean molecular velocities; deviations from actual thermal conductivity may be accounted for in the wide spectrum of molecular velocities in a mixture (Poling, Prausnitz, and O'Connell, 2001). Therefore, there is a greater expected error in HeXe gas mixture thermal conductivities than in gas mixture viscosities.

\section{Chapman and Enskog}

As described previously, the rigorous kinetic theory of Chapman and Enskog was derived by solving the Boltzman equation using the Sonine polynomial expansion of infinite terms. While the convergence of the Sonine polynomial provides an accurate representation of the mixture viscosity coefficient using only the first term in the expansion, this is not true for thermal conductivity. Therefore, a third order approximation; by truncation of the Sonine polynomial after three terms, is required. Kestin (Kestin et al., 1984) and Singh (Singh, Dham, and Gupta, 1992) provide higher order correction factors, up to a third order approximation to account for the second and third order terms in the Sonine polynomial. Singh's third order correction factor is an empirically derived correction factor for $\mathrm{HeXe}$, while the Kestin higher order correction factor is applied to the $\lambda_{12}$ term, which represents the thermal conductivity of a hypothetical pure substance of molecular weight $2 M_{1} M_{2} /\left(M_{1}+M_{2}\right)$. Singh's third order correction factor can also be theoretically defined in the absence of experimental data (Singh, Dham, and Gupta, 
1992). The equations for binary gas thermal conductivity (Hirschfelder, Curtiss, and Bird, 1954 and Kestin, et al., 1984) and the corresponding third order correction factor (Singh, Dham, and Gupta, 1992) are as follows:

$$
\begin{aligned}
& {\left[\lambda_{\text {mix }}\right]_{1}=\frac{1+Z_{\lambda}}{X_{\lambda}+Y_{\lambda}} \quad(W / m \cdot K)} \\
& X_{\lambda}=\frac{x_{1}^{2}}{\left[\lambda_{1}\right]_{1}}+\frac{2 x_{1} x_{2}}{\left[\lambda_{12}\right]_{1}}+\frac{x_{2}^{2}}{\left[\lambda_{2}\right]_{1}} \\
& Y_{\lambda}=\frac{x_{1}^{2}}{\left[\lambda_{1}\right]_{1}} U^{(1)}+\frac{2 x_{1} x_{2}}{\left[\lambda_{12}\right]_{1}} U^{(Y)}+\frac{x_{2}^{2}}{\left[\lambda_{2}\right]_{1}} U^{(2)} \\
& Z_{\lambda}=x_{1}^{2} U^{(1)}+2 x_{1} x_{2} U^{(Z)}+x_{2}^{2} U^{(2)} \\
& U^{(1)}=\frac{4}{15} A_{12}^{*}-\frac{1}{12}\left(\frac{12}{5} B_{12}^{*}+1\right) \frac{M_{1}}{M_{2}}+\frac{1}{2} \frac{\left(M_{1}-M_{2}\right)^{2}}{M_{1} M_{2}} \\
& U^{(2)}=\frac{4}{15} A_{12}^{*}-\frac{1}{12}\left(\frac{12}{5} B_{12}^{*}+1\right) \frac{M_{2}}{M_{1}}+\frac{1}{2} \frac{\left(M_{2}-M_{1}\right)^{2}}{M_{1} M_{2}} \\
& U^{(Y)}=\frac{4}{15} A_{12}^{*}\left(\frac{\left(M_{1}+M_{2}\right)^{2}}{4 M_{1} M_{2}}\right) \frac{\left[\lambda_{12}\right]_{1}^{2}}{\left[\lambda_{1}\right]_{1}\left[\lambda_{2}\right]_{1}}-\frac{1}{12}\left(\frac{12}{5} B_{12}^{*}+1\right)-\frac{5}{32 A_{12}^{*}}\left(\frac{12}{5} B_{12}^{*}-5\right) \frac{\left(M_{1}-M_{2}\right)^{2}}{M_{1} M_{2}} \\
& U^{(z)}=\frac{4}{15} A_{12}^{*}\left[\left(\frac{\left(M_{1}+M_{2}\right)^{2}}{4 M_{1} M_{2}}\right)\left(\frac{\left[\lambda_{12}\right]_{1}}{\left[\lambda_{1}\right]_{1}}+\frac{\left[\lambda_{12}\right]_{1}}{\left[\lambda_{2}\right]_{1}}\right)-1\right]-\frac{1}{12}\left(\frac{12}{5} B_{12}^{*}+1\right) \\
& {\left[\lambda_{12}\right]_{1}=(418.4)\left(1.9891 \times 10^{-4}\right) \frac{\sqrt{T\left(M_{1}+M_{2}\right) /\left(2 M_{1} M_{2}\right)}}{\sigma_{12}^{2} \Omega_{12}^{(2,2)^{*}}}(1+\Delta) \quad(W / m \cdot K)} \\
& {\left[\lambda_{\text {mix }}\right]_{3}=\left[f_{\lambda \text { mix }}\right]_{3}\left[\lambda_{\text {mix }}\right]_{1}}
\end{aligned}
$$

where:

$\left[\lambda_{\text {mix }}\right]_{1}=$ the binary mixture thermal conductivity of the species 1 and $2(\mathrm{~W} /(\mathrm{m} \mathrm{K}))$

$X_{\mu}, Y_{\mu}, Z_{\mu} U^{(1)}, U^{(2)}, U^{(Y)}, U^{(Z)}=$ parameters that account for the interaction of the gas molecules

$\mathrm{x}_{1}, \mathrm{x}_{2}=$ mole fractions of species 1 and 2

$\mathrm{M}_{1}, \mathrm{M}_{2}=$ molecular weights of species 1 and 2

$\mathrm{A}_{12} *=$ ratio of collision integrals that are functions of $\mathrm{T}_{12}{ }^{*}=\mathrm{T} /\left(\varepsilon_{12} / \mathrm{k}\right)$ 


$$
\begin{aligned}
& \mathrm{B}_{12}{ }^{*}=\text { ratio of collision integrals that are functions of } \mathrm{T}_{12}{ }^{*}=\mathrm{T} /\left(\varepsilon_{12} / \mathrm{k}\right) \\
& \mathrm{T}=\text { temperature }(\mathrm{K}) \\
& \varepsilon_{12} / \mathrm{k}=\sqrt{\varepsilon_{1} / \mathrm{k} \cdot \varepsilon_{2} / \mathrm{k}} \text {, parameter in the potential function characteristic, of } 1-2 \text { interaction }(\mathrm{K}) \\
& {\left[\lambda_{1}\right]_{1}=\text { the pure component thermal conductivity of species } 1(\mathrm{~W} /(\mathrm{m} \mathrm{K}))} \\
& {\left[\lambda_{2}\right]_{1}=\text { the pure component thermal conductivity of species } 2(\mathrm{~W} /(\mathrm{m} \mathrm{K}))} \\
& {\left[\lambda_{12}\right]_{1}=\text { coefficient of thermal conductivity of a hypothetical pure substance, the molecules of which have }} \\
& \text { a molecular weight of } 2 M_{1} M_{2} /\left(M_{1}+M_{2}\right)
\end{aligned}
$$

\section{Mason and Saxena Method}

The method of Wilke was described in the mixed gas viscosity section. The Mason and Saxena method is analogous to the method of Wilke for viscosity, with the components of viscosity replaced with the components of thermal conductivity for the mixture equation. An interaction parameter is included in the mixture equation to account for the interaction of atoms and molecules with each other. Wilke's interaction parameter was modified by Mason and Saxena, where the ratio of viscosities of the pure components is multiplied by the inverse of the ratio of molecular weights. All simplifications to the kinetic theory are the same as described in the Wilke method.

\section{Wassiljewa Formulation}

The Wassiljewa formulation is analogous to the Mason and Saxena modification of the Wilke method. The difference is in the formulation of the interaction parameter. The parameter is further simplified by a corresponding states method that uses critical temperature and pressure to determine the value. The advantage gained in this formulation is that the pure component viscosities are not needed; however, the pure component thermal conductivities are still needed.

\section{Chung Method}

The method of Chung is a corresponding states method derived in a manner similar to the Lucas Rules, but utilizes the mixing and combining rules determined by Chung. This method produces less accurate results, but has the advantage of not requiring pure component viscosities or thermal conductivities.

\section{Gas Mixture Thermal Conductivity Comparisons}

The empirical data obtained by INL for HeXe gas mixture thermal conductivity are provided at five temperatures for several mole fractions. The temperatures are $291.2 \mathrm{~K}, 302.2 \mathrm{~K}, 311.2 \mathrm{~K}, 793.2 \mathrm{~K}$, and $1500 \mathrm{~K}$. The experimental data were obtained from several different researchers. As a result, the mole fractions of the various empirical data at different temperatures do not match. Therefore, it is not possible to compare the theoretical results to empirical data as a function of temperature for one mole fraction, as was done with viscosity. Because of this, Table 1 is provided to compare the various mixture methods to INL empirical data at only the mole fractions of interest (0.1 to 0.4 xenon) to Project Prometheus for the available temperatures. To show the divergence of methods at higher temperatures, Figure 6 was included for the baseline Prometheus xenon mole fraction $(0.216$ xenon). This graph does not benchmark against any empirical data, but is used to show divergence of methods as temperature increases. The methods used for the comparison in Figure 6 and labeled as such are as follows: 
- Chapman (DIPPR) - Recommended - This is the method of Chapman and Enskog (Hirschfelder, Curtiss, and Bird, 1954) using DIPPR pure component values (Daubert et al., 1992) and collision integral curve fits of collision integral data provided in (Hirschfelder, Curtiss, and Bird, 1954)

- Mason (DIPPR) - This is the Wilke mixture viscosity method (Poling, Prausnitz, and O'Connell, 2001) using DIPPR pure component values (Daubert et al., 1992) with no collision integrals required

- Wassiljewa Formulation - This is the Wassiljewa formulation (Poling, Prausnitz, and O'Connell, 2001) with no pure component properties or collision integrals required

- Chung Rules - This is the method of Chung (Poling, Prausnitz, and O'Connell, 2001) with no pure component properties or collision integrals required

TABLE 1. HeXe Mixture Thermal Conductivity Comparison Results

\begin{tabular}{|c|c|c|c|c|c|c|}
\hline Temperature (K) & $\begin{array}{l}\text { Xenon Mole } \\
\text { Fraction }\end{array}$ & Empirical & Mason (DIPPR) & Wassiljewa & Chung Rules & $\begin{array}{l}\text { Chapman (DIPPR) - } \\
\text { Recommended }\end{array}$ \\
\hline 291.2 & 0.139 & 0.09127 & $\begin{array}{r}0.0989 \\
\end{array}$ & 0.0763 & 0.0528 & 0.0958 \\
\hline 291.2 & 0.201 & 0.07536 & 0.0832 & 0.0604 & 0.0383 & 0.0801 \\
\hline 291.2 & 0.304 & 0.06029 & 0.0631 & 0.0431 & 0.0255 & 0.0606 \\
\hline 291.2 & 0.401 & 0.04647 & 0.0490 & 0.0325 & 0.0187 & 0.0470 \\
\hline 302.2 & 0.213 & 0.0788 & 0.0826 & 0.0576 & 0.0372 & 0.0793 \\
\hline 302.2 & 0.283 & 0.06406 & 0.0686 & 0.0456 & 0.0282 & 0.0656 \\
\hline 311.2 & 0.1139 & 0.1081 & 0.1113 & 0.0846 & 0.0645 & 0.1078 \\
\hline 311.2 & 0.2603 & 0.07092 & 0.0744 & 0.0487 & 0.0313 & 0.0711 \\
\hline 311.2 & 0.346 & 0.05527 & 0.0595 & 0.0373 & 0.0233 & 0.0567 \\
\hline 793.2 & 0.213 & 0.1658 & 0.1687 & 0.0173 & 0.0701 & 0.1568 \\
\hline 793.2 & 0.283 & 0.1369 & 0.1416 & 0.0160 & 0.0538 & 0.1303 \\
\hline 1500 & 0.1 & 0.358 & 0.3715 & 0.0142 & 0.1973 & 0.3472 \\
\hline 1500 & 0.1 & 0.3364 & 0.3715 & 0.0142 & 0.1973 & 0.3472 \\
\hline \multirow[t]{2}{*}{1500} & 0.3 & 0.1893 & 0.2232 & 0.0192 & 0.0769 & 0.1955 \\
\hline & & & $\%$ Discrepancy & $\%$ Discrepancy & $\%$ Discrepancy & $\%$ Discrepancy \\
\hline 291.2 & 0.139 & & $\begin{array}{r}8.37 \\
\end{array}$ & 16.45 & 42.19 & 4.95 \\
\hline 291.2 & 0.201 & & 10.34 & 19.82 & 49.20 & 5.92 \\
\hline 291.2 & 0.304 & & 4.73 & 28.47 & 57.76 & 0.03 \\
\hline 291.2 & 0.401 & & 5.53 & 30.13 & 59.66 & 0.61 \\
\hline 302.2 & 0.213 & & 4.86 & 26.95 & 52.78 & 0.34 \\
\hline 302.2 & 0.283 & & 7.04 & 28.78 & 56.01 & 1.98 \\
\hline 311.2 & 0.1139 & & 2.93 & 21.76 & 40.31 & 0.42 \\
\hline 311.2 & 0.2603 & & 4.87 & 31.37 & 55.87 & 0.17 \\
\hline 311.2 & 0.346 & & 7.60 & 32.50 & 57.90 & 2.10 \\
\hline 793.2 & 0.213 & & 1.77 & 89.57 & 57.70 & 5.67 \\
\hline 793.2 & 0.283 & & 3.44 & 88.34 & 60.69 & 5.17 \\
\hline 1500 & $\begin{array}{l}0.1 \\
\end{array}$ & & 3.76 & 96.02 & 44.89 & 3.12 \\
\hline 1500 & 0.1 & & 10.42 & 95.77 & 41.35 & 3.10 \\
\hline 1500 & 0.3 & & 17.89 & 89.85 & 59.37 & 2.89 \\
\hline \multirow{2}{*}{\multicolumn{3}{|c|}{$\begin{array}{l}\text { Sum of Discrepancies } \\
\text { Root Mean Square (RMS) of Discrepancies }\end{array}$}} & 93.55 & 695.79 & 735.68 & 36.47 \\
\hline & & & 7.80 & 59.01 & 53.04 & 3.33 \\
\hline
\end{tabular}




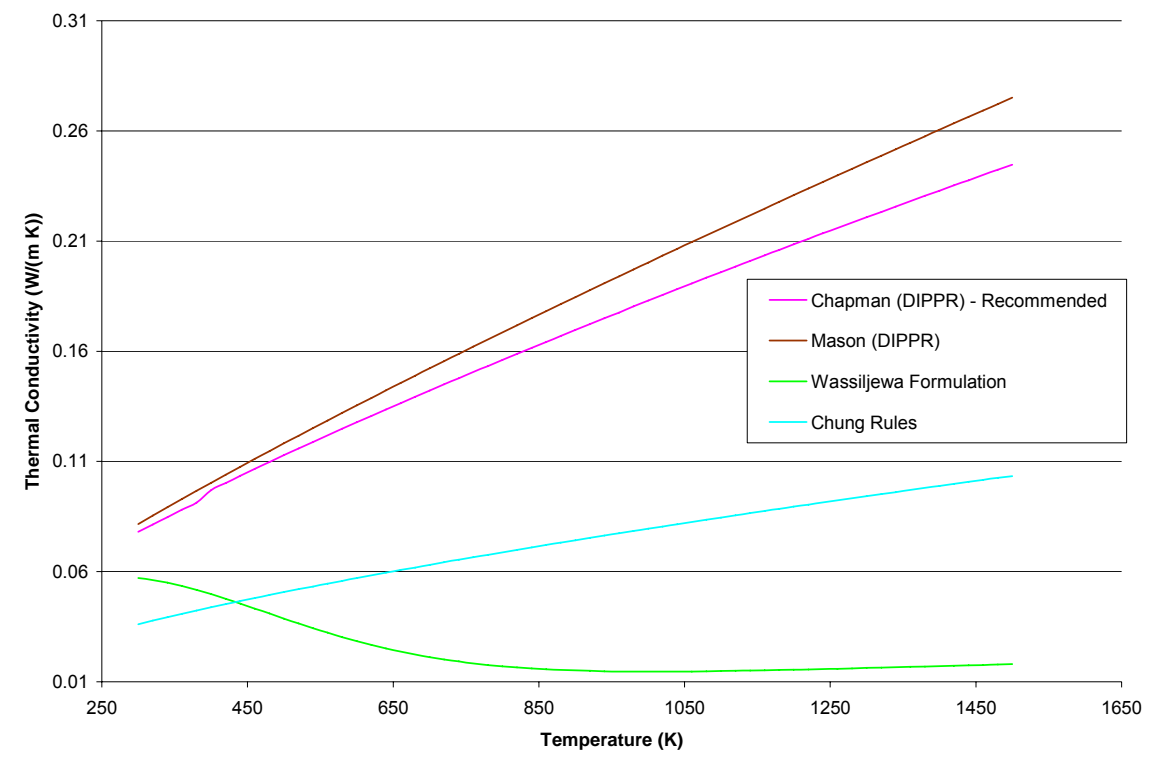

FIGURE 6. HeXe Thermal Conductivity as a Function of Temperature at 21.6 Atom \% Xenon.

HeXe gas mixture thermal conductivity estimates are not as consistent as the mixture viscosity estimates and do not compare as well to empirical data. The Wassiljewa formulation and the method of Chung were very inaccurate. The Chapman (DIPPR) method stayed within $5.7 \%$ of INL provided empirical data, while the Mason (DIPPR) method was less accurate.

Chapman (DIPPR) uses the Chapman and Enskog mixture method for calculating thermal conductivity (Hirschfelder, Curtiss, and Bird, 1954) with higher order correction factors given by Kestin (Kestin et al., 1984) and Singh (Singh, Dham, and Gupta, 1992).

When the Chapman and Enskog method is extended beyond binary mixtures, it becomes significantly more difficult to implement. This is caused by the need to take the determinants of larger matrices whose sizes are determined by an $(\mathrm{n}+1)$ by $(\mathrm{n}+1)$ matrix and an (n) by (n) matrix (Hirschfelder, Curtiss, and Bird, 1954), where $\mathrm{n}$ is the number of elements in the mixture. A potential solution to the added difficulty is to utilize programs that include matrix calculations as built in functions.

\section{FUTURE WORK}

Currently, only five thermal conductivity and six viscosity mixed gas data points have been identified in the literature for xenon mole fractions ranging from 0.1 to 0.4 with temperatures greater than $390 \mathrm{~K}$ (the lowest $\mathrm{HeXe}$ temperature in the SNPP), all at atmospheric pressure. Unless further literature review were to provide substantial additional data, it would be necessary to recommend obtaining additional experimental data against which to benchmark the recommended mixture method. In addition, the effects of pressure on viscosity and thermal conductivity and the deviation of density and specific heat from ideal gas behavior need to be assessed for the ranges of Prometheus system temperature and pressure.

\section{CONCLUSIONS}

Helium and xenon pure component and mixture viscosity and thermal conductivity were required for Project Prometheus calculations of a direct cycle Brayton nuclear power plant concept. The purpose of this evaluation was to recommend the best methods to calculate the transport properties with the current available information. 
Adequate helium and xenon pure component viscosity and thermal conductivity data exist to allow the use of curve fits of experimental data. The method recommended to calculate the viscosity and thermal conductivity of pure helium and pure xenon is to use equations provided by the Design Institute for Physical Property Data (DIPPR) (Daubert et al., 1992). These equations were produced from curve fits of experimental data and include a quality estimate with each correlation. The quality estimate represents the average reliability of data plus error from regression. DIPPR indicates less than 3\% error for helium and xenon viscosity and less than $5 \%$ error for helium and xenon thermal conductivity.

By contrast, mixture data are relatively few. Presumably, this is because of a lack of applications for HeXe use as a heat transfer or working fluid. While a number of methods exist for estimating gas mixture transport properties, the selection of the optimal method in this case is complicated by the lack of actual data for comparison. Future work may be required to obtain additional experimental data.

The method recommended to calculate the viscosity and thermal conductivity of HeXe mixtures is the rigorous kinetic theory described by Hirschfelder (Hirschfelder, Curtiss, and Bird, 1954) with the addition of two higher order thermal conductivity correction factors provided by Kestin (Kestin et al., 1984) and Singh (Singh, Dham, and Gupta, 1992). This mixture method; when coupled with the use of DIPPR pure component equations, is referred to as the Chapman (DIPPR) method. Of the mixture methods evaluated, the results of the Chapman (DIPPR) method compare best to the limited amount of experimental mixture data currently available. Different system calculations and component designs have different sensitivities to variations in transport property values, but impacts are potentially significant.

\section{ACKNOWLEDGMENTS}

The Naval Reactors Prime Contractor Team acknowledges the support received from NASA Glenn Research Center and Idaho National Laboratory.

\section{REFERENCES}

Daubert, T. E. et al., "Physical and Thermodynamic Properties of Pure Chemicals," DIPPR Project 801 Evaluated Process Design Data, American Institute of Chemical Engineers and the Design Institute for Physical Property Data, 1992.

Hirschfelder, J. O, Curtiss, C. F., and Bird, R. B., Molecular Theory of Gases and Liquids, John Wiley \& Sons, New York, 1954.

Kestin, J., Knierim, K., Mason, E. A., Najafi, B., Ro, S. T., and Waldman, M., "Equilibrium and Transport Properties of the Noble Gases and Their Mixtures at Low Density," Journal of Physical and Chemical Reference Data, Vol. 13, No. 1, 1984.

Singh, K., Dham, A. K., and Gupta, S. C., "Empirical Relationship for Higher Order Contributions to Thermal Conductivity of Gas Mixtures," Journal of Physics B, Atomic, Molecular, and Optical Physics 25, 679-685, 1992.

Linstrom, P.J. and Mallard, W.G., NIST Chemistry WebBook,NIST Standard Reference Database 69, June 2005, National Institute of Standards and Technology, Gaithersburg MD, 20899 (http://webbook.nist.gov).

Bird, R. B., Stewart, W. E., and Lightfoot, E. N., Transport Phenomena, Second Edition, John Wiley \& Sons, New York, 2002.

Poling, B. E., Prausnitz, J. M., and O'Connell, J. P., The Properties of Gases and Liquids, Fifth Edition, McGraw-Hill, New York, 2001.

Hashimoto, K., Matsunaga, N., Nagashima, A., and Mito, K., "Determination of the Thermal Conductivity of Xenon-Helium Mixtures at High Temperatures by the Shock Tube Method", International Journal of Thermophysics, 13 (2), 211-221, 1992.

Kestin, J., Khalifa, H. E., and Wakeham, W. A., "The Viscosity and Diffusion Coefficients of Binary Mixtures of Xenon With Other Noble Gases," Physica A, 90 (2), 215-228, 1978.

Mason, E. A., and Von Ubisch, H., "Thermal Conductivities of Rare Gas Mixtures,” Phys. Fluids, 3 (3), 255-361, 1960.

Mastovsky, J., "High-Temperature Conduction of Helium-Xenon Mixtures,” Journal of Engineering Physics, 33 (4), 1170-1175, 1977.

Saxena, S. C., and Gandhi, J. M., "Thermal Conductivity of Multicomponent Mixtures of Inert Gases," Reviews of Modern Physics, 35 (4), 1022-1023, 1963. 
Enclosure 15 to

SPP-SEC-0039

\title{
Modeling Compact Counter-Flow Heat Exchangers with RELAP5-3D
}

\author{
Crittenden, J.T.
}


This page is intentionally blank.

PRE-DECISIONAL - For planning and discussion purposes only 


\title{
Modeling Counter Flow Heat Exchangers with RELAP5-3D
}

\author{
Jacob T. Crittenden \\ Space Plant Systems - Bettis Laboratory \\ Bechtel Bettis, Inc.
}

\section{STAIF 2006}

February 2006 
- Introduction \& Project Overview

- Modeling Counter Flow Heat Exchangers with Control Volume Codes

- Staggered Mesh Solution

- Accounting for End Volumes

- Errors Introduced

- Limitations

- Compact Heat Exchangers

- Heat Convection Coefficient Correlations

- Conclusion 


\section{Introduction \& Project Overview}

- Bechtel and Lockheed Martin collaborated on a design of a nuclear reactor for the NASA Jupiter Icy Moons Orbiter (JIMO) under Naval Reactors' cognizance.

- The JIMO mission would have required $100-300 \mathrm{kWe}$ to propel the spacecraft to the outer planets, orbit the moons, and perform scientific investigations from lunar orbit.

- A gas-cooled fast reactor (GFR) directly connected to one or more closed-loop Brayton cycles was chosen as the best candidate to meet the mission requirements based on current technology.

- A RELAP5-3D model of the reactor and closed-loop Brayton cycle was developed to perform dynamic analysis of the JIMO reactor plant.

- The RELAP5-3D computer code is used at Bechtel and widely in the commercial nuclear industry for dynamic analysis of nuclear reactor plants.

- The remainder of this presentation discusses a technique developed at Bettis to model the compact counter-flow heat exchangers used in the Brayton cycle. 


\section{Introduction \& Project Overview}

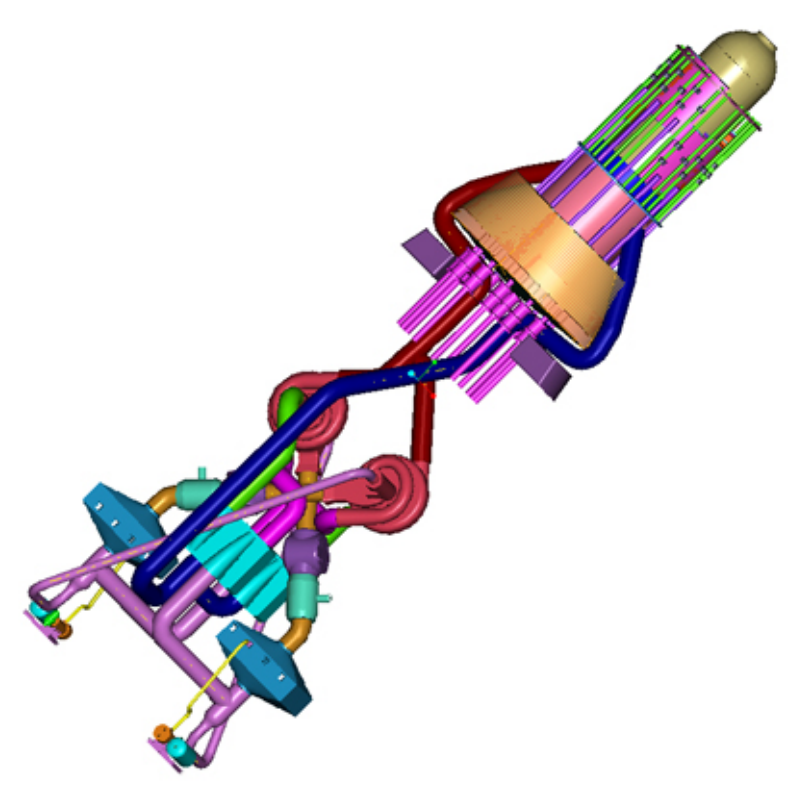

- Gas coolant is 22\% Xenon, $78 \%$ helium by mole fraction

- Low Prandtl Number

- Two Brayton loops depicted here, actual model concept utilized two but the number on the flight unit was yet to be determined.

- Recuperator included in each loop to improve cycle efficiency

- Gas Cooler included in each loop to transfer waste heat 


\section{RELAP5-3D Model}

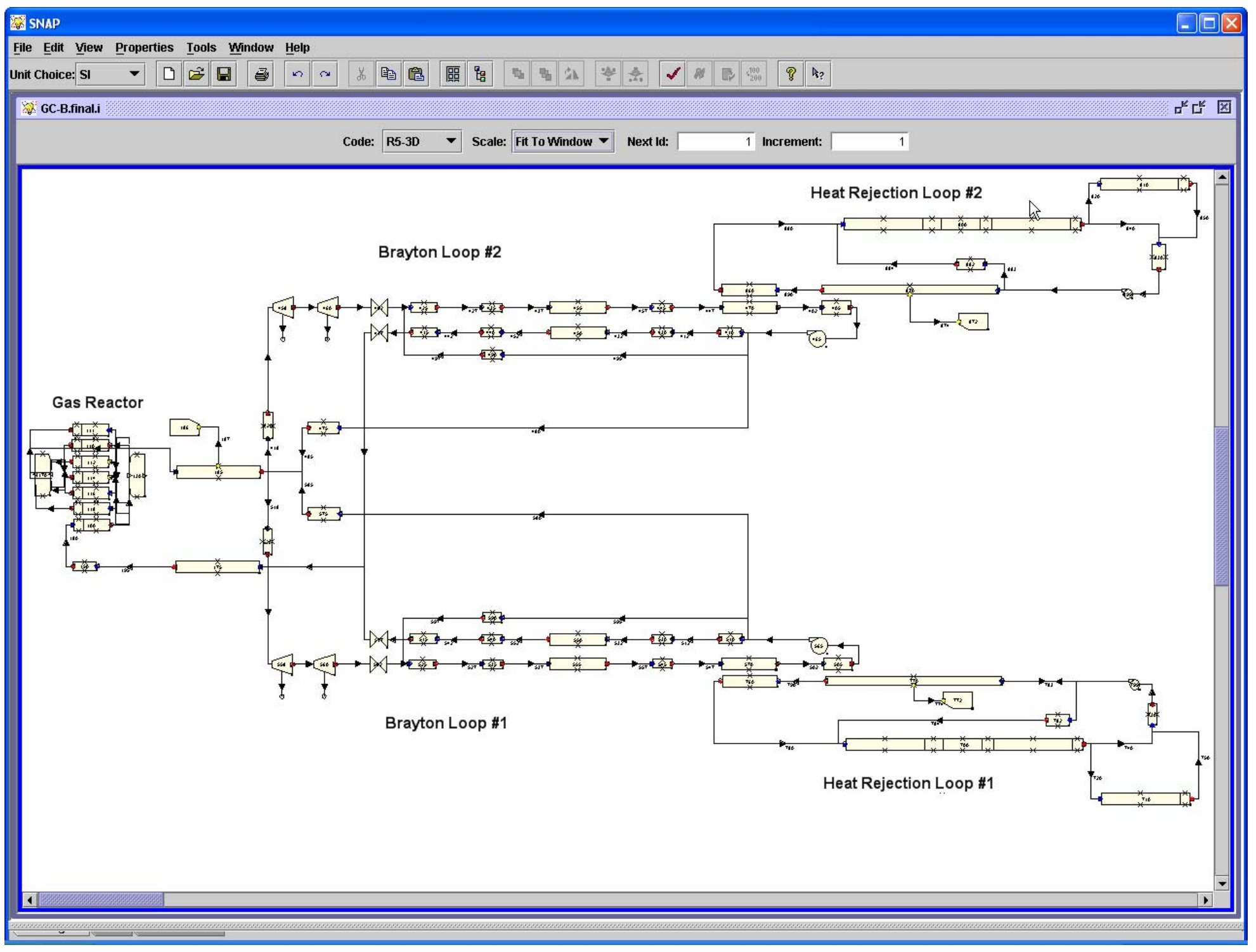




\section{Counter Flow Heat Exchangers}

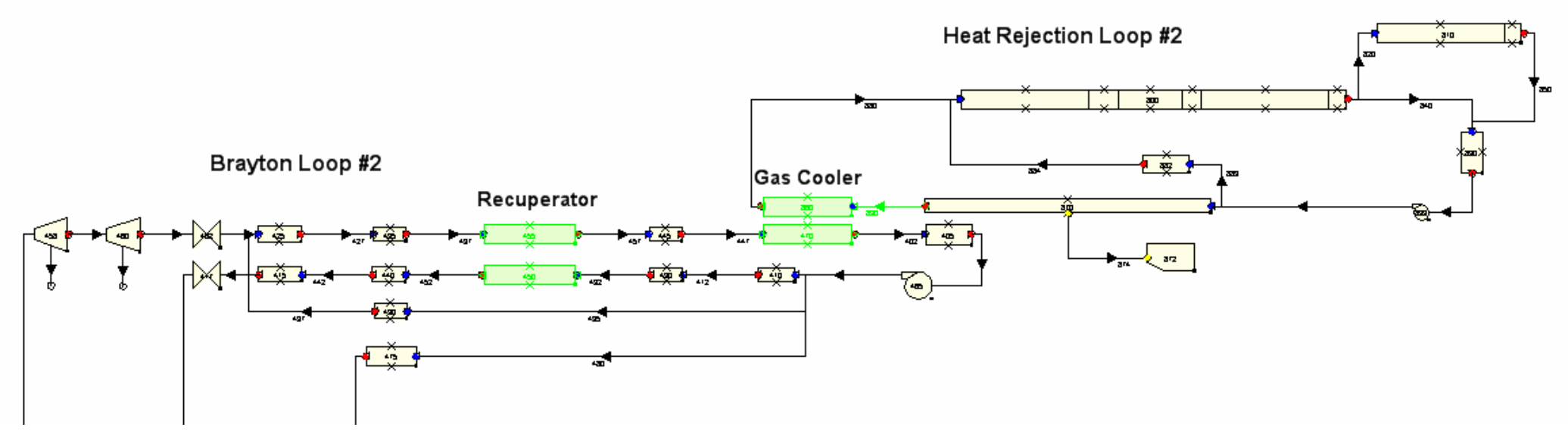


- Numerous control volumes required to model counter-flow heat exchangers in RELAP5-3D and other similar codes.

- Constant temperature assumption over control volume

- Control volume temperature based on outlet temperature derived from energy conservation

- Large number of control volumes increase problem run time

- Reduces material Courant Limit

- Increases number of calculations

- Large number of control volumes may invalidate constitutive requirements

- Not a concern for single phase heat exchangers

- Small number of control volumes increase calculation error due to constant exit temperature assumption 


\section{Temperature Error}

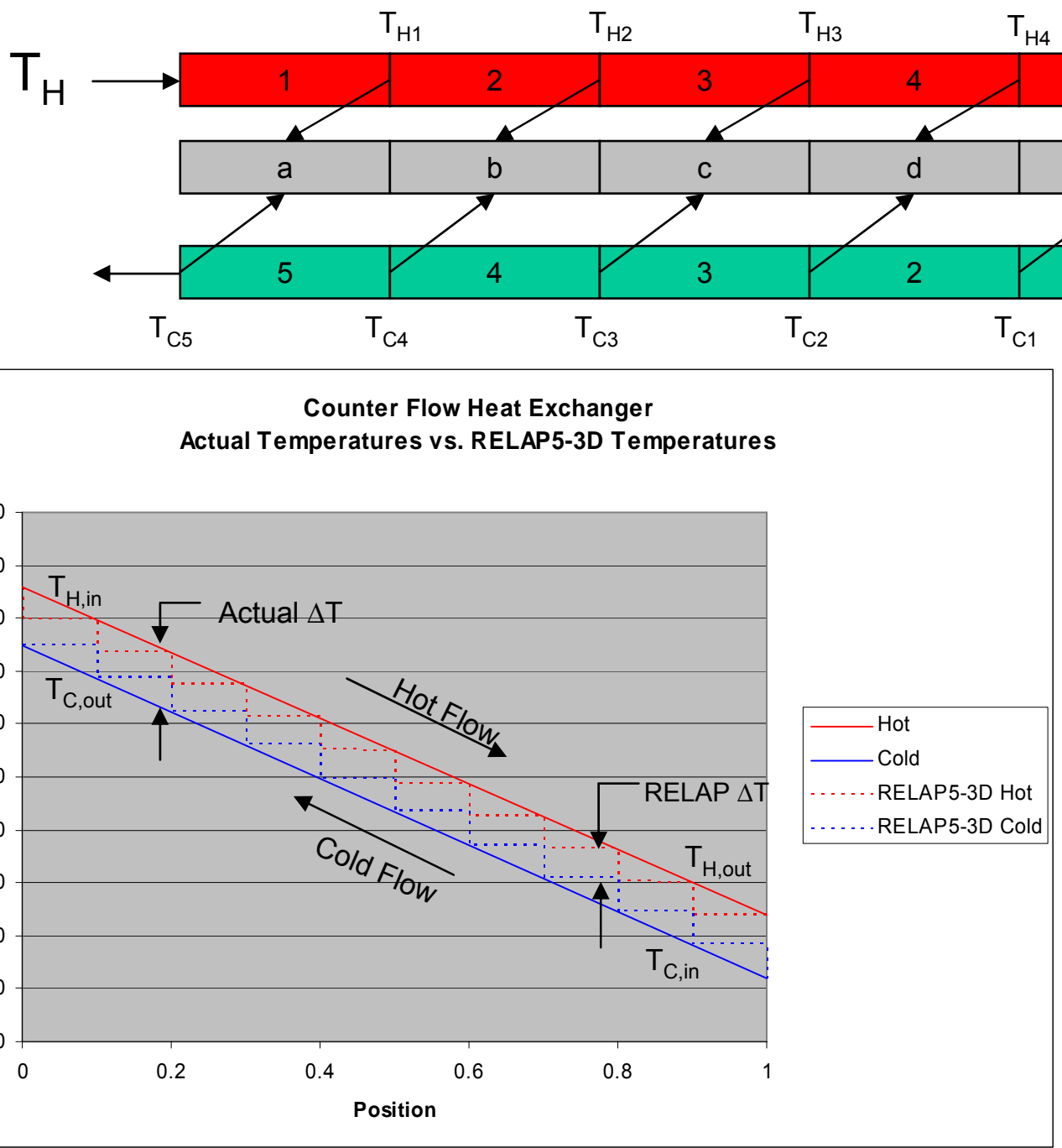

- Wall temperature boundary conditions applied from different axial planes

- Error introduced into the $\Delta T$ applied across the heat structure

- Error inversely proportional to number of sub-volumes

- Current wall temperature coupling imposes a lower sub-volume limit 


\section{Correcting Temperature Error}

\section{$Q=U A \Delta T$}

Correct the Heat Transfer

- Use code multipliers to artificially increase U

- May alter transient behavior

- Diminishing returns as number of control volumes is decreased

- All codes may not have this capability

- Arbitrarily increase A

- May alter transient behavior

- Diminishing returns
Minimize the $\Delta \mathrm{T}$ Error

- Increase sub-volumes

- Slows problem execution

- Lowers courant limit

- Increases calculations

- May invalidate constitutive models

- May require excessive subvolumes to minimize error

- JIMO recuperator required 1000 sub-volumes to reduce error below $1 \%$ 


\section{Staggered Mesh Solution}
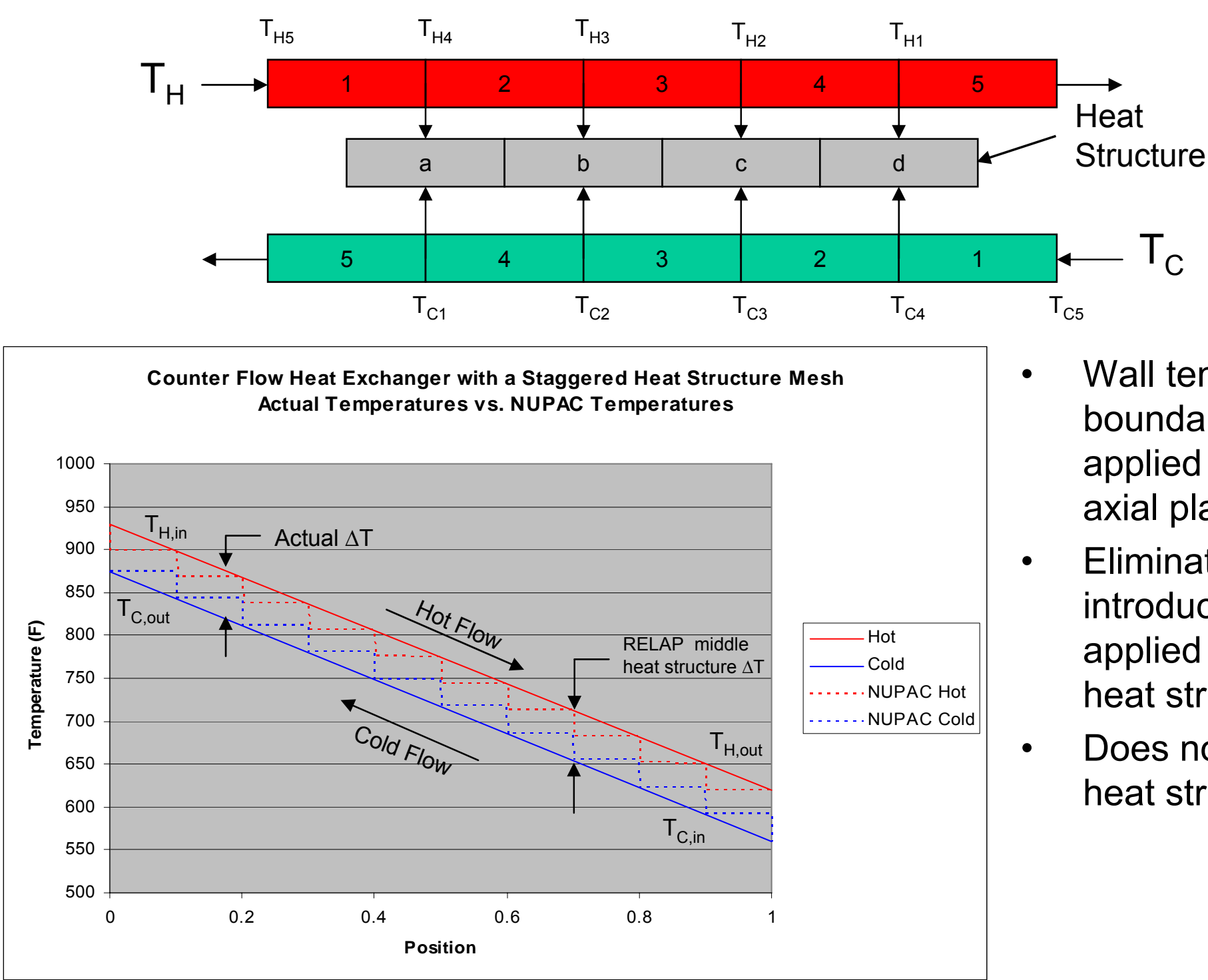

- Wall temperature boundary conditions applied from same axial plane

- Eliminates error introduced into the $\Delta T$ applied across the heat structure

- Does not account for heat structure ends 


\section{Accounting for End Volumes}

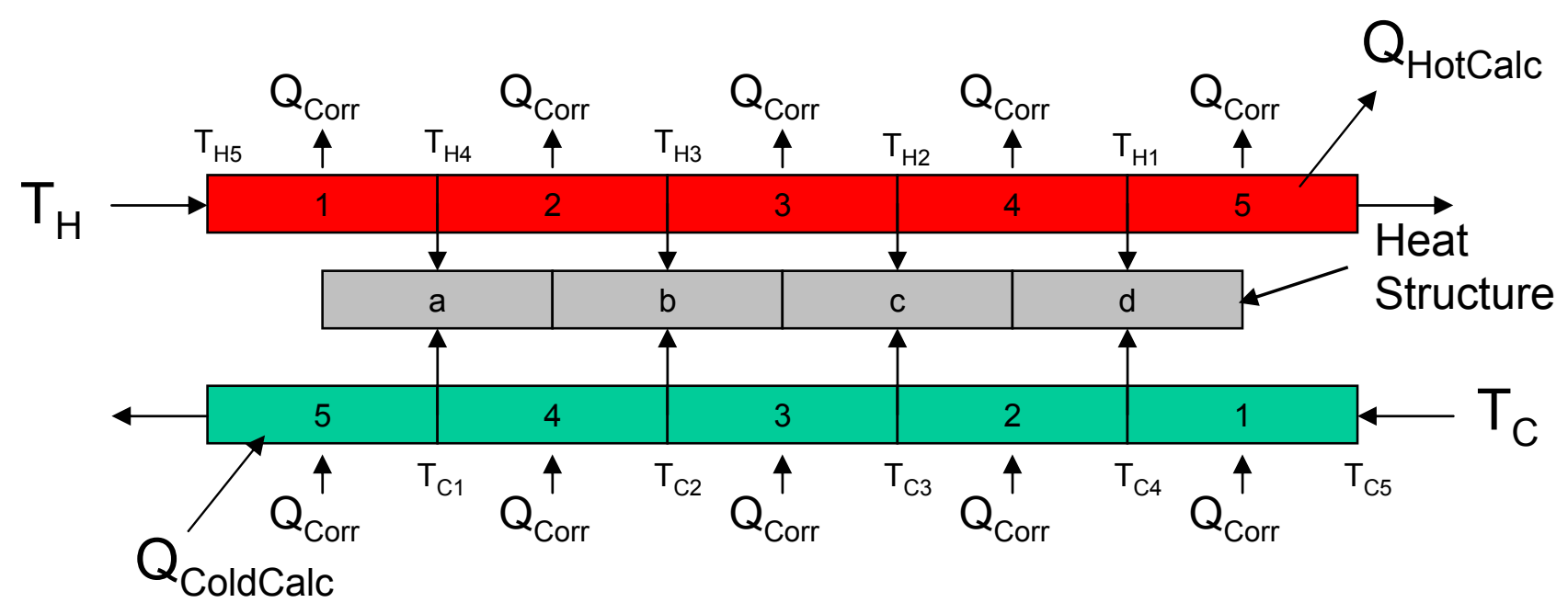

- End volume extrapolated heat added/subtracted to respective volumes

- Thermal equilibrium maintained by evenly dividing the difference between hot and cold side extrapolated heat values among all heat exchanger volumes

- Successful application of this method for the JIMO project resulted in steady state heat exchanger effectiveness values within 1 percent of those calculated by CCEP calculations carried out at NASA GRC 


\section{Errors Introduced}

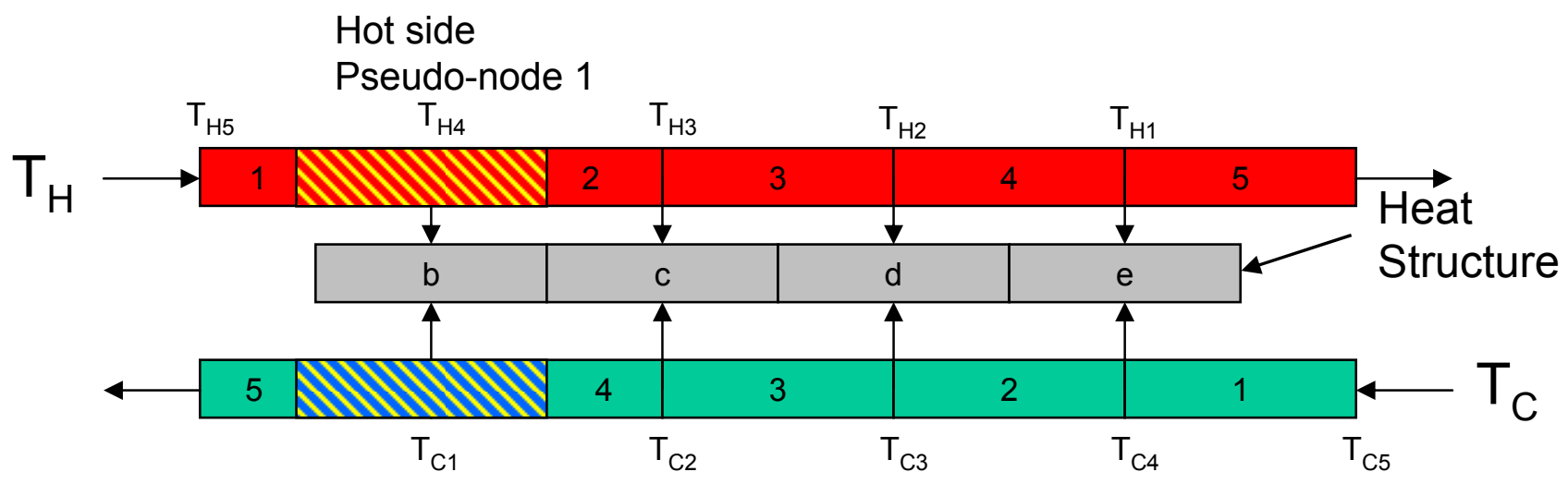

Cold side

Pseudo-node n-1

- Method correctly calculates how much heat should be transferred between pseudo-nodes as depicted in the above picture

- Pseudo-nodes comprised of $1 / 2$ the sub-volume before and after the temperature point

- Heat is transferred "forward" from hot side 1 to cold side $n-1$, hot side 2 to cold side $\mathrm{n}-2$, etc.

- Results in a slight discrepancy between this method and the analytic solution

- Total steady state error was less than 1 percent relative to CCEP 


\section{Limitations}

- Method provided excellent agreement with steady state benchmarking

- Transient solution was not rigorously tested due to project termination

- Method would not have correctly calculated heat transfer during reverse flow conditions

- No reverse flow operations were planned or anticipated

- Any reverse flow conditions brought on by equipment malfunctions would have been quickly corrected or isolated

- Calculations would have returned to normal once the flow reversal was corrected 


\section{Compact Heat Exchangers}

- Offset strip fin design

- Required an overall temperature effectiveness to decrement the total heat transfer area used in the analysis code

- Enhanced heat transfer by preventing fully developed flow

- Required modifications to the heat convection correlations

- The He Xe mixture proposed for the primary system had an extremely low Prandtl number ( 0.2$)$

- Required modified heat convection correlations 


\section{Temperature Effectiveness}

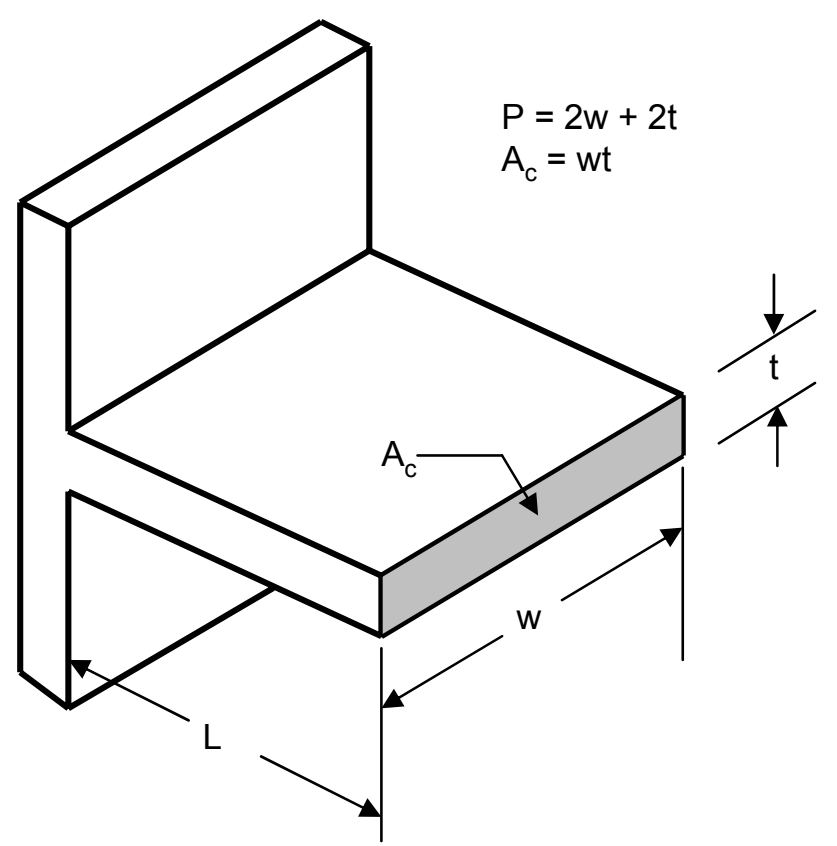

Temperature Effectiveness:

$$
\eta_{0}=1-\frac{A_{f}}{A} \cdot\left(1-\eta_{f}\right)
$$

Fin Effectiveness:

$$
\eta_{\mathrm{f}}=\frac{\tanh (\mathrm{m} \cdot \mathrm{L})}{\mathrm{m} \cdot \mathrm{L}}
$$

Fin Parameter:

$$
\mathrm{m}=\sqrt{\frac{\mathrm{h} \cdot \mathrm{P}}{\mathrm{k} \cdot \mathrm{A}_{\mathrm{c}}}}=\sqrt{\frac{2 \cdot \mathrm{h}}{\mathrm{k} \cdot \mathrm{t}}}
$$

- Temperature effectiveness used as a heat transfer design factor to directly decrement the heat transfer coefficient. It could also be used in pre-processing to decrement the heat transfer area.

- Temperature effectiveness is a function of heat transfer coefficient (h) and may vary during transients.

- Input as a constant for JIMO. This would have been investigated had the project continued. 


\section{Heat Convection Coefficient Correlations}

- Two constant Nusselt Number laminar correlations available in RELAP5-3D

- Exact solution for circular tubes (Sellars, Tribus, and Klein )

$$
\mathrm{Nu}=4.36
$$

- Exact solution for large aspect ratio flat plates (ORNL)

$$
\mathrm{Nu}=7.63
$$

- Flat plate solution more accurately represents the compact heat exchangers

- RELAP5-3D also has a Reynolds Number dependency relation for laminar flow (PSU)

$$
\mathrm{Nu}_{\text {lam }}(\mathrm{Re})=\mathrm{Nu}_{\text {analytic }}\left(0.414+5.91 \cdot 10^{-4} \cdot \mathrm{Re}\right)
$$




\section{ORNL/PSU Correlation vs. Kays \& London}

Comparison of Kays \& London and ORNL/PSU Heat Transfer Correlations

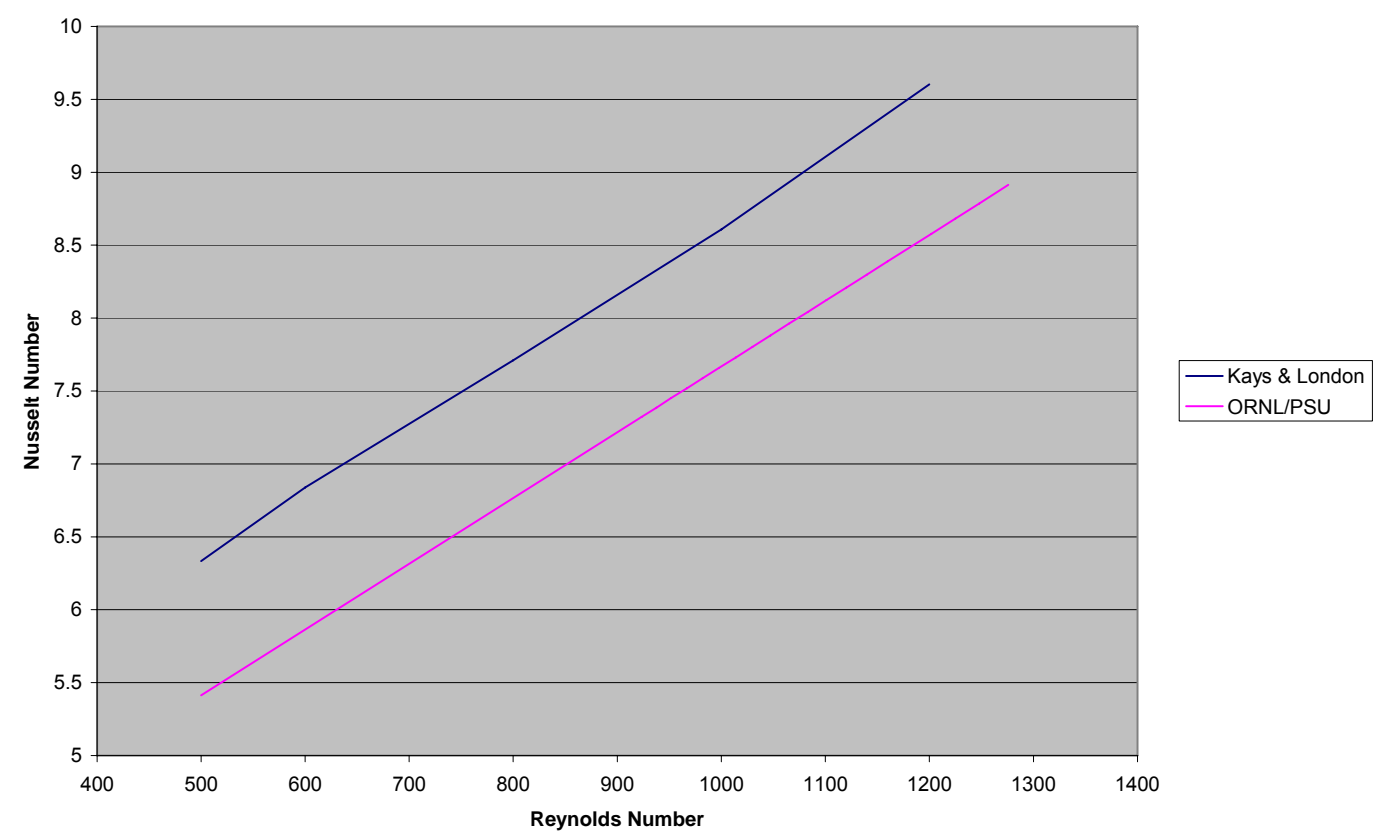

- Modified RELAP correlation has essentially the same slope as the empirical correlation developed by Kays \& London for a similar heat exchanger

- Nusselt Number predictions over the range of Reynolds Number of interest are within 15 percent 


\section{Correction for Entrance Effects}

Comparison of Kays \& London and modified ORNL/PSU Heat Transfer Correlations

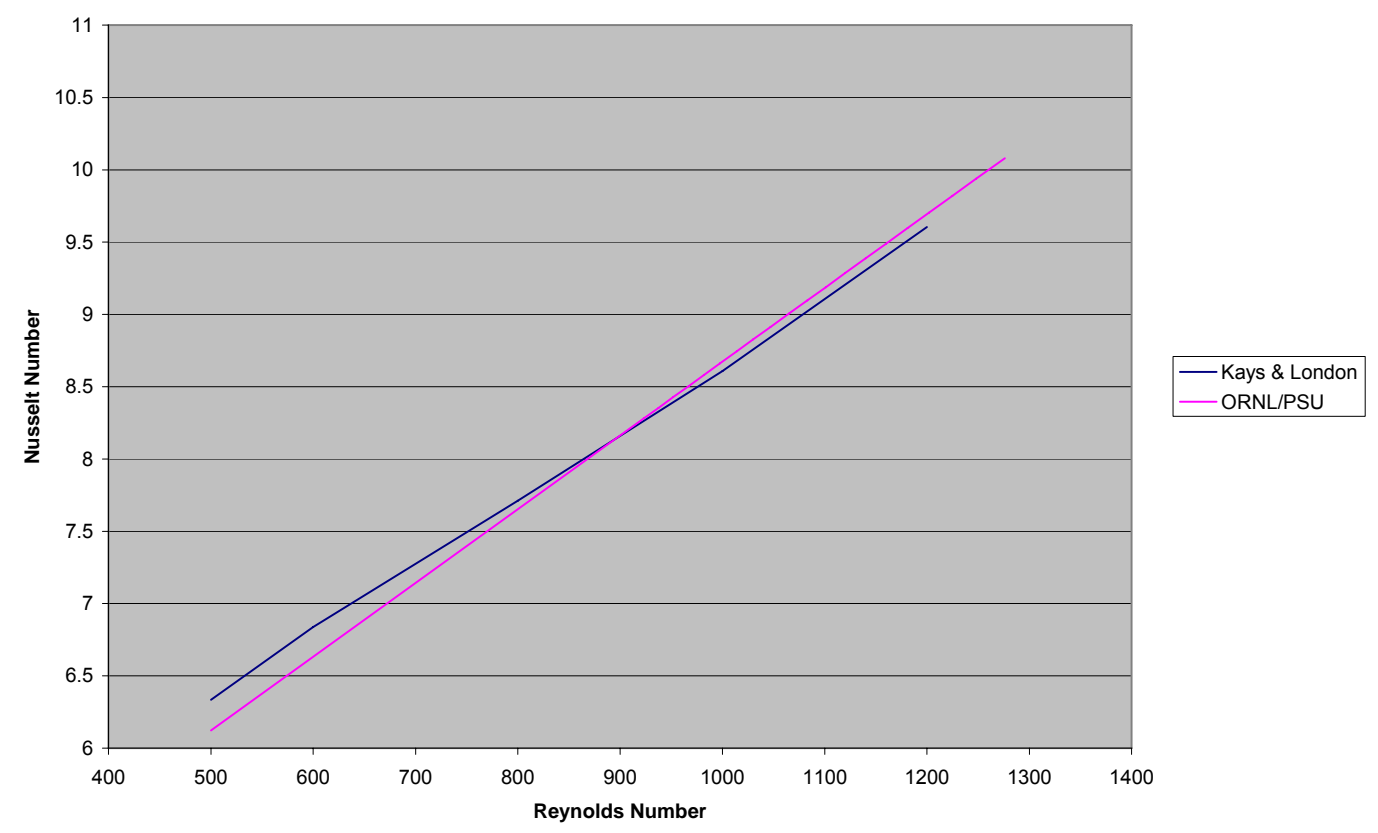

- ORNL Nusselt Number increased by $13 \%(\mathrm{Nu}=8.63)$ to account for entrance effects

- RELAP5-3D prediction nearly identical to Kays and London 


\section{Bounding the Proposed Nusselt Number Increase}

- Each of the strip fins in the compact heat exchangers considered for JIMO had a length of 0.125 in

- Integrating and normalizing the Polhausen analytical solution for the heat transfer coefficient over the length of a fin provides an upper bound for the Nusselt Number increase

$$
\begin{array}{cc}
N u=\frac{h x}{k}=0.332 \operatorname{Re}^{\frac{1}{2}} \operatorname{Pr}^{\frac{1}{3}} & \bar{h}=\frac{1}{L} 0.332 k\left(\frac{\rho u}{\mu}\right) \operatorname{Pr}^{\frac{1}{3}} \int_{0}^{L} x^{-\frac{1}{2}} d x \\
h(x)=0.332 k\left(\frac{\rho u}{\mu}\right)^{\frac{1}{2}} x^{-\frac{1}{2}} \operatorname{Pr}^{\frac{1}{3}} & \bar{h}=0.332 k\left(\frac{\rho u}{\mu}\right) \operatorname{Pr}^{\frac{1}{3}\left[2 L^{-\frac{1}{2}}\right]} \\
\bar{h}=\frac{1}{L} \int_{0}^{L} 0.332 k\left(\frac{\rho u}{\mu}\right) x^{-\frac{1}{2}} \operatorname{Pr}^{\frac{1}{3}} d x & \frac{\bar{h}}{h(L)}=\frac{2\left(0.332 k\left(\frac{\rho u}{\mu}\right) \operatorname{Pr}^{\frac{1}{3}}\left[L^{-\frac{1}{2}}\right]\right)}{0.332 k\left(\frac{\rho u}{\mu}\right)^{\frac{1}{2}} L^{-\frac{1}{2}} \operatorname{Pr}^{\frac{1}{3}}}=2
\end{array}
$$

- 13 percent is well within the factor of two increase shown here 


\section{Results}

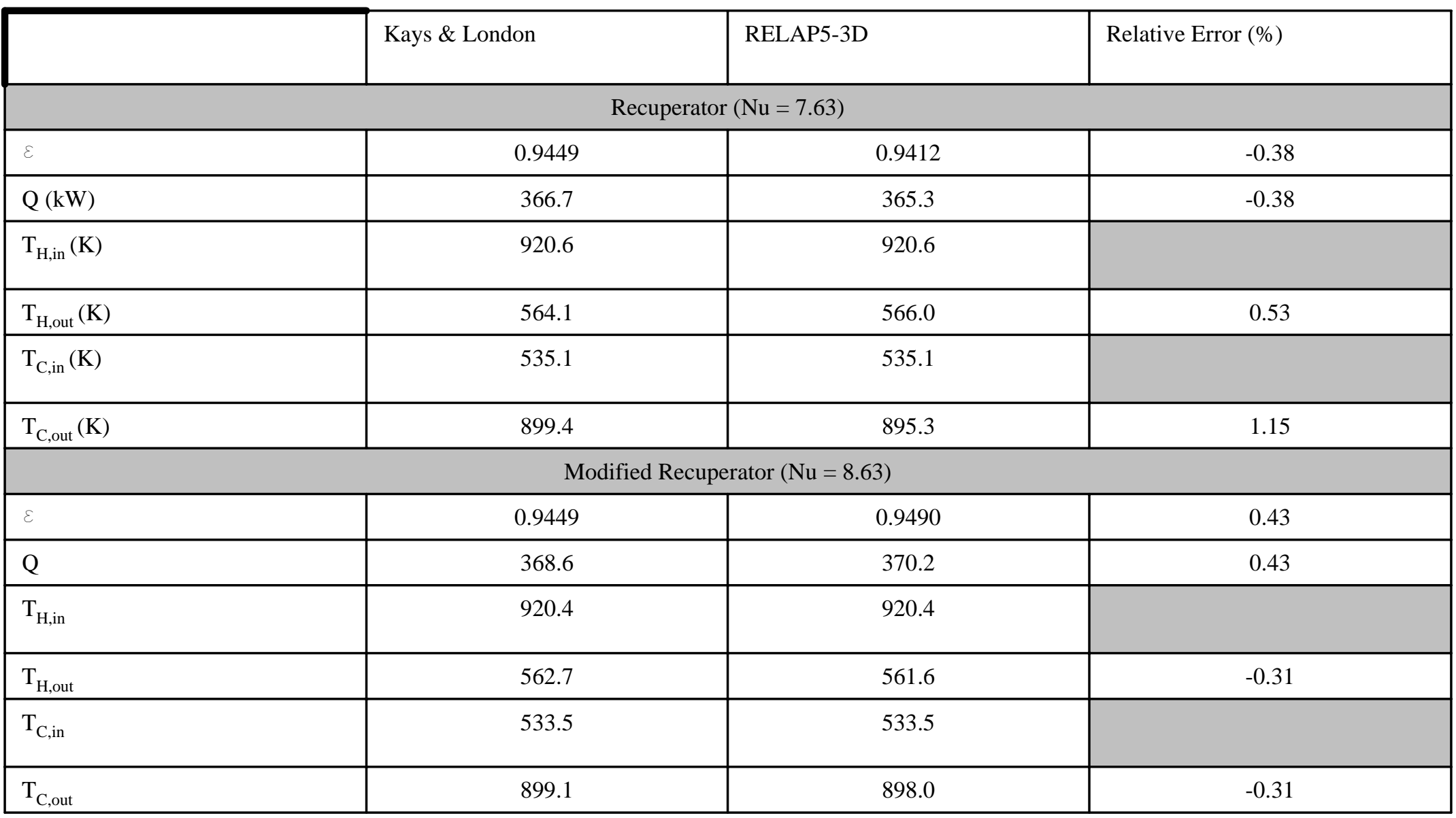




\section{Conclusions}

- Improved calculation accuracy

- Staggered heat structure mesh imposed more realistic wall temperatures

- Temperature effectiveness corrected heat transfer area

- ORNL/PSU convection correlation agrees closely with empirical data

- Staggered heat structure mesh reduced JIMO heat exchanger sub-volumes by a factor of 4 .

- Increased Material Courant Limit

- Decreased problem run-time

- Increased volume aspect ratio to satisfy RELAP5-3D constitutive requirements

- Code modifications being made by the INL to allow volume average temperature selection for wall boundary conditions 


\title{
Modeling Compact Counter-Flow Heat Exchangers with RELAP5-3D
}

\author{
Jacob T. Crittenden \\ Bechtel Bettis Incorporated \\ Bettis Atomic Power Laboratory \\ PO Box 79 \\ West Mifflin, PA 15122-0079 \\ 412-476-5660 crittend@bettis.gov
}

\begin{abstract}
This paper describes a technique for modeling counter-flow heat exchangers using RELAP5-3D, a nuclear analysis code developed and maintained by the Idaho National Laboratory (INL) that is also extensible to other control volume codes. The technique addresses calculation errors resulting from using control volume exit temperatures as boundary conditions and allows more rapid problem run time for numerically implicit advancement schemes. The RELAP5-3D (version 2.4.1) computer program was used to perform the analyses in this study. A Brayton system recuperator and gas cooler employing these modeling methodologies were successfully incorporated by the Bettis Atomic Power Laboratory into a scoping model of the Project Prometheus directly coupled gas reactor using a parallel Brayton cycle energy conversion system.
\end{abstract}

\section{INTRODUCTION}

The Naval Reactors Program developed a RELAP5-3D model to analyze both steady-state and dynamic behavior of a reactor coupled to a parallel pair of closed-loop Brayton-cycle systems (McCann, 2006). Figure 1 depicts the entire RELAP5-3D input model.

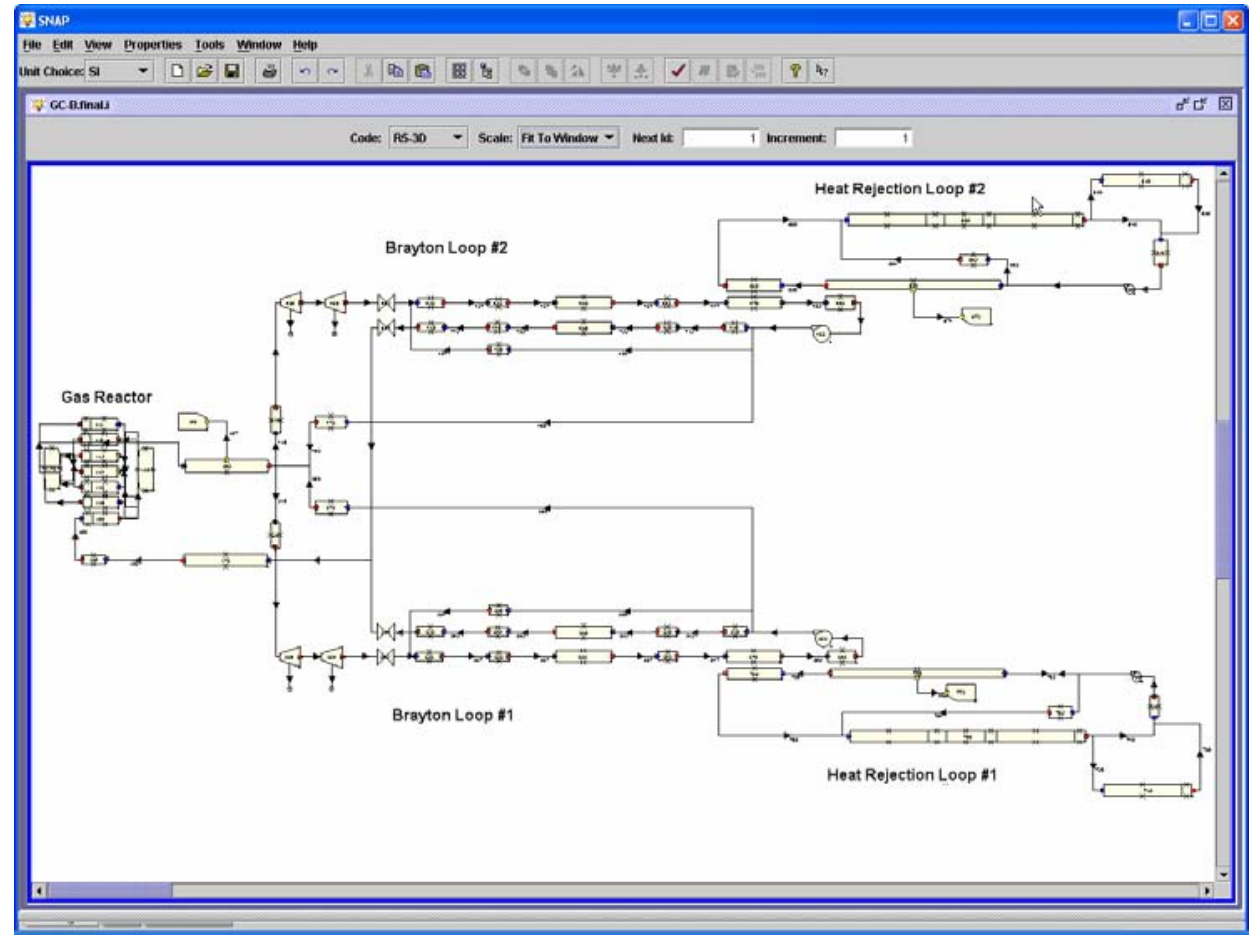

Figure 1 RELAP5-3D Model of the JIMO Reactor Plant 
Compact counter-flow heat exchangers are commonly used in gas cycles in order to improve the efficiency and heat transfer characteristics in the cycle. For this particular concept, each Brayton / heat rejection loop pair has two compact heat exchangers. The first is a recuperator used to extract unused heat downstream of the turbine to preheat the gas returning to the reactor thereby improving cycle efficiency. The second is a gas cooler used to transfer waste heat to the heat rejection system where it can be radiated to space. Figure 2 shows one of the Brayton loops and its associated heat rejection loop with the two compact counter flow heat exchangers highlighted.

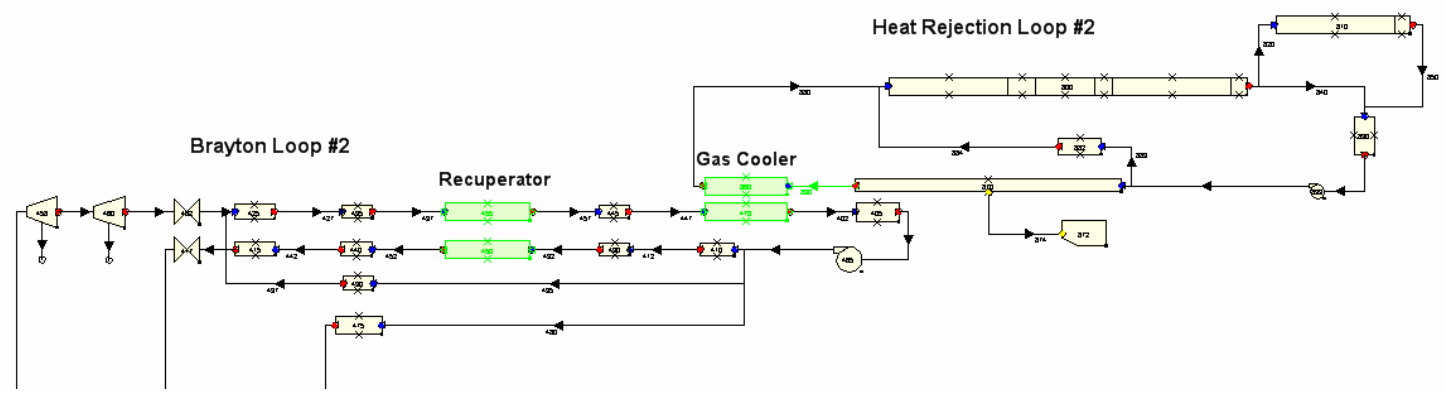

Figure 2 JIMO Reactor Plant Recuperator and Gas Cooler

\section{COUNTER FLOW HEAT EXCHANGERS AND CONTROL VOLUME CODES}

Numerous control volumes are required to model heat exchangers in RELAP5-3D and similar control volume codes for two reasons. First, the temperature is assumed to be constant over the length of a modeled control volume, while temperature continuously varies in a real heat exchanger. Second, the value used for control volume temperatures represents temperature at the exit rather than the center of the control volume. RELAP5-3D generates both a hydrodynamic and heat transfer solution for any heat exchanger by modeling the hydraulic network of the working fluid streams and the heat transfer medium (heat structure) between them. The hydraulic solution is used to characterize the fluid flow conditions in order to select an appropriate heat transfer convection coefficient correlation. In addition, RELAP5-3D establishes boundary conditions by applying a source/sink temperature based on the volume temperatures on either side of the heat structure. RELAP5-3D is a control volume code and the temperature used throughout the fluid volume is equivalent to its exit temperature, derived from the energy balance for that volume, rather than the volume average temperature. This same exit temperature is also used as the wall temperature for attached heat structures. Using the exit temperature in this fashion introduces an error in the heat transfer solution when modeling heat exchangers. This error is exacerbated when modeling counter flow heat exchangers, which have fluid streams traveling in opposite directions, by using temperatures that are not in the same axial plane.

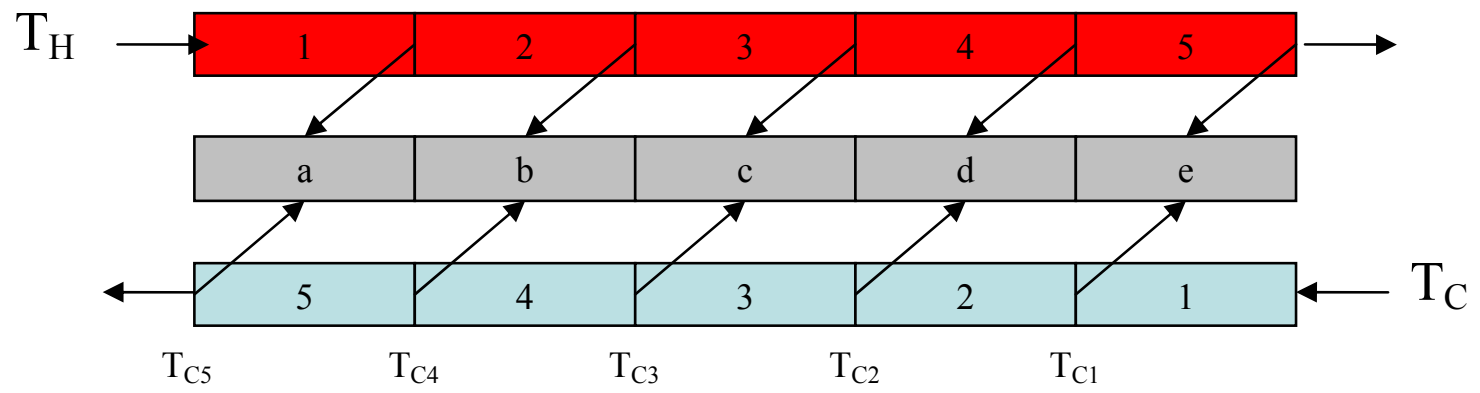

Figure 3 Control volume code model of a counter flow heat exchanger 
Figure 3 depicts a simple five control volume counter flow heat exchanger. Five control volumes are used strictly for clarity in the diagram. All heat exchangers in the actual model have a minimum of 20 control volumes. As shown in Figure 3, the heat structure connecting the hot side of the heat exchanger (shown in red) and the cold side (shown in blue) is receiving its boundary condition wall temperatures from different axial locations in the heat exchanger based on the length of the hydraulic mesh. Fewer control volumes in the heat exchanger increases the length of the hydraulic mesh and compounds the error by increasing the axial separation of the source and sink temperatures.

The error introduced by this control volume temperature approximation is illustrated in Figure 4 for a 10 control volume heat exchanger. The temperature difference $\left(\Delta \mathrm{T}_{\mathrm{HX}}\right)$ across the heat exchanger for a control volume code is significantly affected by the number of heat exchanger control volumes. As the number of control volumes is increased, the $\Delta \mathrm{T}$ approaches the actual curves in Figure 4. However, the number of control volumes required to adequately reduce the error results in a very slow running model to maintain numerical stability in the hydraulic solution.

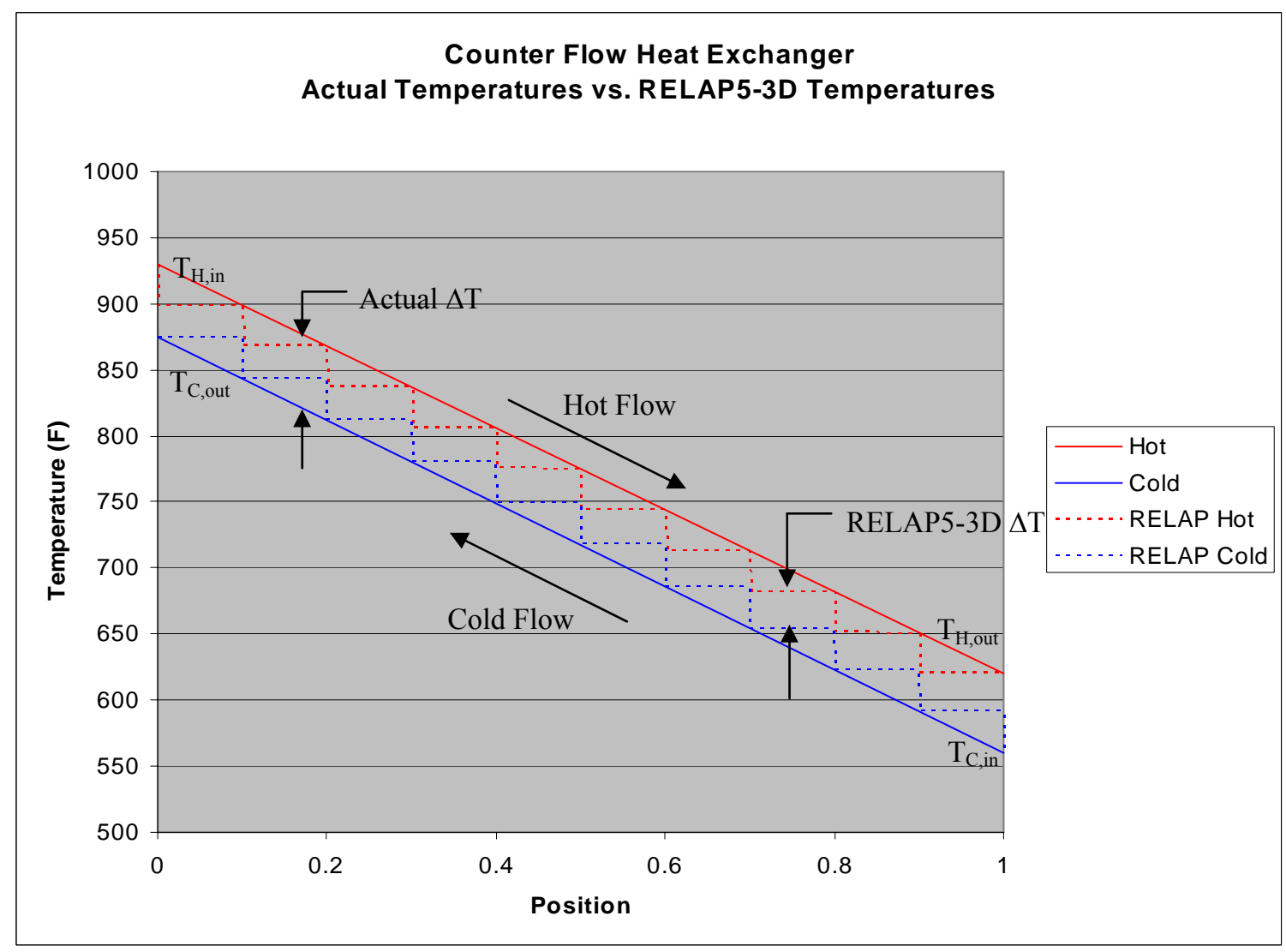

Figure 4 Counter flow heat exchanger temperature profile

Heat transfer $(\mathrm{Q})$ across a heat exchanger is directly proportional to $\Delta \mathrm{T}_{\mathrm{HX}}$ :

$$
\mathrm{Q}=\mathrm{U} \cdot \mathrm{A} \cdot \Delta \mathrm{T}_{\mathrm{HX}}
$$

If the number of volumes in the heat exchanger is decreased, there is an artificial reduction in $\Delta \mathrm{T}$ because of the axial mismatch in temperature. The decrease in $\Delta \mathrm{T}$ could be counteracted with an increase in the overall heat transfer coefficient (U) in order to transfer the correct amount of heat. However, that is simply treating the symptom and not addressing the root cause. Increasing the heat transfer coefficient tends to reduce $\Delta \mathrm{T}$ resulting in diminishing returns. In addition, there is a limit to how far the number of control 
volumes can be reduced. As can also be seen in Figure 4, if the control volumes in the heat exchanger were reduced to five with the same terminal temperatures, $\Delta \mathrm{T}_{\mathrm{HX}}$ between the hot and cold side would be less than zero. Therefore, using volume exit temperatures as heat structure boundary conditions for a counterflow heat exchanger introduces unacceptable error into the heat transfer solution and imposes a lower limit on the number of heat exchanger volumes that can be used while still providing an accurate solution.

A control volume code with directly coupled heat structures results in a hot side boundary condition that is too cold for all of the heat structures and a cold side boundary condition that is too hot. Therefore, the temperature difference across the heat structure in RELAP5-3D will always be less than the actual temperature difference across the wall of the heat exchanger. This error can be minimized by increasing the number of control volumes in the heat exchanger effectively shortening each of the volume lengths. If the mesh is made fine enough, the answer converges to the analytic solution. However, unless the control volume lengths are made infinitesimally small, there will always be an error introduced using this solution technique. In fact, for a typical Brayton cycle recuperator that was being considered for the Prometheus project, the total hot and cold side $\Delta \mathrm{T}$ is approximately $300 \mathrm{~K}$ while the $\Delta \mathrm{T}_{\mathrm{HX}}$ across the heat exchanger is approximately $30 \mathrm{~K}$. The relative error in $\Delta \mathrm{T}$ is equivalent to half the temperature difference across a hot and cold side individual control volume divided by the $\Delta \mathrm{T}$ across the heat exchanger. For the case of a balanced flow recuperator, the $\Delta \mathrm{T}$ across each of the hot and cold side control volumes is equal allowing a further simplification of the error calculation.

$$
\operatorname{Err}_{\Delta \mathrm{T}}=\frac{\frac{1}{2} \Delta \mathrm{T}_{\mathrm{CV} . \text { Hot }}+\frac{1}{2} \Delta \mathrm{T}_{\mathrm{CV} . \text { Cold }}}{\Delta \mathrm{T}_{\mathrm{HX}}}=\frac{\Delta \mathrm{T}_{\mathrm{CV}}}{\Delta \mathrm{T}_{\mathrm{HX}}}
$$

$\Delta \mathrm{T}_{\mathrm{CV}}$ can be reduced by increasing the number of heat exchanger control volumes. To bring the relative error to 1 percent would require 1000 control volumes on each side of the heat exchanger. This is excessive since it is rare for an entire RELAP5-3D model to utilize 1000 control volumes.

It is undesirable to greatly increase the number of control volumes in the heat exchangers since reducing the length of any fluid control volume in a numerical analysis may result in longer run times due to the Courant limit. The Courant limit is the time it takes for all of the fluid in the limiting (smallest) volume of a problem to be completely flushed out of that volume. It is customary to characterize time advancement using the Courant number, which is the time-step size divided by the Courant limit. So, operating at a Courant number of one implies that the time-step is exactly equal to the Courant limit while a Courant number of five implies that the time-step is five times larger than the Courant limit. For the nearly implicit time advancement scheme utilized by RELAP5-3D, and many similar codes, the error introduced by the numerical solution varies linearly with the Courant number. Therefore, increasing the number of heat exchanger fluid volumes to minimize the error introduced to the heat transfer solution increases the Courant number and the analyst must either decrease the time-step size resulting in longer problem run times or maintain the time-step size at the expense of increasing the numerical error.

Since the Courant limit is controlled by both the length of the volume and fluid velocity, higher velocities, such as those seen in gas Brayton cycles, exacerbate the increase in problem run time. The parallel Brayton system model used in this study includes four counter flow heat exchangers. In order to approach the analytically determined gas state points, it was necessary to model each heat exchanger with 80 control volumes. This resulted in a Courant limit of approximately 0.5 milliseconds and problems that ran roughly 25 times slower than real time on the super computers used by the Naval Nuclear Program. Since most of the initial scoping jobs require 1000 seconds of problem run time, these jobs would take almost 7 hours to run.

Another limit on control volume length is that the length should always be at least as large as the volume diameter, since the constitutive models in codes such as RELAP5-3D are based on average or macroscale parameters. Shorter volume lengths than the volume diameter may render these constitutive models invalid. This was not a concern for the Project Prometheus heat exchangers, which, like most compact heat exchangers, had very small hydraulic diameters $(2 \mathrm{~mm})$. In addition, the validity of the constitutive models 
is not a concern for single phase analyses like those necessary for Project Prometheus. However, the same methodology described herein can also be applied to conventional two phase heat exchangers where macroscale parameters would be a concern.

\section{Staggering the Heat Structure Mesh}

It is possible to approximate the temperature boundary conditions of a counter flow heat exchanger with a control volume code if the heat structure mesh is staggered relative to the fluid volume mesh and the boundary condition connections are altered. For example, if the heat structure mesh is offset by $1 / 2$ the fluid control volume length as shown in Figure 5, and the connection scheme is staggered so the first hot side control volume is connected to the second to last cold side control volume, it is possible to model a significant portion of the heat structure with boundary conditions that more accurately represent the heat exchanger. Once again, a five control volume heat exchanger is used in the figure for clarity.

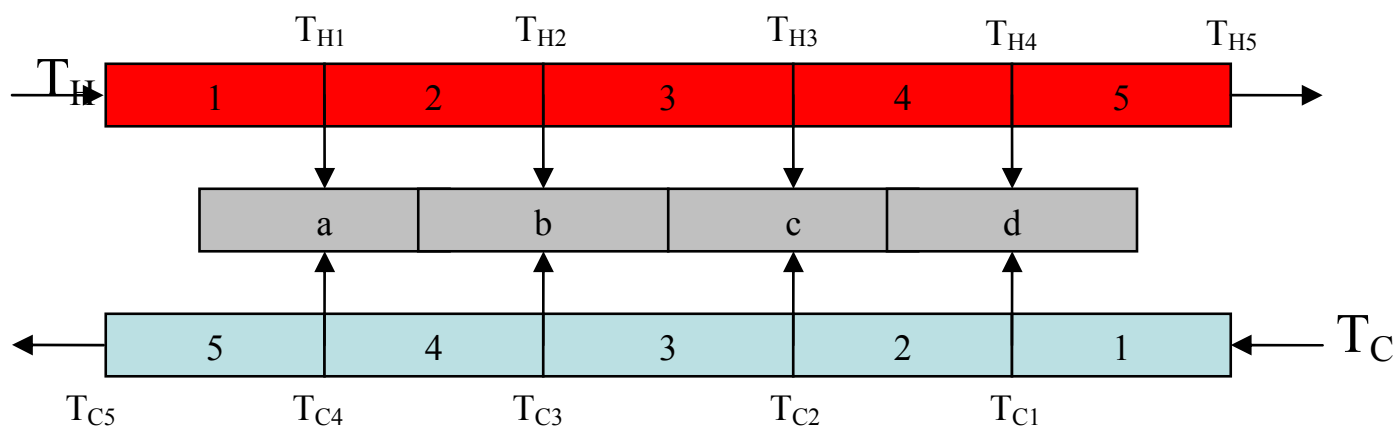

Figure 5 Counter flow heat exchanger model with staggered heat structure mesh

Staggering the heat structure mesh and altering the boundary volume connections results in the correct boundary condition temperature being applied across all of the heat structures. The improved temperature boundary condition application is illustrated in Figure 6. 


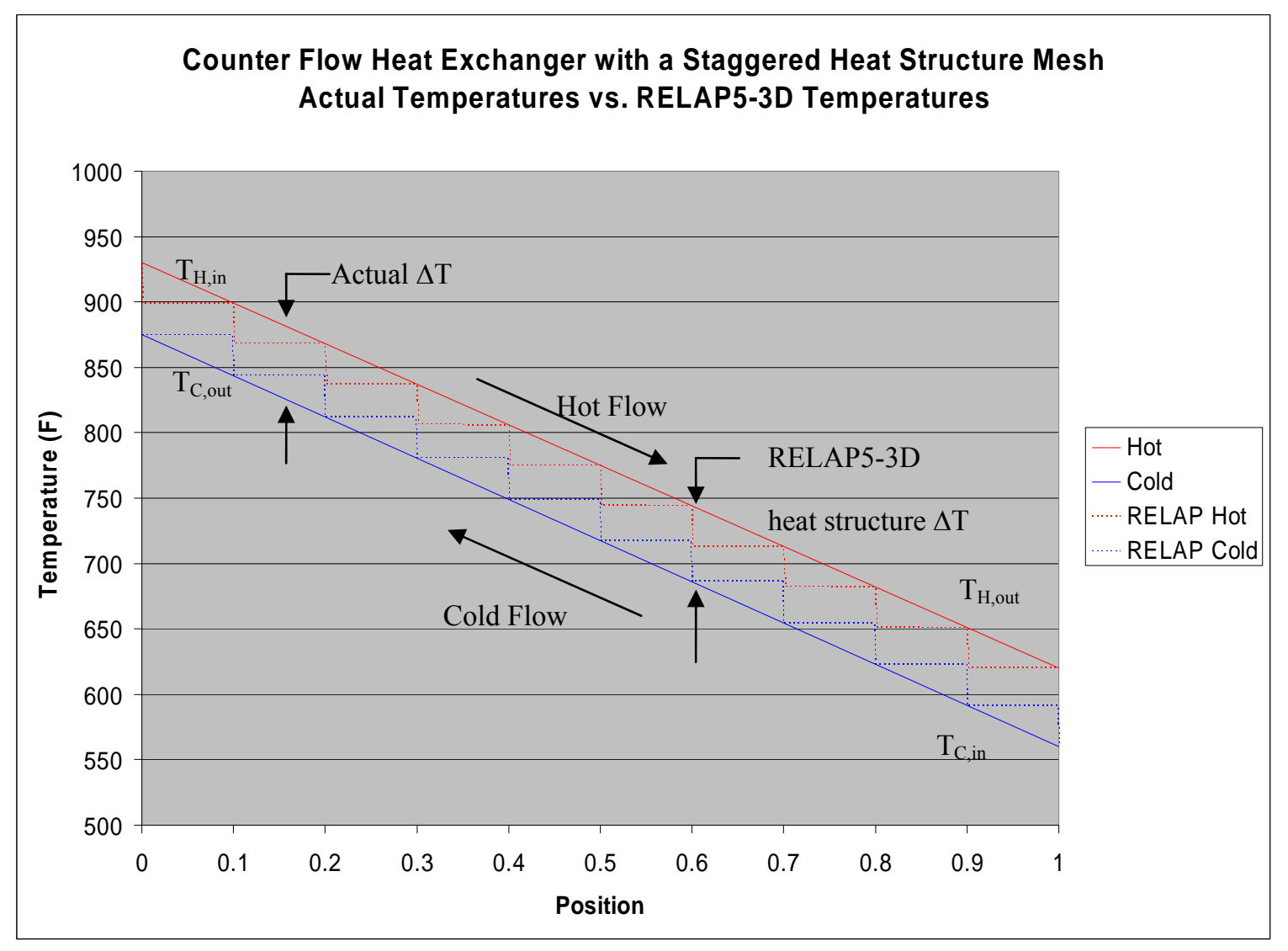

Figure 6 Staggered mesh counter flow heat exchanger temperature profile

\section{Accounting for the End Control Volumes}

Although the heat structure boundary conditions are improved, the modeled heat structure is now missing a portion of structure equivalent to one control volume length $(1 / 2$ control volume at the entrance and exit respectively). Because of the way the heat structures are connected, this missing structure results in no heat being transferred from the last control volume of the hot side or to the last control volume of the cold side (Figure 5). In order to account for the majority of this "missing" heat transfer, a control structure was written in RELAP5-3D to determine how much heat would be transferred from/to these control volumes based on linear extrapolation as shown in Figure 7, which is an actual plot of RELAP5-3D output data from a 20 volume heat exchanger. This heat $\left(\mathrm{Q}_{\mathrm{HotCalc}}\right.$ and $\left.\mathrm{Q}_{\text {ColdCalc }}\right)$ was then artificially introduced to the respective hot and cold side nodes as shown in Figure 8, which once again only uses five volumes for clarity. 
Recuperator Cold Side Heat Transfer

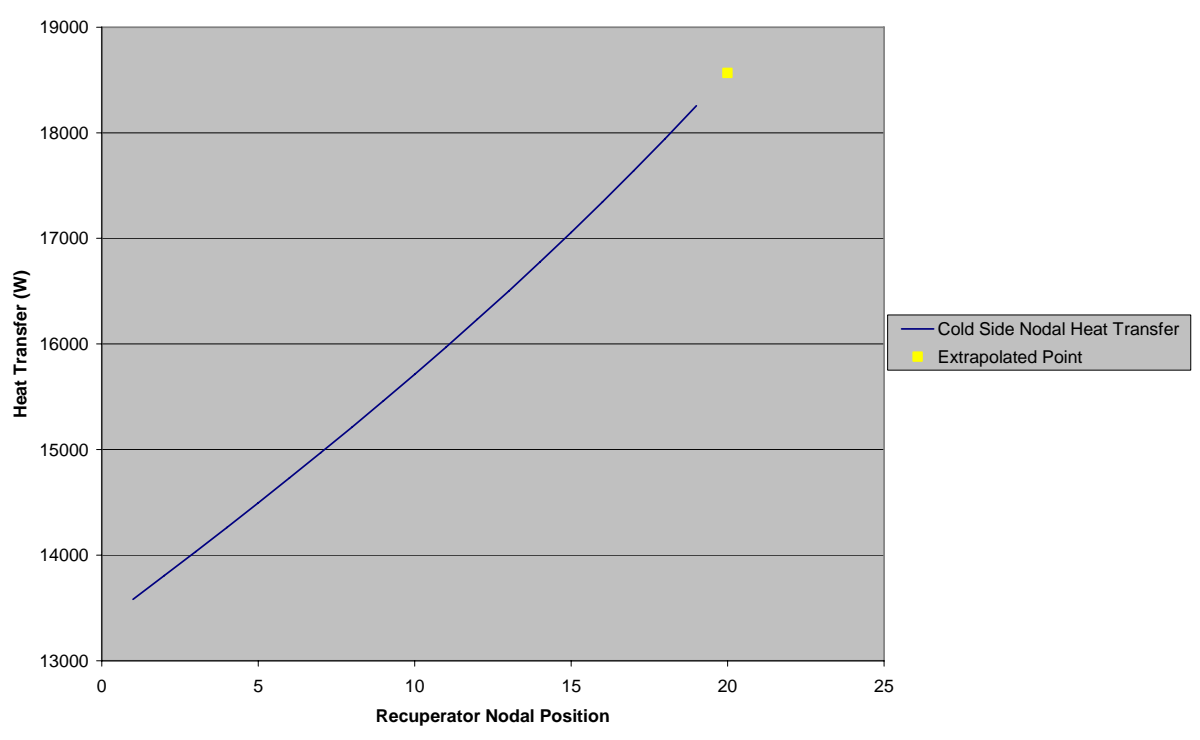

Recuperator Hot Side Heat Transfer

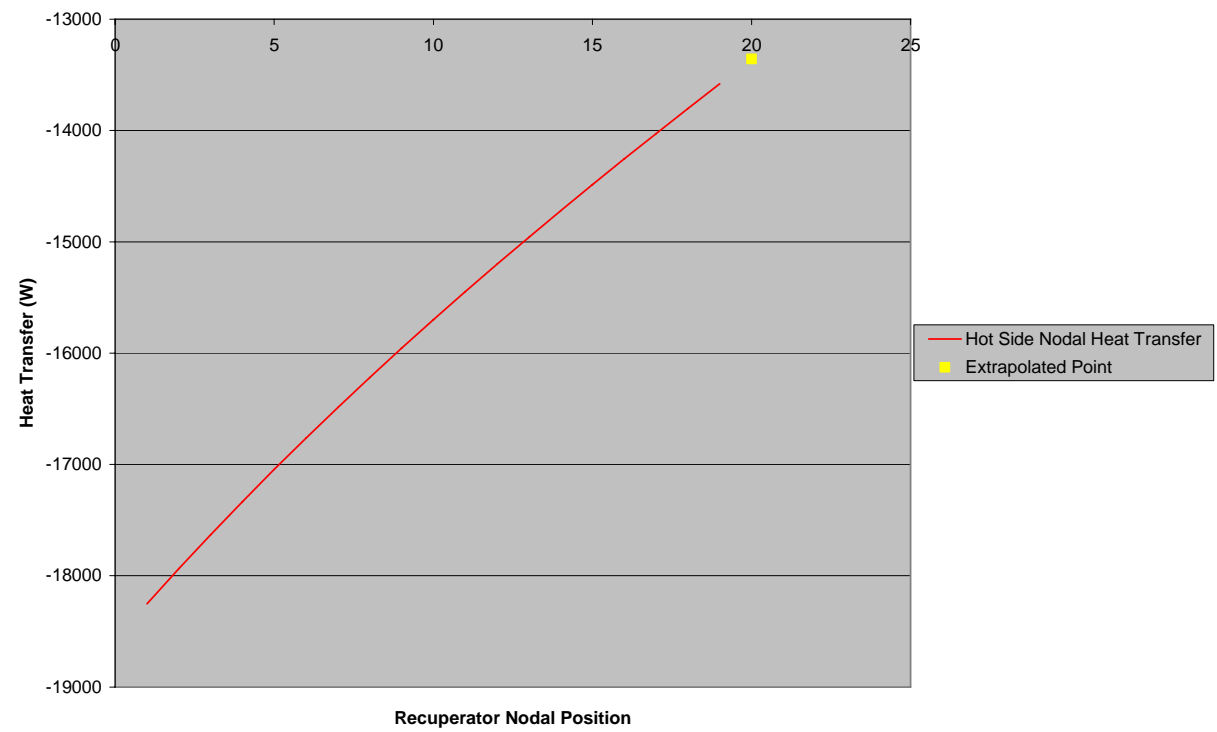

Figure 7 Extrapolating end control volume heat transfer

Since there is a different amount of heat being transferred per control volume on the hot side of the heat exchanger relative to the cold side, this calculation results in two different amounts of heat. In order to prevent disturbing the heat balance, the discrepancy between the amounts of heat added to the end nodes was divided into equal portions $\left(\mathrm{Q}_{\mathrm{Corr}}\right)$ and artificially introduced into each node on both sides of the heat exchanger as shown in Figure 8. Adding this corrected heat term into each node preserves the heat exchanger's heat balance and shifts the heat transfer in each node closer together, mitigating the error introduced by staggering the heat structure mesh. 


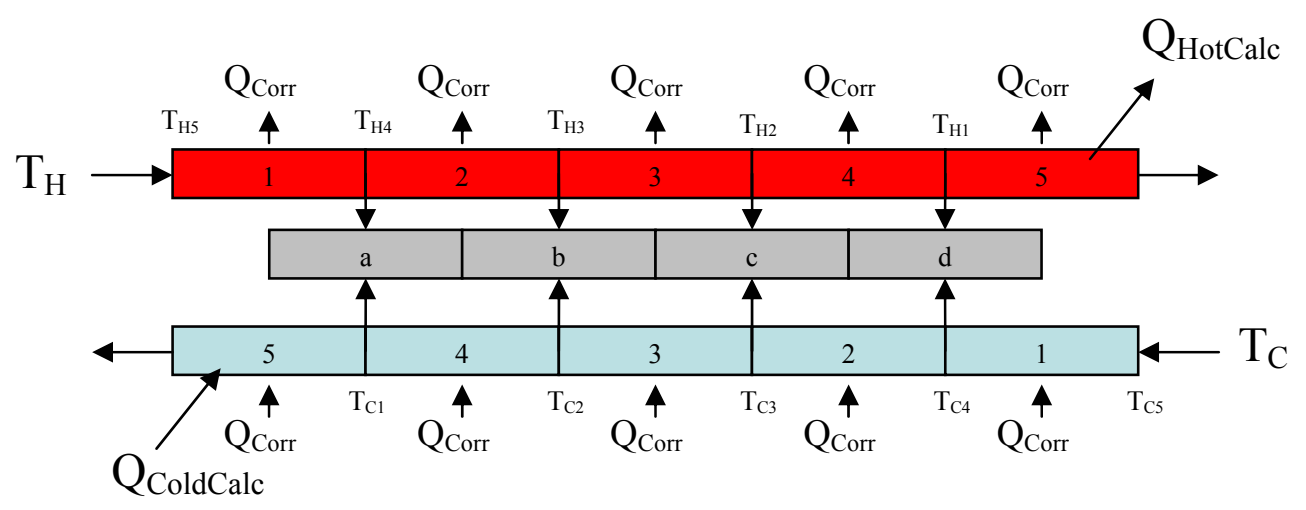

Figure 8 Five volume staggered mesh counter flow heat exchanger with control volume heat corrections

\section{Errors Introduced Relative to the Analytic Solution}

In addition to the heat transfer discrepancy just discussed, this method introduces a subtle error into the heat transfer solution. As can be seen from Figure 7, the amount of heat transferred from the hot side per control volume is decreasing along the length of the heat exchanger. Staggering the heat structure and coupling the first n-1 hot side volumes to the first n-1 cold side volumes has the effect of creating "pseudocontrol volumes" for the boundary conditions comprised of the half volumes surrounding the temperature coupling point. For example, connecting hot side volume one to cold side volume four is effectively creating a pseudo-control volume from the second half of hot side volume one and the first half of hot side volume two. This pseudo-control volume provides the hot side boundary condition to heat structure "a." The cold side boundary condition is supplied by a pseudo-control volume on the cold side made up of the second half of volume four and the first half of volume five. These pseudo-control volumes are depicted in Figure 9.

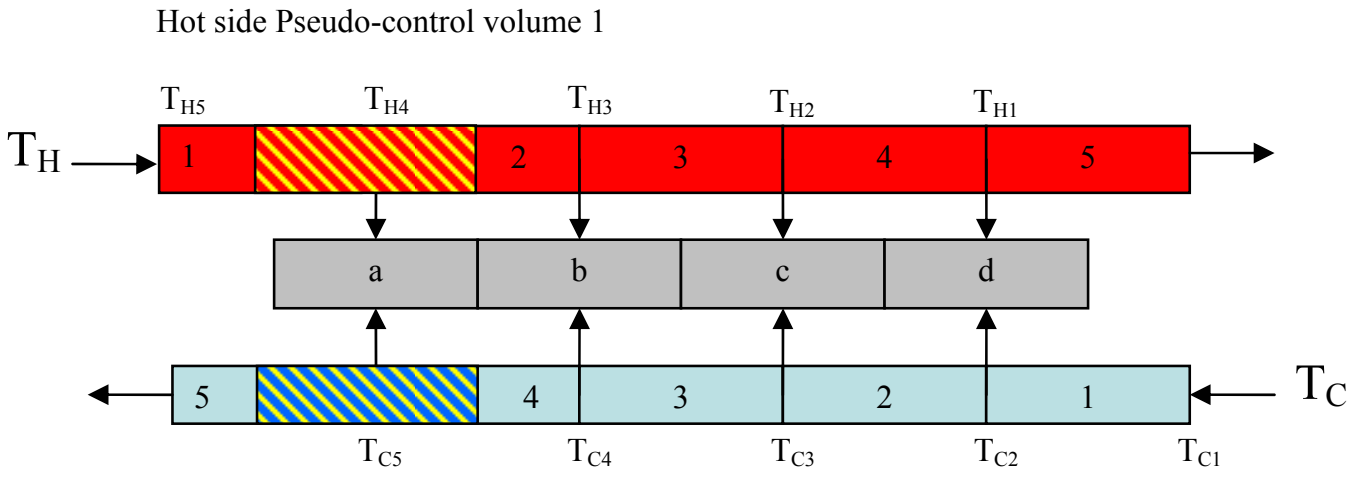

Cold side Pseudo-control volume n-1

Figure 9 Counter flow heat exchanger model depicting pseudo-control volumes

The amount of heat being transferred across the heat structure control volumes will also decrease along the length of the heat exchanger. Since the heat is being transferred between the actual control volumes, and not the pseudo-control volumes, slightly less heat is being transferred from the first n-1 hot side volumes and slightly more heat is being transferred to the first n- 1 cold side volumes than the analytic solution. This is mitigated by reintroducing the heat discrepancy into each of the volumes as discussed in the previous section. The total heat transfer and effectiveness for the heat exchangers modeled with RELAP5-3D using this staggered mesh approach are within 1 percent of the predictions made by the NASA Glenn Research Center using their high fidelity Brayton cycle design code (CCEP). 


\section{Limitations}

Staggering the heat structure mesh has proven to be extremely effective for steady state calculations allowing the volume count for the heat exchangers to be reduced from 80 to 20 per side while largely eliminating the temperature error across the heat exchanger. No anomalies were noted in transient heat exchanger performance. Had the Naval Reactors involvement in Project Prometheus continued, transient performance would have been investigated. Finally, flow reversal in one or both sides of the heat exchanger would probably invalidate the arbitrary heat addition calculations. However, if the flow reversal was brief in duration, the methodology should have corrected itself once flow was re-established.

\section{COMPACT HEAT EXCHANGERS}

Since both the recuperator and gas cooler use gas as the working fluid on at least one side of the heat exchanger, they both employ offset strip fins (Kays \& London, 1984) common to compact heat exchangers to enhance heat transfer. Rather than trying to explicitly represent the complex geometry of offset strip fins, a multiplier was developed to account for the overall temperature effectiveness of the heat transfer surfaces on both sides of the heat exchanger. The temperature effectiveness $\left(\eta_{0}\right)$ is a combination of both the ratio of fin area $\left(\mathrm{A}_{\mathrm{f}}\right)$ to total heat transfer area $(\mathrm{A})$ and the efficiency of the fins themselves.

$$
\eta_{0}=1-\frac{A_{f}}{A} \cdot\left(1-\eta_{f}\right)
$$

(Equation 11.3 (Incropera \& DeWitt, 1985))

Where fin efficiency $\left(\eta_{\mathrm{f}}\right)$ can be calculated from the fin parameter $(\mathrm{m})$ and effective fin length $(\mathrm{L})$ as shown in Figure 10.

$$
\eta_{\mathrm{f}}=\frac{\tanh (\mathrm{m} \cdot \mathrm{L})}{\mathrm{m} \cdot \mathrm{L}}
$$

(Equation 11.4 (Incropera \& DeWitt, 1985))

The fin parameter can be calculated from the convection coefficient $(\mathrm{h})$, the fin perimeter $(\mathrm{P})$, the fin thermal conductivity $(\mathrm{k})$ and the fin cross sectional area $\left(\mathrm{A}_{\mathrm{c}}\right)$ as shown in Figure 10. 


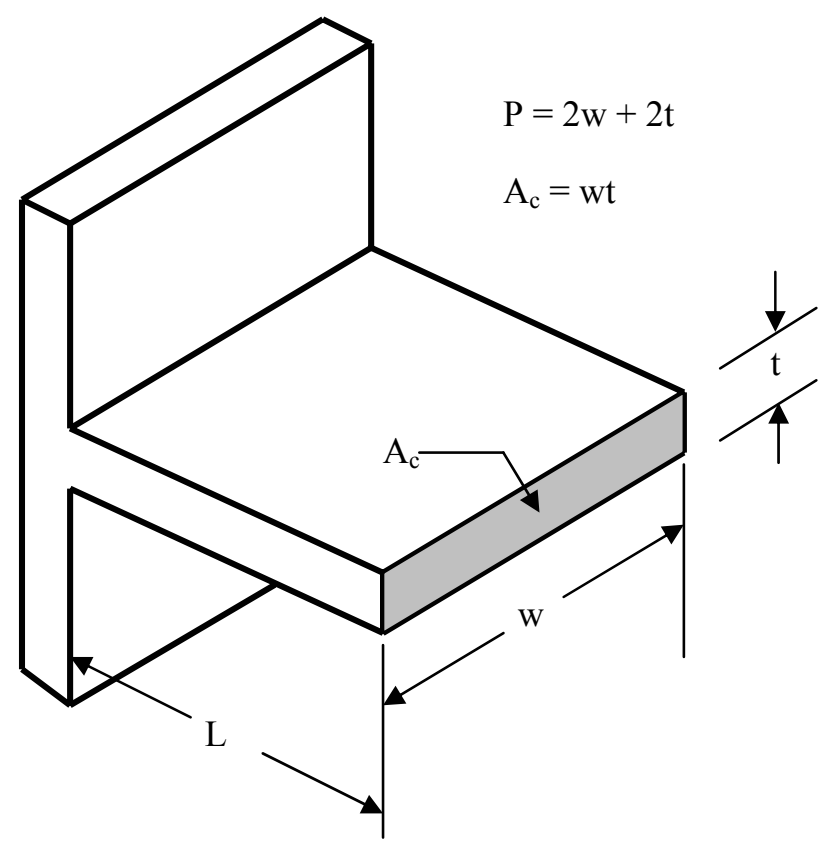

Figure 10 Fin geometry diagram

$$
\mathrm{m}^{2}=\frac{\mathrm{h} \cdot \mathrm{P}}{\mathrm{k} \cdot \mathrm{A}_{\mathrm{c}}}
$$

(Equation 3.64 (Incropera \& DeWitt, 1985))

For long thin fins, the following approximation can be made:

$$
\frac{\mathrm{P}}{\mathrm{A}_{\mathrm{c}}}=\frac{2}{\mathrm{t}}
$$

Substituting into the fin parameter equation yields:

$$
\mathrm{m}=\sqrt{\frac{2 \cdot \mathrm{h}}{\mathrm{k} \cdot \mathrm{t}}}
$$

The RELAP5-3D model uses total heat transfer area, including the fins, in the heat structure, so $\eta_{0}$ is used as the heat transfer fouling factor to decrement the convection coefficient. The fin parameter varies as a function of the convection coefficient while the RELAP5-3D fouling factor must be entered as a constant. Currently, the RELAP5-3D models are using a fin parameter calculated at design full power conditions for all transients. Had the Naval Reactors involvement in Project Prometheus continued, an evaluation would have been made to determine the range of fin parameters expected for normal operation and their effect on transient solutions.

\section{Heat Convection Coefficient Correlations}

Both the recuperator and gas cooler are laminar flow heat exchangers with a low Prandtl number working fluid $(\mathrm{HeXe})$ on at least one side. The NRPCT was unable to locate a well documented convection coefficient correlation that was applicable to both laminar flow and low Prandtl number gases. The Kays 
and London empirical correlations, which are not available in RELAP5-3D, have been used by some members of the NRPCT for preliminary heat exchanger calculations. However, the experimental data from which these correlations were drawn was based on air as the working fluid, which has a Prandtl number of 0.7 , as opposed to the HeXe mixture, which has a Prandtl number of approximately 0.2 . Kays and London recommend their empirical correlations be restricted to fluids in the "Prandtl number range of gases," which is typically 0.5 to 1.0 .

RELAP5-3D has two laminar flow correlations from which the analyst may choose. The first is an exact solution for fully developed laminar flow in a circular tube (Sellars et al, 1956) with a uniform wall heat flux and constant thermal properties. This is a constant Nusselt number solution of the form:

$$
\mathrm{Nu}=4.36
$$

The second correlation was developed by the Oak Ridge National Laboratory (ORNL) for the Advanced Neutron Source Reactor (INEEL, 2003) for flat vertical plates with an aspect ratio of 68:11. The compact heat exchangers envisioned for Project Prometheus would best be characterized as finned plates with a high plate width to separation aspect ratio. The ORNL correlation is also a constant Nusselt number solution of the form:

$$
\mathrm{Nu}=7.63
$$

In 2004, Bettis, with the help of the Pennsylvania State University (PSU), performed a literature search in the area of forced an mixed convection heat transfer. Bettis and PSU were able to develop a laminar heat transfer correlation relating calculated Nusselt numbers to their geometry dependent counterparts by combining the experimental results for three separate geometries. The Reynolds number dependent laminar Nusselt number takes the form:

$$
\mathrm{Nu}_{\text {lam }}(\mathrm{Re})=\mathrm{Nu}_{\text {analytic }}\left(0.414+5.91 \cdot 10^{-4} \cdot \mathrm{Re}\right)
$$

Where $\mathrm{Nu}_{\text {analytic }}$ takes either the Sellars value of 4.36 or the ORNL value of 7.63 depending on which correlation is chosen in RELAP5-3D.

A comparison was made between the Kays and London empirical correlations and the ORNL correlation with the PSU developed Reynolds number dependency. The comparison (Figure 11) revealed that the Nusselt number predicted by both correlations is within 15 percent and, more importantly, the slope of both correlations is nearly identical. The ORNL/PSU correlation can be adjusted to be nearly identical to Kays and London by increasing the analytic Nusselt number from 7.63 to 8.63 (Figure 12). 


\section{Comparison of Kays \& London and ORNL/PSU Heat Transfer Correlations}

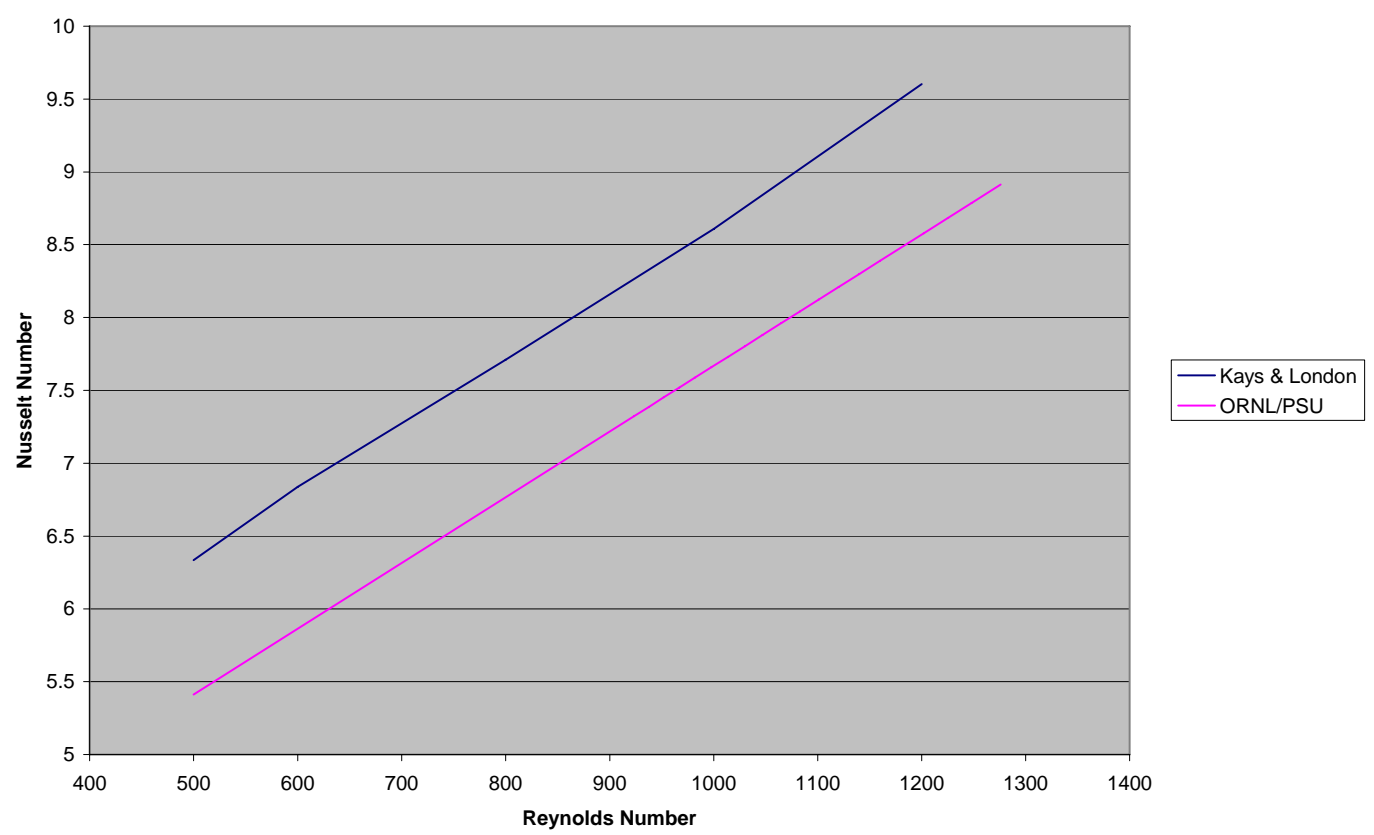

Figure 11 RELAP5-3D to Kays \& London heat transfer correlation comparison

Comparison of Kays \& London and modified ORNL/PSU Heat Transfer Correlations

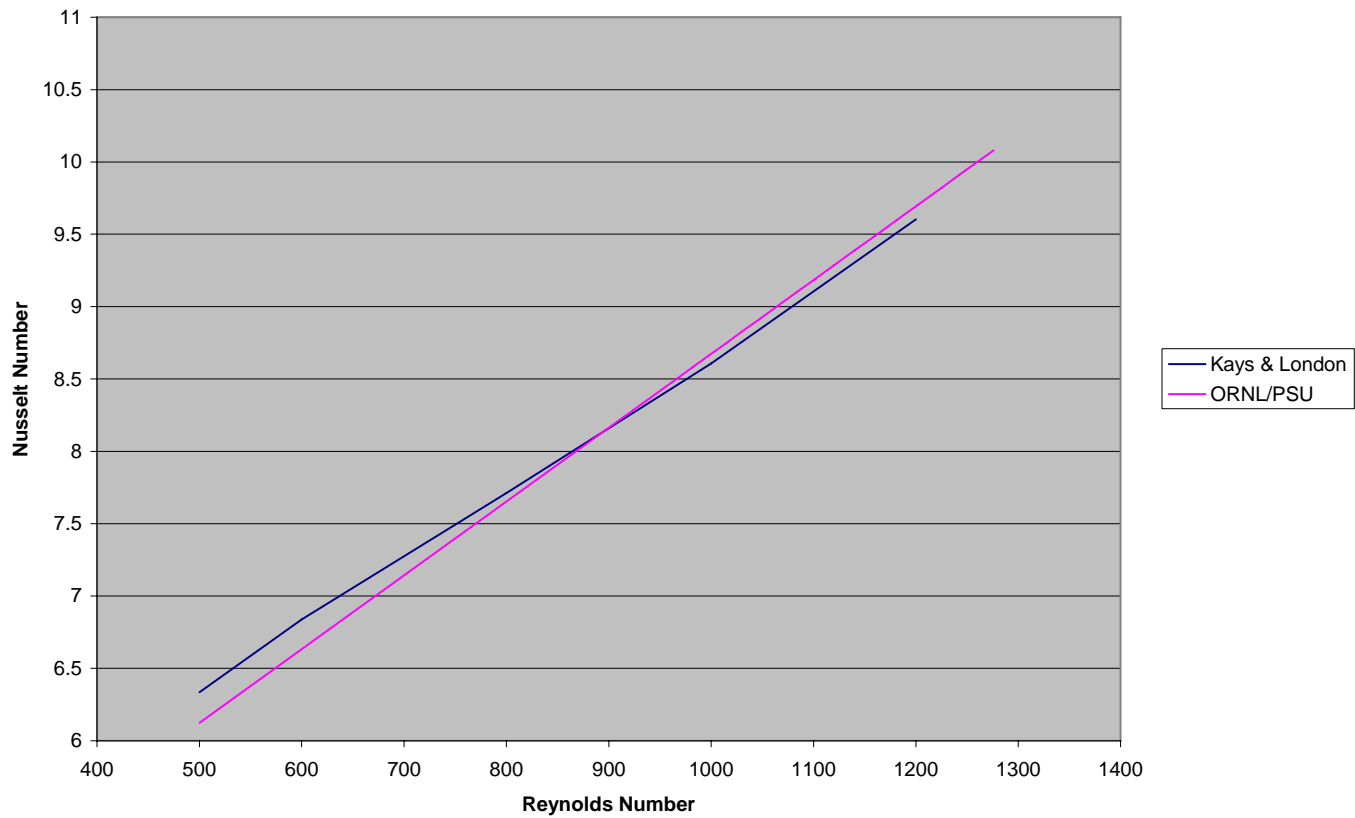

Figure 12 Modified RELAP5-3D to Kays \& London heat transfer correlation comparison

An increase in the Nusselt number can be justified since the ORNL prediction was for fully developed laminar flow. Since one of the purposes of offset strip fins is to break up the boundary layer, the modeled heat exchangers will have their entire heat transfer surface in the entrance effects region of laminar flow 
boundary layer formation. The thinner boundary layer in the entry length region is characterized by higher heat transfer relative to the fully developed region. Although the actual increase in heat transfer in the entry length region is not currently known, increasing the Nusselt number from 7.63 to 8.63 resulted in excellent agreement with the Kays \& London offset strip fin correlation, which is based on actual air test data of an offset strip fin recuperator. In order to ensure this Nusselt number increase could be supported, the Polhausen analytic solution was solved over the length of a single strip fin:

$$
N u=\frac{h x}{k}=0.332 \operatorname{Re}^{\frac{1}{2}} \operatorname{Pr}^{\frac{1}{3}}
$$

solving for the heat transfer coefficient:

$$
h=0.332 \frac{k}{x} \operatorname{Re}^{\frac{1}{2}} \operatorname{Pr}^{\frac{1}{3}}
$$

where:

$$
\operatorname{Re}(x)=\frac{\rho u x}{\mu}
$$

substituting for the Reynolds number gives an analytic solution for the local heat transfer coefficient:

$$
h(x)=0.332 k\left(\frac{\rho u}{\mu}\right)^{\frac{1}{2}} x^{-\frac{1}{2}} \operatorname{Pr}^{\frac{1}{3}}
$$

The average heat transfer coefficient from the beginning of the boundary layer to a distance L can be determined by integrating the previous expression.

$$
\bar{h}=\frac{1}{L} \int_{0}^{L} 0.332 k\left(\frac{\rho u}{\mu}\right) x^{-\frac{1}{2}} \operatorname{Pr}^{\frac{1}{3}} d x
$$

This is a trivial integration since all the terms are constant with respect to distance except for $\mathrm{x}$ and $\mathrm{dx}$.

$$
\begin{aligned}
& \bar{h}=\frac{1}{L} 0.332 k\left(\frac{\rho u}{\mu}\right) \operatorname{Pr}^{\frac{1}{3}} \int_{0}^{L} x^{-\frac{1}{2}} d x \\
& \bar{h}=0.332 k\left(\frac{\rho u}{\mu}\right) \operatorname{Pr}^{\frac{1}{3}}\left[2 L^{-\frac{1}{2}}\right]
\end{aligned}
$$

Normalizing the average heat transfer coefficient from 0 to $\mathrm{L}$ by the local value at $\mathrm{L}$ yields:

$$
\frac{\bar{h}}{h(L)}=\frac{2\left(0.332 k\left(\frac{\rho u}{\mu}\right) \operatorname{Pr}^{\frac{1}{3}}\left[L^{-\frac{1}{2}}\right]\right)}{0.332 k\left(\frac{\rho u}{\mu}\right)^{\frac{1}{2}} L^{-\frac{1}{2}} \operatorname{Pr}^{\frac{1}{3}}}=2
$$


Therefore, the average heat transfer coefficient over the boundary layer build-up region is equivalent to twice the local heat transfer coefficient in the fully developed region. The solution of the Polhausen equation clearly bounds the 13 percent increase in Nusselt number for compact heat exchanger modeling. In fact, increasing the Sellars' solution $(\mathrm{Nu}=4.36)$ by a factor of two would also bound the proposed Nusselt number.

Several steady state RELAP5-3D runs of a notional direct gas Brayton cycle reactor plant recuperator with the ORNL/PSU correlation in both its unmodified $\left(\mathrm{Nu}_{\text {analytic }}=7.63\right)$ and modified $\left(\mathrm{Nu}_{\text {analytic }}=8.63\right)$ form were performed. These results were compared to a steady state prediction of an identical heat exchanger analyzed with the Kays and London method. The heat exchanger predictions for both RELAP5-3D runs were in excellent agreement with the Kays and London predictions as shown in Table 1. Effectiveness and heat transfer errors were calculated relative to Kays \& London and temperature errors were calculated relative to the Kays \& London heat exchanger $\Delta \mathrm{T}\left(\mathrm{T}_{\mathrm{H}, \text { in }}-\mathrm{T}_{\mathrm{H}, \mathrm{out}}\right)$.

The RELAP5-3D Project Prometheus model was modified to include the staggered heat structure mesh approximation presented above and used the modified ORNL/PSU laminar heat transfer correlation. Had the project continued, a more rigorous correlation would have been developed. The modified $(\mathrm{Nu}=8.63)$ ORNL/PSU engineering approximation was chosen due to its agreement with Kays and London.

Table 1 ORNL/PSU Correlation as Compared to Kays \& London

\begin{tabular}{|c|c|c|c|}
\hline & Kays \& London & RELAP5-3D & Relative Error (\%) \\
\hline \multicolumn{4}{|c|}{ Recuperator $(\mathrm{Nu}=7.63)$} \\
\hline$\varepsilon$ & 0.9449 & 0.9412 & -0.38 \\
\hline $\mathrm{Q}(\mathrm{kW})$ & 366.7 & 365.3 & -0.38 \\
\hline $\mathrm{T}_{\mathrm{H}, \text { in }}(\mathrm{K})$ & 920.6 & 920.6 & \\
\hline $\mathrm{T}_{\mathrm{H}, \text { out }}(\mathrm{K})$ & 564.1 & 566.0 & 0.53 \\
\hline $\mathrm{T}_{\mathrm{C}, \text { in }}(\mathrm{K})$ & 535.1 & 535.1 & \\
\hline $\mathrm{T}_{\mathrm{C}, \mathrm{out}}(\mathrm{K})$ & 899.4 & 895.3 & 1.15 \\
\hline \multicolumn{4}{|c|}{ Modified Recuperator $(\mathrm{Nu}=8.63)$} \\
\hline$\varepsilon$ & 0.9449 & 0.9490 & 0.43 \\
\hline Q & 368.6 & 370.2 & 0.43 \\
\hline $\mathrm{T}_{\mathrm{H}, \mathrm{in}}$ & 920.4 & 920.4 & \\
\hline $\mathrm{T}_{\mathrm{H}, \text { out }}$ & 562.7 & 561.6 & -0.31 \\
\hline $\mathrm{T}_{\mathrm{C}, \text { in }}$ & 533.5 & 533.5 & \\
\hline $\mathrm{T}_{\mathrm{C}, \text { out }}$ & 899.1 & 898.0 & -0.31 \\
\hline
\end{tabular}

\section{CONCLUSION}

Using the staggered heat structure mesh, it was possible to decrease the fluid volume nodalization in the Prometheus counter flow heat exchanger models from 80 to 20 control volumes increasing the Courant limit by a factor of four and eliminating the differential temperature error across the heat exchanger. 
Numerical stability was also improved enabling a further increase in time-step size. This enabled a time step increase from $1.5 \mathrm{~ms}$ to $10 \mathrm{~ms}$. However, the remaining fluid structures in the problem could only support a $9 \mathrm{~ms}$ time step. So, utilizing this methodology enabled the heat exchangers to become nonlimiting with regard to time step sizing. The resulting problem runs approximately 1.7 times slower than real time allowing a 1000 second job to be completed in less than 30 minutes (a decrease in run-time of more than an order of magnitude). Larger time step sizes could have been used and supported for slow transients. However, model flexibility is enhanced by using a time step size of one to five times the Courant limit thereby increasing model speed and having the flexibility to accurately respond to rapid transients.

The INL is investigating modifications to the RELAP5-3D code to use more appropriate heat structure temperature boundary conditions for heat exchanger applications. This would simplify heat exchanger modeling by not requiring the staggered heat structure connection scheme detailed in this letter. However, the modified ORNL/PSU engineering approximation would still be required in order to accurately model the heat transfer characteristics of compact heat exchangers until a better correlation became available.

\section{NOMENCLATURE}

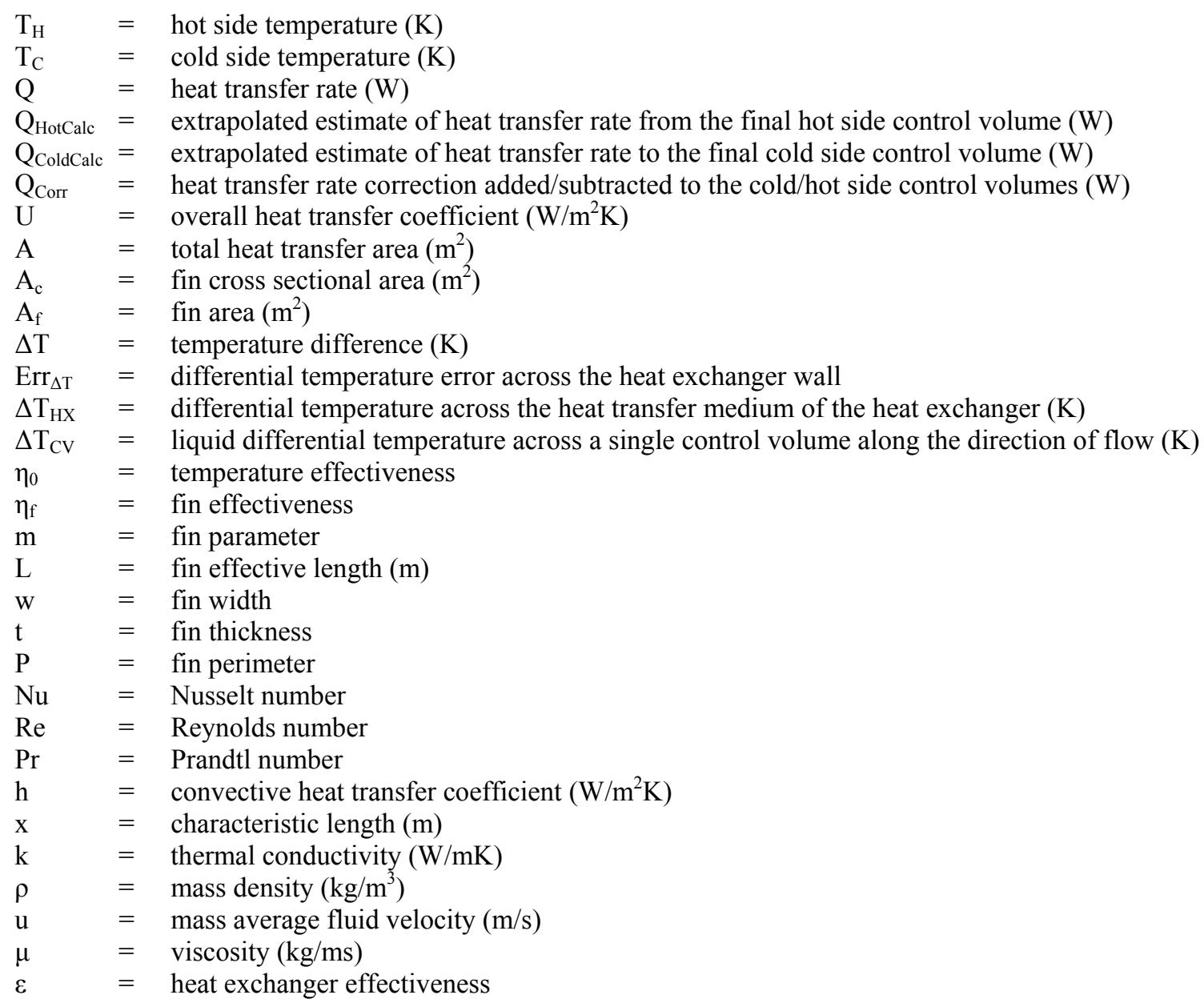




\begin{abstract}
AKNOWLEDGMENTS
The author thanks Dr. Larry McCann at the Bettis Atomic Power Laboratory for providing the JIMO reactor plant model and assisting with numerous modeling runs and comparisons. Thanks to Dr. Ed Tomlinson at the Bettis Atomic Power Laboratory for assistance with the RELAP5-3D code use and several modifications that enabled this effort. Thanks to Dr. David Aumiller also at the Bettis Atomic Power Laboratory for his assistance with time advancement schemes, heat transfer correlations, and helping the author to recall heat transfer calculation methods and techniques that should never have been forgotten. Thanks to Paul Johnson at the NASA Glenn Research Center for providing information about the compact heat exchangers envisioned for the JIMO Project. Thanks to Dr. Michael Barret also at the NASA Glenn Research Center for recommendations on bounding the proposed heat transfer correlations.
\end{abstract}

\title{
REFERENCES
}

McCann, Larry D., "Use of RELAP5-3D for Dynamic Analysis of a Closed-Loop Brayton Cycle Coupled To a Nuclear Reactor," STAIF, February, 2006.

W.M. Kays and A.L. London, Compact Heat Exchangers, $3^{\text {rd }}$ Edition. McGraw-Hill, New York (1984). F.P. Incropera and D.P. De Witt, Fundamentals of Heat and Mass Transfer, $2^{\text {nd }}$ Edition. John Wiley \& Sons, New York (1985).

J. R. Sellars, M. Tribus, and J. S. Klein, "Heat Transfer to Laminar Flows in a Round Tube or Flat Conduit: The Graetz Problem Extended," Transactions, American Society of Mechanical Engineers, 78, 1956, p. 441.

INEEL-EXT-98-00834, RELAP5-3D ${ }^{\complement}$ Code Manual Volume IV: Models and Correlations, Revision 2.1, April 2003 
Enclosure 16 to

SPP-SEC-0039

NRPCT Perspective on Lithium Hydride for Use in a Space Shield

Campbell, B. et al 
This page is intentionally blank.

PRE-DECISIONAL - For planning and discussion purposes only 


\title{
NRPCT Perspective on Lithium Hydride for Use in a Space Shield
}

\author{
Brian Campbell \\ Barri Gurau \\ Rose Lewis \\ Jane Oppenlander \\ Dean Poeth \\ James Vollmer \\ Naval Reactors Prime Contract Team
}

STAIF February 2006 


\section{Lithium Hydride Discussion Points}

- LiH Swelling Findings

- Background:

- Scope of LiH Research

- Prometheus Shield Plan

- Gamma-Induced Swelling

- Mixed Neutron/Gamma-Induced Swelling

- Swelling Mechanisms

- Next Steps Towards LiH Qualification

- Conclusions

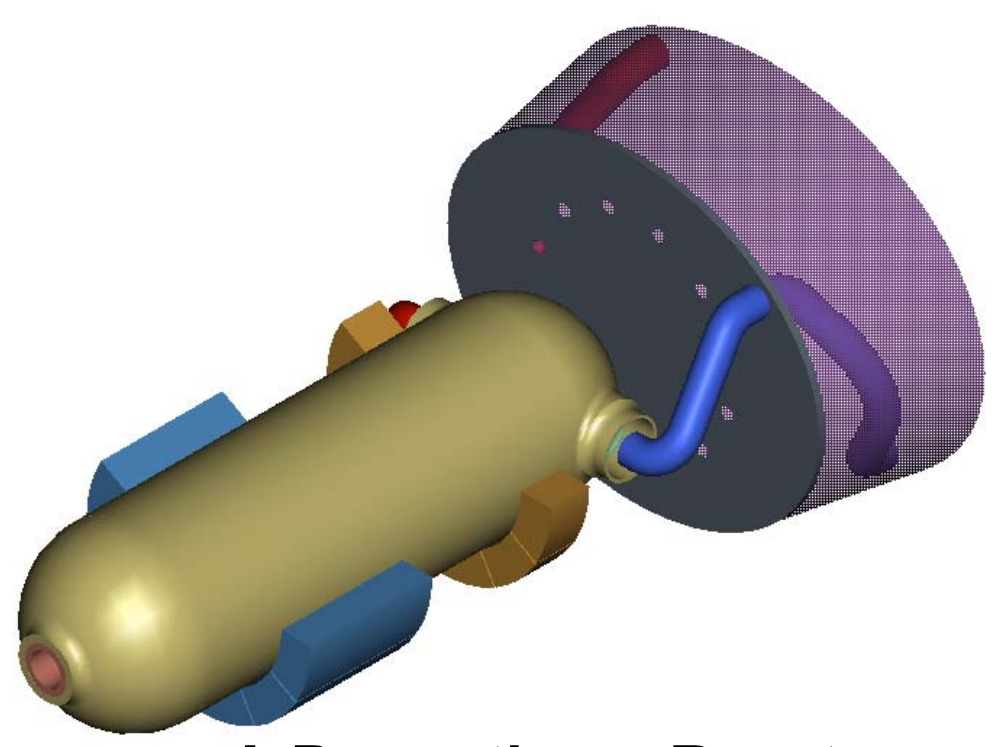

A Prometheus Reactor and Shield

References for this presentation are provided in the backup slides 


\section{Findings Concerning LiH Swelling Under Irradiation}

$\mathrm{LiH}$ irradiation-induced swelling is the key remaining issue its use.

- Volumetric swelling has ranged from 0 to $\sim 25 \%$ in the prior 50 tests. However, most cast or pressed and out-gassed $\mathrm{LiH}$ specimens swelled $<\sim 2 \%$

Hypothesis: $\mathrm{LiOH}$ contamination on $\mathrm{LiH}$ may accelerate swelling.

- $\mathrm{LiOH}$ forms on $\mathrm{LiH}$ powder, and can be trapped in pressed samples. Casting or out-gassing samples reduces $\mathrm{LiOH}$ contamination. These samples perform better.

Swelling mechanism is not clear. Two LiOH-related ideas:

1) Inside Grains: $\mathrm{LiOH}$ adds $\mathrm{H}_{2}$ to $\mathrm{LiH}$ grains: $\mathrm{LiOH}+\mathrm{LiH} \rightarrow \mathrm{Li}_{2} \mathrm{O}+\mathrm{H}_{2} \cdot \mathrm{H}_{2}$ nucleates bubbles. Bubble formation drives swelling.

2) On Grain Boundaries: $\mathrm{LiOH}$ converts to denser $\mathrm{Li}_{2} \mathrm{O}$, creating gaps on grain boundaries. $\mathrm{H}_{2}$ accumulates in the gaps driving swelling.

Alternate Hypothesis: Casting or out-gassing change microstructure in an unknown, beneficial way.

Bottom Line: cast or out-gas specimens/shields 


\section{Reviewed ANP, LLNL, SNAP, and SP-100 Information}

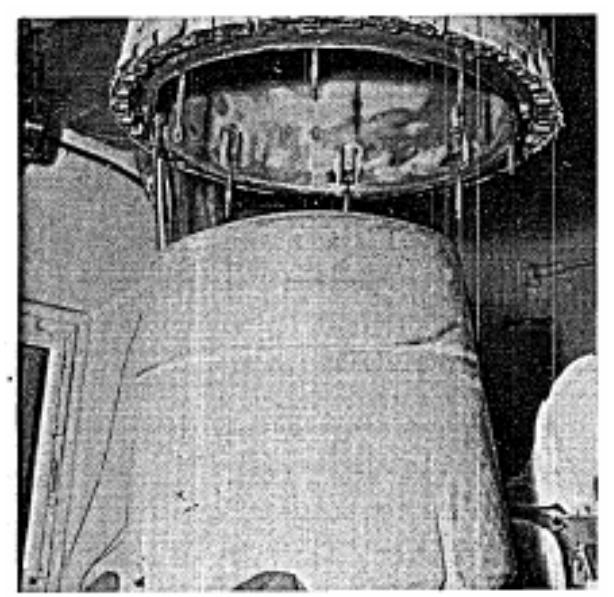

8-3-66 CRD (GP-1)

\section{SNAP 10AFS3} Shield-LiH Block

$8 \mathrm{LiH}$ data points (mixed $\mathbf{n}, \gamma)$ 1 full shield test $(\operatorname{mixed} n, \gamma)$

\section{LLNL Tests}

$37 \mathrm{LiH}$ data points $(\gamma)$

Additional $\mathrm{Li}(\mathrm{H}, \mathrm{T})$ data

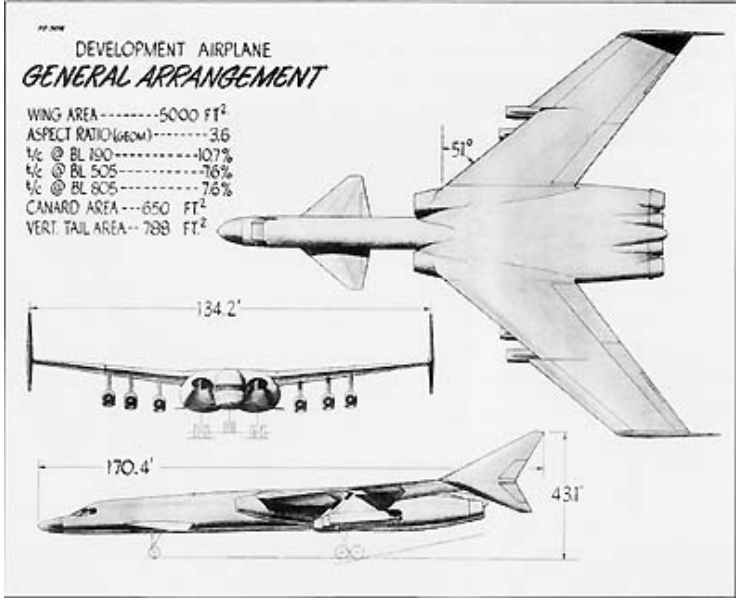

Schematic of Nuclear Powered Aircraft

$32 \mathrm{LiH}$ data points $(\operatorname{mixed} \mathbf{n}, \gamma)$

\section{Talked to LiH Consultants:}

D. Bias (Y-12)

Dr. R.K. Disney (SP-100)

D. Little (Y-12)

Dr. G. Schmidt (SNAP)

Dr. L.L. Snead (ORNL)

Dr. A. Weitzberg (SP-100)

Dr. S. Zinkle (ORNL)

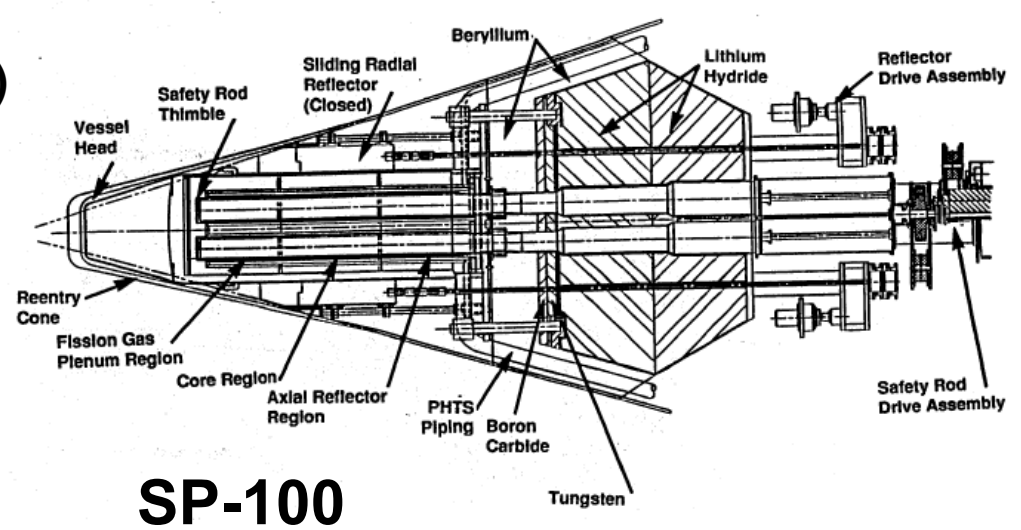

$16 \mathrm{LiH}$ data points (mixed $\mathbf{n}, \gamma$ ) $24 \mathrm{LiH}$ data points $(\gamma)$ 


\section{Prometheus Shield Plan}

- Many materials were considered for the Prometheus shield

- Be, $\mathrm{B}_{4} \mathrm{C}, \mathrm{W}, \mathrm{LiH}$ and $\mathrm{H}_{2} \mathrm{O}$ were chosen for focused development/qualification

- The three foremost notional shield concepts included:

- a low risk but higher mass $\mathrm{Be} / \mathrm{B}_{4} \mathrm{C}$ shield;

- a low mass SP-100 analog $\mathrm{Be} / \mathrm{B}_{4} \mathrm{C} / \mathrm{W} / \mathrm{LiH}$ shield;

- and a variant of the $\mathrm{LiH}$ shield with water substituted for $\mathrm{LiH}$

- Early plans for LiH testing were underway

- Focus for LiH testing was irradiation-induced swelling 


\section{SP-100 LiH Mixed Neutron/Gamma Irradiation}

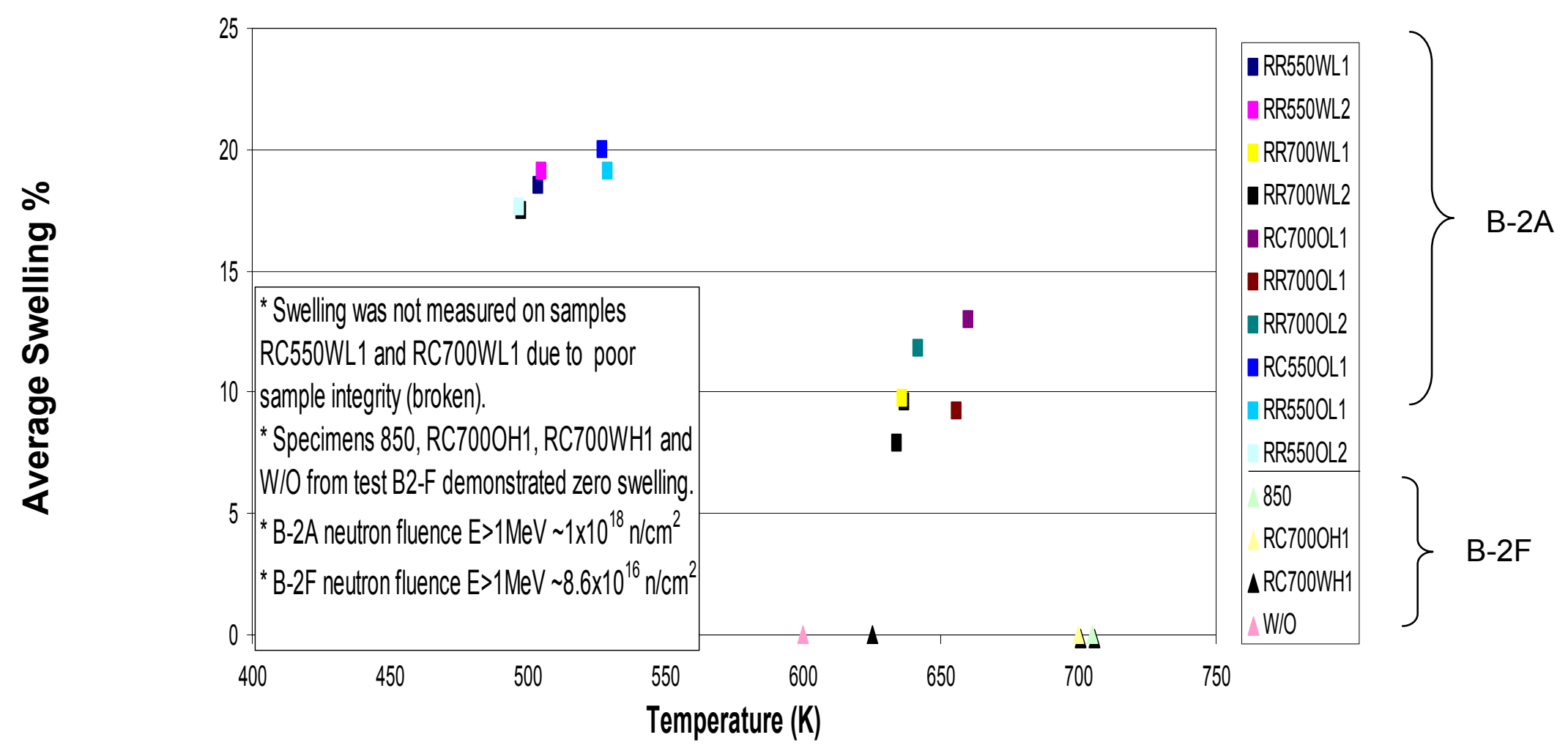

\section{Example of the uncertainty in LiH swelling}




\section{LiH Gamma Irradiation - Historical Information}

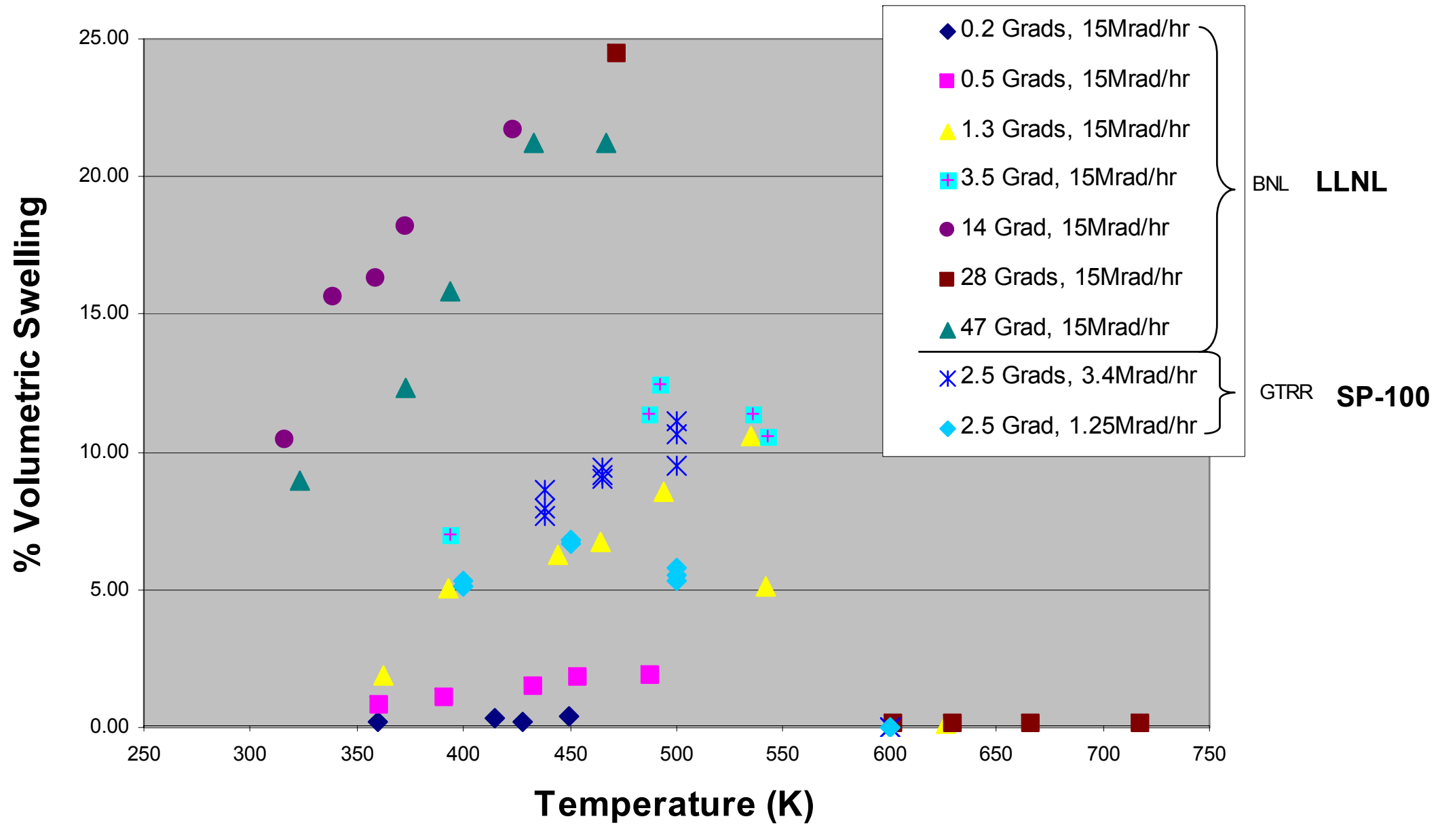

Swelling increases with total gamma dose and drops off to $\sim 0 \% \geq 600 \mathrm{~K}$.

Dose rates are $\sim 750$ times higher than predicted Prometheus rates. 


\section{LiH Gamma Irradiation - Dose Rate Affect}

\section{Dose Rate Comparison}

(450-500K; 1.3-3.5 Grads; 1.25-15 Mrad/hr)

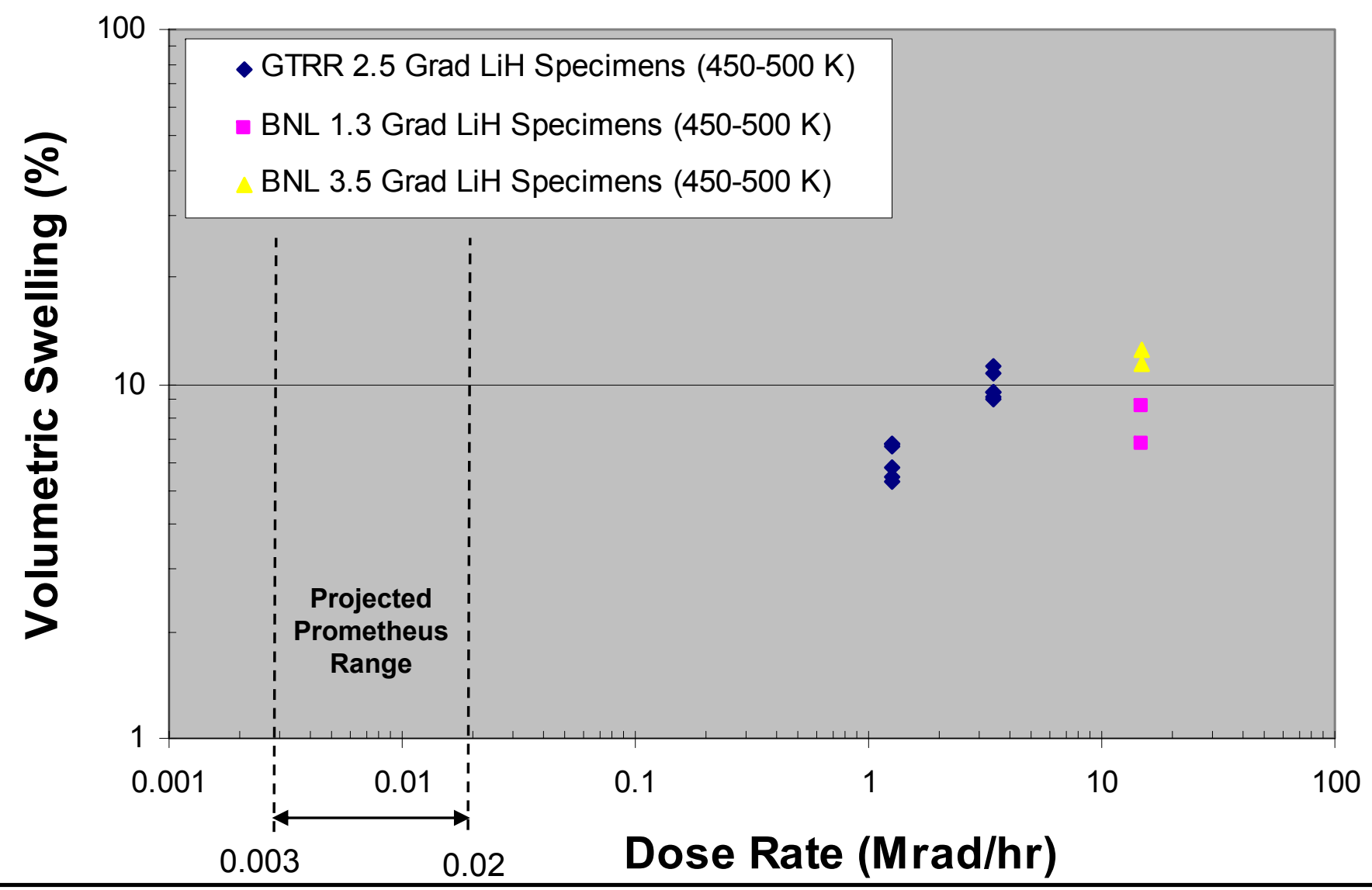

Gamma testing suggests increased dose rate leads to increased swelling.

Additional testing is necessary. 


\section{Historical LiH Mixed Neutron/Gamma Irradiation Tests}

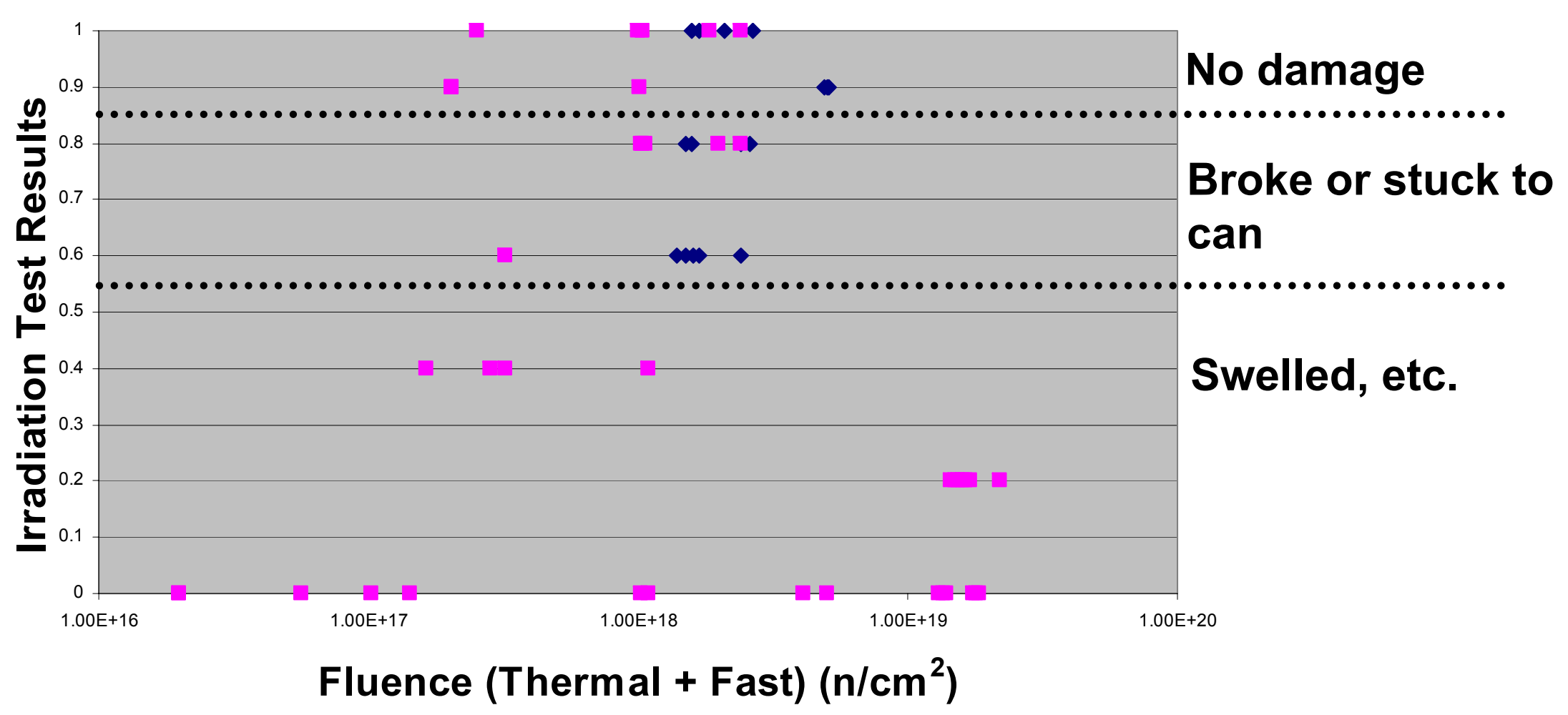

- Cast or Pressed and Out-gassed Specimens

- Pressed or LiOH Contaminated Specimens

\begin{tabular}{|l} 
Key to Results Column \\
$0.0=$ turned to dust/powder, can rupture, swelling $~ 20 \%$ \\
$0.2=$ turned to dust/powder, no can rupture, swelling $\sim 10 \%$ \\
$0.4=$ sample black, flakey, possible chunks, measurable swelling $<3 \%$ \\
$0.6=$ negligible powdering or stuck to can \\
$0.8=$ broke into chunks on sectioning capsule \\
$0.9=$ no powdering/intact, some blackening \\
$1.0=$ no change
\end{tabular}




\section{Historical LiH Mixed Neutron/Gamma Irradiation Tests}

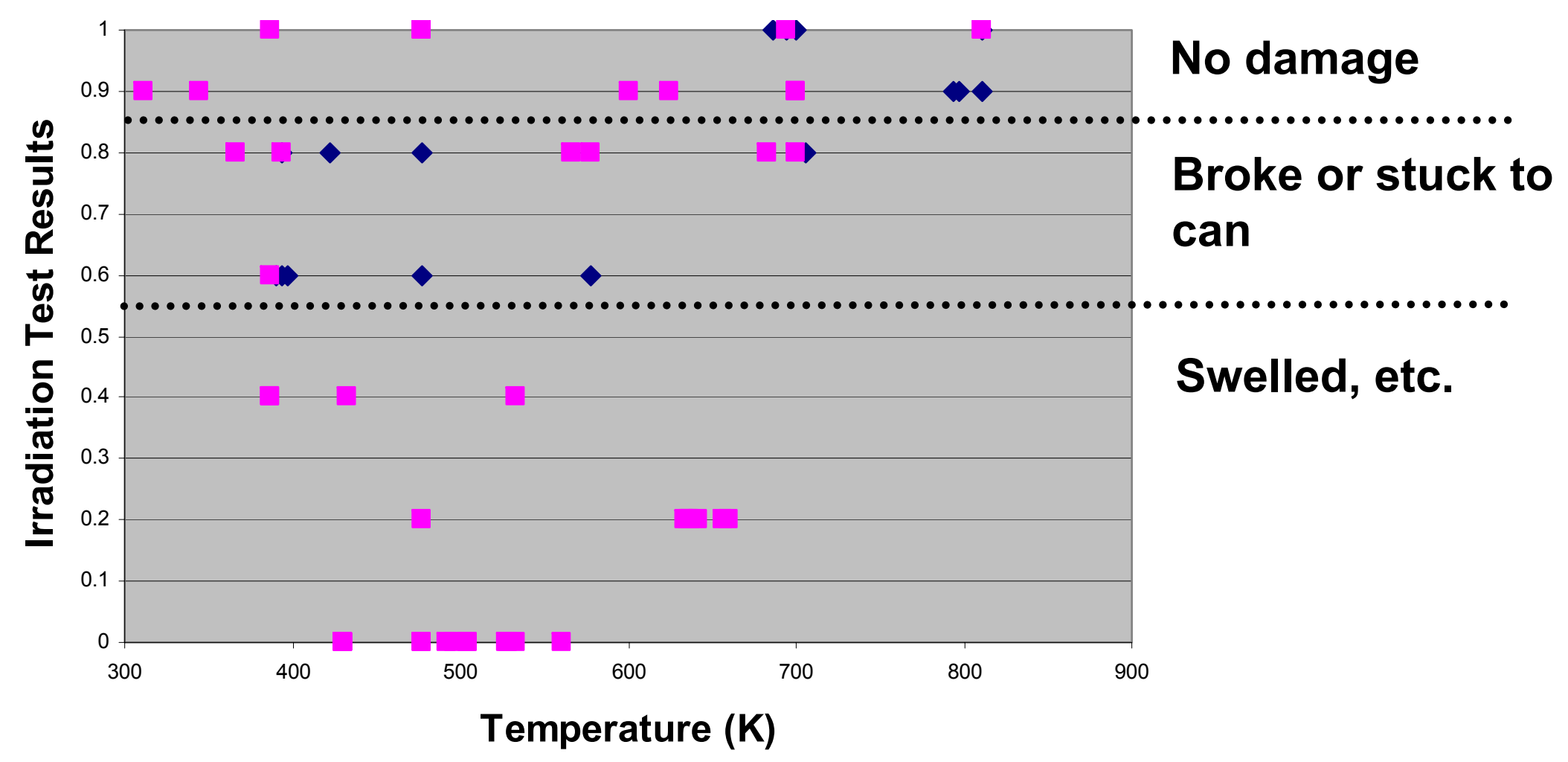

- Cast and Pressed and Out-gassed Specimens

- Pressed or LiOH Contaminated Specimens

Key to Results Column

$0.0=$ turned to dust/powder, can rupture, swelling $\sim 20 \%$

$0.2=$ turned to dust/powder, no can rupture, swelling $\sim 10 \%$

0.4 = sample black, flakey, possible chunks, measurable swelling $<3 \%$

$0.6=$ negligible powdering or stuck to can

$0.8=$ broke into chunks on sectioning capsule

$0.9=$ no powdering/intact, some blackening

$1.0=$ no change 


\section{LiH Mixed Neutron/Gamma Irradiation - Meta Analysis}

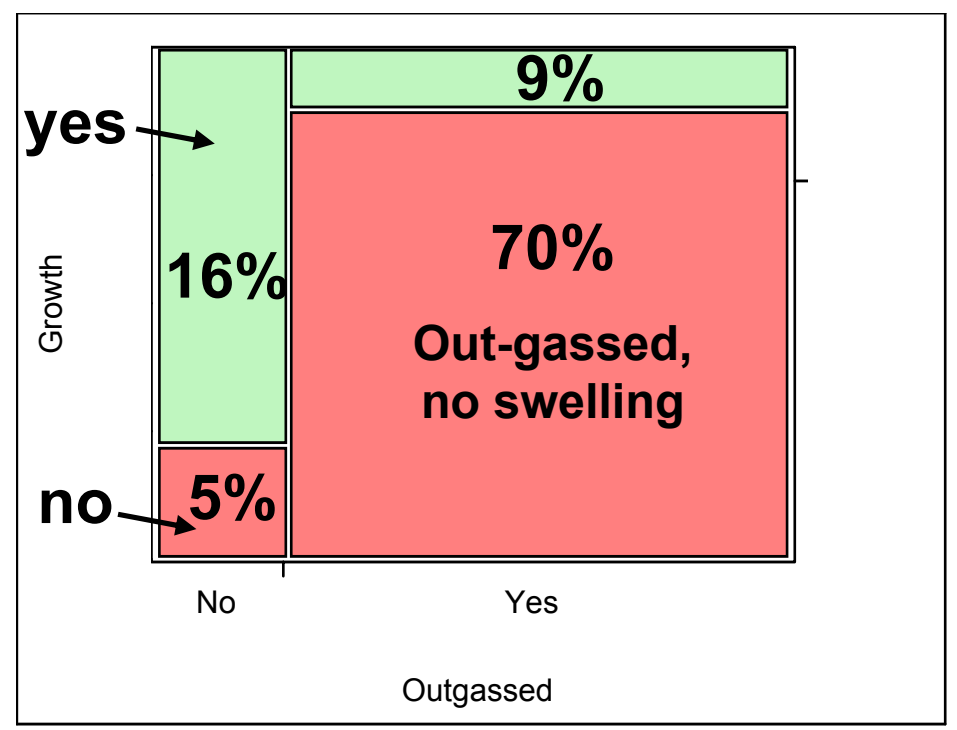

Most out-gassed specimens did not swell

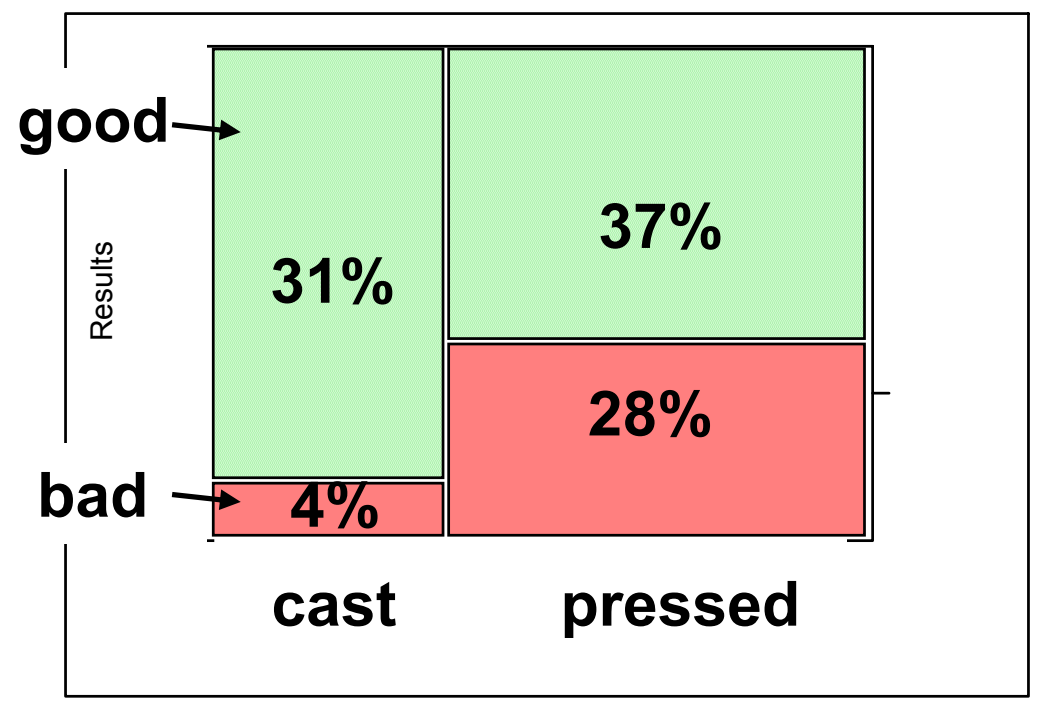

Most cast specimens performed "good". Performance of pressed specimens was mixed "good" and "bad".

These plots do not include SP-100 data. 


\section{Background: LiH Radiation Damage}

Radiation creates:

$\mathrm{Li}$ and $\mathrm{H}$ vacancies (diffuses slowly: barrier $\sim 40-90 \mathrm{~kJ} / \mathrm{mol}$ )

$\mathrm{Li}+$ and $\mathrm{H}$ - interstitials (diffuses quickly: barrier $\sim 7-25 \mathrm{~kJ} / \mathrm{mol}$ )

$\mathrm{LiH}$ vacancy pairs, etc.

$2 \mathrm{H}$ can form $\mathrm{H}_{2}$ but barrier is high $(\sim 100 \mathrm{~kJ} / \mathrm{mol})$

LiOH forms in humid air: $\mathrm{LiH}+\mathrm{H}_{2} \mathrm{O} \rightarrow \mathrm{LiOH}+\mathrm{H}_{2}(\mathrm{~g})$

$\mathrm{LiOH}$ reacts with $\mathrm{LiH}$ to produce $\mathrm{H}_{2}$ : $\mathrm{LiOH}+\mathrm{LiH} \rightarrow \mathrm{Li}_{2} \mathrm{O}+\mathrm{H}_{2}(g)$

$\mathrm{H}_{2}$ diffuses slowly (barrier $\sim 70 \mathrm{~kJ} / \mathrm{mol}$ ) 


\section{Hypothesis: In-Grain Swelling Mechanism}
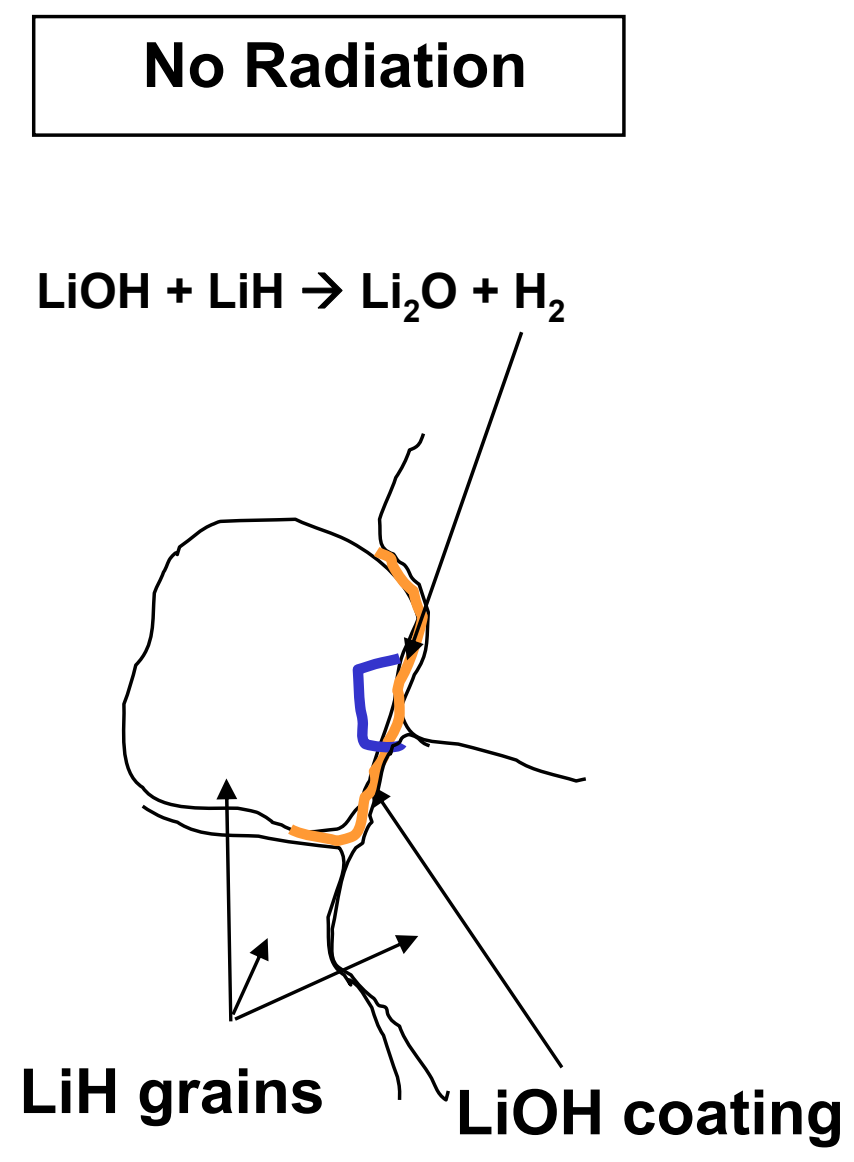
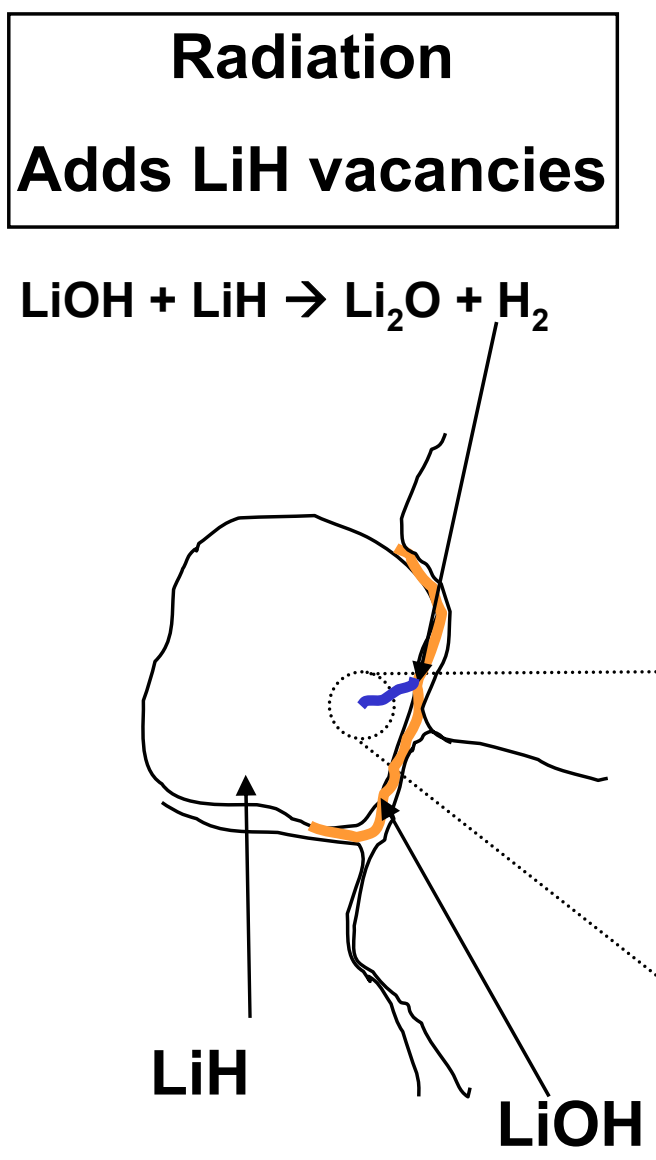

$\mathrm{H}$ is white. $\mathrm{Li}$ is purple. $\mathrm{H}_{2}$ is blue. 


\section{Hypothesis: Grain Boundary Swelling Mechanism}
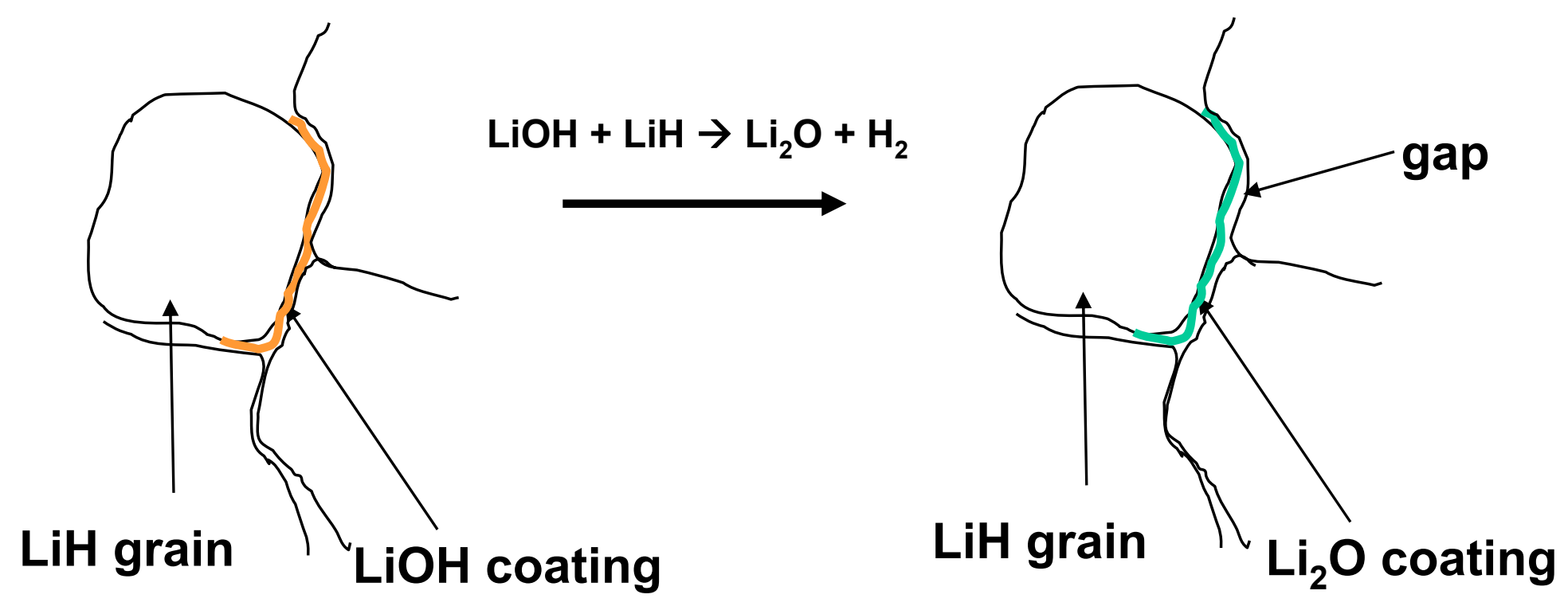

- $\mathrm{Li}_{2} \mathrm{O}$ denser than $\mathrm{LiOH}--$ opens up gaps.

$\cdot \mathrm{H}_{2}$ collects in voids, and bubbles form/grow. 


\section{Next Steps Towards LiH Qualification}

- Perform unirradiated thermal tests of $\mathrm{LiH}$ with corresponding modeling work. Test to determine the role of $\mathrm{LiOH}, \mathrm{H}_{2}(\mathrm{~g})$, out-gassing and cast vs. pressed performance.

- Perform X-ray irradiation tests to quickly screen various parameters, e.g. dose, dose rate, impurities, temperature, processing, etc.

- Perform mixed neutron/gamma irradiation tests, testing several dose rates, one of which should be $<10 x$ of actual application rate, and spanning temperatures and fluences relevant to the application.

- Perform gamma irradiation tests to generate confirmatory data compared with past gamma tests, testing several dose rates, one of which should be $<10 x$ of actual application rate. 


\section{Conclusions}

- $\quad$ Based on a literature review of ANP, SNAP, LLNL studies and SP-100, as well as quantum mechanical modeling, $\mathrm{LiH}$ swelling under mixed neutron and gamma radiation may be minimized by optimizing fabrication techniques. The most promising methods are:

- Casting

- Pressing with pre-irradiation out-gassing

- $\quad \mathrm{LiOH}$ may be a key contributor to the observed swelling by adding $\mathrm{H}_{2}$ to the $\mathrm{LiH}$. The $\mathrm{H}_{2}$ may then accelerate $\mathrm{H}_{2}$ bubble formation, however, the mechanism is not known.

- Gamma induced $\mathrm{LiH}$ swelling shows patterns with temperature and dose, and possibly with dose rate. Using gamma-only swelling data to design space shields is not recommended due to observed differences from existing mixed neutron and gamma swelling data.

- Next actions should include unirradiated testing of $\mathrm{LiH}$ and $\mathrm{LiOH}$, as well as irradiated testing. 


\title{
ACKNOWLEDGEMENTS
}

\author{
Bechtel - Bettis Atomic Power Laboratory \\ Bechtel Plant and Machinery, Inc. \\ Lockheed Martin - Knolls Atomic Power Laboratory \\ Oak Ridge National Lab \\ Y12 National Security Complex
}




\section{Back up Slides}




\section{References}

Gamma Slides

1. P.C. Souers, T.S. Blake, R.M. Penpraze, and C. Cline. 1969. "Pulsed Nuclear Magnetic Resonance of Gamma-Irradiated Lithium Hydride." Journal of Physical Chemical Solids 30 (1969) pp 2649-2656.

2. R.K. Disney, "Status Report on the SP-100 Program Investigations of Irradiation-Induced Swelling of Lithium Hydride Shield Materials," Westinghouse Electric Corporation, February 25, 1993.

Mixed Neutron/Gamma Slides

1. R.K. Disney, "Status Report on the SP-100 Program Investigations of Irradiation-Induced Swelling of Lithium Hydride Shield Materials," Westinghouse Electric Corporation, February 25, 1993.

2. P. Bauer, F.H. Welch, and E.P. Kilb. 1959. Irradiation Testing of XMA-1A Shield Materials. GE Document DC 59-5-81.

3. B. Minushkin. 1956. Final Report: Lithium Hydride Radiation Stability. Nuclear Development Corporation of America Document NDA-23.

4. E.A. Aitken and D.L. Henry. 1956. Radiation Damage To Lithium Hydride. General Electric Document APEX-323.

5. M.P. Reagan. 1958. Radiation Testing of Shield Specimen: Test LTHx-5 and 6. GE Document DC 58-1-211.

6. F.H. Welch. 1967. Lithium Hydride Technology: III. Properties of Lithium Hydride for SNAP Shielding Applications. Atomics International Document NAA-SR-9400 Volume III.

7. C.W. Hamill and F.B. Waldrop. 1964. Shielding Studies: Neutron Irradiation Damage to a Lithium Hydride Compact. Union Carbide Corporation, Y-12 Plant Document Y-1454. 


\section{Historical Mixed Neutron/Gamma Tests}

- 1950's XMA-1A Shield Materials Testing

- $23 \mathrm{LiH}$ specimens tested (pressed and cast)

- $366-811 \mathrm{~K}$, thermal neutron fluence $10^{16}$ to $10^{18} \mathrm{n} / \mathrm{cm}^{2}$

- 2 pressed specimens swelled—both had capsule leaks (one not confirmed)

- 1956 Minushkin LiH Radiation Stability Study

- 6 LiH specimens tested (5 pressed, 1 crystal)

- 477-594K, fluence $10^{15}$ to $10^{18} \mathrm{n} / \mathrm{cm}^{2}$ in Brookhaven BNL reactor

- 4 pressed specimens swelled or powdered

- 2 unirradiated specimens tested showed no growth or discoloration

- Aitken and Henry Radiation Damage to Lithium Hydride Study

- $3 \mathrm{LiH}$ specimens (1 cast, 2 pressed) (all out-gasses before testing)

- $~-800 \mathrm{~K}$, fluence $4 \times 10^{18} \mathrm{n} / \mathrm{cm}^{2}$ thermal, $10^{18}$ fast in LITR at ORNL

- No measurable swelling. Some powdering. 


\section{Historical Mixed Neutron/Gamma Tests_continued}

- 1957 LTHx-5 and LTHx-6 Lithium Hydride Test

- $2 \mathrm{LiH}$ specimens tested (pressed)

- LTHx-5: 588K, thermal fluence of $3 \times 10^{17} \mathrm{n} / \mathrm{cm}^{2}$. Swelled and some powdering. Post-irradiation testing revealed $\mathrm{LiOH}$ present.

- LTHx-6: $\sim 344 \mathrm{~K}$, thermal fluence of $1 \times 10^{16} \mathrm{n} / \mathrm{cm}^{2}$. No swelling. No $\mathrm{LiOH}$ present.

1962 NARF Experiment

- $4 \mathrm{LiH}$ specimens tested (out-gassed).

- $\sim 430 \mathrm{~K}$, fast fluence $1.6 \times 10^{17} \mathrm{n} / \mathrm{cm}^{2}$ (E>0.1Mev). Test terminated when suspected seal comprise. Testing confirmed air in the cans and chemical analysis determined $\sim 11 \% \mathrm{LiOH}$ in the specimens (no moisture controls in the hot cell). Swelled from 3.7-6.2\%.

- NARF concluded proper handling of LiH in a dry atmosphere would prevent $\mathrm{LiOH}$ formation and reduce gas evolution.

- STIR Experiment-Theory: $\mathrm{LiH}$ swelling is due to $\mathrm{Li}_{2} \mathrm{O}$ and $\mathrm{Li}$ metal

- $4 \mathrm{LiH}$ specimens tested (2 cast, 2 pressed); different $\mathrm{LiOH}$ contamination

- $\sim 390 \mathrm{~K}$, fast fluence $\sim 2 \times 10^{17} \mathrm{n} / \mathrm{cm} 2$ ( $\mathrm{E}>0.1 \mathrm{Mev}$ )

- Results difficult to interpret due to too many variables in play at once. 


\section{Historical Mixed Neutron/Gamma Tests_-continued}

- SNAP10AFS3 Shield Irradiation Test

- Shield cold pressed and canned in stainless steel (estimated to contain $<2-3 \% \mathrm{LiOH}$ )

- $533-685 \mathrm{~K}$, fast fluence $\sim 3 \times 10^{18} \mathrm{n} / \mathrm{cm}^{2}$

- 10,000 hour test

- No measurable swelling within measurement capability of $1.2 \%$

- SP-100 B-2A ATR Test

- $12 \mathrm{Li}(2 \%) / \mathrm{LiH}$ specimens tested (pressed)

- $\sim 500-650 \mathrm{~K}$ maximum temperature-probably less due to swelling.

- Fast fluence $\sim 1 \times 10^{18} \mathrm{n} / \mathrm{cm}^{2}$ (E>1MeV), (neutron flux $5 \times 10^{11}$ to $3 \times 10^{12} \mathrm{n} / \mathrm{cm}^{2}-\mathrm{s}(\mathrm{E}>1 \mathrm{MeV})$ )

- Specimens @ 500-550K swelled 17-20\%

- Specimens@625-650K swelled 7-14\%

- 1 specimen @ 500K ruptured the test container, swelling $>20 \%$

- SP-100 B-2F ARMF Test

- $4 \mathrm{Li}(2 \%) / \mathrm{LiH}$ specimens tested (pressed)

- 600-700K, fast fluence $\sim 9 \times 10^{16} \mathrm{n} / \mathrm{cm} 2(\mathrm{E}>1 \mathrm{MeV})$, (neutron flux 2x1011 n/cm²-s $(\mathrm{E}>1 \mathrm{MeV})$ )

- Gamma dose 0.9 Grads

- The specimens were run at temperature for 24 hours but only exposed to irradiation for $\sim 8$ hours per day

- Dimensional analysis detected no measurable swelling. 


\section{Modeling Li and H Diffusion}

Barriers to Diffusion for $\mathrm{Li}$ and $\mathrm{H}$ Interstitials and Vacancies Between Adjacent Sites in LiH, and an Estimate of the Successful Movements Per Second

\begin{tabular}{|c|c|c|c|c|c|c|c|}
\hline \multirow{2}{*}{$\begin{array}{l}\text { Diffusing } \\
\text { Defect }\end{array}$} & \multirow{2}{*}{$\begin{array}{c}\text { \# H } \\
\text { Atoms }\end{array}$} & \multirow{2}{*}{$\begin{array}{c}\text { \# Li } \\
\text { Atoms }\end{array}$} & \multirow{2}{*}{$\begin{array}{c}\text { Barrier } \\
\text { Height } \\
\left(E^{\ddagger}\right)^{a} \\
(k J / m o l)\end{array}$} & \multicolumn{3}{|c|}{$\exp \left(-E^{\ddagger} /(R T)\right)$} & \multirow{2}{*}{$\begin{array}{c}\exp \left(E^{\ddagger} /(R \cdot 500 \mathrm{~K})\right) \\
\cdot v\left(\sec ^{-1}\right)^{\mathrm{b}}\end{array}$} \\
\hline & & & & $400 \mathrm{~K}$ & $500 \mathrm{~K}$ & $600 \mathrm{~K}$ & \\
\hline $\mathrm{Li}_{\text {int }}$ & 108 & 108 & 9.0 & $6.68 \mathrm{E}-02$ & 1.15E-01 & 1.65E-01 & 2.0E10 \\
\hline $\mathrm{H}_{\text {int }}$ & 33 & 32 & 24.7 & $5.95 \mathrm{E}-04$ & 2.63E-03 & 7.07E-03 & 8.8E8 \\
\hline $\mathrm{H}_{\text {int }}$ & 108 & 108 & 4.3 & $2.74 \mathrm{E}-01$ & 3.55E-01 & $4.22 \mathrm{E}-01$ & 1.2E11 \\
\hline $\mathrm{Li}_{\mathrm{vac}}$ & 108 & 108 & 43.7 & 1.97E-06 & $2.72 \mathrm{E}-05$ & 1.57E-04 & $4.8 \mathrm{E} 6$ \\
\hline $\mathrm{H}_{\mathrm{vac}}$ & 108 & 108 & 91.0 & $1.31 \mathrm{E}-12$ & $3.11 \mathrm{E}-10$ & 1.20E-08 & 1.0E2 \\
\hline $\mathrm{H}_{2 \text { int }}$ & 108 & 108 & 72.3 & $3.62 \mathrm{E}-10$ & $2.80 \mathrm{E}-8$ & $5.08 \mathrm{E}-7$ & $9.4 \mathrm{E} 3$ \\
\hline
\end{tabular}

a Energies are relative to the isolated defect site.

${ }^{b}$ Product of Boltzmann distribution (at 500K) with approximate jump frequency (1.77E11 attempted jumps $/ \mathrm{sec}^{-1}$ for Li and 3.36E11 attempted jumps $/ \mathrm{sec}^{-1}$ for $\mathrm{H}$ ) for respective diffusion species. 
Enclosure 17 to

SPP-SEC-0039

\section{Reflector Material Selection for Space Nuclear Applications}

Campbell, B., et al 
This page is intentionally blank.

PRE-DECISIONAL - For planning and discussion purposes only 


\title{
Reflector Material Selection for Space Nuclear Applications
}

\author{
Brian Campbell \\ James Nash \\ Bren Phillips \\ Tristan Schaefer \\ Dr. Jonathan Witter
}

Naval Reactors Prime Contractor Team

STAIF February 2006 


\section{Reflector Design}

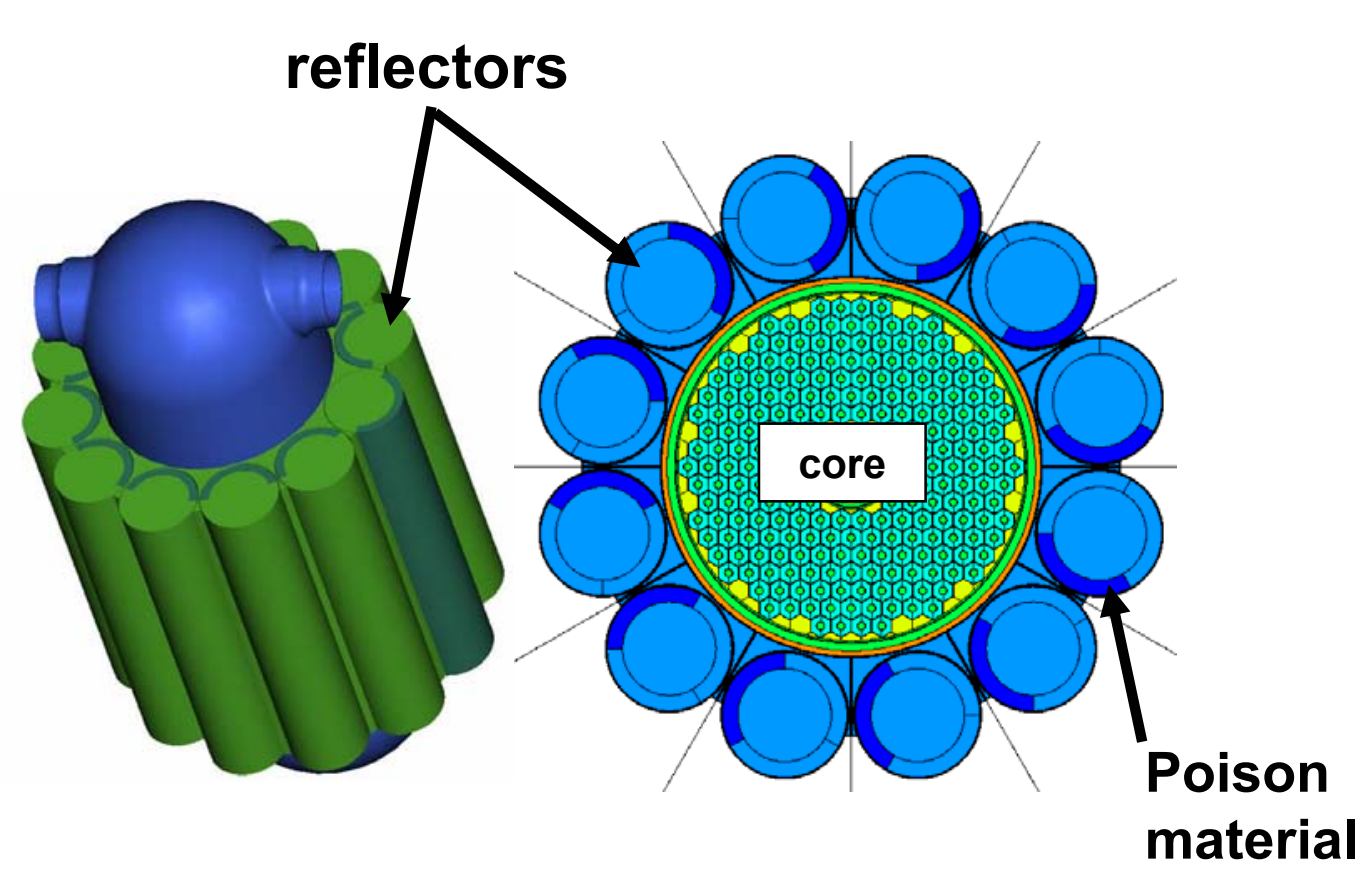

Drums

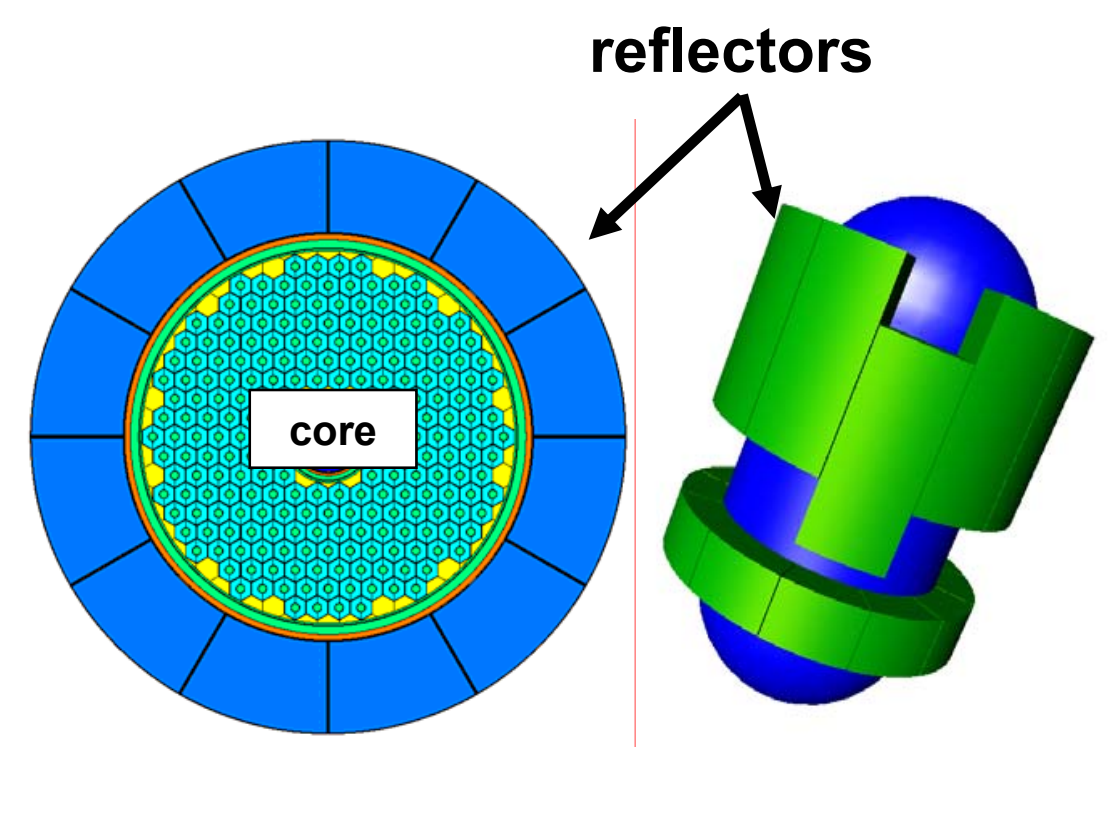

Sliders

- Drums will result in a more massive system $(\sim 200-300 \mathrm{~kg})$

$>$ May be other benefits

$>$ More drums may reduce, but not eliminate mass delta

$>$ Reflector outer radius and length will greatly impact shield mass 


\section{Reflector Material Requirements}

- Minimize Mass

$>$ Reflector mass is $\sim \mathbf{5 0} \%$ total reactor core mass in some designs

- Temperature Stability

$>$ Thermochemical stability

- Radiation Stability

$>$ Irradiated material properties must be understood

$>$ Dimensional stability (i.e. irradiation swelling)

- Neutronic Properties

$>$ High neutron scattering cross section

$>$ Low neutron absorption cross section 


\section{Predicted Operating Conditions}
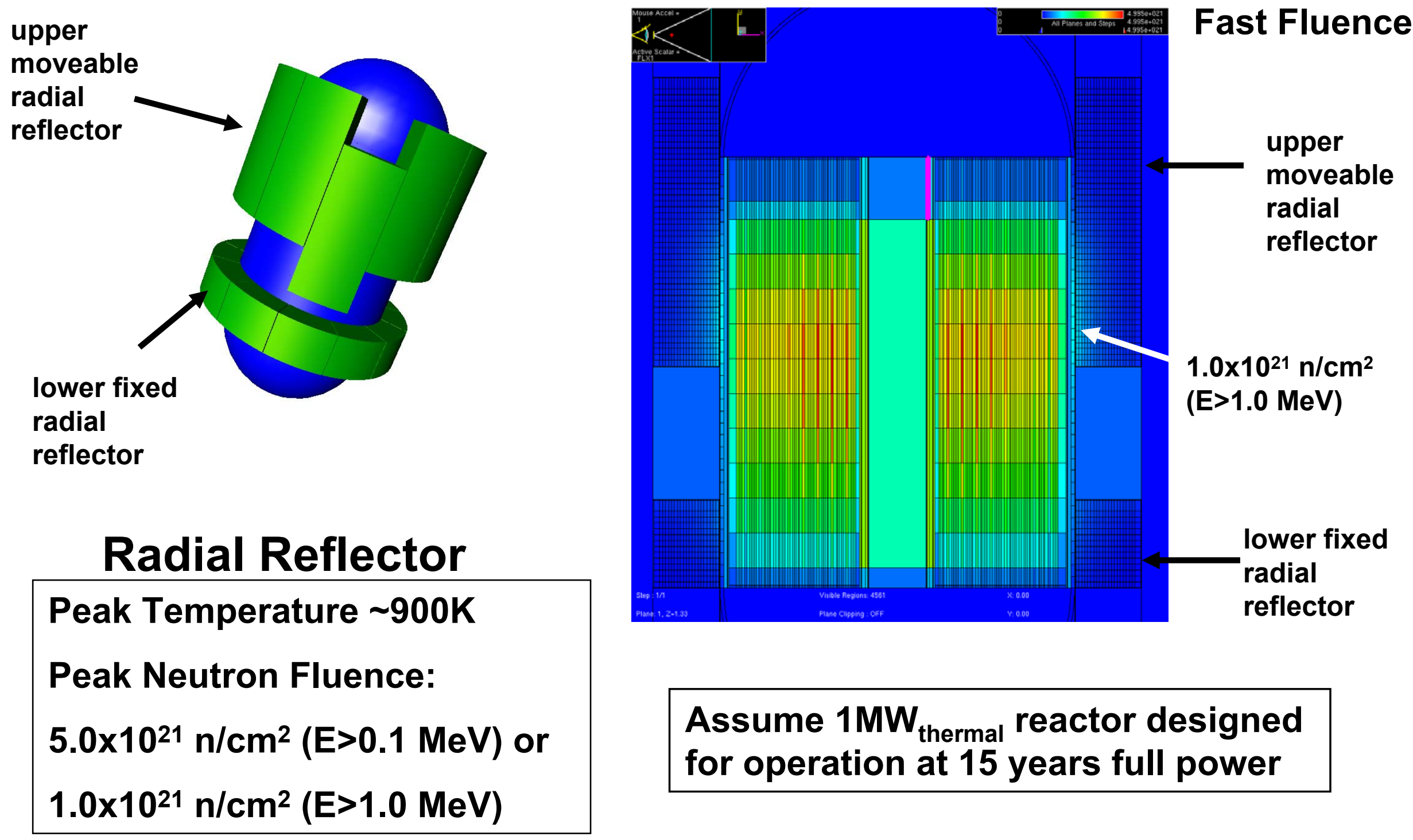

Assume $1 \mathrm{MW}_{\text {thermal }}$ reactor designed for operation at 15 years full power 


\section{Predicted Operating Conditions}

\section{Fuel Pin}

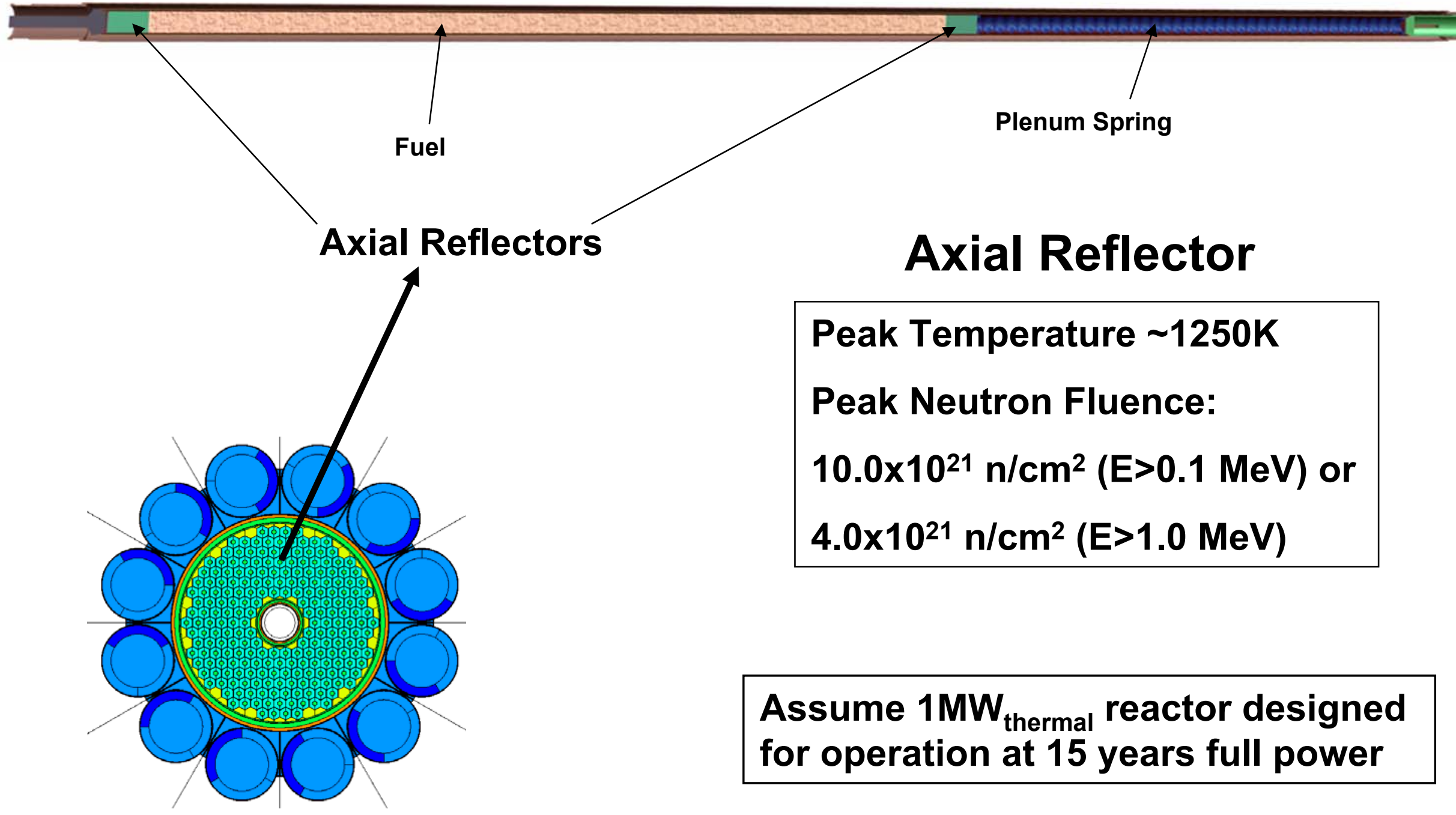




\section{Key Outcomes of Material Study}

- A variety of materials were identified as possible reflector materials

$>$ "Moderating" (Be and $\mathrm{BeO})$

$>$ "Non-Moderating" $\left(\mathrm{Al}_{2} \mathrm{O}_{3}, \mathrm{MgO}, \mathrm{MgAl}_{2} \mathrm{O}_{4}\right.$ and $\left.{ }^{11} \mathrm{~B}_{4} \mathrm{C}\right)$

- Of the reflector materials studied beryllium $(\mathrm{Be})$ and beryllium oxide $(\mathrm{BeO})$ were given the most attention

- Based on Prometheus design requirements more irradiation testing is required for $\mathrm{BeO}$

- Further study of non-moderating reflector materials is required 


\section{Material Candidates}

\section{Moderating Reflector}

\section{Beryllium (Be)}

- $\rho=1.85 \mathrm{~g} / \mathrm{cm}^{3}$

- High neutron scattering cross section

- Low thermal neutron capture cross section

- Significant (n, 2n) neutron multiplication cross section

- Toxic

Beryllium Oxide (BeO)

- $\rho=3.01 \mathrm{~g} / \mathrm{cm}^{3}$

In addition to the advantages of Be:

- Oxygen inelastic scattering

- Toxic
Non-Moderating Reflector

Enriched ${ }^{11} \mathrm{~B}_{4} \underline{\mathrm{C}}$

- $\rho=2.52 \mathrm{~g} / \mathrm{cm}^{3}$

Magnesia ( $\mathrm{MgO})$

- $\rho=3.58 \mathrm{~g} / \mathrm{cm}^{3}$

Alumina $\left(\alpha-\mathrm{Al}_{2} \underline{\mathrm{O}}_{3}\right)$

- $\rho=3.97 \mathrm{~g} / \mathrm{cm}^{3}$

Spinel $\left(\mathrm{MgAl}_{2} \underline{\mathrm{O}}_{4}\right)$

- $\rho=3.60 \mathrm{~g} / \mathrm{cm}^{3}$

Alternatives-in depth evaluation not presented herein 


\section{Reflector Effectiveness vs. Thickness}

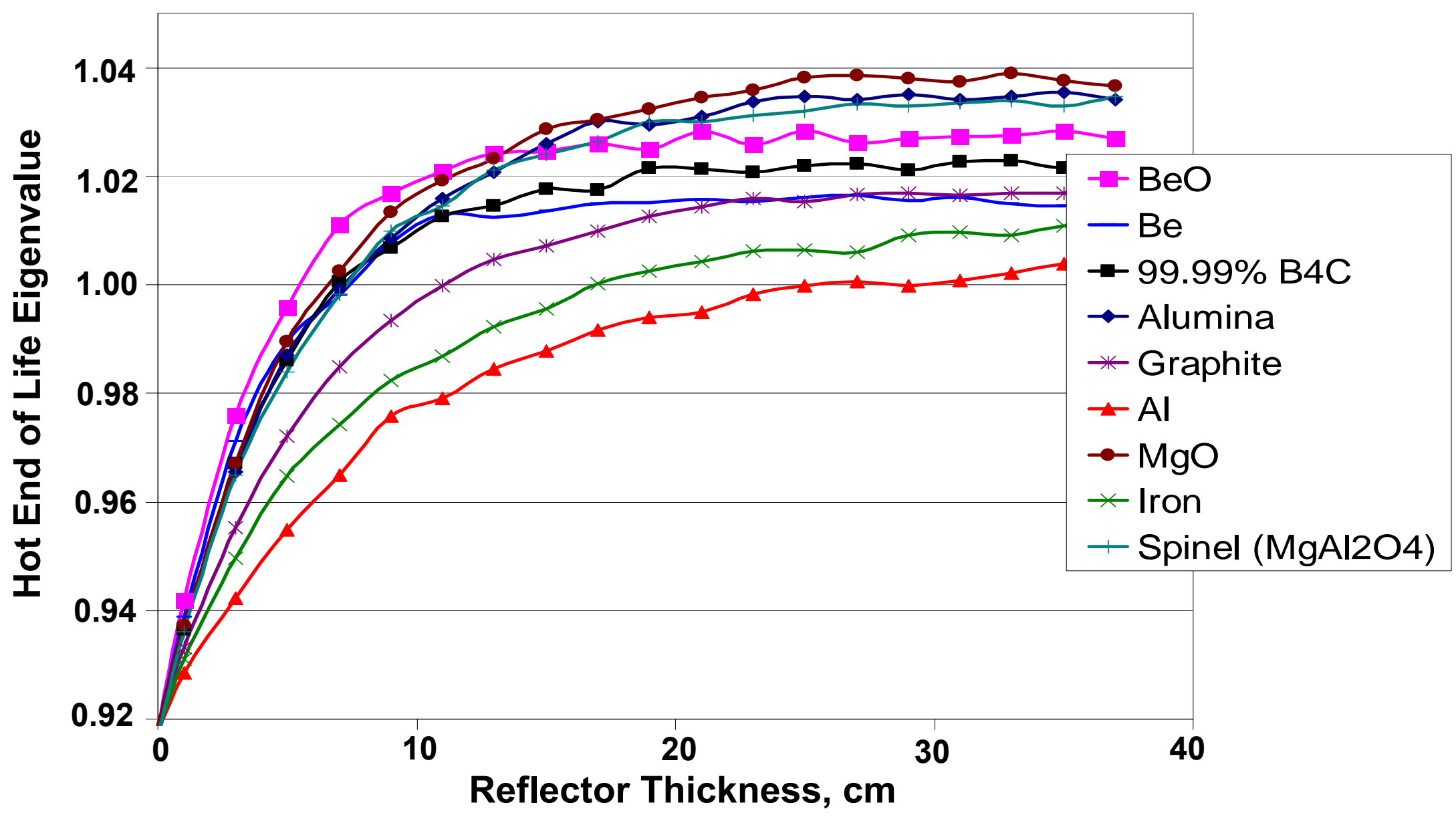

$\mathrm{Be}, \mathrm{BeO}, \mathrm{Al}_{2} \mathrm{O}_{3}, \mathrm{MgO}$, Spinel and ${ }^{11} \mathrm{~B}_{4} \mathrm{C}$ all produce competitive reflectors. Mass differences and ES\&H concerns will likely drive material selection. 


\section{Material Properties}

- Irradiation Swelling

Design difficulties

$>$ Effects thermal and mechanical properties of reflector material

$>$ Associated cracking and/or fracture may detrimentally impact performance

- Thermal Conductivity

$>$ Heat transfer from axial and radial reflectors

o Surface emissivity

o Canning and gaps

$>$ Will be degraded by microcracking associated with irradiation swelling

- Mechanical Properties (Compressive Strength)

$>$ Swelling, contact with reflector canning/structure system could introduce compressive stresses

$>$ Microcracking and/or fracture will detrimentally affect mechanical properties 


\section{Beryllium Swelling*}

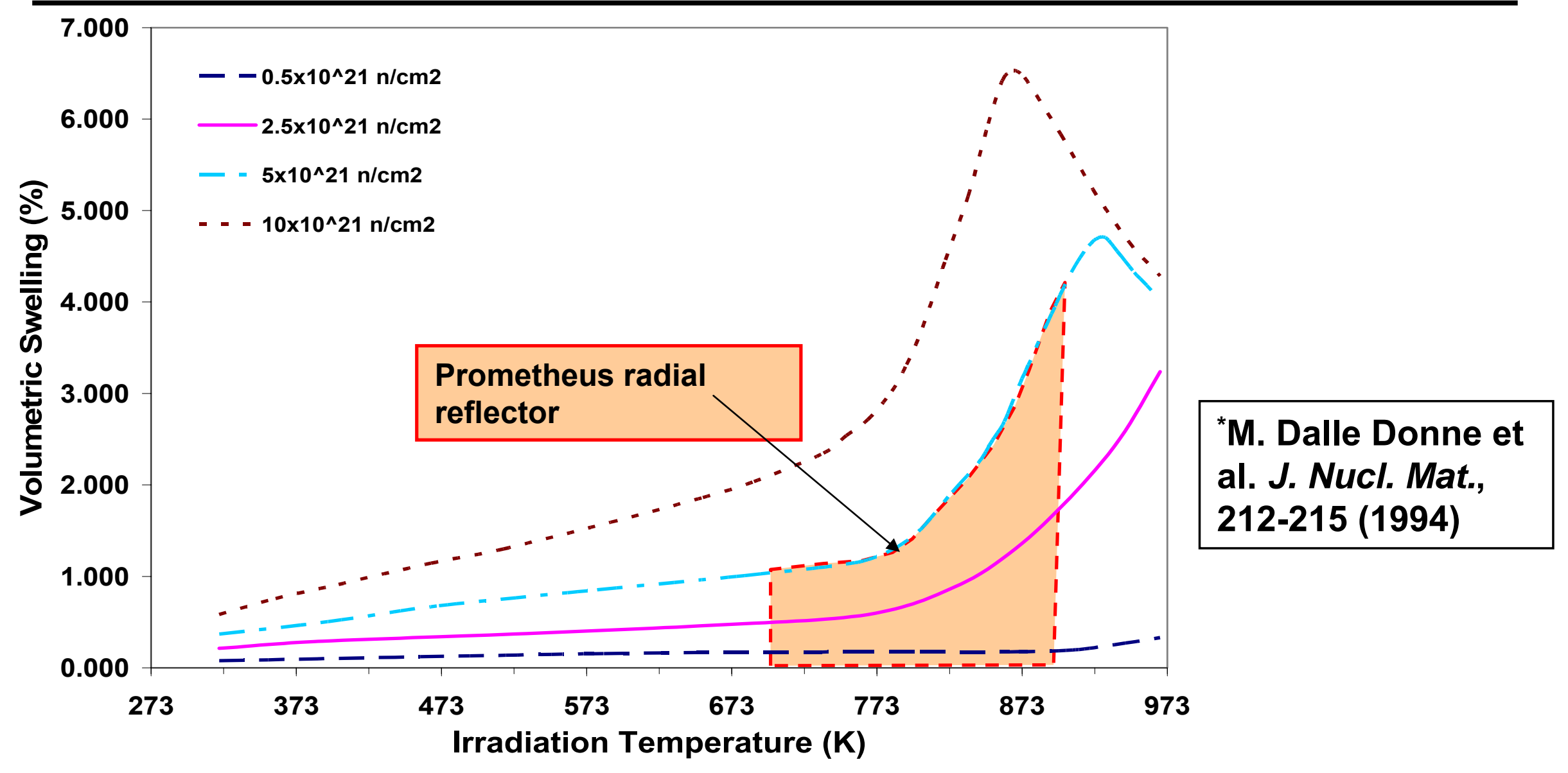

Not determined if this swelling is acceptable for reflector design. 


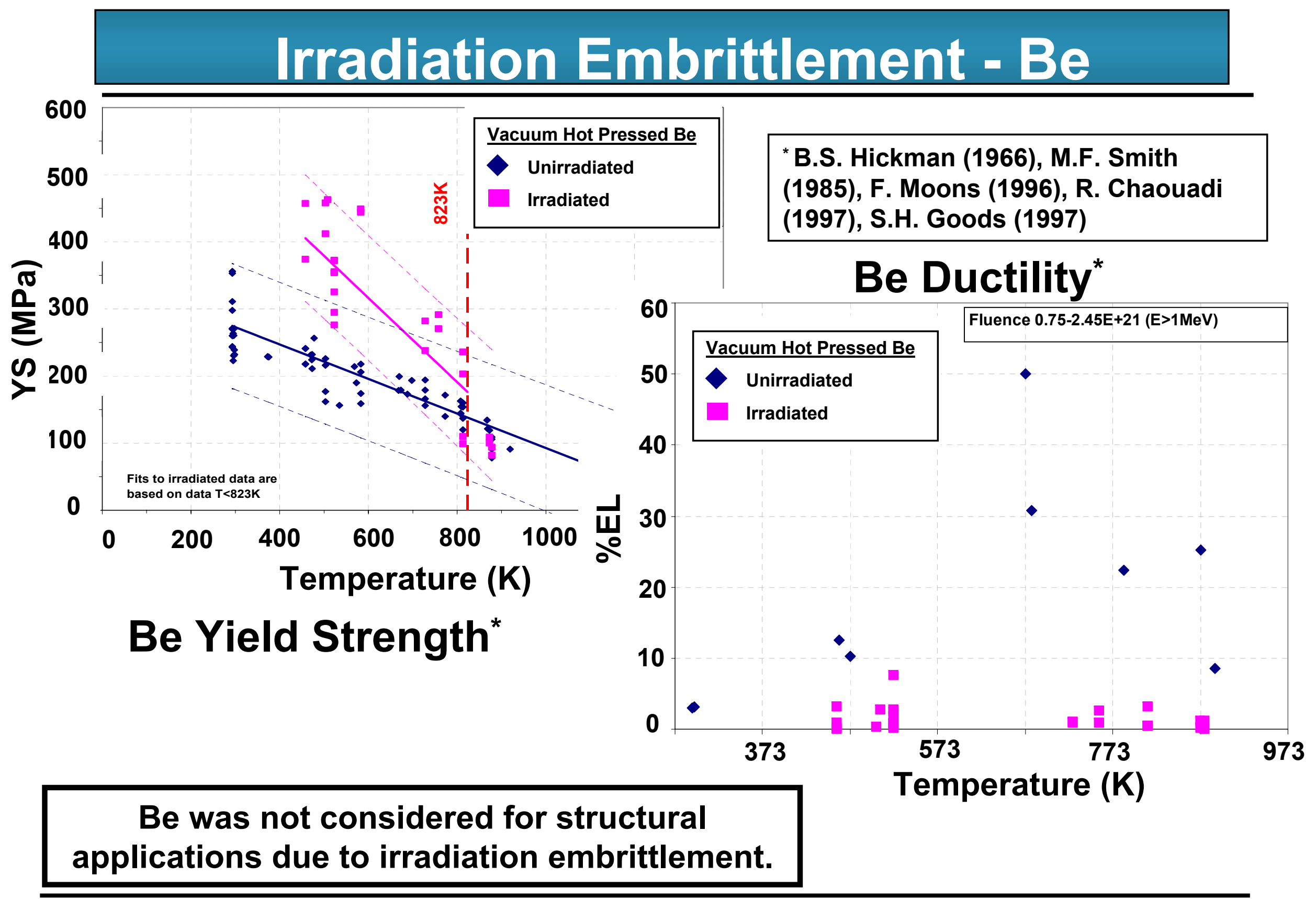




\section{BeO Thermal Conductivity*}

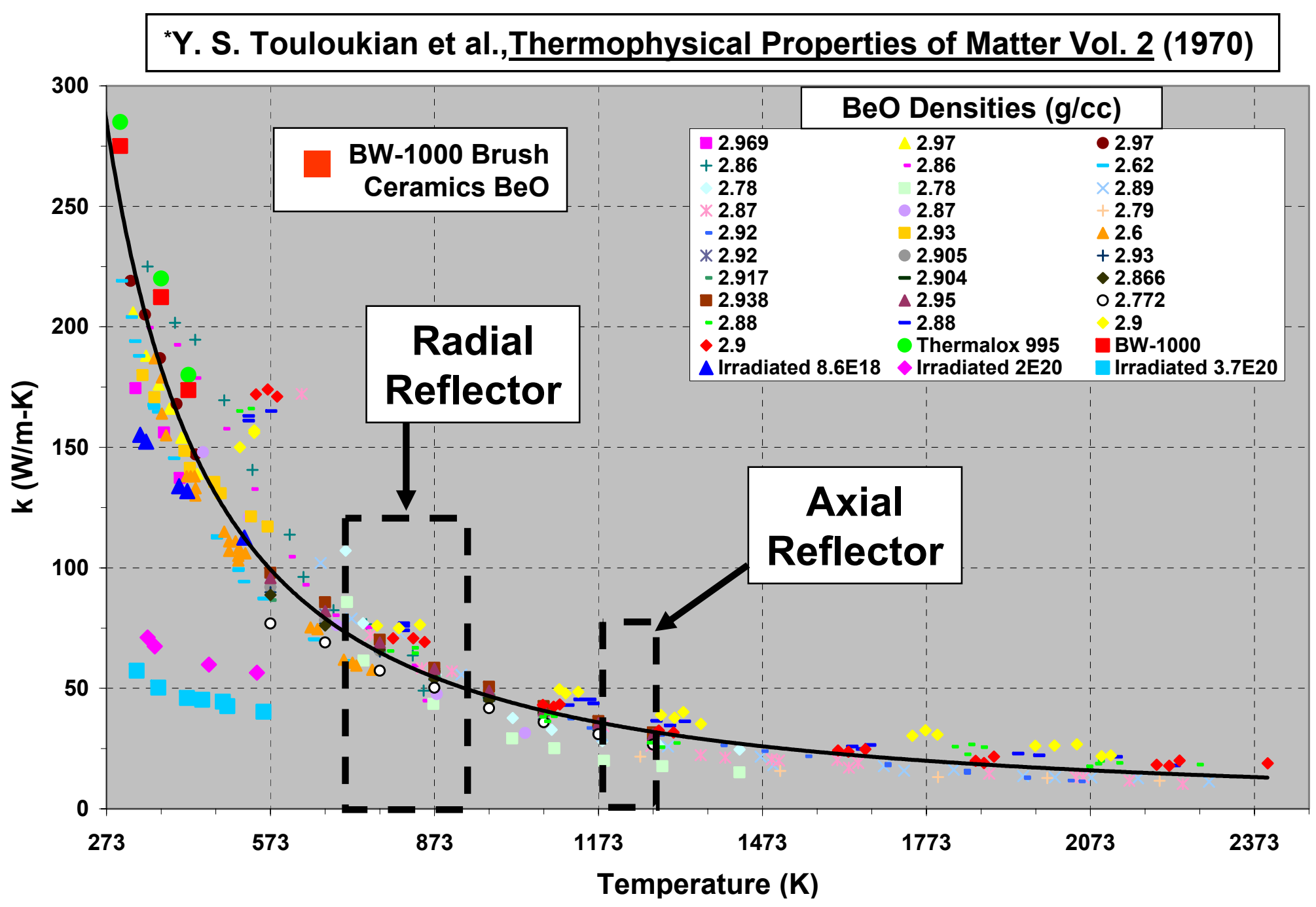

$\mathrm{BeO}$ irradiated thermal conductivity requires further characterization. 


\section{BeO Irradiation Swelling*}

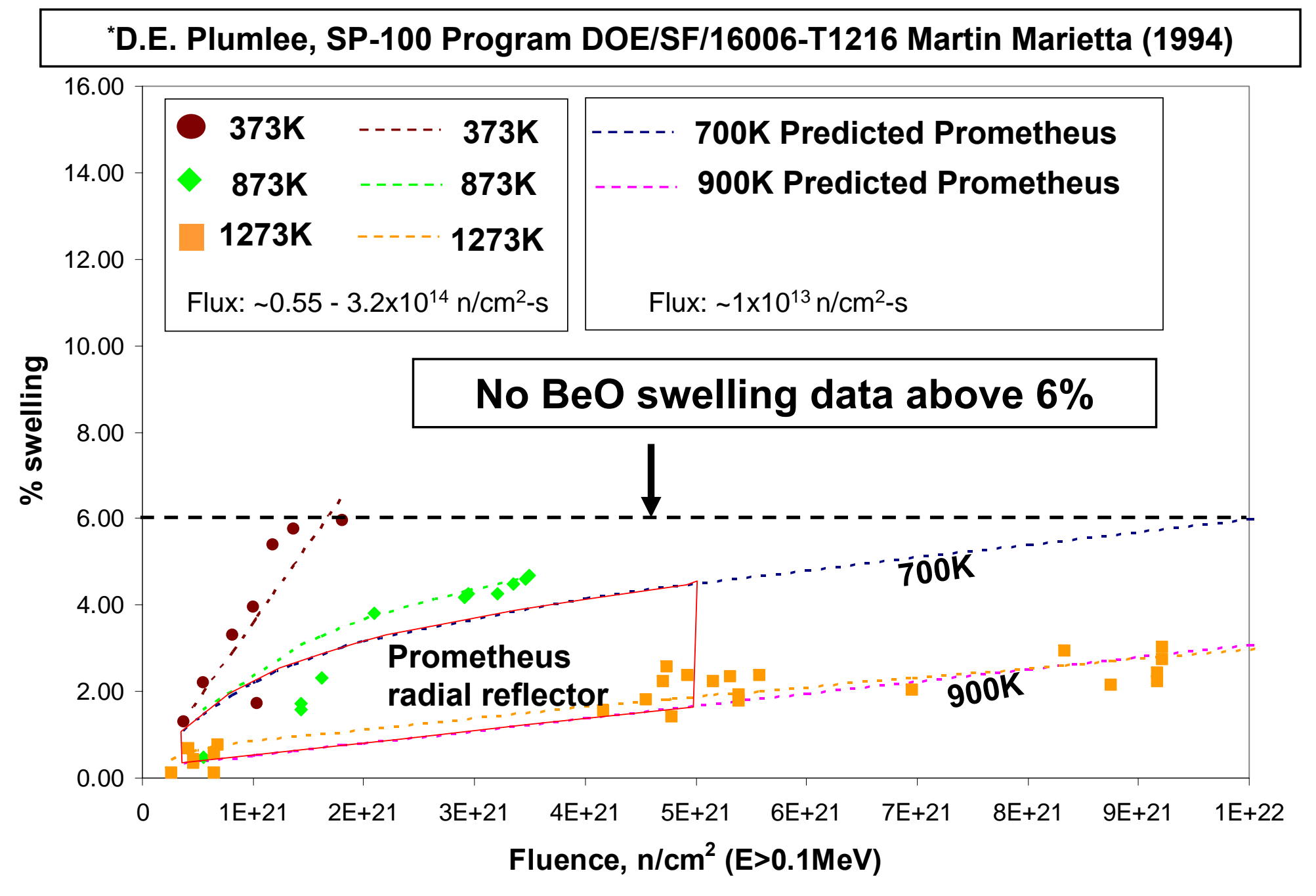

Not determined if this swelling is acceptable for reflector design. 


\section{Irradiation Swelling Mechanisms of BeO}

- Anisotropic lattice expansion and defects

$>$ Due to anisotropic crystal structure

- Microcracking

$>$ Grain boundary separation

- He bubble formation

$>$ He bubbles form at T>873K

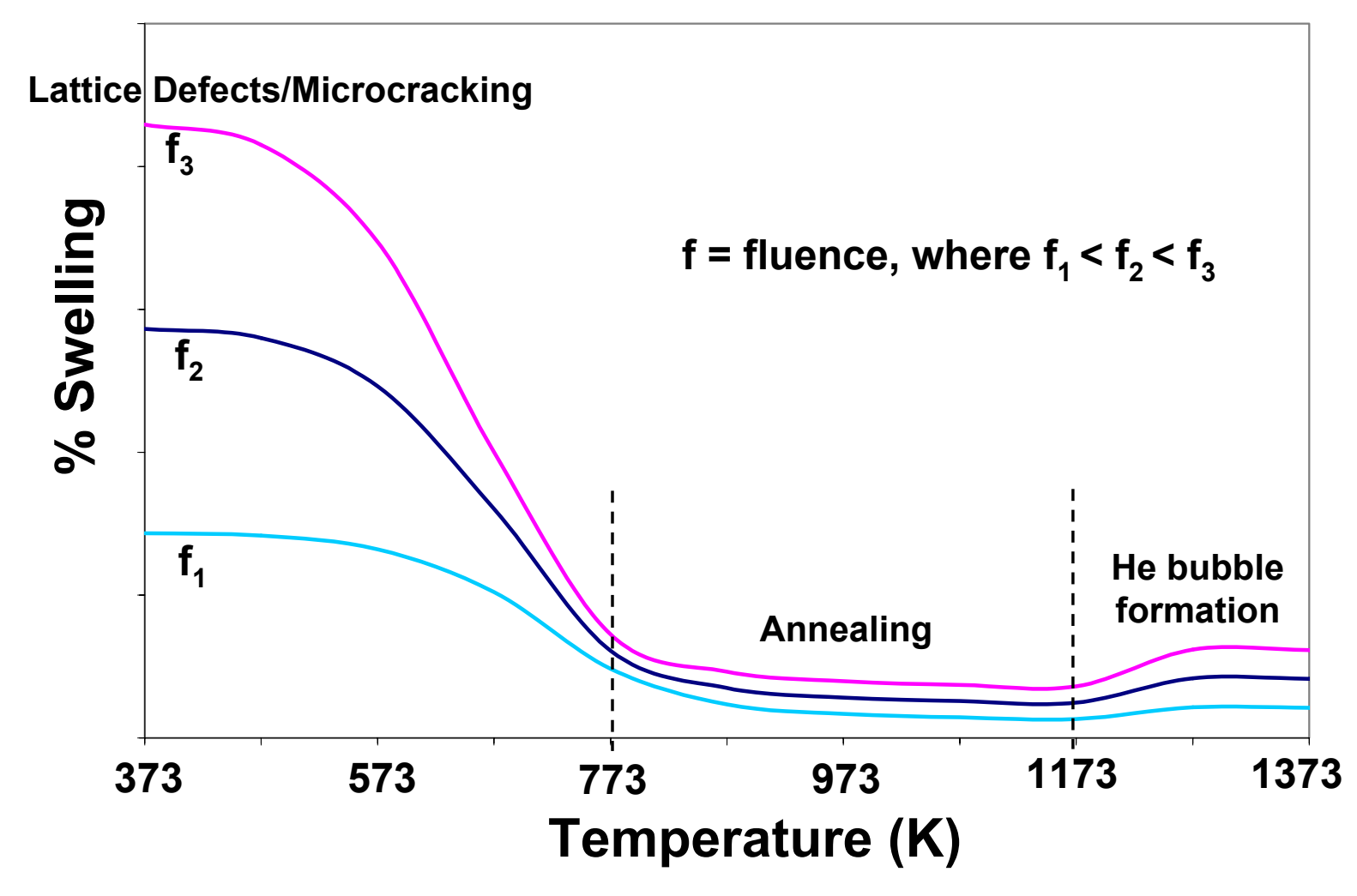

$>$ He bubbles contribute to swelling at $\mathrm{T}>1173 \mathrm{~K}$

At $373 \mathrm{~K}<\mathrm{T}<873 \mathrm{~K}$, swelling of $\mathrm{BeO}$ should be attributed only to lattice defect growth (anisotropic crystal expansion) and microcracking. 


\section{Anisotropic Crystal Expansion of BeO}
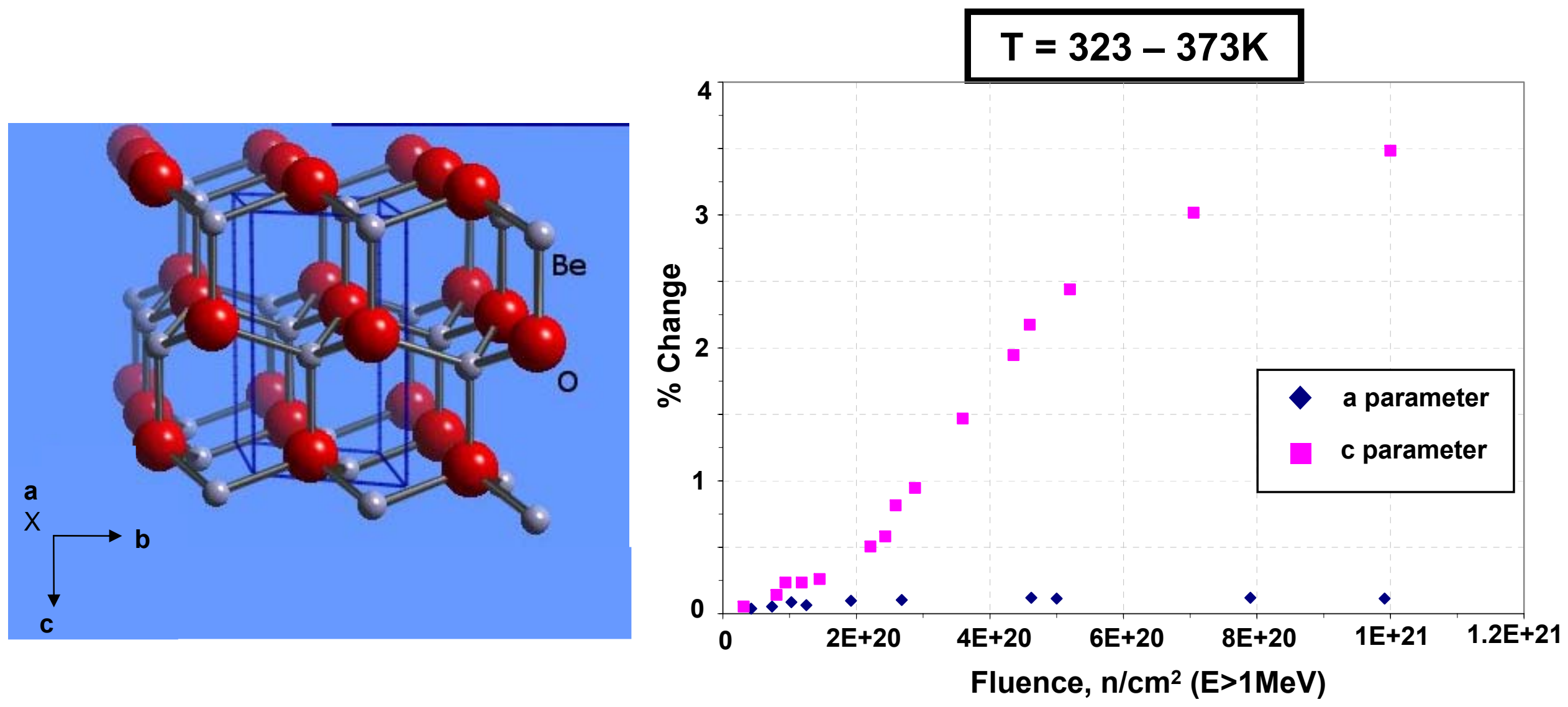

The anisotropic $\mathrm{BeO}$ crystal structure leads to anisotropic crystal expansion of $\mathrm{BeO}$ and microcracking. 


\section{BeO Grain Size*}

Neutron dose required to produce microcracking in $\mathrm{BeO}$ at $373 \mathrm{~K}$
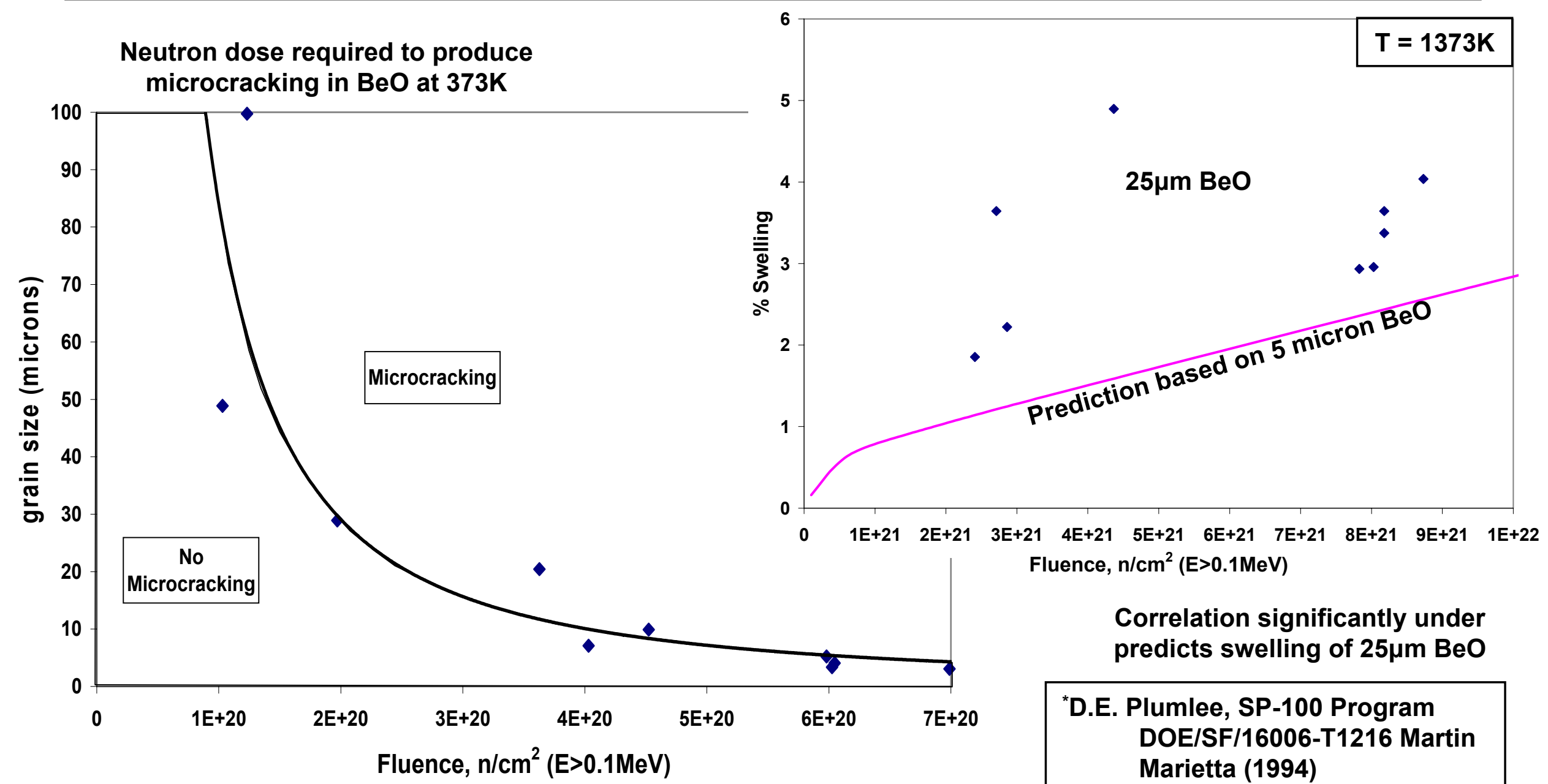

\section{Reducing BeO grain size is one factor in minimizing irradiation swelling.}




\section{Conclusions}

- Be and $\mathrm{BeO}$ material properties were gathered and material property gaps were identified

$>$ Be does not have the high temperature capability of $\mathrm{BeO}$ or other ceramics, but likely requires less additional materials testing

- All reflector material candidates require more examination

$>\mathrm{BeO}$ requires further irradiation testing (swelling, thermal conductivity, compression)

$>$ Neutronic studies indicate $\mathrm{Al}_{2} \mathrm{O}_{3}, \mathrm{MgO}$ and $\mathrm{MgAl}_{2} \mathrm{O}_{4}$ could be used but with mass penalty and differences in neutronic characteristics

$>\mathrm{Al}_{2} \mathrm{O}_{3}, \mathrm{MgO}$ and $\mathrm{MgAl}_{2} \mathrm{O}_{4}$ may require irradiated material property testing

$>11 \mathrm{~B}_{4} \mathrm{C}$ requires enrichment and may also require irradiated material property testing 


\section{Acknowledgments}

Bechtel - Bettis Atomic Power Laboratory

Bechtel Plant and Machinery, Inc.

Lockheed Martin - Knolls Atomic Power Laboratory

Oak Ridge National Lab 


\section{Backup Slides}




\section{BeO Material Form}

- Solid, sintered ceramic part $\sim 95 \%$ TD (theoretical density $=3.01 \mathrm{~g} / \mathrm{cm}^{3}$ )

- Parts are machined from stock material

- Rockwell C hardness - 55

- Surface texture - 64 Ra ( 70 RMS converted value)

- Tensile Strength - $124 \mathrm{MPa}(18,000 \mathrm{psi})$

- Compressive Strength - 1.55 GPa (225,000 psi)

- Flexural Strength - $207 \mathrm{MPa}(30,000$ psi)

- Average grain size 9-12 microns 
Enclosure 18 to

SPP-SEC-0039

\title{
Assessing the Radiation Damage of Ni-base Superalloys for Prometheus Space Nuclear Power
}

\author{
Angeliu, T. \\ Ward, J.T. \\ Witter, J.K.
}


This page is intentionally blank.

PRE-DECISIONAL - For planning and discussion purposes only 


\section{Assessing the Radiation Damage of Ni-base Superalloys for}

Prometheus Space Nuclear Power

Tom Angeliu, John Ward and Dr. Jonathan Witter

Naval Reactors Prime Contractor Team

STAIF, February 2006 


\section{Pressure Vessel}

Design Considerations for JIMO Mission

Temperature Vessel $\sim 900 \mathrm{~K}$, other designs hotter

Thimble, to be determined (<1050 K)

(hot leg gas $\sim 1150 \mathrm{~K}$ )

Stress

$70 \mathrm{MPa}(10 \mathrm{ksi})$

Strength

$<2 / 3$ yield or $1 / 3$ ultimate tensile

Ductility

Primarily for lift off, $>1 \%$

Concern for ground test unit cycling

Toughness

Needs to be determined

Creep strain $1 \%$ in 15 years

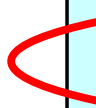
Fivence $80 \times 10^{20} \mathrm{n} / \mathrm{cm}^{2}, \mathrm{E}>0.1 \mathrm{MeV}$ (vessel) to $160 \times 10^{20} \mathrm{n} / \mathrm{cm}^{2}, \mathrm{E}>0.1 \mathrm{MeV}$ (thimble)

Environment

Other Outside: space vacuum Inside: He/Xe with impurities? $\sim 8 \mathrm{~mm}$ wall, mass \& neutronics concerns

\section{Candidate vessel material was Ni-based Can these withstand the neutron fluence?}




\section{Concerns for Alternative Materials}

\section{$\underline{\text { Refractory Metal Alloys }}$}

Susceptible to radiation hardening and embrittlement

Generally pronounced for $\mathrm{T}_{\text {irr }}<0.3 \mathrm{~T}_{\text {Melting point }}$ Concern for transients and ground-based testing of a pressure boundary material.

\section{Dissimilar Metal Joint}

Eventual joint between refractory metal alloy pressure vessel and conventional metal alloy plant.

Susceptible to embrittling intermetallic phases.
S. Zinkle, ASM-TMS Spring Symposium, Niskayuna, NY (2005)

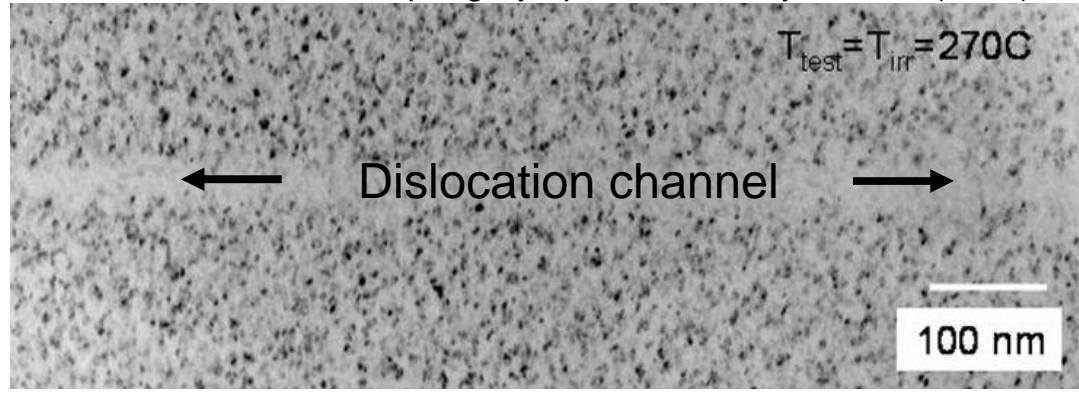

\section{Hastelloy $X$}

\section{intermetallics}

$\mathrm{T}-111$

NASA-GRC

$20 \mu \mathrm{m}$

Single point failure of pressure boundary would end the mission. Primary concern for the direct gas cooled Brayton concept. 


\section{Concerns with Ni-base Pressure Vessel}

\section{Thermal Creep}

Nominal operating temperature near practical limits of these alloys

Very sensitive to temperature increases above an application T of $\sim 900 \mathrm{~K}$

\section{Environmental Effects}

Corrosion from impurities (including fission products), carburization/decarburization, and internal oxidation

\section{$\underline{\text { Joining }}$}

Dissimilar material interactions with the core material (refractory metal alloy or $\mathrm{SiC}$ )

\section{Radiation Damage}

Previous studies have shown severe radiation-induced embrittlement 


\section{Swelling}

\section{US National Cladding/Duct Material Development Program}

\section{EBR-II Exposure B-109}

673 to $923 \mathrm{~K}$ (400 to $700 \mathrm{C}$ )

Up to $1500 \times 10^{20} \mathrm{n} / \mathrm{cm}^{2}$ $(\mathrm{E}>0.1 \mathrm{MeV})$

Ni-base alloys exhibited very low swelling, $<1 \%$

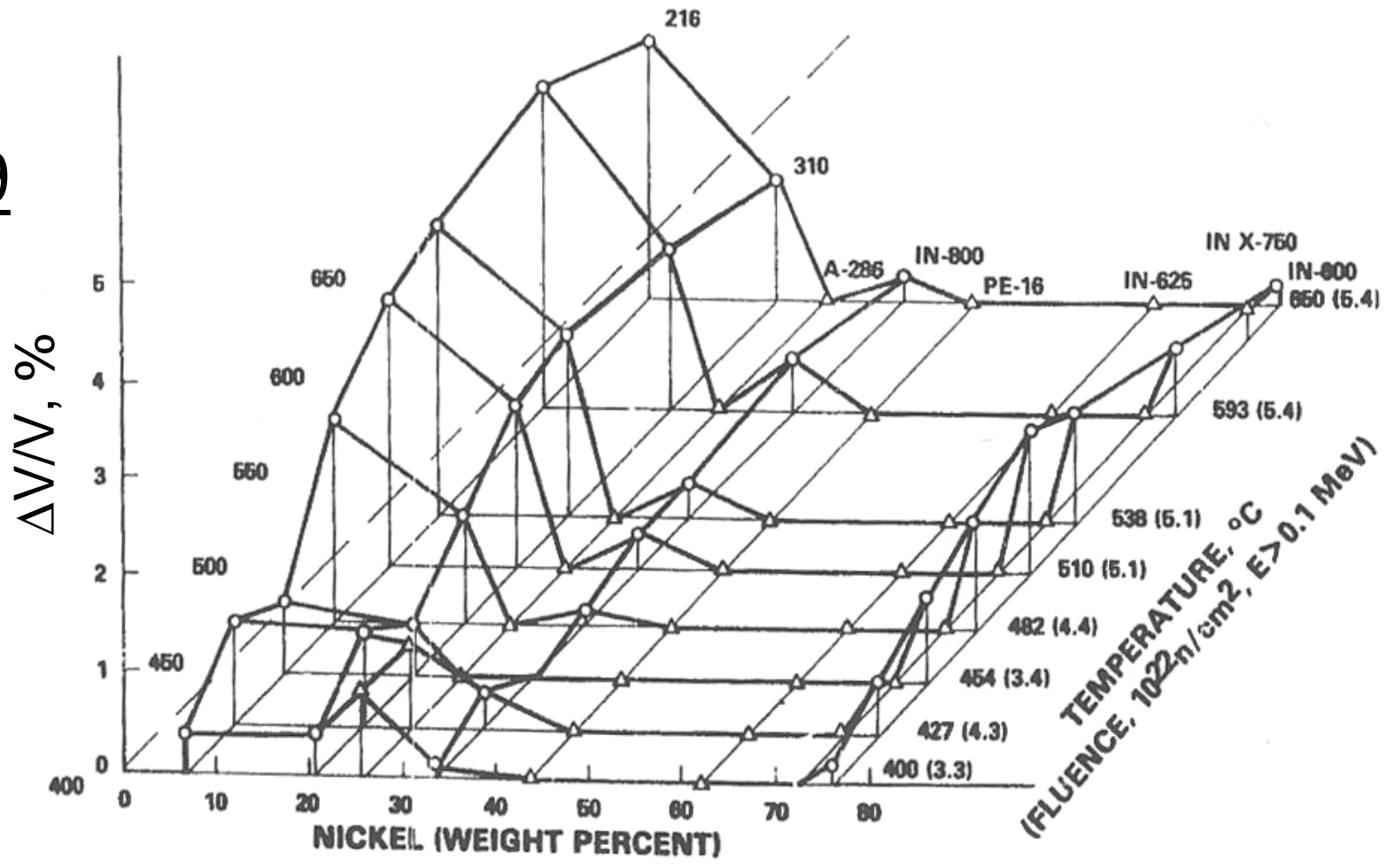

J.F. Bates and R.W. Powell, Journal of Nuclear Materials, 102 (1981) 200-213.

\section{Swelling is not a concern, $<1 \%$ expected}




\section{Radiation-Induced Creep}

\section{EBR-II Biaxial Creep}

Pressurized tubes, in situ creep

Nimonic PE16

$813 \mathrm{~K}$, up to $170 \mathrm{MPa}$

$200 \times 10^{20} \mathrm{n} / \mathrm{cm}^{2}(\mathrm{E}>0.1 \mathrm{MeV})$

Ni-base alloys exhibited very low creep strain, $<0.4 \%$

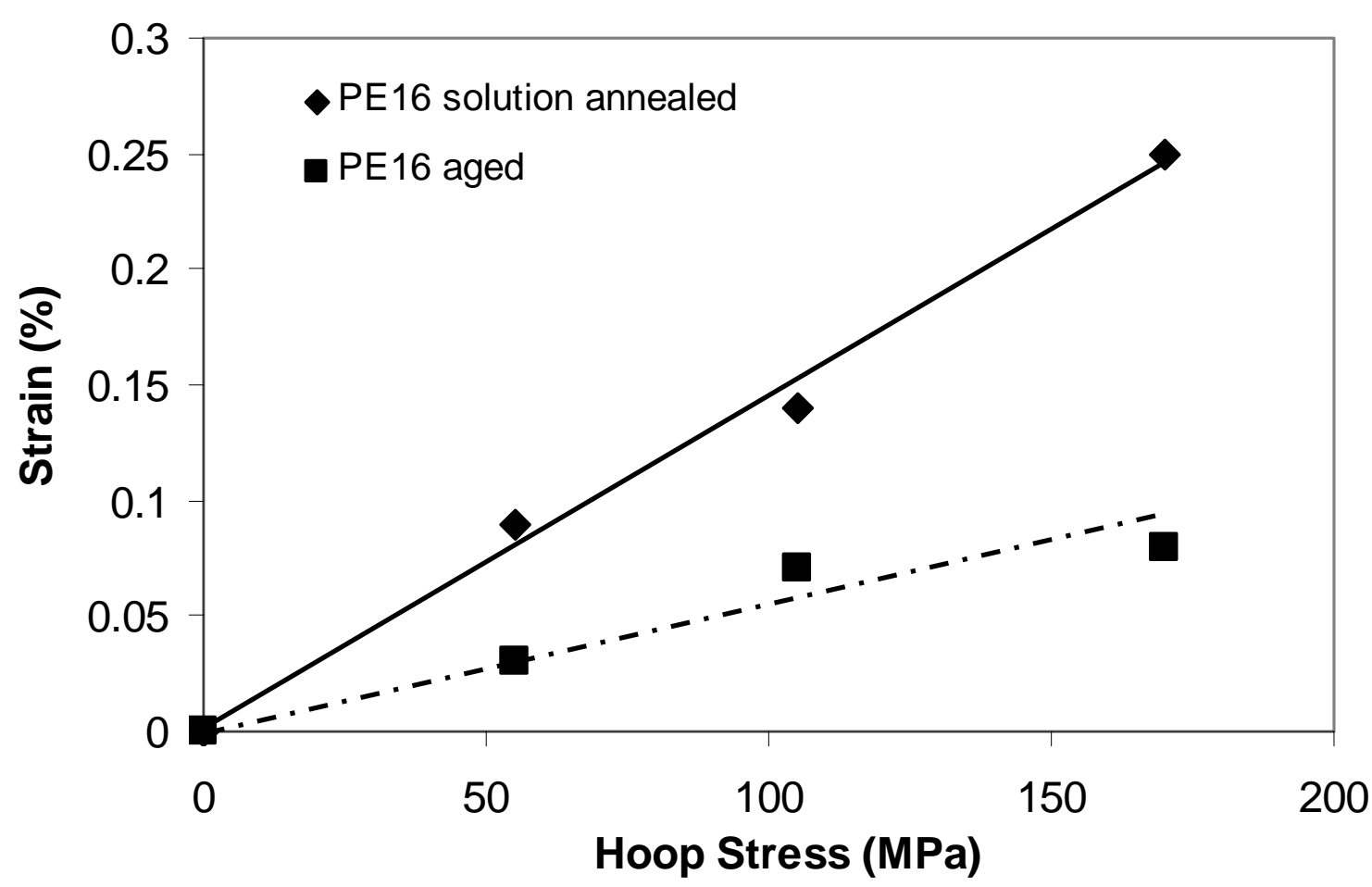

M.M. Paxton, B.A. Chin, E.R. Gilbert and R.E. Nygren, Journal of Nuclear Materials, vol. 80 (1979) 144-151.

\section{Radiation-induced creep is not a concern, $<1 \%$ expected}




\section{Phase Instability ( 0.3-0.6T $\left.\mathrm{TP}_{\mathrm{MP}}\right)$}

Point defects are created by neutron-atom collisions Defects anneal out by migration to sinks Migrating defects drag solute to sinks, including grain boundaries

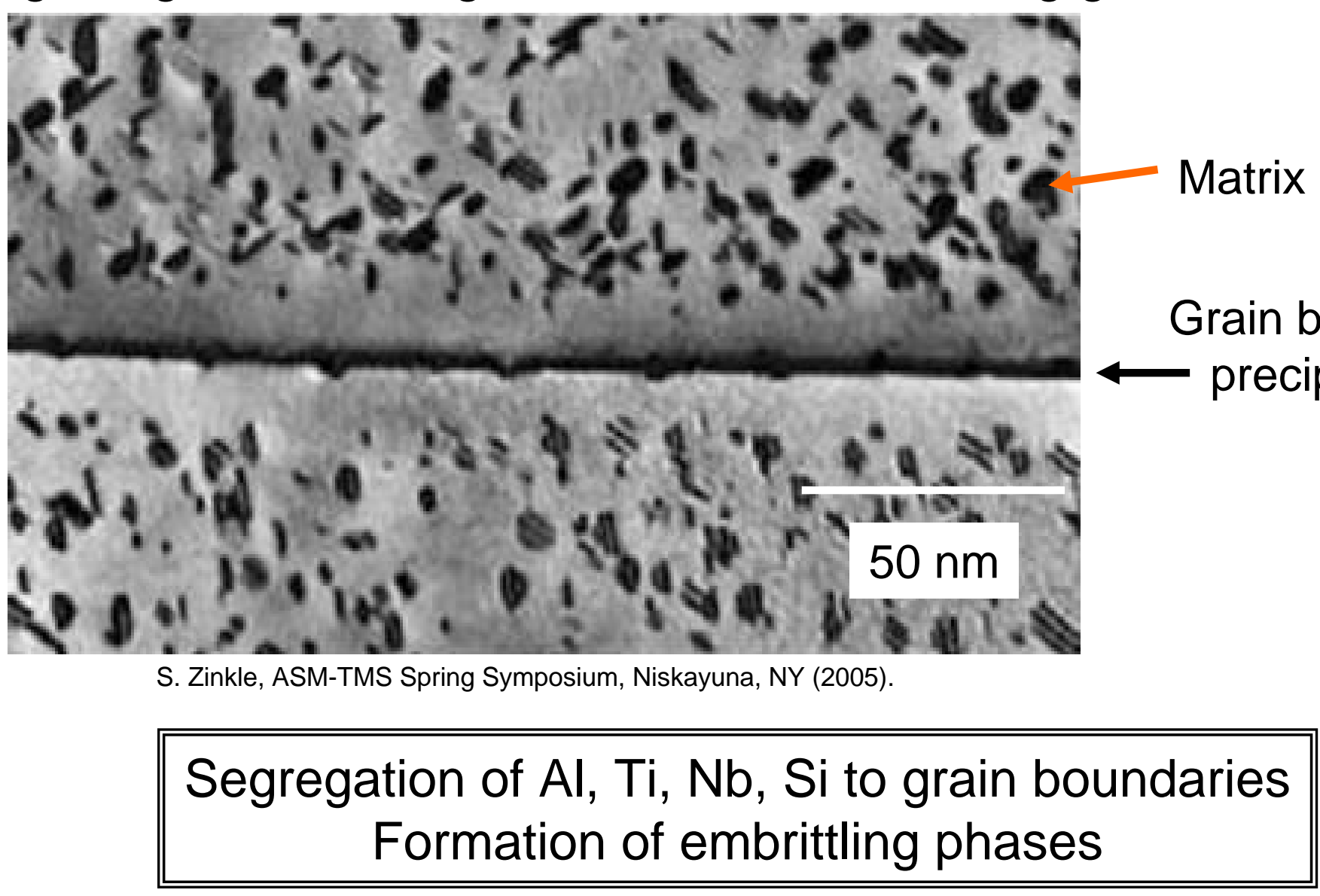




\section{Nuclear Reactions That Produce Helium}

\section{$\underline{\text { Neutron Transmutations of Interest }}$}

${ }^{10} \mathrm{~B}+\mathrm{n} \longrightarrow{ }^{7} \mathrm{Li}+{ }^{4} \mathrm{He}$

Natural B contains $\sim 20 \%{ }^{10} \mathrm{~B}$

${ }^{58} \mathrm{Ni}+\mathrm{n} \longrightarrow{ }^{59} \mathrm{Ni}+\gamma$

${ }^{59} \mathrm{Ni}+\mathrm{n} \longrightarrow{ }^{56} \mathrm{Fe}+{ }^{4} \mathrm{He}$

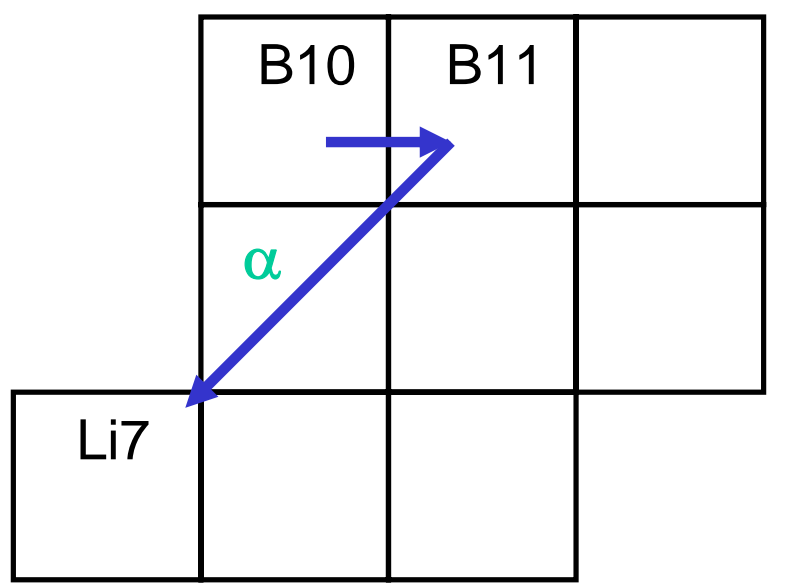

${ }^{58} \mathrm{Ni}+\mathrm{n} \longrightarrow{ }^{55} \mathrm{Fe}+{ }^{4} \mathrm{He}(\mathrm{MeV}$ Threshold $)$

${ }^{60} \mathrm{Ni}+\mathrm{n} \longrightarrow{ }^{57} \mathrm{Fe}+{ }^{4} \mathrm{He}(\mathrm{MeV}$ Threshold $)$

Natural Ni contains

$$
\begin{array}{r}
68 \%{ }^{58} \mathrm{Ni} \\
0 \%{ }^{59} \mathrm{Ni} \\
26 \%{ }^{60} \mathrm{Ni}
\end{array}
$$

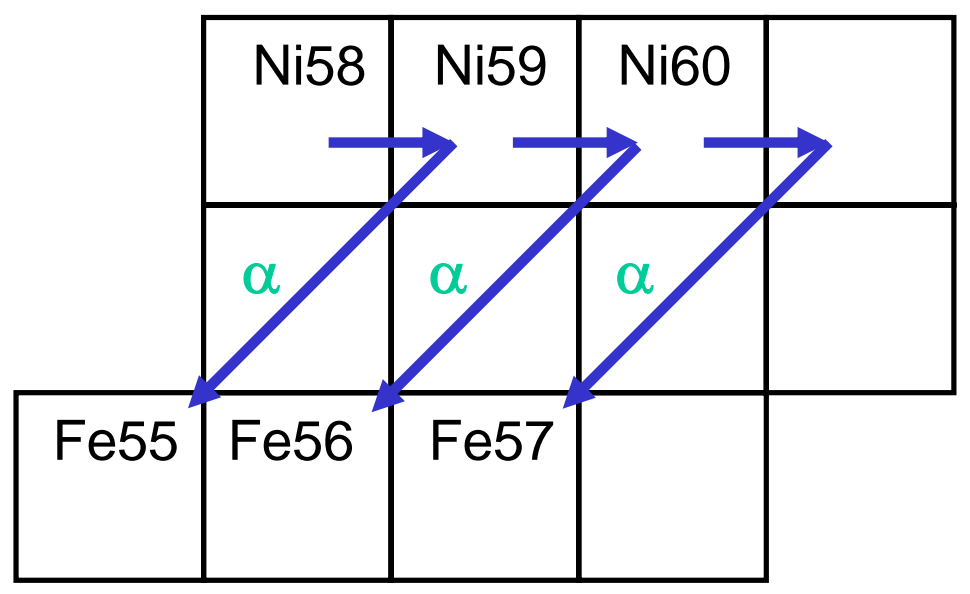




\section{Helium Embrittlement ( $\left.>0.5 \mathrm{~T}_{\mathrm{MP}}\right)$}

He generated by transmutation reactions He migrates and bubbles form at grain boundaries

Ductility is severely degraded

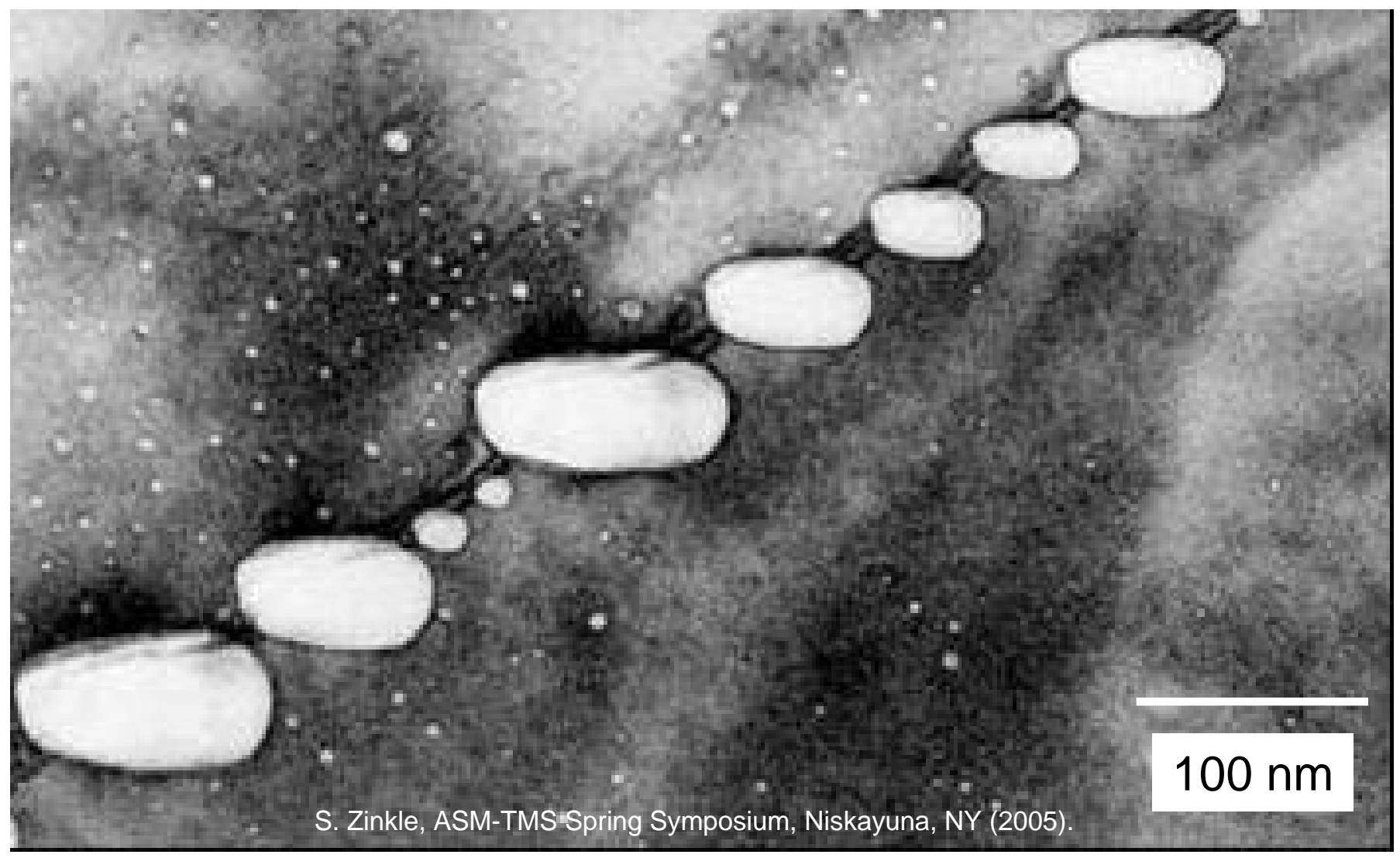




\section{Calculation Model for He Generation}

\section{Procedure}

RACER Monte Carlo Neutron Transport Code Alloy 617 pressure vessel with 50 wppm Boron Monoblock refractory metal alloy core 15 years at $1 \mathrm{MWth}$
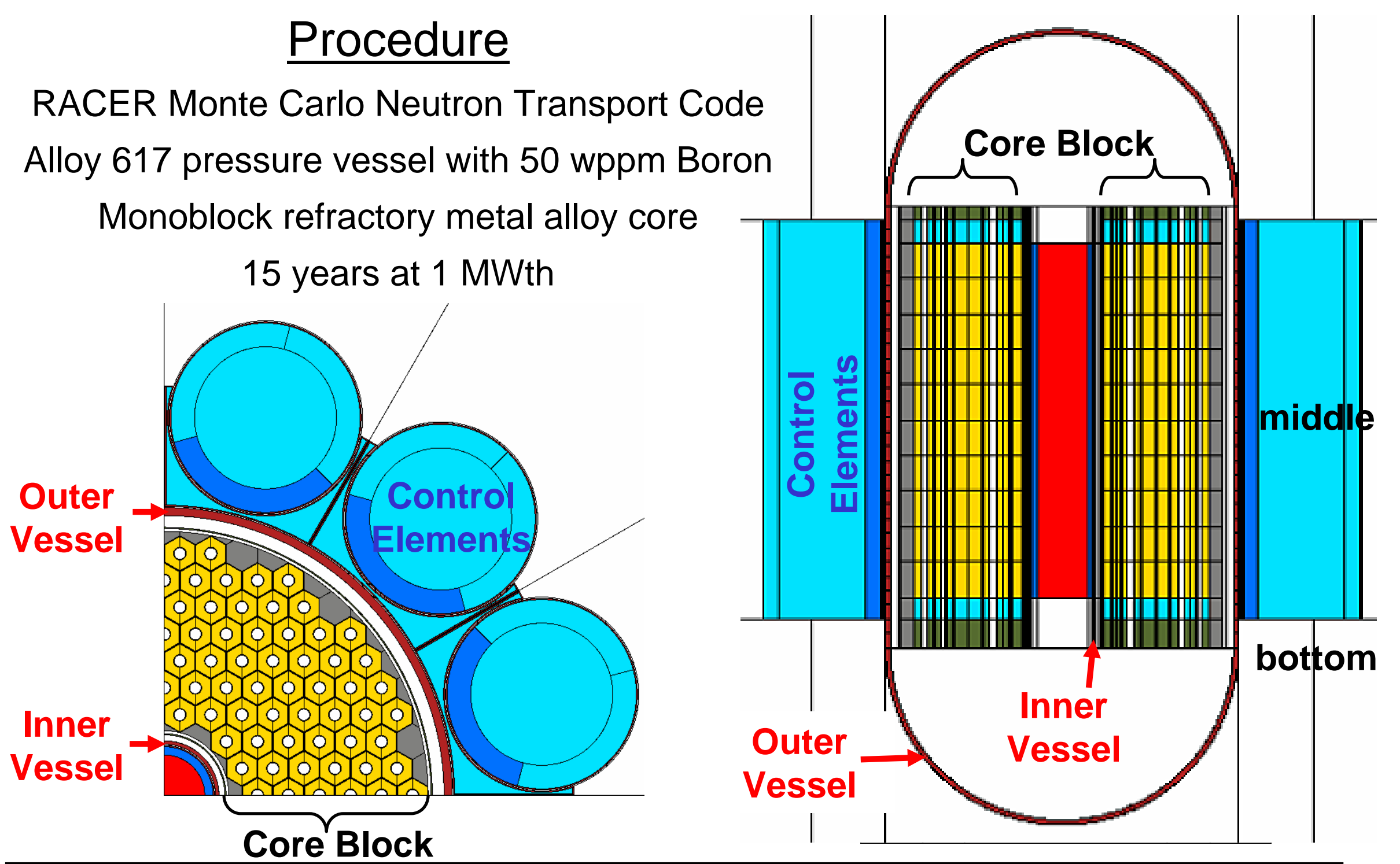


\section{Flux Spectrum in the Reactor Vessel}

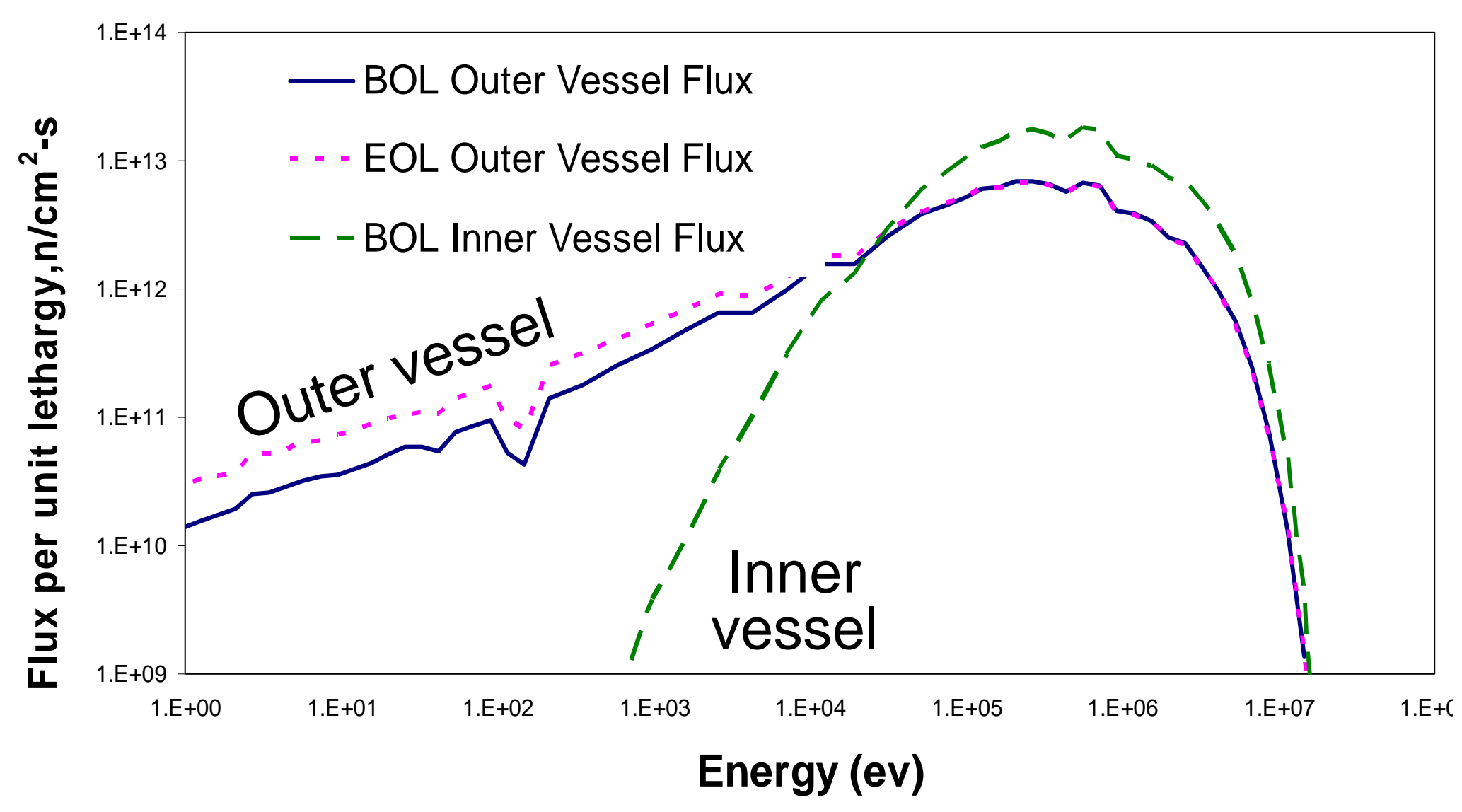

Reactor has a mixed energy spectrum Vessel flux is highly dependent on location 


\section{Predicted Helium Generation}

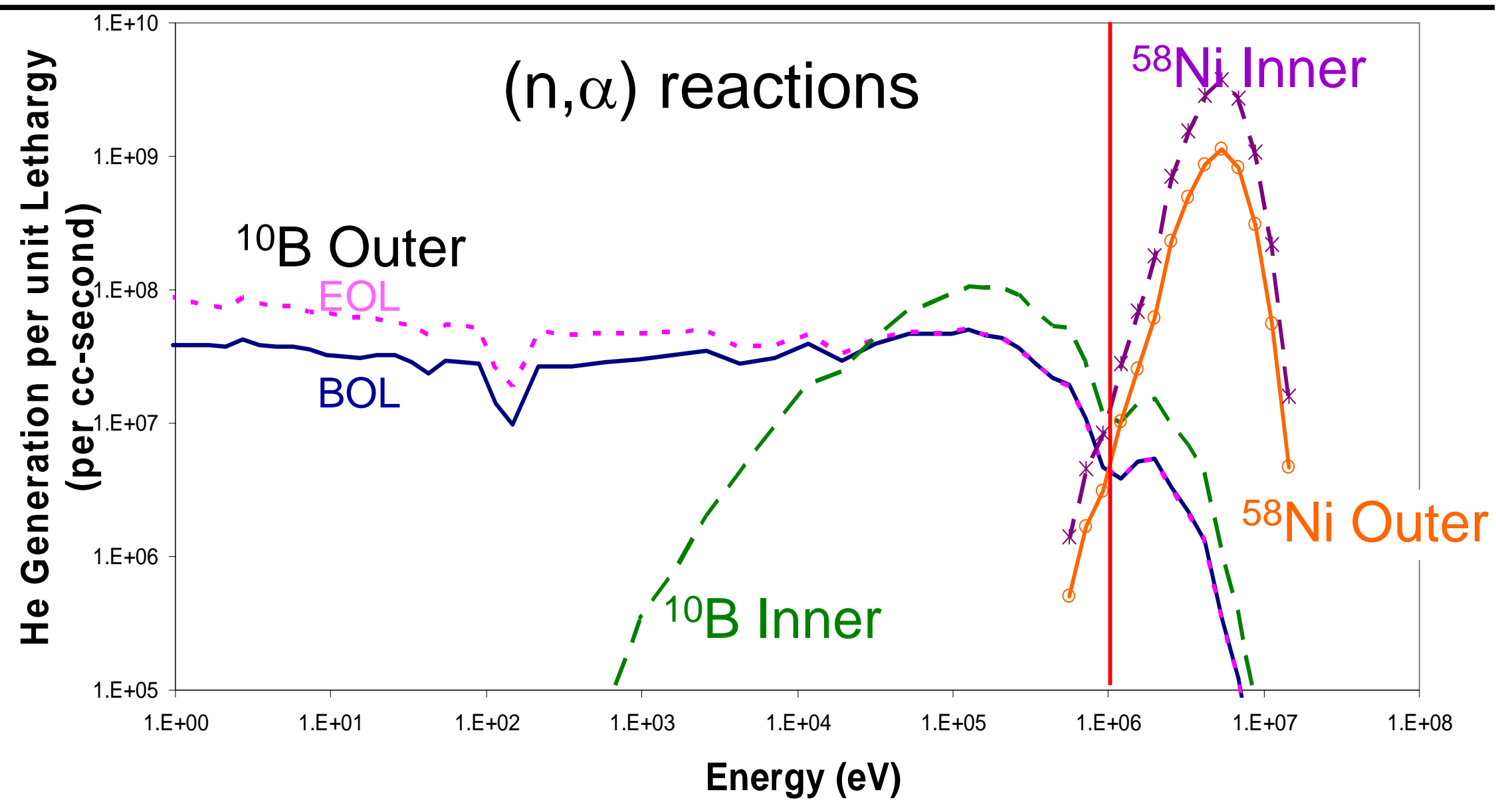

${ }^{10} \mathrm{~B}(\mathrm{n}, \alpha)$ reaction is non-threshold ${ }^{58} \mathrm{Ni}(n, \alpha)$ reaction has a threshold energy 


\section{Reaction Rate Figure Of Merit}

As the spectrum becomes harder:

Contributions of ${ }^{10} \mathrm{~B}$ and ${ }^{59} \mathrm{Ni}$ decrease

Contributions of ${ }^{58} \mathrm{Ni}$ and others increase

\begin{tabular}{|c|c|c|c|}
\hline Isotope & $\begin{array}{c}\text { Outer Vessel } \\
\text { FOM }\end{array}$ & $\begin{array}{c}\text { Inner Vessel } \\
\text { FOM }\end{array}$ & $\begin{array}{c}\text { FOM Ratio } \\
\text { Inner/Outer }\end{array}$ \\
\hline B-10 & $\mathbf{1 . 0}$ & $\mathbf{0 . 5 0}$ & $\mathbf{0 . 5 0}$ \\
\hline Ni-59 & $1.7 \mathrm{E}-02$ & $2.7 \mathrm{E}-03$ & 0.16 \\
\hline Ni-58 & $2.4 \mathrm{E}-04$ & $8.1 \mathrm{E}-04$ & 3.4 \\
\hline Cr-50 & $8.5 \mathrm{E}-05$ & $2.9 \mathrm{E}-04$ & 3.4 \\
\hline Ni-61 & $6.6 \mathrm{E}-05$ & $2.2 \mathrm{E}-04$ & 3.3 \\
\hline Ni-60 & $4.0 \mathrm{E}-05$ & $1.4 \mathrm{E}-04$ & 3.4 \\
\hline Co-59 & $3.6 \mathrm{E}-06$ & $1.3 \mathrm{E}-05$ & 3.5 \\
\hline
\end{tabular}

Figure of Merit (FOM) is Energy Integrated Reaction Rate of the Isotope Relative to B-10 Outer Vessel Energy Integrated Reaction Rate (All materials at number density of 1.0) Actual Generation Rate is then Proportional to the Real Atom Concentration of the Isotope 


\section{Helium Results for A617 Vessel}

\begin{tabular}{|c|c|c|c|c|c|c|}
\cline { 2 - 7 } \multicolumn{1}{c|}{} & $\begin{array}{c}\text { With 50 } \\
\text { wppm B }\end{array}$ & \multicolumn{3}{c|}{ Contribution \% From } & $\begin{array}{c}\text { With 0 } \\
\text { wppm B }\end{array}$ \\
\hline $\begin{array}{c}\text { Vessel } \\
\text { Region }\end{array}$ & $\begin{array}{c}\text { appm } \\
\text { Helium }\end{array}$ & $58 \mathrm{Ni}$ & $59 \mathrm{Ni}$ & $60 \mathrm{Ni}$ & ${ }^{10} \mathrm{~B}$ & $\begin{array}{c}\text { appm } \\
\text { Helium }\end{array}$ \\
\hline Outer, middle & 10.4 & 53.5 & 1.4 & 3.4 & 38.6 & $\mathbf{6 . 4}$ \\
\hline Outer, bottom & $\mathbf{1 . 2}$ & 59.2 & 0.1 & 3.9 & 33.4 & $\mathbf{0 . 8}$ \\
\hline Inner, middle & 22.2 & 82.0 & 0.1 & 5.3 & 7.6 & 20.5 \\
\hline Inner, bottom & $\mathbf{5 . 6}$ & 78.0 & 0.0 & 5.0 & 12.4 & $\mathbf{4 . 9}$ \\
\hline
\end{tabular}

Majority of helium comes from ${ }^{58} \mathrm{Ni}\left(\mathrm{n}_{\text {fast }}, \alpha\right)$ reactions Increased fraction from ${ }^{10} \mathrm{~B}$ at outer diameter vessel Inner vessel, middle still too high with 0 wppm B 


\section{Correlating Radiation Damage to Mechanical Behavior}

J. Barnaby, P.J. Barton, R.M. Boothby, A.S. Fraser and G.F. Slattery, International Conference: Radiation Effects in Breeder Reactor Structural Materials, The Metallurgical Society of AIME (1977) 159-175.

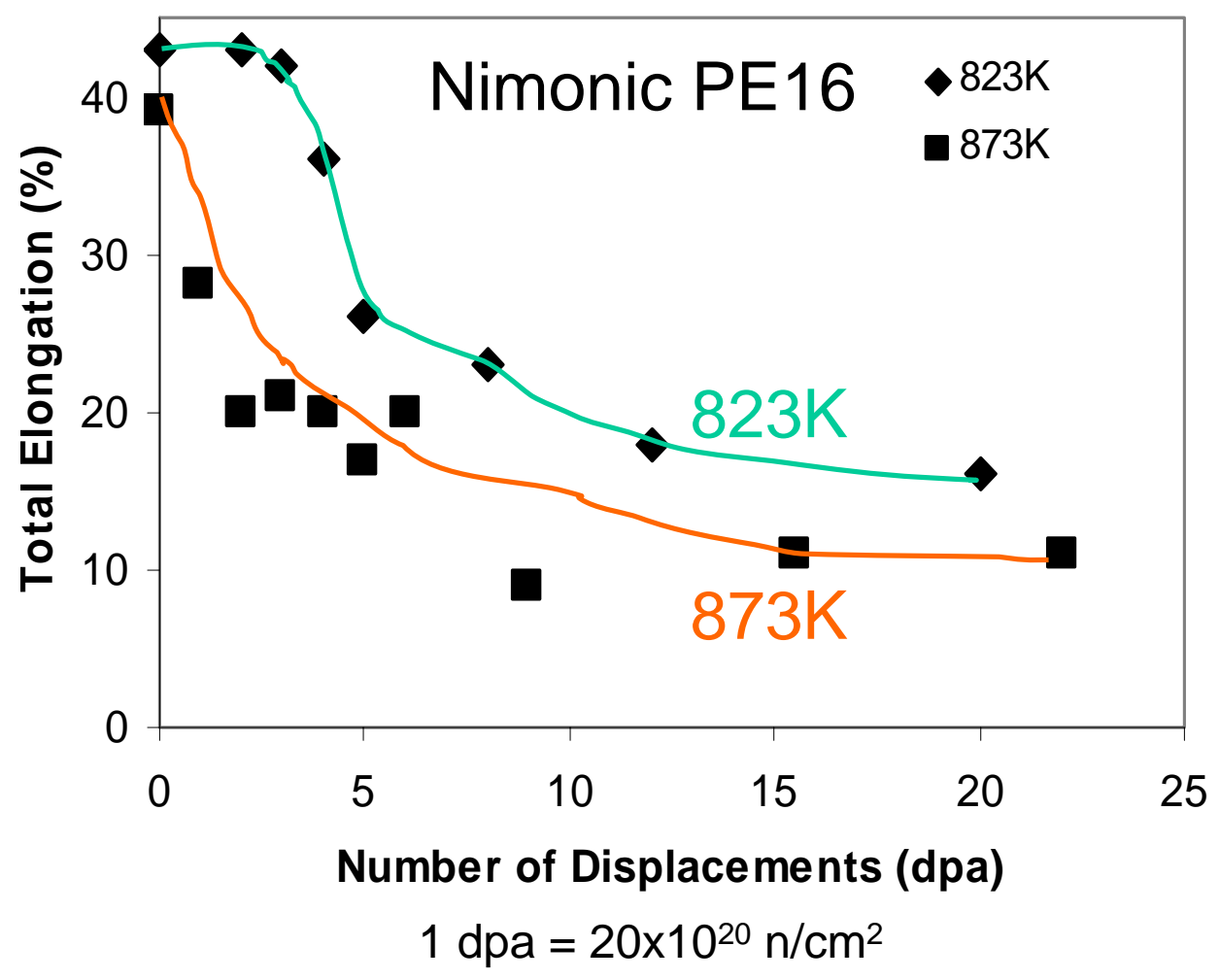

J.R. Lindgren, Nuclear Technology, vol. 66 (1984) 607-618.

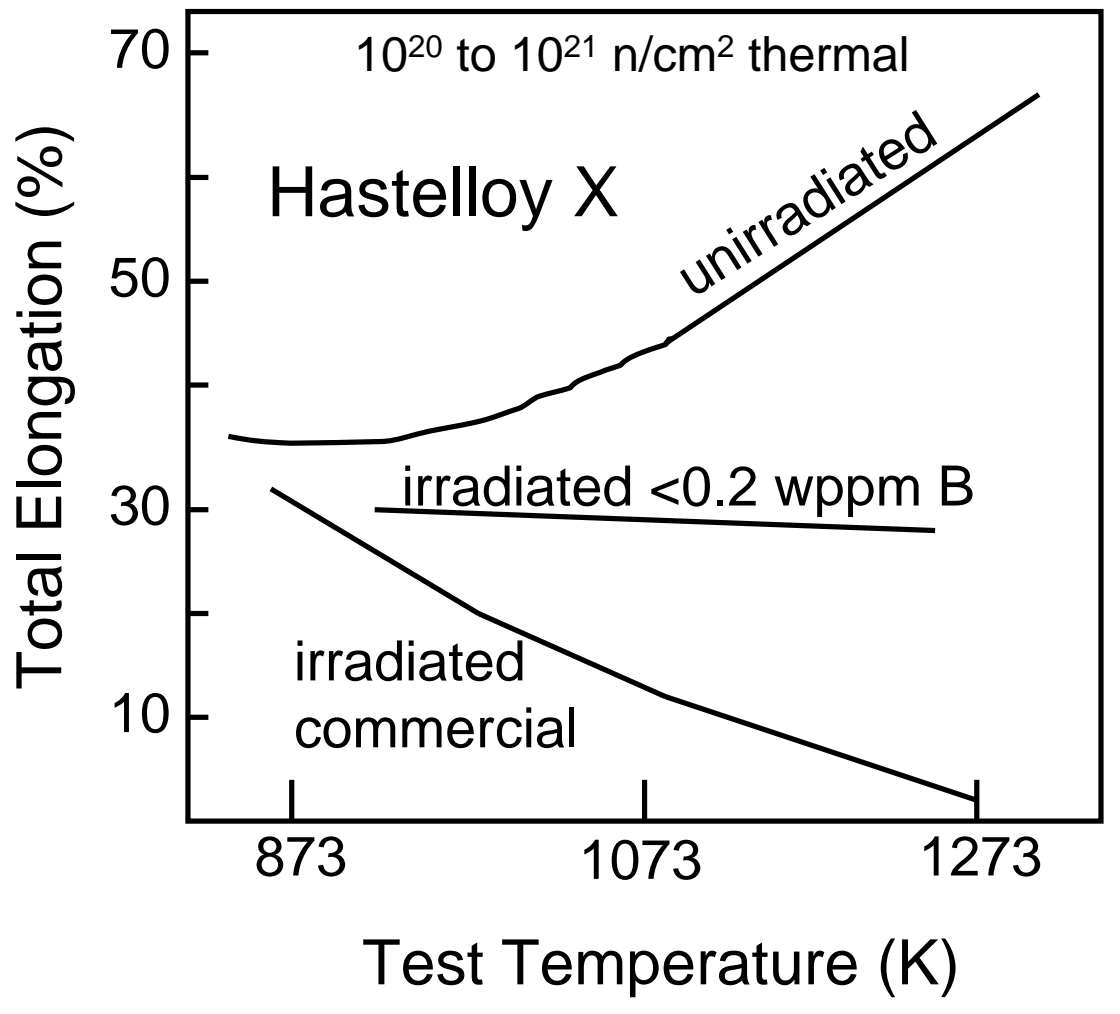

\section{No correlations between $\mathrm{He}$ and mechanical properties possible at this time due to very limited experimental data}




\section{Operating Conditions}

Need less helium and solute segregation

Lower the fluence

Lower the temperature

Pursue alternate design to the internal safety rod

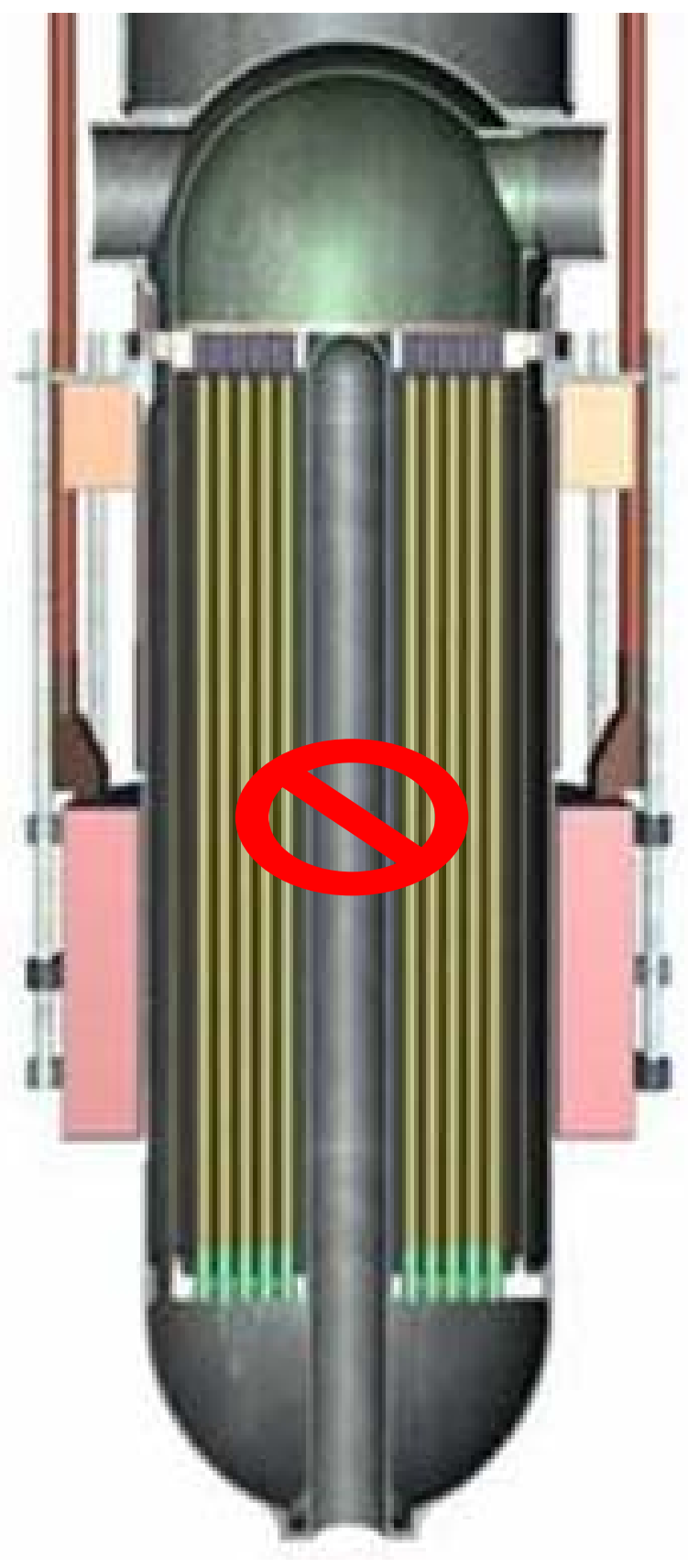




\section{Mitigation}

\section{Alloy Design}

Limit detrimental elements $\left(\mathrm{Ti}, \mathrm{Al},{ }^{10} \mathrm{~B}, \mathrm{Ni}\right)$ Evaluate balance of properties

\begin{tabular}{|l|c|c|c|c|c|c|c|c|c|}
\hline \multicolumn{1}{|c|}{ Alloy } & $\underline{\mathbf{N i}}$ & $\underline{\mathbf{C r}}$ & $\underline{\mathbf{M o}}$ & $\underline{\mathbf{W}}$ & $\underline{\mathbf{C o}}$ & $\underline{\mathbf{T i}}$ & $\underline{\mathbf{A l}}$ & $\underline{\mathbf{B}}$ & $\underline{\mathbf{C}}$ \\
\hline Alloy 617 & 54 & 22 & 9 & - & 12.5 & 0.3 & 1.0 & $\sim 50 \mathrm{wppm}$ & 0.07 \\
\hline Alloy 617NG & 54 & 22 & 9 & - & 12.5 & 0.3 & 0.8 & $<1 \mathrm{wppm}$ & 0.07 \\
\hline Alloy 617L & 54 & 22 & 9 & - & 12.5 & - & - & $<1 \mathrm{wppm}$ & 0.07 \\
\hline Alloy 230 & 57 & 22 & 2 & 14 & $<5$ & 0.2 & 0.2 & $150 \mathrm{wppm}$ & 0.10 \\
\hline Alloy 230NG & 61 & 22 & 2 & 14 & 0.5 & - & - & $<1$ wppm & 0.10 \\
\hline Alloy 230L & 61 & 22 & 2 & 14 & 0.5 & - & - & $<1$ wppm & 0.10 \\
\hline Alloy 188 & $\mathbf{2 2}$ & 22 & & 14 & $\mathbf{3 9}$ & & & & \\
\hline
\end{tabular}

\section{Develop nuclear grade Ni-base alloys Consider Co-base alloys}




\section{Irradiation Test Programs}

Evaluation of material performance under neutron exposure at elevated temperatures is required

Phase transformations (thermal and irradiation-induced)

Radiation-induced segregation, embrittlement (creep, swelling)

Multiple programs were planned to obtain these data

Irradiation in a mixed neutron spectrum (HFIR, Oak Ridge National Lab) Irradiation in a fast neutron spectrum (JOYO, Japan)

Nuclear and L-grade Ni-base alloys were to be included

\section{Several multi-year test programs were required}




\section{Conclusions}

\section{Pressure Vessel Material Selection}

Pre-decisional concept considered a Ni-base vessel due to concerns with refractory metal alloy radiation hardening and embrittlement and dissimilar metal joint.

\section{Radiation Embrittlement of Ni-base Alloys}

Little concern with radiation-induced creep and swelling

Literature reports severe embrittlement, but quantification is lacking

Calculations for JIMO mission show:

Majority of helium is produced from fast reactions with ${ }^{58} \mathrm{Ni}$

More helium from broad spectrum reactions with ${ }^{10} \mathrm{~B}$ at outer vessel

\section{Mitigation}

Radiation-induced embrittlement may be minimized by

Less radiation and/or lower T: Pursue alternative design to inner safety rod

Composition: Develop nuclear grade alloys (low Al, $\mathrm{Ti}^{10}{ }^{10} \mathrm{~B}$ )

Consider cobalt-base alloys to reduce the Ni content

Significant materials testing and development programs were required 